Hauke Christiansen

\title{
Schulentwicklung proaktiv, kreativ, effektiv
}

Rückenwind für Schulleitungen

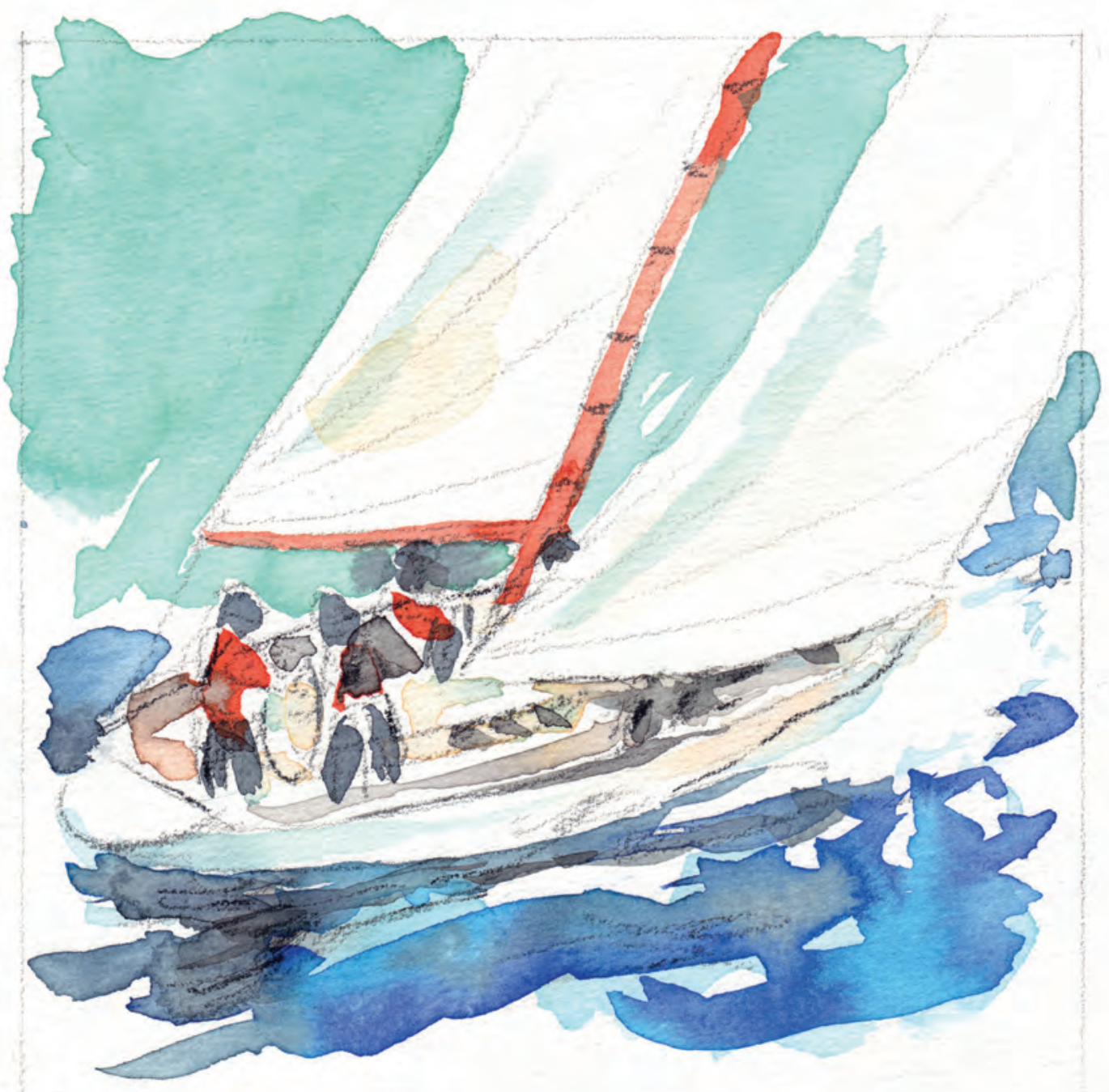



Hauke Christiansen

\section{Schulentwicklung proaktiv, kreativ, effektiv \\ Rückenwind für Schulleitungen}

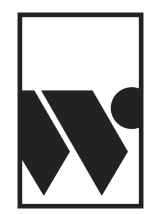

Waxmann 2020

Münster · New York 


\section{Bibliografische Information der Deutschen Nationalbibliothek}

Die Deutsche Nationalbibliothek verzeichnet diese Publikation in der Deutschen Nationalbibliografie; detaillierte bibliografische Daten sind im Internet über http://dnb.dnb.de abrufbar.

Print-ISBN 978-3-8309-4211-5

E-Book-ISBN 978-3-8309-9211-0

DOI 10.31244/9783830992110

(C) Waxmann Verlag GmbH, 2020

Steinfurter Straße 555, 48159 Münster

www.waxmann.com

info@waxmann.com

Umschlaggestaltung: Anne Breitenbach, Münster Umschlagbild: (C) Henning Christiansen, Hamburg Satz: satz\&sonders GmbH, Dülmen

Dieses E-Book ist unter Lizenz CC BY-NC-ND 4.0 veröffentlicht: Namensnennung - Nicht-kommerziell - Keine Bearbeitung 4.0 International https://creativecommons.org/licenses/by-nc-nd/4.0/deed.de 


\section{Inhalt}

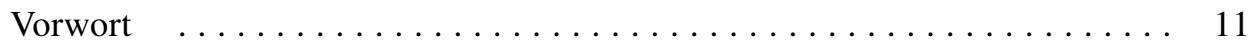

Kapitel 1: Wie können Sie anfangen? $\ldots \ldots \ldots \ldots \ldots \ldots \ldots \ldots \ldots$

1.1 Struktur und Kultur einer Organisation $\ldots \ldots \ldots \ldots \ldots \ldots \ldots \ldots$

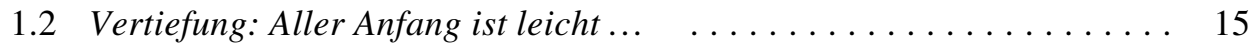

Kapitel 2: Zentrale Perspektive: Schule als Lernende Organisation $\quad \ldots \ldots \quad 17$

2.1 Die fünf Dimensionen einer Lernenden Organisation $\ldots \ldots \ldots \ldots 17$

2.2 Schulische Beispiele für die fünf Dimensionen $\ldots \ldots \ldots \ldots \ldots \ldots 21$

2.3 Internationale Erfahrungen mit dem Modell in Schulen $\ldots \ldots \ldots .22$

2.4 Konkretisierung der fünf Dimensionen durch Meso- und Mikro-

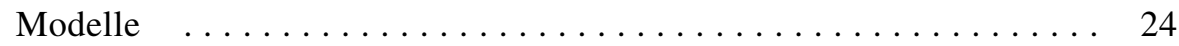

Kapitel 3: Systemdenken: Leitungsrolle und Schulentwicklung $\ldots \ldots \ldots 27$

3.1 Selbststeuerung in Privatrolle, Fachrolle und Leitungsrolle $\ldots \ldots \ldots 27$

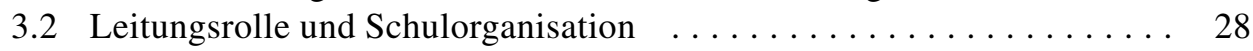

3.3 Systemdenken: Arbeit am System Schule $\ldots \ldots \ldots \ldots \ldots \ldots \ldots$

3.4 Vertiefung: Sawu bona ....................... 31

Kapitel 4: Persönliche Meisterschaft: Zuhören und zum Denken bringen _. 33

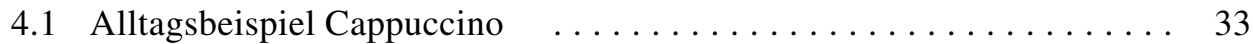

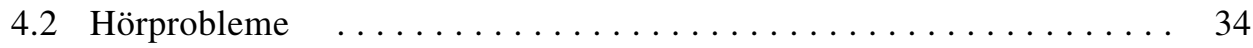

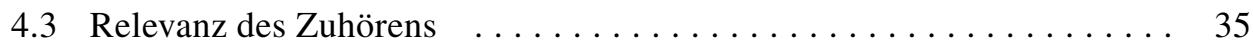

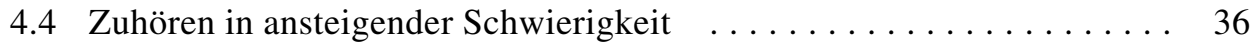

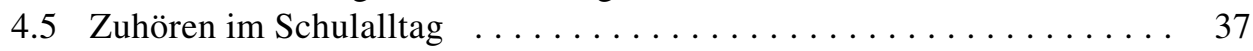

4.6 Vertiefung: Ein hörendes Herz $\ldots \ldots \ldots \ldots \ldots \ldots \ldots \ldots \ldots$

Kapitel 5: Teamlernen: die erweiterte Schulleitung als Steuerzentrum $\ldots .41$

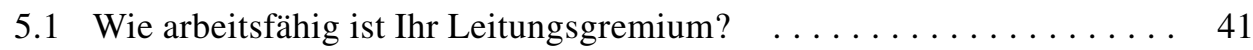

5.2 Schulleitung als Balance von Interaktion und Organisation $\ldots \ldots \ldots 42$

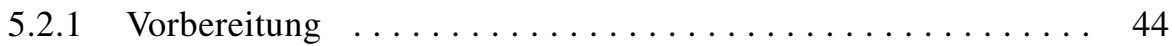

5.2.2 Durchführung $\ldots \ldots \ldots \ldots \ldots \ldots \ldots \ldots \ldots \ldots \ldots \ldots$

5.2.2.1 Regularien und Methodik für die Teamarbeit . . . . 45

5.2.2.2 Bearbeitung komplexer Themen: Sechs Schritte der Problemlösung $\ldots \ldots \ldots \ldots \ldots \ldots \ldots$

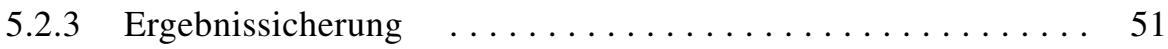

5.3 Kollegiale Beratung im Team: vier Varianten $\ldots \ldots \ldots \ldots \ldots \ldots 52$

5.4 Vertragsarbeit: Sicherung der Arbeitsfähigkeit $\ldots \ldots \ldots \ldots \ldots .57$

5.4.1 Nicht alle Brillen auf einmal aufsetzen - gehen Sie behutsam vor! 
5.4.2 Die Lerninteressen der Geleiteten als Schlüssel zur

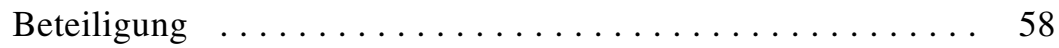

5.4.3 Intervenieren Sie nicht top-down, sondern mit sich selbst! . . 59

5.4.4 Vertragliche Absprachen zur Arbeitsweise Ihres Leitungsteams 60

5.4.5 Metaregeln zum Umgang mit vertraglichen Absprachen . . . . 61

5.5 Vertiefung: Keine Herrschaft von Menschen über Menschen . . . . . 63

Kapitel 6: Schulentwicklung und Konfliktmanagement $\ldots \ldots \ldots \ldots 67$

6.1 Scheiterstrategie als Ressourcenmobilisierung $\ldots \ldots \ldots \ldots \ldots 67$

6.2 Vom Beziehungsohr zur Selbstmitteilung $\ldots \ldots \ldots \ldots \ldots \ldots \ldots 6$

6.3 Das klassische Gewinn-Gewinn-Modell für Konflikte $\ldots \ldots \ldots \ldots .70$

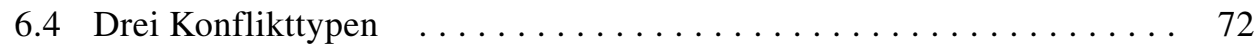

6.4.1 Typ I: Ich habe einen Konflikt mit dir: Wie steuere ich mich? . 72

6.4.2 Typ II: Du hast einen Konflikt mit mir: Wie konzentriere

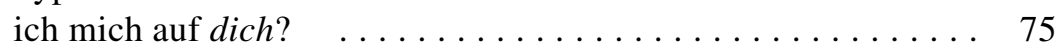

6.4.3 Typ III: Ihr habt einen Konflikt und kommt damit zu mir:

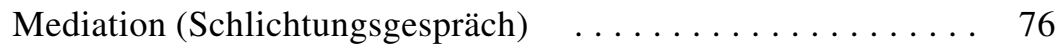

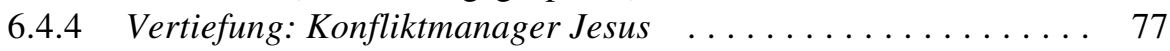

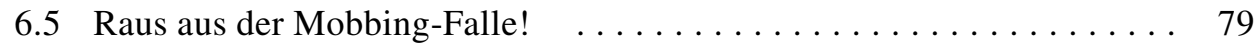

6.6 Der Beitrag der Gewaltfreien Kommunikation $\ldots \ldots \ldots \ldots \ldots .81$

6.7 Feedback geben und nehmen $\ldots \ldots \ldots \ldots \ldots \ldots \ldots \ldots \ldots$

6.7.1 Bedingtes und unbedingtes Feedback $\ldots \ldots \ldots \ldots \ldots \ldots 84$

6.7.2 Feedback und blinder Fleck $\ldots \ldots \ldots \ldots \ldots \ldots \ldots \ldots$

6.7.3 Feedback und Teamlernen $\ldots \ldots \ldots \ldots \ldots \ldots \ldots \ldots 87$

6.7.4 Feedback und Kollegiale Unterrichtsreflexion (KUR) _... 89

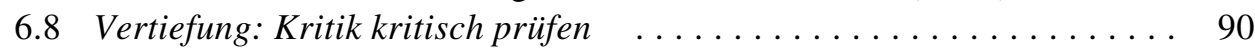

6.9 Transaktionsanalytische Konzepte: Raus aus der Eltern-Kind-

Dynamik! ............................ 91

6.9.1 Verfolger, Retter und Opfer im Dramadreieck .......... 92

6.9.2 Wie steuern Ich-Zustände die Alltagskommunikation? . . . . 95

6.9.3 Vertiefung: Jesus springt nicht im Dreieck . . . . . . . . . 97

6.9.4 Transaktionstypen und Kommunikationsgesetze . . . . . . 97

6.9.5 Ein fiktives Lehrerzimmer: Übungen zum Funktionsmodell . 100

6.9.6 Ursprungsmodell: Wo kommen die Ich-Zustände her? . . . . . . 101

6.9.7 Diagnose von Ich-Zuständen $\ldots \ldots \ldots \ldots \ldots \ldots \ldots \ldots$

6.9.8 Trübungen: realitätsferne mentale Modelle . . . . . . . . . 105

6.9.9 Bezugsrahmen: Filter vor der Realität $\ldots \ldots \ldots \ldots \ldots \ldots 106$

6.9.10 Vertiefung: Geh du aus deinem Land ... . . . . . . . . . 108

6.9.11 Enttrübung realitätsferner mentaler Modelle . . . . . . . . . 108

6.9.11.1 Vertiefung: Der Wassermelonenjäger ........ 110

6.9.11.2 Enttrübung durch Lebensereignisse $\ldots \ldots \ldots \ldots 111$

6.9.11.3 Enttrübung durch Konfrontation $\ldots \ldots \ldots \ldots \ldots 112$

6.9.11.4 Enttrübung durch Feedback .............. 115

6.10 Konfliktklärung durch Prozesskommunikation (PCM) $\ldots \ldots \ldots 116$

6.11 Vertiefung: Dein Nächster ist vielleicht dein Feind! . . . . . . . . . 119 
Kapitel 7: Vision und Steuerung von Prozessen $\ldots \ldots \ldots \ldots$

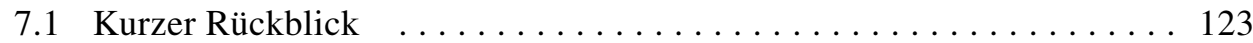

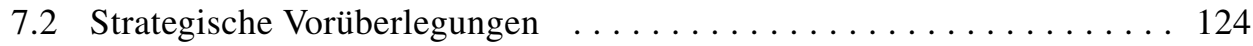

7.3 Kollegiumsklausur als Einstieg in die Erarbeitung einer Vision . . . . . 127

7.4 Partizipative Erarbeitung einer Vision mit dem Konsensverfahren . . . 129

7.5 Das Modell „Partizipativ-kontinuierliche Schulentwicklung“ . . . . . 135

Kapitel 8: Systemdenken: effektive Konferenzstruktur ... . . . . . . . 139

8.1 Das Neuruppiner Beteiligungsmodell . . . . . . . . . . . . . . . . . 139

8.2 Hindernisse und Wege zur Überwindung . . . . . . . . . . . . . . . . . . 142

Kapitel 9: Partizipativ-verbindliches Leitungskonzept . . . . . . . . . 145

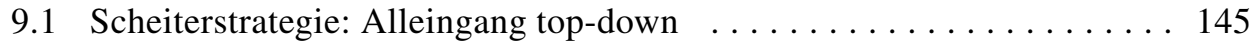

9.2 Diagnose eines Misserfolgs: Was war da los? . . . . . . . . . . . 147

9.3 Einzelfall oder relevantes Problem? . . . . . . . . . . . . . . 148

9.4 Kontakt zwischen Leitungsregion und Kollegium _. . . . . . . . . . 151

9.5 Wie können Sie partizipativ und zugleich verbindlich leiten? . . . . . 152

9.5.1 Zwei Leitungsdimensionen anstelle von drei Typen . . . . . . . 152

9.5.2 Entscheidungs- und Partizipationskontinuum . . . . . . . . 154

9.5.3 Der kritische Blick eines Wirtschaftswissenschaftlers . . . . . 156

9.5 .4 Situative Führung . . . . . . . . . . . . . . . . . . . . . . . 159

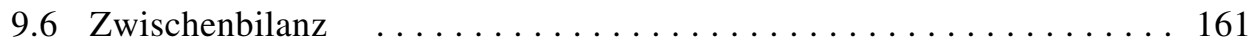

9.7 Vertiefung: Rückschläge überwinden ............... 163

Kapitel 10: Schluss mit Warten auf Godot: alles bedacht? . . . . . . . . . 165

10.1 Skeptische Analyse einer Erziehungswissenschaftlerin: Ilka

Bormann (2001) . . . . . . . . . . . . . . . . . . . . 165

10.2 Demotivierende Analyse eines Soziologen: Stefan Kühl (2007) . . . 166

10.3 Vertiefung: Von der Sklaverei in die Freiheit . . . . . . . . . . . . . 168

10.4 Trias der Schulentwicklung: Hans-Günter Rolff (2010 und 2019) . . 169

Kapitel 11: Persönliche Meisterschaft: Stress erkennen und regulieren _ . . 173

11.1 Balance von Arbeitsleistung und Arbeitskapazität . . . . . . . . . 173

11.2 Eustress und Distress f. . . . . . . . . . . . . . . . . . . . . 174

11.3 Energiequellen und Energieräuber $\ldots \ldots \ldots \ldots \ldots \ldots \ldots$

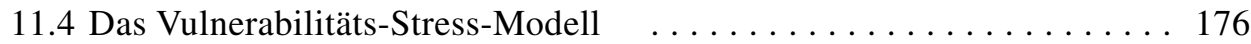

11.5 Wie wir körperlich auf Stress reagieren $\ldots \ldots \ldots \ldots \ldots \ldots$

11.6 Wie mentale Modelle uns unter Stress steuern . . . . . . . . . . . . 176

11.7 Wie mentale Modelle Stress verursachen $\ldots \ldots \ldots$. . . . . . . . . . 179

11.7.1 Antreiber steuern unsere Prioritäten . . . . . . . . . . . . . . . 179

11.7.2 Einschärfungen und Antreiber formen das Lebensdrehbuch . . 181

11.7.3 Antreiber kompensieren destruktive Einschärfungen . . . . . . 182

11.7.4 Antreiber entwickeln Fähigkeiten $\ldots \ldots \ldots \ldots \ldots . \ldots \ldots$

11.7.5 Antreiber springen an bei Distress $\ldots \ldots \ldots \ldots \ldots 183$

11.7.6 Antreiber verhindern Autonomie . . . . . . . . . . . . . . . . . . . 184

11.7.7 Antreiber werden entschärft durch Erlaubnisse . . . . . . . . 185 
11.7.8 Vertiefung: Autonomie oder Freiheit eines Christenmenschen? 186

11.7.9 Antreiber können Sie selbst diagnostizieren . . . . . . . . 189

11.8 Stress und Überlastungsreaktion (Burnout) im Schulalltag . . . . . 190

11.8.1 Die Diagnose steuert die Behandlung ............. 191

11.8.2 Indikatoren für Überlastungsreaktionen (Burnout) $\ldots \ldots \ldots 192$

11.8.3 Systemische Präventionsmöglichkeiten _... . . . . . . . 194

11.8.4 Überlastete MitarbeiterInnen führen _. . . . . . . . . . . . 195

11.9 Konkrete Maßnahmen für den Umgang mit Stress und Antreibern . . . 197

11.9.1 Priorisieren . . . . . . . . . . . . . . . . . . . . . 197

11.9.1.1 Proaktiv sein . . . . . . . . . . . . . . . 197

11.9.1.2 Nein sagen, Grenzen setzen ... . . . . . . . 198

11.9.1.3 Vertiefung: Auch Jesus sagt mal Nein. . . . . . . . . 200

11.9.1.4 Fünf-Minuten-Coaching $\ldots \ldots \ldots \ldots \ldots \ldots 202$

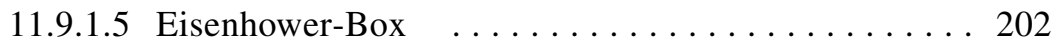

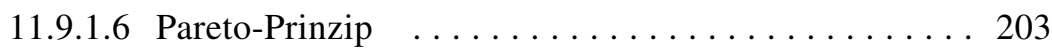

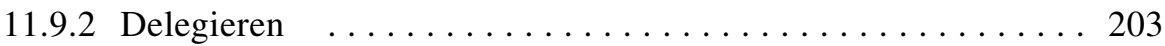

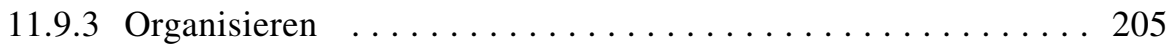

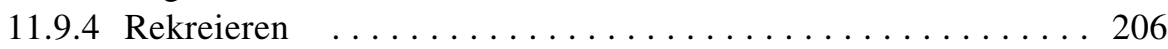

11.9.4.1 Physische Erneuerung $\ldots \ldots \ldots \ldots \ldots \ldots \ldots \ldots$

11.9.4.2 Mentale Erneuerung $\ldots \ldots \ldots \ldots \ldots \ldots 207$

11.9.4.3 Sozial-emotionale Erneuerung $\ldots \ldots \ldots \ldots \ldots 208$

11.9.4.4 Spirituelle Erneuerung _................. 209

11.9.4.5 Vertiefung: Pferd oder Maultier? . . . . . . . . . 209

Kapitel 12: Individuelle Förderung von Lehrkräften oder Teamstärkung? . 211

12.1 Das Mitarbeitergespräch (Personalentwicklungsgespräch,

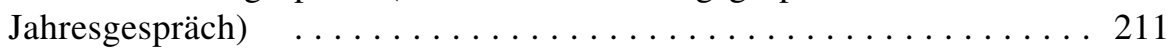

12.1.1 Schwierigkeiten und Chancen des Modells .......... 211

12.1.2 Grenzen des Modells . . . . . . . . . . . . . . . . . . 214

12.1.3 Realistische Zeitstruktur $\ldots \ldots \ldots \ldots \ldots \ldots \ldots \ldots \ldots \ldots$

12.2 Verteilte Führung: Kombination von individueller Förderung und

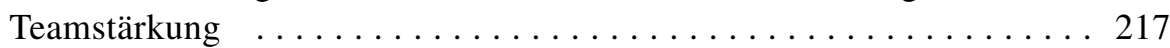

12.3 Gefühle in der Kommunikation $\ldots \ldots \ldots \ldots \ldots \ldots \ldots \ldots \ldots \ldots$

12.3.1 Rückblick und Überblick $\ldots \ldots \ldots \ldots \ldots \ldots \ldots \ldots \ldots \ldots$

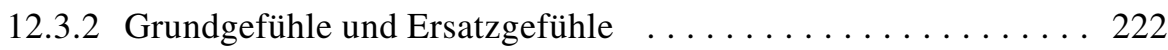

12.3.3 Auflösung von Blockierungen $\ldots \ldots \ldots \ldots \ldots \ldots \ldots 226$

12.3.4 Gefühl und Urteilskraft $\ldots \ldots \ldots \ldots \ldots \ldots \ldots \ldots \ldots . \ldots \ldots$

12.3.5 Vertiefung: Alle Gäste sagen $a b \ldots \ldots \ldots \ldots \ldots \ldots \ldots \ldots \ldots$

Kapitel 13: Die Freiheit „freier“ Schulen . . . . . . . . . . . . . . 237

13.1 Vorgaben der Freiheit: Allgemeine rechtliche Rahmenbedingungen _. 237

13.2 Was nicht verboten ist, ist erlaubt: Das Grundrecht der Privatschulen . 239

13.3 Beispiele: Wie Schulen ihren Spielraum erweitern $\ldots \ldots \ldots \ldots .241$

13.4 Die Schlüsselfunktion mentaler Modelle . . . . . . . . . . . . 246 
Kapitel 14: Religiös frei, säkular frei - worin unterscheiden wir uns? . . . 249

14.1 Innere Freiheit, protestantisch verstanden . . . . . . . . . . . . . . . 249

14.2 Äußere Freiheit, protestantisch verstanden $\ldots \ldots \ldots \ldots \ldots \ldots$

14.3 Säkulare und konfessionelle Schulen - Verschiedenheit und Konsens . 253

14.4 Logische Ebenen als Klärungshilfe . . . . . . . . . . . . . . 254

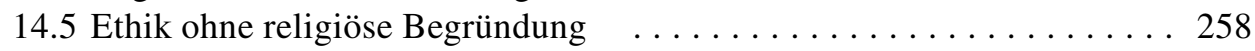

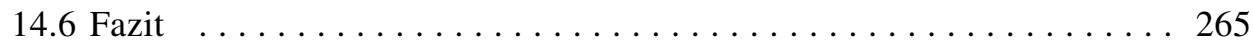

14.7 Vertiefung: Auch Jesus hat dazugelernt _. . . . . . . . . . . . . . 269

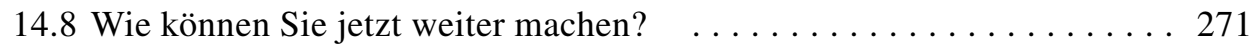

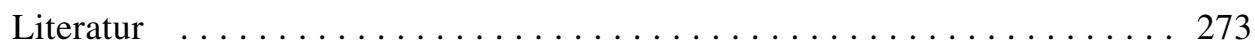

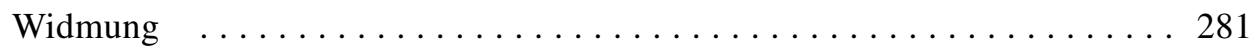

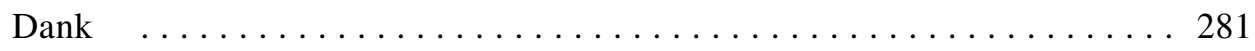

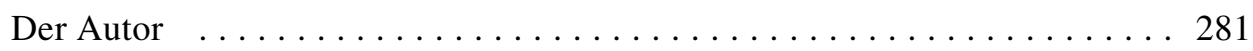

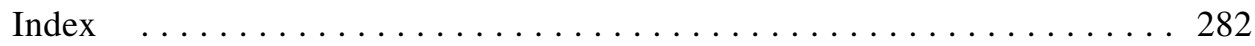

Die zugehörigen Downloads stehen unter http://www.waxmann.com/buch4211 zur Verfügung. 



\section{Vorwort}

Sie leiten eine Schule oder werden demnächst eine leiten? Oder Sie sind Mitglied einer erweiterten Schulleitung mit klarer Teilverantwortung? Dann ist dies Buch für Sie. Für diese anspruchsvolle Aufgabe möchte ich Ihnen Mut machen. Selbst ist die Frau! Selbst ist der Mann! Mobilisieren Sie alle Ressourcen, Ihre eigenen und die aller beteiligten Personen. Entwickeln Sie Ihre Schule, Ihren Teilbereich! Warten Sie nicht, bis die Not groß ist, um dann Hilfe von außen zu suchen. Fangen Sie an, überlegt, nicht besinnungslos, aber mit eigenen Mitteln, proaktiv. „Solange die Pädagogen von sich selbst glauben, sie hätten nicht die Kraft, bedeutungsvolle Veränderungen zu bewirken - und auf einen Erlöser namens Godot warten, der sie von den Widrigkeiten einer verständnislosen Welt befreien wird -, bleiben sie ein Teil des Problems." 1

Also, warten Sie nicht auf Godot! Hilfreiche Orientierung bietet das Konzept der Schule als Lernende Organisation. Es deckt die für Organisationslernen fünf zentralen Dimensionen ab, ohne dass es alle Schulen über einen Leisten schlägt. Spielraum für individuelle Gestaltung jeder einzelnen Schule bleibt genug. Ich sehe die fünf Dimensionen wie große Maschen eines Netzes, das sich über alle Organisationen spannen lässt, auch über Schulen. Damit Sie an den individuellen Besonderheiten Ihrer Schule arbeiten können, brauchen Sie für jede der großen Maschen ein feiner gestricktes Netzwerk. Das können Sie mit den in diesem Buch gesammelten Instrumenten, Modellen, Landkarten für Ihren Bedarf knüpfen, Masche für Masche.

Die Auswahl der Konzepte hängt mit meiner Weiterbildung zum Transaktionsanalytiker für den Organisationsbereich zusammen, mit unserer eigenen Leitungserfahrung und mit den Praxisproblemen, auf die wir, meine Frau und ich, seit 2001 in bisher 19 Weiterbildungskursen gestoßen sind. Im Lauf der Zeit sind weitere nützliche und erprobte Konzepte aus dem Bereich der humanistischen Psychologie hinzugekommen.

Kriterium für meine Auswahl: Alle Modelle, Instrumente, Verfahren unterstützen Sie dabei, die in Ihrem Kollegium vorhandenen Kompetenzen und Begabungen zu aktivieren. Schulen in einer demokratisch verfassten Gesellschaft sollen Beteiligung, Mitwirkung und Verantwortung in dieser Gesellschaft fördern, schon in der Schulzeit. Das erfordert einen Leitungsstil, der auf umfassende Beteiligung und auf verbindliche Vorgehensweisen setzt. Den Schulen heute ist ein Freiheitsspielraum eingeräumt, der von vielen noch nicht ausgeschöpft ist.

Die Teilnehmerinnen und Teilnehmer unserer Kurse haben die Tauglichkeit aller Verfahren gründlich überprüft, im Kurs und auch im rauen Schulalltag. Sie lassen sich wirkungsvoll nutzen, setzen aber geduldige Einübung und einigen

1 Sarason, S.: The Predictable Failures of Educational Reform, 1990, S. 217; zitiert nach Fullan 1999,194. - In einem Satz lässt sich Samuel Becketts weltberühmtes Drama „Warten auf Godot“ zusammenfassen: Zwei Männer warten auf einen dritten, der niemals kommt. 
Durchhaltewillen voraus. Theorie gehört auch dazu, Rezepte allein tun es nicht. „Nichts ist so praktisch wie eine gute Theorie.“ Literatur zur Schulentwicklung ist reichlich vorhanden. ${ }^{2}$,Wie, das sollen wir auch noch lesen?“ Das war die typische Reaktion, wenn in unseren Kursen für Schulleitungen der Blick auf den Büchertisch fiel. ${ }^{3}$

Also habe ich aus dem Schatz der Literatur herausgesucht und zusammengefasst, was mir als Handwerkszeug unverzichtbar erscheint. Mindestens so wichtig wie das WAS ist das WIE: Darum liegt mir vor allem an konkreten methodischen Anleitungen zur Frage, was Sie ganz praktisch tun können, um dem Ziel einer Lernenden Schule näherzukommen.

Die elektronische Fassung des Buches ist dazu gedacht, dass Sie dies methodische Konzept Ihrem ganzen Kollegium problem- und kostenlos bekannt machen können. Wer geleitet wird, interessiert sich vermutlich dafür, nach welchen Grundsätzen die Leitung operiert. Sie können so in Ihrer Leitungsgruppe und in Ihrem Kollegium Interessierte entdecken, mit denen Sie die für Ihre Schule aktuellen Baustellen finden und bearbeiten können. Der Hinweis Download verweist auf kurze Arbeitspapiere, die für eine solche Zusammenarbeit nützlich sein können.

Immer wieder beziehe ich einzelne Themen auf den Hintergrund christlicher, aber auch humanistischer Tradition, jeweils als „Vertiefung“ markiert. Nicht als dogmatische Belehrung, sondern als Einladung zu freiem Austausch unterschiedlicher Sichtweisen. Ein Merksatz von Pinchas Lapide gibt dabei die Richtung an: „Es gibt im Grunde nur zwei Arten des Umgangs mit der Bibel: Man kann sie wörtlich nehmen, oder man nimmt sie ernst." (Lapide 1988, 50) Wörtlichkeit endet in Absurditäten (vgl. Download 1). Der Haupttext ist unabhängig von diesen Einschüben verständlich.

Dies Buch ist aus der Arbeit mit ca. 300 Leitungspersonen aus evangelischen Schulen entstanden. Ihnen ist das Buch gewidmet.

Ihr Feedback ist willkommen (s.u. 14.8). Mein Wahlspruch: „Prüfet alles; das Gute haltet fest!“ (1. Thessalonicher 5, 21). Variante für säkulare Geister: „Der Normale lernt immer ..." (I.H. Schultz, der Erfinder des Autogenen Trainings).

Ratzeburg, August 2020

2 Am Ende jedes Kapitels finden Sie Lesetipps.

3 Kursausschreibung: http://www.evangelischer-schulbund-nord.de/fortbildung; seit 2001 leite ich jährlich einen Kurs $(5 \times 3$ Tage $)$, seit 2005 zusammen mit meiner Frau, Dr. med. Veronika Christiansen. 


\section{Kapitel 1: Wie können Sie anfangen?}

Sie sind zuständig für Schulentwicklung. Wie können Sie anfangen? Fangen Sie mit sich selbst an! Nehmen Sie sich Zeit. Besinnen Sie sich: Wie sieht Ihre derzeitige Leitungsrolle aus? In unserem Weiterbildungskurs für Schulleitungen bietet sich uns da immer ein buntes Bild. Einige haben die volle juristische und pädagogische Verantwortung für eine Schule, schon seit Jahren, manche sind noch ganz neu im Amt und suchen Orientierung. Die „Neuen“ sind teils von außen gekommen, teils waren sie vorher Kollegen bzw. Kolleginnen in dem System, das sie jetzt zu leiten haben. Auch Stellvertretungen besuchen den Kurs, ebenso Lehrerinnen und Lehrer mit Teilverantwortung: Koordinatorinnen, Stufenleiter, Stundenplaner, Fachleiterinnen, die in dieser Funktion oft auch Mitglieder einer erweiterten Schulleitung sind. ${ }^{4}$

Also, fangen Sie mit sich selbst an. Für welchen Leitungsbereich genau sind Sie zuständig? Wenn Sie neu im System sind, verfügen Sie noch über den ,fremden Blick“, die Vogelperspektive auf Ihre Schule. Noch können Sie sich wundern über Strukturen und Abläufe, die den Insidern gar nicht auffallen. Fragen Sie nach, wenn Sie etwas nicht verstehen, machen Sie sich Notizen, vermeiden Sie aber vorschnelle Urteile.

\subsection{Struktur und Kultur einer Organisation}

Wenn Sie nicht so neu im System sind, könnte eine Metapher Ihnen helfen, dennoch diesen Vogelperspektivenblick einzunehmen. Ein schönes Beispiel fand ich in der Zeitung:

\section{Natürlicher Kreislauf}

PARIS, 10. Oktober (ap). Frankreichs Außenminister Hubert Védrine hat nicht nur mit Politik zu kämpfen, sondern auch mit Algen, Fischen, Füchsen und Reihern. Im Garten eines Gästeschlosses seines Ministeriums bei Paris ließ er einen Teich mit einem ausgeklügelten Kanalsystem wieder bewässern. Alsbald siedelten sich nach offiziellen Angaben Enten an, aber auch Algen gediehen. Der Politiker ließ Fische aussetzen, die das Grünzeug verspeisen sollten. Das lockte einen Reiher an, der den Fischbestand dezimierte. Védrine wollte ihn von Füchsen vertreiben lassen. Die bevorzugten die Enten. Die überlebenden Enten wurden in den Ministeriumsgarten evakuiert, wo sie die Statue eines Ministers beschmutzten. Die Statue wurde in den Park zu Reihern und Füchsen gebracht. Diese hatten sich inzwischen vermehrt. Der

4 Um den Text lesbar zu halten, wechsle ich (unregelmäßig) zwischen männlicher und weiblicher Sprachform ab. Unsere Kurse besuchen mehr Frauen als Männer; das kann sich gern in der Sprache zeigen. 
Teich ist wegen eines Defekts der Kanalisation wieder ausgetrocknet. (Die Ecke 2000)

Dies amüsante Gartenteich-Drama lässt sich als hilfreiches Bild für die spannungsreiche Beziehung von Struktur und Kultur einer Organisation verstehen. R. Balling analysiert das so: „Struktur ist Mechanik, und sie kann als solche behandelt werden. Ausgehend von einem Plan kann ich die Struktur im Vorhinein genau bestimmen - konstruieren. Und wenn ich ein guter Ingenieur bin und mit den geeigneten Mitteln ausgestattet, kann ich die Struktur des Gartenteiches genau nach meinen Vorstellungen herstellen lassen. Das Ökosystem kann ich nicht in gleicher Weise schaffen, ich kann es nur beeinflussen."

Je nach Situation werden einige Pflanzen wachsen, andere nicht. Fische vermehren sich oder gehen ein. Das Ökosystem ist im Austausch mit der größeren Umwelt (Würmern, Bakterien, Vögeln). Wenn ich ein bestimmtes Ökosystem haben möchte, muss ich die Strukturen so schaffen, dass sie dieses begünstigen. Dabei bleibe ich immer im ,Dialog ‘ mit dem Ökosystem; als Gärtner, nicht als Ingenieur. Rechtsform, Aufbauorganisation, Ablauforganisation, Betriebsvereinbarungen u.a. machen die Organisationsstruktur aus. Solche Strukturen haben einen massiven Einfluss auf die Organisationskultur, geplant und ungeplant. „Die Organisationskultur selber ... kann nur stimuliert und nur in Grenzen gestaltet, keineswegs allerdings konstruiert oder eingeführt werden."5

Diese Zusammenhänge zwischen Struktur und Kultur zu verstehen und zu nutzen, macht nach Balling die Kunst von Organisationsentwicklerinnen aus. Auch Künstler müssen lernen. Es gibt fantastische Klaviervirtuosen. Aber auch Amateure können einige Fertigkeit im Klavierspiel erreichen. Ohne Üben geht es nicht. Großmeister im Schachspiel zu werden, erfordert zehn Jahre Praxis selbst bei hoher Begabung. ${ }^{6}$ Schach ist komplex. Eine Schule nicht minder. Also - bleiben Sie geduldig! Denken Sie in längeren Zeiträumen.

Eine Schule braucht eine Kultur, in der möglichst alle motiviert dabei sind, ihr Potential einbringen, sich gegenseitig unterstützen, voneinander lernen. Das erfordert geeignete Kommunikationsstrukturen, die für solche kulturellen Prozesse Raum und Zeit bieten. Fangen Sie an, indem Sie Struktur und Kultur Ihrer Schule bewusst wahrnehmen. Schauen Sie hin, hören Sie zu, verändern Sie nichts, was nicht sofort verändert werden muss.

5 Beide Zitate: Rolf Balling, unveröffentlichtes Arbeitspapier

6 Kindermann / v. Weizsäcker $(2010,142)$. Die Autoren bieten in ihrer Münchner Schach-Akademie Schach-Kurse für Führungskräfte an, um deren strategisches Denken zu fördern. Viele Schach-Prinzipien, z. B. innerer Seitenwechsel (s. u. 6.4), Prozessverlangsamung (s. u. 6.4.4), Ressourcenaktivierung (s.u. 4.4) u.v.a.m., lassen sich auf Führungsaufgaben übertragen. 


\subsection{Vertiefung: Aller Anfang ist leicht ...}

„Aller Anfang ist leicht, und die letzten Stufen werden am schwersten und seltensten erstiegen. " ${ }^{7}$ Eine Schule in eine gute Richtung immer weiter zu entwickeln, ist eine wichtige und anspruchsvolle Aufgabe.

Wenn ich mit dem Lernen Fortschritte mache, dann nehme ich, biblisch gesprochen, zu an Weisheit und Einsicht. „Die Furcht des Herrn ist der Weisheit Anfang. "(Psalm 111,10) Das Wort „Anfang “ steht in Israel für Wesen: Die Furcht des Herrn ist das Wesen der Weisheit. Wenn die Bibel Anfangsgeschichten erzählt, dann erzählt sie Wesensgeschichten: „Adam, wo bist du?" So gefragt zu sein, gehört nach Auffassung Israels zum Wesen des Menschen. Nebenbei: Erzählungen wie die Paradiesgeschichte konkurrieren nicht mit Astrophysik und Evolutionstheorie; als Wesensgeschichten kann ich sie ernst nehmen, als naturwissenschaftliche Belehrung nicht.

Wieso gehört Furcht wesentlich zur Weisheit? Richard Schröder gibt einen Hinweis: „Ein Christ beugt sich vor seinem Gott dankbar und dann nie wieder vor einem andern, sondern nur für einen andern. " Also: Gottesfurcht ja, Ehrfurcht vor der Quelle des Lebens, der ich alles verdanke; aber keine Furcht vor Menschen. Ein hoher Anspruch. Vielleicht kann ich wenigstens lernen, mich nicht von Furcht bestimmen zu lassen. Also: Lernen in Freiheit, von gleich zu gleich, ohne Furcht voreinander, ohne Furcht vor Kolleginnen und Kollegen, vor vorgesetzten Instanzen, vor kritischen Geistern.

\section{Lesetipp}

Enja Riegel (2004): Schule kann gelingen. Die ehemalige Leiterin der HeleneLange-Schule in Wiesbaden berichtet spannend davon, wie sie gegen massiven Widerstand ihre Leitungsrolle behauptet hat und mit der Zeit das Kollegium für ungewöhnliche Veränderungen gewonnen hat - ein eindrucksvolles Modell dafür, wie eine Leiterin ein klares Gegenüber leben und gleichzeitig Zusammenarbeit fördern kann (s. u. Anm. 50).

Hiebl/Seitz (2014): Wegweiser Schulleitung. Hier finden Sie einen umfassenden Überblick über die Aufgaben einer Schulleitung mit vielen Checklisten und Reflexionsfragen. Den kapitelweise angefügten Leseempfehlungen füge ich jeweils eine Fundstelle bei Hiebl und Seitz an. So können Sie überprüfen, wieweit Sie die wichtigen Themen im Blick haben. Abschnitt 3.2 bei Hiebl und Seitz (2014) wäre ein möglicher Anfang.

7 Johann Wolfgang Goethe: Wilhelm Meisters Wanderjahre I, 4 



\section{Kapitel 2: Zentrale Perspektive: Schule als Lernende Organisation}

Die Gartenteich-Metapher zeigt: Eine gute Schule braucht geeignete Strukturen und eine förderliche Kommunikationskultur, wenn sie eine gedeihliche, lebendige, Leben fördernde Schule sein soll. Nutzen Sie die Metapher, um aus einer Vogelperspektive auf Ihre Schule zu blicken. Wenn Sie neu in Ihrer Leitungsfunktion sind: Tun Sie, was routinemäßig zu tun ist, lassen Sie sich von erfahrenen Kolleginnen oder Kollegen helfen, ändern Sie erstmal nichts. Keine Sorge: Normalerweise funktioniert so ein System recht stabil.

Gönnen Sie sich regelmäßig Zeit für Besinnung. Wenn Sie dafür keine Zeit haben, dann stimmt etwas nicht, dann arbeiten Sie besinnungslos. Dann lassen Sie sich steuern: von Routineaufgaben, von Anfragen, von Störungen, von Krisen. Das gilt auch für alle anderen Organisationsmitglieder. Nehmen Sie sich immer wieder Zeit, Ihre Schule mit allen Sinnen wahrzunehmen, studieren Sie die vorhandenen Strukturen, die Gremienzusammensetzung, die Kommunikationsabläufe, hören Sie auf den Umgangston, auf leicht hingeworfene Bemerkungen, auf Seufzer, auf Lachen, auf den Ton des Lachens; achten Sie auf den Umgang mit Zeit und Ressourcen. Und behalten Sie Ihre Wahrnehmungen für sich. Bleiben Sie geduldig, und schärfen Sie Ihre Wahrnehmung weiter. Machen Sie sich Notizen. Führen Sie ein Lerntagebuch, nur für Sie selbst.

\subsection{Die fünf Dimensionen einer Lernenden Organisation}

Eine weitere Brille für den Blick von oben bietet das Modell der Lernenden Organisation. Genauer: Sie bekommen eine wohl überlegte Kombination von mehreren Brillen, von fünf Dimensionen, die allesamt zu beachten sind, wenn eine Organisation sich dem Lernen verschreiben will, alle fünf. Sie sind nicht additiv, sondern multiplikativ verknüpft. Bewegt sich auch nur ein Faktor um Null, dann wird es nichts mit der Lernenden Organisation. ${ }^{8}$ Hier folgt ein Überblick. In Tabelle 1 ergänze ich diesen Überblick, indem ich die Vorschläge zweier Experten auf die fünf Dimensionen beziehe.

Vision - die erste Dimension einer Lernenden Organisation. Organisationen sind auf Dauer nur erfolgreich, wenn sie sich an gemeinsamen Perspektiven, Zielen und Wertvorstellungen orientieren. Denken Sie an Ihren Traum: Was wäre eine sinnvolle Vision für eine Schule? Wie hätten Sie selbst sich in Ihrer Jugend Ihre Schule gewünscht? Alle Beteiligten waren selbst einmal Schülerinnen oder

8 Zum Folgenden vgl. Senge 1998, Kap. 9-12; kurze Zusammenfassung bei Holtappels 2010, 101 
Schüler, haben also einiges beizutragen. ${ }^{9}$ Kools and Stoll $(2016,33)$ zitieren aus einer UNESCO-Kommission vier fundamentale Lernarten, die eine Schule anbieten sollte und die eigene Formulierungen anregen können: ,learning to know, learning to do, learning to live together and learning to be. Learning to be focuses on what is required for a person to develop to their fullest potential psycho-socially, affectively as well as physically, so that they can be , an all-round complete person“".

Die Schule als ein Haus des Lernens - welche Organisation käme dafür mehr in Frage als eine Schule? Nicht nur für die Schülerinnen und Schüler, sondern für alle, auch für die Lehrenden, auch für Sekretärinnen und Hausmeister. Wie sieht es damit in Ihrer Schule aus? Welche Personen bewegen sich schon in diese Richtung?

\section{Persönliche Meisterschaft}

Gemeint ist persönliche Kompetenz, die ständige Erweiterung der eigenen Fähigkeiten als lebenslanges Lernen, insbesondere zur deutlichen Wahrnehmung der Realität, nicht nur kognitiv, sondern auch emotional und pragmatisch. Wie organisieren Sie Ihr Lernen? Allein für sich, durch Nachdenken? Wie lernen Sie von anderen? Wo, von wem bekommen Sie nützliches Feedback, von dem Sie lernen können?

„Lernen ist wie Rudern gegen den Strom. Hört man damit auf, treibt man zurück." (Chinesisches Sprichwort, Krieghofer 2019) Wie erleben Sie den Strom, in dem Sie rudern? Gleichmäßig dahinfließend, ruhig, manchmal träge oder schnell und heftig strömend, mit lauernden Stromschnellen, unverhofften Windungen? Wann haben Sie zuletzt gemerkt, dass Sie gegen den Strom vorangekommen sind? Und wie war das möglich?

Welche Stromschnellen nehmen Sie inzwischen sportlich souverän? Welche finden Sie bedrohlich? Wo meldet sich Stress? Auf welche Ressourcen können Sie zurückgreifen? Manche Menschen sind natürlich begabt - beneidenswert. Aber jeder und jede kann durch Übung Meisterschaft erreichen. Eine Disziplin zu meistern, ist ein lebenslanger Prozess.

\section{Teamlernen}

„Wie ist es zu erklären, daß ein Team von engagierten Managern, die einen individuellen Intelligenzquotienten von über 120 haben, einen kollektiven IQ von 63 aufweisen?“ Ein IQ von 100 gilt als Durchschnitt. Senge erläutert: „Häufig ist das Verhalten eines Teams von tiefen Abwehrstrukturen geprägt. Wenn diese Strukturen nicht erkannt werden, machen sie jedes Lernen unmöglich. Aber wenn man sie erkennt und sich kreativ damit auseinandersetzt, können sie das Lernen

9 Auf die Frage, wie eine Schule sein müsste, antwortete z.B. der Wissenschaftsjournalist Ranga Yogeshwar: „Ganz anders ... offen und frei und voller Freude am Neuen. Dort gibt es keine Schüler mehr, sondern nur noch Lernende. Diese Schule ist das schönste Gebäude der Stadt, bestens ausgestattet, wohnlich und ein Treffpunkt für alle. Die Schulglocke wurde abmontiert, und wir lieben es, dort zu sein - auch am Wochenende.“ (Interview „Alte Schule“ in der SZ Nr. 272, 25. 11.2019, S. 25) 
auch vorantreiben." (Senge, 1998, 19) Dann kann die Intelligenz eines Teams die Intelligenz des Einzelnen bei weitem überragen.

Die Disziplin des Team-Lernens beginnt mit dem Dialog, mit der Fähigkeit der Teammitglieder, sich auf gemeinsames Denken einzulassen, wodurch eine Gruppe zu Einsichten gelangen kann, die dem Einzelnen verschlossen sind. „Lernen ist wie Rudern gegen den Strom." Man kann allein rudern, aber auch zu zweit und zu mehreren.

In welchen Gremien kommen Sie gemeinsam voran? Wo gibt es eine Art Steuerzentrum, in dem an gemeinsam geteilten Zielen gearbeitet wird? Bei welchen Zielen ist man sich einig? Wie unterstützt man sich gegenseitig? Was ist besonders hilfreich? Was ist zusätzlich noch wünschenswert? Wer hält sich raus? Wer macht mit?

\section{Mentale Modelle}

Mentale Modelle sind Annahmen, vermeintliche Gewissheiten, Glaubenssätze und Haltungen, mit denen wir die Welt wahrnehmen und in ihr handeln. Wie sehr die uns steuern, ist uns oft völlig verborgen. Jemand, der einmal länger im Ausland lebt und sich unbefangen so gibt wie zu Hause, fühlt sich leicht als Exot. Was immer selbstverständlich war, wird von anderen als fremd wahrgenommen. Weil Mentalitäten so selbstverständlich scheinen, verhindern sie häufig neue Erfahrungen, neue Erkenntnisse, neue Einblicke über unseren Horizont hinaus. Sie verhindern Lernen.

„Aus Fehlern wird man klug!“ Ein verbreitetes mentales Modell. Stimmt aber nicht, wie eine aktuelle Studie belegt (Herrmann 2019), jedenfalls nicht immer. Der Befund der zwei Forscherinnen: Wer Fehler macht und kritisches Feedback bekommt, lässt als Reaktion die kognitiven Jalousien runterrattern und verabschiedet sich aus der anstehenden Aufgabe. Zwar provozieren negative Reize eher Aufmerksamkeit. Sie werden aber nicht als wichtige Signale genutzt, im Gegenteil: Ein Misserfolg kann zehn gute Erfahrungen vergessen lassen. Warum? Weil wir kränkbar sind.

„Scheitern verletzt das Ego“, erklären die Autorinnen; das Ego fürchtet sich vor allem vor Kränkung. Scheitern löst Versagensgedanken aus: „Ich bin nicht gut genug, nicht schlau genug, nicht fleißig genug, ich schaffe das sowieso nicht.“ Erfolge festigen viel eher Lerninhalte und stärken das Selbstvertrauen. Ohne Zweifel ein wichtiges Thema in Schulen. Der Streit um Bedeutung und Wirkung von Zensuren belegt die Macht unterschiedlicher mentaler Modelle.

Also Erfolge feiern, Mut machen, Selbstvertrauen stärken, so folgern die Autorinnen. Fehler können als Chance zum Lernen genutzt werden, auch in einem Kollegium. Der Polaroid-Gründer Ed Land hatte einen Merkspruch an seiner Wand: „Ein Fehler ist ein Ereignis, dessen großer Nutzen sich noch nicht zu deinem Vorteil ausgewirkt hat." (Senge 1998, 189)

Schüler können schwierig sein. Wer würde da nicht zustimmen? Anders herum: „Bevor ein Kind Schwierigkeiten macht, hat es welche.“ (Alfred Adler zugeschrieben.) Was für Schwierigkeiten? Mit den Mitschülerinnen? Mit der Darbietung des Stoffs? Mit meinem Interaktionsstil? Oder mit Problemen zu Hause, in der Familie? 
Ein erster Impuls könnte sein: Dies Kind gehört auf eine andere Schule. Ein zweiter Impuls: Vielleicht bildet sich da gleich wieder eine ähnliche Konstellation. Dritte Idee: Welche Personen müssten miteinander sprechen, um das Symptom besser $\mathrm{zu}$ verstehen und eine konstruktive Lösung zu konstruieren? Wie lässt sich das Symptomverhalten als sinnvolle Reaktion auf das soziale System verstehen, in dem das Kind lebt? Damit ist die fünfte Dimension schon angesprochen.

\section{Systemdenken}

Systemdenken ist die integrative Disziplin, die alle Dimensionen miteinander verknüpft und sie zu einer ganzheitlichen Theorie und Praxis zusammenfügt. Fundamentales Umdenken ist das eigentliche Herzstück einer Lernenden Organisation. In einer Lernenden Organisation entdecken Menschen kontinuierlich, dass sie ihre Realität selbst erschaffen und dass sie sie verändern können. Sie machen nicht länger einen Widersacher da draußen für all ihre Probleme verantwortlich; sie erkennen, wie sie selbst durch ihr Handeln zu ihren Problemen beitragen. Systemdenken versteht Schwierigkeiten in Organisationen nicht als Problem einzelner Personen. Schwierigkeiten werden eher als Symptom für suboptimales Zusammenspiel mehrerer Akteure gesehen.

Wie wirksam mentale Modelle auf der Ebene der Politik wünschenswerte Veränderungen im deutschen Bildungssystem behindern, zeigt die Präsidentin des Wissenschaftszentrums Berlin für Sozialforschung, J. Allmendinger, anhand von fünf verbreiteten Mythen. In Kurzfassung:

Mythos 1: Ein bestimmter Teil der Gesellschaft könne nicht ge- und ausgebildet werden. „Beweis“: $13 \%$ der heute 25- bis 34-Jährigen haben keinen Sekundarabschluss. Contra: In 16 von 28 Mitgliedstaaten der EU ist der Anteil von Jugendlichen ohne Schulabschluss niedriger als in Deutschland.

Mythos 2: Soziale Selektivität sei unvermeidlich. Contra: Die Chancen von Kindern aus Akademikerfamilien auf einen Gymnasialbesuch sind fast vierbis sechsmal so hoch wie für Facharbeiterkinder bzw. für Kinder von Un- und Angelernten.

Mythos 3: Die Bildungsexpansion senke die Bildungsrendite. Man solle nicht zu vielen Menschen das Abitur oder ein Hochschulstudium ermöglichen. Contra: Die Lohnspreizung zugunsten von Akademikern ist heute größer denn je. Eine Sättigung des Bedarfs an Hochqualifizierten ist nicht in Sicht.

Mythos 4: Die Systeme beruflicher und akademischer Bildung seien durchlässig genug. Contra: Falsch! Im Schuljahr 2016/17 lag der Anteil der Studienanfänger über den dritten Bildungsweg bei mageren $3 \%$.

Mythos 5: Die Ausgaben für Bildung lägen auf hohem Niveau. Contra: Das Budget für Bildungseinrichtungen in öffentlicher und privater Trägerschaft betrug 2017 nur 5,1\% des Bruttoinlandprodukts (BIP). Um diesen Wert schwanken die Bildungsausgaben bereits seit über zehn Jahren; sie liegen im europäischen Durchschnitt. 
Fazit der Autorin: Die fünf Mythen sind empirisch nicht zu halten. „Es sind Mythen. Und sie sind schädlich.“ (Allmendinger 2019)

Systemtheoretiker warnen (oft vergeblich): Systeme lassen sich nicht direkt per Anweisung steuern. Andererseits wird ein System allmählich zum Museum, wenn es relevante Veränderungen in seinem Umfeld ignoriert. Wie kann es also $\mathrm{zu}$ einer besonnenen Verarbeitung von äußeren Einflüssen kommen, wenn direkte Steuerung zu Abschottung führt? Wo ist ein Ort und eine regelmäßige Zeit, in der Ideen zur weiteren Entwicklung Ihrer Schule diskutiert, systematisiert und umsetzungsreif präsentiert werden?

\subsection{Schulische Beispiele für die fünf Dimensionen}

Das Modell der Lernenden Organisation liegt meiner Gesamtdarstellung zugrunde, als umfassendes Makro-Modell, in das sich viele nützliche Meso- und MikroModelle einfügen lassen. Zwei interessante Darstellungen zur Lage der Schulen im deutschsprachigen Raum zeigen, wie die fünf Dimensionen konkretisiert werden könnten: Tabelle 1.

Tabelle 1: Zwei Beispiele zur Konkretisierung der fünf Dimensionen einer Lernenden Organisation

\begin{tabular}{|c|c|c|}
\hline $\begin{array}{l}\text { Peter Senge (1998) Die } \\
\text { 5. Disziplin; Definitionen: }\end{array}$ & $\begin{array}{l}\text { Jürgen Kluge: Wege aus der } \\
\text { Bildungsmisere, 2003! }\end{array}$ & $\begin{array}{l}\text { Klaus Scala: Supervision in } \\
\text { der Schule, 1997! }\end{array}$ \\
\hline $\begin{array}{l}\text { Vision / Ziele: } \\
\text { gemeinsam entwickeln, nicht } \\
\text { von oben verordnen. }\end{array}$ & $\begin{array}{l}\text { Schule als Lern- und Lebens- } \\
\text { raum verstehen: Frühförderung, } \\
\text { Ganztagsschulen, kürzere } \\
\text { Schulzeit, Straffung der } \\
\text { Studiengänge. }\end{array}$ & $\begin{array}{l}\text { Schule als Expertenorganisa- } \\
\text { tion für relevante Lernprozesse; } \\
\text { Professionalisierung des } \\
\text { Lehrerberufs; Qualifizierung } \\
\text { der Leitungsrolle; Schule ist } \\
\text { verantwortlich für ihre eigene } \\
\text { Entwicklung. }\end{array}$ \\
\hline $\begin{array}{l}\text { Mentale Modelle: } \\
\text { Annahmen, Bilder, Symbole, } \\
\text { nach denen wir die Welt } \\
\text { wahrnehmen und in ihr } \\
\text { handeln. }\end{array}$ & $\begin{array}{l}\text { Bildung ist nicht als Kostenfak- } \\
\text { tor, sondern als Investition zu } \\
\text { verstehen. Lehrerrolle: Mentor, } \\
\text { Experte für Lernprozesse. } \\
\text { Schwache fördern, Starke } \\
\text { fordern: Früh investieren; } \\
\text { soziale Gerechtigkeit, } \\
\text { Autonomie als Orientierung. }\end{array}$ & $\begin{array}{l}\text { Schulklasse ist Ort sozialen } \\
\text { Lernens. Hauptrolle der Schul- } \\
\text { leitung: soziale Architektin. } \\
\text { Konferenzen orientieren sich } \\
\text { an sinnvoller Nutzung der } \\
\text { Ressourcen der Teilnehmenden. } \\
\text { Denken in Strukturen statt } \\
\text { Schwierigkeiten einseitig mit } \\
\text { persönlichen Defiziten zu } \\
\text { erklären. }\end{array}$ \\
\hline $\begin{array}{l}\text { Team-Lernen: } \\
\text { Mit der Weisheit der Gruppe } \\
\text { rechnen und sie nutzen. }\end{array}$ & $\begin{array}{l}\text { Das Kollegium denkt für das } \\
\text { Ganze: Arbeit am System; } \\
\text { hohe Eigenverantwortlichkeit. } \\
\text { Abschied von Frontalunterricht } \\
\text { und 45-Minuten-Einheiten. } \\
\text { Kooperation mit SchülerInnen, } \\
\text { Eltern und externen Institutio- } \\
\text { nen. }\end{array}$ & $\begin{array}{l}\text { Einrichtung von Lehrerteams } \\
\text { pro Klasse; die einzelnen } \\
\text { Klassen sind Subunternehmen } \\
\text { unter einem gemeinsamen } \\
\text { Dach. Aufbau einer Feedback- } \\
\text { Kultur, in der gemeinsam und } \\
\text { voneinander gelernt wird. }\end{array}$ \\
\hline
\end{tabular}




\begin{tabular}{|c|c|c|}
\hline $\begin{array}{l}\text { Peter Senge (1998) Die } \\
\text { 5. Disziplin; Definitionen: }\end{array}$ & $\begin{array}{l}\text { Jürgen Kluge: Wege aus der } \\
\text { Bildungsmisere, 2003! }\end{array}$ & $\begin{array}{l}\text { Klaus Scala: Supervision in } \\
\text { der Schule, 1997! }\end{array}$ \\
\hline $\begin{array}{l}\text { Personal Mastery: } \\
\text { Die persönliche Vision ständig } \\
\text { klären und geduldig und } \\
\text { professionell an den relevanten } \\
\text { Zielen arbeiten. }\end{array}$ & $\begin{array}{l}\text { Lehrerin versteht sich als } \\
\text { Expertin für individuelle } \\
\text { Förderung, lernt lebenslang. } \\
\text { Schulleiterin ist Bildungsmana- } \\
\text { gerin (Personal, Finanzen, } \\
\text { Managementtechniken, } \\
\text { Öffentlichkeitsarbeit). } \\
\text { Fortbildungsverpflichtung } \\
\text { für alle. Auswertungen } \\
\text { anhand von überprüfbaren } \\
\text { Qualitätsmaßstäben. }\end{array}$ & $\begin{array}{l}\text { Schulleitung ist soziale } \\
\text { Architektin für kommunikati- } \\
\text { onsfördernde Strukturen mit } \\
\text { dem Ziel, konkrete Aufgaben } \\
\text { zu lösen. }\end{array}$ \\
\hline $\begin{array}{l}\text { Systemdenken: } \\
\text { die integrative Disziplin, } \\
\text { die alle Einzeldisziplinen } \\
\text { miteinander verknüpft. }\end{array}$ & $\begin{array}{l}\text { Es geht nicht um Einzelrepa- } \\
\text { raturen, sondern um einen } \\
\text { Systembruch: Nationale } \\
\text { Bildungsstandards (Mindest- } \\
\text { kriterien); Schulinspektionen } \\
\text { sollten Konsequenzen haben. }\end{array}$ & $\begin{array}{l}\text { Autonome Schulen bekommen } \\
\text { Entscheidungskompetenz. } \\
\text { Binnenstrukturen werden } \\
\text { ausdifferenziert. Die Qualifizie- } \\
\text { rung von Leitungskräften greift } \\
\text { zu kurz, wenn nicht zugleich } \\
\text { in die Strukturentwicklung } \\
\text { investiert wird. }\end{array}$ \\
\hline
\end{tabular}

\subsection{Internationale Erfahrungen mit dem Modell in Schulen}

Senge $(1998,14)$ unterscheidet Erfindung und Innovation: Eine Erfindung funktioniert im Labor. Zur Innovation wird sie, wenn sie in angemessener Stückzahl zu vernünftigen Kosten zuverlässig reproduziert werden kann. Mehrere Komponenten müssen sich zusammen fügen, so z. B. bei dem ersten erfolgreichen Verkehrsflugzeug, der DC-3: Verstellpropeller, einziehbares Fahrgestell, leichte Schalenbaukonstruktion, luftgekühlter Sternmotor und auftriebserhöhende Klappen. Alle fünf Bestandteile waren notwendig, vier hätten nicht ausgereicht. Nach dieser Definition ist eine Lernende Organisation bislang eine Erfindung, aber noch keine Innovation.

Senges Buch erschien 1990 in Deutschland. Kluge und Scala schrieben ihre Forderungen der wünschenswerten Schulveränderungen deutlich später. Jetzt, ca. 30 Jahre danach, kann von einer selbstverständlichen Innovation in Senges Sinn in deutschen Schulen noch immer keine Rede sein. Das gilt auch weltweit. M. Kools und L. Stoll publizierten im Jahr 2016 zum internationalen Stand der Dinge ihre Studie: What Makes a School a Learning Organisation? Demnach hat das Konzept starke internationale Resonanz gefunden; seine wirksame Realisierung lässt jedoch weithin zu wünschen übrig. Der kanadische Erziehungswissenschaftler M. Fullan bestätigt das. Eins seiner Beispiele: Eine amerikanische Stiftung investierte 40 Millionen Dollar in die Schulen von vier mittelgroßen Städten. Das Urteil nach drei Jahren: „Das Programm hat so gut wie keine grundlegenden Veränderungen, weder im Lernstoff noch in der Geisteshaltung ... der Schulen ausgelöst." (Fullan 1999, 86 ff). Fullan sieht eine Reihe von Problemen bei der Umsetzung des Modells und leitet daraus wichtige Empfehlungen ab. Seine wichtigsten Punkte: 
- Wer Schulentwicklung betreibt, muss sich auf einen langfristigen Prozess einstellen, der viel Geduld und Beharrlichkeit erfordert.

- Die Schulleitung spielt dabei eine entscheidende Rolle.

- Die Aufgabe ist so komplex, dass eine einzelne Person sie nicht bewältigen kann.

- Alle wünschenswerten Veränderungen haben nur Bestand, wenn sie dauerhaft von den Beteiligten gewollt und getragen werden, also vor allem von den Lehrkräften.

Das leitende mentale Modell müsste darin bestehen, dass alle Beteiligten sich als Veränderungsexperten nicht nur verstehen, sondern sich auch als solche qualifizieren. Effektive Arbeit im Team muss das Einzelkämpfertum ablösen. Das Modell nennt an erster Stelle die Notwendigkeit einer gemeinsam geteilten Vision von der jeweiligen Schule. Doch sollte dieser Punkt keinesfalls zu Beginn des Prozesses angegangen werden. Vorgaben aus höherer hierarchischer Position, „Topdown-Lösungen“, scheitern allesamt. Sollten ausgerechnet Lehrexperten an einer Belehrungsallergie leiden? (Näheres dazu s.u. Anm. 46.)

Aus den von Kools und Stoll untersuchten Schulen kommt die Rückmeldung, das Modell sei zu vage. ${ }^{10}$ Für eine Reihe von Fragen fehlten klare Antworten, z. B.:

- Wie sind die Dimensionen, um die es geht, zu konkretisieren?

- Was genau sollten Lehrkräfte lernen, wenn es um lebenslanges Lernen geht?

- Wie kann man aus einer Gruppe von Einzelkämpfern ein Team bilden?

- Wie kann ein ganzes System sich zu einem Veränderungsprozess bereit finden, wenn komplexe Systeme nicht direkt steuerbar sind?

- Wie kann eine Schulleitung die nötige Ambiguitätstoleranz, die Ausdauer, die Kontaktfähigkeit, die Begeisterung, den Überblick entwickeln, die für eine so lange Reise mit so vielen zu erwartenden Störfällen nötig sind?

Das Modell beantwortet diese Fragen nicht. Die Forscher und Forscherinnen beschreiben die Schwierigkeiten und die wünschenswerten Notwendigkeiten. Hinweise darauf, wie all dies konkret zu lehren und dann auch umzusetzen ist, habe ich nicht gefunden. Und eine weitere Frage ist zu klären:

Wie kann ein Modell für alle sinnvoll sein und trotzdem jede Schule in ihrer Besonderheit und Einzigartigkeit fördern?

Im Nachwort zu Fullans Buch zitiert R. Kahl (nach dem Besuch der erfolgreichen kanadischen Modellschule in Durham) einen Staatssekretär aus einem deutschen Kultusministerium, der in Durham mit dabei war: ,Wenn wir vom Staat her mehr Gestaltungsfreiheit geben, wird das von vielen Lehrern schon wieder als Zumutung, die von oben kommt, begriffen. Diese Grundhaltung ist in Deutschland sehr schwer zu verändern. Es wird alles als etwas von außen Gesetztes wahrgenom-

10 „However, though the concept of the school as learning organisation, also known as the learning school, has managed to inspire the hearts and minds of a steadily growing body of scholars, educators and policy makers all over the world for around 25 years, relatively little progress has been made in advancing the concept - either in research or practice. This lack of progress partly stems from a lack of clarity around the concept.“ (Kools and Stoll 2016, 10) 
men und nicht als eigener Anspruch, für den ich jetzt Raum kriege.“ (Fullan 1999, 255) Schulentwicklung kann demnach nur gelingen, wenn die Lehrkräfte sie als ihre eigene Sache verstehen. Und Sie, die Schulleitung, sind gefragt, wie Sie dies Verständnis wecken und fördern können. Alles Weitere soll Ihnen dabei nützlich sein. Warten auf Godot hilft nicht.

\subsection{Konkretisierung der fünf Dimensionen durch Meso- und Mikro-Modelle}

Die genannten Schwierigkeiten lassen sich lösen, wenn die fünf Makro-Dimensionen einer Lernenden Organisation mit vielen Meso- und Mikro-Konzepten kombiniert werden. Dass diese Modelle zur Konkretion zu vage seien, hat in unseren Kursen niemand eingewandt. Dass sie anspruchsvoll sind, Konzentration, Umdenken, Lernen und Mut in der Umsetzung, Arbeit an persönlicher Meisterschaft erfordern - das allerdings wird deutlich empfunden.

Die einschlägige Fachliteratur legt nahe, den Schulentwicklungsprozess da beginnen zu lassen, wo die Hauptverantwortung liegt: bei Ihnen, bei der Schulleitung. Also bei der Dimension ,persönliche Meisterschaft“. Und da wiederum nicht mit vorschnellem Aktionismus, sondern mit dem Studium des Modells, mit sorgfältiger Wahrnehmung und Analyse Ihrer Schule und mit der Bereitschaft, mit dem Lernen bei sich selbst anzufangen. Die einzelnen Konzepte lassen sich verständlich darstellen. Wirksam werden sie nur, wenn Sie sie im Verbund praktizieren. EinFaktor-Lösungen sind zu einfach.

Kluge (2003) setzte vor allem auf politische Maßnahmen, auf strukturelle Veränderungen (s.o. 2.2). Schön, wenn die richtigen Politiker sein Buch läsen. Angesichts der seit Kluges Buch verstrichenen, bildungspolitisch wenig genutzten Zeit setze ich eher auf Scala (1997), also auf gemeinsames Lernen, vor allem auf Lernen der Schulleitungen im Rahmen von Fort- und Weiterbildung, Coaching, Intervision.

Kurt Lewin meinte: „Wenn Du eine Organisation verstehen willst, ändere sie“. Die unweigerlich auftauchenden Schwierigkeiten kann ich resignativ verarbeiten; ich kann sie auch als Lernchancen sehen. Schwierigkeiten in der Praxis lassen sich mit Humor und überlegter Selbstorganisation - als Fortsetzung der Weiterbildung im Alltag verstehen, wenn es Ihnen gelingt, immer wieder einmal innezuhalten, sich zu besinnen und die Hürden des Alltags als Training für Ihre persönliche Meisterschaft aufzufassen.

Der Aufbau der weiteren Darstellung ergibt sich von selbst: Einstieg mit persönlicher Meisterschaft, Fortsetzung mit Teamlernen, dann erst Arbeit an einer gemeinsamen Vision und anschließend an Systemaspekten. Wenn das gelingt, müssten sich unterwegs auch immer wieder hinderliche mentale Modelle gezeigt und hoffentlich verflüchtigt haben. Alle Dimensionen stelle ich aus Ihrer Perspektive dar, aus der Leitungsperspektive. Ihre Kompetenz ist vor allem gefragt, wenn Ihre Schule in allen fünf Dimensionen stark werden soll. 


\section{Lesetipp}

M. Rasfeld (2012): EduAction. Wir machen Schule.

Die Autorin berichtet über ihr Lebenswerk: eine Schule, die sich konsequent auf individuelle Förderung der Schülerinnen und Schüler konzentriert: Lernbüro, Verantwortungsprojekte, Herausforderungen sind highlights.

Hiebl und Seitz (2014): 2.1 und 2.2 



\section{Kapitel 3: Systemdenken: \\ Leitungsrolle und Schulentwicklung}

Wenn Sie aus dem Kollegium heraus in einer Schule ein Leitungsamt übernehmen, ändert sich etwas auf der Beziehungsebene, obwohl Sie selbst sich gar nicht verändert fühlen. Waren Sie vor kurzem noch Kollege oder Kollegin, so ersterben jetzt die Plaudereien, sobald Sie das Lehrerzimmer betreten. Durch Ihren Rollenwechsel stehen plötzlich auch Ihre bisherigen Beziehungsmuster in Frage: Lässt die neue Chefin jetzt ihre Leitungsposition heraushängen? Kommt sie mit Anforderungen? Lässt sie uns ihre Positionsmacht spüren? Muss man sich jetzt gut mit ihr stellen? Als ehemalige Kollegin, jetzt in der Leitungsrolle, fragen Sie sich: Gehöre ich nicht mehr dazu? In verschärfter Form spielen solche Fragen eine Rolle, wenn jemand von außen in ein Kollegium kommt. Wie nimmt die neue Chefin, der neue Chef Kontakt auf? Der erste Eindruck prägt enorm. Alle duzen sich - und die Leitung? Betont sie den Abstand? Leitung macht einsam, sagt man. Wie kommt der Neue, die Neue damit zurecht?

\subsection{Selbststeuerung in Privatrolle, Fachrolle und Leitungsrolle}

Bernd Schmid (1994, 55 ff) hat ein instruktives Rollenmodell entworfen, das weitere Überlegungen zum Verständnis der Leitungsrolle anregt. Er unterscheidet zwischen drei „Welten“, die unterschiedliches Rollenverhalten prägen und die als Privatrolle, Professionsrolle und Organisationsrolle gelebt werden (Grafik 1).

Grafik 1: Drei-Welten-Modell

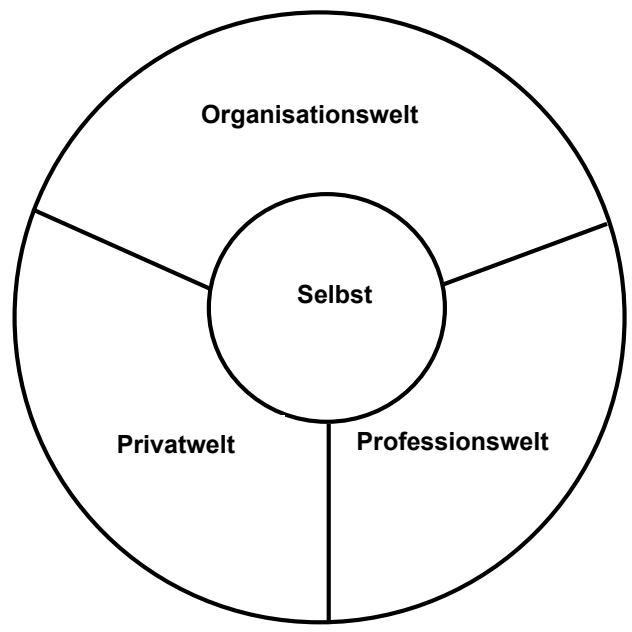

Ein Beispiel aus einem nichtschulischen Bereich: Ein Chirurg hat die Professionsrolle Operateur gelernt; da ist er Fachmann, da kennt er sich aus und beherrscht sein Handwerk; irgendwann wird er Oberarzt. Geht sein Chef in den Ruhestand 
oder wechselt er die Stelle, wird manchmal der Oberarzt Nachfolger. Jetzt hat er eine Klinik zu leiten und muss in die Organisationsrolle Führungskraft wechseln, die ganz andere Kenntnisse, Einstellungen und Verhaltensweisen erfordert als die Fachrolle Operateur.

Fredmund Malik (2006) hält das für einen so gravierenden Unterschied, dass er die Leitungsrolle in einer Organisation, in einem Unternehmen, in einem Krankenhaus für einen eigenen Beruf hält, mit eigenen Aufgaben, Grundsätzen und Werkzeugen. Von einer gewissen Systemgröße an sind die Leitungsaufgaben so umfangreich und komplex, dass sie den größten Teil der Arbeitszeit beanspruchen und die Fachrolle zeitlich entsprechend einschränken. 2017 konstatiert Rolff: „Weitgehende Übereinstimmung besteht darin, dass Schulleitung ein eigener Beruf ist...“, zu dem u. a. folgende Kernkompetenzen gehören: Strategie-Entwicklung, ProzessSteuerung, Kooperations- und Konfliktkompetenz und Management-Kompetenz. Im Blick auf diese anspruchsvollen Tätigkeiten benötigen Schulleitungen darum mehr Leitungszeit, vor allem die Grundschulleitungen (Rolff 2017, 24. 49)

\subsection{Leitungsrolle und Schulorganisation}

Trotz der wesentlichen Unterschiede zwischen Fachrolle und Organisationsrolle bleibt das Gelingen des Rollenwechsels meist dem autodidaktischen Geschick der einzelnen Leitungsperson überlassen. Dann wirkt sich aus, wie Sie selbst in Ihrer beruflichen Biographie prägende Leitungspersonen erlebt haben, welche Aspekte als Vorbild taugen und welche eher als abschreckendes Beispiel. Überlegen Sie einen Moment: Welche Modelle kommen Ihnen aus Ihrer beruflichen Laufbahn in den Sinn? Wen haben Sie bewundert? Unter wem haben Sie gelitten? Woran lag das jeweils?

Ein Modell wird eher nachgeahmt, wenn die Beziehung zu ihm gut ist, wenn es Autorität verkörpert und wenn es mit seinem Verhalten Erfolg hat. Wenn wir uns im Weiterbildungskurs Zeit für diese Fragen nehmen, werden vor allem Beziehungsaspekte genannt, persönliche Qualitäten wie Offenheit, Wertschätzung, Empathie. Der Blick richtet sich eher auf kulturelle Merkmale, kaum dagegen auf strukturierende Kompetenz.

Beziehungsfähigkeit ist in einer Schule absolut wesentlich, hilfreich und wichtig. Aber Vorsicht, falls Sie einfach das Gegenteil von abschreckenden Modellen praktizieren möchten. Mit einem Bonmot von B. Schmid (2016): Auf der anderen Seite vom Pferd gefallen ist auch nicht geritten! Wenn Sie sich einseitig auf Beziehungsaspekte konzentrieren, übersehen Sie leicht die mit der Leitungsrolle verbundenen Strukturierungsaufgaben.

In der Leitungsrolle ist über die Beziehungsaspekte hinaus Ihr Blick aufs Gesamtsystem gefordert. Hohe Priorität hat jetzt, in der Organisationsrolle, die Arbeit am System, weniger (nach Malik überhaupt nicht!) die Arbeit im System. „Gute Schulleitungen arbeiten an der Schule, weniger gute nur in der Schule.“ (Rolff 2017, 23) ${ }^{11}$

11 Aufgabe der Schulleitung ist nicht primär die Einführung einzelner Innovationen, sondern der Aufbau einer „Kapazität für Wandel“. Es geht dabei „,um die Weiterentwicklung der ganzen 
Blickt man mit diesem Modell auf die Leitung einer Schule, so wird schnell klar: Eine Schulleitung, die ihre Fachrolle beherrscht, die guten Unterricht gibt, die macht nicht zwingend eine gute Schule! Sie braucht jetzt, spätestens jetzt, Ideen, wie Arbeit am System zu verstehen ist, was dazu gehört, wie man ein System überhaupt steuern kann und wohin die Reise gehen sollte.

Eine besondere Schwierigkeit kommt in so gut wie allen „freien“ Schulen hinzu. Die Leitungsperson muss zusätzlich zur Leitungsaufgabe auch noch unterrichten, z. T. mit erheblichem Zeitaufwand. Manche Schulleitungen müssen mit zehn Leitungsstunden („Abminderungsstunden“) ein großes Schulsystem leiten. Dieser Spagat zwischen Fach- und Organisationsrolle ist nach Malik eine strukturelle Schieflage, die sich zu Lasten der Konzentration auf die Leitungsaufgabe auswirkt und die verrät, dass die Anforderungen an die Leitungstätigkeit von Schulträgern massiv unterschätzt werden.

Wie Sie dabei vermeiden können, sich selbst zu überfordern und über kurz oder lang ins Burnout zu rutschen, bleibt Ihnen selbst überlassen. Insofern ist bewusstes und gekonntes Selbst- und Zeitmanagement für Sie eine ernsthafte Überlebensfrage. Es geht nicht nur um Ihre physische und psychische Gesundheit, sondern auch um das Ziel, genügend Zeit und Spielraum für die Arbeit am System zu gewinnen.

Mit den beruflichen Anforderungen stellt sich die Aufgabe, sich ,,selbst“ in wechselnden Rollen zu steuern, nicht nur für die Führungskräfte an der Spitze einer Organisation. Organisations-, Fach- und Privatrolle enthalten jeweils eine Fülle von Teilrollen: In der Privatrolle bin ich Mutter oder Vater, Sohn bzw. Tochter, Partnerin, Partner, Freund, Freundin, Fußballkumpel, Mitglied eines Chors usw. In der Professionsrolle Lehrerin bin ich Expertin für mehrere Fachgebiete, aber auch für Didaktik, Pädagogik usw.

Die Organisationsrolle umfasst viele Teilrollen: Vertretung der Schule nach außen, Personalarbeit, Leitung von Teams, von Fachkonferenzen, Moderation von Fallgesprächen usw. Insofern wäre es fatal, wenn nur eine oder zwei Personen den Blick aufs Ganze richten, sich als Leitende verstehen. Alle müssen Leitungsverantwortung wahrnehmen, wenn die Schule eine Lernende Organisation sein will, aber nicht alle in derselben Weise. Schulentwicklung kann nur gelingen, wenn alle Beteiligten sich über ihre Fach- und Privatrolle hinaus auch ihrer spezifischen Organisationsrolle immer klarer bewusst werden. Da das nur selten vorausgesetzt werden kann, ist es in Ihrem wohlverstandenen persönlichen Interesse, diesen Punkt im Blick zu behalten, sich selbst also nicht zu überfordern.

Die Art, wie die drei Rollenaspekte gelebt werden, ist immer persönlich gefärbt; die Person mit ihrer biographisch geprägten Identität scheint mehr oder weniger durch. ${ }^{12}$ Person bzw. Selbst verstehe ich als lebensgeschichtliche Prägung, als

Schule zur lernenden Organisation. Kapazität für Wandel bedeutet in diesem Fall ,Kapazität für Schulentwicklung ““. (Rolff 2017, 23; Näheres dazu s.u. 7.4)

12 Schmid $(1994,56)$ unterscheidet zwar begrifflich das Selbst bzw. die Person von den drei Rollen, betont aber: „Das Modell sieht vor, daß der Mensch nur durch seine Rollen in seinem Menschsein existieren und erfahren werden kann.“ 
prozesshafte, dauernd sich weiter entwickelnde Identität. Damit stellt sich zugleich die Frage, wie mein gewachsenes „Selbst“ zu meinen unterschiedlichen Rollen, insbesondere aber zu meiner Leitungsrolle „passt“, wie es mein Rollenverhalten prägt und auch, wie meine Erfahrungen in der Rolle mein Selbst beeinflussen. So fordert die Leitungsrolle z. B., in bestimmten Konflikten im Interesse der Organisation Schule regulierend oder auch konfrontierend einzugreifen, auch wenn mir ,persönlich“ Konflikte unlieb sind. Das ist zugleich die Chance, mich „selbst“ in diesem Verhaltensbereich weiter zu entwickeln. Angstbedingte Konfliktvermeidung dagegen schädigt auch die Organisation.

\subsection{Systemdenken: Arbeit am System Schule}

Leitungskräfte, mit denen wir gearbeitet haben, reagieren sehr angeregt auf das Modell; einige Äußerungen:

- In Schulen bleibt die Arbeit im System (Unterricht) wichtig, um fachlich urteilsfähig zu bleiben, aber auch, weil die Abminderungsstunden für die Leitungsaufgabe zu knapp bemessen sind.

- Die Fachrolle ist oft verführerisch, weil sie als sicherer erlebt wird.

- Wenn private Interessen, z.B. persönliche Freundschaften, mit der Organisationsrolle in Konflikt geraten, ist es wichtig, die Entstehung destruktiver „Spielregeln“ zu verhindern. Die Leitung sollte ein klares unbestechliches Gegenüber bieten.

- Die Organisationsrolle kann mehr Konfliktbereitschaft erfordern, als dem Selbst lieb ist. Es gibt Persönlichkeitstypen, die Konflikte für ihr tägliches Adrenalin brauchen. Die Mehrheit empfindet anders.

- Die Charakteristika der Person, des Selbst, färben die Wahrnehmung der Rollen; sich selbst gut zu kennen hilft, sich in der professionellen Rolle bewusst zu steuern.

- Es ist wichtig, als Person erkennbar zu sein. Andernfalls würde ich nicht als authentisch erlebt, als jemand, der oder die nicht zu sich selbst steht und sich selbst nicht zeigen mag.

Arbeit am System - diese Aufgabe entspricht der fünften Dimension des Modells der Lernenden Organisation, dem Systemdenken. Aber Vorsicht! Wenn Sie als neue Schulleitung voranpreschen und gleich am System herumschrauben, provozieren Sie vermutlich Widerstand. Der Versuch, das ganze Kollegium an Schulentwicklung zu beteiligen, wird durchweg als zusätzliche Belastung erlebt. Einige haben das probiert und von der Resonanz berichtet: „Wie, das sollen wir auch noch machen? Soll doch die Leitung ...!" Und schon liegt es nahe, über das Verständnis der Lehrerrolle zu streiten: Experte für zwei, drei Fächer - reicht das nicht? Jetzt auch noch Experte für Lernprozesse und für Pädagogik? „Erziehung ist Sache der Eltern!" So geht die Abwehrschlacht weiter.

Ein Grüppchen Gutwilliger, das solche Blockaden überwinden möchte, kommt dann auf die rettende Idee: Wir brauchen Experten von außen, Beratung, Coaching, Fachleute für Schulentwicklung. Auch wir haben auf diesem Weg einige Schulen 
kennengelernt. Manche standen am Abgrund, manche produzierten tolle Ideen, die aber nicht umgesetzt wurden. Einige haben es geschafft, Schulentwicklung als ihre eigene Aufgabe zu akzeptieren, dafür geeignete Arbeitsformen zu schaffen und mit langem Atem diese Arbeit als fortlaufenden Prozess zu betreiben. Es ist mühsam, und es ist möglich. Bleiben Sie also besonnen. Ich wiederhole als Mantra: Gönnen Sie sich Zeit für Besinnung, arbeiten Sie nicht besinnungslos!

\subsection{Vertiefung: Sawu bona}

Sawu bona! Ich sehe dich. - Sikhona! Ich bin da.

Das ist die gebräuchlichste Grußformel bei den Stämmen der Provinz Natal in Südafrika. Solange ich nicht gesehen werde, existiere ich nicht. Indem Sie mich wahrnehmen, erwecken Sie mich sozusagen zum Leben. (Senge 1997, 3)

Gesehen werden verleiht Ansehen. Schüler möchten gesehen werden. Lehrer, Lehrerinnen werden gesehen, täglich, stündlich. Wie wollen sie gesehen werden? Und Leitungsverantwortliche sollen alle sehen - und wollen auch gesehen werden. Wie wollen Sie gesehen werden, wenn Sie Leitungsverantwortung ausüben? Ansehen steht für Autorität: Welche Autorität schreibt man Ihnen zu? Fachlich kompetent? Mitreißende Charismatikerin? Postenfixierter Formalist?

Eine biblische Szene, Jesus unterwegs. Ein Blinder schreit am Wegrand um Erbarmen. Die Leute darauf: Halt die Klappe! Jesus will wissen, worum es geht: „Was willst du, dass ich dir tun soll?“ (Markus 10, 46ff). Antwort: „Herr, dass ich wieder sehen kann. "Biblische Texte sind oft doppelbödig. Es gibt immer mal Leute, die nicht wollen, dass uns die Augen aufgehen.

Autoritäten sehen und sehen manchmal doch nicht. Ein Priester unterwegs in den Feierabend trifft unterwegs auf einen Überfallenen, der halbtot am Weg liegt. „Da er ihn sah, ging er vorüber.“ Ein Levit desgleichen: „Da er ihn sah, ging er vorüber. “ Dann ein Ketzer, gleiche Situation: „Da er ihn sah, fuhr es ihm in die Gedärme. "Eine heftige physiologische Reaktion. So die Erzählung vom barmherzigen Samariter (Lukas 10, $25 \mathrm{ff}$ ).

Wie sehe ich mich selbst? Wie rede ich mit mir? Das Sirachbuch warnt: „Sprich nicht: Der Herr sieht nach mir nicht! “ (16,15) Rede dich nicht selbst ins Abseits, ins Aus! „Der Mensch sieht, was vor Augen ist“, auch wenn er sich selbst ansieht; „, Gott aber sieht das Herz an. “(1. Samuel 16,7) Wir haben nicht das letzte Wort, nicht über andere und nicht über uns selbst:

„, Sähest du mich / mit meinen Augen, / du sähest mich / nicht. “ (Peter Hamm) ${ }^{13}$

13 „Was für ein Mensch ich in Wahrheit bin, darüber kann keine weltliche Instanz entscheiden. Darüber kann nicht einmal ich selbst entscheiden. Das Urteil über das Sein der Person ist allen irdischen Personen und Instanzen entzogen.“ „In den Augen anderer Menschen mag ich zwar das sein, was ich aus mir mache oder gemacht habe. Sogar mir selbst mag ich als Produkt meiner Taten erscheinen. Doch vor Gott bin ich schlechterdings nicht in der Lage, etwas aus mir zu machen." (Jüngel 1990, 205 mit Bezug auf Luthers Disputation gegen die scholastische Theologie 1517). 


\section{Lesetipp}

Covey (1995): Die sieben Wege zur Effektivität

Sehr persönlich geschriebenes Buch, das Ihnen helfen kann, Ihre eigene Vision von Leitung zu präzisieren. Die Logik der ersten drei Wege beeindruckt mich besonders. Ich kann nur dann Prioritäten setzen, wenn mir meine Ziele klar sind. Ich kann mir nur Ziele vornehmen, wenn ich mich als selbstwirksam wahrnehmen kann. Ich kann nur selbstwirksam sein, wenn ich mir meine Einflussmöglichkeiten klar mache, wenn ich mich als proaktiv verstehe. Mit diesem Verständnis von Proaktivität fängt alles an.

Hiebl und Seitz (2014): 3.3 


\section{Kapitel 4: Persönliche Meisterschaft: Zuhören und zum Denken bringen}

Als ich mich 2001 auf den Weiterbildungskurs für Schulleitungen vorbereitete, habe ich mir bekannte Lehrerinnen und Lehrer gefragt: Was sollten Schulleitungen vor allem lernen? Unisono bekam ich die Antwort, das Wichtigste sei das Zuhören. Ein guter Tipp. Gesprächsführung, Beratungskompetenz, Coaching wird im Kurs von Anfang an geübt, von Mal zu Mal detaillierter und komplexer. Kompetenz in Gesprächsführung ist grundlegend für persönliche Meisterschaft. Die gute Nachricht: Man kann sie lernen.

\subsection{Alltagsbeispiel Cappuccino}

In unserer Lokalzeitung ${ }^{14}$ stand eine amüsante Randnotiz aus dem Bereich Gastronomie, eine Szene in einem sommerlichen Straßencafé. Ich habe aus dem kleinen Text einen Dialog gemacht, als Einstieg in das Thema Gesprächsführung:

Kunde: Ich hätte gern einen Cappuccino!

Kellnerin: Ähh... (Schaut den Kunden an, als ob das ein Problem wäre.)

Kunde: Kann ich bei Ihnen nicht bestellen?

Kellnerin: Doch, aber das muss ich Ihnen extra aufschreiben.

Kunde: Extra? Extra zu was?

Kellnerin: Ich dachte, Sie sitzen schon länger hier?

Kunde: Ich sitze auch schon länger hier.

Kellnerin: Ja, dann geht das extra.

Kunde: Heißt das, das wird teurer?

Kellnerin: Ja, ein Cappuccino ist nicht inbegriffen.

Kunde: In was inbegriffen, im hier Sitzen?

Kellnerin: Nein, in Ihrem Frühstück.

Kunde: Ich hatte doch gar kein Frühstück.

Kellnerin: Sie sagten doch, Sie sitzen schon länger hier.

Kunde: Ja, aber ohne Frühstück. Ich hatte noch nichts bestellt.

Kellnerin: Also dann ein Frühstück für Sie und einen Cappuccino extra?

Kunde: Nein, nur einen Cappuccino! Meinetwegen schreiben Sie ihn auch extra auf. Hauptsache, das wird dadurch nicht teurer.

Was war da los? Im Kurs ist das schnell analysiert: Kunde und Kellnerin gehen von unterschiedlichen mentalen Modellen aus. Die Sicht der Kellnerin: Der Kunde sitzt da schon länger, hat sein Frühstück immer noch nicht bekommen; dann wird das wohl Zeit; und jetzt will er auch noch einen Cappuccino, also mit Aufschlag. Der Kunde aber will gar kein Frühstück und muss echt kämpfen, bis er verstanden wird. 
Als Kontrast dazu lassen wir eine zweite Version folgen:

Kellnerin: Guten Tag, was hätten Sie gern?

Kunde: Ich hätte gern einen Cappuccino.

Kellnerin: Einen Cappuccino, gern. Sie hatten sonst noch gar nichts bestellt?

Kunde: Nein. Ich sitze zwar schon länger hier ...

Kellnerin: Oh, tut mir leid. Möchten Sie denn noch etwas außerdem?

Kunde: Danke, nein, nur einen Cappuccino!

Kellnerin: Kein Frühstück?

Kunde: Kein Frühstück. Nur einen Cappuccino.

Kellnerin: In Ordnung, kommt sofort.

Die Unterschiede sind offensichtlich. Die Kellnerin nimmt von sich aus Kontakt auf, zeigt Interesse am Wunsch des Kunden. Sie wiederholt seinen Wunsch und klärt, dass es dem Kunden nicht um ein „Frühstückspaket“ geht. Sie bedauert, dass er warten musste und vergewissert sich nochmals, dass wirklich nur ein Cappuccino gewünscht wird. Auffällig: Durch genaues Zuhören wurde das Gespräch kürzer und die Stimmung entspannt. So folgt als paradoxes Motto: Langsamer ist - manchmal - schneller!

Dazu gibt es ein interessantes Forschungsergebnis: Psychologen haben herausgefunden, dass das Trinkgeld in Restaurants signifikant erhöht ausfällt, wenn die Bedienung schlicht und einfach wörtlich wiederholt, was der Kunde bestellt. ${ }^{15}$ Durchaus nachvollziehbar: Der Kunde, die Kundin wird gehört, fühlt sich verstanden und wichtig genommen: Sawu bona - Ich sehe dich! - ganz praktisch. Meine Frau hat als Studentin gekellnert und dabei exakt diese Erfahrung gemacht: Um sich die Wünsche der Gäste besser merken zu können, hat sie alle Bestellungen wörtlich wiederholt. Und am Ende des Tages hatte sie deutlich mehr Trinkgeld als der lang gediente Profi - sehr zu dessen Verdruss.

\subsection{Hörprobleme}

Nach dieser kurzen Einführung stelle ich im Kurs die Aufgabe, Gruppen zu dritt zu bilden und drei Rollen zu verteilen: Eine Person soll ein eigenes Thema aus dem Leitungsalltag als „Klientin“ oder „Klient“ darstellen, kein besonders dramatisches, aber ein echtes Problem: Das ist die Rolle A. Rolle B soll zuhören, nur zuhören, von Zeit zu Zeit kurz in eigenen Worten das Gehörte zusammenfassen, aber partout keine Lösungen anbieten. Rolle C hat einzugreifen, wenn Rolle B aus der Rolle fällt und aus dem eigenen Erfahrungsschatz nun doch Lösungen anbietet. $^{16}$

15 Fundort: https://www.alltagsforschung.de/die-psychologie-von-trinkgeld

16 Covey $(1995,219 f)$ benutzt eine schöne Metapher, um uns den Unsinn dieser Lösungsfixierung bewusst zu machen. Stellen Sie sich vor, Sie hätten Probleme mit den Augen. Ihr Augenarzt hört sich das an, nimmt seine Brille ab und gibt sie Ihnen: „Die hilft mir schon 10 Jahre. Nehmen Sie sie. Ich habe zu Hause noch eine Ersatzbrille." - Sie setzen sie auf, 
Sich nur darauf zu konzentrieren, das Gehörte zu verstehen, ohne es zu kommentieren, zu interpretieren, Ratschläge anzubieten - das ist für die meisten Teilnehmenden eine enorme Hürde. Wieso? Weil sie, wie sie selbst in der Auswertung feststellen, sich sofort unter Druck setzen, eine Lösung für ihr Gegenüber zu ersinnen und ihm die anzudienen. Innere Botschaften verhindern die Konzentration auf die andere Person: Streng dich an! Sei gefällig! Sei zu Diensten! Löse das Problem für den anderen! Es ginge darum, sich von den eigenen Lösungsideen in Freiheit zu lösen. Wenn ich innerlich besetzt bin, gelingt es nicht, mich auf die Individualität, die Eigenart, das Anderssein meines Gesprächspartners zu konzentrieren. Eine hübsche Geschichte illustriert die Schwierigkeit dabei.

„Es heißt, daß die Inder sich beim Affenfang einer besonders geschickten Methode bedienen. Sie schneiden in das eine Ende einer Kokosnuß eine Öffnung, gerade groß genug für eine Affenhand, bohren zwei Löcher in das andere Ende, ziehen einen Draht hindurch und befestigen die Kokosnuß an dem Baum, auf dem der Affe hockt, den sie fangen möchten. Dann schieben sie eine Banane in die Kokosnuss und verstecken sich. Der neugierige Affe kommt alsbald vom Baum, steckt die Hand in die Kokosnuß, fühlt die Banane und packt sie. Das Loch ist so beschaffen, daß die schmale, ausgestreckte Affenhand zwar hineinpaßt, die zur Faust geballte Hand samt Banane aber nicht mehr herausgezogen werden kann. Er brauchte die Banane nur loszulassen, um wieder frei zu sein, aber die meisten Affen schaffen es einfach nicht, ihre Beute freizugeben." (KabatZinn 1998, 54)

Es ist ein mühsames Üben, sich von den brillanten eigenen Lösungsideen innerlich zu verabschieden und die Ohren in Freiheit nur auf Empfang zu stellen. Nur zuhören, das klingt so einfach. Man kann es lernen; es ist Handwerk. Indem Sie es üben, können Sie Erfahrungen mit der Innenseite des Zuhörens machen, mit der Freiheit, die eigenen Lösungsideen loslassen zu können. An die Affen denken! Andernfalls werten Sie die Fähigkeiten Ihres Gegenübers, selbst zu denken, selbst kreativ zu sein, ab; das sehen im Prinzip auch alle ein - und trotzdem!

\subsection{Relevanz des Zuhörens}

Umfragen zufolge halten sich 96 Prozent der Erwachsenen für gute Zuhörer. Aber Studien zeigen, dass wir uns nur ein Viertel von dem, was wir hören, auch merken können. Dummerweise haben die Gesprächspartner oft den Eindruck, dass noch weniger des Gesagten ankommt. ${ }^{17}$ Wer etwas zu sagen hat, muss zuhören können; sonst hört man auch ihm nicht zu. Wer aktiv zuhören kann, erzielt in Verhandlungen bessere Ergebnisse. Richtiges Zuhören ist harte Arbeit.

alles ist verschwommen. Der Arzt: „Bei mir funktioniert sie. Geben Sie sich etwas mehr Mühe.“ Nach einem weiteren Versuch: „Denken Sie positiv!“ Und schließlich: „Sie sind ja ganz schön undankbar - bei all der Mühe, die ich mir gebe." - Covey: Wie oft tun wir in der Kommunikation genau das? Und wie groß ist die Chance, dass Sie diesen Augenarzt nochmal konsultieren werden?

17 Fundort: ZEIT Online, 17. Februar 2016; Catarina Specht und Paige R. Penland; https://www. zeit.de/autoren/P/Paige-R__Penland/index 
Untersucht wurde auch, warum Mitarbeitergespräche in Organisationen oft scheitern. Die Ergebnisse (Walter 2000, 50): Führungskräfte hören nicht zu $(76,7 \%)$. Sie sind unter Zeitdruck $(67,4 \%)$. Sie sind voreingenommen $(48,8 \%)$. Sie suchen nach schnellen Patent-Lösungen $(39,5 \%)$. Sie fragen unstrukturiert $(39,5 \%)$. Sie erledigen nebenbei anderes $(32,6 \%)$.

Warum ist diese grundlegende Kompetenz so wichtig? Einige Punkte:

- Menschen wollen wahrgenommen werden. Sawu bona!

- Es tut gut und es schafft Vertrauen, wenn jemand zuhört, aufmerksam, um Verstehen bemüht, ohne Kritik, ohne voreilige Ratschläge.

- Unsere Beratungseinheiten vermitteln die ungewohnte Erfahrung, über die Schwierigkeiten des Leitens offen sprechen zu können, ohne dabei Besserwisserei zu erfahren. Erstaunlich schnell bildet sich so ein tragfähiges Wir-Gefühl in allen Gruppen.

- „Wofür wir Worte haben, darüber sind wir auch schon hinaus.“ (Nietzsche 1974, Nr. 26, 427) Indem ich ausspreche, was mich beschäftigt, bedrückt, belastet, gewinne ich bereits Abstand. Der Abstand hilft, weitere Aspekte zu erforschen.

- Probleme und Konflikte sind nicht lösbar, wenn wir aneinander vorbei reden.

- Mit Hilfe der fünf Dimensionen einer Lernenden Organisation und mit den zusätzlichen Meso- und Mikro-Konzepten lässt sich einkreisen, fokussieren, wo der Kern eines Problems sitzt. Das ermöglicht neues Nachdenken, neue Sichtweisen, kreative Ideen.

\subsection{Zuhören in ansteigender Schwierigkeit}

Zuhören können Sie lernen, vorausgesetzt, Sie scheuen die Mühe des Übens nicht. Die handwerkliche Seite können Sie in mehreren Stufen mit ansteigender Schwierigkeit praktizieren:

Stufe 1: Sie zeigen nonverbal, dass Sie sich auf die andere Person einstellen, indem Sie sich räuspern, „Mhmmm“ oder „Ach!“ sagen. Schon das ist wirksam. Wenn Sie in einem Telefonat nichts dergleichen von sich geben, wird die andere Person schon nach zehn Sekunden fragen: „Bist du noch da?“

Stufe 2: Sie fassen kurz zusammen, was Sie gehört haben, immer wieder, in passendem Abstand. Eine Kellnerin kann das ruhig wörtlich tun. In einem lebendigen Gespräch wirkt das papageienhaft. Also besser: Fassen Sie in Ihren eigenen Worten von Zeit zu Zeit kurz zusammen, was bei Ihnen angekommen ist. So hören Sie aktiv zu.

Beispiel: Jemand klagt in beredten Worten über die Passivität eines Teams. Mögliche Paraphrase: „Sie haben schon eine Menge probiert, wie Sie Ihre Leute aktivieren könnten, und Sie merken wenig Bewegung.“

Überfällt Sie jemand mit einem langen Wortschwall, dann stoppen Sie freundlich, z. B. so: „Entschuldigen Sie, wenn ich Sie unterbreche. Ich würde mich gern vergewissern, ob ich das Wichtigste mitbekommen habe." Und dann geben Sie Ihre Kurzfassung. So hören Sie in kleinen Schritten zu, sorgen für „Dosierung“ und überfordern sich nicht. 
Wenn einmal eine längere Schweigephase eintritt, bleiben Sie entspannt. Das fällt anfangs schwer, ist aber sinnvoll. Vermutlich denkt die andere Person nach. Genau das ist wünschenswert. Hält das Schweigen sehr lange an, können Sie nachhelfen, z. B.: „Sie wirken innerlich sehr beschäftigt. Mögen Sie etwas davon mitteilen?“ Etwas burschikoser: „Schalten Sie doch mal den Außenlautsprecher an!"

Stufe 3: In Beratungssituationen ist es sehr hilfreich (aber auch schwieriger), wenn Sie nicht nur den Inhalt des Gesagten in eigenen Worten wiedergeben, sondern auch die Bedeutung ansprechen, die das Gesagte für die andere Person hat. Beispiel: „Sie geben sich Mühe, Ihr Team in Gang zu bringen, Sie merken wenig Effekt und werden allmählich ärgerlich?"Wenn Sie so die Gefühlsebene ansprechen, gewinnt Ihr Gegenüber vertiefte Klarheit über sich selbst.

Wichtig: Stimmen Sie nicht in die Klage über Dritte ein. Klagen über andere, über das Team lenken vom Potential des Klienten ab. Konzentrieren sie sich ganz darauf, wie es Ihrem Gegenüber geht.

Vielleicht ist das alles nicht neu für Sie. Wir können heute wissen, was gute Kommunikation ausmacht. Die Literatur dazu ist uferlos. ${ }^{18}$ Und trotzdem sagen die Geleiteten: Eine Schulleitung sollte zuhören lernen, das ist das Wichtigste. Also versteht sich das nicht von selbst.

Wie wirksam freundlich zugewandtes aktives Zuhören schon in der einfachsten Form ist, hat Virginia Axline in ihrer spieltherapeutischen Arbeit mit dem Jungen Dibs gezeigt (Axline, 2004). Covey $(1995,224)$ zeigt an einem längeren Gespräch zwischen Vater und Sohn, wie wichtig die emotionale Dimension von Kommunikation ist. Der Junge wendet sich an seinen Vater: „Mann, Vati, mir reicht's. Die Schule ist wirklich für die Katz!“ Covey zeigt, wie mitfühlende Kommunikation verhindert wird: durch Bewertungen, durch Sondieren, durch Ratschläge, durch Interpretationen. Und er zeigt, wie der Junge auf ganz neue Gesichtspunkte kommt, sobald der Vater die Bedeutung des Gesagten, die Gefühle des Jungen wichtig nimmt.

\subsection{Zuhören im Schulalltag}

Gelegenheit zum Üben haben Sie jeden Tag. Sie können das im Alltag, in Ihrem Familien- und Freundeskreis praktizieren, möglichst nicht gestelzt. Z. B. so (Paarbeziehung): „Du würdest gern öfter mal verreisen, aber lieber mit mir zusammen?“ Oder so: „Um gut in den Tag zu kommen, brauchst du morgens Ruhe?“

Wenn Sie das in Normalton hinkriegen, können Sie das auch in Ihrem beruflichen Kontext praktizieren. Üben Sie sich darin, auf die vielen Äußerungen, die Sie im Laufe eines Tages zu hören bekommen, nicht „,spontan“, nicht reflexartig zu reagieren. Halten Sie einen Moment inne. Manchmal werden die erstaunlichsten Dinge in beiläufigem Ton geäußert. Lassen Sie sich Zeit. Widerstehen Sie der Versuchung, Lösungsvorschläge zu machen.

18 Eine guten Einstieg bieten z. B. Schulz von Thun (1981), Basu/Faust (2013, bes. 77 ff). 
Meisterin der Kommunikation werden Sie, wenn Sie in das aktive, konzentrierte Zuhören von Zeit zu Zeit einen Impuls einstreuen, der die andere Person zum Nachdenken bringt. Sehr wirksam geht das mit offenen Fragen, mit ,konstruktiven W-Fragen“. M. Prior (2009, 63 f) gibt ein Beispiel:

„Ein Lehrer spricht einen Schüler darauf an, dass er häufig zu spät kommt.

Lehrer: Ich weiß es nicht mehr genau, aber es gab sicher auch Tage, an denen du pünktlich gewesen bist. An welche Tage erinnerst du dich, an denen du pünktlich warst?

Schüler: Ja, während der Projektwoche war ich jeden Morgen pünktlich da. Da habe ich sogar einen früheren Bus genommen .. na, und ... hm ..., dienstags, wenn wir in den ersten beiden Stunden Sport haben, komme ich eigentlich auch nie zu spät. ... denn sonst komme ich in so ne Doofenmannschaft und das will ich nicht.

Lehrer: Wie machst du das, dass du den früheren Bus kriegst oder dienstags rechtzeitig von zu Hause losgehst, damit du in eine gute Mannschaft kommst?

Schüler: Hmm, wie mach ich das ... Den Wecker stell ich am Abend auf den Schrank und meiner Mutter sag ich, dass sie mich auf jeden Fall wecken soll, weil es so wichtig ist.

Lehrer: Wie könntest du es denn gemeinsam mit deinem Wecker und deiner Mutter hinkriegen, morgen zur ersten Stunde Deutsch pünktlich zu kommen?“

So geht „MiniMax für Lehrer“ - minimale Interventionen mit maximaler Wirkung: dies Büchlein von M. Prior empfehlen wir dringend. Über die W-Fragen hinaus erläutert Prior 14 weitere Möglichkeiten, die das Nachdenken und damit die Eigenaktivität von Schülerinnen, Kollegen, Eltern fördern. Prior zeigt auch, wie Ja-NeinFragen dem Schüler Passivität ermöglichen, so dass der Lehrer sich abstrampelt, ohne dass der Schüler Verantwortung für sich selbst übernimmt. ${ }^{19}$

Lesen lässt sich Priors Buch in ein bis zwei Stunden. Umsetzen dauert länger. Wer damit anfängt, kann erstaunliche Erfahrungen machen. Eine Schulleiterin berichtete uns: „Ich habe diese W-Fragen im Gespräch mit meinem Sohn ausprobiert, der mitten in der Pubertät steckt. Das war das beste Gespräch mit ihm seit langem.“

Im Kurs reservieren wir jeden Tag im Schnitt mindestens eine Stunde, um das zu üben. Ein Buch kann dazu bestenfalls motivieren. Sie werden einige Wochen brauchen, um das zu verinnerlichen. Repetitio est mater studiorum - Wiederholung ist die Mutter des Lernens. Der Gewinn wird sein, dass Sie in Gesprächs- und Beratungssituationen Souveränität und Professionalität zeigen und andere zum Denken anregen können. Und darum geht es beim Lernen: zum Denken anregen. Das ist ein unverzichtbares Element in der Dimension ,,persönliche Meisterschaft“. Sie wissen ja: Ist auch nur eine der fünf Dimensionen gleich Null, ist das Gesamtergebnis auch Null, dann bleibt die Lernende Organisation ein schöner Traum.

19 Mit offenen Fragen können Sie auch Informationen gewinnen, die Ihnen das Verständnis der anderen Person erleichtern, ebenso natürlich mit geschlossenen (Ja-Nein-)Fragen. In Beratungssituationen ist entscheidend, dass Sie Ihr Gegenüber zum Denken bringen (vgl. auch Mentzel 2001, 34 ff). 


\subsection{Vertiefung: Ein hörendes Herz}

Das 1. Königsbuch der Bibel schildert die Unsicherheit eines neu ins Führungsamt gekommenen Mannes. König David war in hohem Alter gestorben; einer seiner Söhne, Salomo, der Sohn Bathsebas, war jetzt sein Nachfolger. Zu Beginn seiner Regentschaft hatte Salomo einen Traum. Gott spricht zu ihm: „Tue eine Bitte! Was soll ich dir geben?"

Salomo antwortete: „Du hast deinem Knecht, meinem Vater David, große Huld erwiesen. ... Und nun, Herr, mein Gott, hast du deinen Knecht an meines Vaters David Statt zum König gemacht; ich aber bin noch ein Kind und weiß nicht aus noch ein. Und nun steht dein Knecht inmitten deines Volkes, das du erwählt hast .... So wollest du denn deinem Knechte ein hörendes Herz geben, dein Volk zu regieren und zu unterscheiden, was gut und böse ist; denn wer vermöchte sonst dieses dein gewaltiges Volk zu regieren?"

Ein hörendes Herz - das brauchen die Regierenden, die Mächtigen, auch die etwas weniger Mächtigen wie z.B. Schulleitungen. Kontakt gelingt nicht, wenn die Beteiligten nicht hinhören. Es kommt darauf an, innerlich von Sendung auf Empfang umzuschalten. Das sagt auch ein arabisches Sprichwort: „Gott hat uns zwei Ohren gegeben und nur einen Mund, damit wir doppelt so viel hören wie reden."

$\mathrm{Zu}$ einem hörenden Herzen gehört, dass ich mich berühren lasse, dass ich $z u$ verstehen suche, was dem anderen das bedeutet, was er mir sagt, wie es ihm damit geht, wie er das erlebt und fühlt. Salomo war so weise, diese Fähigkeit als Geschenk, als Gabe Gottes zu verstehen. Ein hörendes Herz setzt voraus, dass es wenigstens für eine kleine Weile - frei ist von sich selbst, von den eigenen Sorgen, Bekümmernissen, Bedürfnissen. Wie wird man frei von sich selbst? (Näheres dazu: 11.7.8)

\section{Lesetipp}

Prior (2009): MiniMax für Lehrer. Grundlegend für alle Gespräche, in denen Sie die andere Person zugewandt und unterstützend zum eigenen Denken bringen möchten.

Hiebl und Seitz (2014): 4.4; 5.1; 5.5 



\section{Kapitel 5: Teamlernen: die erweiterte Schulleitung als Steuerzentrum}

Eine Leitungsperson allein kann eine Schule nicht entwickeln. Sie brauchen Mitstreiterinnen, Kollegen, die sich für die Qualität der Schule insgesamt interessieren, Ideen einbringen, auf Schwachstellen hinweisen, getroffene Entscheidungen umsetzen usw.

Lange Zeit gab es auch in großen Schulsystemen nur zwei Personen als Leitung: Schulleiterin bzw. Schulleiter und eine Person als Stellvertretung. Je größer eine Schule mit der Zeit wird, desto schwieriger wird es für die Leitung, in wirksamen und sinnvollen Kontakt mit einem Kollegium zu kommen, das nicht selten 60 bis 100 Mitglieder zählt. Inzwischen ist es üblicher geworden, Leitung und Stellvertretung um mehrere Kolleginnen oder Kollegen zu einer erweiterten Schulleitung zu ergänzen. So wird die Leitungsarbeit auf mehrere Schultern verteilt; der Kontakt zwischen Leitung und Kollegium kann (und sollte) so strukturell gefestigt werden. ${ }^{20}$

Sie haben dann ein mehr oder weniger regelmäßiges Treffen entweder des gesamten (kleinen) Kollegiums oder einer kleinen Leitungsgruppe. Das könnte und sollte das Steuerzentrum der Schule sein, in dem aktuelle Aufgaben und strategische Themen besprochen und Entscheidungen getroffen werden.

\subsection{Wie arbeitsfähig ist Ihr Leitungsgremium?}

Angenommen, Sie sind neu im Amt, haben die Leitungsrolle übernommen und haben jetzt dies Leitungsgremium zu leiten. Sie sehen hoffentlich keine akuten Krisen, vielleicht aber einige Dinge, die Sie verändern möchten. Fullans Warnung haben Sie nicht vergessen: Vorsicht mit Top-down-Veränderungsimpulsen! Wie könnten Sie dann vorgehen?

Viel spricht dafür, dass Sie sich zunächst an die Üblichkeiten halten und die Sitzungen im Rahmen dieser Üblichkeiten leiten. Dabei werden Sie viele wichtige Informationen bekommen: Wie ist die Mitgliedschaft in diesem Gremium geregelt? Wie oft, wie regelmäßig, in welchen Zeitgrenzen trifft sich dies Gremium? Wie

20 Verteilte Führung bringt weitere Personen über die Schulleiterin bzw. den Schulleiter hinaus in Führungsfunktionen; über die Chefin bzw. den Chef hinaus kommt die erweiterte Schulleitung hinzu, die die Abteilungsleiter bzw. die Stufenleiter in Führungsverantwortung bringt, ebenso Stellvertreter, didaktische Leiter oder Verwaltungsleiter (Rolff 2017, 14f). Umso wichtiger, dass diese Personen offiziell als Führungsverantwortliche vorgestellt, ,inthronisiert“ werden und klare Aufgaben bekommen. So müssen nach Rolff $(2017,15)$ die Leiter der Fachkonferenzen die Führungsrolle erst einmal annehmen und erlernen, und die anderen Lehrkräfte müssen sie akzeptieren. Z.Zt. seien Fachkonferenzen, die nur zweimal im Jahr tagen, eher „schlafende Riesen“ mit einem riesigen Potential als Plattform für Unterrichtsentwicklung. 
förderlich ist die Sitzordnung? Können sich alle sehen? Wie kommt eine Tagesordnung zustande? Wie werden die Tagesordnungspunkte gesammelt? Wie werden sie gewichtet? Wie werden Ergebnisse gesichert? Wie erleben Sie den Kommunikationsstil insgesamt? Wie wird die Qualität der Sitzungen ausgewertet?

Viele W-Fragen, offene Fragen, die zum Denken anregen. In diesem Fall dienen sie zur Gewinnung von Information, sollen nicht die Geleiteten zum Denken bringen, sondern Ihnen als Leitung Übersicht verschaffen. W-Fragen sind auch zum Gewinnen von Informationen gut geeignet, Ja-Nein-Fragen weniger. Generell fragen Sie mit alledem: Wie geht es zu in unserem „Gartenteich“? Welche Strukturen sind erkennbar? Welche vermissen Sie? Und wie wirkt die Kultur auf Sie? Freundlich, kühl, distanziert, lebendig, hektisch, fröhlich, missmutig ...?

Mit den angeführten W-Fragen diagnostizieren Sie die Arbeitsfähigkeit Ihres Steuerzentrums. Es gehört zur Arbeit am System, sich selbst solche Fragen zu stellen. Im Blick auf das Modell der Lernenden Organisation geht es jetzt ums Teamlernen, genauer: Es geht um die Frage, wie Sie im Sinne Ihrer persönlichen Meisterschaft Teamlernen in „Ihrer“ Schule fördern können. Die Gartenteich-Metapher legt nahe, mit strukturellen Aspekten zu beginnen. Kultur braucht Struktur.

Wenn Sie Ihre ersten Eindrücke von Ihrem Schulleitungsgremium Revue passieren lassen: Wie hoch schätzen Sie die professionelle Arbeitsfähigkeit dieses Gremiums ein? Auf einer Skala von 0 bis 10: Welchen Punkt wählen Sie zum jetzigen Zeitpunkt? 10 wäre optimal. Welche Stärken bewegen Sie, z. B. den Punkt 3 oder 5 zu wählen? (Pause zum Nachdenken und zum Griff nach Ihrem Lerntagebuch.) Und was müssten Sie (Sie, nicht die anderen) tun, um einen Punkt weiter in Richtung 10 zu kommen? (Erneute Pause)

\subsection{Schulleitung als Balance von Interaktion und Organisation}

Sie können Ihre Ideen mit einem Modell vergleichen, mit dem wir viele gute Erfahrungen gemacht haben, mit der „Managerkonferenz" von Thomas Gordon (1989). Nicht gerade neu, aber ein Bestseller, immer wieder neu aufgelegt. So gut wie allen Leitungsteams, die wir kennengelernt haben, unbekannt. „Effektiv führen mit L. E. T." - so wird aktuell für eine Fortbildung geworben, die auf Gordons Modell basiert: Leader Effectiveness Training. Die Einladung verspricht: „L.E.T. eignet sich für Führungskräfte, die auf Teamwork, Partizipation der Mitarbeiter und Produktqualität setzen." Ich habe Gordons Konzept als Mindmap visualisiert (Grafik 2, S. 43). Sie können das wie eine Checkliste benutzen, wenn Sie die Arbeitsfähigkeit Ihres Leitungsteams diagnostizieren wollen. Nochmals: Es geht jetzt zunächst um ein nützliches Konzept für Ihre Diagnose und für Ihre eigene Planung; die Frage der Umsetzung wird ab Abschnitt 5.4 behandelt.

Zur Erläuterung des Mindmaps greife ich einige Punkte heraus, die mir besonders vordringlich erscheinen. Es geht um Vorbereitung (1), Durchführung (2) und Ergebnissicherung (3) Ihrer Leitungskonferenzen; viele Punkte erklären sich von selbst, sind aber nicht übliche Praxis. 


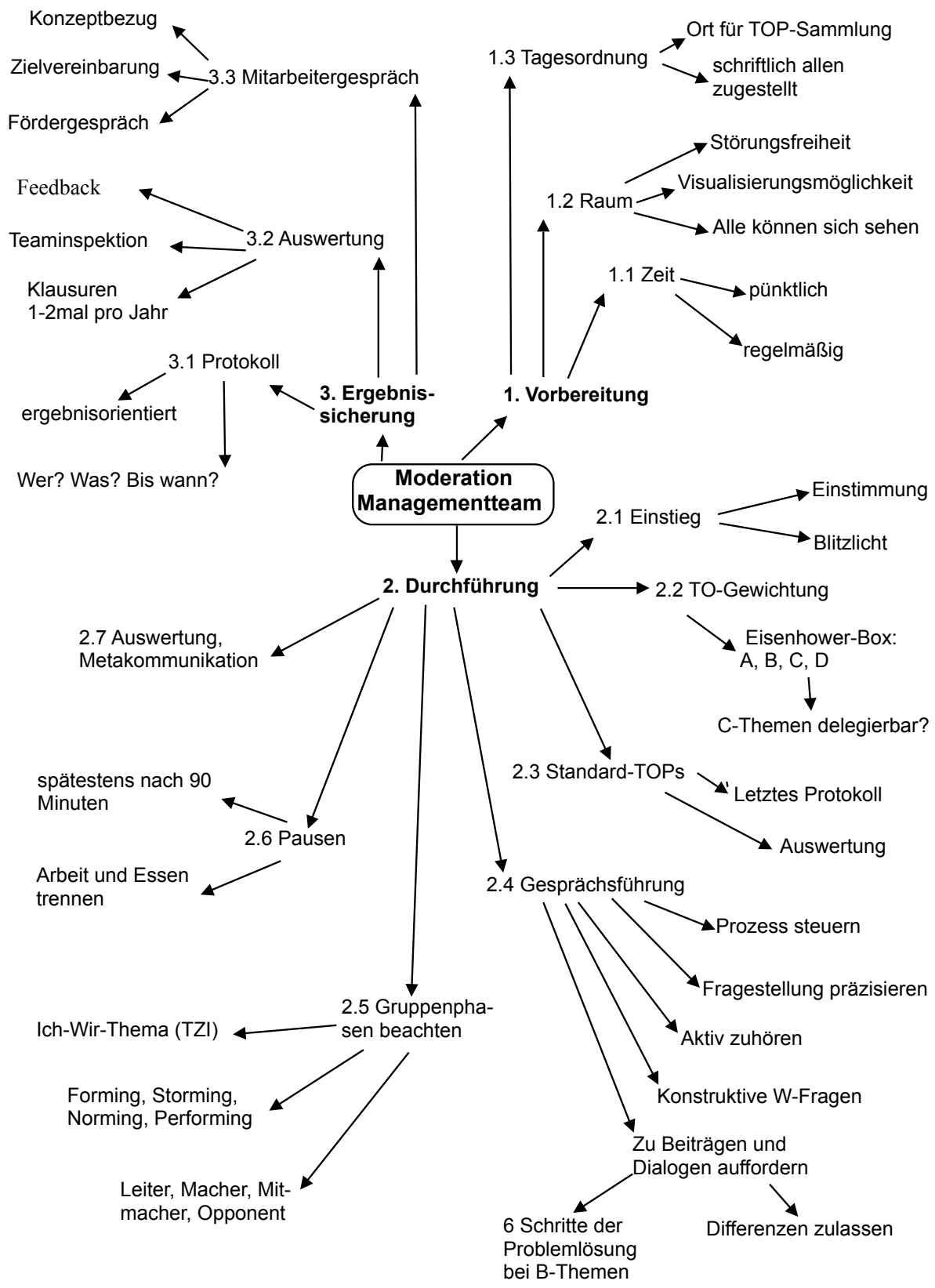

Grafik 2: Mindmap zur Moderation eines Managementteams nach Gordon (1989) 


\subsubsection{Vorbereitung}

Struktur ist wichtig. Denken Sie an den Gartenteich. Zeit, Raum und Tagesordnung sind festzulegen.

Zur Zeit: Das Treffen sollte regelmäßig stattfinden, zu einer festen Zeit im Stundenplan. Leitungszeit ist Regiezeit. Es geht um Steuerung eines oft sehr komplexen Systems. Im Interview mit einer lokalen Zeitung (Juni 2019) blickt der Schulleiter eines großen Gymnasiums kurz vor seinem Ruhestand zurück: Die Schülerzahl sei seit 2001 von rund 600 auf 1.200 gestiegen. Auch der Arbeitsalltag des Schulleiters habe sich rapide geändert - vom Pädagogen hin zum Manager. In den letzten beiden Jahren habe er überhaupt nicht mehr unterrichten können. „Ein Schulleiter ist heute eher mit einem Vorstandsvorsitzenden eines großen Unternehmens zu vergleichen." (Sander 2019) Malik lässt grüßen! Große Unternehmen lassen sich nicht mit knappen zwei Stunden Teamzeit pro Monat steuern! Die oft absurd niedrige Zahl der Abminderungsstunden für die Leitungstätigkeit demonstriert, wie unzureichend die Rahmenbedingungen sind, leider auch, wie wenig die jeweiligen Schulträger für notwendige Strukturen sorgen (können).

Pünktlichkeit - in Schulen selbstverständlich? Seien Sie pünktlich, und beginnen Sie die Sitzung pünktlich. Wenn das für die Beteiligten nachvollziehbar schwierig ist, gehört das als Thema auf die Tagesordnung.

Zum Raum: Das Setting, die Raumgestaltung beeinflusst die Qualität der Kommunikation erheblich. Sitzen z. B. acht Leute um einen langen rechteckigen Tisch, können sich nicht alle sehen. Nonverbale Reaktionen werden dann kaum beachtet, könnten aber einiges über das Arbeitsklima verraten. Wie in alten (?) Schulzeiten muss man sich melden, indem man den Finger hebt. Die Leitung sitzt am Kopfende, weil sie so alle sehen kann, und moderiert, indem sie eine Rednerliste führt. Und so gerät die Diskussion zu einer Aneinanderreihung von statements, die nicht erkennen lassen, wie sie sich aufeinander beziehen. In Fernseh-Talkshows ist das gewollt, leider; die sind jedoch kein geeignetes Modell für die Arbeit an wichtigen Entscheidungen und Strategien.

Zur Tagesordnung: Jedes Mitglied des Gremiums muss die Möglichkeit haben, eigene Themen für die Tagesordnung anzumelden, und zwar nicht erst zu Beginn der Sitzung. Alle stöhnen über Zeitknappheit; also empfiehlt sich ein einfaches transparentes Verfahren, manuell oder digital, das festlegt, wo und bis zu welchem Datum Themen angemeldet werden können. Ob und wie ein Thema es schafft, auf die Tagesordnung zu kommen, ist noch zu klären (s. u. zur Eisenhower-Box).

\subsubsection{Durchführung}

Eine (kurze) Einstimmung in die Sitzung spricht für die Kultur des Treffens. Der Kreativität sind keine Grenzen gesetzt. Fundstücke aus der Zeitung, dem Fernsehen, der Literatur, verbunden mit einem persönlichen Einfall, Gedanken und auch einer offenen Frage sind geeignet. Eine gute Hilfe, sich zu sammeln, sich gemeinsam zu konzentrieren, im Team anzukommen. Perfektionismus und Dogmatismus würden stören. 


\subsubsection{Regularien und Methodik für die Teamarbeit}

Blitzlicht - ein Erbe aus den 70er Jahren des letzten Jahrhunderts. Es geht um die Vergewisserung, ob alle Beteiligten innerlich präsent und konzentrationsfähig sind. Eine Krankheit, ein Todesfall in der Familie, ein Unfall, ein akuter Konflikt usw. können die innere Präsenz einschränken, sogar verhindern. Das zu benennen, halte ich für humanen Umgangsstil. Dass aus so einer Äußerung ein Tagesordnungspunkt wird, gehört manchmal dazu.

Wird aus einem kurzen (!!) Blitzlicht ein „Dauerdämmerlicht“, greifen Sie ein, freundlich und bestimmt. Präventiv z.B. so: „Bitte denkt dran: Blitzlicht heißt: Knapp das Wesentliche nennen, ohne Diskussion." Und später, wenn es anfängt, zu „dämmern“: „Ich merke, dass ich an unsere Tagesordnung denke. Blitzlicht bitte kurz und knapp!“ Oder so ähnlich. Das gehört zum Moderationsamt. Falls Unmut dabei entsteht, geben Sie dafür Raum in der Sitzungsauswertung am Schluss.

Das Protokoll der vorangehenden Sitzung ist kurz zu überprüfen, nicht zu diskutieren: Sind die Ergebnisse korrekt festgehalten? Näheres dazu beim Punkt Ergebnissicherung (Punkt 3 im Mindmap).

Für wichtige Informationen ist als Standard ein TOP vorzusehen: Kurz, knapp und wirklich wichtig sollten diese Informationen sein. Damit dieser Punkt nicht zeitlich aus dem Ruder läuft, setzen Sie ihn besser ans Ende der Tagesordnung.

Ein weiterer „Zeitfresser“: Jemand will gerade noch schnell einen zusätzlichen Punkt auf die Tagesordnung setzen. Nur krisenhaft wichtige Themen sollten Sie akzeptieren. Andernfalls untergraben Sie die Disziplin, TOPs bis zum vereinbarten Termin schriftlich anzumelden. In der Regel sind „spontane“ Wünsche also für die nächste Sitzung vorzumerken.

Kriterien für die Gewichtung der TOPs bietet die Eisenhower-Box (Grafik 3). Mit ihrer Hilfe können Sie Themen nach hoher bzw. niedriger Dringlichkeit und Wichtigkeit unterscheiden. So ergibt sich ein Vierfelder-Schema: Was weder wichtig noch dringlich ist, gehört nicht auf die Tagesordnung: ab in den Papierkorb (D-Thema). Manches ist dringlich, aber nicht wichtig (C-Themen), z. B. die Weitergabe von Daten an anfragende Stellen, Routineaufgaben. Strenge Zeitmanager

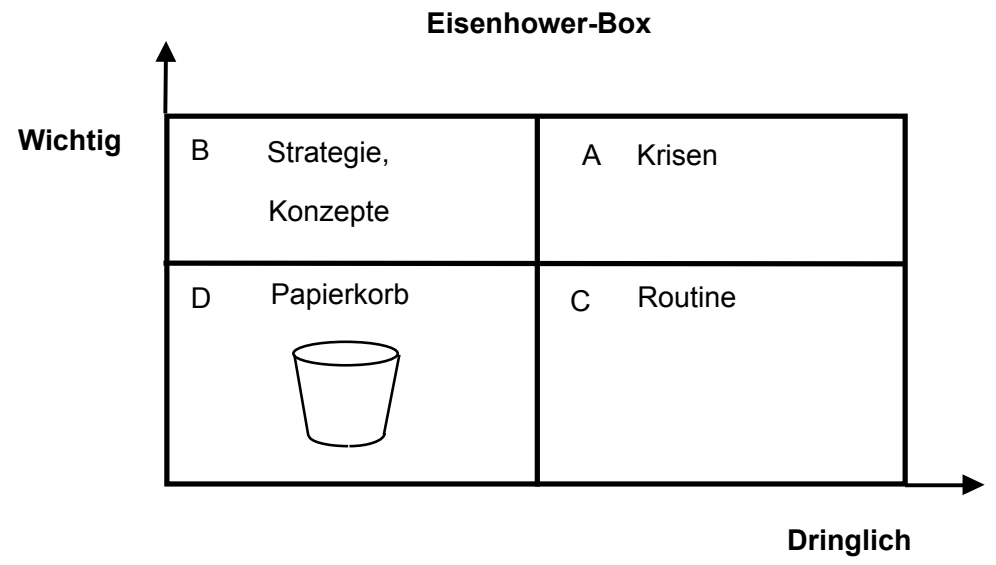

Grafik 3: Eisenhower-Box 
verbannen auch die von der Tagesordnung (Covey 1995, $132 \mathrm{ff}$ ). Leitungsgremien sind hochrangige Treffen, die Zeit für die wirklich wichtigen Themen brauchen, also für Krisen (A-Themen) und für strategische Entwicklung (B-Themen).

A-Themen sind Krisen: Feuer im Haus, akutes Mobbing, Gewalt, Vandalismus u.ä. B-Themen sind die wirklich wichtigen Themen, die die Schulentwicklung voranbringen, strategische Vorhaben, Arbeit am Schulkonzept, Vorbereitung einer großen Konferenz usw. Covey $(1995,90)$ unterscheidet zwischen Effizienz und Effektivität. Beispiel: Ein Maler streicht eine Wand an, fachgerecht, effizient und gewissenhaft. Sein Chef kommt dazu und fragt: „Was machst du da?“ Antwort: „Ich streiche diese Wand an." Der Chef: „Aber es ist die falsche Wand!“

Weitere (makabre) Beispiele: Ein Zahnarzt extrahiert fachgerecht einen Zahn. Dann stellt sich heraus: Es war der falsche Zahn. Ein Operateur amputiert ein Bein... usw. Gute Frage also: Steht meine Leiter an der richtigen Wand? Arbeite ich wirklich effektiv oder nur effizient? Nochmals Covey: „Man kann ganz leicht in eine Aktivitätsfalle geraten, in der Geschäftigkeit des Lebens gefangen sein, härter und härter für die nächste Sprosse auf der Erfolgsleiter arbeiten, nur um dann zu entdecken, daß die ganze Leiter an die falsche Mauer gelehnt ist. Es ist möglich, sehr, sehr beschäftigt, aber nur wenig effektiv zu sein.“

B-Themen fallen erfahrungsgemäß immer wieder unter den Tisch. Begründung: keine Zeit! Keine Zeit für Schulentwicklung!! Wenn das erstmal eingerissen ist, wäre das der wichtigste Punkt für die nächste Tagesordnung: Wie finden wir Zeit für die Arbeit an der Entwicklung unserer Schule? Vielleicht verhindern Krisen, echte oder nur vermeintliche, die Arbeit am System. Wenn die alle Aufmerksamkeit auf sich ziehen, sollte diese Erkenntnis selbst ein B-Thema werden: Wieso sind wir ständig in einem Feuerwehr-Modus? Notaufnahmen im Krankenhaus sind ein gutes Beispiel dafür, wie man häufigen Krisen strategisch begegnen kann: durch gute Organisation und Spezialisierung.

Ein wichtiger Teil der Sitzungsvorbereitung ist also die kritische Durchsicht aller angemeldeten Themen: Was sind strategisch wichtige konzeptionelle Themen? Welche Krisen müssen wirklich sofort bearbeitet werden? Und wie lassen sich die C-Themen außerhalb der Sitzung bearbeiten, zu zweit, oder zu dritt? Themen, die nicht alle Mitglieder betreffen, gehören nicht auf die Tagesordnung - so Thomas Gordon.

Aber Vorsicht! Zwar ist nicht jedes Thema für jedes Teammitglied interessant, nicht in jedem Thema kennen sich alle gleich gut aus. Das ist normal. Aber jedes Mitglied einer erweiterten Schulleitung hat Leitungsverantwortung. Alle müssen bereit sein, sich in die als wichtig klassifizierten Themen hineinzudenken. Eine gute, wenn auch anspruchsvolle Lösung dafür: Wer ein Thema am wenigsten interessant findet, sollte für diesen Punkt die Moderation übernehmen. Methodische Beratung für den Themengeber bewirkt konzentriertes Interesse, gemeinsames fachliches und methodisches Lernen bei allen Beteiligten. So kann das Organisationswissen wachsen. (Näheres dazu s.u. 5.3)

Pausen sind wichtig, keine Zeitverschwendung; die Konzentrationsfähigkeit lässt mit der Zeit nach. Manchmal werden gute Ideen eher in Pausen entwickelt oder weiter gesponnen. Mit Essen und Trinken kann man sich stärken. 15 Minuten dafür sind gut investiert. Vom Essen während der Arbeit rate ich dringend ab: Denn dann 
werden Tische gebraucht, die die Beweglichkeit behindern, wenn Kleingruppenarbeit hilfreich wäre. Geschirrgeklapper, Hin- und Herreichen von Essbarem stört die Konzentration. Eine erweiterte Schulleitung ist ein gut bezahltes, hochrangiges Gremium, das ein Setting braucht, in dem konzentriert gearbeitet werden kann.

Ein Gespräch gut zu moderieren ist eine anspruchsvolle Aufgabe; im Mindmap nimmt dieser Teil darum den größten Raum ein. Wenn Sie sich darauf beschränken, Redebeiträge zu erbitten und eine Rednerliste zu führen, unterfordern Sie Ihr Team (und sich selbst). Rednerlisten produzieren Statements, die selten aufeinander bezogen sind. Ein interessantes, lebendiges, zielführendes Gespräch kann so nicht entstehen. Es geht ja darum, die fachliche Kompetenz aller Beteiligten ans Licht zu bringen, noch fehlende Informationen zu identifizieren, Aufgaben zu verteilen und Entscheidungen zu treffen, die von allen getragen und im Gesamtkollegium vertreten werden.

Sie moderieren die Sitzung. Bei jedem TOP ist der Rahmen des Themas zu klären, die Fragestellung zu präzisieren und der Prozess zu steuern. Welche Rahmenbedingungen sind zu berücksichtigen? Inwiefern ist Ihr Team zuständig für das Thema? Bis wann spätestens muss eine Entscheidung fallen? Wer hat bei diesem Thema welche Interessen? Worum genau geht es? Welche Informationen fehlen noch?

Vielleicht hatten Sie anfangs Zweifel, ob das aktive Zuhören wirklich so wichtig ist. Spätestens jetzt werden Sie froh sein, wenn Sie das beherrschen. Beginnen Sie mit „Problemsprache“, mit der Analyse des Problems. Fassen Sie immer wieder kurz zusammen, was Sie verstanden haben. Bitten Sie weitschweifig Redende freundlich, auf den Punkt zu kommen. Formulieren Sie den Erkenntnisstand, wenn die Argumente sich wiederholen. Wechseln Sie dann von der Problemsprache zur Lösungssprache: Welche Ideen haben wir schon? Was könnte ein nächster Schritt sein?

Nutzen Sie das Potential der Gruppe. Wie sind die Teammitglieder vom Thema berührt? W-Fragen regen zum Denken an, Ja-Nein-Fragen eher nicht. Was am Thema interessiert sie (Ich-Bezug)? Was verstehen die einzelnen von der Sache (Sach-Bezug), um die es geht? Dringen Sie darauf, dass die Redenden sich aufeinander und aufs Thema beziehen: „Wie sehen Sie den Zusammenhang Ihres Arguments mit der Äußerung von Frau Y?“21 Wie passt Ihr letzter Beitrag zu unserem Thema? Aktivieren Sie die Schweigenden: Was halten Sie von den bisherigen Argumenten? Wo stimmen Sie zu? Was würden Sie ergänzen? Wie arbeitet

21 „Frauen beziehen sich häufiger auf vorhergegangene Redebeiträge und beziehen sich damit öfter auf ihre GesprächspartnerInnen als dies Männer tun (Gesprächsarbeit). Männer unterbrechen Frauen bewußt, oder aber meist unbewußt häufig. Frauen lassen sich unterbrechen. Interessanterweise spielt der Status dabei eine geringe bis keine Rolle." (Frech/Schmidt 1996, 289) Ein interessanter Punkt für die Auswertung von Teamsitzungen. Die Autorinnen halten als Doppelbindung fest: Will eine Frau ernst genommen werden, muss sie reden wie ein Mann, gilt dann aber nicht mehr als feminin. Redet sie aber wie eine Frau, höflich, beschwichtigend, liebenswürdig, unsicher, dann wird sie nicht ernst genommen und braucht nicht gehört zu werden. - So war das 1996. Wie gängig ist das heute? Newmark (2020, 95 u. 113) hält das Dilemma für unverändert aktuell. 
die Gruppe zusammen (Wir-Bezug)? Ruth Cohn (2018) hat ein anspruchsvolles Modell entwickelt, das lebendiges Lernen fördert: die Themenzentrierte Interaktion (TZI). Lernen wird lebendig, wenn die drei genannten Aspekte Ich - Wir Sache balanciert werden, wenn sie insgesamt zu etwa gleichen Teilen gewichtet werden. So wird das Teamlernen im Konzept der Lernenden Organisation konkret ermöglicht.

Aktivieren Sie Ihr Team gleich beim Einstieg ins Thema: Lassen Sie die Mitglieder ein paar Minuten lang zu zweit oder zu dritt die Köpfe zusammenstecken und nachdenken: Wie berührt mich das Thema? Welche Erfahrungen habe ich dazu? Mein Ziel dabei? Immer wieder kommt stereotyp der Einwand: „Das brauchen wir nicht. Wir können gleich los reden.“ Bleiben Sie hartnäckig; widerstehen Sie dem Kaltstart; es lohnt sich. Zwei, drei Minuten Mini-Austausch, Murmelgruppen verändern viel. Fragen Sie dann im Plenum, was die Paare beschäftigt hat. Und schon haben sich alle im Plenum einmal kurz geäußert. Die Hemmschwelle ist gesunken, unterschiedliche Sichtweisen werden angehört, vorschnelle Entscheidungen vermieden.

Manchmal gibt es schnellen Konsens nur, weil niemand seine „Hausaufgaben“ gemacht hat. Offen präsentierter Dissens schützt vor unangebrachten Schnellschüssen. Als leuchtendes Beispiel verweist Malik auf Alfred Sloan, einen amerikanischen Top-Manager, der eine Leitungssitzung unterbrach, als alle vorschnell und eifrig eine oberflächliche Lösung abnicken wollten. Er wünschte Dissens und schickte sie zurück in ihre Büros (Malik 2006, 209 f; s. u. 9.5.3).

In der Art, wie das Team arbeitet, zeigt es zugleich den eigenen Entwicklungsstand. Tuckman und andere haben vier Entwicklungsphasen identifiziert, die erfolgreiche Gruppen durchlaufen: forming - storming - norming - performing (Frech 1996, 327 f). Ist das Team neu zusammengesetzt, steht forming an: Unsicherheit und Abhängigkeit überwindet die Gruppe, indem sie Zuständigkeiten, Rollen, Rahmenbedingungen klärt. Irgendwann zeigen sich Reibungen, Konflikte, strittige Meinungen (storming); die Aufgabenanforderungen werden emotional abgelehnt. Wird diese Phase nicht überwunden, zerfällt die Gruppe. Werden sie konstruktiv ausgetragen und bereinigt, kann man sich auf gemeinsame Vorgehensweisen einigen und Kooperation entwickeln (norming). Sind die interpersonellen Probleme gelöst, kann die Gruppe ihre Energie konstruktiv ganz auf die Aufgabe richten (performing).

Bleibt die Gruppe trotz ungelöster Konflikte zusammen, wird sie ihre Aufgaben mit qualitativ weit unter ihren Möglichkeiten liegenden Ergebnissen bearbeiten. Entsprechend wichtig ist die Kompetenz, Konflikte zu erkennen, sie als Hinweis auf notwendige Klärungen zuzulassen und konstruktiv zu bearbeiten (s. u. Kapitel 6). Sejkora und Schulze (2016, 235-273) zeigen an ausführlichen Praxisbeispielen, auf welche Signale Sie achten können, um den Entwicklungsstand Ihres Teams zu erkennen, und welche Interventionen in dieser Phase angebracht sind.

Zum Wir-Bezug hat S. Fourier (o.J.) ein interessantes Modell beigesteuert: In der Art, wie die Gruppe arbeitet, lassen sich archetypische Rollen erkennen: Leiter, Macher, Mitmacher und Opponenten. Die Pointe dabei: Wenn Sie als Leitung in die Macherrolle gehen, ziehen die Macher sich zurück. Tun Sie also nicht alles selbst! Fragen Sie sich immer: Muss wirklich ich das tun, was ich gerade 
tue? Halten Sie die Rolle des Regisseurs bzw. der Regisseurin durch, und fördern Sie die Macher. Trauen Sie ihnen Verantwortung zu. Delegieren Sie sorgfältig und gezielt (Näheres dazu s.u. 11.11)! Dann werden die Mitmacher die Macher bei beschlossenen und delegierten Aktivitäten unterstützen.

Opponenten gibt es mit Sicherheit auch. Die können Sie einbinden, indem Sie sie bitten, ihre kritische Sicht zu benennen, zu dokumentieren und zu gegebener Zeit, bei der Auswertung einer Entscheidung, auf Stichhaltigkeit und Relevanz zu überprüfen (s.u. 9.5.3).

\subsubsection{Bearbeitung komplexer Themen: Sechs Schritte der Problemlösung}

Wie können Sie komplexe strategische Themen methodisch Schritt für Schritt so bearbeiten, dass Sie am Ende des Prozesses ein gemeinsames Ergebnis erreichen, das von allen Beteiligten auch dem Kollegium gegenüber loyal vertreten wird? Gordon empfiehlt sechs Schritte, die die Moderation erheblich erleichtern. Das Team sollte das Verfahren vorab kennenlernen (Download 3, Gordon 1989, Kap. 9). Ich stelle es Ihnen hier mit einigen zusätzlichen Hinweisen zur Moderation vor (Download 4). Von der Fragestellung an sind alle Beiträge schriftlich festzuhalten, auf Flipchart, durchnummeriert und für alle sichtbar.

Die Fähigkeit, eine Projektgruppe nach diesem Modell $\mathrm{zu}$ moderieren, ist eine wichtige Vorbedingung, wenn Sie z. B. im Rahmen von Kollegiumsklausuren Schulentwicklung vorantreiben wollen; Näheres dazu: s.u. 7.4.

Start: Bestehen Sie darauf, die Fragestellung sorgfältig zu formulieren, als W-Frage: aktivierend, konkret, erreichbar, verhaltens- und handlungsbezogen und differenziert in mehrere Teilziele.

Beispiel aus einer Schulklausur: Wie können wir inklusiven Unterricht so planen und gestalten,

- dass bei den Schülerinnen und Schülern deutliche Lernentwicklung stattfindet,

- dass die Lehrenden methodisches Handwerkszeug bekommen und ihre Arbeit kritisch reflektieren können und

- dass die Lehrenden diese Arbeit gern tun?

Schritt I: Das Problem wird erkannt und definiert.

A. Zahlen, Daten, Fakten (ZDF), soweit sie dem Verständnis des Problems dienen, z. B. Raumsituation, Klassengrößen usw. werden gesammelt.

B. Hintergründe, weiche Daten, z. B. Klagen über Stress in Teilen des Kollegiums sind wichtig.

C. Wünsche, Interessen (Wünsche und Interessen sind Kriterien für spätere Lösungen!), z. B. Erwartungen von Eltern an den Träger der Schule.

Schritt I kann eine ganze Sitzung lang dauern. Die Teamsitzung ist dann ein Treffen zur Problemfindung. Probleme sind Trüffel! Leitungspersonen sollen die Trüffel suchen. Sie sind Modell dafür, dass man sich für Schwierigkeiten interessieren soll (Qualitätssicherung!), und auch dafür, dass man Schwierigkeiten konstruktiv angehen kann. 
Schritt II: Alternative Lösungen werden entwickelt (Brainstorming).

Kreative Phase: Man darf „spinnen“, exotische Ideen äußern. Technik: Brainstorming. Alle Ideen werden gesammelt und nummeriert aufgeschrieben, auf Flipchart. Konkrete handlungsbezogene Maßnahmen sind gefragt, keine allgemeinen Empfehlungen. Leitfrage: Was würden Sie tun, wenn es nach Ihnen ginge?

Wichtig: keine Wertungen! Die Moderationsperson muss Wertungen sofort unterbinden, z.B. so: „Bitte keine Kritik an anderen; nennen Sie stattdessen Ihre Idee." Die Diskussion über die Ideen folgt erst in Schritt III. Falls ein Team darin noch nicht geübt ist, kann man Metaplan-Kärtchen zur Ideensammlung nutzen, sollte dann aber ganze Sätze schreiben! Nachteil: Mündliche Äußerungen regen immer wieder neue Ideen an; das geht bei Kärtchenabfragen verloren.

\section{Schritt III: Die alternativen Lösungen werden bewertet.}

Jetzt darf diskutiert und auch gestritten werden, aber zur Sache und zum einzelnen Punkt. Als Moderatorin können Sie zu Dialogen auffordern, um noch mehr Aspekte herauszufinden.

Welche Lösungsvorschläge leisten einen Beitrag zur Wunscherfüllung?

Welche Lösungsvorschläge berücksichtigen hinreichend die geltenden Rahmenbedingungen (vgl. Schritt I A)?

Welche Lösungsideen haben einen Haken?

Oft kommt es zu Optimierungen der gesammelten Ideen; die können Sie der Liste am Ende hinzufügen. Ideen, auf die das Team sich einigt, markieren Sie mit einem Plus-Zeichen; Minus- und Fragezeichen sind entsprechend anzubringen.

\section{Schritt IV: Die Entscheidung wird getroffen.}

Erst jetzt! Beginnen Sie mit der Umsetzung bei den Ideen, zu denen Sie einen klaren Konsens erreicht haben. Oft empfiehlt sich eine Lösung ganz von selbst, sobald erst einmal alle Fakten und Interessen ausgebreitet sind. Nicht überreden!

\section{Schritt V: Die Entscheidung wird ausgeführt.}

Jetzt ist (schriftlich!) festzuhalten: Wer tut was bis wann? Falls jemand sich nicht an Abmachungen hält: Intervenieren Sie mit Ich-Botschaften. Solche Konflikte gehören zur Arbeit am System; s.u. Kap. 6 zum Konfliktmanagement.

\section{Schritt VI: Auswertung}

Auf keinen Fall vergessen: Verabreden Sie einen konkreten Termin (Wiedervorlage!), an dem Sie die Tragfähigkeit der gefundenen Lösungen überprüfen. Andernfalls besteht die Gefahr, dass gute Ansätze versickern und dass sich die Norm ausbreitet: Was wir miteinander erarbeiten und beschließen, nehmen wir anschließend selbst nicht ernst. Näheres dazu beim Thema „heimliche Verträge“ (5.4.5).

Diese systematische Arbeit an strategischen Themen wird in Schulen nur selten praktiziert, bedauerlicherweise. Viele Entwicklungschancen werden damit verspielt. Das Verfahren hilft ganz praktisch bei der Arbeit an schwierigen Sachthemen. Zugleich werden im Prozess dieser Arbeit alle Beteiligten methodisch 
geschult. So wächst die Fähigkeit, im Team konstruktiv miteinander zu arbeiten, und nicht zuletzt entsteht ein tragfähiges Gruppenklima.

Schulen täten gut daran, ihr gesamtes Zeitbudget so zu durchforsten, dass sie in diesem Sinn die Leiter an die richtige Wand stellen. Immer wieder ist zu hören: „,Dafür haben wir keine Zeit!“”Wieso nicht? „,Weil unsere Zeit für ,Alltagskram “ und Informationen drauf geht." Das ist weder effizient noch effektiv! Das ist schlicht absurd, in Schulen, die sich frei nennen! Die Absurdität hat aber Gründe, die noch $\mathrm{zu}$ bedenken sind.

\subsubsection{Ergebnissicherung}

Unverzichtbar für die Sicherung der Arbeitsergebnisse einer Leitungssitzung und damit der Verbindlichkeit von Beschlüssen ist ein schriftliches Protokoll, das allen Beteiligten zugänglich ist. Das sollte nicht episch breit sein. Es genügt, genau festzuhalten, was beschlossen wurde. Dazu gehört auch, was zur Umsetzung von Beschlüssen zu tun ist: Wer tut was bis wann? Wann wird das überprüft? Wer führt die Wiedervorlage? Wenn Sie das locker nehmen, riskieren Sie heimliche Verträge (s. u. 5.4.5). Kleiner Hinweis auf persönliche Meisterschaft: Protokoll schreiben ist unbeliebt. Aber: Protokoll schreiben fördert die Fähigkeit, konzentriert zuzuhören, und es erweitert das Organisationswissen.

Ans Ende einer Sitzung gehört ein Blick zurück, aus der Metaperspektive: Wie haben wir heute gearbeitet? Was ist gut gelungen? Also eine kurze Feedback-Phase. Das geht in den meisten Sitzungen unter. Wieso? Standardantwort: Keine Zeit. Darum empfehle ich: Setzen Sie den TOP „Sitzungsfeedback“ auf die vorletzte Position der Tagesordnung, nicht auf die letzte.

„Keine Zeit!“ Mit der Begründung wird die Auswertung von Sitzungen vermieden. Ein weiterer Grund sitzt tiefer: Angst vor Feedback ist in Schulen stark verbreitet. (Näheres dazu zum Konfliktmanagement, s.u. 6.7) Diese Angst sollte im Lauf der Zeit überflüssig werden. Denn: Ohne Feedback kein Lernen, also auch keine Lernende Organisation. Umso wichtiger ist es, positive Erfahrungen mit Feedback selbst zu erleben und anderen zu vermitteln. Sonst steuert Angst den Prozess.

Ein einfacher Tipp: Fangen Sie als Moderatorin, als Moderator selbst damit an. Setzen Sie sich für die erste Zeit eine niedrige Hürde. Weisen Sie zu Beginn einer Sitzung kurz darauf hin, dass Sie am Ende gern ein Feedback zu Ihrer Moderation hätten. Sagen Sie einen, höchstens zwei Punkte, zu denen Sie gern Rückmeldung bekommen möchten. Zum Beispiel: „Wie ist es mir gelungen, das Team zu aktivieren? Wie habe ich den roten Faden gehalten?“ Noch einfacher: „Was fanden Sie heute an meiner Moderation förderlich? Bitte sagen Sie nur Positives." Damit sind Sie ein Modell für den Umgang mit Feedback: Sie können es steuern, dosieren. Sie vermitteln so die Erfahrung, dass Feedback hilfreich ist, keine Verdammung, keine Entwertung, sondern ein unverzichtbares Mittel, zu lernen und sich in Richtung persönlicher Meisterschaft weiter zu entwickeln.

Es gibt Listen mit Auswertungsfragen (Download 5), von denen Sie sich jeweils einen oder zwei Punkte aussuchen können. Empfehlenswert sind zusätz- 
lich Auswertungsklausuren, in denen die Teamarbeit eines Halbjahres oder Jahres reflektiert wird, Verbesserungsideen gesammelt und neue Verabredungen getroffen werden - zum Beispiel mit Hilfe der „Sechs Schritte der Problemlösung“ (s.o. 5.2.2.2). Beispiel für eine Themenstruktur: „Wie können wir unsere Arbeit im Team so verbessern, dass wir ... 1., 2., 3.?“"

Wenn Sie auf diese Weise allmählich eine Feedback-Kultur in Ihrer Schule aufbauen, legen Sie eine entscheidende Grundlage für den Aufbau einer Lernenden Organisation. Der Schulforscher Hans-Günther Rolff hält zielführendes Handeln, Teamlernen und Feedback-Kultur für die drei entscheidenden „Treiber“ der Schulentwicklung (Rolff 2011, 4).

Als weiteres Verfahren zur Ergebnissicherung nennt das Mindmap das Mitarbeitergespräch (Personalentwicklungsgespräch; in Gordons Terminologie: PPK = Periodische Planungskonferenz). Näheres dazu im Kapitel 12.

Das Amt der Moderation ist wichtig und anspruchsvoll. Manche Teams lassen die Moderation rotieren; jeder und jede kommt dann mal dran. Wenn das darauf hinausläuft, dass eine Person im Wesentlichen nur eine Rednerliste führt, steckt darin eine qualitätsschädigende Abwertung der Moderationsrolle. Beschränken Sie die Rotation lieber auf dafür qualifizierte Personen. In jedem Fall ist empfehlenswert, die Rotation mit einem Lernprozess zu verbinden, also mit der ehrlichen Auswertung der Moderation am Ende einer Teamsitzung.

\subsection{Kollegiale Beratung im Team: vier Varianten}

Der hohe Rang des Teamlernens im Modell der Lernenden Organisation fordert den entschlossenen Abschied vom Einzelkämpfertum. Das betrifft natürlich nicht das lebenslange individuelle Lernen im Sinne persönlicher Meisterschaft. Aber: Die komplexen Anforderungen sowohl im Leitungsgeschäft wie im Unterrichtsgeschehen lassen sich eher bewältigen, wenn niemand ohne Netz und doppelten Boden arbeiten muss, wenn stattdessen alle Ressourcen und Potentiale genutzt werden.

Das kann gelingen, wenn alle Beteiligten eine regelmäßige Zeit und einen festen Ort wissen, zu denen sie in schwierigen Situationen Hilfe bekommen können, Hilfe z. B. in Konfliktsituationen mit Schülerinnen und Schülern oder mit kritischen Eltern. Dafür ist kollegiale Beratung im Team gedacht. Es geht nicht um den Austausch von Tipps zwischen Tür und Angel, sondern um methodische Verfahren, deren Einsatz der Personalentwicklung dient, also strategische Bedeutung hat (B-Thema in der Eisenhower-Box).

Lehrerinnen und Lehrer können erheblich von Beratung profitieren. Lernbereitschaft und Reife eines Leitungsteams zeigen sich daran, dass die Tagesordnung regelmäßig die Möglichkeit kollegialer Beratung vorsieht. Die Fähigkeit, aktiv zuzuhören, ist die Basis für alles Weitere, nicht nur für Beratungssituationen, sondern auch in Konflikten. Ich skizziere mehrere Möglichkeiten, aktives Zuhören und darüber hinausgehende Kompetenz einzuüben, mit ansteigender Komplexität. 


\section{Ein einfaches Grundmodell:}

Eine Person A stellt im Rahmen des TOPs „,kollegiale Beratung“ ein eigenes Thema aus dem Leitungsalltag vor, nimmt also die Rolle „Klient“ oder „coachee“ ein. Eine Kollegin übernimmt Rolle B und hört zu, hört aktiv zu, indem sie von Zeit zu Zeit kurz in eigenen Worten das Gehörte zusammenfasst. Diesen Teil nennen wir Problemsprache. Er sollte nicht zu lange dauern; ca. 10 Minuten genügen meistens (s. o. Kapitel 4.4).

Danach, wenn das Problem im Wesentlichen verstanden ist, wechselt Person B in die Lösungssprache. Nicht so, dass sie selbst Lösungen vorschlägt, sondern so, dass sie Person A zum Denken anregt. Das geht sehr gut mit den MiniMaxInterventionen, die zu kennen und benutzen zu können zum Repertoire von Leitungspersonen gehört. M. Prior (2002 und 2009) empfiehlt: viermal pacing (= aktiv zuhören), einmal leading (ein Impuls, z. B. eine W-Frage, die zum Denken anregt). $\mathrm{Zu}$ viele Denkanregungen in Folge erhöhen das innere Tempo und erschweren die Verarbeitung in Person A. Die anderen Teammitglieder hören aufmerksam zu.

Variante 1: Das einfache Grundmodell mit Auszeit: Rolle B kann zwischen Problem- und Lösungssprache eine Auszeit nehmen und die restliche Gruppe auffordern, ihre Sicht der Problembeschreibung zu geben: Was ist da los? Welche Dynamik spielt sich da ab? Welches Muster kann man vermuten?

Wichtig: Möglichst jedes Teammitglied äußert kurz seinen Eindruck, spricht dabei weder Person A noch Person B an und diskutiert auch nicht die Beiträge der Kolleginnen. Schlicht additiv wird ausgesprochen, was die einzelnen beschäftigt. Unterschiedliche Resonanz ist gefragt, aber keine Lösungsideen! Auch das soll nicht zu lange dauern, ca. 10 Minuten oder weniger.

Dann kann Person B die Einzelberatung ganz unangestrengt und elegant fortsetzen, z. B. so: „Was beschäftigt Sie jetzt, nachdem Sie das alles gehört haben?“ Die weiteren 10 Minuten nutzt Rolle B für weiteres aktives Zuhören und weitere (nicht zu viele) Denkanstöße. Perfektion ist weder möglich noch nötig. Darum empfiehlt sich ein einfacher (vorläufiger) Abschluss: „Wie weit sind Sie mit Ihrem Problem auf einer Skala von 0 bis 10 gekommen?“ Abwarten, nachdenken lassen. Und nach der Antwort ganz zum Schluss: „Und was müssten Sie tun, um von Ihrem Skalenpunkt einen Punkt weiter in Richtung 10 zu kommen?“

Das Problem muss nicht sofort perfekt gelöst sein. Wichtig ist die Erfahrung für Rolle A: Ich werde gehört, verstanden, ich spüre Interesse an meinem Thema. Und ich bin auf Aspekte gestoßen, an die ich vorher nicht gedacht hatte.

Variante 2: Variante 1 wird um Zielklärung ergänzt. Nach dem Teil Problemsprache gibt die ausdrückliche Frage nach den Zielen der Person A die Richtung für den Lösungsteil an: „Was genau wollen Sie erreichen?“ „Woran würden Sie merken, dass Sie Ihr Ziel erreicht haben?“ Zur Konkretisierung von Zielen hilft das Akronym SMART: spezifisch, messbar, aktivierend, realistisch, terminiert (d.h., bis wann soll was geschehen?). ${ }^{22}$

22 Ausführliche Anregungen zum Denken in Zielen bei Deister (2008, $19 \mathrm{ff}$ und $99 \mathrm{ff})$. 
Variante 3: B. Lohmann (2000) hat ein Supervisionsmodell entworfen, in dem die Elemente von Variante 2 enthalten sind. An den Anfang setzt sie drei Fragen zur Vorklärung:

A: Was ist das Anliegen der Klientin? Bitten Sie um eine kurze (!) Antwort im Sinne eine Romantitels, eines Filmplakats, eines Dramas usw. Beispiel: „Angriff des Vaters einer Schülerin!“

Z: Welches konkrete und im Rahmen der Zeit bearbeitbare Ziel hat Ihr Gegenüber für dieses Beratungsgespräch? Das Ziel in der Beratungssituation wird vom Ziel im Lebensalltag, dem das Problem entstammt, deutlich unterschieden.

A: Auftrag an die Beraterin und die Gruppe: „Was erwarten Sie von mir als der Beraterin?“ Beispiel: „Ich möchte verstanden werden, mich vergewissern, ob meine bisherigen Lösungsversuche sinnvoll sind, und Lösungsideen von Ihnen bzw. von der anwesenden Gruppe hören.“

Auf diese Vorklärung folgt dann:

P: Problembeschreibung und -analyse,

Z: Klärung des arbeitsbezogenen Ziels,

I: Interventionsmöglichkeiten, Lösungsideen.

Wenn Sie diese Abfolge von sechs Schritten (A - Z - A - P - Z - I) verinnerlichen und Beratungsgespräche mit Eltern, Kolleginnen, Schülerinnen danach strukturieren, werden Sie spürbar an Professionalität und Konzentration auch bei schwierigen Themen gewinnen. Und Sie werden sich zunehmend daran freuen können, dass Ihr Gegenüber auf Lösungsideen kommt (Download 6).

Im Rahmen einer Intervisionsgruppe können Sie auch bei dieser Variante zwischendurch in der Rolle B eine Auszeit nehmen und Resonanz von der Gruppe erbitten; nach der Problembeschreibung (P) kann das sehr anregend wirken. Als Beraterin können Sie dann, wie gesagt, so fortsetzen: „Nach all dem, was Sie von der Gruppe gehört haben - was beschäftigt Sie jetzt?“”

Variante 4: Das Göttinger Stufenmodell der Supervision

Ein weiteres Modell kollegialer Beratung setzt von Anfang an auf die hilfreiche Resonanz einer Gruppe: Die Stufentechnik der Supervision, von Annelise HeiglEvers (1975, 43 ff) ursprünglich für die Ausbildung von Psychoanalytikerinnen konzipiert.

Das Modell vereint wichtige Elemente guter Beratung: Es verlangsamt den Verstehensprozess (für Lehrerinnen und Lehrer eine erhebliche Herausforderung); es verlangt genaues Zuhören; es thematisiert ausdrücklich die jeweils beteiligten Gefühle, sowohl im geschilderten Fall als auch bei den Gruppenmitgliedern; es erlaubt, sich einmal freien Einfällen, Ideen, scheinbar unpassenden Assoziationen hinzugeben (denken Sie an die freie Assoziation auf der Freud'schen Couch); es konzentriert sich nicht auf eine einzelne schwierige Person, fokussiert vielmehr die Beziehung zwischen den beteiligten Personen; und es verbannt die immer schnell sich einstellenden Lösungsideen an den Schluss des Prozesses.

Jedes Gruppenmitglied wird auf jeder der fünf Stufen um einen Beitrag gebeten; Kritik untereinander ist strikt untersagt. So entsteht ein sicheres und tragfähiges 
Klima. Wer moderiert, muss vor allem die Struktur einhalten und frühe Lösungsideen freundlich, aber bestimmt auf Stufe V verschieben, z. B. so: „Merken Sie sich den Punkt für Stufe V; wir sind jetzt bei Stufe II.“

Vorzeitige Diagnosen sind dementsprechend auf Stufe IV zu schieben. Unbedingt erforderlich ist ein akzeptierendes Gruppenklima. ${ }^{23}$ Die oft auftretende Tendenz, der Äußerung eines anderen Gruppenmitglieds zu widersprechen, ist darum sofort zu unterbinden: „Bitte keine Kritik! Sagen Sie stattdessen Ihren Einfall!“ Ich erläutere einige Einzelheiten zu den fünf Stufen:

\section{Einstieg: Bericht}

Eine Teilnehmerin berichtet über ein Vorkommnis aus dem Kern ihrer Arbeit: Eine Irritation (erfreulich oder unerfreulich), ein Unbehagen, eine körperliche Reaktion o. ä., kein langer Bericht, drei bis fünf Minuten, kein Aktenvortrag, sondern frei gesprochene Darstellung, die mit einer Frage an die Gruppe endet. Informationsfragen zum Bericht sind erlaubt, aber kurz zu halten. Die Fallgeberin kann sich nach dem Bericht zurücklehnen, hört nur zu, wird nicht direkt angesprochen.

\section{Stufe I: Wahrnehmung}

Was habe ich gehört? (Sammlung der Passagen, die die Einzelnen besonders beeindruckt haben.) Wörtliche Zitate, keine Interpretationen, keine Diagnosen! Aktives Zuhören in der einfachsten Form! Als Moderatorin werden Sie merken, wie schwer es vielen fällt, wörtlich zu zitieren, ohne zu interpretieren.

\section{Stufe II: Emotionale Resonanz}

Die KollegInnen teilen ihre persönliche Resonanz mit, keine Kritik (!!), sondern Stimmungen und Gefühle (Näheres dazu: 12.3.2). Die Moderatorin fragt die Fallgeberin, was davon sie besonders angesprochen hat.

\section{Stufe III: Assoziationen, Einfälle, Fantasien}

Die KollegInnen nennen Einfälle, Phantasien, innere Bilder (Ich-Sätze!), Geschichten, Märchen, Filmszenen, die ihnen im Zusammenhang des Berichts eingefallen sind bzw. die ihnen einfallen, wenn sie jetzt danach suchen. Die Moderatorin fragt die Fallgeberin, was davon sie besonders angesprochen hat.

\section{Stufe IV: Diagnose der Situation}

Die KollegInnen äußern Hypothesen zur Diagnose der Situation: Was ist da los zwischen den Beiden oder zwischen den Beteiligten? Welche Dynamik spielt sich da ab? Teufelskreise? Sackgassen? Psychologische „Spiele“? Die Moderatorin fragt die Fallgeberin, was davon sie besonders angesprochen hat.

23 Damit eine Fallberatungsgruppe Sicherheit bieten kann, ,,muss die Atmosphäre von Wohlwollen, gegenseitiger Anerkennung und Wertschätzung geprägt sein. Genau diese aber würde gar nicht erst entstehen, wenn eine falleinbringende Person methodisch erst , ausgefragt " und anschließend mit Rat- und Löungsvorschlägen bedacht würde.“ (Mosing 2006, 1006) 
Die KollegInnen sagen, was sie selbst in so einer Situation täten bzw. was sie der Fallgeberin vorschlagen möchten: neue Sichtweisen, erste Schritte, konkrete Verhaltensweisen. Die Moderatorin fragt die Fallgeberin, was davon sie besonders angesprochen hat, an welcher Stelle sie möglicherweise Ideen zu ihrem weiteren Vorgehen bekommen hat, und zum Abschluss, wie es ihr jetzt geht und wie die Gruppe den Prozess erlebt hat.

Mit diesem Modell haben wir gute Erfahrungen gemacht, sowohl in den Weiterbildungskursen als auch in großen schulinternen Lehrerfortbildungen (SchiLF), bei denen mehrere Gruppen parallel einmal die Arbeit mit dem Stufenmodell erlebt haben, um es dann unmittelbar in einem zweiten Durchgang eigenständig auszuprobieren. Dieser zweite Schritt, die eigenständige Moderation, stößt immer wieder auf Bedenken, zusammen mit weiteren Fragen.

Häufig gestellte Fragen zum Stufenmodell:

Frage: Wie kann ich vorgehen, wenn meine Kolleginnen meiner Moderationskompetenz nicht viel zutrauen?

Antwort: Wenn Sie in Ihrer Schule oder in Ihrem Umkreis z. B. eine Beratungslehrerin, einen Sozialpädagogen mit entsprechender Vorerfahrung haben, dann können Sie die um die Einführung des Modells bitten.

Frage: Wie kann man Lehrerinnen für die Arbeit mit so einem personenbezogenen Modell gewinnen?

Antwort: Indem Sie die Struktur als Arbeitsblatt austeilen und das Modell und den Sinn des Modells gut erklären (Download 7).

Frage: Kann man das moderieren, wenn man keine psychoanalytische Ausbildung hat?

Antwort: Ja, wichtig ist aufmerksames Zuhören und klares Bestehen auf der Einhaltung der Stufen. ${ }^{24}$ Wenn Sie gelernt haben, Teams und Klassen zu moderieren, dann ist der Schritt nicht groß.

Frage: Wie kann ich mich auf die Moderation vorbereiten?

Antwort: Wir haben einige Hinweise für die Moderation in einem Arbeitsblatt zusammengestellt (Download 8). Der m. E. wichtigste Punkt: Kritik an Äußerungen anderer Gruppenmitglieder ist sofort zu unterbinden.

Frage: Wie schnell kann man lernen, eine Gruppe so zu moderieren?

Antwort: Im Prinzip genügt es, das einmal vorzumachen. Danach hat sich immer jemand gefunden, der mutig die Moderationsrolle übernommen hat. Es schadet nicht, wenn es anfangs etwas holprig zugeht. Es geht um Lernen, nicht um Perfektion.

24 Mosing (2006, 1027) orientiert sich am Modell einer Balint-Gruppe, deren Moderation deutlich höhere Anforderungen stellt. Ihre Hinweise auf die nötige Qualität der Moderation sind so deutlich, dass die Bereitschaft, die Moderation einer Beratungsgruppe zu übernehmen, gedämpft werden könnte. Sie spricht sich aber ausdrücklich dafür aus, dass die Gruppenmitglieder diese Moderationskompetenz erlernen sollten. Im Göttinger Modell bieten die fünf Stufen dafür ein sehr hilfreiches Geländer. 
Frage: Welche Gruppengröße ist für dies Verfahren geeignet?

Antwort: Je größer die Gruppe, desto höher der Zeitbedarf. Je kleiner, desto weniger

Vielfalt in der Resonanz; 6-12 Personen sind eine günstige Größe.

Frage: Ist das Verfahren nicht viel zu zeitaufwendig und umständlich?

Antwort: Die Zeit für eine Beratung variiert zwischen einer halben und einer

Stunde. Stressexperten empfehlen solche Gruppenberatungen als effektives Mittel gegen Burnout und für die Förderung von Teamzusammenhalt. (Näheres dazu in Kapitel 11.) Bedenken Sie: Es geht darum, die richtigen Dinge zu tun.

Wenn dies Verfahren als so nützlich, unterstützend, entlastend erlebt wird - wie kommt es dann, dass es in Schulen kaum einmal regelmäßig praktiziert wird? Antwort unserer Kursgruppen: Dafür haben wir keine Zeit! ${ }^{25}$ (Näheres dazu s.u. $11.8)$

\subsection{Vertragsarbeit: Sicherung der Arbeitsfähigkeit}

Am Anfang dieses Kapitels stand die Frage: Wie können Sie ein arbeitsfähiges Steuerzentrum aufbauen, wenn Sie Ihre Schule in Richtung einer Lernenden Organisation entwickeln wollen? Kools und Stoll (2016) weisen darauf hin, das Modell Lernende Organisation werde von Schulleitungen als zu vage empfunden (s. o. 2.3). Schon jetzt aber haben Sie zu den Dimensionen Systemdenken, persönliche Meisterschaft und Teamlernen eine Reihe differenzierender „Brillen“ kennengelernt, denen man kaum vorwerfen kann, vage und unkonkret zu sein. Weitere kommen noch hinzu. Eher werden Sie sich fragen, wie Sie sich, stark gefordert durch das Alltagsgeschäft, all diese in den Modellen vorausgesetzten Kompetenzen aneignen können.

\subsubsection{Nicht alle Brillen auf einmal aufsetzen - gehen Sie behutsam vor!}

Sie müssen nicht alles auf einmal können. Konzentrieren Sie sich auf wenige Punkte, auf solche, die Sie vor allem brauchen, um Arbeitsfähigkeit in Ihrem Leitungsgremium zu optimieren. Jede Schule ist anders, jede hat ihre spezifischen Möglichkeiten entwickelt. Die Erwartungen von Eltern, von weiterführenden Schulen, Universitäten, Wirtschaft sind in ständiger Wandlung. Die Einflüsse, denen die Schülerinnen und Schüler ausgesetzt sind, unterscheiden sich dramatisch von früheren Jahren und Jahrzehnten. Überall lauern Konflikte. Nichts ist so konstant wie die Veränderung. Jede Schule muss sich auf Veränderungen einstellen und sich dabei ihren eigenen Weg bahnen.

25 „Zum Alltag von Leitungsmitgliedern gehört fast immer ein enormer Zeit-und Leistungsdruck: Es erscheint selbstverständlich, schnelle und gute Lösungen angesichts von Problemen und Konflikten zu finden. In der Schule - und nicht nur hier - wachsen aber auch Konflikte proportional zur fehlenden Zeit, an ihnen und über sie nachdenken zu können. So besteht die Gefahr, dass unter Zeit- und Lösungsdruck allmählich eine atemlose ,Reparaturmentalität entsteht, die mehr neue Probleme schafft, als alte dauerhaft zu lösen.“ (Mosing 2006, 1005 f) 
Proaktive, mutige Leitungspersonen werden gebraucht. Aber: Leitungspositionen sind wenig begehrt - wieso? Typische Antwort von Lehrerinnen und Lehrern: „Dem Stress will ich mich nicht aussetzen.“ Die wissen ganz gut, welchem Druck ihre Leitungen ausgesetzt sind, wie wenig Rückenwind sie von der Politik, von Schulämtern, von den Trägern und nicht zuletzt vom eigenen Kollegium bekommen.

\subsubsection{Die Lerninteressen der Geleiteten als Schlüssel zur Beteiligung}

Gehen Sie darum behutsam vor. Strategische Themen sind wichtig, aber nicht eilig. Mit ihnen richten Sie Ihren Blick in die Zukunft, auf wünschenswerte Entwicklungen. Kleine, der strategischen Entwicklung dienende Schritte dorthin sind taktischer Natur. Wenn es Ihnen gelingt, die zusammen mit Ihrem Team zu gehen, sind sie effektiv; große Schritte, mit denen Sie allein voraus eilen, sind es nicht. M. Fullan warnt vor schnellen Top-down-Interventionen: „Am besten werden Führungskräfte fahren, die sich selbst konsequent als Designer, nicht als Kreuzritter betrachten. Viele der bestgemeinten Anstrengungen zur Förderung neuer Lerndisziplinen scheitern, weil die verantwortlichen Leiter die wichtigste Regel beim Lernen vergessen: Menschen lernen, was sie selbst für notwendig erachten, und nicht, was jemand anderer für lernenswert hält.“" (Fullan 1999, 121)

Dass so Experten für Lernprozesse ticken, also Lehrerinnen und Lehrer, habe ich erst allmählich verstanden. In unseren Weiterbildungskursen treffen wir ja auf gut motivierte, lernwillige Leute, die sich bis dahin meistens nicht kannten, die offen sind für neue Erfahrungen. Ohne Fullan damals zu kennen, war ich vorsichtig genug, gleich am Anfang zu fragen, was diese motiviert erscheinenden Leute selbst für lernnotwendig erachteten: „Welche Ziele haben Sie mitgebracht?“ Diese Frage kannte ich aus meinen eigenen Weiterbildungen. Wenn ich weiter zurückdenke, in meine Studienzeit, dann wird mir klar, dass auch ich nur dann mit dem Herzen dabei war, wenn mich etwas wirklich interessierte, ein Thema oder eine bestimmte Kompetenz, die mir wichtig war und die mir fehlte. Fullan hat Recht.

„Was wollen Sie in diesem Kurs erreichen?“ Am ersten Tag des Kurses, nach einer kurzen Begrüßung, stelle ich diese Frage, mit einem Strukturelement, das so einfach und so wirkungsvoll ist, dass ich es immer wieder eingesetzt habe, nämlich so: „Setzen Sie sich zu zweit zusammen und sprechen Sie miteinander sieben bis zehn Minuten über die Ziele, die Sie hier erreichen möchten." Das bedeutet: Schon in der ersten Viertelstunde des Kurses haben alle schon einmal den Mund aufgemacht, mit jemandem geredet und erfahren, dass sie ernst genommen werden. Nach dieser ersten Sprecherfahrung wurden die Ziele der Einzelnen im Plenum ausgesprochen und auf Flipchart mit Namen festgehalten. So hat schon nach kurzer Zeit jeder und jede im Plenum einmal etwas angesprochen, nicht irgendetwas, sondern ein persönlich relevantes Thema. Als Methode zur Aktivierung Ihres Leitungsgremiums habe ich Ihnen dies Vorgehen bereits ans Herz gelegt (s. o. 5.2.2.1).

Damit sind gute Voraussetzungen für den nächsten Schritt geschaffen: für die Verabredung eines Lehr- und Lernvertrags. Wohlgemerkt: im Kurs. Wenn Sie jetzt an Ihr Leitungsteam denken: Haben Sie da ebenso gut motivierte lernwillige Leute, 
mit klaren eigenen Zielen, offen für neue Erfahrungen, so wie wir es in den Kursen erlebt haben? Wenn nicht, bleiben Sie vorsichtig, behalten Sie Ihr strategisches Ziel (Aktivierung aller Beteiligten) im Auge, gefährden Sie es aber nicht durch voreilige Taktik.

Sicherung von Arbeitsfähigkeit ist eine wichtige Voraussetzung auch für einen Weiterbildungskurs. Darum klären wir nach der Zielsammlung Rechte und Pflichten sowohl der Kursleitung als auch der Lerngruppe, differenziert nach Inhalt (WAS) und Prozess (WIE); s. Tabelle 2. Worum soll es hier inhaltlich gehen, und wie wollen wir unsere Arbeit gestalten? Die Teilnehmerinnen reagieren darauf erstaunt, aber auch interessiert. Sie werden als Vertragspartnerinnen angesprochen, die zusammen mit der Kursleitung einen Lehr- und Lernvertrag erarbeiten. Nach der Frage nach ihren Zielen werden sie damit ein zweites Mal zu Aktivität angeregt. Auch das geht gut mit ein paar Minuten zu zweit; anschließend werden die Voten im Plenum angehört und schriftlich festgehalten. Das geht problemlos.

Tabelle 2: Vertragsquadrat für die Klärung der Zusammenarbeit

\begin{tabular}{|c|c|c|}
\hline & LEHRKRÄFTE & SCHULLEITERIN \\
\hline WAS & & \\
\hline WIE & & \\
\hline
\end{tabular}

Geht das auch im Schulalltag, in Ihrem Leitungsteam? Der laufende Schulbetrieb steht unter ganz anderem Druck als ein oasenhafter Weiterbildungskurs. Selbst wenn Sie ein optimales Leitungsteam haben - überstürzen Sie nichts. Übereilte Veränderungen können allzu leicht als Überfall aufgefasst werden. Wichtige Ansätze wären dann ,,verbrannt“. Optimale Bedingungen sind nicht der Normalfall. Ich skizziere darum zunächst eine Vorgehensweise, die die Tücken einer Top-downIntervention vermeidet.

\subsubsection{Intervenieren Sie nicht top-down, sondern mit sich selbst!}

Fangen Sie bei sich selbst an! Sie haben Ihren diagnostischen Blick inzwischen geschärft. Sie wissen sich zuständig für die Moderation Ihres Leitungsteams. Sie haben einige Ideen, wie Sie die Arbeit im Team optimieren möchten. Ich skizziere Ihnen eine mögliche Folge von kleinen Interventionen, in ansteigender Komplexität, verteilt über die Zeit, Sitzung für Sitzung.

Intervention 1: Sie können mit einer wahrscheinlich überraschenden Veränderung anfangen, indem Sie am Ende der Teamsitzung um ein Feedback bitten, z.B. so: „Mir liegt daran, dass wir hier gut zusammenarbeiten. Ich möchte mit meiner Moderation dazu beitragen und bitte Sie um eine kurze Rückmeldung: Was an meiner Moderation fanden Sie heute hilfreich? Ich übe noch den Umgang mit Feedback. Machen Sie's mir leichter und nennen Sie erstmal für heute nur 
positive Aspekte.“ Dann: abwarten, anhören, danken, nicht kommentieren, nicht diskutieren.

Intervention 2: In der nächsten Sitzung können Sie Ihren Feedback-Wunsch präzisieren. Nennen Sie jetzt schon am Anfang der Sitzung einen bis zwei Punkte, zu denen Sie am Ende gern Rückmeldung hätten, z. B.: „Wie ist es mir heute gelungen, das Team zu aktivieren? Und wenn ich den Stand der Diskussion zusammengefasst habe - wie wirkte das auf Sie?" Wiederum: abwarten, anhören, danken, nicht kommentieren, nicht diskutieren. Effekt: Die Mitglieder wissen, dass am Ende Ihre Frage kommt. Das heißt, sie werden aufmerksam auf das WIE der Arbeit, auf Metakommunikation. Und das ist gut so.

Intervention 3: Welche Strukturelemente würden Ihrem „Gartenteich“ gut tun? Schauen Sie sich die Strukturthemen des Mindmap zur Moderation eines Managementteams nochmal an, und setzen Sie eins dieser Themen auf die Tagesordnung, z. B. den Wunsch, in Zukunft (falls das nicht schon selbstverständlich ist) die Punkte für die Tagesordnung bis zu einem bestimmten Termin vor der Sitzung zu sammeln, als Notiz in Ihrem Postfach oder (in großen Schulen) im Sekretariat o. ä. Sie erläutern die Vorteile (Zeitökonomie; bessere Vorbereitungsmöglichkeit) und weisen darauf hin, dass Nachmeldungen von TOPs zu Beginn der Sitzung in Zukunft auf das nächste Treffen vertagt werden, ausgenommen echte Krisen. Zusätzlich zu diesem Strukturelement bitten Sie wieder um ein konkretes Feedback zur Sitzungsleitung.

Intervention 4: So können Sie weiter machen, Schritt für Schritt; in jeder Sitzung lassen Sie ein weiteres Strukturelement folgen (z.B. rechtzeitige Zusendung einer schriftlichen Tagesordnung an alle Teammitglieder usw.; s. o. 5.2.2.1 Mindmap Managementteam), und Sie holen sich weiter Feedback.

Sie sind mit alledem Modell für den Umgang mit Feedback. Sie machen vor: Feedback kann ich steuern, in Form von „kleinen Brötchen“, so dass es konkret, positiv, nicht beängstigend ausfällt. Und Sie werben in kleinen Schritten um Unterstützung für Ihre Arbeit durch strukturelle Verbesserungen. Und Ihre Kolleginnen und Kollegen werden neugierig werden, was Sie das nächste Mal wieder an kleinen Interventionen mitgebracht haben.

\subsubsection{Vertragliche Absprachen zur Arbeitsweise Ihres Leitungsteams}

Intervention 5: Irgendwann wird die Zeit gekommen sein, die Arbeitsweise im Team insgesamt zum Thema zu machen. Klare Verabredungen erleichtern die Moderation und ebenso die Beteiligung aller Teammitglieder. Zeichnen Sie ein Vierfelder-Schema mit leeren Feldern (s. o. Tabelle 2).

Erläutern Sie kurz: Es geht darum, sich gemeinsam über Rechte und Pflichten der Teammitglieder und der Sitzungsleitung zu verständigen. Welche Inhalte gehören in dieses Gremium? Wie sollen sie bearbeitet werden? Geben Sie den Teammitgliedern einige Minuten Zeit, allein oder auch zu zweit ihre Ideen zu sammeln. Sie selbst haben sich auf diesen Punkt gut vorbereitet und wissen, was Sie gern in „Ihren“ Quadranten verankern möchten. Während die Teammitglieder ihre Interessen besprechen, können Sie Ihre eigenen Punkte in die Quadranten für 
die Schulleiterin eintragen. Schreiben Sie die Punkte auf, die Ihnen die Arbeit erleichtern würden, z. B. zum WAS: Arbeit an strategischen Themen; Möglichkeit für kollegiale Beratung. Zum WIE: Regelmäßiges gegenseitiges Feedback; GFK (= gewaltfreie Kommunikation; wird beim Konfliktmanagement erläutert).

Sammeln Sie die Wünsche der Teammitglieder im Plenum, tragen Sie sie in die Quadranten für die Lehrkräfte ein, und prüfen Sie gemeinsam, wie das Ergebnis auf Sie alle wirkt. Vielleicht sind noch Änderungen vorzunehmen. Wenn Sie einen Konsens erreicht haben, wird es ernst: „Gilt das jetzt als Verabredung bis zu einem noch festzulegenden Auswertungstermin?" Sichtbares Nicken gehört dazu. Wenn alle genickt haben, sind Sie ein großes Stück vorangekommen. Ein wichtiges Stück Arbeit am System haben Sie geschafft. Sie haben jetzt eine gemeinsam verabredete Arbeitsbasis, an die zu halten sich alle verpflichtet haben. Sie könnten das in Schönschrift auf ein großes Plakat schreiben lassen und im Sitzungszimmer für alle sichtbar dauerhaft aufhängen. Dann können Sie im Rahmen der Sitzungsauswertung am Ende jeder Sitzung fragen, wie gut es allen gelungen ist, sich an den Vertrag zu halten.

\subsubsection{Metaregeln zum Umgang mit vertraglichen Absprachen}

Also alles gut? Nicht unbedingt. Es kann unterschiedliche Auffassungen geben, wie die einzelnen Punkte gemeint sind. Manches wird von manchen nicht so wichtig genommen. Im Alltag geht vieles unter. Also brauchen Sie zusätzlich eine Verständigung über die Frage, wie Sie diesen Vertrag praktizieren wollen. Zur Orientierung folgen hier einige wichtige Hinweise zum Verständnis von Verträgen in Organisationen:

- Ein Vertrag ist eine ausdrückliche Vereinbarung zwischen zwei oder mehreren Personen, die gemeinsame Ziele und die Art, wie sie erreicht werden sollen, festlegt. Beispiele: Arbeitsvertrag, Stellenbeschreibung, Leitlinien, Konzepte, Standards, Qualitätsverabredungen usw. (vgl. z. B. Sejkora und Schulze 2016, 183).

- Beide Seiten binden sich durch den Vertrag. Verträge können verändert werden, doch darf das nicht einseitig und ohne Absprache geschehen. Das heißt, jede Vertragsveränderung bedarf einer gemeinsamen Verabredung.

- So wie es immer „Wetter“ gibt, so gibt es in Organisationen immer Verträge, keine vertragsfreien Räume; häufig sind die offiziellen Verträge vielen Beteiligten nicht bewusst. Dann lässt sich am Verhalten der Beteiligten ablesen, an welchen inoffiziellen, heimlichen Verträgen sie sich orientieren.

- Heimliche Verträge kommen zustande, wenn niemand bei Vertragsverletzungen einschreitet. Der heimliche Vertrag lautet dann: Was wir hier offiziell besprechen, gilt gar nicht. Das heißt, heimliche Verträge entwerten das Engagement, das für die Verabredung offizieller Vereinbarungen aufgewendet wurde. Das Problem dabei: Heimliche Verträge sind in der Regel verhaltenswirksamer als offizielle.

- Grundsätzlich ist jede beteiligte Person berechtigt, Vertragsverletzungen anzusprechen. Mindestens aber ist das von allen Leitungsverantwortlichen zu erwarten, die per Rolle dazu verpflichtet sind, Hüter und Wächter von Regularien und Verfahren zu sein: Arbeit am System. 
- Ein guter Vertrag wirkt im Sinne von Konfliktprävention. Klare Absprachen erleichtern es, Abweichungen vom Vertrag anzusprechen.

Das beschriebene Vertragskonzept ist ein wesentliches Element der Transaktionsanalyse, die noch Thema sein wird (s. u. 6.9).

Ihr bisheriges Vorgehen enthält wichtige Botschaften:

- Sie zeigen Ihr Interesse an konstruktiver Zusammenarbeit.

- Sie wollen Beteiligung und organisieren die Möglichkeit dafür.

- Sie leiten partizipativ und zugleich verbindlich.

- Sie führen Feedback in die gemeinsame Arbeit ein. Zur Erinnerung: Ohne Feedback kein Lernen.

- Sie setzen auf fortlaufende Entwicklung: Verträge sind immer wieder zu überprüfen und auszuwerten.

- Sie lenken die Aufmerksamkeit auf den Unterschied von offiziellen und heimlichen Verträgen und zeigen damit, dass Sie mit heimlichen Verträgen auch in Ihrer Schule rechnen.

- Sie geben zu verstehen, wie und wann man Sie als Konfliktpartner kennenlernen wird: Wenn nämlich jemand Vertragsaspekte einseitig, auf eigene Faust, ändert. Näheres dazu beim Thema Konfliktmanagement (Kap. 6).

- Und schließlich: Sie legen sich öffentlich darauf fest, dass auch Sie sich an Verabredungen binden und Kritik akzeptieren werden, wenn Ihnen ein Versäumnis unterläuft. Die Bereitschaft, das einzugestehen, stärkt Ihre Autorität eher, als dass es sie mindert (vgl. Newmark 2020, 104 f; s. a. 6.7.3).

Sie etablieren mit diesem Vorgehen wichtige Spielregeln, deren Beachtung Ihnen bei der anspruchsvollen Aufgabe der Schulentwicklung, insbesondere beim Umgang mit Konflikten, helfen wird. Um Sie ein wenig einzustimmen, was für heimliche Verträge da zum Vorschein kommen könnten, folgen hier einige Beispiele, die in unseren Kursen genannt wurden:

- Verträge sind bekannt, aber Einzelne halten sich nicht dran. Beispiele: versäumte Pausenaufsicht, Nichteinhalten der Handy-Regelung, Unpünktlichkeit (später kommen, früher gehen), unterlassene Abmeldungen; unaufgeräumtes Klassenzimmer; nicht geführtes Klassenbuch. Entsprechende Hinweise werden als dirigistisch abgewehrt.

- Sonderwunscherfüllungen schaffen immer wieder heimliche Verträge, Rücksicht auf private Interessen bei der Festlegung des Stundenplans.

- Ein Kollege ignoriert den gemeinsamen Beschluss, ein bestimmtes Lehrwerk zu benutzen.

- Abgabefristen für Zensuren werden nicht eingehalten.

- Die nach A 15 beförderten Lehrkräfte ignorieren ihre zusätzlichen Aufgaben.

- Ältere Kollegen sehen die neuen Regeln als für sie nicht gültig an.

- Mitglieder der erweiterten Schulleitung werden durch Bypässe umgangen.

- Beschlüsse tendieren zum Versanden; wichtig wären Auswertungen. Das aber erfordert Mut, offenes Feedback zu äußern.

Schon die Sammlung solcher Schleichwege schärft das Bewusstsein nicht nur für wichtige Baustellen, sondern auch für Optimierungsmöglichkeiten: 
- Wenn die Einhaltung von Verabredungen nicht kontrolliert wird und sie darum versanden, zeigt sich darin eine fatale Selbstabwertung aller Beteiligten: Was wir hier verabreden, hat keine praktische Bedeutung, ist also Zeit- und Energievergeudung.

- Rahmenbedingungen wie Schulgesetze, Erlasse, Konzepte, Schulordnung haben Vertragscharakter; je klarer sie bewusst sind, desto transparenter ist auch bei Entwicklungsfragen der jeweilige Handlungsspielraum.

- Wünschenswert ist eine Kommunikationskultur, in der man miteinander statt übereinander redet.

- Neue Lehrkräfte können als eigene Gruppe einen aufschlussreichen fremden Blick auf das Gesamtsystem und die Regularien liefern.

- Heimliche Verträge sollten offiziell werden, wenn die regulären sich destruktiv auswirken.

So leiten Sie partizipativ, und so leiten Sie verbindlich. Das geht gut zusammen.

\subsection{Vertiefung: Keine Herrschaft von Menschen über Menschen}

„Lasst uns Menschen machen - ein Bild, das uns gleich sei.“ (1. Mose 1,26) Im biblischen Schöpfungsbericht wird der Mensch als Abbild Gottes entworfen, als ein „Bild, das ihm gleich“ ist. Das erste hebräische Wort heißt „Abbild“ und „Statue“, das zweite „Ähnlichkeit“ und „Entsprechung “. So hießen im alten Orient die Königsstatuen, die die Großkönige in den von ihnen unterworfenen Reichen als Abbilder ihrer selbst aufstellen ließen, um klar zu machen, wer das Sagen hat, wem Ehre zu erweisen und Steuern zu entrichten sind.

Im Schöpfungsbericht der Bibel werden wir Menschen also als Königsdenkmäler bezeichnet, als lebende Erinnerungszeichen an den einen, den einzigen König, der der Herr der Menschen ist. Jeder Mann ein König, jede Frau eine Königin! So sind wir gedacht.

Erzählt haben das Israels Priester den Verbannten in Babylon, in der Zeit nach der Zerstörung Jerusalems und des Tempels 587 v. Ch., nach dem Zusammenbruch des Staates Juda. Naiv waren diese Priester nicht. Wahrscheinlich haben sie sich mit dieser Sicht des Menschen ihren Unterdrückern gegenüber überlegen gefühlt, den tatsächlichen Machtverhältnissen zum Trotz. Ein Mensch kommt als Herr von Menschen nicht in Frage, und sei er ein noch so mächtiger Potentat. Die Bibel erzählt subversiv, immer wieder, sie bezieht grundsätzlich kritisch Stellung gegenüber aller Herrschaft von Menschen über Menschen.

In der Erzählung der Priester steckt ein enormer Anspruch: Wie kann man das leben: Verbannt sein, unterdrückt sein, ein missachteter Ausländer, eine missachtete Ausländerin sein - und gleichzeitig ein Königs-, ein Königinnen-Denkmal, Denkmal für einen Gott, der nicht so klar zu sehen ist wie die babylonischen Götter Sonne, Mond und Sterne? Man kann auf diesen Anspruch mit Zynismus reagieren; man kann aber auch Ermutigung darin finden und sich einer Würde innewerden, die sich auch in äußeren Widrigkeiten als Halt erweist. 
Wenn das das uns in christlichen Schulen leitende Menschenbild ist - was wird dann aus der Hierarchie, der ,heiligen Herrschaft“? Wie können Führungsverantwortliche führen und leiten, ohne über Menschen zu herrschen?

Einen Hinweis gibt ein zentraler Abschnitt aus dem zweiten Testament: „Ihr wisst, dass die Herrscher ihre Völker niederhalten und die Mächtigen ihnen Gewalt antun. So soll es nicht sein unter euch; sondern wer unter euch groß sein will, der sei euer Diener. “ (Matthäus 20, 25f) Empfohlen hat Jesus das nicht irgendwelchen unbekannten Menschen , an der Basis“, sondern seinen Jüngern, den prominenten Leitfiguren der Urkirche.

Die Bekenntnissynode von Barmen hat in der Auseinandersetzung mit den nationalsozialistischen „Deutschen Christen“ den genannten Abschnitt 1934 so erläutert: „Die verschiedenen Ämter in der Kirche begründen keine Herrschaft der einen über die anderen, sondern die Ausübung des der ganzen Gemeinde anvertrauten und befohlenen Dienstes. " (Nachzulesen im Evangelischen Gesangbuch, EG 858, Nr. 4)

Führen und Leiten, ohne zu herrschen, kann man also, wenn man die Führungsaufgabe als Dienst versteht. Moderne Führungslehren empfehlen den Führungsverantwortlichen, sich auch als Berater, als Coach der ihnen Nachgeordneten zu verstehen. ${ }^{26}$ Das schließt die Arbeit am System und an der Arbeitsfähigkeit des Teams durchaus ein. Andere erfolgreich machen - das ist die Aufgabe der Führungspersonen. Eine anspruchsvolle, reizvolle Rolle, die zu ständiger Entwicklung anregt.

Der damit gestellte Anspruch ist hoch. Die königliche Freiheit, die eben auch die Freiheit des anderen und der anderen ist, geht durch Missbrauch verloren. Die Bibel weiß auch das: „Gott hat die Menschen gerade gemacht; sie aber suchen viele krumme Wege. " (Prediger 7,29)

Wir rechnen wohl besser damit, dass uns nicht immer gelingt, was uns vorschwebt. Gerade dann ist entscheidend, dass wir uns daran erinnern lassen, wie wir gemeint sind, als wer wir geschaffen sind: als Königinnen und Könige, ausgestattet mit einer Würde, die unseren Leistungen und Fehlleistungen weit voraus und von ihnen unabhängig ist.

Ohne diesen Geist bleiben alle Strukturen, Grundsätze, Führungsleitlinien usw. steril. Wir können solchen Geist nicht erzwingen, weder bei uns noch bei anderen; wir können und sollen aber hoffen, dass dieser Geist in unserer Alltagsarbeit wie in der Alltagsarbeit aller Beteiligten spürbar werden will, wenn wir auf ihn setzen: „Wenn ihr mich von ganzem Herzen suchen werdet, so will ich mich von euch finden lassen. " (Jeremia 29,13)

26 „Die größte aller Führungsünden besteht darin, Mitarbeiter klein zu halten. Nur mit , großen“ Leuten lassen sich große Dinge anstellen. Firmen sind am wenigsten gefährdet, wenn ihre Mitarbeiter ,mitmischen', d.h., wenn sie ihre eigene Meinung haben und diese äußern, wenn sie die Möglichkeit haben, jederzeit Kritik anzubringen und bei Entscheidungen mitzuwirken.“ „Die Führungskraft ist ,Dienstleister“ ihrer Mitarbeiter und interessiert an deren Erfolg.“ „Erstklassige Führungskräfte sind bekanntlich von erstklassigen Mitarbeitern umgeben, zweitklassige in der Regel nur von drittklassigen." (Haberleitner u. a. 2012, 16 f) 


\section{Lesetipp}

Th. Gordon (1989): Managerkonferenz: Ein immer noch nicht selbstverständliches umfassendes Leitungskonzept, das Ihnen hilft, gewohnte Arbeitsabläufe zu überprüfen und bei Bedarf effektive Arbeitsstrukturen für Ihre Gremienarbeit zu entwickeln. Außerdem finden Sie Alltagsbeispiele, wie Sie sich mit IchBotschaften und aktivem Zuhören gut durch den Arbeitsalltag steuern können.

Sejkora und Schulze (2016): Die Kunst der starken Führung. Hintergrund des Buches sind lehrreiche Erfahrungen der Autoren aus dem Coaching mit Führungskräften in verschiedenen Organisationen. Der 5. Teil zeigt an typischen Führungsherausforderungen, wie Sie mit transaktionsanalytischen Konzepten auch in schwierigen Situationen handlungsfähig bleiben können.

Hiebl und Seitz (2014): 5.6 



\section{Kapitel 6: Schulentwicklung und Konfliktmanagement}

Bisher ging es um die Frage, wie Sie die Arbeitsfähigkeit Ihres Leitungsteams optimieren und vertraglich sichern können, ohne in einen Top-down-Leitungsstil zu geraten. Sie können partizipativ und zugleich verbindlich leiten, indem Sie sich mit Ihrem Team über Inhalte und Prozess, über WAS und WIE verständigen. Ein so konstruierter Arbeitsvertrag soll die Verbindlichkeit von gemeinsam verabredeten Beschlüssen sichern; garantiert ist sie damit noch nicht. Aber wie staatliche Gesetze nicht überflüssig sind, weil sie immer mal wieder übertreten werden, so bieten auch gemeinsam getroffene Verabredungen im System Schule eine tragfähige Grundlage, wenn Vereinbarungen verletzt werden und Klärung angesagt ist.

Ihre Leitungsrolle fordert von Ihnen vornehmlich Arbeit am System. Das wird nicht ohne Konflikte gehen. Was in einer Organisation ohne Konflikte verändert werden kann, ist schon verändert. Wenn Verabredungen verletzt werden, sind Sie als Leitung gefordert. Sie sind Hüter und Wächter von Regularien und Verfahren (vgl. Weil 2004). Dann kommen Sie um Konflikte nicht herum, auch wenn Ihnen „,selbst“ das persönlich nicht liegt. Harmonie ist für die meisten erfreulicher, auch für mich. Wenn aber die Arbeitsfähigkeit gefährdet ist, braucht sie Schutz, aktives Eingreifen. Dann ist Konfliktkompetenz gefragt. Erfahrene Leitungskräfte sagen dann: Das höhere Gehalt der Leitung ist Schmerzensgeld. Wenn Sie diesen Rollenanspruch verinnerlichen, können Sie - zusätzlich zum Schmerzensgeld - eine wichtige Lebenskompetenz weiter entwickeln, in der Arbeitszeit! Und Sie werden merken, dass Ihr Kollegium kompetenten Umgang mit Konflikten achtet.

\subsection{Scheiterstrategie als Ressourcenmobilisierung}

Wie können Sie wirksam in Konflikten intervenieren? Ich empfehle, die nötige Kommunikationskompetenz in „Friedenszeiten“ zu erwerben. Dann ist die Chance größer, dass Sie sie unter Stress nutzen können. Wie wäre es, wenn Sie diese Kompetenz nicht nur für sich selbst entwickeln, sondern Ihr Team daran beteiligen? Teamlernen schließt ein, das WIE der Zusammenarbeit zu reflektieren und zu pflegen. Wenn Sie dafür nicht immer, aber doch regelmäßig in Ihren Teamsitzungen Zeit reservieren, betreiben Sie Personalentwicklung - ein wichtiges B-Thema.

Ein gruppenaktivierendes und sogar amüsantes Verfahren bietet die Arbeit mit Scheiterstrategien. In vielen stressigen Situationen kann man sich und andere mit einer verblüffenden Frage überraschen und zum Denken bringen: „Wie könnten Sie das alles schlimmer machen?“ Konkret wäre also zu fragen: „Was müssten Sie tun, damit in den Konflikten Ihres Lebens alles noch schlimmer würde?“ Im Weiterbildungskurs löst diese Frage begeisterte Reaktionen in kleinen Gruppen aus. Für begrenzte Zeit ist es erlaubt, die tief verborgenen eigenen Schattenseiten mal hypothetisch ans Licht zu bringen. 
Gleichzeitig aktiviert dies systemische Verfahren die Ressourcen des Teams, geht also bottom-up statt top-down vor: Denn wenn ich weiß, wie ich etwas schlimmer machen kann, weiß ich in der Regel auch, wie ich es besser machen kann z. B. schon dadurch, dass ich die Verschlimmerung unterlasse.

In kurzer Zeit lassen sich Scheiterstrategien sammeln und auf Flipchart im Plenum festhalten. Danach fragen Sie weiter: „Wenn Sie wissen, wie Sie alles verschlimmern könnten, wissen Sie dann auch, was Sie besser machen könnten? Wie sähen die Positivversionen der Scheiterstrategien aus?" Einige Beispiele aus einem Kurs (Positivversionen kursiv in Klammern):

- Unbeteiligte Personen mit einbeziehen; Lagerbildung. (Sprich mit denen, die es angeht.)

- Persönlich beleidigt reagieren. (Fragen: Worum geht es der anderen Person?)

- Die andere Person nicht zu Wort kommen lassen. (Aktiv zuhören!)

- Hinter dem Rücken über andere reden. (Direkt ansprechen.)

- Fehler prinzipiell bei der anderen Person suchen. (Eigenes Fehlverhalten reflektieren.)

- Alte Kamellen aufwärmen. (Nach vorne schauen: Wie soll es weiter gehen?)

- Anklagen. (Ich-Botschaften statt Du-Botschaften einsetzen.)

- Die eigene Meinung rechthaberisch voranstellen. (Aktiv zuhören; Ich-Botschaften.)

- Die nächst höhere Instanz gleich mit einbeziehen. (Sprich mit denen, die es angeht.)

- Die andere Person herabwürdigen. (Verhalten klären, die Person schützen.)

- Cholerisch schreien. (Abstand halten, Interaktion zeitlich unterbrechen.)

- Den anderen wie Luft behandeln. (Sawu bona!)

Das Vorgehen zeigt, dass man mit einer Gruppe in kurzer Zeit eine Orientierung für das Verhalten in Konflikten erarbeiten kann - auch mit Kollegien oder Schulklassen. Es zeigt weiterhin, dass bestimmte Konzepte sich herumgesprochen haben, vor allem die Ich-Botschaft: Ich rede von mir, lasse in mich hineinsehen, statt mit einer Du-Botschaft über die andere Person herzuziehen. M. Prior (2002, 88 ff; 2009, 115) empfiehlt die knappe VW-Regel: Aus Vorwürfen (V) Wünsche (W) machen.

Alte Kamellen lassen auf das Sammeln von „Rabattmarken“ schließen; viele Einzelheiten (Leichen im Keller) werden präsentiert; wenn „,das Heftchen“ voll, das innere Ärgerfass übergelaufen ist, darf ich mir einen cholerischen Ausbruch leisten.

Häufig wird (vor allem von Männern) empfohlen, in Konflikten ganz sachlich zu bleiben. Bei Gefühlen begebe man sich auf rein subjektives Gelände. Ja, stimmt, dennoch sind sie wichtig. M. Rosenberg (2002, 67 ff) weist darauf hin, dass Gefühle (auch Ärger, Wut usw.) Hinweise auf unsere Grundbedürfnisse sind, und die sollten in Konflikten berücksichtigt werden (s. u. 6.6).

\subsection{Vom Beziehungsohr zur Selbstmitteilung}

Die Scheiterstrategie zeigt: Wir wissen recht gut, was in Konflikten hilfreich ist. Wie kommt es dann, dass das in gespannten Situationen so schwer zu beherzigen 
ist? Watzlawick hatte gelehrt: Jede Äußerung hat einen Inhalts- und einen Beziehungsaspekt. Schulz von Thun (1990, 13. $26 \mathrm{ff})$ hat diese Erkenntnis um zwei Aspekte erweitert. Jede menschliche Mitteilung lässt sich auf vier Aspekte hin abklopfen: auf Sachverhalt, Appell, Beziehung und Selbstmitteilung. (,Selbstoffenbarung“ klingt mir zu feierlich.) Diesen ,,vier Seiten einer Nachricht“ entsprechen auch vier Hörweisen, kurz: vier Ohren. Einfaches Beispiel:

A sagt (in Gegenwart von B): „Es zieht.“

Auf dem Sachohr hört B: Aha, A bemerkt einen Luftzug.

Auf dem Appellohr hört B: Sie will, dass ich das Fenster zu mache!

Auf dem Beziehungsohr: Ich hab mal wieder die Schuld, dass A leidet.

Auf dem Selbstmitteilungsohr: Sie fürchtet, sich zu erkälten.

Je nach dem von B aktivierten „Ohr“ wird B unterschiedlich reagieren:

Vielleicht sagt B: Ja, ich merk's auch. (Sach-Ohr)

Oder: Moment, ich mach das Fenster zu. (Appell-Ohr)

Oder aber B hört auf dem Beziehungsohr: Oh, tut mir leid.

Oder schließlich: Du sorgst dich um deine Gesundheit. (Selbstmitteilungsohr)

Wenn Sie jetzt noch einmal die Scheiterstrategien anschauen, dann wird klar, dass es sehr nahe liegt, sie allesamt auf dem Beziehungsohr zu hören. Bei Vorwürfen, Beschimpfungen usw. ist es sehr wahrscheinlich, dass die so angesprochene Person gekränkt reagiert. Auf Kränkung folgt dann Verteidigung, Gegenangriff oder innerer Rückzug, schlechte Stimmung, die niemand mag. Immer eifriger hören wir dann auf dem Beziehungsohr, richten unser inneres Radarsystem auf den Ton in der $\mathrm{Mu}-$ sik, überprüfen laufend, wie unser Bedürfnis nach Achtung, nach Wertschätzung von anderen respektiert wird.

Dann klopfe ich jede harmlose Bemerkung daraufhin ab, ob da eine versteckte oder offene Abwertung meines Verhaltens oder - noch schlimmer - meiner Person mitschwingt. Wenn ich das anspreche, kann das eskalieren. Dann wird mir empfohlen: „Sei nicht so empfindlich!“ Oder man behandelt mich wie eine Mimose. Wenn mir daran liegt, von schwierigen Aufgaben oder heiklen Themen verschont zu werden, kann ich mein Gekränktsein als wirksame Strategie einsetzen. In einem Team wäre das ein Zeichen für Phase 2: storming (s. o. 5.2.2.1).

Das Beispiel mit der Zugluft zeigt: Ich kann selbst entscheiden, auf welchem Ohr ich höre. Ich kann gekränkt reagieren, wenn ich es darauf anlege. Sie können das mal ausprobieren. Bitten Sie eine Ihnen vertraute Person darum, Sie anzuschauen und irgendetwas Triviales zu äußern. Und reagieren Sie dann ,,auf Deubel komm raus“" gekränkt. Beispiel:

Triviale Äußerung: „Hübscher Pullover, den du anhast.“ Gekränkte Reaktion: „Immer achtest du nur auf Äußerlichkeiten!““

Tröstlich dabei: Auch bei bestem Willen haben Sie es letztlich nicht in der Hand, wie die andere Person reagiert. Man muss sich nicht automatisch schuldig fühlen, wenn jemand gekränkt reagiert. Es kann durchaus sein, dass die andere Person Gekränktheit manipulativ einsetzt: zur Ausübung von Macht, zur Abwehr von Feedback.

Sie können allerdings - eingedenk der Positivversionen - einiges dazu tun, um die Wahrscheinlichkeit zu senken, dass die andere Person gekränkt reagiert. In 
einem Konflikt kann es z. B. sinnvoll sein, vorweg zu versichern: „Es geht mir nicht darum, Sie persönlich zu kränken.“

Wenn Sie selbst sich von jemandem angegriffen fühlen, dann könnten Sie, bevor Sie spontan, automatisch reagieren, die kränkende Äußerung überprüfen, z. B. mit der einfachen Frage: „Wie meinen Sie das?“ Oder: „Worum geht es Ihnen?“ Merken Sie sich zwei bis drei solcher Standardsätze.

Schalten Sie vom Beziehungsohr um auf das Selbstmitteilungsohr: Was sagt die andere Person über sich, ohne es klar zu formulieren? Sie hören vielleicht einen Vorwurf; fragen Sie nach dem Wunsch, der hinter dem Vorwurf steckt. Mit dieser freundlich zugewandten Grundhaltung wird es Ihnen mit der Zeit immer besser gelingen, gespannte Situationen zu deeskalieren. Immer öfter werden Sie herausfinden, worum es wirklich geht. Lassen Sie sich von Spinoza inspirieren: „Was Peter über Paul sagt, sagt mehr über Peter als über Paul.“

Wenn Sie sich missverstanden fühlen, können Sie sich vergewissern: „Wie läuft gerade unser Gespräch? Was hast du mich sagen gehört?““

Wenn Sie massiv attackiert werden, atmen Sie durch, nehmen Sie sich den „Torero“ als Modell: Lassen Sie den Stier nicht auf sich zu stürmen. Gehen Sie elegant einen Schritt zur Seite, lassen Sie den „Stier“ an sich vorbeirennen, ,studieren“ Sie ihn: Worum geht es dem Konfliktpartner? Was regt ihn auf? Was ist sein Interesse? Üben Sie, auch unter Stress aktiv zuzuhören! Keine Kleinigkeit, wirklich nicht, aber ein erheblicher Kompetenzzuwachs.

Ich übe noch immer - immer wieder -, vom Beziehungsohr auf die Selbstmitteilung der anderen Person umzuschalten. Worum geht es dieser Person? Und wie gewinne ich die notwendige innere Freiheit, von mir weg und der anderen Person aktiv zuzuhören? Diesen Ansatz finde ich in einem berühmten Bestseller wieder, im Harvard-Konzept der Verhandlung, verständlich und unterhaltsam beschrieben.

\subsection{Das klassische Gewinn-Gewinn-Modell für Konflikte}

Die Frage „Worum geht es dir?“ zielt auf die Selbstmitteilung des Gegenübers, auf seine Interessen, Wünsche, Grundbedürfnisse. Die Autoren des Harvard-Konzepts (Fisher u. a. 1995) heben diesen Punkt besonders hervor. Hören auf die Selbstmitteilung des anderen heißt im Konflikt vor allem: auf die Interessen des anderen hören und nicht auf oft vorweg gefasste Lösungspositionen.

Mit einem (vielleicht fiktiven) Alltagsbeispiel illustrieren die Autoren das so: Zwei Schwestern streiten sich um eine Orange. Schließlich teilen sie die in zwei Hälften. Dann isst die eine die Frucht, weil sie durstig ist, und wirft die Schale weg. Die andere aber wirft das Fruchtfleisch weg, nimmt die Schale und backt einen Kuchen. Hätten sie darüber gesprochen, was sie mit ihrer Hälfte vorhatten, dann hätte jede doppelt so viel bekommen können. Das wäre das Modell GewinnGewinn.

Gegensätzliche Lösungsideen enden in Blockaden. Man hilft sich dann mit Kompromissen, indem jede Seite Abstriche macht. So werden oft intelligente, kreative Lösungen verhindert. Weiter kommt man, wenn beide Seiten ihre hinter den Lösungsideen steckenden Interessen sich selbst und der anderen Seite klar 
machen und dann darüber nachdenken, wie sich zu diesen Interessen eine intelligente Lösung als gemeinsames Dach konstruieren ließe. Lösungspositionen sind oft unvereinbar, unterschiedliche Interessen nicht unbedingt. Die Schwierigkeit dabei: Innehalten, sich über die eigenen Interessen klar werden und sie auch mitteilen, den anderen in meine Karten gucken lassen! Das gehört dazu. Und dann die Interessen der anderen Seite aktiv zuhörend erfragen (im Sinne der Selbstmitteilung). Wenn das gelingt, kann kreative Fantasie zum Zuge kommen.

Häufig bleibt es bei faulen Kompromissen, besonders in der Politik. Aber nicht immer. Es gibt ein welthistorisches Beispiel für die Arbeit mit diesem Modell: die Verhandlungen zwischen Israel und Ägypten in Camp David 1978, unter Moderation des US-Präsidenten Jimmy Carter. Streitpunkt war der Sinai, den Israel im Sechs-Tage-Krieg militärisch besetzt hatte. Die Lösungsfixierungen: Sadat, also Ägypten, will den Sinai zurück haben; Begin, also Israel, will ihn nicht hergeben. Es hat 14 Tage gedauert, bis es den Top-Diplomaten gelungen ist, sich von ihrer Lösungsfixierung zu lösen, sich stattdessen auf die Interessen beider Seiten zu konzentrieren und dann einen kreativen Vertrag zu konstruieren.

Die Interessen: Ägypten will Souveränität, Israel will Sicherheit. Wie könnte das zusammenpassen? Schließlich die Lösung: Der Sinai wird entmilitarisiert; an der Grenze weht die ägyptische Flagge. Ergebnis: ein bis heute haltender Friedensvertrag. Ein diplomatisches Meisterstück, von L. Wright (2016) spannend beschrieben.

Also, wenn Sie in den Veränderungsprozessen in Ihrer Schule auf gegensätzliche Lösungsideen stoßen: Denken Sie an die Orange! Oder an Camp David. Erst Interessen klären, bevor Lösungen gesucht werden. Das ist das zweite Prinzip des Harvard-Konzepts von insgesamt vieren.

Das vierte Prinzip sollte gleich zu Beginn der Konfliktklärung berücksichtigt werden: Sind wir uns einig darüber, welchen Kriterien die noch zu suchende Lösung genügen soll? Welche Vertragsaspekte, welche Konzepte, Rahmenbedingungen, juristischen Grenzen sind bei der Lösungskonstruktion zu beachten?

Immer wieder gibt es in Schulen Streit, z. B. um die Stundenplangestaltung. Dann wäre es sinnvoll, zunächst die Gütekriterien für einen sinnvollen Stundenplan festzulegen und erst danach Einzelwünsche auf Realisierbarkeit zu überprüfen.

Das dritte Prinzip spricht Kreativität und Fantasie bei der Suche nach Lösungen an: Optionen erweitern. Es geht darum, Scheuklappen zu überwinden, das spezielle Problem in einem größeren Kontext anzuschauen. Watzlawick $(1974,44)$ illustriert das mit dem bekannten Neun-Punkte-Problem (s.u. Grafik 4): Verbinden Sie die neun Punkte mit vier geraden Linien, ohne den Stift dabei abzusetzen.

Praktisches Beispiel: Wenn Sie in einer jahrgangsübergreifenden Klasse schon eine Doppelbesetzung haben, ist eine weitere Stelle nicht unbedingt die geeignete Lösung für auftretende Schwierigkeiten. Es könnte eher um die Klärung der Rollen und der Zusammenarbeit gehen, um eine Lösung auf einer anderen Ebene, um einen Gangwechsel.

Ein nicht so seltenes Beispiel: Für das Fach Chemie oder Physik sind weitere Lehrkräfte nicht zu gewinnen. Also hilft man sich mit einem Quereinsteiger, der sich als ungeeignet erweist, von dem man aber nicht lassen mag, damit überhaupt irgendetwas stattfindet. Hat man wenigstens eine Expertin für so ein Fach, dann 


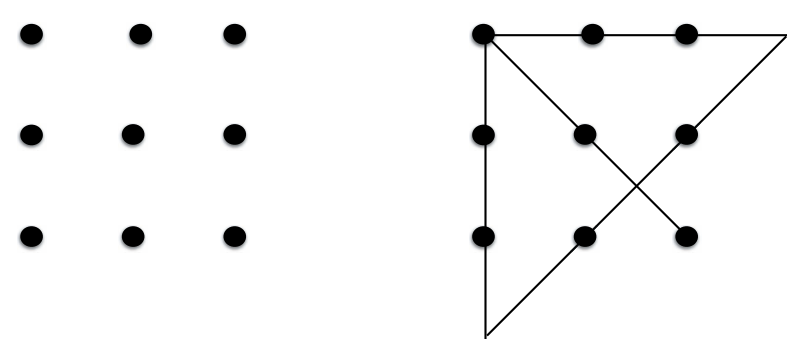

Grafik 4: Das Neun-Punkte-Problem und seine Lösung

könnte Optionen erweitern heißen: Man erarbeitet ein Konzept, das zentrale Unterrichtszeiten für zwei Klassen gleichzeitig mit guten Unterrichtsfilmen aus dem Internet vorsieht, baut ein Lernbüro auf (M. Rasfeld 2012, 93 ff; 133 ff) und organisiert Schüler-Mentoren für individuelle Nacharbeit. Es geht also darum, Denk- und Verhaltensgewohnheiten aufzugeben, die neue Lösungen blockieren.

Das erste Prinzip klang schon an: Hart in der Sache, weich (besser: respektvoll) zu den Menschen! Also nicht: Boxen Sie Ihre Lösungsidee durch! Vielmehr: Stehen Sie zu Ihren Interessen, nehmen Sie die wichtig, die der anderen Seite aber auch. Menschen und Probleme sind getrennt zu behandeln. Das können Sie, wenn Sie de-

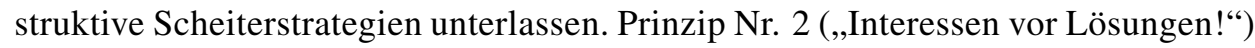
empfiehlt, Distanz zu einer vorgefassten Lösungsidee zu gewinnen, sich vielleicht ganz von ihr zu verabschieden, wenn eine kreative Lösung Ihr Interesse wahrt und auch die Interessen der anderen Seite einbezieht. Eine weitere Gelegenheit, an die Affen zu denken (s.o. 4.2).

\subsection{Drei Konflikttypen}

Kurze Rekapitulation: Ihre Leitungsrolle fordert von Ihnen Arbeit am System. Die können Sie nur leisten, wenn Sie die Arbeitsfähigkeit des Systems Schule im Blick haben und sichern. Insofern sind Sie Hüter und Wächter von Regularien und Verfahren. Arbeit am System bringt Veränderungen mit sich. Die lösen Konflikte aus, auch wenn sie gut verabredet wurden. Denn, wie gesagt: Was in einer Organisation ohne Konflikte verändert werden kann, ist schon verändert. Also gehört Entwicklung von Konfliktkompetenz auf Ihre persönliche Prioritätenliste, weit nach oben, als Teil Ihrer persönlichen Meisterschaft. Der folgende Überblick soll Ihnen helfen, Ihre derzeitigen Erfahrungen mit Konflikten zu überprüfen. Eine einfache Frage hilft, sich in Konflikten zurecht zu finden, die Frage: In welcher Hinsicht bin ich jetzt beansprucht? So lassen sich drei Konflikttypen unterscheiden.

\subsubsection{Typ I: Ich habe einen Konflikt mit dir: Wie steuere ich mich?}

Ein typischer Anlass für Konflikte im Arbeitsalltag: Jemand verletzt eine vertragliche Vereinbarung. Wenn Sie das mitbekommen, sind Sie als Leitung gefragt. Sie 
haben Regularien und Verfahren zu sichern. Vertragsbrüche, die nicht konfrontiert werden, wirken als heimliche Verträge. Die sind wirksamer als offizielle.

Welche Interessen (Harvard-Prinzip Nr. 2) sind in Arbeitskonflikten zu berücksichtigen? Vor allem die Interessen der Organisation Schule, die ihrerseits die Interessen der Schülerinnen und Schüler zu vertreten hat. Werden diese Interessen verletzt, ist die Leitungsrolle gefragt.

Eine häufige Frage: Woran kann ich erkennen, wann ich einen Konflikt aufgreifen sollte? Erste Antwort also: Immer dann, wenn Regularien ignoriert werden, spätestens dann, wenn der Primärauftrag der Organisation oder das Bild der Organisation in der Öffentlichkeit Schaden nimmt. Die Leitung kann verlangen, persönliche Animositäten zugunsten der Auftragserfüllung zurückzustellen.

Ein weiteres Indiz: Achten Sie darauf, wie es Ihnen geht, wenn Sie unsicher sind. Wenn mich in der Leitungsrolle etwas am Arbeitsverhalten z. B. eines Lehrers massiv stört, muss ich initiativ werden und von mir sprechen: Meine Selbstmitteilung ist gefragt. Wie bin ich als Leitung von der Vertragsverletzung berührt? Wie geht es mir? Bin ich ärgerlich, irritiert, ratlos? Wenn ich merke, dass es in mir ,brodelt“, wenn mir also meine emotionale Beteiligung bewusst wird, dann ist das ein Indiz dafür, dass mein Eingreifen gefragt ist. Und dann kann meine emotionale Beteiligung mir auch die Energie liefern, die ich brauche, um den Konflikt anzusprechen und zu klären.

Als Standard hat sich (seit Gordon 1989 u.a.) eingebürgert, in solchen Situationen mit „Ich-Botschaften“ zu intervenieren, drei Aspekte anzusprechen: (1) Was genau, welche Verhaltensweise an der anderen Person in welcher Situation, stört mich? (2) Wie bin ich davon emotional berührt? (3) Was wünsche ich mir stattdessen?

Die XYZ-Regel fasst diese Struktur knapp zusammen: Sie verhalten sich $\mathrm{X}$; damit geht's mir Y; ich wünsche mir Z. Schopenhauers Mutter in Kurzform: „Arthur, du ergehst dich in ständigen Klagen. Das drückt meine Stimmung. Bitte, verhalte dich wie ein Gast. “27

Mit Ich-Botschaften beziehen Sie sich auf das störende Verhalten des anderen, nicht auf seine Person (Harvard-Prinzip Nr. 1). Abwertung der Person ist ein sicheres Mittel, den Konflikt zu eskalieren. Wenn ich das vermeiden möchte, kann ich Scheiterstrategien erwägen: Wie könnte ich den Konflikt schlimmer machen? Wenn ich das weiß, weiß ich auch, was ich besser machen kann.

27 Eine eindrucksvolle Ich-Botschaft hat Johanna Schopenhauer ihrem Sohn Arthur brieflich zuteil werden lassen. Kurzer Auszug: „Dein Mißmut ist mir drückend und verstimmt meinen heiteren Humor, ohne daß es Dir etwas hilft. Sieh, lieber Arthur, Du bist nur auf Tage bei mir zu Besuch gewesen, und jedesmal gab es heftige Szenen um nichts und wieder nichts und wieder nichts, und ... ich atmete erst frei, wenn Du weg warst, weil Deine Gegenwart, Deine Klagen über unvermeidliche Dinge, Deine finsteren Gesichter, Deine bizarren Urteile, die wie Orakelsprüche von Dir ausgesprochen werden, ohne daß man etwas dagegen einwenden dürfte, mich drückten... Höre also, auf welchem Fuß ich mit Dir sein will. Du bist in Deinem Logis zu Hause; in meinem bist Du ein Gast, wie ich es etwa nach meiner Verheiratung im Hause meiner Eltern war, ein willkommener, lieber Gast, der immer freundlich empfangen wird, sich aber in keine häusliche Einrichtung mischt." (Böhmer 1996, 87 f) 
Ein häufiger Einwand: Als Leitung habe ich so gut wie keine juristisch-disziplinarischen Mittel, um in Konflikten wirksam einzugreifen. Sind Ich-Botschaften da nicht viel zu schwach? Antwort: Schon dass Sie das Problemverhalten ansprechen, wird der anderen Person Eindruck machen. Es ist selten jemandem egal, wie er oder sie von der Leitung gesehen wird. (Sawu bona!) Mit einer Ich-Botschaft lassen Sie die andere Person in sich hinein sehen; Sie zeigen, inwiefern Sie von ihrem Verhalten berührt (ärgerlich, enttäuscht, wütend, genervt) sind. Dass wirksame Führung nicht auf Anordnung und Ausübung von Zwang beruht (s. dazu 9.5) und dass Teamlernen auch die Fähigkeit einschließt, sich situationsangemessen leiten zu lassen, muss sich noch deutlich weiter herumsprechen (Rolff 2017, $12 \mathrm{f}$; s. u. Anm. 46)

Nächste Frage: Ist das nicht ein Zeichen von Leitungsschwäche, wenn ich meine Gefühle äußere? Antwort: Nein, persönlich zu reagieren ist kein Zeichen von Schwäche, sondern von Stärke. Sie nehmen die andere Person und sich selbst wichtig.

Frage: Und wenn jemand sagt: „Ist mir doch egal, wie Sie sich fühlen!“? Mögliche Antwort: „Ist das Ihr Ernst? Ihnen ist egal, wie es mir geht?“ Das wäre ein neues Thema, das wichtiger sein könnte als der konkrete Konfliktanlass. Denn jetzt geht es um gewaltfreie Kommunikation. Die sollte in jeder Schule, ganz gewiss aber in einer freien christlichen Schule transparent vereinbart sein, z. B. in einem gemeinsam erarbeiteten Konzept (dazu s.u. 6.6). Dann wäre die Äußerung „Ist mir doch egal, wie Sie sich fühlen!“ Anlass, auf die bestehende Vertragslage zurück zu kommen. Falls Gewaltfreie Kommunikation (GFK) in Ihrem Vertrag nicht thematisiert ist, sollte das nachgeholt werden.

Frage: Sind diese Vertragssicherungen nicht letztlich doch Ausübung von Herrschaft? Antwort mit einem Beispiel: Jemand pfeift auf die Pausenaufsicht. Sie reagieren innerlich stark angespannt, weil Sie in einem Unglücksfall bei Ihrer Leitungsverantwortung behaftet würden. Sie sind also darauf angewiesen, dass Sie sich auf die Einhaltung der Regularien zur Pausenaufsicht verlassen können. Falls nicht, kommt eine schriftliche Ermahnung in Frage, als Schutz für Sie selbst und als Warnung an die andere Person. Ob die Situation eskaliert, liegt nicht in Ihrer Hand, sondern in der der betroffenen Person. Darauf hinzuweisen ist m. E. Leitung als Dienst, keine Willkürherrschaft.

F. Glasl hat neun Eskalationsstufen dargestellt, mit denen sich die Intensität eines Konflikts abschätzen lässt (Risto 2003, 54 ff). Mäßig intensive Konflikte lassen sich mit eigenen Mitteln lösen (Stufe 1-3); mittelschwere ab Stufe 4 erfordern die Hilfe eines Dritten; ab Stufe 7, wenn der Konflikt wichtiger wird als die Arbeit, sind organisatorische Eingriffe zur Sicherung der Arbeitsfähigkeit des Systems Schule nötig (Abmahnung, Versetzung, Entlassung). Die bisher genannten Beispiele gehören in die Stufen 1-3. Je mehr Konfliktkompetenz in einem gesamten Kollegium vorhanden ist, desto seltener sind Maßnahmen ab Stufe 4 oder gar ab Stufe 7 zu ergreifen. ${ }^{28}$

28 Die Stufen 1-3: Verhärtung, Polarisierung, Konfrontation; 4-6: Vom Gegner zum Feind; Vom Feind zur „unerwünschten Person“; unverhüllte Drohungen; 7-9: Schlacht; Vernichtung des 
Konflikte sind zeitnah zu regeln. Ich muss aber nicht impulsiv, ich kann besonnen reagieren. Ich kann mir Zeit nehmen; manchmal genügt es schon, zehn Sekunden zu schweigen, einen Kaffee zu holen oder die Toilette aufzusuchen.

Ich-Botschaften sind ein geeigneter Einstieg in eine Konfliktklärung, sie sind nicht schon die fertige Lösung. Nach diesem Einstieg, nachdem Sie Organisationsund Leitungsinteressen benannt haben, sind die Interessen des Konfliktpartners dran. Schalten Sie um, hören Sie ihm zu: „Worum geht es Ihnen? Welches Interesse steckt hinter Ihrer Vertragsverletzung? Wie werden Sie sichern, dass das Problemverhalten nicht wieder vorkommt?“"

Grundsätzlich: Handwerkszeug ist wichtig, aber nicht alles; wesentlich ist oft der Mut, überhaupt einen Konflikt anzusprechen, trotz Druckgefühl im Magen. ${ }^{29}$ Die Vertrautheit mit einigem „Handwerkszeug“ kann diese Überwindung erleichtern.

\subsubsection{Typ II: Du hast einen Konflikt mit mir: Wie konzentriere ich mich auf dich?}

Eine hoffentlich seltene, aber nicht ganz unrealistische Situation: Jemand macht mir Vorwürfe, wertet mich ab, beschimpft mich, schlägt unter die Gürtellinie aus heiterem Himmel, für mich völlig überraschend. Aus meiner Sicht ist das die härteste Variante. Umso wichtiger, auch darauf vorbereitet zu sein, mir in guten Zeiten ein kleines Arsenal von konstruktiven Reaktionsmöglichkeiten zuzulegen, für alle Fälle.

Wenn ich so überfallen werde, ist meine wahrscheinlichste Reaktion, das als Angriff auf meine Person aufzunehmen, alles auf dem Beziehungsohr zu hören, irgendeine spontane Abwehrreaktion zu produzieren, also eine Scheiterstrategie zu wählen. Wie komme ich weg von meinem Beziehungsohr hin zur Selbstmitteilung der anderen Person? Zuhören unter Stress - wie kann das gehen?

Ein guter Tipp: Abstand halten! Wer so heftig zuschlägt, zeigt keine Konfliktkompetenz. Wenn Sie gleich gekränkt reagieren und zurückschlagen, übernehmen Sie die Spielregeln des Aggressors, dann schießen Sie mit Gegenvorwürfen zurück, eskalieren so den Konflikt und zeigen sich selbst nicht souverän. Lassen sie sich etwas Zeit. ${ }^{30}$

Feindes; gemeinsam in den Abgrund (Herzlieb 2008, 100 ff). Nähere Erläuterungen auch bei Risto (2003, 53 ff) und bei Haeske (2008, 91 ff).

29 Stein $(2008,22$ f) bietet viele nützliche Anregungen für den Wunsch, einen eigenen Standpunkt überzeugend vertreten zu können. Durchsetzungsfähigkeit in diesem Sinn hat nichts mit Egoismus oder Rücksichtslosigkeit zu tun. Sie besteht allein in einer konsequenten Ausrichtung auf die eigenen Ziele.

30 Lufthansa-Piloten werden darin trainiert, in kritischen Situationen zehn Sekunden lang nichts zu tun, nur nachzudenken! Vgl. Vertiefung 6.4.4. 
Nutzen Sie die Zeit zum Luftholen; M. Rosenberg $(2002,115)$ rät, in so einer Situation fürsorglich mit sich selbst umzugehen, sich zu schützen und zu sammeln, um wieder aktionsfähig zu werden. „Wir können andere nicht empathisch hören, wenn wir selbst Empathie brauchen.“ (Basu u. Faust 2013, 82)

Schaffen Sie ein förderliches Setting. Wenn Sie zwischen Tür und Angel angegriffen werden, ginge das z. B. so: „Ich bin völlig überrascht. Ich möchte das genauer verstehen. Kommen Sie bitte mit in mein Büro, damit wir das klären können." Damit haben Sie schon ein wenig Zeit und Abstand gewonnen. Falls das in dem Moment nicht geht, verabreden Sie ein Gespräch für ein paar Stunden später.

Sodann, wenn Sie aktionsfähig sind: Aktivieren Sie den Torero, der in Ihnen steckt. Vor dem „Stier“ stehen zu bleiben, wäre selbstschädigend; wegrennen löst kein Problem. Darum: Treten Sie elegant einen Schritt zur Seite. Lassen Sie den Stier an sich vorbei stürmen. „Studieren“ Sie ihn: Wie geht es ihm? Was will er? Was stört ihn? Wenn er weiter stürmt, fassen Sie zusammen, was Sie hören, in Ihren Worten, mit aktivem Zuhören. Also: zuhören unter Stress! Nicht einfach, aber lernbar: vom Beziehungsohr weg hin zur Konzentration auf die Selbstmitteilung des Gegenübers (s. o. 6.2).

Wenn die Lage sich etwas beruhigt hat, bitten Sie um Klärung: Worum geht es Ihnen? Was genau stört Sie an meinem Verhalten? In welchen Situationen? Was wünschen Sie sich stattdessen? Nutzen Sie die VW-Regel, fragen Sie nach den Wünschen hinter den Vorwürfen. Fassen Sie immer wieder zusammen, was Sie gehört haben, und stellen Sie dann lösungsorientierte W-Fragen.

Falls Sie den anderen (unabsichtlich) gekränkt haben: Erklären Sie das, drücken Sie Ihr Bedauern aus. Treffen Sie eine Vereinbarung für die nächste Zeit, und verabreden Sie einen Termin zur Überprüfung Ihrer Vereinbarung. Vielleicht hat $\mathrm{Ihr}$ Gegenüber einen diskutablen Wunsch an Sie; den müssen Sie nicht gleich erfüllen; Sie können aber Ihre Bereitschaft äußern, darüber nachzudenken. (Näheres dazu s. u. zum Thema Feedback, 6.7.1)

Falls dieser Konflikttyp verschärft auftritt, z. B. als massive Kritik eines Teils des Kollegiums an der Art, wie Sie Ihre Leitungsrolle wahrnehmen, holen Sie sich Hilfe, aber nicht von innen, sondern von außen; Möglichkeiten: ein externer Schulleiter, dem Sie vertrauen; eine externe Gruppe, die sich regelmäßig zu kollegialer Beratung trifft; oder ein externes Coaching.

\subsubsection{Typ III: Ihr habt einen Konflikt und kommt damit zu mir: Mediation (Schlichtungsgespräch)}

Mehrere Varianten dieses Typs sind zu unterscheiden:

Erster Fall: Zwei Kontrahenten wollen unterschiedliche Lösungsideen durchsetzen und kommen damit nicht weiter. Beide sind von ihrer eigenen Lösung überzeugt, beide können argumentieren; sie sind gleich mächtig, keiner ist von vornherein im Nachteil. Wenn so ein Konflikt z. B. in Ihrer Leitungssitzung auftritt, sind Sie als Moderatorin gefragt. Was da hilfreich wäre, wurde bei Typ I und Typ II besprochen. Das Modell der vier Ohren und das Harvard-Konzept geben Orientierung: Zur Erinnerung: 
(Prinzip 1) Weich zu den Menschen, hart in der Sache.

(Prinzip 4) Fragen Sie beide Konfliktpartner nach den Gütekriterien für die noch zu konstruierende Lösung.

(Prinzip 2) Fragen Sie beide Seiten nach ihren Interessen (Selbstmitteilung).

(Prinzip 3) Regen Sie an, den „Kuchen“ größer zu machen: Optionen erweitern, den Tunnelblick öffnen.

Hören Sie im Sinne dieser vier Prinzipien beiden Kontrahenten aktiv zu; fordern Sie sie zu Ich-Botschaften, zu Selbstmitteilungen auf. Überprüfen Sie die Zuhörfähigkeit der Beteiligten. Fragen Sie Person A: Wie hast du B verstanden? Und B: Wie hast du A verstanden? Wenn das gelingt, werden hinter den Lösungsfixierungen die treibenden Interessen deutlich. Dann ist der Weg frei für kreative Fantasie: Welche Lösungen sind denkbar, unter deren Dach die geklärten Interessen friedlich zusammen Platz finden? Wie immer die aussehen - sie müssen mit dem Primärinteresse der Schule vereinbar sein.

Zweiter Fall: Möglicherweise wendet sich eine Lehrerin mit der Bitte an Sie, einen Konflikt mit einer Kollegin zu klären, beansprucht Sie also in der Rolle einer Schlichterin oder Mediatorin. Die damit möglicherweise verbundenen Fallstricke haben Boettcher/Mosing (2006, 943 ff) sehr differenziert dargestellt; insbesondere warnen sie davor, sich in der Leitungsrolle auf einen längeren Schlichtungsprozess einzulassen. Als Leiterin haben Sie auf Arbeitsfähigkeit zu achten; insofern müssen Sie auf einer Lösung in absehbarer Zeit bestehen, wenn ein Dreiergespräch keinen Erfolg hat.

Dritter Fall: Wenn Sie als Schlichterin in einem Konflikt zwischen den Eltern einer Schülerin und einer Lehrkraft beansprucht werden, müssen Sie in allparteilicher Haltung die Interessen der Schule im Blick haben und beide Seiten darin unterstützen, ohne Gesichtsverlust zu einer Vereinbarung zu kommen. Das ist anspruchsvoll, im Ernstfall nicht abzuweisen, bei hoher Eskalation ein guter Grund für Sie selbst, externes Coaching in Anspruch zu nehmen.

Vierter Fall: Eine Lehrerin beklagt sich, sie würde gemobbt. Bei Mobbing lassen sich Angreifer, Verfolger einerseits und Opfer, Angegriffene andererseits unterscheiden. In Schulklassen, in Kollegien - auch in freien Schulen - ist Mobbing leider keine Seltenheit. Hier sind Sie als Moderatorin stark gefordert. Für diesen Konflikttyp habe ich eine entscheidende Intervention bei John Brinley gelernt, einem virtuosen Gestalttherapeuten. Er schärfte uns ein: „Wende dich dem Angreifer zu!" So wird das Opfer am wirksamsten geschützt. Bringen Sie den Angreifer zur Selbstmitteilung. Fragen Sie ihn: „Worum geht es dir?“ Bestehen Sie auf Ich-Botschaften. Angriffe sind das Gegenteil von Offenheit; sie verbergen den Hintergrund der Aggression: Wut, Ärger, Enttäuschung, Lust am Zündeln, Minderwertigkeitsgefühl usw. (Näheres zum Umgang mit Mobbing: s.u. 6.5; zur Rolle von Gefühlen in der Kommunikation s. u. 12.3)

\subsubsection{Vertiefung: Konfliktmanager Jesus}

Jesus lehrt im Tempel. Da bringt man eine Frau zu ihm, auf frischer Tat beim Ehebruch ertappt. Die Schriftgelehrten stellen Jesus zur Rede: „Mose hat geboten, 
solche zu steinigen. Was sagst du?" (Johannesevangelium 8, 1-5). Das klingt wie eine offene W-Frage. Aber was in ihr steckt, merkt man, wenn man mögliche Antworten probiert.

Sagt Jesus: Mose hat Recht - was heißt das für die Frau?! Dann ist das ihr Todesurteil. Sagt Jesus: Mose könnt ihr vergessen - was heißt das für Jesus, für seine Autorität? Dann wäre klar: Diesen Rabbi muss man nicht ernst nehmen.

„Was sagst du?" Strukturell eine Frage wie die des Richters, der den Angeklagten fragt: Haben Sie endlich aufgehört, Ihre Frau zu schlagen? Eine vertrackte Ja-Nein-Frage: Hat Mose Recht - ja oder nein? Eine Falle. Entweder gibt er die Frau auf oder seine Autorität.

Fortsetzung: Er aber bückte sich nieder und schrieb mit dem Finger in den Sand. Er tut nichts, genauer: Er tut etwas demonstrativ ganz Anderes. Er verweigert die Ja-Nein-Alternative. Kommt er damit durch? Wer die Geschichte kennt, weiß: Das wird nicht reichen. Aber immerhin, er gewinnt Zeit, Zeit zum Nachdenken vielleicht. Also: Empfehlung für Konfliktsituationen (mit dieser Geschichte): Nimm kein Problem so, wie es dir unter die Nase gehalten wird! Lass dir Zeit! Es könnte eine Falle sein.

Vielleicht steckt darin noch mehr als Zeitgewinn. Der Evangelist kannte seine Bibel: „Die Sünde Judas ist geschrieben mit eisernem Griffel und mit diamantener Spitze gegraben auf die Tafel ihres Herzens und auf die Hörner an ihren Altären... “- unauslöschlich, für alle Zeiten! (Jeremia 17,1) Jesus dagegen schreibt die Sünde in den Sand, der beim nächsten Windstoß verweht.

Die Geschichte geht weiter: Als sie nun anhielten, ihn zu fragen, richtet er sich auf und sagt: „Wer unter euch ohne Sünde ist, der werfe den ersten Stein. “ Seine Antwort lässt die Autorität des Mose bestehen. Er diskutiert nicht das Gesetz; er wendet sich den Angreifern zu. Dazu eine Geschichte aus unserer Zeit:

Amos $\mathrm{Oz}$, israelischer Friedensvordenker, hört von seinem Freund Sami ein Erlebnis mit einem israelischen Taxifahrer. Der Chauffeur hielt ihm den üblichen Vortrag darüber, wie wichtig es „für uns Juden“ sei, die Araber zu töten. Und anstatt zu schreien: „Was für ein schrecklicher Mensch sind Sie, sind Sie ein Nazi, ein Faschist?", hörte Sami ihm zu; er hatte entschieden, auf andere Art und Weise damit umzugehen, und fragte den Chauffeur: „Und wer, denken Sie, soll all die Araber töten?“ Der Chauffeur: „Was meinen Sie? Wir! Die israelischen Juden! Wir müssen! Wir haben keine Wahl, schauen Sie nur, was die uns jeden Tag antun!“ „Aber wer genau soll Ihrer Meinung nach den Job ausführen, die Polizei oder vielleicht die Armee oder die Feuerwehr oder Ärzteteams, wer soll die Arbeit machen?"

Der Chauffeur kratzte sich am Kopf und sagte: „Ich denke, das sollte schön auf uns alle aufgeteilt werden. Jeder von uns sollte ein paar von denen töten. " Und Sami spielte das Spiel noch weiter, er sagte: „O.K., ich nehme an, Sie greifen sich einen Wohnblock in Ihrer Heimatstadt Haifa heraus, klingeln oder klopfen an jede Tür und sagen: Entschuldigen Sie, mein Herr oder meine Dame, sind Sie zufällig Araber? Und wenn die- oder derjenige mit, ja' antwortet, dann erschießen Sie sie. Dann sind Sie fertig mit dem Block und wollen gerade nach Hause gehen, und just da hören Sie irgendwo im 4. Stock Ihres Blocks ein Baby schreien. Würden Sie zurückgehen und das Baby erschießen? Ja oder nein? “ Es war einen Moment still, 
und dann sagte der Chauffeur zu Sami: „Wissen Sie, Sie sind ein sehr grausamer Mensch. “ $(\mathrm{Oz}$ 2004, 46f)

Also die entscheidende Intervention, wenn jemand einen anderen angreift und ich in die Rolle gerate, diesen Konflikt zu moderieren: Wende dich dem Angreifer zu. Die Geschichte geht glücklich aus. Die Angreifer lassen sich erreichen. Ob das jemals so passiert ist, lasse ich mal lieber offen. Die Geschichte stammt frühestens aus dem 2. Jahrhundert. Ihre Botschaft ist aktuell. Wende dich dem Angreifer zu! Damit bietest du zugleich der angegriffenen Person den besten Schutz.

Johannes schreibt im gleichen Kapitel: „Die Wahrheit wird euch frei machen! " Die Wahrheit öffnet Spielräume, in denen sich leben lässt. Daran kann man sie erkennen.

\subsection{Raus aus der Mobbing-Falle!}

Mobbing ist in unserer Gesellschaft ein verbreitetes Phänomen, auch in Schulen, auch in christlichen Schulen. Wenn es in Ihrer Schule vorkommt, ist es ein Krisenthema, wichtig und dringlich (A-Thema in der Eisenhower-Box). Wenn Sie das Thema in „guten“ Zeiten auf Ihre Tagesordnung setzen, behandeln Sie es als ein B-Thema, schärfen Sie die Aufmerksamkeit für oft nicht leicht zu entdeckende destruktive Prozesse. Eine halbe Stunde gemeinsamer Aufmerksamkeit in Ihrem Kollegium für dies Thema ist gut investiert. Prävention ist weniger aufwendig als Feuerwehr-Interventionen. Trifft der Ernstfall Sie unvorbereitet, brauchen Sie viel Zeit und Energie, die psychischen Scherben zusammenzukleben, Kränkungen zu heilen, Krankheitsausfälle zu ertragen. Klein und Frank (2008) bieten einen guten Überblick (Download 9).

\section{Was ist Mobbing?}

Mobbing ist ein aus den Fugen geratener Konflikt; Mobbing dauert an; es findet statt, wenn die betroffene Person (Lehrer, Lehrerin, Schüler, Schülerin) mindestens einmal in der Woche mindestens ein halbes Jahr lang von einer oder mehreren Personen attackiert wird (Leymann 1993, 83; Risto 2003,191 ff) - hohe Hürden für die Diagnose. Ziel ist es, eine Person auszuschließen, loszuwerden. Die gemobbte Person fühlt sich diskriminiert, zu Unrecht angegriffen, abgewertet.

Die Angriffe richten sich auf die Möglichkeit, sich mitzuteilen, auf die sozialen Beziehungen, das soziale Ansehen, die Qualität der Berufs- und Lebenssituation, die Gesundheit. Leymann (1993, 33 f) listet 45 mögliche Mobbing-Aktivitäten auf. Wenn solche Angriffe über längere Zeit andauern, handelt es sich um Mobbing.

ABER: 95\% derjenigen, die sich „gemobbt“ fühlen, werden gar nicht gemobbt! Übliche Reibereien, die als unsensibel, unhöflich, ungerecht empfunden werden, ein nicht erwiderter Gruß, eine unsachliche Kritik - das alles ist nicht schon Mobbing, kann aber dazu werden, wenn daraus Konflikte entstehen, wenn die eskalieren und wenn niemand sich traut, Konflikte beherzt anzupacken. 
Der Mobbing-Experte Heinz Leymann betont: Mobbing entsteht, weil die Leitung es zulässt! Das heißt, die Leitung muss so leiten, dass Mobbing gar nicht erst entstehen kann. Wenn es aber entstanden ist, muss die Leitung massiv eingreifen, indem sie Mobbing untersagt. „Es ist kein Fall bekannt, wo nicht ein Vorgesetzter (und wenn der mobbt: dessen Vorgesetzter) den Konflikt schon früh hätte in den Griff bekommen können, wenn... Aber man sieht zu oder weg. Man kümmert sich nicht darum und läßt es weiterlaufen.“ (Leymann 1993, 61)

Darum ist es absolut wichtig, gewaltfreie Kommunikation im Schulkonzept vertraglich zu verankern (Näheres dazu s.u. 6.6). Wo immer Mobbing-Tendenzen auftreten, gilt die Devise: Reden Sie mit dem Angreifer! Worum geht es dem? Was ist sein Interesse? Wie kann er sein Interesse wichtig nehmen, ohne sein Opfer zu schädigen?

Die Auslöser sind zahlreich und liegen im Bereich der Unternehmensstruktur (Arbeitsdruck, Personalabbau usw.), der Arbeitsmoral (Klima, Feedback-Kultur usw.), des Führungsstils (Umgang mit Konflikten, Laissez-faire-Stil) und der gesellschaftlichen Situation (Arbeitslosigkeit, Zukunftsängste).

Grundsätzlich kann jeder und jede Mobbing betreiben; wer Kritik sehr persönlich nimmt, wer gern stichelt, auf Höflichkeit pfeift, Angst vor Abstieg hat, auf „Opfer-Typen“ herabsieht, der sucht möglicherweise im Mobbing Entlastung für sich selbst.

\section{Wer ist betroffen?}

Es kann jeden treffen, einige mit größerer Wahrscheinlichkeit. Klein und Frank nennen die Betriebsnudel, den Moralapostel, den Karrieristen, den Macher und den Softi als besonders gefährdet.

\section{Welche Folgen hat Mobbing?}

In Unternehmen sinkt die Arbeitsleistung; die Gemobbten fallen durch Krankheit aus, die Fehlerquote steigt. Etwa 1,6 Mio. Menschen leiden unter Mobbing am Arbeitsplatz; im Jahr 2000 lagen in der Bundesrepublik die Kosten, die durch Mobbing entstehen, bei 15-50 Mrd. Euro jährlich (pro Fall 15.000 bis 50.000 Euro).

Betroffene reagieren mit psychischen Störungen (Gereiztheit, zerstörtem Selbstwertgefühl, Nervenzusammenbruch, psychosomatischen Beschwerden und sozialer Isolation). Täter sind auf personalrechtliche Folgen hinzuweisen; Kündigung kann die Folge sein (Konflikt-Eskalationsstufe 7-9).

\section{Gegenmaßnahmen}

Die Autoren raten Ihnen, der Leitung: Stärken Sie die Konfliktkompetenz im Unternehmen, ächten Sie Mobbing, fördern Sie konstruktive Kritik, engagieren Sie notfalls Berater.

Den Betroffenen empfehlen sie: „Suchen Sie Unterstützung; fordern Sie Schutz von Leitung und Betriebsrat. Nutzen Sie Beratung, Supervision, Coaching, 
engagieren Sie notfalls einen Anwalt. Studieren Sie Mobbing-Literatur (Internet!)!“ Ich ergänze noch: der pauschalen persönlichen Abwertung auf keinen Fall Glauben schenken. Denn das ist die böse Falle für die Gemobbten: Dass sie selbst glauben, sie hätten das verdient.

\section{Rechtlicher Hintergrund}

Klein und Frank $(2008,122)$ verweisen auf den Schutz der Menschenwürde durch das Grundgesetz und auf die Definition von Mobbing im Sozialgesetzbuch (SGB) als „berufsbedingte gesundheitliche Gefährdung“. „Die Krankenkassen werden dort aufgefordert, Fälle von Mobbing an die zuständigen Stellen für Arbeitsschutz und die Unfallversicherungsträger zu melden." Das Strafgesetzbuch erfasst als Mobbing-Handlungen „Beleidigungen, Verleumdung, üble Nachrede, Körperverletzung, Nötigung und Bedrohung' (a.a.O. 122).

Letzte Anmerkung: Dass die gemobbte Person in der Regel so zermürbt wird, dass sie den Arbeitsplatz bzw. die Schule verlässt, ist skandalös. Wo das geschieht, hat Prävention vermutlich nicht stattgefunden.

\subsection{Der Beitrag der Gewaltfreien Kommunikation}

Vier Punkte sind nach M. Rosenberg (2002 u. a.) zu beachten, wenn ich gewaltfrei kommunizieren möchte. Im Vergleich mit Konflikttyp I („Ich habe einen Konflikt mit dir") zeigt sich deutliche Ähnlichkeit mit der Ich-Botschaft bei Gordon, jedoch mit einer wichtigen Ergänzung:

1. Beobachtungen: Was passiert in einer Situation? Ich beschreibe das Verhalten der anderen Person, bewerte es aber nicht!

2. Gefühle: Was lösen die Beobachtungen in mir aus? Bin ich verletzt, erschrocken, verärgert, irritiert o. ä.?

3. Bedürfnisse: Welche Bedürfnisse stecken hinter meinen Gefühlen? Worum geht es mir dabei? Was ist mir wichtig? Was brauche ich? (Dies ist die wichtige Ergänzung zur Ich-Botschaft.)

4. Bitten: Ich teile mit, was ich von der Konfliktpartnerin will. Was kann sie tun, um meine (und auch ihre) Lebenssituation zu verbessern?

In einem Konfliktgespräch sind diese Orientierungspunkte nicht stur in einem Zug abzuhandeln. Wenn Grundbedürfnisse in die Klärung einbezogen werden, wird das Gespräch wesentlich vertieft. Denn so wird verständlich, dass die oft als destruktiv und gefährlich erlebten Gefühle eine wichtige Funktion haben. Sie sind Wegweiser; sie machen mir selbst verständlich, welche Verletzung mich so wütend, ärgerlich, unruhig, missmutig macht.

Immer wieder erschallt in kontroversen Diskussionen der Ruf, meist von Männern, bei der Sache zu bleiben, nicht etwa emotional zu reagieren. Rosenberg zeigt, dass man so Gefahr läuft, oberflächlich zu diskutieren und Lösungen an der wirklichen „Sache“, den Grundbedürfnissen, vorbei zu konstruieren. Es geht nicht darum, destruktive Gefühle auszuleben, sich von ihnen hinreißen zu lassen. Es geht vielmehr darum, die eigenen Gefühle bewusst wahrzunehmen und sie als 
Wegweiser zu nutzen, als Wegweiser zu den Grundbedürfnissen, die oft verletzt werden, die aber für das Leben stehen; sie sind die „Sache“, um die es geht (s.u. 12.3 zu Gefühlen in der Kommunikation).

Beispiele für existentielle Grundbedürfnisse:

- Autonomie: die eigenen Träume, Ziele, Werte.

- Integrität: Authentizität, Kreativität, Sinnhaftigkeit, Selbstwert.

- Interdependenz/Kontakt mit anderen: Wertschätzung, Nähe, Rücksichtnahme, emotionale Sicherheit, Respekt, Verständnis.

- Nahrung für den Körper: Luft, Essen, Bewegung, Schutz vor gefährlichen Lebewesen, Ruhe.

- Spielen.

- Spirituelle Verbundenheit: Schönheit, Harmonie, Inspiration, Ordnung, Friede.

Für Konflikttyp II (Du hast einen Konflikt mit mir) bedeutet das: Ich höre aktiv zu (auch unter Stress!) und erkunde:

1. Was an meinem Verhalten, welche Situation genau meinst du?

2. Wie geht es dir dabei? Wie fühlst du dich?

3. Welches Grundbedürfnis empfindest du als verletzt?

4. Was wünscht du dir von mir?

Rosenberg (2004, $69 \mathrm{ff})$ hat erlebt, wie schwierig es sein kann, unter Stress aktiv zuzuhören und empathisch zu reagieren. Er gibt in einer „schwarzen“ Kirchengemeinde in St. Louis einen Workshop zur gewaltfreien Kommunikation (GFK), in dem plötzlich der Anführer einer schwarzen Gang aus diesem Viertel auftaucht und Rosenberg attackiert: „Weißt du, wie du den Schwarzen hier in der Gegend helfen kannst? Gib ihnen dein Geld, damit sie sich Knarren kaufen und Leute wie dich umlegen können.“

Rosenberg vergaß seine GFK-Predigt und fuhr den Mann an: „Was haben Sie eigentlich hier zu suchen? Bitte lassen Sie uns in Ruhe arbeiten." Das brachte den anderen erst richtig in Fahrt, bis schließlich Rosenberg sich sammelte und versuchte, empathisch zu hören, worum es dem Störer ging: „Sind Sie wütend darüber, dass ein Weißer einfach daherkommt und den Schwarzen erklären will, wie sie miteinander reden sollen? Wollen Sie, dass ich Ihre Art, mit Konflikten umzugehen, respektiere?“

Der Störer sah Rosenberg völlig überrascht an und sagte: „Sie haben es begriffen, Mann!" Setzte sich, sagte nichts mehr, sprach Rosenberg aber nach der Veranstaltung an. Er wollte verstehen, was da passiert war. Daraus entwickelte sich eine wunderbare Kooperation. Rosenbergs Angebot: „Pass auf, wir machen einen Deal: Ich zeig' dir, wie du das Zeug den Zulus beibringen kannst [sc. GFK-Training für seine Gang], und du kommst am Donnerstag mit nach Washington D.C. und hilfst mir, den Lehrern dort zu erklären, warum die schwarzen Kids die Schule anzünden." Und so geschah es - lohnende Lektüre! 
Schulleitungen werden in großen Konferenzen nicht selten heftig angegangen. Vielleicht hilft Ihnen diese Geschichte, gefasst zu bleiben, an GFK zu denken und konstruktiv zu reagieren.

Der Konflikttyp III (Ihr habt einen Konflikt miteinander und kommt damit zu mir) wird im Modell der GFK entsprechend verändert. Als Moderator verhalte ich mich ,allparteilich“ und lasse mit Hilfe konstruktiver W-Fragen (s. o. 4.5)

1. beide Seiten ohne Wertung die kritischen Situationen beschreiben,

2. beide Seiten deutlich machen, wie sie sich dabei fühlen,

3. beide Seiten herausfinden, auf welche Grundbedürfnisse die Gefühle verweisen,

4. beide Seiten ihre Wünsche formulieren und Gewinn-Gewinn-Lösungen erfinden.

Rosenberg gibt auch Beispiele, wie Schüler Konflikte mit Hilfe von GFK lösen (2004, $120 \mathrm{ff})$. Besonders dramatisch verlief eine Mediation mit verfeindeten Stammesältesten in Nigeria. Einer begann: „Ihr seid alle Mörder.“ Der andere antwortete: „Ihr habt immer versucht uns zu unterdrücken.“

Rosenberg brauchte zwei Stunden harter Arbeit, bis die beiden in der Lage waren, Vorwürfe beiseite zu lassen und auf die Grundbedürfnisse (Sicherheit, Respekt) zu hören. Am Ende zog ein bis dahin schweigsamer Chief dies Resümee: Wir können diese Art der Kommunikation nicht an einem Tag lernen. Wenn wir aber auf diese Art zu kommunizieren wüssten, dann müssten wir einander nicht umbringen (2013 b, 19f).

In einem Interview definiert Rosenberg sein Verständnis von Gewalt: „Für die meisten Menschen bedeutet Gewalttätigkeit zu versuchen, jemanden körperlich zu verletzen. Für uns bedeutet Gewalttätigkeit auch jegliche Machtausübung auf andere Menschen, es bedeutet, sie zu zwingen zu versuchen, bestimmte Dinge zu tun. Dazu würde jegliche Anwendung von Bestrafung, Belohnung, Schuldzuweisung, Beschämung und Verpflichtung gehören.

Gewalttätigkeit in diesem weiteren Sinne beinhaltet jede Anwendung von Druck, mit dem wir Menschen zwingen, etwas zu tun. Zu Gewalttätigkeit gehört auch jedes System, das Menschen diskriminiert und gleichen Zugang zu Ressourcen und Gerechtigkeit für alle Menschen verhindert. Mit dieser Definition könnten viele Aspekte unserer Unternehmenskultur, unserer Erziehung, des Sportes und der formalen Ausbildung als gewalttätig betrachtet werden.“

Demgegenüber sagt die Gewaltfreie Kommunikation: „Werde gut darin, zwei Dinge auszudrücken: Was in dir los ist und was dein Leben schöner machen würde. Lerne nur dies zu sagen, ohne Kritik und ohne Forderungen. Sag' einfach nur, was in dir lebendig ist, in anderen Worten, wie es dir geht, und was dein Leben wunderbar machen würde. Und egal, was andere sagen, höre nur, was in ihnen lebendig ist und was ihr Leben wunderbar machen würde.“ (Pásztor 2004)

Angenommen, Sie würden das Konzept der Gewaltfreien Kommunikation mit Ihren Kollegen und Kolleginnen diskutieren - welchen Protest würden Sie erwarten? Auf welche Definition von Gewalt könnten Sie sich einigen? 


\subsection{Feedback geben und nehmen}

Konflikte sind eher lösbar, wenn die Beteiligten „weich“, respektvoll miteinander umgehen (Harvard-Prinzip Nr. 1). Geschieht das nicht, sind Gegenangriffe, Abwehrreaktionen wahrscheinlich. Wir wollen wahrgenommen, freundlich gesehen werden (Sawu bona!). Ich kann fragen, wie jemand mein Verhalten erlebt oder mich als Person sieht. Wenn ich so um Feedback bitte, kann ich etwas über meine blinden Flecken erfahren, also darüber, wie andere mich bzw. mein Verhalten erleben. So zu fragen, kann einigen Mut erfordern; ich kann ja nicht wissen, was ich zu hören bekomme. Der Gewinn dabei: Ich kann Missverständnisse ausräumen, von vornherein auf Verständnisschwierigkeiten achten, mir fremde Sichtweisen erschließen, sogar manche Verhaltensweisen ändern, wenn sie mir bewusst werden und mich selbst befremden. Das Problem dabei: Feedback ist angstbesetzt.

\subsubsection{Bedingtes und unbedingtes Feedback}

Hattie und andere Pädagogen sagen mit Recht: Ohne Feedback kein Lernen! (Hattie 2007; Steffens \& Höfer 2012, 3 f) Also ist es ratsam, sich Feedback zu holen, am Ende einer Unterrichtsstunde, als Auswertung einer Unterrichtssequenz, nach einer Konferenz, in der Auswertung einer Beratung. Das geschieht selten, und wenn es geschieht, neigt man zu umständlichen anonymen Fragebogenerhebungen. Direkte, persönliche Begegnung entsteht so nicht.

Feedback macht Angst, und ohne Feedback kein Lernen. Wie ist diesem Dilemma zu entkommen? Meine eigene Lernerfahrung: Indem ich es steuere, indem ich mit ,kleinen Brötchen“ beginne, die genießbar sind. Feedback ist eine Form von Zuwendung. Die Transaktionsanalyse bietet in dem Zusammenhang hilfreiche Unterscheidungen. Wir Menschen sind zuwendungsbedürftige Wesen, wir brauchen Zuwendung; andernfalls verkümmern wir. Wir bevorzugen positive, freundliche Zuwendung, wir fürchten negative, abwertende, unfreundliche Zuwendung.

Zusätzlich ist zu unterscheiden, ob die Zuwendung, ein Feedback z. B., bedingt oder unbedingt formuliert ist, ob es sich also auf eine spezifische Situation, ein spezifisches Verhalten, eine spezifische Bedingung bezieht oder ob die Zuwendung mich als Person, also unbedingt, meint. Tabelle 3 zeigt die vier grundsätzlichen Möglichkeiten.

Tabelle 3: Zuwendungsmuster

\begin{tabular}{|l|l|l|}
\hline bedingt & positiv & negativ \\
& $\begin{array}{l}\text { „Ihren Lösungsvorschlag } \\
\text { finde ich toll.“ }\end{array}$ & $\begin{array}{l}\text { „Ich werde ärgerlich, } \\
\text { wenn Sie unsere } \\
\text { Verabredungen nicht einhalten.“ }\end{array}$ \\
\hline unbedingt & „Ich freue mich, dass Sie hier sind.“ & $\begin{array}{l}\text { „Mit Ihnen hat das keinen } \\
\text { Zweck!“”,Sie sind unmöglich!““ }\end{array}$ \\
\hline
\end{tabular}

Bedingt negative Zuwendung gibt mir die Chance, mein Verhalten zu ändern. Unbedingt negative Zuwendung dagegen lehnt mich insgesamt, als Person, ab. Solche totale Ablehnung kann dadurch entstehen, dass viele einzelne Vorfälle sich summieren, wenn sie nicht zeitnah geklärt werden. Das passiert, wenn jemand 
„Rabattmarken“ bei jeder kleinen Verstimmung sammelt und sie einlöst, wenn der berühmte Tropfen das Fass zum Überlaufen bringt. Heftig wird es, wenn ich als Person so massiv, so unbedingt negativ angegriffen werde. Wenn ich einigermaßen geistesgegenwärtig und standfest bin, kann ich (hoffentlich) nachfragen: Worum geht es Ihnen? Welches Verhalten bringt Sie so auf?

Rosenberg hat das mit dem Gang-Mitglied erlebt. Er hat es geschafft, die verbalen Attacken zu überhören und sich auf die Grundbedürfnisse seines Angreifers zu konzentrieren. Als Ideal: wunderbar! Er hat aber auch geraten, sich in solchen Situationen erstmal selbst freundliche Zuwendung zu geben (2002, 114 f). Ich kann z.B. zu meinem Schutz meine Ohren vor der unbedingten Ablehnung verschließen, kann mir Beschimpfungen und abwertenden Tonfall verbitten, kann den Raum für eine Weile verlassen und ein klärendes Gespräch zu einer späteren Zeit anbieten. (Ein heftiges Beispiel finden Sie in Anm. 50.)

Die unbedingte Zuwendung entscheidet darüber, ob wir so etwas wie Lebensberechtigung empfinden oder nicht. Überwiegt der negative Pol, ist die Lebensbasis brüchig (s. Grafik 5). Häufig versuchen wir, das durch Leistung und Anstrengung auszugleichen, durch die wir bedingt positive Zuwendung erreichen wollen. Typische innere Antreiber halten uns dann in Gang und setzen uns unter Stress (Näheres dazu s.u. 11.7). ${ }^{31}$ Leistung ist wichtig, liefert aber keine tragfähige Lebensbasis. Unsere Lebensbasis ist uns geschenkt - so die christliche Sicht (s. o. Anm. 13); sie ist unsere Würde - so die humanistische Sicht. Würde ist - nach Kant - das, was keinen Preis hat, was nicht gekauft oder erworben werden kann, ganz gewiss nicht durch Antreibergehorsam.

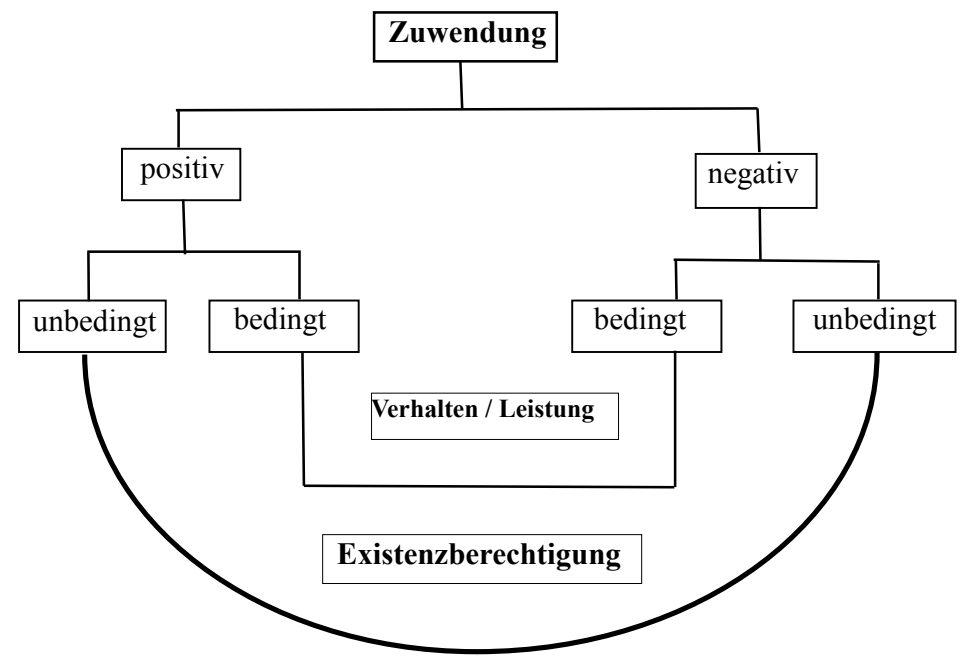

Grafik 5: Existenzberechtigung als Wirkung von positiver und negativer Zuwendung

Das Konzept der „,vier Ohren“ macht auf unsere Neigung aufmerksam, durchgängig alle Äußerungen von anderen auf dem Beziehungsohr abzuklopfen; mehr oder weniger sind wir anfällig für solche paranoiden Tendenzen. Das legt die Devise

31 Tabelle 3 und Grafik 5 verdanke ich einem Fortbildungskurs bei Rolf Rainer Kiltz. 
nahe: Von meinem Beziehungsohr weg und hin auf die Selbstmitteilung der anderen Person hören. Wenn ich also eine Kritik höre, kann ich nachfragen: Welches Verhalten meinerseits hat dich gestört? In welcher Situation? Und (im Sinne der GFK) was wünscht du dir von mir in Zukunft? Ich muss nicht jeden Wunsch sofort umsetzen. Ich kann aber versprechen: Ich denke drüber nach. Also: lernen und prüfen.

Ganz anders reagieren wir auf positive Zuwendung. Da fragen wir selten nach: Wie meinst du das? Sondern wir freuen uns, und können das auch sagen. Es lohnt sich aber, auch da nachzufragen: Was genau hat dir gefallen? Was genau war denn gut? Da bin ich häufig überrascht, und der Bereich meines blinden Flecks wird kleiner, der Bereich, den andere an mir wahrnehmen, der mir selbst aber unbekannt bleibt, wenn ich mich gegen die Wahrnehmung anderer abschotte.

Dem Dilemma zwischen Angst und Lernnotwendigkeit kann ich also entkommen, indem ich mir Feedback erbitte und es steuere: Was genau hat dir gefallen? Wie habe ich heute als Moderator das Team aktiviert? Wie habe ich auf den roten Faden geachtet? Antworten, die mich bestätigen, tragen ebenfalls zum Lernen bei, genauer: Sie vermitteln Erfolgserlebnisse, und die sind lernwirksamer als Misserfolge (s. o. 2.1 Stichwort: „Mentale Modelle“).

\subsubsection{Feedback und blinder Fleck}

Das bekannte Johari-Fenster verdeutlicht: Ich kann nicht wissen, wie ich gehört werde, wie mein Verhalten auf andere wirkt, wenn es mir nicht gesagt wird (Luft 1971, 22; s. Tabelle 4). Wenn ich mich aber danach erkundige, kann ich sehr erfreuliche, stärkende Erfahrungen machen. Wenn ich selbst aktiv blinde Flecken reduziere und mich anderen mitteile, vergrößere ich mein öffentliches Selbst und reduziere damit den Bereich, der mir selbst nicht bewusst ist.

Tabelle 4. Das Johari-Fenster

\begin{tabular}{|l|l|l|}
\hline & Dem Selbst bekannt & Dem Selbst unbekannt \\
\hline $\begin{array}{l}\text { Anderen } \\
\text { bekannt }\end{array}$ & $\begin{array}{l}\text { Öffentliches Selbst, z.B. mein } \\
\text { Beruf, Familienstand: Bereich } \\
\text { der freien Aktivität }\end{array}$ & $\begin{array}{l}\text { Bereich des blinden Flecks, } \\
\text { z.B.: Was schätzen andere an } \\
\text { mir? Was nervt oder ärgert sie? }\end{array}$ \\
\hline $\begin{array}{l}\text { Anderen } \\
\text { unbekannt }\end{array}$ & $\begin{array}{l}\text { Privates Selbst, Hobbies, } \\
\text { politische Ansichten, Konflikte } \\
\text { in der Familie: Bereich des } \\
\text { Vermeidens oder Verbergens }\end{array}$ & $\begin{array}{l}\text { Unbewusstes Selbst: Denk-, } \\
\text { Gefühls- und Verhaltensmuster, } \\
\text { die mich steuern. }\end{array}$ \\
\hline
\end{tabular}

Selbstmitteilung, z. B. in Form von Ich-Botschaften, und Resonanz von anderen, also ehrliches Feedback, würden demnach den Spielraum meiner Freiheit vergröBern. Will ich das? Bin ich innerlich frei genug, das zu riskieren? Leichter geht das, wenn ich schrittweise mit der Bitte um freundliches Feedback anfange. ${ }^{32}$ Auch das

32 In unserem Weiterbildungskurs haben wir schriftliches Feedback abgeschafft, werten stattdessen täglich aus, wie gut sich alle an den Lehr- und Lernvertrag gehalten haben, und fordern am Schluss eines Seminars dazu auf, im Raum wie auf einem Markt umherzugehen und zwei, drei Personen ein freundliches Feedback zum Verhalten im Kurs mit auf den Heimweg 
schützt Sie nicht vor Überraschungen, wenn z.B. an Ihrem Verhalten etwas positiv auffällt, was Ihnen gar nicht wichtig war. Mit einiger Übung können Sie sich auch heikleren Fragen stellen. Wir alle haben blinde Flecken, die von einer Außensicht aufgehellt werden könnten: „So meinen z. B. in Befragungen Lehrpersonen, sie würden nur ca. $20 \%$ des Unterrichts sprechen, während Schüler die Lehreranteile auf $80 \%$ schätzen.“ (Rolff 2017, 28) Wenn das ein gemeinsames Überprüfungsprojekt würde und sich beide Schätzungen als verzerrt herausstellen sollten, hätten beide Seiten gelernt. Schlimm wäre nicht die Diskrepanz zwischen IST und SOLL; die wäre eine Erweiterung der Wahrnehmung und ein Anlass zum Lernen. Schlimm wäre ein vorwurfsvoller oder moralisierender Stil der Aufdeckung. (Einige Hinweise zum Bereich des Unbewussten finden Sie im Abschnitt 12.3.2 und in Anm. 108.)

\subsubsection{Feedback und Teamlernen}

Ein effektiv arbeitendes Team braucht klare Rahmenbedingungen und gute Moderation. Es ist immer wieder auf der Suche nach den strategisch richtigen Themen, die die Schule voranbringen, und arbeitet kreativ an Lösungsideen. In mancher Hinsicht kann man ein Team mit einer Jazzband vergleichen, nicht mit einem klassischen Orchester, das sich an vorgegebene Noten hält. Wesentlich ist die Fähigkeit zu kreativer, inspirierender und zugleich geordneter Improvisation.

Improvisation ist kreativ im Rahmen bestimmter Vorgaben. Diese Fähigkeit braucht ein Team auch. Jazz-Musiker verabreden sich auf eine Reihe von Standards; das ist ihre Tagesordnung. Pro Einzelstück wird ein Rahmen festgelegt, die Menge der Takte für einen Durchgang und die Tonart. Das ist die Form, für alle verbindlich; die haben alle im Kopf; ohne die gäbe es Chaos. In Analogie zum Arbeitsteam wäre das z.B. die Berücksichtigung der organisatorischen Rahmenbedingungen, wenn Sie mit den sechs Schritten der Problemlösung arbeiten (s. o. 5.2.2.2). Innerhalb dieser Form darf und soll jeder Solist die Melodie variieren, verändern, rhythmisieren, in Einzelteile zerlegen - da ist Kreativität willkommen. Damit das aber wie Jazz klingt, sollte man mindestens die Blues-Tonleiter kennen und wissen, wie aus punktierten Noten Swing wird. Analogie: Beim Brainstorming alle Ideen zulassen, konkrete Handlungsschritte vorschlagen und die Ideen der anderen nicht kritisieren.

Jazz-Musiker sollten das eigene Instrument natürlich gut kennen; eine gewisse persönliche Meisterschaft ist Voraussetzung und bleibt Daueraufgabe. Jeder muss aber auch auf die Stimmen der anderen hören und sich auf sie einstellen; ein Team wird zum Team nicht dadurch, dass einzelne Personen zu einer Gruppe addiert werden. Ein Team entsteht erst, wenn die Einzelnen sich aktiv auf gemeinsame Ziele verständigen und gemeinsam daran arbeiten, diese Ziele zu erreichen. Eigene Ideen entwickeln und sich wieder einfügen, also persönliche Meisterschaft und

zu geben. Dieses einfache, auch auf Arbeitssituationen übertragbare Verfahren löst immer fröhliche Stimmung aus. 
Teamlernen - das gehört zusammen. Das gilt für eine Jazzband, und das gilt auch für ein heterogen zusammengesetztes Team, wenn es professionell arbeitet.

Im Jazz geht das nur, wenn alle den Bandleader als Autorität akzeptieren: Der verabredet den Rahmen, steuert die Einsätze und sichert damit den Spielraum, in dem jede Stimme mit ihrer Eigenart und ihren Ideen mitmachen kann. ${ }^{33}$ Auch der Bandleader spielt mal ein Solo. Aber entscheidend ist, dass er seine Instrumentalisten zum Spielen bringt. In mancher Teamsitzung spielen zwei, drei Leute sich ihre Soli zu, und die anderen schweigen andächtig oder gelangweilt. Da sollte die Leitung eingreifen.

Manchmal neigt auch eine Teamleitung zu einem allzu langen Solo, mit dem sie die Geleiteten zutextet. Sie kippt dann leicht aus der Führungsrolle in die Macher-Rolle; damit degradiert sie die Macher zu Mitmachern (s.o. 5.2.2.1 zu Fourier). Mitmacher warten ab; für zündende Ideen fühlen die sich nicht zuständig worüber die Führungsperson dann beredt klagen kann. Ist die Leitung aber bereit, entsprechendes Feedback anzunehmen und zu verarbeiten, verliert sie keineswegs an Autorität; eher gewinnt sie an Achtung. Autorität ist hart zu erarbeiten; eine hierarchische Position genügt nicht (Newmark 2020, $102 \mathrm{f}$ ).

Jazz ist geordnete Improvisation. Alle orientieren sich an der festgelegten Form. In einer Organisation sind das die Verträge: Leitbild, Schulprogramm, Rahmenbedingungen. Wenn diese Form zerbröselt oder wenn der Prozess stockt, muss die Leitung eingreifen. Sonst wird die Musik zu Geräusch, die Arbeitsfreude zu dicker Luft, und statt Arbeit an den Primärzielen entsteht interner Grabenkrieg.

Dann ist Feedback angesagt. Klare, verhaltensbezogene Rückmeldungen sind kein überzeugender Grund, sich persönlich abgewertet und gekränkt zu fühlen; es geht um Verhalten in bestimmten Situationen, nicht um das Jüngste Gericht über Personen. Das Jüngste Gericht ist als mentales Modell unangebracht, und das unterscheiden zu können gehört zur persönlichen Meisterschaft.

Wie lässt sich gerichtsähnliche Kritik vermeiden? Zur persönlichen Meisterschaft gehört ein Grundverständnis von konstruktivem Feedback (s. o. 6.7.1). Hilfreich sind Rituale, Reflexionsroutinen, die in guten, konfliktfreien Zeiten eingeübt

33 Reisner (1995) beschreibt weitere anregende Metaphern für Manager (im Sinne von Führungskräften), die für unterschiedliche Ausgangssituationen Orientierung bieten: Der Manager als Rangierer, der den Bremsklotz im geeigneten Moment wegschlägt und dabei Energien freisetzt, die ein Vielfaches der Schlag-Energie ausmachen. - Der Manager als Gänse-Hütejunge marschiert nicht vorneweg, sondern geht hinter seinen Mitarbeitern. Ziel: Die Gänse wachsen in einem selbstbestimmten Tempo und Spielraum auf. - Der Manager als Enzym muss mit jedem wichtigen Mitglied innerhalb und außerhalb des Unternehmens in Kontakt treten, muss vor dem Hintergrund einer klaren Vision ständig informieren und kommunizieren. - Der Manager als Zeltbauer spannt das Gestänge des Unternehmenszeltes auf, damit die MitarbeiterInnen darunter ungestört ihren Aufgaben nachgehen können. Der Manager als Kommandant eines verrosteten Flugzeugträgers stellt sich der Aufgabe, ein vergreistes Unternehmen wieder auf die Beine zustellen. - Die Leiterin einer preisgekrönten Schule: „Ich leite die Schule, wie meine Großmutter kochte.“ (Rolff 2017, 4) Welche Metapher finden Sie für die Ausrichtung Ihrer Arbeit in Ihrer augenblicklichen Situation? 
werden. Z. B. können Sie zu Beginn jeder Sitzung zwei Teammitglieder bitten, am Ende der Sitzung Feedback zum Prozess zu geben, mit Hilfe von zwei, höchstens drei guten Fragen, die das WIE der Arbeit ansprechen: Welche Phasen unseres Treffens heute waren nützlich für unsere Arbeit? An welchen Punkten war die Beteiligung am stärksten? Womit könnte das zusammenhängen? In welchem Ausmaß ist es mir gelungen, Sie zu aktivieren? Wie hat sich die zeitweilige Arbeit zu zweit, zu dritt, zu viert auf den Gesamtprozess ausgewirkt? Welche guten Vorsätze haben wir heute umgesetzt? (Download 5 enthält weitere Auswertungsfragen.)

Dadurch kommt eine Metaperspektive ins System, ein Blick von außen, eine wohlwollende Resonanz, die nur anzuhören ist und nicht durch kritische Diskussion zerfleddert werden sollte. Unterschiedliche Sichtweisen werden nebeneinander gestellt und nicht nach richtig oder falsch bewertet.

Solche Rituale zählen zur 5. Disziplin der Lernenden Organisation, zum Systemdenken (Senge 1998). Das System Team als Ganzes wird in den Blick genommen: die Art, wie es lebt, die Prozesse werden studiert. Verhaltensweisen verstärken sich kreisförmig. Zwei, drei Leute beteiligen sich aktiv, weil - aus ihrer Sicht - der Rest unmotiviert schweigt. Der Rest schweigt, weil - aus seiner Sicht - zwei, drei Leute sich gern reden hören. Hinderliche mentale Modelle sind zu entmachten: „Viele sind durch ein Bildungssystem gegangen, in dem es eine richtige Sichtweise der Dinge gab. Diese wurde zumeist vom Lehrer, Professor oder Erzieher lobhaft unterstützt, so dass sich mehrere Sichtweisen eines Phänomens im bisherigen Denk- und Bildungssystem ... nur sehr schwer entwickeln konnten." (J. Christiansen 2002, 158)

Systemdenken heißt: Alles hängt miteinander zusammen, kleine Veränderungen haben manchmal ungeahnte Wirkungen. Wenn eine erweiterte Schulleitung an ihrer eigenen Entwicklung arbeitet, wirkt sich das auf das ganze Kollegium aus. Einem ehemals zutiefst zerstrittenen Lehrerkollegium gelang es nach längerer Beratung, sinnvoll zu kooperieren. Überrascht stellte man fest, dass auch die Schüler viel ruhiger geworden waren, und das waren verhaltensgestörte Jugendliche, die die Regelschulen überfordert hatten! Ein Teammitglied hatte im Beratungsprozess geseufzt: „Im Grunde leiten nicht wir die Schule, sondern die Schülerinnen und Schüler.“

\subsubsection{Feedback und Kollegiale Unterrichtsreflexion (KUR)}

Mehr und mehr spricht sich herum, „dass die Komplexität und die Forderungen des Unterrichtens ständiges Weiterlernen für die Lehrkräfte notwendig machen, zugleich nicht allein bewältigt werden können, sondern den Austausch im Kollegium über Unterricht erfordern." (Holtappels 2010, 104) Der Gewinn dabei: Sie arbeiten weniger isoliert, schaffen eine unterstützende Umgebung und verbessern die Qualität des Unterrichts. Feedback ist der Schlüssel für diese erfreulichen Verbesserungen. Eingesetzt wird es in der „Kollegialen Unterrichtsreflexion“ (KUR), einem Modell, das eine hilfreiche Struktur für die Arbeit mit Feedback im Unterricht bietet (Böttcher 2010).

Feedback soll die unterrichtende Lehrerin nicht klein machen, sondern Rückenstärkung vermitteln. Schon der Mut, sich dem Feedback auszusetzen, ist an- 
zuerkennen. Die unterrichtende Lehrerin steuert das Feedback, indem sie auswählt, zu welchen Aspekten genau sie sich Rückmeldung wünscht. Das Modell sieht in sechs Schritten detaillierte Fragen an die Lehrerin vor:

1. Anliegen erheben:

Was beschäftigt dich über die konkrete Unterrichtszeit hinaus? Wie heißt das Problem? Was macht dich unzufrieden? Was möchtest du besser machen?

Dabei: aktiv zuhören, nachfragen, zusammenfassen, innerlich mitgehen und nicht die eigene Sicht dazugeben!

2. Anliegen als offene Frage formulieren:

„Ich“ kommt vor; das Ziel wird positiv „smart“ formuliert (d.h. spezifisch, messbar, aktivierend, realistisch, terminiert).

3. Bisherige Lösungsversuche: Welche Ergebnisse wurden erzielt?

4. Lösungsideen: Welche unterstützenden und hemmenden Faktoren sind zu berücksichtigen?

5. Beobachtungswünsche: Worauf soll die Unterrichtsbesucherin besonders achten?

6. Vereinbarungen:

Ort und Zeit der Unterrichtsbeobachtung und des Reflexionsgesprächs werden vorab verabredet.

Dieser Kern ist eingebettet in ein umfangreiches Projekt, das nicht nur eine einzelne Unterrichtsstunde, sondern das gesamte Unterrichtskonzept thematisiert und darum mit einigem Aufwand verbunden ist. Wenn dies Verfahren fester Bestandteil der pädagogischen Arbeit werden soll, muss auch der Stundenplan so konstruiert werden, dass Feedback-Besuche möglich sind - ein Beispiel dafür, dass Unterrichtsentwicklung mit Organisationsentwicklung einhergeht. ${ }^{34}$

\subsection{Vertiefung: Kritik kritisch prüfen}

Kritiker können enorm einflussreich sein. Vor Jahren erschien die Zeitungsmeldung, dass ein französischer Koch in der regelmäßigen Michelin-Bewertung um einen Stern herabgestuft wurde. Das hat er sich so zu Herzen genommen, dass er sich umgebracht hat. (o. V. 2017)

R.L. Stevenson hat in einer Nacht einen ganzen Roman geträumt. Am Morgen blieb er im Bett und hat die ganze Geschichte in einem Rutsch aufgeschrieben:

34 Horster und Rolff $(2006,805)$ betonen, ,dass Unterrichtsentwicklung nach Organisationsentwicklung verlangt: Die vorhandenen Arbeitsstrukturen für Unterrichtsentwicklung müssen genutzt und darüber hinaus neue geschaffen werden. Beides ist eine Domäne der Organisationsentwicklung. Sie verlangt vor allem nach der Managementfunktion der Schulleitung.“ „Vor allem muss die Schulleitung dafür sorgen, dass die Notwendigkeit der Unterrichtsentwicklung vom gesamten Kollegium verstanden, akzeptiert und angegangen wird - dazu gibt es keine Alternative." Wie die Schulleitung dies Thema ins System bringen kann, wird in Kapitel 7 dargestellt. 
60.000 Wörter. Als er das seiner Frau zu lesen gab, sagte die: Zu sensationell, zu wenig gehaltvoll. Daraufhin verbrannte Stevenson das Manuskript. (1974, 1099)

Der renommierte Schweizer Theologe Karl Barth berichtet von einem Professorenkollegen. Dessen Lebenswerk wurde von einem Kritiker öffentlich verrissen. Kurz nach Erscheinen dieser Kritik starb der Kritisierte. Dazu Karl Barth: Das hätte er eben nicht tun sollen! Man stirbt nicht an der kritischen Rezension eines Gegners! Das gehört sich nicht für einen Christen. Ein Christ darf sich in solchen Fällen ruhig eine dicke Haut wachsen lassen. (1970, III/4, 781f)

Ein gutes Vorbild bietet Paulus, auf den Barth sich bezieht. Den haben die Korinther kräftig kritisiert: Aus der Ferne schreibst du tolle Briefe, und wenn du hier bist, zeigt sich: Du bist ein Stümper in der freien Rede. Du versprichst Besuche und sagst immer wieder ab. Die gnostischen Prediger sprühen nur so vor Begeisterung, power, Kraft und halten mitreißende Predigten. Und du redest von Schwachheit und Niedrigkeit, die Gott auf sich genommen hat.

Wie reagiert Paulus? Mit einem starken Satz: , Es ist mir etwas ganz Geringes, von euch beurteilt zu werden. “(1. Korinther 4,3) D. h.: Ihr seid nicht meine Richter. Ihr seid nicht die für mich zuständige Instanz. Ich bin bejaht, und von dem Ja lebe ich. Paulus weiß, wovon er lebt, und das macht ihn souverän gegenüber Kritik. Es gibt viele Beispiele für schöne Souveränität, säkulare und religiöse.

Einige Jahre nach der Zeitungsmeldung über den verzweifelten Koch war zu lesen, dass wieder einem Koch in Frankreich ein Michelin-Stern entzogen wurde. Aber dieser Koch nahm sich das nicht zu Herzen. Er pfiff auf den Stern, kochte, was ihm Spaß machte, bodenständig, und hatte großen Erfolg bei seinen Gästen.

Stevenson hat auf seine Frau gehört und sein Manuskript verbrannt. Dann besann er sich. Sechs Tage später schrieb er das Ganze nochmal. Und der Roman wurde ein großer Erfolg: Dr. Jekyll und Mr. Hyde - mehrfach verfilmt. Fazit: Hör auf deine Frau, aber tu nicht immer gleich, was sie sagt.

Lebe ich davon, dass alle mich akzeptieren, bewundern, mögen? Werde ich wertlos, wenn jemand mich kritisiert? Wieso gebe ich anderen so viel Macht über mich?

\subsection{Transaktionsanalytische Konzepte: Raus aus der Eltern-Kind-Dynamik!}

Jede Führungsperson ,erbt“ das einstige Kind, das in jedem von uns steckt - so Thomas Gordon (1989, 23). Führungspersonen sind wie eine weiße Leinwand, auf die die Geführten ihre individuellen Erfahrungen mit früheren Autoritätspersonen projizieren. Erfahrungen aus Kinder- und Jugendzeit mischen sich in die aktuellen Begegnungen und behindern Verständigung auf Erwachsenenniveau - Familiendynamik statt Professionalität. Die Privatrolle greift über in die Organisationsrolle. Mehrere transaktionsanalytische Konzepte im Mikro-Maßstab sind geeignet, diese Dynamik im Detail zu verstehen und konstruktive Interventionsmöglichkeiten zu entwerfen. Am Drama-Dreieck, einem Spezialfall des Konflikttyps III (s. o. 6.4.3), lässt sich das lebensnah studieren. 


\subsubsection{Verfolger, Retter und Opfer im Dramadreieck}

Ein Lehrer sitzt in der Klemme. Sein Problem: Ein Kollege hat ihn um Hilfe gebeten. Die Schulleitung habe ihm eine Abmahnung angedroht, weil er die Pausenaufsicht nicht wahrgenommen hat. Der Freund und Kollege sei doch Mitglied der erweiterten Schulleitung; da könnte er doch ein gutes Wort für ihn einlegen? Die beiden haben eine kumpelhafte Beziehung; in der Freizeit spielen sie zusammen Fußball.

Eine heikle Dreiecks-Konstellation, eine Beziehungsstruktur, wie sie häufig auftritt. Drei Rollen sind am Konflikt beteiligt: Der säumige Lehrer sieht sich als Opfer, erlebt die Schulleitung als hartherzige Verfolgerin und appelliert an seinen Kumpel als Retter.

Der angesprochene Kollege ist unsicher; er empfindet einen Loyalitätskonflikt. Als Mitglied der Schulleitung will er die Autorität der Chefin nicht untergraben. Andererseits möchte er weiter unbefangen mit dem Kollegen Fußball spielen können. Beide Interessen sind nachvollziehbar. Wie kann er beide leben? Er spürt einen Sog in die Privatrolle. Wenn er dem aber folgt, handelt er sich Schwierigkeiten mit der Chefin ein.

Familiendynamik bestimmt das Geschehen. Das Opfer ist jemand, der sich klein und hilflos gibt, andere um Hilfe angeht; eigene Fähigkeiten zeigt er nicht; die wertet er ab. Wer in die Retter-Rolle geht, stimmt dem Opfer in dieser Selbstabwertung zu: selbst denken, eigene Initiative ergreifen - das traut ein Retter dem Opfer nicht zu. In dieser Rolle übernimmt man Denken und Problemlösen für andere. In der Verfolger-Rolle setzt jemand andere herab, kritisiert sie übermäßig, wertet schlimmstenfalls Wert und Würde, manchmal sogar Lebensrecht und Gesundheit des Opfers ab. In der Mobbing-Dynamik findet genau das statt. Das Beispiel mit dem Sportskollegen wirkt dagegen eher alltäglich.

Grafik 6a zeigt die Konstellation der drei Rollen, die aufeinander bezogen sind: Retter und Verfolger oft in Konkurrenz, Retter und Opfer gemeinsam in einer Falle. Oft reicht die Hilfe nicht, nach unzureichenden Aktionen wird der Retter allmählich frustriert; das Opfer beklagt sich, wird zum Verfolger und der Retter zum Opfer. Die Rollen wechseln. Man springt im Dreieck.

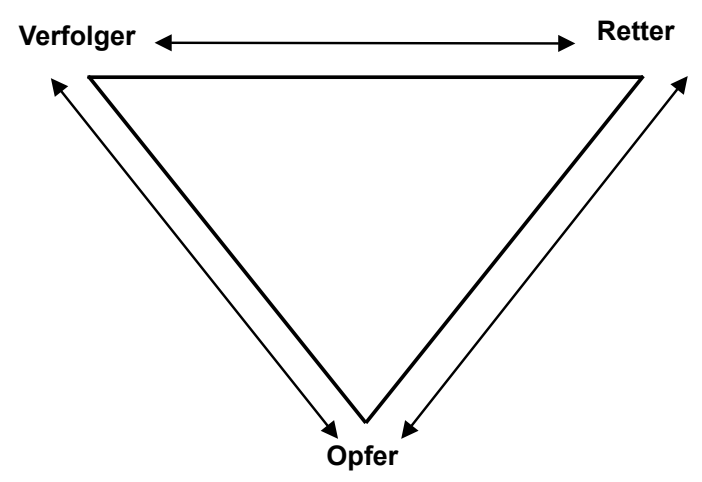

Grafik 6a: Die drei Rollen im Drama-Dreieck

Was in allen drei Rollen ausgeblendet wird, ist die Fähigkeit, einen Konflikt auf Augenhöhe, von gleich zu gleich, verantwortlich und realistisch auszutragen. Das 
wäre erwachsenes Verhalten. Im Drama-Dreieck dominiert jedoch elterlich und kindlich wirkendes Verhalten. Die Transaktionsanalyse konzipiert diese drei grundsätzlichen Verhaltensmöglichkeiten als Ich-Zustände, stellt sie graphisch als Kreise dar und gewinnt so die Möglichkeit, Interaktionsverläufe plastisch und anschaulich darzustellen und zu analysieren. Grafik $6 \mathrm{~b}$ zeigt die drei Ich-Zustände pro Person mit den Kürzeln El für Verhalten im Eltern-Ich-Zustand, ER für Verhalten im Erwachsenen-Ich-Zustand und K für Verhalten im Kind-Ich-Zustand.

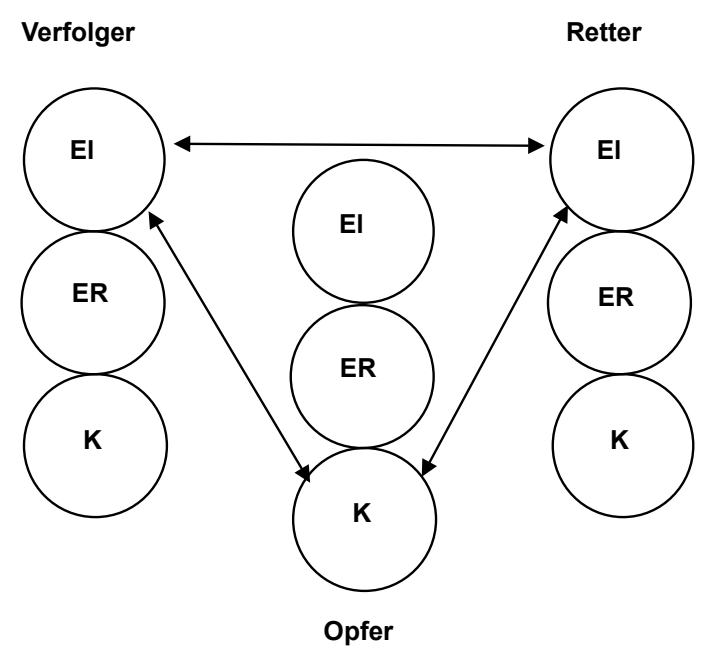

Grafik 6b: Die Ich-Zustände im Drama-Dreieck

Die Grafik 6b zeigt nicht, dass das elterliche Verhalten sich deutlich unterscheiden kann: in der Verfolger-Rolle herabsetzend, kritisch (Kürzel dafür: kEl), in der Retter-Rolle zugewandt, fürsorglich (Kürzel: fEl). Auch das Opfer kann im Laufe des „Herumspringens“ aus der Hilflosigkeit in Anklagen und Vorwürfe wechseln; die Kürzel dafür: aK für angepasst, hilflos und rK für rebellisch, anklagend. Kreative, spontane Möglichkeiten sind in der Opfer-Rolle ausgeblendet, wären im Prinzip aber möglich; Kürzel dafür: fK (freies Kind). Die erwachsenen Möglichkeiten schließlich sind ebenfalls vorgesehen, werden im Drama-Dreieck aber kaum oder gar nicht aktiviert; Kürzel dafür: ER. Diese Differenzierungen sehen Sie in Grafik 7a. Sie zeigt, wie diese Ich-Zustände im einzelnen „funktionieren“, wie sie

Grafik 7a: Die Ich-Zustände im Funktionsmodell der Transaktionsanalyse

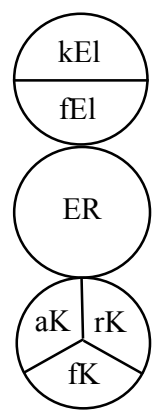


sich für einen aufmerksamen Beobachter im Verhalten zeigen. Dieses Modell heißt darum „,Funktionsmodell“".

Grafik 7b zeigt die im Drama-Dreieck aktivierten Ich-Zustände des Funktionsmodells (Fettdruck). Elterlicher und kindlicher Ich-Zustand dominieren. Professionelles (erwachsenes) Verhalten wird nicht aktiviert. Das Opfer besetzt die kindliche Option mit Energie, entweder hilflos, angepasst (aK) oder aggressiv, rebellisch $(\mathrm{rK})$; die Verfolgerin wirkt elterlich-kritisch $(\mathrm{kEl})$; ein Retter würde ebenfalls elterlich auftreten, aber nicht kritisch, sondern fürsorglich (fEl), väterlich oder mütterlich.

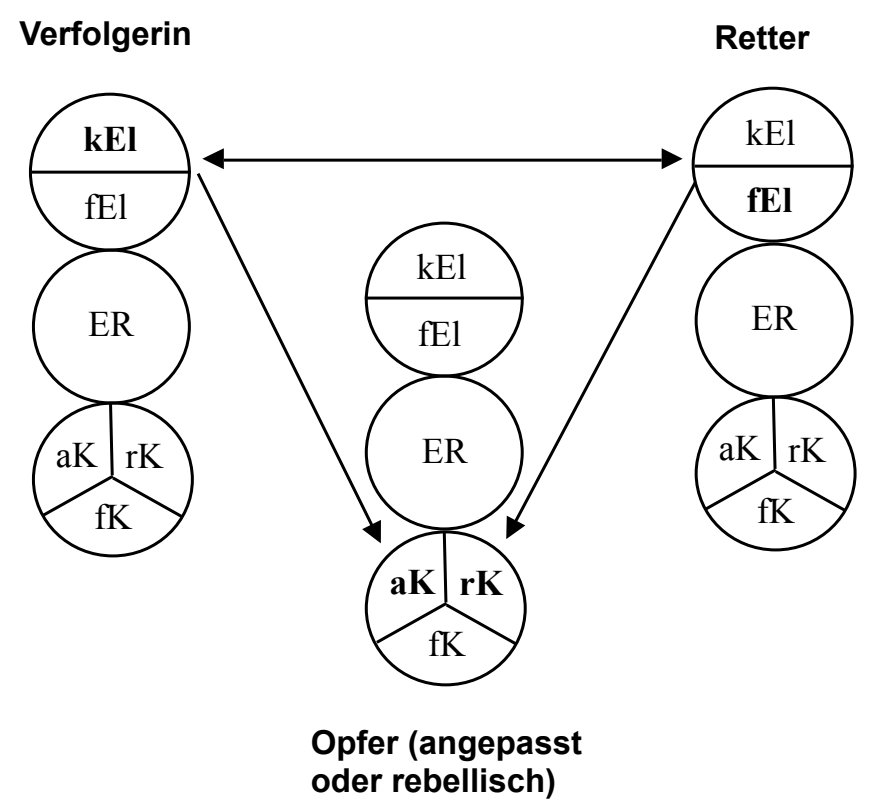

Grafik 7b: Die Ich-Zustände des Funktionsmodells im DramaDreieck

Die folgenden Konzepte der Transaktionsanalyse werden Sie besser verstehen, wenn Sie sich diese Ich-Zustände des Funktionsmodells gut einprägen. Manche Sitzungen werden Ihnen Anschauungsmaterial bieten.

Zur Entspannung und Eingewöhnung in dieses nicht seltene Kommunikationsmuster folgen zwei Beispiele, die zeigen, wie diese Rollenverteilung im Familienkontext Stress produziert. In einem Fortbildungskurs habe ich das Drama-Dreieck vorgestellt. Am nächsten Morgen berichtet eine Teilnehmerin, wie sie genau diese Konstellation am Vorabend in ihrer Familie erlebt hat:

Mutter (zum Kind): So, ich gehe jetzt zum Elternabend in den Kindergarten. Papa passt auf.

Kind: Nein, du sollst hier bleiben. Du sollst hier bleiben! (Jammert; Kind: Opfer)

Vater: Na, was ist denn los mit meinem kleinen Schätzchen? (Vater: Retter)

Kind: Mama soll hier bleiben, du kannst zum Elternabend gehen. (Kind: Verfolger, Vater: Opfer) 
Vater: Nun mal Schluss mit dem ganzen Theater! Mama geht jetzt, und du schläfst schön! (Vater: Verfolger)

Kind: Mama, bleib hier! Ich hab’ Angst! (Kind: Opfer)

Mutter: Ist ja schon gut, ein bisschen bleib ich noch. (Mutter: Retterin)

Vater: So geht das auch nicht. Die Kleine muss auch mal akzeptieren, dass nicht alles nach ihrer Nase geht (Vater: Verfolger, Kind: Opfer).

Kind: Lass Mami in Ruhe! Schimpf nicht mit ihr! (Kind: Verfolgerin des Vaters, Retterin der Mutter)

Das Beispiel zeigt lehrbuchreif, wie die Rollen im Dreieck häufig wechseln; man „,springt im Dreieck“. Der Retter wird plötzlich verfolgt. Das Opfer kann erst zum Verfolger und dann noch zum Retter werden. Meine eigene Erfahrung belegt, dass das nicht einfach aufhört, wenn eine Tochter größer geworden ist; hier eine Familienszene an einem frühen Abend:

Tochter: Mama, fährst du mich zur Disco? (Tochter: Opfer; Köder für den Vater)

Vater: Nimm doch die Straßenbahn! (Vater: Verfolger)

Tochter: Wieso mischst du dich ein? (Tochter: Verfolgerin, Vater wird Opfer)

Vater: Mama ist k.o.! Sie hatte einen langen Arbeitstag. (Vater: Verfolger der Tochter, Retter der Mutter)

Mutter: (zum Vater) Bist du mein Pressesprecher? (Mutter: Verfolgerin des Vaters, Retterin der Tochter)

Auch Sie werden Beispiele in Ihrem familiären Kontext finden und können so Ihren Blick für diese Dynamik schärfen, die auch im Arbeitskontext Verwirrung stiftet.

Woran können Sie merken, dass Sie in so einer Dreier-Konstellation dabei sind, mit zu ,springen“? Wenn Sie sich hilflos, ohnmächtig, abhängig fühlen, spricht das für die Opferrolle. Wenn das Verhalten des Opfers manipulativ wirkt, wenn Sie Loyalitätsdruck spüren, wenn Ihr ,gutes Herz“ stark aktiviert ist, dann werden Sie gerade in die Retter-Rolle eingeladen. Bedenken Sie (Faustregel!): Der letzte Retter wird das nächste Opfer. Wenn Sie Realitätsgesichtspunkte so schroff vertreten, dass die gemeinte Person nicht auf die Sache, sondern auf den Ton hört, dann sind Sie wahrscheinlich auf dem Verfolgertrip.

Und wenn Sie merken, dass die Rollen schnell wechseln, dann könnten Sie Geistesgegenwart vorausgesetzt - innerlich einen Schritt zurücktreten und sich fragen: Wie komme ich hier raus? Der Königsweg: Besetzen Sie Ihr ErwachsenenIch mit Energie. Steuern Sie sich selbst als autonome Person. Autonom im Sinne der Transaktionsanalyse agieren Sie, wenn Sie sich nicht in manipulativen Rollen verfangen, sich die Konstellation des Drama-Dreiecks bewusst machen und sich nicht auf die Polaritäten Oben-Unten, Richtig-Falsch, Recht-Unrecht versteifen (Schlegel 1995, 149).

\subsubsection{Wie steuern Ich-Zustände die Alltagskommunikation?}

Die Analyse des Drama-Dreiecks legt einige Differenzierungen nahe. Der elterliche Modus kann verfolgerisch kritisch oder fürsorglich rettend gelebt werden. Ein Opfer kann sich gegenüber Autoritäten hilflos angepasst, aber auch rebellisch ab- 
weisend verhalten. Im Kind-Modus gibt es außerdem die Möglichkeit, Autoritäten schlicht zu ignorieren, sich wie ein freies Kind zu verhalten; neben dem ER-Ausstieg aus dem Drama-Dreieck öffnet das einen weiteren Weg, aus dem Clinch heraus zu kommen (s. o. Grafik 7a).

Diese sechs Verhaltensmöglichkeiten werden graphisch als Funktionsmodell dargestellt. Das Modell bezieht sich auf alles, was ein aufmerksamer Beobachter wahrnehmen kann. Beispiel: Ein Teamkollege macht einem anderen einen Vorwurf: „Nie hältst Du Deine Zusagen ein!“ Wer so redet, ist mit großer Wahrscheinlichkeit im kritischen Eltern-Ich-Zustand (kEl). So jemand erwartet, dass der Angesprochene einknickt, Besserung verspricht, in den angepassten Kind-Ich-Zustand (Kurzbezeichnung dafür: aK) geht. Der so Kritisierte kann das aber auch empört von sich weisen (rebellischer Kind-Ich-Zustand: rK). Oder er lässt das alles von sich abprallen (freier Kind-Ich-Zustand: fK). Und schließlich: Er könnte erwachsen, verantwortlich reagieren, z. B. so: ,Welche Situationen genau meinst du?“ (Erwachsenen-Ich-Zustand: ER) Das Funktionsmodell zeigt also, wie die Ich-Zustände in der alltäglichen Kommunikation ,funktionieren“.

Elterliches Verhalten kann sich kritisch oder fürsorglich zeigen; beides kann sinnvoll, aber auch destruktiv sein - immer abhängig davon, was eine Situation im Hier und Jetzt erfordert. Fürsorglich elterliches Verhalten (fEl) kann man von überfürsorglichem unterscheiden; Kurzform: fEl+ und fEl-.

Kritisch-elterliches Verhalten kann sinnvolle Orientierung bieten (kEl+), kann aber auch die andere Person runtermachen, beschämen usw. (kEl-).

Auch das Verhalten aus dem Kind-Ich-Zustand heraus (angepasst, rebellisch oder frei und spontan) kann situationsangemessen sein $(\mathrm{ak}+, \mathrm{rK}+$; $\mathrm{fK}+)$, es kann aber auch Entwicklungen verhindern, Konflikte eskalieren und schlimmstenfalls sogar ein ganzes Team oder Kollegium ruinieren (aK-, rK-, fK-).

Tabelle 5 zeigt einige Beispiele für Merkmale, die auf den jeweiligen Ich-Zustand schließen lassen (in Anlehnung an Brown/Woollams/Huige 1995,19). Es sind kulturelle Klischees, in Auswahl; die auf dieser Basis getroffenen Einschätzungen

Tabelle 5: Merkmale, die auf die Ich-Zustände im Funktionsmodell schließen lassen

\begin{tabular}{|l|l|l|l|l|}
\hline & Worte & Stimme & Gestik, Mimik & Wirkung \\
\hline kEI & Nicht! Lass das! & Kritisch, scharf & $\begin{array}{l}\text { Stirnrunzeln, } \\
\text { Zeigefinger }\end{array}$ & $\begin{array}{l}\text { Urteilend, } \\
\text { abschätzig }\end{array}$ \\
\hline fEI & $\begin{array}{l}\text { Gut gemacht! } \\
\text { Wunderbar! }\end{array}$ & $\begin{array}{l}\text { Liebevoll, tröstend, } \\
\text { besorgt }\end{array}$ & $\begin{array}{l}\text { Offene Arme, } \\
\text { zugewandt }\end{array}$ & $\begin{array}{l}\text { Verständnisvoll, } \\
\text { fürsorglich, } \\
\text { wertschätzend }\end{array}$ \\
\hline ER & Wie, was, warum? & $\begin{array}{l}\text { Gleichbleibend } \\
\text { ruhig }\end{array}$ & $\begin{array}{l}\text { Nachdenklich, } \\
\text { aufgeweckt }\end{array}$ & $\begin{array}{l}\text { Aufrecht, abwä- } \\
\text { gend, interessiert }\end{array}$ \\
\hline fK & $\begin{array}{l}\text { Toll, Spaß, will, } \\
\text { will nicht }\end{array}$ & Frei, laut, lebendig & Ungehemmt, locker & $\begin{array}{l}\text { Neugierig, lustig; } \\
\text { kein Bezug auf } \\
\text { Autoritäten }\end{array}$ \\
\hline aK & $\begin{array}{l}\text { Kann nicht, weiß } \\
\text { nicht }\end{array}$ & $\begin{array}{l}\text { Weinerlich, } \\
\text { besänftigend }\end{array}$ & $\begin{array}{l}\text { Traurig, Blick und } \\
\text { Kopf gesenkt }\end{array}$ & $\begin{array}{l}\text { Gegen Autoritäten, } \\
\text { unwillig }\end{array}$ \\
\hline rK & $\begin{array}{l}\text { Will ich nicht! Fällt } \\
\text { mir nicht ein! }\end{array}$ & $\begin{array}{l}\text { Trotzig, nölig, } \\
\text { schmollend }\end{array}$ & Verschränkte Arme & $\begin{array}{l}\text { Gegen Autoritäten, } \\
\text { unwillig }\end{array}$ \\
\hline
\end{tabular}


sind Hypothesen, mit Vorsicht, nicht rechthaberisch oder dogmatisch zu treffen. (Näheres zur Diagnose von Ich-Zuständen in Abschnitt 6.9.7).

\subsubsection{Vertiefung: Jesus springt nicht im Dreieck}

Die biblische Geschichte von der Ehebrecherin vor Jesus lässt sich als Einladung in ein Drama-Dreieck verstehen (s. o. 6.4.4). Aber Jesus verfängt sich nicht in der Retter-Rolle; er hält Abstand, malt in den Sand, gewinnt Zeit und demonstriert, was er von unerbittlichem Richten (Jeremia 17,1) hält. Dann wendet er sich den Verfolgern zu, konfrontiert sie mit ihren Schattenseiten, sehr souverän. Ein freier Mensch. Im selben Kapitel (8, 32) sagt er: „Die Wahrheit wird euch frei machen."

\subsubsection{Transaktionstypen und Kommunikationsgesetze}

Aktion und Reaktion - beide zusammen bilden eine Transaktion. Mit Hilfe des Funktionsmodells lassen sich Interaktionsverläufe veranschaulichen; dazu einige typische Beispiele (mehr davon bei Schlegel 1993, $371 \mathrm{ff}$ ):

Paralleltransaktion, Beispiel 1 (Grafik T 1):

A: Wann kann ich Sie heute kurz sprechen? ER $\rightarrow$ ER

B: Um 13 Uhr. ER $\leftarrow$ ER

Parallel heißt eine Transaktion, wenn die Antwort aus dem angesprochenen IchZustand erfolgt.

Kommunikationsgesetz Nr. 1:

Parlallel verlaufende Transaktionen können ungestört weiter laufen.

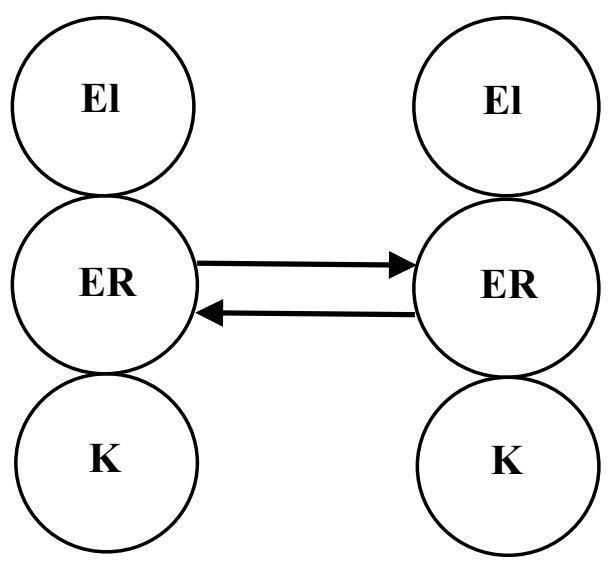

Grafik T 1: Paralleltransaktion ER $\rightarrow$ ER, $\mathrm{ER} \leftarrow \mathrm{ER}$ 
Paralleltransaktion, Beispiel 2

(Grafik T 2):

A: Ich bin so k.o.; könntest du mir die Pausenaufsicht abnehmen? aK $\rightarrow \mathrm{fEl}$

B: Aber gern, kein Problem! $\mathrm{fEl} \rightarrow \mathrm{aK}$

Auch diese Konstellation könnte im Prinzip so weiter laufen, würde aber auf Dauer bei A erlernte Hilflosigkeit fördern. Paralleltransaktionen sind nicht unbedingt produktiv.

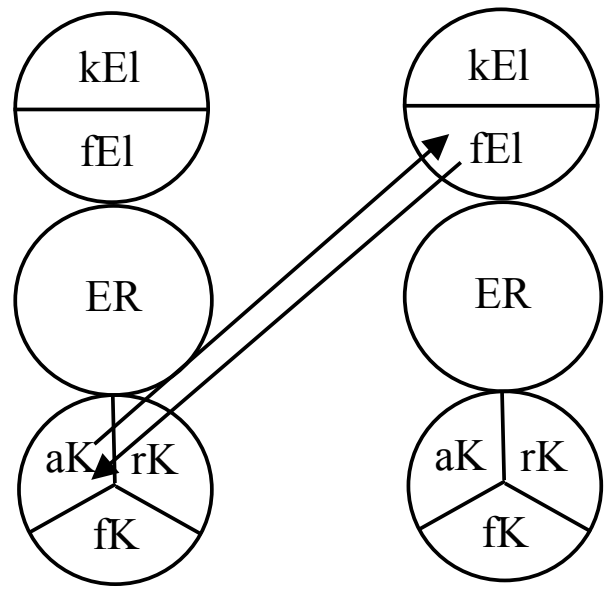

Grafik T 2: Paralleltransaktion aK $\rightarrow$ fEl; $\mathrm{fEI} \rightarrow \mathrm{aK}$

Überkreuztransaktion, Beispiel 1 (Grafik T 3):

A: Nach Ihrem Unterricht sah der Fachraum unmöglich aus! $\mathrm{kEl} \rightarrow$ aK

B: Tut mir leid. Ich war in Zeitdruck.

Wie kann ich das wieder gut machen? ER $\leftarrow$ ER

Die Antwort kommt nicht aus dem angesprochenen Ich-Zustand aK, sondern aus dem ER; es handelt sich also um eine Überkreuztransaktion B kommt A zunächst entgegen (Tut mir leid, aK), antwortet dann aber aus dem ER und wendet sich an das

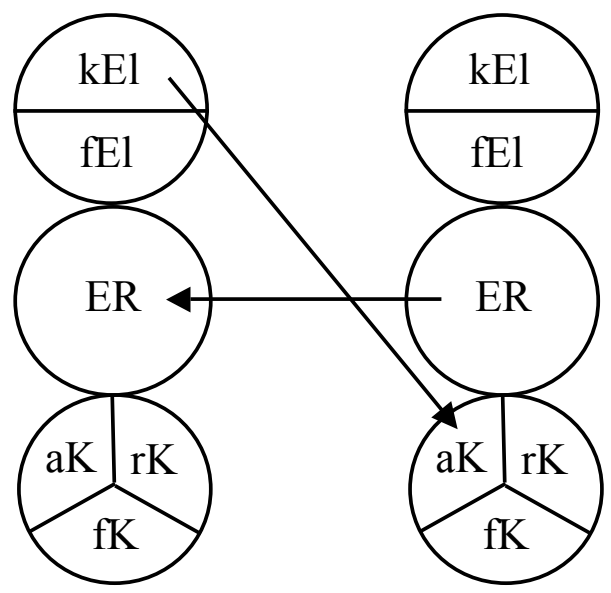

Grafik T 3: Überkreuztransaktion $\mathrm{aK} \rightarrow \mathrm{fEI}$; $\mathrm{kEI} \rightarrow \mathrm{aK}$

Erwachsenen-Ich von A. Die Antwort kreuzt die kritische Richtung von A. 
Überkreuztransaktion, Beispiel 2 (Grafik T 4):

A: Morgen will diese nervige Mutter mich sprechen. Können Sie mir da ein paar Tipps geben? aK $\rightarrow \mathrm{fEl}$

B: Tipps? Glauben Sie immer noch an Rezepte? $\mathrm{kEl} \rightarrow \mathrm{aK}$

Kommunikationsgesetz Nr. 2:

Überkreuztransaktionen stören den erwarteten Ablauf, lösen Irritation, Verblüffung o. ä. aus und erfordern eine neue Orientierung im weiteren Verlauf, was je nach Situation sehr produktiv sein kann.

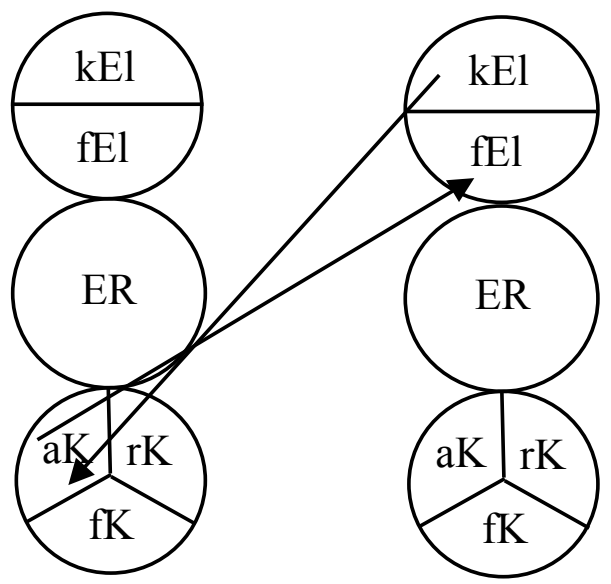

Grafik T 4: Überkreuztransaktion aK $\rightarrow$ fEl; $\mathrm{kEI} \rightarrow \mathrm{aK}$

\section{Verdeckte Transaktion}

(Eigenkreuzung) (Grafik T 5):

Schulleiter: Wo sind (denn nun) Ihre Zeugnisentwürfe? ER $\rightarrow$ ER, zugleich: $\mathrm{kEl} \rightarrow \mathrm{aK}$

Lehrerin: die hab ich Ihnen (doch) ins Fach gelegt. ER $\leftarrow$ ER, zugleich: $\mathrm{kEl} \leftarrow \mathrm{aK}$

Der Schulleiter äußert sich scheinbar rein sachlich; sein Stimmton verrät aber Ungeduld und Kritik. Auch die Antwort klingt sachbezogen, verrät aber auch Anpassung und Beschwichtigung.

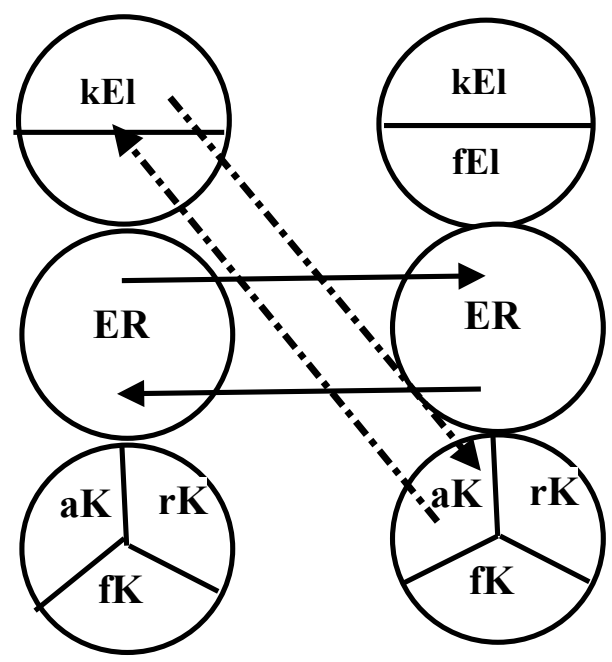

Grafik T 5: Eigenkreuzung

\section{Kommunikationsgesetz Nr. 3:}

Wenn die verdeckte psychologische Botschaft die eigene ausgesprochene Botschaft auf der sozialen Ebene kreuzt, bestimmt die psychologische Ebene den weiteren Verlauf. Der Ton macht die Musik; das „Beziehungsohr“ entscheidet (s. o. 6.2 und Stewart/Joines 1993, 109). 


\section{Verdeckte Winkeltransaktion:}

(Grafik T 6):

Fiktives Beispiel aus dem Schulbereich:

Schulleiter: Diese Fortbildung ist sehr anspruchsvoll. Ob Sie so viel Einsatz durchhalten werden?

Lehrer: Genau die will ich mitmachen!

Einem scheinbar erwachsenen Hinweis wird verdeckt, auf der psychologischen Ebene, ein Köder beigesellt, der den Protest der angesprochenen Person erregen soll.

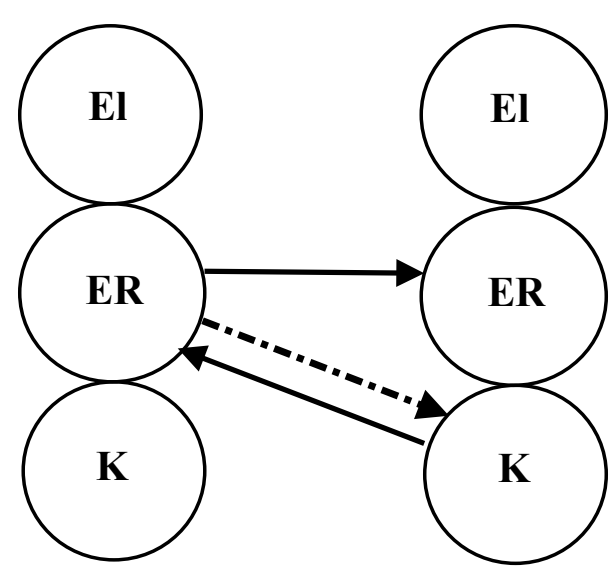

Grafik T 6: Verdeckte Winkeltransaktion

Lehrbuchbeispiel zur verdeckten Winkeltransaktion (,Verkäufertransaktion“):

Verkäufer: Dieser Staubsauger ist der beste. Aber den können Sie sich vermutlich nicht leisten.

Kundin: Genau den will ich!

Dieser Typ wird hier nur als Warnung aufgeführt: Wer sie einsetzt, manipuliert und setzt sich über den ethischen Grundsatz der Transaktionsanalyse, Autonomie zu fördern, hinweg; wer da anbeißt, lässt sich manipulieren.

\subsubsection{Ein fiktives Lehrerzimmer: Übungen zum Funktionsmodell}

Sie sind jetzt in der Lage, auf Ich-Zustände in der Alltagskommunikation zu achten. Gekreuzte Transaktionen unterbrechen den Fluss. Das werden Sie merken, wenn Sie aus dem Erwachsenen-Ich-Zustand heraus Äußerungen aus dem Eltern- und Kind-Ich-Zustand durchkreuzen. So entsteht ein Sog, mit dem Sie Ihrem Gegenüber nahe legen, seinerseits aus dem Erwachsenen-Ich-Zustand zu reagieren.

Zur Übung: Stellen Sie sich vor, Sie schnappen im Lehrerzimmer Gesprächsfetzen auf: Wie diagnostizieren Sie die? Aus welchem Ich-Zustand heraus agiert Person A? Und aus welchem kommt die Antwort der Person B? Welche Transaktionen verlaufen parallel, welche gekreuzt? Ihre Einschätzungen werden vom Stimmton, den Sie sich bei den Texten vorstellen, beeinflusst sein.

A. Würden Sie mich heute bei der Lehrerkonferenz entschuldigen? Ich habe da einen Termin mit der Mutter einer Schülerin.

B. Nein, tut mir leid; wir haben unsere Termine im Jahresplan fest verabredet.

A. Dass Sie verlangen, meinen Termin mit der Mutter umzulegen, finde ich ziemlich autoritär.

B. Autoritär? Womit genau bin ich denn geringschätzig gewesen?

A. Wann ändern wir endlich unseren 45-Minuten-Rhythmus? 
B. An wen richten Sie Ihre Frage?

A. Ich habe einem Kollegen in einer Modellschule unsere Rhythmisierung erklärt; der fand das Steinzeit.

B. Hör auf! Ich brauche die Einzelstunden; sonst lernen die Kinder die Sprachen nicht.

A. Ich finde, wir sollten die Zeiten für schriftliche Klausurarbeiten radikal kürzen. Dann schaffen wir die Korrekturen schneller.

B. Das geht doch nicht! Im Abi sind fünf Stunden vorgeschrieben.

A. Mir ist aufgefallen, dass Sie unsere Handy-Regelung nicht durchsetzen.

B. Na und? Ich habe keine Lust, den Kids die Stimmung zu verderben.

A. Sie sind für heute als Pausenaufsicht eingetragen. Ich habe Sie nicht auf dem Schulhof gesehen.

B. Tut mir leid, da wollte mich ein Vater sprechen.

A. Ich höre von Ihrem Klassensprecher, dass Sie häufiger zu spät zum Unterricht kommen.

B. Völlig übertrieben! Ein- oder zweimal bin ich im Stau stecken geblieben.

A. Das Gekreische auf den Fluren macht mich fertig.

B. Und auf dem Schulhof geht's weiter !

A. Teamlernen! Dauernd höre ich: Teamlernen! Ist mein Unterricht denn schlecht?

B. Eben! Der Senge sagt doch selbst, manches Team sei blöder als ein Einzelner.

\subsubsection{Ursprungsmodell: Wo kommen die Ich-Zustände her?}

Das Funktionsmodell erfasst, wie die Ich-Zustände funktionieren, was sich im Verhalten beobachten lässt, wenn sie mit Energie besetzt werden. Das Ursprungsmodell unterscheidet ebenso Eltern-, Erwachsenen- und Kind-Ich-Zustand, beschränkt sich aber nicht auf beobachtbares Verhalten, versteht vielmehr Denken, Fühlen und Verhalten als eine integrierte, stimmige Einheit. Es erfasst, woher die persönliche Färbung der Ich-Zustände kommt, welche biographischen Einflüsse sich darin auswirken und wie Autonomie im Inneren der Person dabei eingeschränkt oder auch ermöglicht wird. Ich-Zustände habe ich entweder von Autoritätsfiguren übernommen (El) oder als Reaktion auf Autoritäten und Rollenmodelle im Laufe meines Lebens von Kindheit an entwickelt $(\mathrm{K})$, oder sie zeigen sich als eine direkte Reaktion auf die gegenwärtige Realität, aufs Hier und Jetzt (ER); s. Grafik 8 .

In der Regel passt unser Verhalten zu unseren Gedanken und Gefühlen. Manchmal aber erleben wir uns innerlich zerrissen wie z. B. der Lehrer mit dem Loyalitätsproblem (s. o. 6.9.1). Die Bitte seines Fußball-Kollegen spricht die Freundschaft mit dem Kumpel an, die Freude am Fußballspiel; damit reagiert er aus seinem KindIch-Zustand. Was der Kumpel über die Leiterin sagt, aktiviert elterliche Erfahrungen: Lass niemanden dir auf der Nase rumtanzen! Seine Denkfähigkeit verweist ihn an seine professionelle Rolle: Verträge sind einzuhalten. Er ist blockiert, sitzt in einem „Engpass“ fest (Näheres dazu s. u. 12.3.3) Wie kann er sich ,erwachsen“ verhalten, stimmig, autonom, selbst- und nicht fremdgesteuert? 


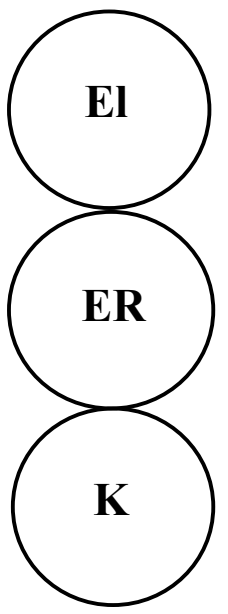

Eltern-Ich-Zustand:

Verhalten, Denken und Fühlen, das von den Eltern oder anderen Autoritätsfiguren übernommen wurde.

Erwachsenen-Ich-Zustand:

Verhalten, Denken und Fühlen, das eine direkte Reaktion auf das Hier und Jetzt ist.

Kind-Ich-Zustand:

Verhalten, Denken und Fühlen, das aus der Kindheit stammt und jetzt wieder abläuft.

Grafik 8: Das Ursprungsmodell der Transaktionsanalyse

Jeder Ich-Zustand kann konstruktiv, aber auch destruktiv verwendet werden. Erwachsenes Denken, Fühlen und Verhalten ist die Basis der Autonomie. Ziel der Transaktionsanalyse ist es nach Berne, die Ich-Zustände dahin zu bringen, auf beste Art zusammen zu arbeiten, d.h., ,die Bedürfnisse eines jeden Ich-Zustandes zu befriedigen, ohne daß sie sich sozusagen im Wege stehen." (Schlegel 1993, 377) Besetze ich elterliche oder kindhafte Ich-Zustände mit Energie, sollte der Erwachsenen-Ich-Zustand die Steuerung einnehmen; je entschiedener das gelingt, desto größer die Autonomie. ${ }^{35}$

Berne empfiehlt Menschen, die in gestörten Beziehungen leben, sie sollten sich darin üben, als „Erwachsenenperson“ zu reagieren. „Es gelingt ihnen damit besser, bewußt und realitätsgerecht mit schwierigen Situationen fertig zu werden.“ (Schlegel 1993, 377) Schwierige Situationen gibt es nicht nur in Familien, sondern auch in Lehrerteams, in Leitungsgremien, in Konferenzen, in Schulklassen. Wie gewinnen wir die Freiheit, erwachsen zu denken, zu fühlen und zu handeln, wenn wir uns in Beziehungsprobleme verstrickt haben? Das Antreiber-Konzept der Transaktionsanalyse gibt darauf Antworten (s.u. 11.7).

35 Autonomie verstehe ich als eine bestimmte Art innerer und auch äußerer Freiheit, wobei die Qualität der inneren Freiheit die der äußeren prägt. Für ,freie Schulen“, mindestens für evangelische Schulen, legt sich damit die Frage nahe: Inwiefern entspricht die von der Transaktionsanalyse angestrebte Autonomie der „Freiheit eines Christenmenschen“, die Luther 1520 als das wesentliche Merkmal christlichen Lebens bestimmt hat? Gibt es Schnittmengen zwischen beiden Auffassungen? Und ist Luthers damaliger Fanfarenstoß überhaupt noch aktuell? (Textbasis: Luther 1982; Näheres dazu in Kap. 13) 


\subsubsection{Diagnose von Ich-Zuständen}

Mit zunehmender Übung können Sie Ihr Ohr für die Ich-Zustände Ihres jeweiligen Gegenübers schärfen. Je besser Ihnen das gelingt, desto leichter werden Sie in Kontakt kommen, statt aneinander vorbei zu reden. Berne unterscheidet vier Möglichkeiten, Ich-Zustände zu erkennen:

Die Verhaltensdiagnose bezieht sich auf die oben dargestellten Ich-Zustände des Funktionsmodells (kEl, fEl, ER, aK, rK, fK); die stehen für gesellschaftliche Rollen-Stereotype, die nicht ohne weiteres mit dem tatsächlichen Ich-Zustand eines Menschen übereinstimmen. Beispiel: Ein halbwüchsiges Kind übernimmt Verantwortung für einen suchtkranken Elternteil, verhält sich also „sichtlich“ im Sinne eines souverän wirkenden fürsorglichen Eltern-Ichs; tatsächlich aber fühlt das Kind sich überfordert, hat Angst um Vater oder Mutter und weiß keinen besseren Ausweg; das aber würde erst - bei entsprechendem Interesse - in einem längeren Kontakt deutlich.

In einer Beratung erwähnte eine Lehrkraft, dass ihre Kolleginnen des Öfteren ärgerlich auf sie seien, weil sie regelmäßig die Leitung gegen Kritik in Schutz nehme und damit Feedback verhindere. Auf Nachfragen hin wurde ihr klar, dass sie diese Schutzhaltung schon immer gegenüber ihren jüngeren Geschwistern eingenommen hatte.

Wenn Ihnen gegenüber jemand einen dieser elf Ich-Zustände einnimmt (bzw. einzunehmen scheint), können Sie differenziert auf Ihr Gegenüber eingehen. Die folgende Übersicht (Tabelle 6) zeigt einige Möglichkeiten. (Erläuterung: Jemand verhält sich Ihnen gegenüber abkanzelnd; konstruktive Reaktionsmöglichkeit: nachfragen.)

Tabelle 6: Ich-Zustände des Funktionsmodells und konstruktive Interventionen

\begin{tabular}{ll}
\hline Verhalten (Funktionsmodell): & $\begin{array}{l}\text { Konstruktive Interventionen: } \\
\text { \# gekreuzte bzw. = parallele Transaktion }\end{array}$ \\
\hline kEl- abkanzeln & nachfragen: Worum geht's Ihnen? (\# aus ER) \\
kEl+ orientieren & annehmen, schätzen (= aus aK+) \\
fEl- überbehüten & danken und sich abgrenzen (= aus aK+ und \# aus ER) \\
fEl+ schützen & danken (= aus aK+) \\
ER informieren & danken, nachfragen (= aus ER) \\
ak- sich hilflos geben & fordern, zum Denken bringen, direktiv führen (\# aus ER) \\
ak+ sich sinnvoll einfügen & anerkennen (= aus kEL+) \\
rK- sich verweigern & standhalten und nachfragen: Was willst du? (\# aus ER) \\
rK+ Zivilcourage zeigen & anerkennen, unterstützen (= aus kEl+) \\
fk- unberechenbar handeln & Grenzen setzen (\# aus kEl+) \\
fK+ kreativ agieren & lange Leine lassen (= aus kEl+) \\
\hline
\end{tabular}

Mit der sozialen Diagnose schließe ich von meinem Ich-Zustand auf den meines Gegenübers (Schlegel 1993, 164). Beispiel: Ein neuer Schulleiter verkündet in seiner ersten Lehrerkonferenz: „In zwei Jahren muss unsere Schule Spitze sein!“ Als Reaktion erntet er vernehmliches Murren. Der rebellische Impuls zeigt, dass der Schulleiter als kritisches Eltern-Ich erlebt wird. Wenn ich mich jemandem 
gegenüber fügsam, unterwürfig oder rebellisch trotzig erlebe, dann kann ich auf eine kritisch abwertende Haltung bei meinem Gegenüber schließen. Umgekehrt merke ich vielleicht, dass ich in eine elterliche Haltung rutsche, wenn jemand mir hilflos oder trotzig begegnet.

In jedem von uns steckt die Neigung, dem Sog des Ich-Zustands einer anderen Person nachzugeben. Wir sehen dann z. B. in die Leitungspersonen die eigenen Erfahrungen mit idealen Eltern oder auch mit unerfreulichen Rollenmodellen hinein, wir projizieren. Diese Neigung steckt nicht nur in den Geleiteten, sondern auch in jeder Leitungsperson! Und damit stellt sich für Leitungspersonen die Aufgabe, nicht unreflektiert und automatisch in diese früheren Autoritätskonstellationen hinein zu rutschen. Die Psychoanalyse spricht hier von Gegenübertragung und verlangt von Therapeuten, dass sie solche Impulse wahrnehmen und für die Therapie nutzen und nicht unreflektiert ausleben.

Wie oben bemerkt: Jede Führungsperson ,erbt“ das einstige Kind, das in jedem von uns steckt. Wenn mir jemand aus dem Kind-Ich-Zustand entgegen kommt, kann ich im Prinzip dem Sog widerstehen - wenn ich ihn spüre, wenn er mir bewusst wird und wenn ich mir einen anderen Kommunikationsverlauf wünsche. Ich habe Einfluss darauf, in welchen Ich-Zustand ich mich begebe. Ich kann wählen.

Wenn ich als Leitung den Eindruck habe, dass jemand frühere autoritäre Rollenmodelle in mich hineinsieht, dann wird diese Projektionsneigung erst nach einer Reihe von gegenteiligen Erfahrungen mit meinem Leitungsstil nachlassen. Es gibt immer mehrere Möglichkeiten, und das zu erkennen, ist Voraussetzung für praktizierte Autonomie. Würde ich die Projektion ärgerlich und abwertend beantworten, dann würde ich die Projektion verstärken, Autonomie bei der anderen Person erschweren. Autonomie ist das zentrale Ziel der Transaktionsanalyse. In einer Schule, die sich als Lernende Organisation versteht, müsste das ein zentrales mentales Modell sein. Und das sollte einer evangelischen Schule willkommen sein, wenn sie es mit der Freiheit eines Christenmenschen ernst meint (s. o. Anm. 35).

Die historische Diagnose fragt nach biographischen Erfahrungen: „Wie haben Sie diesen Ich-Zustand früher schon erlebt?" So zu fragen, kann in einem vertraulichen Setting im Rahmen einer kollegialen Beratung sinnvoll sein, wenn die Beteiligten einen entsprechenden Vertrag geschlossen haben. Für die Alltagskommunikation empfiehlt sich das nicht.

Die phänomenologische Diagnose gehört in die Therapie: Ein Klient erlebt einen mit dem gegenwärtigen Ich-Zustand zusammenhängenden früheren IchZustand nochmals; Freud spricht von der Wiederbelebung eines früher erlebten Affekts. In der Therapie kann das zu wichtigen Einsichten führen. In der Alltagskommunikation hieße das, dass jemand emotional wie früher als Kind reagiert. ${ }^{36} \mathrm{Im}$ beruflichen Kontext wäre das eine besondere Herausforderung, aus dem Erwachsenen-Ich-Zustand heraus zu antworten.

36 Die rätselhafte Bezeichnung erkläre ich mir so, dass ein früheres emotionales Phänomen (,Erscheinung“) in der Gegenwart wieder ,aufscheint“. 


\subsubsection{Trübungen: realitätsferne mentale Modelle}

In Konfliktsituationen ist es wünschenswert, mit Hilfe des Erwachsenen-Ich-Zustands Orientierung zu behalten bzw. zu gewinnen. Realitätsbezogenes Denken, Fühlen und Verhalten kann kommunikative Knoten entwirren und Gewinn-Gewinn-Lösungen ermöglichen. Jedoch, häufig haben sich biographische Erfahrungen im Laufe des Lebens so in den Erwachsenen-Ich-Zustand eingemischt, dass seine segensreiche Funktion eingeschränkt, behindert, „,getrübt“ wird. Solche Trübungen sind Auffassungen von mir selbst, von anderen, von der Welt, die ich ungeprüft von Rollenmodellen übernommen oder aber selbst entwickelt habe; die hindern mich, die Realität vorurteilsfrei wahrzunehmen, und schränken meine Sicht auf das Leben ein.

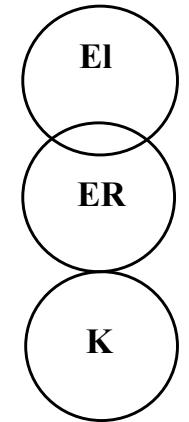

Trübung aus dem ElternIch-Zustand:

„Einer muss sagen, wo's lang geht!“

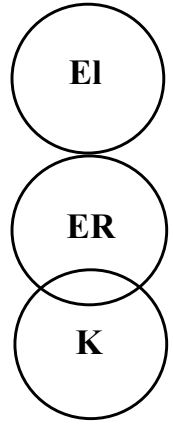

Trübung aus dem KindIch-Zustand:

„Wenn ich Konflikte anspreche, sind alle gegen mich."

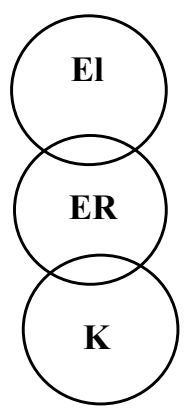

Doppelte Trübung: El:

„Mitarbeiter muss man pampern."

$\mathrm{K}$ : „Die Leitung muss immer erreichbar sein."

Grafik 9: Beispiele für Trübungen

Aus beiden Richtungen also können Trübungen sich breit machen: durch erlebte Rollenmodelle, z.B. durch elterliche Botschaften (also aus dem El), und durch eigene Verarbeitung von Erfahrungen aus dem Kind-Ich-Zustand heraus (aus dem K; vgl. Schlegel 1993, $171 \mathrm{ff}$ ).

Grafik 9 illustriert einige Trübungen, von denen manche Leitungspersonen befallen sind. Sie lassen sich leicht vermehren. Eine weitere Trübung, die nicht selten in Konflikten um ,schwierige“ Schülerinnen und Schüler auftaucht. Manche Lehrerinnen und Lehrer meinen, für Erziehung seien sie nicht zuständig. Das sei Aufgabe des Elternhauses - was ja stimmt. Was diese Einstellung aber ausblendet, ist die Realität, dass auch in Schulklassen ständig Lernprozesse über kognitive Themen hinaus stattfinden, unvermeidlicherweise. Die Art, wie eine Lehrerin den Unterrichtsprozess steuert, setzt Spielregeln für das Verhalten in einer Klasse. Ob die Lehreräußerungen reversibel sind, ob die Schüler ernst genommen werden, auch wenn sie nicht so geschliffen argumentieren wie die Lehrerin, das ist für das Lernklima und damit für emotionale Lernprozesse wesentlich. Das WIE ist oft wichtiger als das WAS. Stimmt die Beziehung zum Lehrer, zur Lehrerin nicht, verliert manche Schülerin das Interesse am Fach. 
Lehrerinnen und Lehrer sind prägende Modelle, ob sie wollen oder nicht; Kinder und Jugendliche beobachten sie sehr aufmerksam. Sie interessieren sich dafür, was das für Menschen sind, mit denen sie täglich zu tun haben. Einfach gesagt: Die grundlegenden Lerngesetze, der Einfluss von Modellen und Verstärkern, sind wie Wetter: Sie sind immer da. Es gibt kein Nicht-Wetter. Und wo Menschen zusammen sind, wirken Modelle, Verstärker und oft auch Verletzungen und Nichtbeachtung (in der Lerntheorie als Bestrafung bzw. Löschung konzipiert), auch wenn das gar nicht bewusst beabsichtigt ist. ${ }^{37}$

Die genannten lernpsychologischen Argumente beanspruchen, realistisch zu sein, und werden aus dem Erwachsenen-Ich-Zustand heraus geäußert. Wird die Verantwortung für Erziehungsaspekte grundsätzlich verweigert, wird dieser IchZustand doppelt getrübt: Zum einen aus dem kritischen Eltern-Ich-Zustand heraus

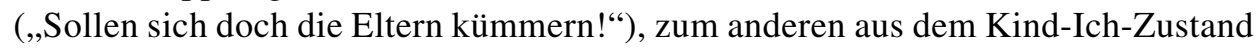
heraus (,Das soll ich auch noch machen?“).

Wie kommt man aus solchen Trübungen heraus? Die drei Ich-Zustände sind klar zu benennen und voneinander zu unterscheiden. Damit wird die ErwachsenenPosition gestärkt. Und dann steht die wichtige strategische Frage an, wie schulischer Unterricht im Kontrast zu den oft desolaten Zuständen in vielen Familien „korrigierende emotionale Erfahrungen“ vermitteln kann.

Ein drastisches Beispiel (aus einer Klausurtagung in einer evangelischen Schule!): Schülerinnen und Schüler einer Klasse reden ungeniert und permanent in einer sexistisch geprägten Fäkalsprache, wie sie sie von zu Hause als „normal“ gewohnt sind. Dass die Lehrerin ein Gegenmodell vorlebt, reicht nicht. Strafen für ein als normal empfundenes Verhalten wären ebenfalls unangebracht; allenfalls würden die Kinder das unerwünschte Verhalten dann in Gegenwart dieser Lehrerin vermeiden. Sinnvoller wäre ein gemeinsam geplanter Selbstveränderungsprozess. ${ }^{38}$

\subsubsection{Bezugsrahmen: Filter vor der Realität}

Über einzelne spezifische Trübungen hinaus kann die gesamte Sicht einer Person auf sich selbst, auf die Menschen und die Welt verzerrt sein, der umfassende „Bezugsrahmen“ (frame of reference) eines Menschen. Der Bezugsrahmen ist Sammelbegriff für alle mentalen Modelle, mit denen eine Person sich in der Welt

37 Eine gut verständliche Darstellung der Lerngesetze bieten Watson/Tharp (1975) - antiquarisch sehr preiswert zu bekommen. Rosenberg (2013a) schreibt über „Erziehung, die das Leben bereichert“, und erläutert die Praxis der gewaltfreien Kommunikation für den Schulalltag. Omer / von Schlippe (2015) stellen die Prinzipien gewaltfreien Vorgehens gegen Gewalt aus systemischer Sicht sehr praxisnah dar.

38 Skizze dazu: (1) die Bedeutung des Problemverhaltens nachvollziehbar erklären; (2) eine wöchentlich wechselnde Projektgruppe bilden, die eine Woche lang eine Strichliste zum Auftreten des Problemverhaltens führt; (3) Zielsetzung (nach Absprache): z. B. Verminderung der Häufigkeit um $10 \%$ im Lauf der nächsten Woche; (4) als Verstärkung für den Erfolgsfall ein für die ganze Klasse erfreuliches Ereignis planen usw.; die betreffende Lehrerin reagierte optimistisch auf diesen Plan. 
orientiert. Man kann ihn sich vorstellen als einen „Filter vor der Realität“ oder als „,eine Haut, die die Ich-Zustände umgibt und damit zusammenhält und miteinander verbindet." (Stewart/Joines 1993, 273) Er enthält also auch alle Trübungen aus den elterlichen und kindlichen Ich-Zuständen. „So wie ich die Welt aufgrund meines einzigartigen Bezugsrahmens wahrnehme, schaffe ich mir auch meine einzigartige Zusammenstellung von Ich-Zustands-Reaktionen auf die so wahrgenommene Welt." (Stewart/Joines Kap. 19, 274)

Jeder und jede von uns hat eine persönliche Zusammenstellung elterlicher Definitionen dafür, was gut, schlecht, falsch, richtig, beängstigend, leicht, schwierig, schmutzig, sauber, gerecht, ungerecht ist. Auf diese Zusammenstellung von Definitionen stützen wir unsere Ansichten über uns selbst, über andere und über die Welt. Und entsprechend entscheiden wir, wie wir auf unterschiedliche Situationen reagieren.

Der Bezugsrahmen eines Menschen ist einerseits individuell geprägt. Andererseits teilen wir bestimmte Bezugsrahmen mit anderen: Das bewirkt die familiäre Prägung, die Zugehörigkeit zu Gruppen, das Aufwachsen in der gesellschaftlichen Kultur. Politischen Verführern ist bewusst, welche Macht in gemeinsam geteilten Vorstellungen und Überzeugungen steckt.

Hitler und Goebbels haben es fertig gebracht, der Mehrheit von Deutschen zwei sich widersprechende Sichtweisen über die Juden einzuimpfen: Einerseits seien sie minderwertige, subhumane Wesen, die wie Ungeziefer vernichtet werden müssten; andererseits zögen sie als internationales Finanzjudentum sowohl die Fäden des plutokratischen Kapitalismus als auch des proletarischen Kommunismus. (Sacks, 2015a, 71) ${ }^{39}$

Im Unterschied zu einem Ich-Zustand ist der Bezugsrahmen eine überdauernde Einstellung und Haltung. Ein geeigneter, weltoffener Bezugsrahmen kann das Leben erheblich erleichtern; ist er getrübt, wirkt er destruktiv. In der Psychotherapie ist die Veränderung des Bezugsrahmens eines Patienten darum oft der entscheidende Schritt, zu dem eine Therapeutin dem Klienten verhilft. Ein drastisches Beispiel dafür, wie schwierig das sein kann:

Ein Psychiater behandelt einen Mann, der glaubt, er sei eine Leiche. Er isst nicht, geht nicht zur Arbeit, sitzt nur da und behauptet, er sei eine Leiche. Die beiden streiten lange miteinander. Schließlich fragt der Psychiater: „Können Leichen bluten?“ Der Patient denkt einen Augenblick nach und sagt dann: „Nein. Meine Körperfunktionen sind ja zum Stillstand gekommen.“ Darauf sagt der Psychiater:

39 Zwischen 1935 und 1939 ließ Hitler mehrfach die Vernetzung der Juden in der Welt überprüfen. Erst als er sich so hatte beweisen lassen, dass Juden tatsächlich freund- und machtlos waren (1\% der deutschen Bevölkerung!), war er sich sicher, dass er ihnen (absurderweise) vorwerfen konnte, sie seien so mächtig, dass sie die Welt kontrollieren könnten (Sacks 2015a, a. a.O.). Gleichzeitig mussten Hitler und seine Propagandisten auch hinsichtlich der Rolle des deutschen Volkes zwei völlig gegensätzliche Vorstellungen behaupten: eine, die in der grandiosen Vorstellung einer Herrscherrasse und Weltbeherrschung gründete, die andere in der selbstmitleidigen Paranoia des unschuldigen, angegriffenen Opfers. Größenwahn und Opfervorstellung wurden zugleich behauptet - eine absurde kollektive Doppeltrübung, die den katastrophalen Holocaust ermöglicht hat. (Sacks, 2015a, 59) 
„Gut, dann machen wir jetzt ein Experiment. Ich werde Ihnen mit dieser Nadel in den Finger stechen." Da der Patient eine Leiche ist, kann er nicht viel dagegen einwenden. Der Psychiater piekst ihm in den Finger; heraus kommt ein Tropfen Blut. Der Patient schaut sich das verblüfft an und ruft: „,Verdammt! Leichen bluten tatsächlich!“ (Dilts 1993, 23)

So stur, so borniert, so lernfeindlich kann man als Opfer verdrehter mentaler Modelle sein: Die ganze Welt kann ich mir so zurecht biegen, dass meine Vorurteile, meine Denkgewohnheiten, meine Scheuklappen, meine Glaubensüberzeugungen bestehen bleiben. Jede Infragestellung so eines Modells wird als Angriff, zumindest als Verunsicherung erlebt. Mentale Modelle bieten Sicherheit. Killerphrasen immunisieren gegen Veränderung: „Das haben wir schon immer so gemacht!“ „Das haben wir noch nie so gemacht!“'Lernen ist riskant; es stellt Sicherheit in Frage.

\subsubsection{Vertiefung: Geh du aus deinem Land...}

Ein zentraler Satz der hebräischen Bibel: „ER sprach zu Abram: Geh du aus deinem Land, aus deiner Verwandtschaft, aus dem Haus deines Vaters in das Land, das ich dich schauen lassen werde. “(1. Mose 12,1; Übersetzung von Martin Buber)

Rabbinische Weisheit kennt sich mit Trübungen aus. Rabbi Sussja kommentiert: „Gott spricht zum Menschen: Zuvorderst geh aus deinem Land - aus der Trübung, die du selber dir angetan hast. Sodann aus deinem Geburtsort-aus der Trübung, die deine Mutter dir angetan hat. Danach aus deinem Vaterhaus - aus der Trübung, die dein Vater dir angetan hat. Nun erst vermagst du in das Land zu gehen, das ich dir zeigen werde. “ (Buber 1949, 385)

Psychologische Forschung hat gezeigt, dass der Druck zur Konformität, zur Anpassung an zugeschriebene Rollen stark genug sein kann, um Menschen zu Taten $z u$ verleiten, die sie selbst für falsch halten. „That is why Abraham, at the start of his mission, was told to leave, his land, his birthplace, and his father's house, 'to free himself from the pressure to conform. Leaders must be prepared not to follow the consensus. One of the great writers on leadership, Warren Bennis, writes: ,By the time we reach puberty, the world has shaped us to a greater extent than we realise. Our family, friends, and society in general have told us - by word and example - how to be. But people begin to become leaders at that moment when they decide for themselves how to be. " (Sacks, 2015b,16)

\subsubsection{Enttrübung realitätsferner mentaler Modelle}

Trübungen schränken unsere Realitätswahrnehmung ein und gefährden darum Autonomie. ${ }^{40}$ Der Weg zur Autonomie erfordert Enttrübung, die Bereitschaft und

40 William Saroyan persifliert unsere Selbstbeschränkung mit der Geschichte von einem merkwürdigen Mann. Dieser Mann spielte auf einem Cello mit nur einer einzigen Saite, und er spielte immer nur ein und denselben Ton. Seine ebenso kluge wie geduldige Frau fasste sich eines Tages ein Herz und machte ihn darauf aufmerksam, dass auch andere Männer und 
Fähigkeit zur Realitätsüberprüfung. Dafür wird das Erwachsenen-Ich dringend gebraucht. Wie kann das aber diese Aufgabe lösen, wenn es selbst getrübt ist? Und zwar so getrübt, dass jeder Versuch zur Enttrübung scheitert? In der Psychotherapie werden schädliche Glaubensüberzeugungen und -systeme thematisiert und in Frage gestellt. So lange Patienten sich an diese Glaubenssätze klammern, ist es Zeitverschwendung, sie zu konkreten Veränderungen ihres Verhaltens bewegen zu wollen. Die ganze Welt kann ich mir so zurecht biegen, dass meine Auffassung von Welt und Leben bestehen bleibt. Andernfalls würde das von mir gebaute mentale Lebenskonzept wie ein Kartenhaus zusammenbrechen.

Irvin D. Yalom gesteht, wie er als junger Therapeut in einem Fall gescheitert ist: Ein von Verfolgungswahn gequälter Patient ,behauptete fest, ich sei nicht Dr. Yalom, sondern ein FBI-Agent, und verlangte, dass ich mich auswies. Als ich ihm in der nächsten Sitzung dümmlich meine Geburtsurkunde, meinen Führerschein und meinen Pass präsentierte, erklärte er, dass sich sein Verdacht bestätigt habe: Nur mit FBI-Verbindungen könne man so schnell an falsche Papiere herankommen.“ (Yalom 2001, 57; weitere Beispiele bei Herrmann 2013)

Die Beispiele illustrieren die enorme Verhinderungsmacht mentaler Modelle. Ich zitiere sie, weil mächtige mentale Modelle die Entwicklung von Schulen in Richtung Lernender Organisationen verhindern. Sie sind weniger auffällig, weil sie von vielen als selbstverständlich angesehen werden. Die Entwicklung Ihrer Schule können Sie nur voranbringen, wenn Sie solchen mentalen Modellen in den Köpfen vieler Lehrerinnen und Lehrer mit guten Argumenten, mit attraktiven, produktiven Entwürfen und beispielhaften Erfolgsgeschichten begegnen können. Schnelle Erfolge sind nicht zu erwarten!

Bei Gelegenheit frage ich befreundete Lehrerinnen und Lehrer, Ruheständler, was sie von der Idee halten, eine Schule als Lernende Organisation zu verstehen. Nach nur wenigen erläuternden Sätzen sagen mir diese lebenserfahrenen Pädagogen durchweg: „Das funktioniert in einer Schule nicht!“ In größeren Schulkollegien, so wird uns berichtet, sind es normalerweise gar nicht mehr als 5-10\% Kolleginnen bzw. Kollegen, die sich bei anstehenden Veränderungsprojekten abseits halten. Oft wird ihnen mehr Macht eingeräumt als nach den Prozentzahlen zu erwarten wäre.

Kools und Stoll (2016) berichten, das Konzept sei aus Sicht der Schulen zu vage. Nach unserer Erfahrung lassen sich Leitungsgruppen durchaus für methodisches Vorgehen gewinnen, wenn sie damit ihre eigenen Ziele erreichen. So machen z.B. die Mitglieder einer erweiterten Schulleitung im Rahmen eines Klausurtages die gute Erfahrung, dass sie mit methodischer strategischer Arbeit konkrete Ergebnisse erzielen und sogar mit Spaß bei der Sache sind.

$\mathrm{Ja}$, das methodische Vorgehen ist zeitaufwendiger als die herkömmliche Behandlung solcher Themen, dafür aber deutlich effektiver. Also ist weiter zu fragen: Wie können Sie Zeit für solche sinnvolle Arbeit gewinnen?

Frauen dieses herrliche Instrument spielen. „Aber“, so sagte sie, „deren Cello hat vier Saiten, und sie spielen viele Töne und Melodien darauf!“ Da antwortete der Mann: „Du bist eine Frau! Dein Haar ist lang, dein Verstand kurz! Alle diese Leute suchen den einen wahren Ton. Ich habe ihn gefunden!“ 
Erfolgversprechend sind Veränderungen in der Rhythmisierung der Unterrichtsstunden, die Einrichtung einer regelmäßigen wöchentlichen Konferenzzeit, die Bildung von Teams, die sich dann leichter treffen können, Fortbildung und Unterrichtsvorbereitung im Team während der unterrichtsfreien Zeiten (in den neuen Bundesländern jetzt schon selbstverständliche Praxis), kollegiale Beratung in Gruppen, Gesundheitsförderung durch gezielten Stressabbau, Überprüfung einengender Rahmenbedingungen, die für ,freie“ Schulen nicht verpflichtend sind u.a.m. Die Beispiele lassen sich noch vermehren (s.u. 13.3). ${ }^{41}$ Mit Epiktet: Die Dinge sind weder gut noch schlecht - unser Denken macht sie so.

Mindestens zwei Hürden erschweren die Umsetzung solcher Möglichkeiten. Zum einen die reflexhafte Antwort: „Dafür haben wir keine Zeit!“ Diese „Selbstverständlichkeit" verweist darauf, wie sehr Kultur und Struktur miteinander verflochten sind. $\mathrm{Zu}$ fragen ist: Wie kann die zur Verfügung stehende Zeit so strukturiert werden, dass solche kulturellen Merkmale gedeihen können?

Zum zweiten: Denken Sie an die Warnung vor Top-down-Lösungen. Sie brauchen bei wesentlichen Veränderungen eine Vorgehensweise, die die von Entscheidungen Betroffenen beteiligt. Wie das geht, wird in den Kapiteln 7-9 thematisiert. Je besser ein Kollegium oder wenigstens ein Teil des Kollegiums über förderliche kulturelle und strukturelle Merkmale informiert ist, desto besser für die gemeinsame Erarbeitung von spezifischen Lösungen, d.h. für Lösungen, die zum jetzigen Zeitpunkt für Ihre Schule einen Schritt in die richtige Richtung bedeuten. Dies Buch ist dazu gedacht, solche Diskussionen in Schulkollegien anzuregen.

Eine Frage zum Meditieren: Wann in meinem Leben habe ich bestimmte Aspekte meines Bezugsrahmens verändert? Wie kam es dazu? Wie alt musste ich werden, um so einen Schritt zu tun? Und was hat mir geholfen, mich dadurch nicht fundamental in Frage stellen zu müssen? (Die folgende Vertiefung könnte Ihnen helfen, eine meditative Stimmung einzunehmen. Leitfragen: Welche „Wassermelonen“ sind mir erinnerlich? Und welchen Wassermelonenjägern kann ich dankbar sein?)

\subsubsection{Vertiefung: Der Wassermelonenjäger}

„Es war einmal ein Mann, der sich verirrte und in das Land der Narren kam. Auf seinem Weg sah er die Leute, die voller Schrecken von einem Feld flohen, wo sie Weizen ernten wollten. ,Im Feld ist ein Ungeheuer', erzählten sie ihm. Er blickte hinüber und sah, dass es eine Wassermelone war.

Er erbot sich, das, Ungeheuer' zu töten, schnitt die Frucht von ihrem Stiel und machte sich sogleich daran, sie zu verspeisen. Jetzt bekamen die Leute vor ihm noch größere Angst, als sie vor der Melone gehabt hatten. Sie schrien: ,Als Nächstes wird er uns töten, wenn wir ihn nicht schnellstens loswerden', und jagten ihn mit ihren Heugabeln davon.

41 Riegel (2004, 137): „Während meiner gesamten Berufsjahre wollte ich die Noten abschaffen und durch andere Formen der Rückmeldung an die Schüler ersetzen. Immer wieder bin ich grandios gescheitert." In einer GLK 1972 stellte sie den Antrag auf Abschaffung der Noten. „Das war ein Eklat! Einige aus dem damaligen Kollegium haben mit den Fäusten auf die Tische getrommelt und mir empfohlen, ich solle doch in die DDR gehen.“ 
Wieder verirrte sich eines Tages ein Mann ins Land der Narren, und auch er begegnete Leuten, die sich vor einem vermeintlichen Ungeheuer fürchteten. Aber statt ihnen seine Hilfe anzubieten, stimmte er ihnen zu, daß es wohl sehr gefährlich sei, stahl sich vorsichtig mit ihnen von dannen und gewann so ihr Vertrauen. Er lebte lange Zeit bei ihnen, bis er sie schließlich Schritt für Schritt jene einfachen Tatsachen lehren konnte, die sie befähigten, nicht nur ihre Angst vor Wassermelonen zu verlieren, sondern sie sogar selbst anzubauen." (Aus den Lehr-Erzählungen der Sufis; Kopp 1978, 16)

\subsubsection{Enttrübung durch Lebensereignisse}

Manchmal sorgt ein dramatisches Lebensereignis dafür, dass jemand sich von scheinbaren Selbstverständlichkeiten verabschiedet, die bis dahin fraglose Orientierung geboten haben. J. Sacks (2015a, $177 \mathrm{ff}$ ) gibt ein eindrucksvolles Beispiel: Bis 2012 war der ungarische Politiker Csanad Szegedi eine der aufstrebenden Führungspersonen im Jobbik, einer ultranationalistischen Partei. Innerparteiliche Rivalen suchten in seiner Vergangenheit nach belastenden Faktoren und fanden heraus, dass Szegedis Großeltern mütterlicherseits Auschwitz überlebt hatten. Szegedi überprüfte die ausgestreuten Gerüchte; sie trafen zu.

Szegedi wurde wie ein Aussätziger behandelt. Man riet ihm, sich öffentlich zu entschuldigen. Diese Zumutung war für ihn der Anlass, aus seiner Partei auszutreten: „Ich dachte: Moment mal, ich soll mich dafür entschuldigen, dass meine Familie in Auschwitz getötet wurde?" Er nahm bei einem Rabbi Studien zum Judaismus auf, besuchte die Synagoge und entwickelte eine völlig veränderte Sicht auf die Welt. Als Politiker sieht er seine Aufgabe jetzt darin, die Menschenrechte für jedermann zu verteidigen. J. Sacks dazu: Szegedi ist der Antisemit, der entdeckte, dass er ein Jude ist. „Er war ein Hassender, der entdeckte, dass er zu den Gehassten gehörte. Was seinen Antisemitismus geheilt hat, war die durch inneren Rollenwechsel ermöglichte Entdeckung, dass er selbst ein Jude ist. Für ihn eine lebensverändernde Offenbarung." (Sacks a. a. O., 188) ${ }^{42}$

Wenn massive Ereignisse dieser Art destruktive mentale Modelle, hinderliche Bezugsrahmen erschüttern und Bereitschaft für neue Wege wecken können, sollte man dann für die Entwicklung von Schulen auf dramatische Vorfälle hoffen? Natürlich nicht, obwohl dergleichen vorkommt. Manchmal geraten Schulen durch andauernde interne Konflikte in die Gefahr, vom Träger aufgegeben zu werden. Die Auseinandersetzungen zwischen Leitung und Geleiteten oder auch die Konflikte

42 Die bizarren Paradiesvorstellungen vieler Selbstmordattentäter sind für westlich-aufgeklärte Geister schwer nachzuvollziehen. In einer Fernsehsendung über palästinensische SelbstmordAttentäter wurde ein Interview mit einem Jüngling gezeigt, dessen Attentat misslungen war. Nur der Zünder war losgegangen und hatte ihn verletzt. Als er im Krankenhaus zu sich kam, beugten sich schöne junge Frauen in weißen Kleidern freundlich über ihn, und er war überzeugt, im Paradies zu sein. Schließlich fragte ihn der israelische Geheimdienstler: „Gibt es denn Israelis im Paradies?" Das brachte ihn auf die Erde zurück, auf der er nun den Rest seines Lebens im Gefängnis verbringen wird - falls er nicht irgendwann von einem Häftlingsaustausch profitiert. (Spiegel TV 1.8.1997) 
innerhalb der Region der Geleiteten fressen dann so viel Energie, dass die Primäraufgaben der Schule nicht mehr ausreichend erfüllt werden können (Näheres dazu s. u. 7.3). Wir haben die Erfahrung gemacht, dass so eine Situation der Anfang für eine gründliche Bestandsaufnahme sein kann, dass ein grundlegender Umschwung aber einen anschließenden längeren Verarbeitungsprozess nötig macht.

\subsubsection{Enttrübung durch Konfrontation}

Enttrübung ist harte Arbeit; es geht darum, den Bezugsrahmen einer Person oder auch einer Gruppe zu erweitern. Dafür wird jemand gebraucht, der nicht selbst im hinderlichen Bezugsrahmen gefangen ist, in der Regel eine Therapeutin oder Beraterin. So jemand stellt den eigenen Bezugsrahmen dem des Klienten entgegen, deutlich, klar, bestimmt. Da es dabei immer um Förderung von Autonomie, um Steuerung aus dem Erwachsenen-Ich-Zustand heraus geht, sollte das wohlwollend, nicht verfolgerisch-kritisch geschehen. Die Wirksamkeit so einer Konfrontation zeigt sich daran, dass der Bezugsrahmen des Klienten weiter wird, dass mehr möglich ist, mental, emotional oder im Verhalten.

L. Schlegel empfiehlt, mit Klienten in Therapie und Beratung einen Konfrontationsvertrag zu schließen: „Ich möchte Sie jedesmal darauf aufmerksam machen dürfen, wenn mir an dem, was Sie sagen oder an Ihrem Verhalten etwas auffällt, was mit unseren Abmachungen, mit dem Behandlungsziel, mit Ihren Zielen im Leben allgemein nicht übereinstimmt oder Ihren Beziehungen zu mehreren Menschen oder Ihnen selber schaden könnte. - Sind Sie damit einverstanden?““(Schlegel 1993, 202)

So einen Vertrag können Sie auch mit Ihrem Arbeitsteam schließen. Im Rahmen von Vertragsarbeit gehört das durchaus zu Ihrer Aufgabe. Wichtig ist, dass Sie in der Lage sind, aus Ihrem Erwachsenen-Ich-Zustand heraus zu intervenieren und den nötigen Abstand zu wahren.

In unseren Seminaren haben wir jeweils zu Beginn nach mitgebrachten Themen gefragt. Häufig wurden von Koordinatorinnen oder Stufenleitungen Probleme mit dem direktiven, manchmal abwertenden Leitungsstil einer Schulleiterin bzw. eines Schulleiters genannt. Bei näherer Problembeschreibung wurde dann deutlich, dass unsere Teilnehmerin sich in die Opferrolle begeben hatte. Schon die Frage, welche sonstigen Möglichkeiten es geben könnte, hat eine konfrontierende Wirkung: Change it - leave it - love it? Die Frage, welche dieser Möglichkeiten jemanden am ehesten anspricht, lädt dazu ein, aus der Reaktivität in die Proaktivität zu wechseln.

Eine weitere Konfrontation bedeutet die Frage, wie die Zusammenarbeit der Schulleiterin mit dem Leitungsgremium vertraglich geregelt und wie in diesem Vertrag das Konzept gewaltfreier Kommunikation verankert sei. So ein Vertrag existiert in der Regel nicht. Und schließlich gehört in diesen Zusammenhang auch die Frage, was das Schulkonzept über den Führungsstil der jeweiligen Schule aussagt, wie konkret das formuliert ist, wie bekannt das Konzept im Kollegium ist und wie es als Auswertungsinstrument genutzt wird. Kurzum, die Lerninhalte unseres Kurses bildeten für viele von vornherein eine recht massive Konfrontation mit Struktur und Kultur der eigenen Schule - verbunden mit der nahe liegenden Frage, wie denn die genannten Elemente in das eigene Schulsystem implantiert werden könnten. 
Im Rahmen einer schulischen Organisationsberatung präsentierte die Schulleiterin sich selbstmitleidig als „Mutter der Nation“, die alles tut, um es jedem recht zu machen, und sich durch die Arbeit mit ihrem aus über 20 Personen bestehenden Leitungsteam überfordert fühlt. Sie merkt, dass sie sich in dieser reaktiven Opferrolle unwirksam macht, weiß aber keinen Ausweg. Konfrontiert mit dem Hinweis, dass sie ein Recht hat, für Arbeitsfähigkeit auf der Leitungsebene zu sorgen, reagiert sie verblüfft, ist aber nach einigen Coaching-Treffen doch bereit, ein kleines Leitungsteam zusammenzustellen und dabei Kompetenzkriterien zu berücksichtigen. Ihr Vorgehen wurde vom Kollegium akzeptiert und wirkte stabilisierend auf das ganze Schulsystem.

Wenn wir mit Lehrerinnen und Lehrern kollegiale Beratung einüben (s. o. 5.3), hören wir in der Auswertung, das sei wohltuend, unterstützend, teamfördernd. Auf die Frage, wie sie diese Erfahrung im Schulalltag ermöglichen könnten, folgt regelmäßig die Antwort: „Dafür haben wir keine Zeit!“ Weiteres freundlich konfrontierendes Nachfragen erhellt die Absurdität dieses Sachverhalts. Im Grunde heißt das: So wichtig nehmen wir uns nicht - eine Trübung aus dem KindheitsIch-Zustand. Hattie gibt die Parole aus: Auf den Lehrer, auf die Lehrerin kommt es an! Also sind sie wichtig. Also ist ihnen kollegiale Beratung als regelmäßige Unterstützung und Reflexionsmöglichkeit zu wünschen. In manchen Fällen führt diese Konfrontation dazu, dass schließlich doch konkrete Schritte in der Schule folgen.

Ein letztes Beispiel: Ein Lehrer verteilt seit einiger Zeit extrem schlechte Zensuren in einer Klasse, übernimmt aber keinerlei Verantwortung für die Wirkung auf die Schülerinnen und Schüler, auf die Eltern, auf den Ruf der Schule, auf mögliche Abmeldungen und wirtschaftliche Folgen - eine Doppeltrübung, eine Realitätsausblendung. Die Transaktionsanalyse hat ein hilfreiches Verfahren für die Konfrontation hartnäckiger Realitätsausblendungen entwickelt, die Abwertungstabelle. In vier Schritten, dargestellt als Tabellenstufen, wird die Neigung, sich unwillkommene Realitäten vom Leibe zu halten, konfrontiert (Stewart/Joines 1993, 262 ff). Ein Beispiel aus einem Kurs (stark vereinfacht wiedergegeben):

Der Vorsitzende eines Elternrats beklagt sich beim Direktor über diesen Lehrer, der seit einiger Zeit in Klassenarbeiten nur noch Vieren und Fünfen gibt. Ein Gespräch mit dem Lehrer habe nicht geholfen. Der Direktor lädt den Lehrer zum Gespräch.

\section{Stufe: Existenz des Problems}

Eingangsfrage: Sieht der Lehrer überhaupt, dass da ein Problem existiert? Zunächst nicht. Seine Antwort: „Ich unterrichte wie immer. Ich habe kein Problem damit." Der Direktor verweist auf die Unruhe der Eltern, auf die Frustration der Schülerinnen und Schüler, die in anderen Fächern gut zurechtkommen. Schließlich räumt der Lehrer ein, dass ein Problem existiert.

2. Stufe: Bedeutung des Problems

Welche Bedeutung hat das Problem für den Lehrer? Antwort des Lehrers: „Die Schüler haben sich stark verändert, werden von den Eltern nicht zum Lernen angehalten, und die Eltern versagen." Der Direktor verweist auf das Image der Schule, auf angedrohte Abmeldungen, auf mögliche wirtschaftliche Folgen. 
Wie lässt sich das alles verändern? Der Lehrer: „Ja, das ist ein Problem, aber innerschulisch ist da nichts zu machen."

3. Stufe: Veränderbarkeit des Problems:

Der Direktor: „Wie ist zu erklären, dass die Kinder in den Parallelklassen mit vergleichbarem sozialen Hintergrund auch im betreffenden Fach bei anderen Lehrern deutlich besser abschneiden?“ Der Lehrer hält es schließlich für möglich, dass die Kollegen einen anderen Unterrichtsstil praktizieren.

4. Stufe: Persönliche Fähigkeiten

Der Direktor: „Was könnten Sie persönlich tun, um das Problem zu lösen?“ Der Lehrer: „Ich bin zu alt, um meinen Unterrichtsstil zu ändern.“ Der Direktor spricht einige Möglichkeiten an: Der Lehrer könnte mit den Schülern über das Problem sprechen und dabei einen Beratungslehrer hinzuziehen. Der Direktor oder ein Fachkollege könnte einige Unterrichtsstunden besuchen und anschließend mit dem Betroffenen den Prozess reflektieren.

Das beschriebene Vorgehen empfiehlt sich auch für viele Situationen, in denen Schüler oder Schülerinnen problematisches Verhalten zeigen. Auf jeder der vier Stufen geht es darum, die betroffene Person mit Hilfe geeigneter offener Fragen (W-Fragen) zum eigenständigen Denken zu bringen. ${ }^{43}$ Ein weiteres (fiktives) Beispiel:

\section{Existenz des Problems (Blindheit):}

Eine Lehrerin bemerkt auf dem Schulhof, wie ein großer, starker Junge einen kleineren verprügelt.

Lehrerin: „Hey, hör auf! Sofort!“

Schüler: „Was denn? Worüber regen Sie sich denn so auf, ich hab ihn doch nur so'n bisschen an der Nase gekitzelt."

Lehrerin: „Gekitzelt? Von wegen. Du hast ihn geschlagen, und seine Nase blutet. Sieh mal hin!“

Schüler: „Ach, der soll sich nicht so anstellen, wenn ihm mal die Nase läuft“

Lehrerin: „Dem läuft nicht die Nase. Die Nase blutet!“

Schüler: „An dem bisschen Blut wird er schon nicht sterben.“

[Die Existenz des Problems wird akzeptiert, die Bedeutung aber nicht.]

\section{Bedeutung des Problems (Vernebelung):}

Lehrerin: „Das nicht. Aber Körperverletzung ist das trotzdem. Wir haben verabredet: Bei Problemen reden wir und schlagen nicht einfach zu. Erinnerst Du Dich?“"

Schüler: „Ja, kann schon sein.“

Lehrerin: „Was heißt hier: Kann schon sein! Wir haben das abgemacht, im Sozialkunde-Unterricht, und du hast auch zugestimmt. Aber du hältst dich nicht dran."

43 Wyler-Krisch (2001) orientiert sich im Sinne systemischer Transaktionsanalyse bei der Fokussierung von Beratungsthemen an transaktionsanalytischen Konzepten als Landkarten und fördert die Problemklärung mit systemischen Interventionen - ein Verfahren, das auch für die Arbeit mit anderen Konzepten zu empfehlen ist. 
Schüler: „Sonst halte ich mich ja dran, aber wenn Basti nervt, dann muss ich ihm einfach eine langen!“

[Die Bedeutung wird akzeptiert, aber nicht die Veränderbarkeit.]

\section{Veränderbarkeit des Problems (Scheuklappen):}

Lehrerin: „Wie machen es denn die anderen, wenn die sich von Basti genervt fühlen?“

Schüler: „Einige sagen ihm ganz deutlich: Halt die Klappe! Manche gehen ihm dann aus dem Weg. Aber mit mir geht's dann durch."

[Die Veränderbarkeit wird akzeptiert, aber nicht die persönliche Fähigkeit.]

\section{Persönliche Fähigkeiten (Dummstellen):}

Lehrerin: „Mit dir geht's dann durch. Wann hast du so eine Situation schon mal friedlich hingekriegt?“"

Schüler: „Manchmal stelle ich meine Ohren auf Durchzug. Das hilft schon.“

Lehrerin: „Na prima, das ist schon ein Ansatz. Hast du noch mehr Ideen?“

Schüler: „Naja, wenn ich ihn gar nicht erst anpflaume, dann quatscht er wahrscheinlich auch nicht so blöd.“

Lehrerin: „Kompliment! Jetzt hast du zwei wichtige Punkte erwischt. Wie kannst du es in Zukunft hinkriegen, dass du den Basti einfach nicht mehr anpflaumst?"

Schüler: „Wenn ich in den Pausen mehr mit den Großen zusammen bin, dann müsste das klappen.“

Lehrerin: „Klingt viel versprechend. Ich werd in den nächsten Tagen drauf achten, OK?“

Schüler: „OK.“

Lehrerin: „Und Basti? Was ist mit Basti? Was denkst du, wie’s dem geht?“

Schüler: „Wieso? Ich lass ihn doch in Ruhe.“

Hier könnte ein weiterer Durchgang anschließen, in dem die Beziehung zu Basti thematisiert würde.

\subsubsection{Enttrübung durch Feedback}

Die Beispiele zeigen: Wenn wünschenswerte Entwicklungen stocken, sind oft Trübungen, blockierende mentale Modelle im Spiel. Sie können sich auch selbst fragen, wie Sie Ihren eigenen Trübungen auf die Schliche kommen können. Auch Ihnen sind ja eventuell vorhandene kognitive, emotionale, verhaltensbezogene einschränkende Gewohnheiten nicht ohne weiteres bewusst. Aber den eigenen blinden Flecken auf die Schliche zu kommen, ist für einen partiell Blinden nicht einfach.

Ein längerer Kulturwechsel hilft, die Welt mit den Augen der anderen zu sehen. Einübung in fremde Gepflogenheiten erweitern den Horizont des Verhaltens, des Denkens und mit der Zeit auch des Fühlens. (Vgl. die Vertiefung 6.9.7: „Geh du aus deinem Land...")

Sie müssen dafür nicht unbedingt ins Ausland reisen. Es würde genügen, immer mal wieder im Arbeitskontext um Feedback zu bitten. Die anderen sind unentbehrlich, wenn Sie etwas über Ihre spezifischen blinden Flecken erfahren wollen (vgl. Johari-Fenster, 6.7.2). Interdisziplinär zusammengesetzte Teams sind da homogenen Gruppen gegenüber im Vorteil. 
Sich aktiv um Feedback zu bemühen, ist ungewohnt. Wenn Sie anfangs verstärktes Herzklopfen spüren, können Sie das Feedback so steuern, dass Sie nur nach positiven Aspekten fragen. Ihr Leitungsteam könnte dafür ein geeignetes Übungsfeld sein (oder werden). Mögliche Schritte in diese Richtung habe ich Ihnen schon nahe gelegt (s.o. 6.7).

Eine Kursteilnehmerin hat das ausprobiert und sich Feedback zu ihrer Moderation erbeten. Ihre Erfahrung hat sie mir stolz geschrieben: „Übrigens bekam ich gestern ein positives Feedback einer jungen Kollegin zu meiner Fachgruppenleitung. Sie meinte: ,Du bringst uns zum Denken und Arbeiten, und dann sind wir auch noch früher fertig. ' - Da habe ich doch wirklich was gelernt bei Ihnen und Ihrer Frau."

Und sollte das Feedback mal kritisch ausfallen, halten Sie sich an „Spinoza“: Was Petra über Pauline sagt, sagt mehr über Petra als über Pauline. In jedem kritischen Feedback steckt immer auch eine Selbstmitteilung der Kritikerin (s. o. 6.2).

\subsection{Konfliktklärung durch Prozesskommunikation (PCM)}

Konfliktkompetenz hat zentrale Bedeutung für die Leitungsarbeit. Je vertrauter Sie mit diesem Aspekt Ihrer Arbeit werden, desto weniger kann Ihnen Stress aus dieser Richtung anhaben. Ein für die Arbeit in Schulen gut einleuchtendes Verfahren hat Taibi Kahler gefunden. Sein Modell der Prozesskommunikation (PCM = process communication model) basiert auf sechs Persönlichkeitsmerkmalen, die unseren Beziehungsstil charakterisieren. Die sechs Typen sind: Beharrer, Empathiker, Logiker, Macher, Rebell, Träumer.

Das Modell erinnert stark an das Funktionsmodell der Ich-Zustände (s. o. 6.9.3). Die sechs Persönlichkeitstypen lassen sich als konstruktive Versionen der Ich-Zustände des Funktionsmodells interpretieren. Also: Beharrer $=\mathrm{kEl}+$, Empathiker $=\mathrm{fEl}+$, Logiker $=\mathrm{ER}$, Träumer $=\mathrm{aK}+$, Macher $=\mathrm{fK}+$, Rebell $=\mathrm{rK}+$.

Kahler benutzt eine griffige Metapher: Wir können uns unser Lebenshaus als sechsstöckiges Bauwerk vorstellen. Im Erdgeschoss, also in unserem Basistyp, kennen wir uns gut aus; in ihm bewegen wir uns, ohne groß nachdenken zu müssen, ohne Anstrengung. In der zweiten Etage sind wir auch noch gut orientiert. Die dritte suchen wir seltener auf; der Weg in die 4., 5. und 6. Etage kostet uns immer mehr Anstrengung, Zeitaufwand, bewusste Zielsetzung.

Jeder Basistyp hat seine Stärken in Form von Vorlieben, Bedürfnissen, Sichtweisen. Kurze Charakteristik:

- Beharrer bestehen auf fundierten Urteilen und Meinungen; sie wollen Anerkennung für ihre Überzeugungen und Leistungen.

- Empathiker legen Wert auf gute Beziehungen; sie möchten als Person akzeptiert werden, sich wohl fühlen, ein freundliches Umfeld gestalten.

- Logiker orientieren sich stark an Realitätsaspekten (Zahlen, Daten, Fakten), und wünschen sich, für ihre Leistung geachtet zu werden.

- Träumer beschäftigen sich gern allein, brauchen Zeit für sich, für die eigene Kreativität, bevor sie in Kontakt mit anderen gehen. 
- Macher sind handlungsorientiert, genießen Aufregung; ihr Motto: Probieren geht über Studieren (deeds, not creeds!).

- Rebellen sind auf Kontakt und Reibung aus, stellen Grenzen und Autoritäten in Frage - oft zu Recht.

Wenn Sie die sechs Typen auf sechs Moderationskarten schreiben, können Sie sie wie Stockwerke übereinander vor sich hinlegen und durch Hin- und Herschieben ausprobieren, welche Anordnung Ihnen am besten entspricht. Wie waren Sie als Kind? Was änderte sich durch den Schulbesuch, durch die Ausbildung, das Studium, den Einstieg in den Beruf? Welche Krisen haben einen Phasenwechsel ausgelöst?

Nehmen Sie als Erdgeschoss das Merkmal, in dem Sie sich am leichtesten, mit wenig Anstrengung, bewegen, und legen Sie in den sechsten Stock das Merkmal, das Sie selten zeigen. Dann können Sie die restlichen Etagen so verteilen, dass es für Sie passt. Ich habe mir zu jeder Etage zwei, drei Beispiele aus meiner Entwicklung aufgeschrieben und habe besser verstanden, wieso manche beruflichen Anforderungen mich eher anstrengen als andere. Wenn die berufliche Rolle von einem Basis-Träumer verlangt, öffentlich zu reden, dann hat so jemand einige Treppenstufen zu erklimmen.

Solange wir in unseren Beziehungen mit unserem Basistyp gut zurecht kommen, werden wir uns vor allem in dessen Möglichkeiten bewegen. Falls das Leben uns jedoch mit Herausforderungen konfrontiert, mit Krisen, die mit dem Basistyp nicht zu bewältigen sind, dann entwickeln wir ein zusätzliches Merkmal, eins, das am besten zur jeweiligen Herausforderung passt. Wir gehen in eine andere Phase, wobei das Potential der ersten Phase, die in ihr erworbene Kompetenz, erhalten bleibt. So ein Phasenwechsel ist häufig, auch ein zweifacher Wechsel kann passend sein; es ist auch möglich, dass jemand alle sechs Möglichkeiten stark entwickelt. Doch wird das Gefühl von Leichtigkeit und Anstrengungslosigkeit eher auf zwei, höchstens drei Phasen begrenzt bleiben.

Das Modell erlaubt sehr individuelle Beschreibungen. Die Zahl der möglichen Schichtungen bei 6 Typen beläuft sich auf 6 ! (also auf $6 \times 5 \times 4 \times 3 \times 2 \times 1)=$ 720 Möglichkeiten.

PCM macht gut verständlich, dass die Kommunikation mit anderen erschwert sein kann, wenn die jeweiligen Partner in Beruf, Familie, Schule unterschiedliche Basistypen verkörpern. Wir sind in unterschiedlichen „Etagen“ zu Hause, und dieser Umstand produziert in Begegnungen von vornherein eine gewisse Konfliktwahrscheinlichkeit, bevor wir überhaupt etwas gesagt oder getan haben. Die Kommunikation mit einem unterschiedlichen Etagentyp wird schnell als fremd, seltsam, schwer nachvollziehbar erlebt. Kontakt läuft entspannt, wenn die Basistypen im Hausmodell nicht allzu weit entfernt sind. Wenn aber doch, dann geht es darum, sich auf den Weg in die Basis-Etage des anderen Typs zu machen, die sich bei mir vielleicht im dritten oder vierten Stock befindet, die mir aber doch grundsätzlich zugänglich ist. Die Aufgabe besteht dann darin, sich anhand eigener Erfahrungen in den anderen Basistyp einzufühlen.

Wenn eine Lehrerin einen Schüler schwierig findet, würde Kahler ihr raten, auf die jeweils beteiligten Etagen zu achten. Ist die Lehrerin an ihrer Basis eine Be- 
harrerin, wird sie wahrscheinlich mit einem Rebellenschüler eher Schwierigkeiten haben als mit einer zugänglichen Beharrerschülerin.

Pauley et al. (2012) haben ihre Erfahrungen mit dem Modell in Schule und Erziehung für LehrerInnen beschrieben, die ihre Beziehung zu ihren SchülerInnen verbessern möchten. Jedem Typ ist ein Überblick gewidmet, der Anregungen auflistet, wie er sich erreichen lässt, welche Bedürfnisse ihm vermutlich wichtig sind und wie eine Lehrerin ihre Unterrichtsstunden so abwechslungsreich gestalten kann, dass für jeden Typ ein Angebot dabei ist.

Das Modell legt also nahe, Schwierigkeiten in der Kommunikation nicht als in der Person der einzelnen Schülerin oder der einzelnen Lehrkraft begründet zu verstehen, sondern als Auswirkung unterschiedlicher Prägungen und Basisbedürfnisse. Kahler ermutigt dazu, in schwierigen Beziehungen sich die Basis-Etage der anderen Person zu vergegenwärtigen und dann sich selbst innerlich in diese Etage $\mathrm{zu}$ begeben und von da aus Kontakt aufzunehmen. Eine rebellische Schülerin ist eher zu erreichen, wenn Sie überlegen, wie Ihre eigene Rebellen-Etage aussieht, und wenn Sie der Schülerin zeigen, dass Ihnen solche rebellischen Züge vertraut sind. Damit schützen Sie sich vor dem Impuls, das Problem der Schülerin oder dem Schüler aufzuhalsen und per Definitionsmacht vorschnell für eine andere Schulart zu empfehlen.

In einer kollegialen Beratung mit dem Stufenmodell der Supervision kann das Modell interessante Aufschlüsse bieten, wenn es auf Stufe IV um die Diagnose der Beziehungen im geschilderten Fall geht. Das Modell bietet auch Anregungen für das Teamlernen in Schulen: „In einem Team sind es die Empathiker, die intuitiv atmosphärische oder persönliche Störungen wahrnehmen und präventiv oder konfliktlösend vermitteln." (Feuersenger 2011, 31) ${ }^{44}$

In unseren Kursen hat jedes Gruppenmitglied seine sechs Etagen vor sich auf den Boden gelegt und ist dann umhergegangen, um Ähnlichkeiten und Unterschiede bei den anderen zu entdecken und darüber ins Gespräch zu kommen. Auf welcher Etage ist z. B. die Rebellin gelandet? Rebellion bei Lehrkräften?? Gibt es berufsspezifische Muster? Solchen Austausch können Sie z. B. im Rahmen einer Teamklausur auch in Ihrer erweiterten Schulleitung anregen, wenn sich eine gewisse Vertrautheit und Offenheit miteinander eingestellt hat. Sie können sich in das Modell einüben, indem Sie noch einmal das fiktive Lehrerzimmer (6.9.5) aufsuchen und herausfinden, welche Basistypen da miteinander in Kontakt sind.

44 „Als die NASA vor der Aufgabe stand, für die wochen- bzw. monatelangen Aufenthalte im All im Rahmen der geplanten Raumstation Teams zusammenzustellen, empfahl der psychologische Berater, dass vor allem die Kommandanten über hohe Empathikereigenschaften verfügen sollten. Auf engstem Raum, ohne Ausweichmöglichkeit, für lange Zeit zusammen arbeiten zu können, erfordert nicht nur höchste Fachkompetenz, sondern die Fähigkeit zwischenmenschliche Krisen einfühlsam zu bewältigen.“ (Feuersenger 2011, 31) 


\subsection{Vertiefung: Dein Nächster ist vielleicht dein Feind!}

Was vermag die Kenntnis der dargestellten Modelle zur Analyse und konstruktiven Bearbeitung von Konflikten gegen die verbreitete Grundüberzeugung, dass Menschen von Natur aus zur Bosheit neigen? Wenn ethnologische Studien diese Neigung sogar bei Naturvölkern finden? Auf überraschende destruktive Kreativität bei der Planung kriegerischer Aktionen stieß z.B. der Ethnologe Schiefenhövel (2007) im Naturvolk der Eipo auf Papua-Neuguinea, das bis 1970 noch auf steinzeitlichem Niveau lebte. In einem Interview berichtet Schiefenhövel von seinen Erfahrungen:

Interviewer: Was ist dran an dem paradiesischen Gegenentwurf zu den entfremdeten, korrupten Gesellschaften des Abendlandes? ...

Die Tatsache, dass die Eipo mit und nicht gegen die Natur lebten, lag nicht daran, dass sie bessere Menschen wären. Sie hatten einfach nicht die Mittel, die Natur so auszubeuten, wie etwa wir es tun.

Wenn sie diese zur Verfügung gestellt bekommen ...?

... dann fangen sie sofort damit an, die Natur zu zerstören. Sie tauschen ihr Steinbeil ohne Zögern gegen die Stahlaxt aus und diese gegen die Kettensäge. Und dann ist der Urwald rasch weg. Die Naturvölker sind keine lieben, unbedarften Naturkinder, die in sakralem Einklang mit der Natur leben. Das ist kompletter Blödsinn. Die scheinbare Harmonie ist vor allem Folge fehlender effizienter Techniken.

Die Idee, dass sie untereinander friedliebend sind, kann dann wohl auch aufgegeben werden?

Die Eipo und ihre Nachbarn führten äußerst gewaltsame Kriege, die vor allem dadurch begrenzt wurden, dass ihnen die effizienten Waffen fehlten. Mit den Einheimischen hatte ich in den Bergen eine Start- und Landebahn für kleine Flugzeuge gebaut. Als der Flugplatz nach einem Jahr fertig war und getestet werden sollte, lud der Chefpilot der Missionary Aviation Fellowship zu einem Rundflug ein. Die Eipo-Männer drängten sich sogleich vor. Einer wünschte, dass wir die Tür des Flugzeugs wegnehmen sollten. Außerdem wollte er große Steine mitnehmen. Auf unsere erstaunten Fragen hin hieß es, dass sie Steine abwerfen wollten, sobald der Pilot über das Feinddorf fliegen würde. Anstatt sich am Wunder der Technik zu ergötzen oder die Aussicht auf die Natur zu bewundern, hatten die Eipo den Luftkrieg erfunden, noch bevor sie das erste Mal geflogen waren.

Einen radikalen Perspektivwechsel vollzieht eine der bekanntesten biblischen Geschichten. Ein Gesetzeskundiger fühlt Jesus auf den Zahn: „Wer ist denn mein Nächster?" Der antwortet mit einer Geschichte: Ein Mann wird auf dem Weg zwischen Jerusalem und Jericho von Räubern überfallen und halbtot liegen gelassen. Ein Priester kommt vorüber, auf dem Weg hinab, nach Jericho, also nach Absolvierung seines Tempeldienstes. Danach ein Levit. Beide Male heißt es: Da er ihn sah - ging er vorüber (s. o. 3.4 und Anm. 13).

Zuletzt kommt ein Mann aus Samaria, ein Ketzer, für die Zuhörenden ein Angehöriger einer verfeindeten Volksgruppe. Da er ihn sah - fuhr es ihm in die Ge- 
därme (wörtliche Übersetzung). Er versorgt den Mann, tut das Nötige, organisiert Pflege. Den Perspektivwechsel bringt die Frage am Schluss: Wer von den dreien meinst du, ist der Nächste dem gewesen, der unter die Räuber gefallen war? Die Antwort: „Der die Barmherzigkeit an ihm tat.“ Jesus bestätigt das: Geh hin, handle ebenso!

Menschen sind Gruppenwesen, auch die Eipo. Das Überleben von Individuen hängt von der Bereitschaft von Gruppenmitgliedern ab, Risiken und Opfer für die Gruppe als ganze einzugehen. Insofern sind wir auf Resonanz und Kooperation hin angelegte Wesen; Altruismus spielt eine Hauptrolle beim Überleben der Gruppe.

Jede Gruppe formt ein kollektives Wir, eine gemeinsame Identität - einerseits. Andererseits ist jedes Wir gegen andere Gruppen definiert, die nicht so sind wie wir. Inklusion und Exklusion gehen Hand in Hand. Hier liegt die Quelle sowohl von Gewalt wie von Altruismus. Wir tendieren dazu, die, die nicht wie wir sind, als weniger human anzusehen (Sacks 2015a, 31; vgl. Bauer 2008, 36 in Anm. 76).

Wie lässt sich diese fatale Tendenz überwinden? Den Nächsten, auch den Fremden lieben wie sich selbst? Wo ist die Grenze meiner Zuständigkeit? In einer biblischen Geschichte fühlt ein Frommer Jesus auf den Zahn: „Wer ist denn mein Nächster?“"

„Sag mir, wann ich sprechen kann: / Der da geht mich gar nichts an.

Doch Jesus meint: Nimm einmal an, / du selber wärest jener Mann, du selber lägest da marod / und mehr und mehr vom Tod bedroht.

Wär' dir nicht jeder da willkommen? /Pfeifst du zur Not nicht auf die Frommen?

Der erste Beste wär' es dann! / Und wäre das ein Bettelmann, ein Obdachloser, Fremder gar - / wenn er nur hilft aus der Gefahr!

Er hat damit ganz klar gemeint: / Dein Nächster ist vielleicht - dein Feind!““

(H. Christiansen 1997, 95 ff zu Lukas 10, 25-37)

Die Geschichte spricht - insbesondere in der hier vorliegenden Gedichtform unsere Empathie an, unser Einfühlungsvermögen. Vernunft reicht nicht als fundamentales Motiv für Handeln, wohl aber Gefühle, Emotionen. Weil wir mit anderen fühlen können, ist es möglich, aus der Fixierung von „Wir und die da“ herauszukommen (Sacks 2015a, 29). Über das Gefühl wird ein innerer Seitenwechsel möglich, der sogar Feindesliebe in Grenzsituationen plausibel werden lässt. Genau darauf setzt die biblische Geschichte, die möglicherweise Kindern noch eher als hartgesottenen Erwachsenen spontane Zustimmung entlockt. (Zum inneren Seitenwechsel vgl. Anm. 6; Tabelle 10; S. 251 u. 253 u. 256.) 


\section{Lesetipp}

R. Fisher u.a. (1995): Das Harvard-Konzept der Verhandlung

Das Buch von Fisher u.a. ist ein unterhaltsam und anschaulich geschriebener Bestseller mit vielen Beispielen dafür, wie Sie heil durch die Konfliktklippen kommen, wenn Sie die vier Prinzipien des Modells beherzigen.

M. Rosenberg (2004): Konflikte lösen durch Gewaltfreie Kommunikation. Ein Gespräch mit Gabriele Seils. Zur Vertiefung Ihrer Konfliktkompetenz ein sehr persönliches und lehrreiches Interview mit M. Rosenberg. Wichtige Erkenntnis: Auch bedrohlich scheinende Gefühle sind wichtige Hinweise auf Grundbedürfnisse, deren Berücksichtigung sich entspannend auswirkt.

Hiebl und Seitz (2014): 5.3 und 5.4 



\section{Kapitel 7: Vision und Steuerung von Prozessen}

Jonathan Sacks, der leitungserfahrene hochrangige britische Rabbi, setzt gleich zu Beginn seines Buches über Leadership eine klare Priorität: Wichtiger als alles Erlernen von Managementtechniken ist es für Leitungspersonen, Verantwortung zu übernehmen. Als versierter Rabbi illustriert er das mit dem ersten Buch der Bibel: „Was hast du getan?“ - fragt Gott Adam, den Menschen. Seine Antwort: „Die Frau, die du mir gegeben hast, gab mir von der Frucht.“(1. Mose 3,12)

Im Klartext: Ich bin nicht verantwortlich. Kleiner Seitenhieb gegen Gott: Du hast mir doch diese Frau gegeben! Dann Eva: Die Schlange hat mich verführt. Was kann ich dafür! Botschaft dieses Mythos: So ist der Mensch. Er schiebt Verantwortung ab. (Sacks 2015b, $3 \mathrm{ff}$ )

Und ich mute Ihnen genau dies zu: Verantwortung. Verantwortung dafür, Ihre eigene Kompetenz zu entwickeln, die Entwicklung Ihrer Schule nicht externen Fachleuten zu überlassen, genau diese Aufgabe nicht zu delegieren, Ihre Leitungsrolle von dieser Aufgabe her zu verstehen: proaktiv am System arbeiten, Strukturen herstellen, die die Arbeitsfähigkeit fördern, Regie führen, andere aktivieren, zum Denken bringen, den Blick für das Ganze entwickeln. Viele Aspekte, viele Details. Dies alles beharrlich zu fördern liegt in Ihrer Verantwortung. Verantwortung ist das Vorzeichen vor der Klammer.

\subsection{Kurzer Rückblick}

Trotzdem ist das, was in der Klammer steht, wichtig: die methodischen Zugänge, die Modelle, die Landkarten. In unserem Leitungskurs habe ich öfter den fragenden Seufzer gehört: „Müssen wir das wirklich alles lernen?“ Ich stelle gern die Gegenfrage: „Wie viel Zeit haben Sie investiert, bis Sie mit Ihrem Computer kompetent umgehen konnten?" Die bisher dargestellten Schritte sind für sich genommen hoffentlich - verständlich. Sie müssen aber auch gegangen werden, und dafür brauchen Sie Zeit.

Wenn Sie z. B. anfangen, sich gezielt Feedback holen, in kleinen Dosen, dann gehen Sie ein Risiko ein; Sie können nicht wissen, welche Resonanz Sie bekommen. Vermutlich hören Sie, was Ihnen da gesagt wird, auch auf dem Beziehungsohr (s. o. 6.2). Sie brauchen Geduld mit sich selbst, Zeit, zu verarbeiten, was Sie zu hören bekommen, wegzuhören vom Beziehungsohr, hinzuhören auf die verborgene Selbstmitteilung der anderen Person. Falls jemand - gegen die Absprache - Ihren Wunsch kränkend beantwortet: Aktivieren Sie den Torero in sich, studieren Sie den Stier! Nehmen Sie's sportlich, nicht gleich persönlich.

Sokrates meinte: Wer das Gute weiß, tut es auch. Euripides dagegen: Lang ist der Weg vom Wissen bis zum Tun. Sokrates würde vielleicht einwenden: Wenn du es nicht tust, weißt du es nicht wirklich. Organisationsberater halten sich an Euripides: Gesagt ist noch nicht verstanden. Verstanden ist noch nicht einverstanden. 
Einverstanden ist noch nicht selbst gewollt. Selbst gewollt ist noch nicht getan. Getan ist noch nicht beibehalten.

\subsection{Strategische Vorüberlegungen}

Wenn Sie bis hierher gelesen haben, sind Ihnen sicherlich immer wieder Ideen gekommen, in welche Richtung Sie Ihre Schule, Ihren Verantwortungsbereich gern entwickeln würden. Ihre persönliche Vision ist wichtig. Ich habe Ihnen empfohlen, zu jeder der fünf Dimensionen einer Schule als Lernender Organisation ein bis zwei Ideen zu notieren. Der nächste Schritt jetzt: Wie kommen Sie nach all diesen Überlegungen und Vorbereitungen zu einer gemeinsamen Vision, zu einer Perspektive für die nächsten drei bis fünf Jahre, an der alle mitwirken und die darum auch von (hoffentlich) allen mitgetragen und vertreten wird?

„Es versteht sich eigentlich von selbst, hat sich aber leider noch nicht herumgesprochen, daß bei Top-down-Reformstrategien praktisch keine Aussicht besteht, zu den eigentlichen Problemen vorzustoßen.“(Fullan 1999, 92) Struktur ist wichtig, schafft aber keine Kultur (s. o. 1.1). „Die Veränderung formaler Strukturen ist nicht das gleiche wie eine Veränderung von Normen, Verhaltensweisen, Fähigkeiten und Überzeugungen.“ (Fullan 1999, 90) Veränderungen in Organisationen bedrohen den Bezugsrahmen vieler Beteiligten. Direktive Vorgaben sind entsprechend wirkungslos. „For the school's leadership to simply present a vision to the rest of the school staff may not engage people over the long run, and even risk resistance." (Kools and Stoll 2016, 36)

Systemtheoretiker wissen das seit längerem. Martin Sauer hat einige Erkenntnisse der neueren Systemtheorie knapp zusammengefasst, die die Warnungen der Schulexperten unterstreichen:

1. Grundsätzlich gilt: Komplexe Systeme - Institutionen, Gruppen, Teams - sind nicht direkt steuerbar, vielmehr prinzipiell unvorhersagbar, bestenfalls beeinflussbar. Sie reagieren primär auf eigene, selbst hervorgebrachte Systemzustände.

2. Managen im systemischen Sinne heißt, in Form von Interventionen Steuerungsversuche zu unternehmen; diese Versuche können zum gewünschten Ergebnis, zum Gegenteil des gewünschten Ergebnisses oder zu einem weiteren, nicht vorhergesehenen Ergebnis führen.

3. Der indirekte Weg: Das zu steuernde System gibt die Kriterien vor, unter denen es bereit ist, sich beeinflussen zu lassen.

4. Das Schlüsselloch: Die Leitung kann das soziale System mit seinen Kriterien und Spielregeln verstehen, indem sie dessen Selbstbeschreibung zu rekonstruieren versucht. Das geschieht u.a. durch Beobachten, Verstehen und Deuten. Es reicht dabei nicht, auf Personen zu schauen, wenn man betriebliche Abläufe verstehen will, sondern es ist auf die Interaktionsdynamik, auf Prozesse und dahinter liegende Strukturen zu achten. Lineares Denken (Ursache $\rightarrow$ Wirkung; Input $\rightarrow$ Output) greift entschieden zu kurz. 
5. Der Schlüssel: Die Leitung kann das Selbststeuerungspotential des Systems gezielt fördern. Das geschieht u. a. durch

Bereitstellung geeigneter Rahmenbedingungen,

Mobilisierung von Selbstbeobachtung im System,

Schaffung von Reflexionsmöglichkeiten,

Zulassen bzw. Fördern von Unterschieden,

Fördern von Selbstorganisation,

Akzeptanz der Unsicherheit und Begrenztheit von Außeneinwirkungen. ${ }^{45}$

Steuerungs- und Sinngebungskriterien werden im Diskurs entwickelt, sie entstehen im Austausch. Das von mir scherzhaft „Belehrungsallergie“ genannte Syndrom fällt in Schulen zwar besonders auf, ${ }^{46}$ ist aber auch sonst bekannt; es hat allgemeine Bedeutung für die Steuerung komplexer Systeme und damit auch für ein realistisches Leitungsverständnis. „Das intervenierte System gibt die Kriterien vor, unter denen es bereit ist, sich beeinflussen zu lassen." (Sauer, a.a.O.) Konkret ist also zu fragen: Welche Themen beschäftigen das Kollegium einer Schule? Wo drückt der Schuh? Welche Fragen würden möglichst viele interessieren? Und in welchem Rahmen ließen sich diese Themen sinnvoll bearbeiten?

Für den Anfang brauchen Sie ein allgemein akzeptiertes Thema, das den Blick auf das gesamte System erlaubt. Vielleicht haben Sie selbst ein tolles Thema im Sinn? Dringende Empfehlung: Nehmen Sie das lieber nicht! Bewahren Sie es auf, für später (s.u. 9.6). Sie brauchen Beteiligung; allein stünden Sie auf verlorenem Posten, wenn Sie Schulentwicklung betreiben wollen. Sie brauchen die Kompetenz der Beteiligten. Sie brauchen ein kollegiales Klima, das nur entstehen kann, wenn die Beteiligten merken, dass sie ernst genommen werden. Andernfalls würden sie ihre Kompetenz nicht einbringen.

Und Sie brauchen Trägerschaft für alle Beschlüsse, die in diesem Zusammenhang gefasst werden. Partizipative Leitung fördert Qualität der Entscheidungen, Mitarbeiterzufriedenheit und Trägerschaft. Wird Beteiligung vermisst, ist mit vielen Bremsfaktoren zu rechnen: mit schlichter Verweigerung, mit Passivität, mit

45 Unveröffentlichtes Arbeitsblatt. M. Sauer bezieht sich auf H. Kasper: Vom Management der Organisationskulturen zur Handhabung lebender sozialer Systeme; in: ders.: Post-graduate Managementwissen, Wien 1995,189ff; Rudolf Wimmer (1989): Die Steuerung komplexer Organisationen. Ein Reformulierungsversuch der Führungsproblematik aus systemischer Sicht.

46 Rolff (2017, 12f) unterstreicht, dass Lehrpersonen sich besonders ungern führen lassen; Gründe: hinsichtlich der pädagogischen Funktion unterscheiden sie sich kaum von der der Führungskräfte; zum Beruf gehört die berühmte „,pädagogische Freiheit“. „Hinzu kommt der in Lehrerkollegien in aller Welt verbreitete Mythos von Gleichheit, der traditionell Leitungspersonen als eine der ihren definiert, als Primus oder Prima inter Pares." Dazu gehört das verbreitete allgemeine mentale Modell, dass Führungskräfte, die Mitarbeiter nicht schlimmstenfalls auch entlassen könnten, gar keine echten Führungskräfte seien. Dass wirksame Führung nicht auf Anordnung und Ausübung von Zwang beruht (s. dazu 9.5) und dass Teamlernen auch die Fähigkeit einschließt, sich situationsangemessen leiten zu lassen, muss sich noch herumsprechen. 
Sabotage, mit innerer Kündigung, mit überzufällig hohem Krankenstand usw. Eine Lernende Organisation kann sich so nicht entwickeln.

Günstig ist ein niedrigschwelliges Thema, eins, für das sich möglichst viele spontan kompetent fühlen. Im Laufe der Überlegungen wird sich herausstellen, dass inhaltliche Kompetenz nötig wird, und das ist gut so. Wenn Sie neu im System sind und das Kollegium keine strategischen Fragen gespeichert hat, könnten Sie Themen der folgenden Art vorschlagen, immer mit der vergewissernden Frage: Wäre das ein geeigneter Ausgangspunkt für gemeinsames Nachdenken über unsere Schule?

- Welche Themen sollten im Sinne einer guten Weiterentwicklung unserer Schule bearbeitet werden? (Das könnte gut ankommen. Schulentwicklung fängt nicht bei Null an; was schon gut läuft, wird gewürdigt.)

- Wie sähe eine Schule aus, in die ich mein Kind gern schicken würde? (Das spricht alle an, die selbst Kinder haben.)

- Wenn ich hier was zu sagen hätte - was würde ich ändern? (Ein Thema, wie es in privaten Gesprächen, in einer Kneipe, gängig ist und für das sich jeder und jede kompetent fühlt.)

- Wie können wir uns von Stress in unserer Arbeit entlasten? (Stress in Schulen „ist immer“ - wie Wetter. Das könnte also ebenfalls ein Treffer sein.) ${ }^{47}$

Lehrkräfte wollen gehört werden! Vielleicht fragen Sie sich: Und wo bleibe ich mit meinen Themen? Langsam! Sie bekommen eine doppelte Chance. Erstens: Sie sorgen für die Arbeitsfähigkeit Ihres Systems, indem Sie darauf achten und entsprechend moderieren, dass das Thema des Kollegiums methodisch bearbeitet wird. Das ist eine strategisch erstrangige Aufgabe für die Leitung. Wenn Sie das Kollegium für methodische Arbeit gewinnen, ist es bei weiterer Übung für jedes Thema gewappnet. Sie machen sich damit zuständig für das WIE, fördern die methodische Kompetenz des Kollegiums und akzeptieren dafür (zum Ausgleich) das Thema des Kollegiums für den Einstieg in diesen Prozess. ${ }^{48}$

Der Schulforscher Holtappels $(2010,102)$ setzt auf systematische Organisationsentwicklung und fordert: „Bedürfnisse der Schulmitglieder sind zu berücksichtigen und Überzeugung für Innovation wird erforderlich, neben grundlegender Innovationsbereitschaft und Akzeptanz für das Schulkonzept und die innovativen Vorhaben. Leitbild-Entwicklung und orientierende Ziele in den Schulen werden als Voraussetzungen für Wandel benötigt.“

Nach unserer Erfahrung sind generelle Innovationsbereitschaft und positive Erfahrungen mit Leitbild-Entwicklung keineswegs vorauszusetzen. Vielmehr sehen wir im hier vorgeschlagenen Vorgehen den Einstieg in die Erarbeitung von Leitbild und Schulkonzept. Fangen Sie mit einem vom Schulkollegium akzeptierten Thema an, tun Sie alles für einen motivierenden intensiven Prozess, und setzen Sie auf Fortsetzung dieses Prozesses und kontinuierliche Überarbeitung und Ergänzung der ersten Ergebnisse.

47 Dazu gibt es einen Online-Fragebogen von Schaarschmidt und Kieschke (2007). ABC-L ist der Fragebogen für die ganze Schule; AVEM erfasst die individuelle Lehrereignung und -gesundheit. Fundort im Internet: http://vbe.de

48 Ihre zweite Chance bekommen Sie bei Schritt 8 in Abschnitt 7.4. 


\subsection{Kollegiumsklausur als Einstieg in die Erarbeitung einer Vision}

Die Arbeit mit dem Konsensverfahren haben meine Frau und ich mehrfach erprobt, mit großen Kollegien, mit gutem Erfolg. Glücklicherweise haben praktisch alle Schulen die Möglichkeit, einen Klausurtag einzuplanen, der für strategische Arbeit genutzt werden kann. Angenommen also, Sie haben ein Thema gefunden, das auf allgemeines Interesse stößt. Sie haben einen Klausurtag für die Bearbeitung dieses Themas organisiert. Wie könnten Sie anfangen?

Welches Thema auch immer ansteht, in jedem Fall soll es mit dem Gesamtsystem Schule zu tun haben. Damit ist die Dimension Systemdenken im Blick, die „fünfte Disziplin“ bei Senge. Möglicherweise erwartet das zur Klausur versammelte Kollegium eher reserviert, was da nun auf es zukommt. Wählen Sie also einen passenden Impuls, der alle Beteiligten positiv auf das Thema und auf den Blick aufs Ganze einstimmt. Einige Möglichkeiten:

- Sie könnten die amüsante Geschichte vom Gartenteich des französischen Ministers erzählen (s.o.), die Stichworte Struktur und Kultur mehrfach einfließen lassen und so dazu animieren, den Blick auf die eigene Schule zu richten.

- Sie könnten auch oder stattdessen an vier etablierte Qualitätsmerkmale von Organisationen erinnern: Struktur-, Prozess-, Ergebnisqualität und - zusätzlich Orientierungsqualität und dazu jeweils kurze Erläuterungen geben. Näheres dazu in einem Arbeitsblatt (Download 11).

- Gute Erfahrungen habe ich mehrfach, auch im Bereich der Wirtschaft, mit einem recht differenzierten Modell gemacht, das einen schnellen Überblick über typische Themen in Organisationen ermöglicht: mit dem Organisationsdiagramm nach Eric Berne (1979, 85 ff; Grafik 10). Es lässt sich ohne viel Aufwand auf einem Flipchart präsentieren und erläutern.

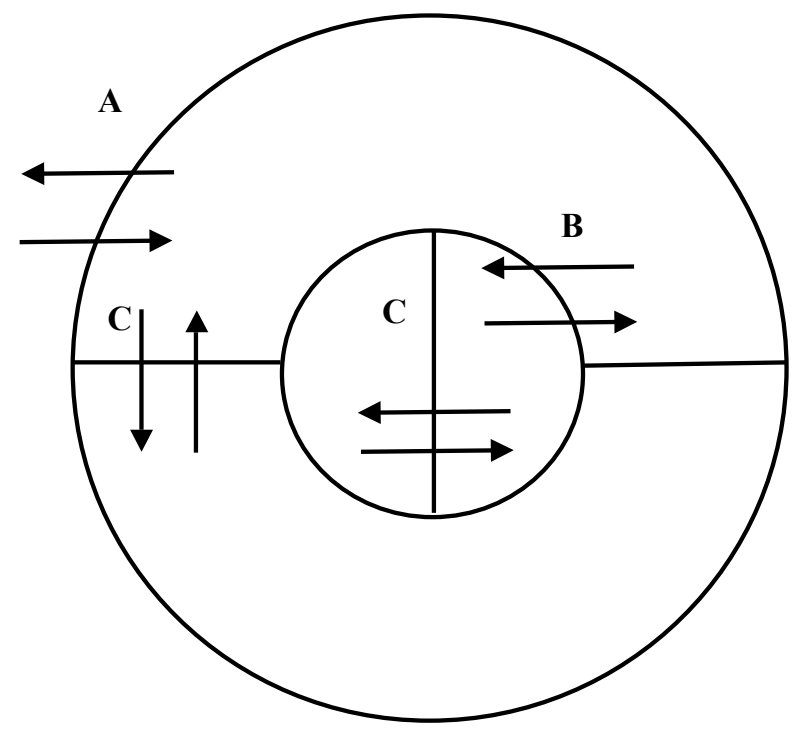

Grafik 10: Organisationsdiagramm nach E. Berne 
Grundlegend für das Modell sind zwei Hauptgrenzlinien: die Abgrenzung des Systems (in diesem Fall: der Schule) von der Umwelt, und die Abgrenzung der Leitungsregion von der Region der Geleiteten. An beiden Grenzen gibt es Einflüsse von außen nach innen und von innen nach außen.

An der ,äußeren Hauptgrenzlinie“ grenzt sich die Organisation gegenüber der Außenwelt ab. Sie definiert, wer zum System gehört und wer nicht. Über diese Linie hinweg kommuniziert das Unternehmen mit der Umgebung. Charakteristische Leitfragen dazu:

- Sind die Kriterien der Systemzugehörigkeit klar? (Wichtig: Schülerinnen und Schüler sind nicht Teil des Systems Schule, sondern dessen Nutzer. Ein guter Schulvertrag mit Unterschrift trägt zur Klärung der Schülerrolle bei und bietet eine gute Grundlage in Konflikten. Ähnlich gilt das für Eltern.) ${ }^{49}$

- Wofür ist die Schule überhaupt da? Auf welche Erwartungen und Forderungen der Eltern zur Förderung der SchülerInnen muss die Schule sich einstellen?

- Was erwartet die Gesellschaft, die Universität, die Wirtschaft? Wie sieht die Antwort der Schule auf diese Erwartungen aus?

- Wie sorgt die Leitung dafür, dass die Primärziele des Systems im Blick sind und erfüllt werden?

- Inwieweit sind die Mitglieder des Systems loyal gegenüber der eigenen Organisation?

Die „,innere Hauptgrenzlinie“ unterscheidet die Leitungs- von der Mitarbeiterregion. An dieser Grenzlinie entscheidet sich, ob bzw. inwieweit die Leitung die Führungsfunktionen im System glaubwürdig und effektiv wahrnimmt und welche Akzeptanz ihr seitens der Mitarbeiterinnen entgegengebracht wird. Leitfragen dazu:

- Ist die Leitungsregion besetzt, oder besteht ein Leitungsvakuum? (Ein Vakuum besteht auch, wenn die Stelle besetzt, aber nicht verantwortlich wahrgenommen wird!) In welcher Weise erfolgt die Wächterschaft über Strukturen und Prozeduren?

- Inwieweit werden strategische Aufgaben und operatives Geschäft voneinander unterschieden und getrennt voneinander wahrgenommen?

- Wie sieht die Beziehung zwischen Leitung und Geleiteten derzeit aus? ${ }^{50}$ Wie wird hierarchie- und bereichsübergreifend kooperiert bzw. Kooperation verhindert?

49 Wenn in Schulkonferenzen Schülerinnen, Schüler und Eltern stimmberechtigt z. B. über pädagogische Konzepte mit entscheiden sollen, scheint mir die äußere Hauptgrenzlinie porös zu sein. Mitglied des Systems Schule ist man m.E., wenn man durch die Arbeit in der Schule sein Gehalt verdient. Wenn man die Außengrenze des Systems Schule anders definiert, hat das Folgen für die Wahrnehmung von Verantwortung z.B. in Konflikten. In manchen Schulkonferenzen hat die Schulleiterin kein Stimmrecht! Meine Empfehlung: Klären Sie die von Bundesland zu Bundesland möglicherweise variierende Rechtslage mit Hilfe von Experten. Einen wichtigen Überblick für freie Schulen bietet die Juristin H. Sattler (2013); s. u.13.2. Beteiligung ist wünschenswert und auch ohne Stimmrecht möglich: s.u. 9.5.2.

50 „An ihrem ersten Tag als Direktorin der Helene-Lange-Schule sah Enja Riegel schwarz. Das Kollegium kam in Trauerkleidung. Ausnahmslos. Die Riegel sollte es nicht werden! Solchen 
Jeder Themenbereich kann konstruktiv oder destruktiv gelebt werden. Wenn Konflikte im B-Bereich dominieren, gerät die Bearbeitung der A-Themen in Gefahr. ${ }^{51}$ Manche Schulen stehen aufgrund schwerer B-Problematik am Abgrund.

An den „Nebengrenzlinien“ kann beobachtet werden, ob bzw. inwieweit Arbeitsbeziehungen professionell gestaltet werden und die Betreffenden in der Lage und willens sind, persönliche Animositäten zu Gunsten der Auftragserfüllung zurückzustellen. Da geht es um Kooperationsprozesse und Konflikte im Kollegium bzw. in der Leitung (wenn die Leitung aus mehr als einer Person besteht). Fragen dazu:

- Welche Unternehmenskultur wird gepflegt?

- Welche Kooperationsstrukturen und -abläufe gibt es? Wie werden Spannungen und Konflikte ausgetragen?

- Welche „geheimen Verträge“ bestimmen Abläufe und Klima?

- Welche dysfunktionalen Kommunikationsmuster bestimmen hierarchie- und bereichsübergreifend die Kommunikation ${ }^{52}$

Als Einstimmung sind das zu viele Details; eine Skizze auf Flipchart und zu jedem Themenpunkt ein paar mündliche Erläuterungen genügen. Die hier gegebene ausführliche Darstellung ist bereits als Beitrag zur fünften Disziplin, zum „Systemdenken" gemeint, das im 8. Kapitel behandelt wird. Für die laufende Arbeit an der Schulentwicklung kann dies Modell immer wieder als hilfreiches Diagnoseinstrument genutzt werden.

Wenn Sie eins der genannten Modelle als Einstimmung benutzen, vermeiden Sie den Nachteil eines „Kaltstarts“ zu Beginn der Klausur. Sie lenken den Blick aufs Ganze, laden ein, die Schule aus innerem Abstand, aus der Vogelperspektive wahrzunehmen, und geben damit die Möglichkeit, auch heikle Aspekte in der schulischen Öffentlichkeit anzusprechen.

\subsection{Partizipative Erarbeitung einer Vision mit dem Konsensverfahren}

Sie haben gelernt, strikt und klar zu moderieren. Sie haben sich auf ein Schulentwicklungsthema geeinigt, das das Interesse des Kollegiums aufnimmt. Ihre erweiterte Schulleitungsgruppe hat sich mit Ihnen auf die Klausur vorbereitet und wird Sie in verabredeter Weise unterstützen. Falls nicht, wäre dieser Schritt zuerst dran. Ein Arbeitsraum steht zur Verfügung, in dem wechselnde Kleingruppen schnell

Protest hatte es in einer Schule noch nicht gegeben. Fast 20 Jahre später bedankte sich das Kollegium zur Pensionierung ihrer Schulleiterin mit einem Fest, das eine deutsche Schule wohl noch nicht nicht erlebt hat.“ (Reinhard Kahl in: Riegel 2004, 236f) Zuwendung am 1. Tag: unbedingt negativ! Wie Enja Riegel durchgehalten hat, ist lesenswert!

51 Die A-, B- und C-Themen in Bernes Modell beziehen sich auf die Grenzlinien im System und sind nicht mit den Themen der Eisenhower-Box zu verwechseln: s. o. 7.3.

52 Diesen von mir etwas gekürzten und ergänzten Überblick verdanke ich einem unveröffentlichten Arbeitspapier von Thomas Weil. 
zusammengesetzt werden können, in dem Tische die Kommunikation nicht verhindern. Ich favorisiere ein „Kneipensetting“: kleine Tische für je sechs Personen, an denen man zu zweit, zu dritt und zu sechst diskutieren kann. ${ }^{53}$ Leitidee dabei: Große Gruppen klein machen (mit R. Cohn 2008)!

Mit ihrer kurzen Einstimmung haben Sie gespannte Aufmerksamkeit erzeugt. Wie es jetzt geordnet und interaktiv weitergehen kann, haben wir in jedem Kurs geübt; ein Beispiel stelle ich Ihnen vor, zu einem Thema, auf das der Kurs sich für das Experiment geeinigt hatte:

Ansage: Konzentrieren Sie sich bitte auf Ihre Frage: „Was ist eine gute Schule? Wie sollte eine Schule sein, in die ich mein Kind gern schicken würde?“

Schritt 1: Einzelarbeit: Notieren Sie auf ein Kärtchen drei Kriterien, die Ihnen wichtig sind (jeweils ein Stichwort und einen Satz dazu; ca. 7 Minuten).

(Angenommen, Ihr Kollegium besteht aus insgesamt 48 Personen, dann sind jetzt maximal $3 \times 48=144$ Ideen notiert. Diese Komplexität ist zu reduzieren und zu diskutieren.)

Schritt 2: Bilden Sie Zweiergruppen; Aufgabe: Einigen Sie sich auf drei Punkte (15 Minuten Zeit).

Schritt 3: Bilden Sie zwölf Vierergruppen; Aufgabe: Einigen Sie sich auf drei Punkte (20 Min. Zeit).

Schritt 4: Bilden Sie Achtergruppen; Aufgabe: Einigen Sie sich auf drei Punkte (maximal 45 Min. Zeit). [Jetzt sind maximal $8 \times 3=24$ Punkte zu erwarten.]

Schritt 5: Sammlung der Punkte im Plenum, nummeriert, auf Flipchart. Reihum nennt jede Gruppe jeweils nur den ihr wichtigsten Punkt; Doppelungen werden erkannt und nicht notiert. (Wer diesen Punkt moderiert, sollte Assistenz bekommen: Eine Person moderiert strikt, bestimmt, deutlich; eine andere Person schreibt, möglichst flott.)

Schritt 6: Zeit für eine Kaffeepause. Ihr Kollegium hat intensiv interagiert. Wahrscheinlich gehen die Diskussionen in der Pause noch weiter. Überlegen Sie in der Pause mit ein, zwei „Assistentinnen“, welche Punkte zusammengehören und auf welchen Leitbegriff die einzelnen Ideen sich bringen lassen. Kriterium: Die Einzelpunkte sollten trennscharf sein, sich also deutlich voneinander unterscheiden.

Wenn Sie dabei auf zwölf Kategorien kommen (den zwölf Uhrzeiten entsprechend), ist das für die weitere Darstellung praktisch. Falls Sie weniger als zwölf Punkte erreichen, kann man Aspekte nachschieben, die in den Kleingruppen zurückgestellt wurden, aber doch sinnvoll sind.

Zum bisherigen Verfahren: Kollegien sind unterschiedlich groß. Bei 24 Personen hätten Sie erst $12 \times 2$, dann $6 \times 4$ und $3 \times 8$ Personen in den Gruppen. Dann

53 Auch die Anordnung der Tische im Klassenraum kann Lernen erschweren oder erleichtern. „Schüler, die in langen Reihen hintereinander mit dem Blick zur Tafel gerichtet sitzen, werden weniger miteinander diskutieren als auf die Fragen des Lehrers antworten. ... In der HeleneLange-Schule stehen die Tische deshalb in Tischgruppen zusammen, die sich um die Mitte des Klassenraumes herumgruppieren. ... Die Sitzordnung kann ständig variiert werden, je nachdem ob in Gruppen oder still allein gearbeitet wird, ob alle miteinander diskutieren oder einem Vortrag zuhören.“ (Riegel 2004, 191; vgl. Anm. 59) 
können Sie von Anfang an vier Kriterien sammeln lassen, so dass Sie am Ende $3 \times 4$ Kriterien aus den Achtergruppen bekommen. Überlegen Sie vorher gut, wie Sie die Gruppengrößen bestimmen, insbesondere bei ungerader Teilnehmerzahl; das sollte nicht zu zeitaufwendigen Diskussionen im Plenum führen.

Schritt 7: Überarbeiten Sie die gesammelten Punkte im Sinne Ihrer Pausen-Überlegungen. Im Plenum wäre das ein Zeitfresser. Seien Sie nicht zu skrupulös, unterbinden Sie detaillierte Begriffsdefinitionen. Kein Text wird jemals so eindeutig sein, dass Diskussionen darüber sich erübrigen. ${ }^{54}$ Das bisherige Verfahren hat genau das gefördert: dass alle Mitglieder eines großen Kollegiums engagiert ihre eigenen Ideen und die der anderen diskutieren.

Schritt 8: Hier folgt als Beispiel das Ergebnis einer Weiterbildungsgruppe, für alle sichtbar auf Flipchart notiert:

1. Handlungskompetenz der Schülerinnen: Ein Ort, der es jedem ermöglicht, seine/ihre größte Handlungskompetenz auszubilden.

2. Individuelle Förderung: Ein Lernort für alle, an dem individuelle Entwicklung gefordert und gefördert wird.

3. Guter Unterricht (fachlich, methodisch, pädagogisch) im Gesamtkonzept.

4. Konfliktmanagement: Ein Ort, an dem die vielfältigen Interessen der Beteiligten erfolgreich ausgehandelt werden.

5. Klare Ziele: Gute Entwicklungs- und Identifikationsmöglichkeiten und klar erkennbare Profile und Ziele.

6. Kooperation nach außen: Eine Schule, die in Entwicklung ist und mit anderen kooperiert.

7. Christliche Identität: Ein Ort, an dem die SchülerInnen sich im Sinne der christlichen Werte weiter entwickeln.

8. Transparente Rahmenbedingungen: Eine Schule, die verlässliche Rahmenbedingungen bietet.

9. Kultur der Annahme: Bietet die Möglichkeit der Identifikation aller Beteiligten mit der Schule; gute Atmosphäre.

10. Teamfähigkeit: Hat engagierte und fachkompetente MitarbeiterInnen.

11. Selbstorganisation: Stärkung der Selbstkompetenz aller Beteiligten.

12. Hohe Identifikation: Ein Ort, an dem eine angenehme Atmosphäre herrscht, so dass sich jeder mit ihm identifiziert.

54 „Die Bedeutung eines Satzes entsteht nicht aus dem bloßen Aufaddieren jeder einzelnen Wortbedeutung, und die Bedeutung eines Textausschnitts entsteht nicht aus dem Aufaddieren jeder einzelnen Satzbedeutung. Bedeutung entsteht vielmehr aus dem Gebrauch der Sprache durch Menschen." (de Shazer 1998, 73 mit Bezug auf Wittgenstein) Daraus folgert WylerKrisch (2001, 3): „Damit muss man sich verabschieden von der Idee, dass ein Wort eine Wahrheit abbildet. Die dadurch entstehende Ungenauigkeit kann zu vielen Missverständnissen führen. Es ist aber auch gerade dieser Ungenauigkeit zu verdanken, dass man über Sprache Fortschritte erzielt. Sprache ist in sich eine Paradoxie. Dies macht es offenbar möglich, dass Menschen sich verstehen und im Gespräch Neues entwickeln. Man kann also sagen, dass gerade die Unschärfe der Sprache eine Weiterentwicklung erlaubt.“ 
Die Vorgabe war: Tun Sie so, als ob Sie ein Kollegium wären. Immer wieder überraschend, aber wohl typisch: Beziehungsaspekte stehen im Vordergrund. Strukturelle Aspekte sind relativ wenig im Blick, obwohl wir die Dimensionen der Lernenden Organisation, die vier Qualitätskriterien und auch das Berne'sche Organisationsmodell vorher besprochen haben! Interessant auch: Christliche Werte werden als Hauptmerkmal der christlichen Identität gesehen. Das Thema verdient ein eigenes Kapitel (s. u. Kap. 14)

Die „Unterbelichtung“ der Struktur sollte mit der Gruppe diskutiert werden. Sie selbst haben natürlich die Möglichkeit, am Konsensverfahren teilzunehmen und solche strukturellen Aspekte kräftig zu vertreten, so dass die am Ende auch vorkommen; das ist Ihre zweite Chance. Wäre ich als Leitung beteiligt, würde ich mich z.B. für ein partizipativ verbindliches Leitungskonzept einsetzen, für eine Konferenzstruktur, die alle Systemmitglieder an der Schulentwicklung beteiligt usw. Diese strukturellen Aspekte werden durchweg unterschätzt; sie sind aber für die Arbeitsfähigkeit des Gesamtsystems absolut wichtig. Finden Sie dafür überhaupt keine Resonanz, empfiehlt es sich, solche Themen auf später zu verschieben. Kein Grund zur Resignation: So ein Klausurtag ist der Anfang von Schulentwicklung, die Initialzündung für einen fortlaufenden Prozess. Das Verfahren liefert nach unserer Erfahrung schon am Anfang reichlich Arbeitsaufgaben.

Schritt 9: Das Ergebnis eignet sich für eine erste Selbstdiagnose. Alle übertragen die Schlagwörter in das Arbeitsblatt „Steuerrad“ (Download 12), das für alle kopiert wurde (Grafik 11). Alle kreuzen pro „Uhrzeit“ an, in welchem Ausmaß die jeweilige Kategorie in der Schule derzeit realisiert wird (optimal wären $100 \%$, minimal: $0 \%$ ). Die Blätter werden eingesammelt und - z.B. während der Mittagspause - von einigen mathematisch versierten Personen zu einem Durchschnittsprofil verarbeitet.

Dies Durchschnittsprofil können sie für das Plenum visualisieren, indem Sie das „Steuerrad“ von einer grafisch begabten Person auf Flipchart übertragen lassen. Bei strikter Moderation lässt sich dieses Zwischenergebnis an einem halben Tag erreichen.

Mit den Differenzen zwischen IST und SOLL haben Sie eine Selbstdiagnose Ihres Kollegiums, einen Überblick über Stärken und Schwächen und damit auch einen Ansatzpunkt für die Bearbeitung von Baustellen, von strategischen Themen, deren Bearbeitung die Schulentwicklung Ihrer Schule, Ihrer spezifischen Schule, voranbringen - erreichbar an einem Vormittag!

Schritt 10: Die zweite Hälfte des Klausurtages dient der anfangsweisen Bearbeitung von Baustellen. Wenn Sie nach der „Halbzeitpause“ das erarbeitete Durchschnittsprofil auf Flipchart präsentieren, können Sie schnell eine Rangfolge aufstellen: Oben die Faktoren, in denen Ihre Schule stark ist, unten die Baustellen. Die Baustellen geben die Richtung für die weitere strategische Arbeit an. Und das erarbeitete Steuerrad ist eine geeignete Grundlage für die Formulierung einer gemeinsamen Vision. (12 Punkte lassen sich schön darstellen; es können aber auch weniger oder mehr sein.) 


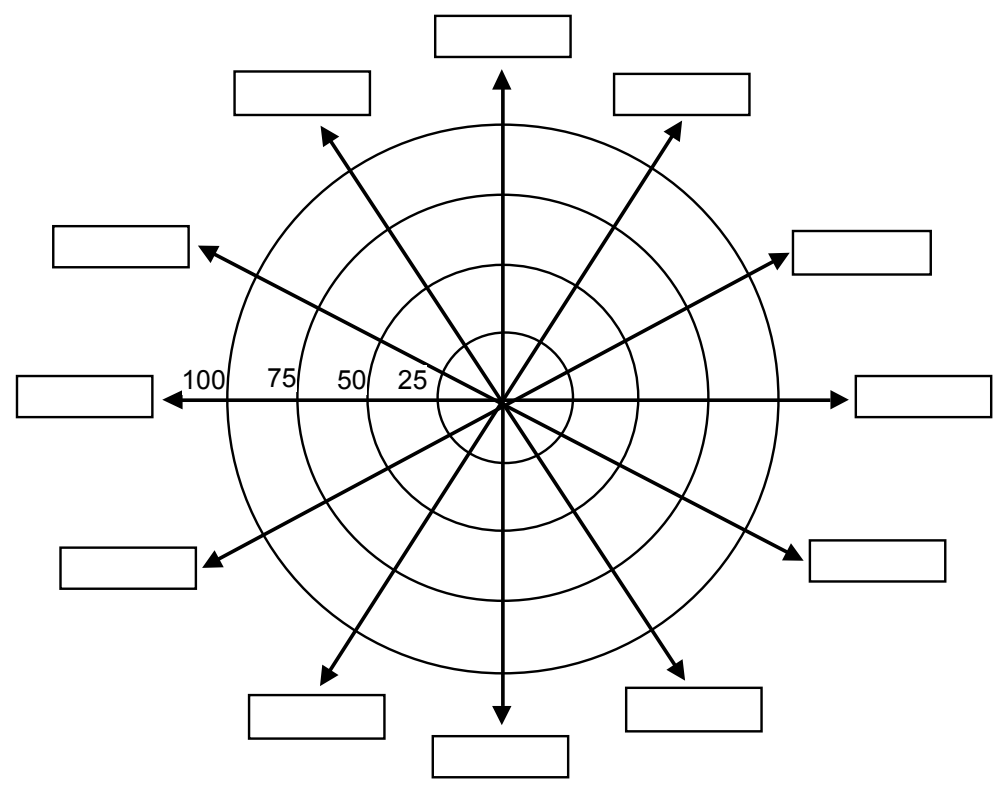

Grafik 11: Arbeitsblatt zur Einschätzung der ermittelten Qualitätsmerkmale nach IST und SOLL

Grundsätzlich empfiehlt es sich sehr, zu jedem der zwölf Punkte drei bis fünf erläuternde Sätze formulieren zu lassen. Diese Textarbeit sollte aber nicht im Rahmen einer Klausur stattfinden. Bei entsprechender Kollegiumsgröße können Sie jeweils zwei Personen mit der Formulierung eines „Uhrzeitenpunktes“ beauftragen, so dass die Kriterien konkret und griffig werden.

Diese Rohtexte kann später eine kleine Redaktionsgruppe überarbeiten; der Textentwurf wird dann dem Kollegium mit der Bitte um schriftliche Korrekturen oder Ergänzungen vorgelegt. Auf diese Weise können Sie die in Lehrerkollegien drohende Gefahr vermeiden, durch hohe Ansprüche an „eindeutige“ Begriffsklärungen und ausgefeilte Formulierungen - und das auch noch im Plenum (!) dringend nötige Zeit für konkrete Weiterarbeit an den ermittelten Baustellen zu verlieren (s. o. Anm. 54: Wyler-Krisch).

Auf diese Weise lässt sich schnell ein Entwurf für ein schriftliches Konzept erarbeiten, das nach der redaktionellen Überarbeitung den derzeitigen Stand einer gemeinsamen Vision des Kollegiums erkennen lässt. Der Text muss nicht perfekt sein. Wichtig ist, dass er nicht in Schubladen verschwindet, sondern immer wieder zur Auswertung der Arbeit als Maßstab benutzt wird und in diesem Prozess auch laufend ergänzt und aktualisiert wird. Einer Schule ist es gelungen, das Ergebnis im DIN-A4-Format farbig unterlegt darzustellen und zu laminieren, so dass man bei der Auswertung von Teamsitzungen schnell einen Blick darauf werfen kann.

Verglichen mit aufwendigen Konzeptentwicklungsprozessen, von denen uns berichtet wurde, ist dies ein sehr zeitökonomisches Verfahren: aus eigener Kraft, 
proaktiv, durch geordnetes gemeinsames Nachdenken entwickelt und darum auch geeignet, als gemeinsame Orientierung akzeptiert und genutzt zu werden.

Schritt 11: Wenn die Baustellen identifiziert sind, sind Prioritäten festzulegen: Welche Baustellen sollen zuerst bearbeitet werden? In großen Kollegien kann man gut mehrere Baustellen parallel bearbeiten lassen; sechs bis zwölf Personen können eine Projektgruppe bilden. Auf diese Weise lassen sich alle (!) aktivieren. Ein kleineres Kollegium wird sich entsprechend weniger Projekte vornehmen können.

Entscheidend für die Weiterarbeit ist jetzt, dass die Projektgruppen ihr Thema methodisch bearbeiten. Das stärkt die Kompetenz eines Kollegiums, strategische Themen eigenständig zu bearbeiten. Dazu eignet sich hervorragend die Arbeit mit den ,sechs Schritten der Problemlösung“ nach Gordon. Wie das geht, wurde oben in Abschnitt 5.2.2.2 ausführlich dargestellt. Wichtig für die Vorbereitung: Sie brauchen für jede Gruppe Möglichkeiten zur Visualisierung; am einfachsten geht das mit Flipcharts.

Damit meldet sich eine neue Notwendigkeit: Jede Gruppe sollte methodisch moderiert werden. Bei diesem Schritt meldet sich oft ein hinderliches mentales Modell: „Ich soll Kollegen moderieren? Das akzeptieren die doch nicht!“ Hier gilt es standzuhalten. Doch, Sie können das, und das wird auch akzeptiert. Damit das geht, sollten Sie vorab im Plenum für alle das Arbeitsblatt mit den sechs Schritten verteilen und kurz erläutern. (Download 3)

Durch laufende Übung wächst die Moderationskompetenz im Kollegium. Sinnvoll ist es auch, die Mitglieder der erweiterten Schulleitung auf die Moderationsaufgabe anzusprechen und (mit Download 4) vorzubereiten. Im Leitungsgremium haben sie - hoffentlich - schon erfahren, wie sich mit Hilfe der ,sechs Schritte" komplexe, strategische Themen methodisch bearbeiten lassen.

Schritt 12: Wie weit die einzelnen Projektgruppen mit ihrem Thema in der zweiten Halbzeit des Klausurtages kommen, hängt von der Komplexität des Themas ab, natürlich auch von der Fähigkeit der Gruppe, konzentriert und methodisch zu arbeiten. Es ist eher unwahrscheinlich und auch nicht nötig, am Ende der Klausur fertige Ergebnisse vorzuweisen. Die Gruppen können kurz den erreichten Stand im Plenum darstellen. Entscheidend ist, wie es weiter geht.

Der erreichte Zwischenstand sollte auf jeden Fall schriftlich festgehalten werden, so dass die Gruppen bei einem weiteren Treffen wieder gut ins Thema einsteigen können. Die Flips sind also aufzubewahren. Besser wäre es, die Flips abzuschreiben und die Datei an die Gruppenmitglieder zu verteilen. Noch besser: Mit Hilfe der elektronischen Medien (Intranet o. ä.) den Stand der Diskussion auch den anderen Gruppen zur Verfügung zu stellen, so dass man voneinander erfahren kann, was und wie im System Schule diskutiert wird, und dazu auch Anregungen geben kann. Falls diese technischen Möglichkeiten fehlen, wäre die Erarbeitung eines Informationsverfahrens ein gutes Thema für eine Projektgruppe. 


\subsection{Das Modell „Partizipativ-kontinuierliche Schulentwicklung"}

Ein Klausurtag der beschriebenen Art kann der Anfang partizipativ-kontinuierlicher Schulentwicklung sein. Bis zur methodischen Bearbeitung der Baustellen wurde das Verfahren erläutert. Irgendwann sind die Projektgruppen so weit, dass sie ein Ergebnis im Sinne eines Lösungsvorschlags präsentieren können - in einer Gesamtlehrerkonferenz (GLK) oder in einer weiteren Klausur. In dieser Phase droht die Gefahr, dass das Plenum durch formale Abstimmung über Annahme oder Ablehnung entscheidet. ${ }^{55}$ Das führt nicht selten dazu, dass das Ergebnis längerer Gruppenarbeit in wenigen Minuten von einer Mehrheit abgeschmettert wird, die sich mit der inhaltlichen Problematik kaum oder gar nicht beschäftigt hat. Als Folge wird die Motivation, sich an solchen Projekten zu beteiligen, gegen Null gehen das Ende gemeinsam getragener Schulentwicklung.

Um das zu vermeiden, empfehlen wir, die Ergebnispräsentation als ersten Lesung aufzurufen, die im Plenum zur Diskussion aufgerufen wird. Kurze Rückfragen zum Verständnis werden beantwortet. In Kleingruppen wird der Lösungsvorschlag diskutiert (15-20 Minuten). Dann wird als Spielregel eingeführt: Wer konkrete Verbesserungsvorschläge zu machen hat, reicht die schriftlich (!) bei der Projektgruppe ein. Die Projektgruppe wird die Vorschläge prüfen und nach Möglichkeit berücksichtigen. Der überarbeitete Text wird dann in zweiten Lesung vorgetragen; vorgenommene Veränderungen werden kurz erläutert. Wenn nötig, kann nochmals kurz in Kleingruppen diskutiert werden. Konkrete konstruktive Einwände sind dann an die Schulleitung zu richten, die in einer regulären Sitzung (nicht während einer Klausur!) ihre Entscheidung trifft (s. Grafik 12).

Dies Verfahren empfiehlt sich auch für das Vorgehen der Redaktionsgruppe, die den Text zu den Schlagwörtern des Steuerrads erarbeitet. Nochmals warne ich (mit Steve de Shazer und aus Erfahrung) vor zu perfektionistischer Begriffsklärung: „Die Bedeutung eines Satzes entsteht nicht aus dem bloßen Aufaddieren jeder einzelnen Wortbedeutung, und die Bedeutung eines Textausschnitts entsteht nicht aus dem Aufaddieren jeder einzelnen Satzbedeutung. Bedeutung entsteht vielmehr aus dem Gebrauch der Sprache durch Menschen." (Vgl. Anm. 54) Auch eine schriftlich fixierte gemeinsam erarbeitete Vision dokumentiert nur einen aktuellen Konsens und sollte regelmäßig ausgewertet, überarbeitet, vor allem aber genutzt werden.

Ist das alles geschafft, haben Sie den ersten Durchlauf partizipativ-kontinuierlicher Schulentwicklung beinahe hinter sich gebracht. Nicht ganz, wie Grafik 12

55 Ein extremes Beispiel (Canerik 2020): Die Autorin, selbst Lehrerin, vermisst Zivilcourage bei jungen Lehrkräften. „Man merkt das zum Beispiel. wenn es bei Lehrerkonferenzen um wichtige Entscheidungen geht. Die Abstimmungen sind offen, die Schulleitungen sehen, wer wie abstimmt. Viele Lehrer haben deshalb Angst, eine ,falsche 'Stimme abzugeben. Ich weiß von Fällen, wo Zukunftsentscheidungen für eine Schule - beispielsweise zum Schulprofil, zur Inklusion oder zum Umgang mit Smartphones - einfach durchgewinkt wurden: 14 JaStimmen, sechs Nein-Stimmen und 42 Enthaltungen. " Das Problem ist hier die Angstkultur, die eine gründliche Debatte verhindert und die durch Anonymität bei Abstimmungen nicht wirksam entschärft wird. 


\section{Partizipativ-kontinuierliche Schulentwicklung}

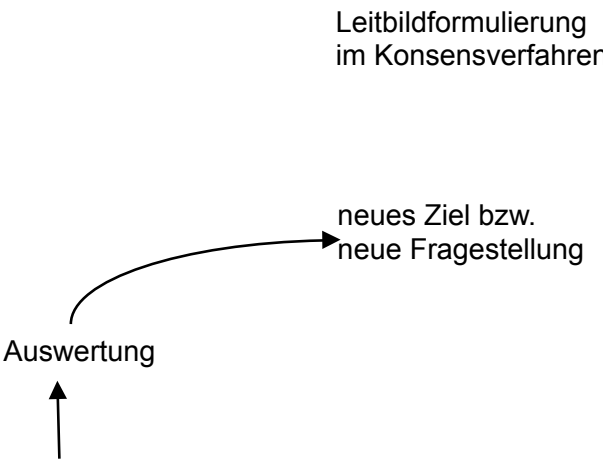

Umsetzung

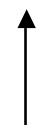

Einarbeitung der schriftlichen

Resonanz aus der Gesamtkonfe-

renz; 2. Lesung und

Entscheidung

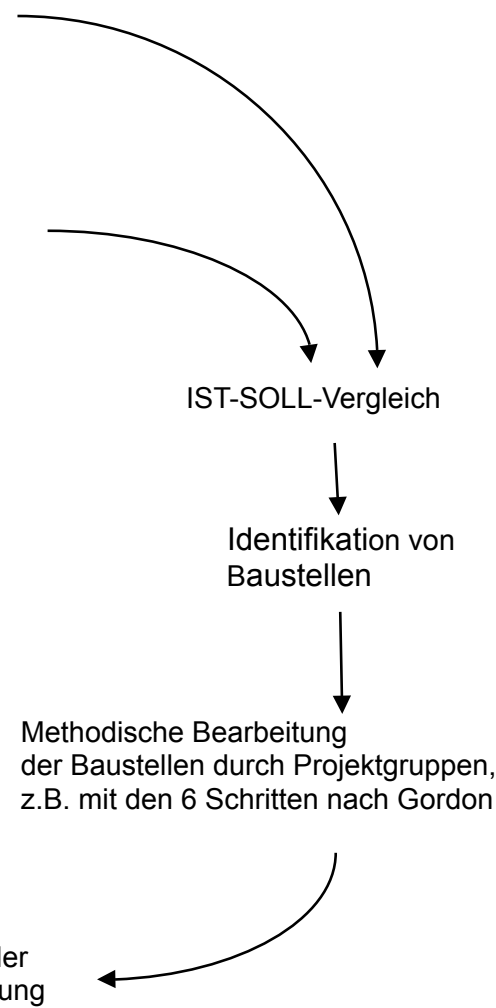

Ergebnispräsentation in der
Gesamtkonferenz: 1. Lesung

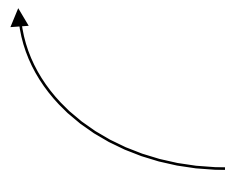

Grafik 12: Partizipativ-kontinuierliche Schulentwicklung (PKS)

zeigt: Nach der Entscheidung folgt die Umsetzung, deren Wirksamkeit nach einer verabredeten Zeit auszuwerten ist. Auf dieser Auswertung aufsetzend wird dann ein neues Ziel gewählt. Dies Vorgehen, das jeweils auf den vorigen Ergebnissen aufbaut, nennt Rolff (2019, 33) „rollende Planung“ bzw. „rollendes Change Management". Wenn das zur selbstverständlichen Arbeitsweise Ihrer Schule geworden ist, haben Sie Grund zum Feiern: Dann sind Sie im immer noch kleinen Klub der Lernenden Schulen angekommen.

Covey (1995, 45 f) vergleicht solche paradigmatischen Veränderungen mit der ersten Mondreise. Um den Mond zu erreichen, musste Apollo 11 aus der gewaltigen Schwerkraft der Erde ausbrechen. „Die ersten wenigen Minuten des Starts und die ersten Kilometer der Reise haben mehr Energie verbraucht als die restlichen 400.000 Kilometer in den folgenden Tagen. ... Auch Gewohnheiten haben eine enorme Schwerkraft - mehr als die meisten Leute erkennen oder zugeben würden. ... Das ,Abheben“ bedarf enormer Anstrengungen, aber wenn wir uns erst von der Schwerkraft freigemacht haben, nimmt unsere Freiheit eine ganz neue Dimension an.“ (ebd.) Mein Interesse richtet sich in diesem Buch ganz auf die ,ersten Kilome- 
ter", auf die Frage, wie Sie diese prozesshafte Arbeit an der Schulentwicklung in Gang bringen können.

Das beschriebene Verfahren ist als Modell für Qualitätsmanagement zu verstehen. Es beginnt mit der Zusammenführung der Zielvorstellungen der Lehrkräfte (der Visionen), mit dem Entwurf einer SOLL-Vorstellung. Darauf folgt als Evaluation die kritische Selbsteinschätzung, der Blick auf das IST. Die Differenzen zwischen IST und SOLL stellen die aktuellen Baustellen dar, deren erfolgreiche Bearbeitung das Qualitätsniveau erhöht. Durch selbstkritische Auswertung werden neue Baustellen identifiziert, und so wird der Regelkreis in Gang gehalten. Rolff (2019, 14 f) beschreibt diesen Prozess als ZEIS-Spirale: Ziele klären - Entwerfen (Maßnahmen) - Implementieren - Sichern von Nachhaltigkeit - revidierte bzw. neue Ziele.

Wichtige Punkte dabei: Die Betroffenen machen das selbst! ${ }^{56}$ Interne Evaluation geht vor; spätere externe Evaluation wird so eher akzeptiert. ${ }^{57}$ Bei externer Evaluation ist mit der Neigung der Systemmitglieder zu rechnen, sich positiv darzustellen. Selbstkritik ist unbestechlich. Die selbst erzeugte SOLL-Vorstellung mag nicht umfassend sein, genügt aber - im Sinne des Pareto-Prinzips (s. u. 11.9.1.6) allemal, weil das erste Ergebnis reichlich Baustellen liefert. Perfektionismus an dieser Stelle wäre kontraproduktiv.

Zielorientiertes Handeln, Teamentwicklung und reziprokes Feedback machen nach Rolff $(2017,29)$ die Treiber von Qualität aus. Evaluation als Bestimmung der Differenz von IST und SOLL ist darum notwendige Voraussetzung für zielorientiertes Handeln. Teamarbeit ist in Schulen mannigfaltig angebracht: Klassen- und Jahrgangsteams, Fachteams, Projektteams und Schulleitungsteams. WIE Teams zu Teams werden, wurde im Zusammenhang mit der erweiterten Schulleitung beschrieben (s.o. Kap. 5).

Reziprokes Feedback bezieht sich auf routinemäßige Rückmeldung von Lehrkräften an Schülerinnen und Schüler, und umgekehrt auch auf Rückmeldungen der Schülerinnen und Schüler an die Lehrkräfte. Die Lehrkräfte geben Rückmeldungen zu Lernergebnissen, Lernverhalten, Lernstilen, Stärken und Defiziten, und zwar förderorientiert, professionell, auf keinen Fall abschätzig (Rolff 2017, 31; Näheres zu Feedback s. o. 6.7); die Schülerinnen und Schüler geben Rückmeldungen dazu, wie lehrreich, verständlich, interessant, abwechselnd sie den Unterricht erleben.

56 E. Riegel $(2004,233)$ sah es schon früh als selbstverständlich an, „die eigene Praxis immer wieder zu überprüfen. Haben wir erreicht, was wir erreichen wollten? Ist eingetreten, was wir erhofften? Eine solche Selbstverständlichkeit kann dann zu dem führen, was eine sich ,evaluierende" Schule ausmachen sollte: Nach und nach aus einer nur belehrenden zu einer lernenden Institution zu werden. Eine Schule also, die die Fähigkeit erwirbt, als Institution über sich selbst nachzudenken, sich die eigenen Erfahrungen unbefangen bewusst zu machen und aus ihnen zu lernen.“

57 „Interne Evaluation hat Priorität. ... D.h. die interne Evaluation sollte der externen zeitlich vorangehen; dann entwickelt sich innerhalb der Schule eine Evaluationskultur, die die Schule auch empfänglicher macht für die Ergebnisse und Verarbeitung der externen Evaluation.“ (Rolff 2017, 28) Auch Systeme können blinde Flecken haben. Top-down-Anordnung von Evaluation ist dennoch nicht zu empfehlen; dazu s. u. 9.1 und 9.2. 


\section{Lesetipp}

Rolff (2019): Schulentwicklung - auf den Punkt gebracht. Ein guter, schneller Überblick über partizipativ gestaltete Schulentwicklung, der mich in meiner Darstellung bestärkt hat.

Weitere praktische Überblicke zu unterschiedlichen Themen finden Sie im Literaturverzeichnis: Fehlau (2000), Haeske (2008), Herzlieb (2008), Klein (2008), Mentzel (2001), Schröder (2008), Seiwert (1995), Stein (2008) - jeweils am Großdruck der Reihe erkennbar.

Hiebl und Seitz (2014): 3.4; 6.3 


\section{Kapitel 8: Systemdenken: effektive Konferenzstruktur}

Das beschriebene Konsensverfahren endete mit der Frage, wie und in welchem Rahmen die angefangene Bearbeitung strategischer Baustellen fortgesetzt werden kann. Im Schulalltag führt das leicht dazu, dass die Projektgruppen sich zu unterschiedlichen Zeiten verabreden. Terminabstimmungen werden dann schwierig. Gruppen, die schnell mit ihrem Projekt fertig wurden, werden ,arbeitslos“. Der Gesamtprozess gerät leicht aus dem Blick. Wie ist dem beizukommen? Lesen Sie selbst:

\subsection{Das Neuruppiner Beteiligungsmodell ${ }^{58}$}

Anke Bachmann, Leiterin der Evangelischen Schule in Neuruppin, hat zu Beginn ihrer Leitungstätigkeit einen entschiedenen Schritt riskiert. Sie hat mit ihrer Schule den Schulpreis des Jahres 2012 gewonnen. In einem Follow-up-Kurs hat sie mir ein Interview zu ihrem Vorgehen gegeben:

Frau Bachmann, Sie haben im Weiterbildungskurs berichtet, dass Sie Ihre große Konferenz radikal umstrukturiert haben. Werfen wir zunächst einen Blick zurück in die Vergangenheit: Wie war es vorher? Wie sah die Zeitstruktur aus?

Da waren etwa 40 KollegInnen versammelt, drei Stunden lang, und es kam wenig dabei heraus. Als einziges methodisches Mittel wurde eine Rednerliste genutzt. Effektiv war das nicht.

Das waren also 40 mal 3, insgesamt 120 Arbeitsstunden mit wenig Wirkung. Wie aktiv waren denn die KollegInnen dabei beteiligt?

Im Grunde haben da nur vier Leute diskutiert; der Rest hat das mehr oder weniger über sich ergehen lassen.

Wie wurde moderiert?

Der Schulleiter hat notiert, wer sich meldet, hat eine Rednerliste geführt und die, die was sagen wollten, der Reihe nach aufgerufen.

Wie zufrieden waren die Beteiligten mit diesem Verfahren?

Die große Mehrheit hat immer nur gehofft, dass es bald zu Ende ist; hinterher hat man sich immer sehr unzufrieden geäußert.

Wie kam es dann zur Veränderung?

Als ich die Schulleitung übernommen hatte, war mir klar, dass ich so nicht weitermachen konnte. Aber ich hatte kein fertiges Rezept. Ich hatte richtig Angst vor diesem Termin und hab mir dann so geholfen, dass ich die erste Konferenz kurz gehalten habe, nur eine Stunde. Und ich habe die Zeit dazu genutzt, nur die

58 Ausführliche Informationen zum Neuruppiner Gymnasium unter: https://www.gymnasiumneuruppin.de 
Wünsche zu sammeln, die das Kollegium an die künftige Konferenzkultur hatte. Die Wünsche habe ich einzeln schriftlich festhalten lassen. Da kam eine ganze Menge zusammen. Und das haben wir dann ausgewertet, die beiden Stellvertreter für Gymnasium und Grundschule, der Oberstufenkoordinator und ich.

Was war die entscheidende Veränderung, die Sie dann vorgenommen haben?

Wir wollten die Passivität des Kollegiums in diesen Konferenzen beenden. Also haben wir immer nur ganz kurze Plenumszeiten vorgesehen. Die eigentliche Arbeit lief immer in kleinen Gruppen - nach dem Prinzip: große Gruppen klein machen ${ }^{59}$. Und wir haben geklärt, welche Gremien für welche Themen überhaupt zuständig sind.

Das heißt, Sie haben ein ganzes Konferenzsystem? Wie sieht das aus?

Ja, wir haben unterhalb der Gesamtkonferenz die Fachkonferenzen und außerdem Jahrgangsteams, für jeden Jahrgang ein Team. Und jeder Lehrer und jede Lehrerin ist Mitglied in einem Jahrgangsteam, ich selbst bin auch in einem. Da laufen die Diskussionen, die für die Qualität des Unterrichts wichtig sind.

Und was ist dadurch besser geworden?

Zum einen natürlich die Beteiligung. Jetzt arbeiten alle mit. In den Gruppen kann viel intensiver diskutiert werden als in einem Plenum. Und wir orientieren uns ja an den Themen, die aus dem Kollegium kommen.

Wie wird das jetzige Verfahren im Kollegium akzeptiert?

Anfangs war das nicht einfach. Es gab auch Kritik. Das sei nicht demokratisch entschieden worden, was auch stimmt. Wir haben die Struktur vorgegeben und darauf bestanden, um überhaupt erst Arbeitsfähigkeit herzustellen. Inzwischen hat sich das eingespielt und bewährt.

Wie bereiten Sie diese Gesamtkonferenzen vor?

Wir orientieren uns vor allem an den Themen, die aus dem Kollegium kommen. Das vierköpfige Leitungsteam hat ja eine regelmäßige Konferenz mit allen Fachkonferenzleitungen, und da hören wir, was die KollegInnen bewegt, was dran ist und geklärt oder bearbeitet werden muss. Die Leitungen hören ja ihrerseits in den Fachkonferenzen, wo der Schuh drückt.

Wie wird die Konferenz moderiert?

Es gibt eine Tagesordnung, der die gesammelten Themen zu entnehmen sind, und dann ist ja entscheidend, dass in Kleingruppen gearbeitet wird. Um deren Moderation geht es ja wesentlich. Und da haben wir Fortbildungen organisiert, um das zu lernen, wie man Gruppen sinnvoll moderieren kann.

Fordert das Schulrecht nicht die Behandlung bestimmter Themen in der Gesamtkonferenz? Wie berücksichtigen Sie das in Ihrem Verfahren?

Das ist nur sehr selten wirklich nötig. Und wenn, dann bereiten wir die Beschlüsse in Diskussionsgruppen vor, die ja ein Teil der Gesamtkonferenz sind, so dass im Plenum nur noch formell abgestimmt werden muss. Das Ergebnis der Diskussionsgruppen wird vorgestellt. Grundsätzlich dürfen diese Ergebnisse kritisiert

59 Vgl. Cohn (2008); s. o. Anm. 54 zum „Kneipensetting“. Tausch \& Tausch (1971, 236; 239 ff) empfehlen diese Anordnung auch für Schulklassen, um interaktiven Unterricht zu fördern, so dass zeitweise auch Schülerinnen sich gegenseitig unterrichten können. 
werden; die Kritikpunkte sind aber schriftlich einzureichen. Die werden dann nach Möglichkeit und Sinn berücksichtigt, und dann sind sie beschlossen.

Wie ist der Zeitaufwand für Konferenzen im Vergleich zu früher?

Im Grunde ist der Zeitaufwand gleich geblieben. Wir haben den Mittwochnachmittag als feste Konferenzzeit, jeweils von 14.30 bis 16 Uhr. In dieser Zeit finden turnusmäßig alle Konferenzen statt, die Gesamtkonferenz fünfmal im Jahr, dann die Fachkonferenz-Leitungssitzungen ebenfalls fünfmal im Jahr und die Jahrgangsteams. Einige Termine sind pro Jahr vorgegeben; die restlichen organisieren die Gruppen selbst.

Sie wissen ja, dass wir allen Kollegien dringend regelmäßige kollegiale Beratung in Kleingruppen empfehlen. Welche Chancen bietet die neue Struktur dafür?

Die läuft ebenfalls in diesem Zeitrahmen. Wir orientieren uns dabei am Göttinger Stufenmodell von Heigl und Heigl-Evers und an einem Fallberatungsmodell von Lanker; bei der Bearbeitung von konzeptionellen Themen arbeiten wir mit den „Sechs Schritten der Problemlösung“ von Thomas Gordon (1989).

Was würden Sie Ihren KollegInnen empfehlen, die sich mit dem Gedanken tragen, ihre Konferenz effektiver zu gestalten?

Am Anfang ist eine Bestandsaufnahme der Konferenzkultur wichtig und die Erfassung der Wünsche und Bedürfnisse der KollegInnen. Danach sollte entsprechend eine Konferenzkultur entwickelt werden. Wichtig ist hierbei, das Prinzip der kleinen Diskussionsgruppen zu ermöglichen und dass alle Kolleginnen und Kollegen mit einbezogen werden. Bevor eine Konferenz stattfindet, sind die Zielformulierungen der einzelnen TOPs festzulegen und das entsprechende Setting. Unbedingt zu bedenken ist: Visualisationsmöglichkeiten (Flipcharts, Laptops, Kärtchen, Mindmapping usw.) zu planen und methodische Vorgaben für die Diskussionsführung (z.B. die Place-Mate-Methode) festzuhalten. Die Zusammensetzung der Diskussionsgruppen richtet sich nach den Themen. Wichtig für die Durchführung von Konferenzen sind auch Fortbildungen der KollegInnen bezüglich der Moderationstechniken und der Gesprächsführung.

Welche Fettnäpfchen sollte man im Veränderungsprozess möglichst vermeiden?

Wichtig ist, dass man in den Strukturen der Konferenzen bleibt und die Moderationsrolle nicht verlässt. Wichtig ist auch, auf Zwischentöne während der Konferenzen zu achten. Die Durchführung von Konferenzen und die Themenauswahl sollten immer vorbesprochen werden. Unbedingt ist auch die Partizipation aller im Auge zu behalten.

In einem weiteren Kurs hat Frau Bachmanns Stellvertreterin, Bettina Labahn, das Verfahren zusätzlich erläutert; Auszug aus dem Protokoll:

- Wichtig ist eine klare Vision der Leitung; in diesem Fall: der Schüler/die Schülerin steht im Mittelpunkt der Aufmerksamkeit.

- Die Einführung der neuen Struktur basierte zwar auf einer Kollegiumsbefragung, wurde aber von der erweiterten Schulleitung dann vorgegeben.

- Die Jahrgangsteams umfassen 8-10 Personen; die KlassenlehrerInnen sind gesetzt; die anderen Lehrer binden sich jeweils in ein Jahrgangsteam.

- Die Tagesordnung der Gesamtkonferenz wird auf der Sitzung der Fachkonferenzleiter (mit der Schulleitung) eine Woche vor Konferenztermin festgelegt. Das 
Setting für die Diskussion der Themen wird vorher geplant und in der Einladung benannt.

- Alle Gremientermine werden im Jahreskalender vorstrukturiert; vier Gesamtkonferenzen pro Jahr, jeweils mit kurzem Plenum und anschließenden Arbeitsgruppen. Fachkonferenzen und Jahrgangsteams finden einmal pro Halbjahr statt. Freie Mittwochnachmittage werden autonom genutzt.

- Einmal pro Woche trifft die Stellvertreterin sich in der großen Pause mit den JahrgangsteamleiterInnen.

- Grundprinzip: Große Gruppen klein machen; Informationsteile zeitlich radikal reduzieren; Arbeit in Projektgruppen initiieren; Ergebnisse der Projektgruppen werden im Plenum präsentiert; Verbesserungsvorschläge sind schriftlich einzureichen und werden eingearbeitet. So wird vermieden, dass mühsam erarbeitete Lösungsmöglichkeiten kurzerhand per Abstimmung entwertet werden. (Vgl. Anm. 55)

- Fortbildung in Moderationskompetenz fördert die Qualität der Arbeit in den Projektgruppen.

Ganz übereinstimmend argumentiert W. Deister (2005, $81 \mathrm{ff})$, Seminarleiter für Pädagogik, aufgrund seiner Erfahrungen mit Schulkollegien zugunsten von methodisch moderierten Projektgruppen; monologische Plenumsveranstaltungen werden von den Betroffenen als die größten kollektiven Zeit- und Energiefresser empfunden. Wie kommt es, dass solche deutlichen Verbesserungsmöglichkeiten bisher nur vereinzelt aufgenommen werden?

\subsection{Hindernisse und Wege zur Überwindung}

Das Neuruppiner Konferenzmodell könnte andere Schulen zu eigenen kreativen Ideen inspirieren. Aber da gibt es viele Hindernisse:

Das Hauptproblem ist die Festlegung einer regelmäßigen verbindlichen Zeit für alle, ausgewiesen im Stundenplan. ${ }^{60}$ Diese Zeit gab es in Neuruppin bereits, als A. Bachmann die Leitung übernahm. Sie hat an der Qualität dieser Zeit gearbeitet; die Struktur war schon da. Top down, per Anordnung hätte die Leitung es sicher schwer gehabt, einen regelmäßigen wöchentlichen Termin - und den auch noch nachmittags! - neu einzuführen.

Übrigens: In der Wiesbadener Helene-Lange-Schule wurde längst so gearbeitet; E. Riegel $(2004,228)$ berichtet in wenigen Zeilen, was in vielen Schulen eine dramatische Veränderung wäre: ,Jeden Montagnachmittag treffen sich alle Teams der Schule zu einer zwei- bis dreistündigen Teamsitzung, bei der Projekte vorbereitet, einzelne Abschnitte reflektiert, Präsentationen geplant, aber auch immer wieder Bilanzen gezogen werden. Das Nachdenken über den vergangenen Unterricht ist bei den Jahresbilanzen der Teams, die ein- bis zweimal im Jahr stattfinden, der Ausgangspunkt für weitere Planungen.“

60 Zur Lehrerarbeitszeit vgl. Dormagen et al. (2010); Kern des Problems ist die Orientierung an der stark variierenden Pflichtstundenzahl und der nach oben offene pädagogische Arbeitsauftrag. 
Warum ist es so schwer, eine solche Struktur einzurichten? Ich sehe folgende Gründe:

Die Betroffenen müssten glauben können, dass eine solche zeitliche Struktur mit aktiver Beteiligung aller wirklich zur Berufszufriedenheit und zu einer wünschenswerten Entwicklung der Schule beiträgt. Eine Klausur mit dem beschriebenen Konsensverfahren könnte diese Erfahrung wenigstens anfangsweise vermitteln, wenn sie gut geplant und strikt moderiert wird und zu konkreten Ergebnissen führt.

Dieser wünschenswerte Glaube wird erschwert durch das verbreitete Leiden an Stress, Überlastung, Krankheitszeiten, notwendigen Vertretungsstunden. Und dann noch eine ,zusätzliche“ Konferenz? Wirksame, spürbare Stressentlastung ist ein wichtiges strategisches Thema.

Dass alle Kollegiumsmitglieder für Schulentwicklung zuständig sind und dass ihre berufliche Erfahrung dafür nötig ist, ist kein flächendeckend verbreitetes mentales Modell, obwohl die entsprechende Verpflichtung in Landesgesetzen nachzulesen ist, ebenso im „Handbuch Schulentwicklung“ (2010): Förderlich für Innovation „sind schulweite Aktivierung und Partizipation der Schulmitglieder sowie die Bildung institutionalisierter Teambildungen im Kollegium ... Die Infrastruktur der Arbeitsorganisation soll dafür garantieren, dass Vision und Motivation gestärkt und Innovationsstrategien angewendet werden, womit Prozesssteuerung ins Spiel kommt.“ (Holtappels 2010, 102)

Nicht zuletzt spielen die mit der Privatrolle verbundenen Interessen eine große Rolle: Familienorganisation, Freizeitgruppen usw.

Alles in allem: Angst vor Veränderung?

An diese Hindernisse habe ich gedacht, als ich auf die Godot-Metapher bei Fullan stieß: „Solange die Pädagogen von sich selbst glauben, sie hätten nicht die Kraft, bedeutungsvolle Veränderungen zu bewirken - und auf einen Erlöser namens Godot warten, der sie von den Widrigkeiten einer verständnislosen Welt befreien wird -, bleiben sie ein Teil des Problems." (Fullan 1999, 194) ${ }^{61}$

Es dürfte darum höchst ratsam sein, den Prozess der Schulentwicklung innerhalb der bestehenden Zeitstruktur anzufangen, in Form von Klausuren, von Gesamtlehrerkonferenzen, die schon jetzt aktive Beteiligung zulassen. Entscheidend ist dann, dass mit Hilfe dieser so genutzten Struktur und kompetenter, strikter Moderation spürbar wird, dass die Schule auf diese Weise vorankommt und als Arbeitsplatz attraktiv ist. Wenn strategische Arbeit auf zwei, drei Klausurtage im Jahr verteilt wird, ist das besser als nichts. Wenn die Gruppen erfolgreich arbeiten, wird hoffentlich auch das Interesse für die strategische Frage wachsen, wie dieser Prozess in Richtung kontinuierlicher Schulentwicklung intensiviert werden kann.

Wenn Sie auf die beschriebene Art engagierte Kolleginnen und Kollegen finden, die Ihre Bemühungen unterstützen wollen, könnte ein nächster Schritt darin bestehen, die Terminlücken zwischen den offiziellen Konferenzen für kreative

61 „Wenn wir ernst nehmen, dass die Schule ein Ort des Lernens ist, dann müssen wir vor allem immer wieder nach der Art und Weise fragen, wie bei uns gelernt wird, gelernt werden könnte, gelernt werden soll. Kein Rahmenplan nimmt es uns ab, nach den Zielen, den Gegenständen und Anlässen dieses Lernens zu fragen. Das müssen wir selbst tun.“ (Riegel 2004, 233) 
Treffen mit diesen motivierten Personen zu nutzen, z. B. für Fortbildung in Gesprächsführung, Moderation und kollegialer Beratung. Von den 5-10\% skeptischen Kolleginnen und Kollegen, die diesen Prozess mit passivem oder rebellischem Verhalten erschweren würden, sind vielleicht doch einige zu gewinnen, wenn sich in der Schule herumspricht, dass Teamarbeit entlastend wirkt, Freude macht und die Qualität des Unterrichts erhöht.

\section{Lesetipp}

Schmidt (2004): Die nächste Sitzung kommt bestimmt; Deister (2005): Der 48-Stunden-Tag (Kap. 6)

Schmidt zitiert eingangs Werner Fincks Bonmot, eine Konferenz sei eine Sache, bei der viele hineingehen und wenig herauskommt, während andere schlankweg vom „Sieg des Gesäßes über den Verstand“ sprächen. Und Deister zitiert Betroffene, die solche Veranstaltungen zu den größten kollektiven Zeit- und Energiefressern zählen. Schmidt empfiehlt strenge, oft juristisch klingende, Maßnahmen, während Deister eine radikale Neustrukturierung von Konferenzen für nötig hält. Vergleichen Sie beide Ansätze, und vergleichen Sie sie auch mit der Praxis in Ihrer Schule.

Hiebl und Seitz (2014): 8.4 


\section{Kapitel 9: Partizipativ-verbindliches \\ Leitungskonzept}

A. Bachmann hat ihr Kollegium an der Veränderung des Konferenzsystems beteiligt, hat Wünsche gesammelt und mit einer Gruppe zusammen ein Konzept erarbeitet, das die Arbeitsfähigkeit der Konferenz und echte Beteiligung ermöglicht. Das ist verantwortliche Arbeit am System. Sie hat nicht gewartet, bis die Veränderung allen eingeleuchtet hat. Herstellung von Arbeitsfähigkeit ist Aufgabe der Leitung. Wie das Beispiel zeigt, schließt das Transparenz des Vorgehens nicht aus. Und es schließt auch nicht aus, das Verfahren auszuwerten, z. B. im Rahmen einer Jahresklausur, und dabei kritische Vorbehalte zu überprüfen.

\subsection{Scheiterstrategie: Alleingang top-down}

Das folgende Beispiel zeigt als Kontrast, wie ein Top-down-Vorgehen im Umgang mit einem Gesamtkollegium schief gehen kann: Ein Telefonat mit einer mir bekannten Beratungslehrerin (B), als Gedächtnisprotokoll aufgezeichnet:

$\mathrm{C}$ : Und wie geht's dir in der Schule?

B: Ach, mir persönlich geht's ja gut. Du weißt ja, ich bin Beratungslehrerin, ich mache viel Fortbildung in anderen Schulen, und ich bin immer wieder auch in der Schulpsychologischen Beratungsstelle für Planungen.

$\mathrm{C}$ : Ja, und in deiner eigenen Schule?

B: Im Moment knirscht es da ziemlich. Unser Chef hat sich da ziemlich blöd angestellt. Seit einiger Zeit ist überall Evaluation angesagt. Und nun wollte er, dass die Lehrer sich evaluieren lassen, mit so einem einfachen Rückmeldebogen. Also dass die Schüler den Unterricht beurteilen und die Atmosphäre und die Schule überhaupt. Und damit ist er krachend gescheitert.

$\mathrm{C}$ : Wie ist denn das passiert?

B: Er hat das in seiner Begeisterung sozusagen aus dem Stand in der GLK vorgetragen. Aber die waren wie vom Donner gerührt.

C: GLK ist die Gesamtlehrerkonferenz?

B: Genau. Und das wurde da abgeschmettert.

C: Also lag's auch mit an der Vorbereitung?

B: Ja, genau.

C: Wie funktioniert denn so eine Konferenz bei euch? Wie viele seid ihr da?

B: Ja, da sitzen so achtzig Leute in einem großen Haufen.

C: Wir hören immer wieder, dass bei so einer Struktur die Leute auf den hinteren Plätzen Sudoku lösen.

B: Bei uns stricken sie, also die Lehrerinnen. Du kannst dir das nicht vorstellen, wie's da zugeht: 30 Leute sitzen mit dem Rücken zum Vortragenden.

C: Da kann ja nicht vernünftig gearbeitet werden. Ist denn der Chef da allein mit seiner Leitungsaufgabe, oder hat er jemanden zur Seite? 
B: Doch, hat er schon, es gibt einen Stellvertreter und auch eine kleine Leitungsgruppe.

C: Wenn es diese Leitungsgruppe gibt-bereiten die denn so ein Thema nicht vor?

B: Doch, doch, die haben das Thema schon länger diskutiert, aber der Schulleiter hat es dann auf eigene Faust unvermittelt eingebracht und eine Bauchlandung gemacht. Beurteilung durch die Schüler - völlig undenkbar! Er war hinterher ganz geknickt und hat einigen schon gesagt, dass er über Rücktritt nachdenkt.

C: Bei so einer Evaluation geht es doch um Feedback. Das ist in vielen Schulen ein schwieriger Punkt, der enorme Angst auslöst. Wir haben jetzt unsere Teilnehmerinnen angeregt, sich aktiv um Feedback zu bemühen. Die Idee ist, dass sie ihre Vorgesetzten fragen, was sie aus deren Sicht im Kurs lernen sollten.

B: Um Gottes willen! Die Frage trifft ja mitten ins Herz! Das ist ja das Persönlichste vom Persönlichen! Weißt du, Lehrer sind schon eine besondere Art von Menschen. In der Klasse haben sie das Heft in der Hand. Und im Kollegium sind sie dann plötzlich allen anderen gleichgestellt. Da fühlen sie sich fast wie die Schüler. Das ist ein Rollenwechsel, der enorm schwerfällt.

C: Ja, wir haben mit der Zeit gelernt, dass die Arbeit mit einem Kollegium von Lehrerinnen und Lehrern so ziemlich der schwerste Teil der Schulleitung ist. Je größer das Kollegium, desto schwieriger. Und wir propagieren seit längerem, so große Gruppen zu strukturieren wie eine Kneipe.

B: Genau, in meinen Fortbildungen mache ich das auch. Da sitzen die dann an Tischen in kleinen Gruppen und diskutieren da vorbereitete Themen. Das funktioniert gut.

C: Und wie siehst du die Möglichkeit, das in deiner Schule einzuführen?

B: In meiner Schule? Unmöglich! Ich sitze ja auch nicht in der Leitungsrunde.

C: Vielleicht kennst du jemanden etwas näher, der oder die in der Leitungsrunde sitzt? Angenommen, du würdest so jemanden mal darauf ansprechen, welche Ideen du z. B. zur Strukturierung von GLK hättest?

B: Ganz unmöglich! Wenn das von mir käme - keine Chance! Ich bin ja sowieso nur noch mit wenigen Stunden in meiner Schule. Das weckt schon Neid. Und wenn ich da noch mit Ideen käme - nein, nein. Das tu ich mir nicht an. Du glaubst nicht, was für eine Rivalität in so einem Kollegium herrscht. Nein, das ist Sache der A-15er. Das ist in einer Schule streng hierarchisch geregelt.

C: Die A-15er, ja, ja. Ich kenne keine andere Organisation, in der die Kommunikation sich derartig nach der Gehaltsgruppe richtet wie in den Schulen. Und ich predige immer, eine Schule sei ein Haus des Lernens, in dem eben alle lernen, nicht nur die Schüler. Und die Lehrer sind Experten für Lernprozesse und lernen voneinander.

B: Ja, schön wär's. Ich mache jetzt ja schon seit Jahren Fortbildung für andere Schulen, ich bin regelmäßig in der Schulpsychologischen Beratungsstelle, und mein Schulleiter weiß das natürlich. Und glaubst du, der hätte mich auch nur einmal gefragt, wie ich unsere Schule sehe, was in anderen Schulen los ist, welche Ideen ich für uns hätte?

C: Was für ein Jammer! Und dabei gibt es so gute Möglichkeiten. Wir haben eine Schule kennengelernt, in der die GLK als großes Plenum nur noch ganz kurz 
zusammentritt; den größten Teil der Zeit nutzt man da für Arbeit in thematischen Kleingruppen. Da sind alle aktiv und beteiligt.

B: Ja, so müsste es sein. Ich bin sicher, euch wird die Arbeit nicht ausgehen, bis zum Ende aller Tage nicht. Da braucht ihr euch keine Sorgen zu machen.

C: Klingt ein bisschen nach Sisyphus!

B: Ja, schon, aber für euch ist das doch gut! -

\subsection{Diagnose eines Misserfolgs: Was war da los?}

Im Weiterbildungskurs habe ich dies Interview mehrfach als Übungsbeispiel genutzt, nachgespielt als Audio-Version. Aufgabe für Dreiergruppen: Welche Diagnose würden Sie als Beraterteam stellen und was wären Ihre ersten Interventionen?

Hypothesen zur Diagnose (Ergebnisse der Gruppenarbeit):

- Setting: Hinderliche Sitzordnung; 30 Personen sitzen mit dem Rücken zum Podium.

- Keine orientierende Geschäftsordnung, keine konstruktive Konferenzordnung vorhanden.

- Direktiver Führungsstil bewirkt bei den Geführten Trübung aus dem KindheitsIch-Zustand: kein erwachsenes Verhalten (Stricken, Sudoku usw.).

- Üblich ist ein Laissez-faire-Stil; der unvermittelte Wechsel in den direktiven Führungsstil funktioniert nicht.

- Der Alleingang des Schulleiters verhindert Trägerschaft.

- Es gilt ein heimlicher Vertrag: Konferenzen muss man absitzen und nicht ernst nehmen.

- Berne-Modell: Es gibt Störungen innerhalb der Leitungsregion und Störungen zwischen Leitung und Geleiteten.

- Prozessqualität: Kein Kommunikationsfluss zwischen der erweiterten Schulleitung und Kollegium.

- Der Sinn des Ziels Evaluation und der Hintergrund dazu werden nicht transparent; die Interessen sind ungeklärt (Harvard-Konzept).

- Das Kollegium hat Angst vor Feedback.

- Gewinn des Problemverhaltens: Anstrengungsvermeidung.

- Ich-Zustand der Schulleitung: kEl- (stark fordernd); Reaktion des Kollegiums: rK (Rebellion).

- Mentales Modell des Leiters: Die Leitung muss Entscheidungen treffen.

- Der Schulleiter sieht das Thema als eilig an; als B-Thema wäre Vorbereitungszeit sinnvoll.

- Der Schulleiter steuert sich nicht aus der Organisationsrolle heraus, sondern agiert emotional.

- Der Schulleiter hört stark auf dem Beziehungsohr, nicht auf die Selbstmitteilung des Kollegiums.

Der Schulleiter geht in die Opferrolle (aK), das Kollegium in die Verfolger-Rolle.

- Die Schulleitung nutzt die Ressource Beratungslehrerin nicht, hat Schwierigkeiten mit starken Frauen. 
- Selbstabwertung der Beratungslehrerin: Opferrolle; Funktion: Konfliktvermeidung. Von der Leitung nicht gesehen, vom Kollegium beneidet.

- Der Beratungslehrerin gilt Neid und Rivalität; so ist sie eine ungenutzte Ressource; sie geht selbst aber nicht in eine proaktive Rolle.

Interventionsideen:

- Vorgehen der Beratungsgruppe: Mit dem Lohmann-Modell Auftrag, Ziel und Anliegen mit dem Schulleiter klären; dann das Problem beschreiben lassen.

- Klären: Was ist das Ziel der Evaluation? Welche Evaluationselemente laufen bereits im Kollegium? Bisherige Erfahrungen sammeln. Wie lässt sich das Ergebnis nutzen?

- Frage nach Ausnahmen: Wann hat die Konferenz einmal gut gearbeitet?

- Benchmarking: Wie machen das andere Schulen?

- Strukturieren: große Gruppen klein machen, Arbeitsgruppen bilden.

- Die Schulleitung könnte als Vorbild Feedback für sich selbst einholen.

- Die Evaluation könnte probeweise durchgeführt werden.

- Die Beratungslehrerin könnte nach persönlichem Feedback fragen und positives Feedback erbitten.

- Falls das Thema „Evaluation“ jetzt „,verbrannt“ ist: Auswertung der Arbeit im Kollegium per Konsensverfahren; dabei den Aspekt „Qualität unserer GLK“ thematisieren, Projektgruppe dazu bilden. Das Kollegium ist allergisiert, also: Selbstdiagnose anregen.

Wie ist ein Thema ins System zu bringen? Auch ein gut formuliertes strategisches Ziel wird nicht ohne weiteres angenommen. Systeme geben selbst die Kriterien vor, nach denen sie sich beeinflussen lassen. Daher ist Selbstdiagnose des Systems ein entscheidender Ansatzpunkt für Veränderung.

Die Ideensammlung zeigt, wie sich die bisher herangezogenen Konzepte für die Diagnose eines Systems und für Interventionsentwürfe nutzen lassen. Die Sammlung ist keineswegs erschöpfend. Leitung ist ein eigener Beruf; darin sind sich z. B. Malik (2006) und Rolff (2017, 24; s.o. 3.1) einig. Dann gehört dazu auch ein umfangreiches Instrumentarium. Wer nur einen Hammer hat, dem wird jedes Problem zum Nagel. Wenn Sie üben, komplexe Situationen immer wieder mal nachträglich in dieser Weise zu analysieren, am besten zusammen mit aufgeschlossenen Leitungsmitgliedern, entwickeln Sie mit der Zeit einen Blick auf Situationen, der Ihnen hilft, auch schon direkt in einer Situation bewusst und gezielt zu intervenieren.

\subsection{Einzelfall oder relevantes Problem?}

In unseren Kursen wurde uns durchweg bestätigt, dass die geschilderte Scheiterstrategie kein exotischer Einzelfall ist. W. Deister $(2005,83)$ zeichnet ein ähnlich düsteres Bild von Konferenzen. ${ }^{62}$ Wenn ich Lehrerinnen und Lehrer in meinem Be-

62 Zeit wird abgesessen; selbstverliebte Vielredner, Clowns, Streithähne dominieren; Ineffektivität durch unverbindliche Ergebnisse usw., mit einem Bibelwort: „Etliche schrieen so, etliche 
kanntenkreis nach ihren Erfahrungen mit Konferenzen frage, bekomme ich ähnliche Reaktionen. Einer befreundeten Oberstudienrätin habe ich das Telefon-Interview geschickt. Sie schrieb mir dazu:

„Genauso lief es in meiner Schule. Gesamtkonferenz: Man setzte sich möglichst nach hinten, viele korrigierten, manche lasen, zwei Kollegen schliefen regelmäßig ein, und man beobachtete mit Vergnügen, wann der herabsinkende Kopf sie aufwecken würde, dann Schreck!! Und sie schliefen wieder ein.

Ich schrieb häufig kleine Briefchen... Vorn saßen Oberstudiendirektor, Konrektor und einige ,Wichtige'. Es war alles vorbesprochen, Ergebnisse waren sicherlich schon formuliert; wenn jemand wagte, den Finger zu heben, stöhnte man auf, weil das nur die Konferenz verlängerte; es war eine Tragödie!

Wegen der Korrekturen, die ich allmählich hasste und wegen dieser absurden Gesamtkonferenzen, die ich nicht mehr ertragen konnte und auf die ich mit Albernheiten reagierte, bin ich etwas früher, in Rente` gegangen. Wehe, man sagte was! Die Hierarchie ist enorm; ich hatte durch meine Fächer und da ich Oberstudienrätin bin, einen gewissen Stand. Aber sagen durfte ich nichts.

Ich denke, es wird sich nur was ändern, wenn man an der Basis anfängt, also die Schüler einübt im Hinnehmen und Geben von Feedbacks, ihr Selbstbewusstsein stärkt, etwa so: ,Mein Nachbar schreibt zwar bessere Noten, aber dafür kann ich super Fußball spielen oder ein Instrument spielen; ich bin toll, auch wenn ich keine Einsen schreibe ...' Wenn die Lehrer das nicht als Jugendliche und Kinder gelernt haben, wie sollen sie das denn später können?

Ich glaube, dass meine Schüler sich wenig an meinen Unterricht erinnern werden, aber bestimmt an unsere regelmäßigen sessions mit Kerze in der Mitte; da wurden Feedbacks gegeben, einfach toll; auch ich bekam Kritik, z. B. dass die Tests zu hart bewertet wurden; und sie übten auch gegenseitig Kritik oder äußerten Lob; all das wirkte sich natürlich sehr auf das Klassenklima aus, und auch ich fühlte mich wohler und sicherer.“

Konferenzen als ineffektive Zeitfresser, als Darstellungsbühne für den Schulleiter, die Schulleiterin, als Gelegenheit, in altes Pennälerverhalten zu regredieren - Einschätzungen dieser Art lieferten uns unsere Kursteilnehmerinnen. In der Summe eine enorme Zeit-, Energie- und Motivationsverschwendung. Und alle fühlen sich ohnmächtig und hilflos, das zu ändern. Konform, uniform, Chloroform?? Irgendwelche Ideen dazu, Herr Kursleiter?

Ja, eine sehr einfache. Aber bevor ich sie nenne, vorweg eine Frage: Ist es möglich, für diese Konferenzen einen Tagesordnungspunkt anzumelden?

Antwort: Ja, kein Problem.

Gut, jetzt die Idee; ich verdanke sie Stephen Covey: Wie wäre es, wenn Sie für eine der nächsten Sitzungen folgenden TOP auf die Tagesordnung setzen lassen: „Auswertung unserer Gesamtlehrerkonferenz: Stärken, Schwächen, Veränderungswünsche“? (Covey 1995; Anhang mit Postkorb-Übung)

Typischer Einwand unserer Kursteilnehmerinnen: Das wird dann in der Konferenz abgeschmettert, von einigen Wortführern, z. B. so: Bringt nichts. Haben wir schon versucht. Wozu soll das gut sein? Usw.

ein anderes. Und die Gemeinde war irre. Und die meisten wussten gar nicht, warum sie zusammengekommen waren.“(Apostelgeschichte 19, 32; Deister 2005, 84) 
Meine Entgegnung: Genau darauf, auf solche Reaktionen, können und sollten Sie sich vorbereiten. Nutzen Sie sozialpsychologische Erkenntnisse, z. B. das berühmte Experiment von S. Asch. Der fand heraus, dass jemand in Gruppen schon dann Gehör in einer kontroversen Frage findet, wenn er auch nur von einer einzigen Person unterstützt wird, besser noch wären zwei oder drei (Zimbardo 1983, $620 \mathrm{ff}^{63}$; Sacks, 2015b,15 f). Mit denen zusammen bereiten Sie sich auf die Begründung Ihres Antrags vor, auch darauf, dass nicht nur Sie allein sich äußern, sondern auch die anderen. Dann haben Sie eine sehr gute Chance, ernst genommen zu werden.

Wenn Sie in einem großen Kollegium in einer „freien“ Schule nicht einmal diese eine unterstützende Person finden, wenn also das ganze Kollegium im Konformitätszwang gefangen ist, dann könnte der Zeitpunkt gekommen sein, die Schule zu wechseln, biblisch gesprochen: fortzugehen und den Staub von den Füßen zu schütteln (Matthäus 10,14). Aber erst dann!

Säkular gewendet: Es gibt immer mindestens drei Möglichkeiten: Change it, leave it, love it! Wenn ,,change it!“ gründlich ausgereizt ist, könnte ,love it!“ heißen: volle Konzentration auf den eigenen Verantwortungsbereich, dort umsetzen, was Sie im großen Kontext vermissen. Wenn auch das nicht geht, bleibt immer noch der dritte Weg. Wenn es Ihnen aber gelingt, Ihr Kollegium für das Thema Auswertung zu gewinnen, dann könnte eine Projektgruppe ähnlich wie in Neuruppin vorgehen. Das Thema wäre (im Sinne der sechs Schritte nach Gordon) etwa so zu formulieren:

Wie können wir unsere Konferenzzeiten so organisieren,

- dass wir in den Konferenzen Unterstützung für unsere Arbeit erfahren,

- dass alle sich an Schulentwicklung beteiligen und

- dass insgesamt ein Klima guter Zusammenarbeit gefördert wird?

Übrigens, das Konferenzproblem betrifft nicht nur Schulen. 16,5 Stunden verbringen Büroangestellte in Deutschland im Durchschnitt monatlich in Meetings und Besprechungen. Das hat eine Befragung des Unternehmens Sharp von mehr als 8000 Angestellten ergeben. Acht von zehn Arbeitnehmern sind demnach der Meinung, dass sie an ihrem eigenen Arbeitsplatz produktiver sind. $55 \%$ der Befragten beklagten, dass die Meetings, die sie besuchen, meist nicht zu klaren Ergebnissen führen. Fast genauso viele $(54 \%)$ gaben zudem an, dass sie die Besprechungen langweilig finden. ${ }^{64}$

Mit unserem Weiterbildungskurs ist natürlich die Hoffnung verbunden, dass „unsere“ Leitungsleute von sich aus Feedback ins System bringen. Schulentwicklung mit der Leitung hat gute Chancen, gegen die Leitung dagegen nicht. Schulentwicklung mit einer Laissez-faire-Haltung der Leitung hat es schwer, ist aber nicht ganz unmöglich, wenn Sie so vorgehen, wie Covey das empfiehlt.

63 Stichwort: Die Macht der Mehrheit

64 Süddeutsche Zeitung Nr. 213, 14./15 September 2019, S. 25 


\subsection{Kontakt zwischen Leitungsregion und Kollegium}

In der Schule in Neuruppin gibt es mehrere Gelegenheiten, bei denen Leitungsmitglieder mit Teams zusammentreffen. Welche Struktur dafür optimal ist, muss wohl jede Schule selbst herausfinden. Es gibt jedoch einige plausible Kriterien, die dabei zu berücksichtigen sind. Die m. E. wichtigste Bedingung: Jedes Mitglied des Systems Schule sollte eine regelmäßige Zeit und einen festen Ort für ein Teamtreffen wissen, bei dem kritische Hinweise und konstruktive Vorschläge zur Verbesserung der Arbeit geäußert und durch eine zuständige Person an die Leitung vermittelt werden können. Gordons Management-Modell plädiert in diesem Sinne für eine Verzahnung unterschiedlicher Gremien; Grafik 13 zeigt das Konstruktionsprinzip.

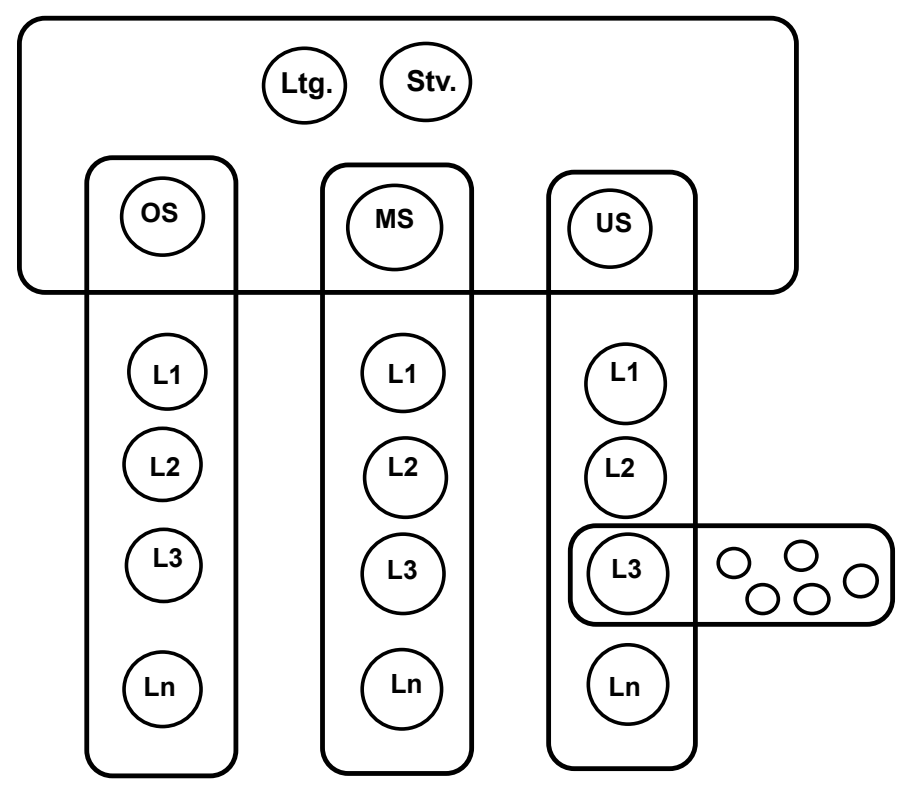

Grafik 13: Infrastruktur für die Verzahnung von Leitungsregion und Kollegium

Eine in großen Schulsystemen häufig anzutreffende Infrastruktur gliedert sich in die drei Abteilungen Unter-, Mittel- und Oberstufe, für die jeweils eine Person die Koordinationsverantwortung hat. Mindestens diese drei Personen bilden zusammen mit der Schulleiterin und dem Stellvertreter die erweiterte Schulleitung. ${ }^{65}$ Die Verzahnung zeigt, dass die Koordinatorinnen ihrerseits Teams, Fachkonferenzen o. ä. zu leiten haben. Und von diesen geleiteten Personen kann wiederum jemand eine Gruppe zu leiten haben (Beispiel in Grafik 13: Lehrerin 3 in der Unterstufe; $n=$ Zahl der Lehrkräfte in der jeweiligen Gruppe). Dieses Grundprinzip hat folgende Vorteile:

65 So ist auch die erweiterte Schulleitung der Ev. Schule Berlin Zentrum (eszb) strukturiert: Schulleiterin, Stellvertreter, pädagogische Leiterin, Mittel- und Oberstufenleiterin, Sprecher der Kleinteams und ein Mitarbeitervertreter (Rasfeld 2012, 241). 
Der Kontakt zwischen Leitung und Kollegium ist strukturell und personell gesichert. Die wichtigste Voraussetzung für eine partizipative Struktur ist damit erfüllt. Die Struktur berücksichtigt, dass niemand mehr eine Schule allein leiten sollte (und auch nicht könnte, ohne ein Burnout zu riskieren). Führung ist auf mehrere Schultern zu verteilen; derart ,,verteilte Führung“ umfasst ein Beziehungsnetzwerk von Personen, Strukturen und Kulturen (Rolff 2017, 14). Bei so ,,verteilter Führung“ führt die Schulleiterin die innerschulischen Führungskräfte, und diese wiederum führen die einzelnen Lehrkräfte (Rolff 2017, 16).

Diese Struktur erlaubt Informationsfluss in beiden Richtungen. Die Leitung kann über die Koordinatoren wichtige Informationen ins System geben. Sie kann die nächste Ebene um Informationen und Anregungen zu strategischen Fragen bitten, mit denen die Leitung sich beschäftigt. Umgekehrt kann die Leitung über die Koordinatoren von Problemen aus dem System hören, die sich mit den Möglichkeiten der jeweiligen Ebene nicht lösen lassen. Gordon nennt das die AbwärtsAufwärts-Methode. So ein Informationsprozess dauert eine gewisse Zeit; das ist bei strategischen Themen, die wichtig, aber nicht eilig sind, kein Schaden.

Schließlich liegt in dem Modell die Chance, eine Kommunikationskultur zu initiieren, durch die eine Lernende Organisation erst möglich wird. Wenn nämlich die verantwortliche Schulleiterin im Leitungsgremium einen partizipativen Moderationsstil modellhaft praktiziert (s.o. Kapitel 5) und von den Mitgliedern der erweiterten Schulleitung erwartet, dass die in ähnlicher Weise in den Teams verfahren, für die sie verantwortlich sind, dann sind die Grundlagen für lebendiges Lernen gelegt.

So ein Prozess wird kaum gradlinig, ohne Hindernisse und Konflikte verlaufen. Darum brauchen die Prozessverantwortlichen immer wieder die Möglichkeit, sich beraten zu lassen, wenn auf diesem Weg Schwierigkeiten auftreten. „Möglichkeit zur Beratung“" sollte als B-Thema regelmäßig auf der Tagesordnung einer erweiterten Schulleitung stehen. Beratungsverfahren, die dafür in Frage kommen, wurden oben besprochen (Kapitel 4). Eine Schule, die so arbeitet, wird sich an ihrem vitalen „Gartenteich“ erfreuen können.

\subsection{Wie können Sie partizipativ und zugleich verbindlich leiten?}

Partizipativ leiten bedeutet nicht, dass die Leitung dazu verdammt ist, es allen recht zu machen. Verbindliches Leiten bedeutet aber auch nicht, dass die Leitung autoritär auftritt. Wie geht beides zusammen?

\subsubsection{Zwei Leitungsdimensionen anstelle von drei Typen}

Kurt Lewin hat in den 1930er Jahren Leitungsverhalten in drei Typen unterschieden: autoritär, laissez-faire und demokratisch - ein Modell, das lange gebräuchlich war, jedoch am Nachteil litt, dass Führungsverhalten sich nur selten so eindeutig 
unterscheiden lässt. ${ }^{66}$ Reinhard und Anne-Marie Tausch haben faktorenanalytisch untersucht, aus welchen Merkmalen sich diese Typen zusammensetzen. Ergebnis: zwei Dimensionen genügen, um die drei Typen und viele, viele Mischtypen hinreichend zu unterscheiden (Tausch \& Tausch 1971, 172; 1998, 111). Die zwei Dimensionen nennen sie „Lenkung“ und „Wertschätzung“.

Autoritärer Führungsstil entpuppt sich als Kombination aus einem hohen Ausmaß an Lenkung und dem krassen Gegenteil von Wertschätzung. Der Laissez-faireStil vermeidet jede Art von lenkendem Eingriff und gibt sich auf der Beziehungsebene völlig gleichgültig. Der sozial-intergrative (kooperative) Stil verbindet hohe Wertschätzung mit einem mittleren Ausmaß an Lenkung. Demgegenüber behindert ein patriarchalischer freundlicher Stil durch seinen hohen Lenkungsanteil die Selbstständigkeit der Geführten (s. Grafik 14). ${ }^{67}$

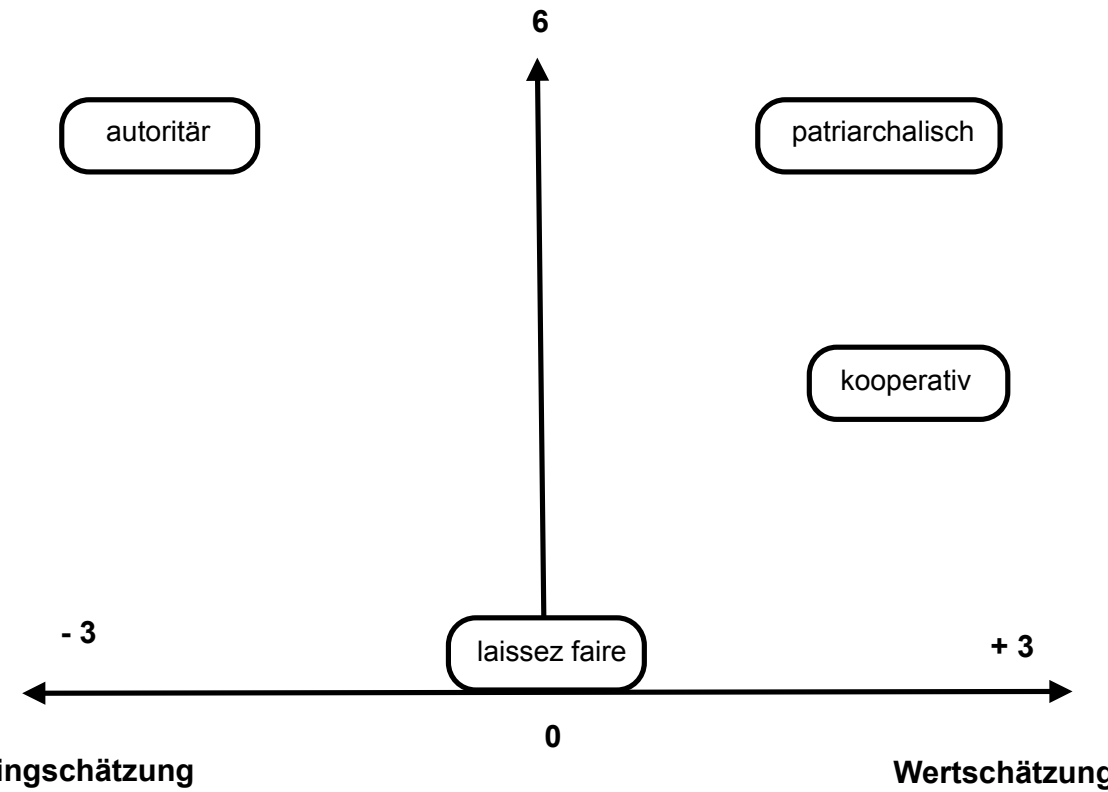

Grafik 14: Typen- und Dimensionsmodell zum Leitungsverhalten

66 „Demokratisches Führungsverhalten führte durchgängig zu positiveren Einstellungen der Gruppenmitglieder gegenüber dem Führer als autoritäres Führungsverhalten. Der Gruppenzusammenhalt war unter autoritärer Führung wesentlich schwächer ausgeprägt als in den demokratisch geführten Gruppen. Demokratisch geführte Gruppen wiesen darüber hinaus eine höhere Beständigkeit, Qualität und Originalität in der Arbeit auf, während in den autoritär geführten Gruppen quantitativ eine etwas höhere Leistung verzeichnet werden konnte.“ (Steyrer 206)

67 In der letzten Auflage hat R. Tausch $(1998,111)$ leider auf diese Grafik verzichtet. Begründung: das Typenmodell sei durch das Dimensionsmodell überholt. Damit hat er zwar Recht; die Typen sind aber noch in den Köpfen, vor allem der autoritäre Typ, und das damit verbundene Problem lässt sich grafisch viel einleuchtender darstellen als durch Text. 
„Autoritäres“ Verhalten ist im Typenmodell immer mit Geringschätzung verbunden. Das Dimensionsmodell demonstriert dagegen, dass hohe Lenkung nicht autoritär sein muss; die beiden Dimensionen sind unabhängig voneinander. Leitungspersonen sind in Konflikten oft hilflos, wenn z. B. nachgeordnete Mitarbeiter Verträge verletzen. Sie reagieren getrübt, aus dem Kindheits-Ich-Zustand heraus: Wenn ich eingreife und mich durchsetze, wirke ich autoritär, falle also aus der gewünschten Gewinn-Gewinn-Haltung heraus. Also halte ich meinen Ärger zurück und bin frustriert. So wird die beherzte Ausübung der Leitungsrolle in sozialen Einrichtungen oft vermieden. Denn autoritäres Verhalten von Leitungspersonen wird als Dementi der ethischen Richtlinien erlebt, die in sozialen Einrichtungen offiziell hochgehalten werden. Vermeidet man dann lenkendes Verhalten überhaupt, hat man das Kind mit dem Bade ausgeschüttet.

Die Enttrübung besteht in der Erkenntnis, dass Verträge nicht einseitig gebrochen werden dürfen und dass nicht einmal ein hohes Ausmaß an Lenkung autoritär im Sinne von Missachtung und Geringschätzung wäre, ein demokratischkooperativer Stil also erst recht nicht.

Falls also mal jemand Sie nebenbei oder gar öffentlich als autoritär kritisiert, empfehle ich die freundliche Rückfrage: „Wann genau habe ich mich geringschätzig oder missachtend verhalten?" Dann könnte sich herausstellen, dass man Sie für lenkendes Verhalten kritisiert. Das aber lässt auf ein problematisches Führungsverständnis bei den Geführten schließen. Strikte, klare Moderation kann durchaus, wenn auch nicht durchgängig, stark lenkendes Verhalten erfordern, um überhaupt erst demokratische Beteiligung zu ermöglichen. ${ }^{68}$

Das Dimensionsmodell lässt sich sehr einfach für ein Leitungsfeedback nutzen. Sie können z.B. ein Blatt mit zwei Skalen an die Mitglieder Ihrer erweiterten Schulleitung verteilen und sie bitten, Ihr Führungsverhalten nach den Dimensionen Lenkung und Wertschätzung auf den beiden Skalen mit zwei Kreuzchen einzuschätzen. Die Einzelwerte lassen sich als Durchschnittswert pro Skala zusammenfassen. Der Schnittpunkt dieser beiden Koordinatenwerte zeigt dann, wie Ihr persönlicher Führungsstil wahrgenommen wird - eine interessante Grundlage für eine Diskussion zum Thema. Auch das wäre ein Beitrag zur Entwicklung von Feedback-Kultur. Einige Leitungen, die das durchgeführt haben, erfuhren zu ihrer Überraschung, dass eher mehr statt weniger Lenkung seitens der Leitung gewünscht wurde.

\subsubsection{Entscheidungs- und Partizipationskontinuum}

Das „mittlere Ausmaß“ an Lenkung ist ein Durchschnittswert aus unterschiedlichen Situationen für demokratische Führung. Die Grafik 15 (nach Steyrer 1996, 204) zum Entscheidungs- und Partizipationskontinuum berücksichtigt solche unterschiedlichen Situationen.

Partizipative Leitung heißt demnach, dass Mitarbeiterinnen immer dann an Entscheidungsprozessen zu beteiligen sind, wenn sie von den Folgen der Entschei-

68 Führung muss ,resolut“ sein, aber keineswegs autoritär. Darin sind sich auch Rolff $(2019,39)$ und Fullan $(1999,127)$ einig. 


\section{Entscheidungskontinuum}

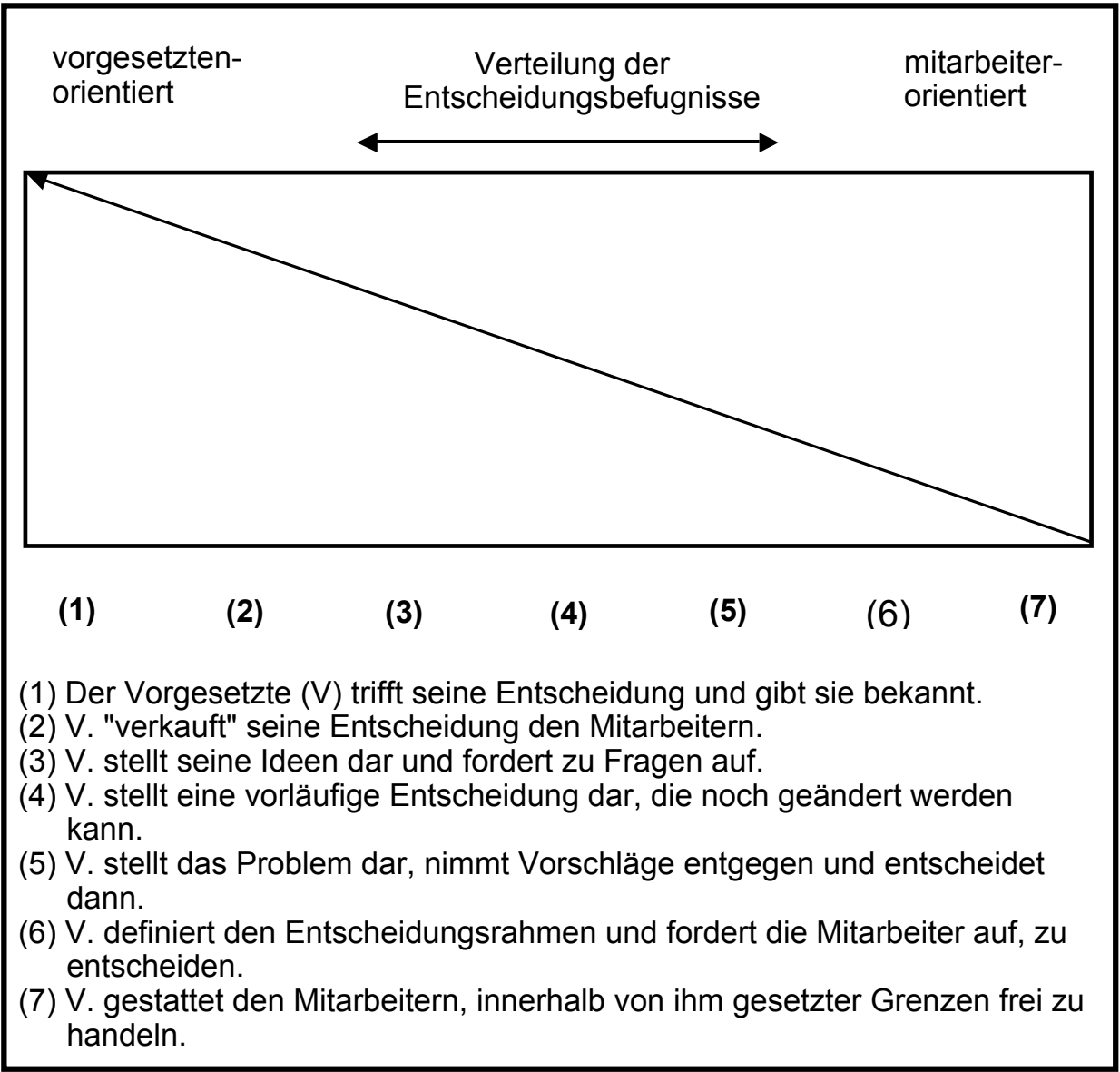

Grafik 15: Entscheidungs- und Partizipationskontinuum, gekürzte Fassung

dungen betroffen sind. Nicht alle müssen über alles nachdenken. Eine arbeitsteilige Infrastruktur mit freiem, vor allem angstfreiem Kommunikationsfluss ist einem autoritären Führungsstil überlegen. In einer sich demokratisch verstehenden Gesellschaft kann es im Arbeitsalltag nicht diktatorisch zugehen. „Dem einen Bürger staatsbürgerliche demokratische Rechte zu geben und ihm Partizipationsrechte in den Bereichen, in denen er Tag für Tag sein Leben zu leben hat, vorzuenthalten, bedeutet seine Aufteilung in mündige Staatsbürgerschaft und gesellschaftliche Ungleichheit." (Brakelmann 1976, 79)

Dem widerspricht es nicht, dass die Leitung für vorgegebene Rahmenbedingungen einsteht, dass sie als Hüter und Wächter von Regularien und Verfahren auftritt, notfalls als Gegenüber zu einer Mehrheit. Dann aber so, dass sie die Notwendigkeit der Rahmenbedingungen transparent und verständlich macht. In diesem Sinn lässt sich das Vorgehen von A. Bachmann als Beteiligung auf dem 
5. Skalenpunkt der Grafik verstehen. Sie hat das Problem dargestellt, Vorschläge erbeten und dann zusammen mit der Leitungsgruppe entschieden.

Viele Leitungspersonen, eher Männer als Frauen, hängen der Überzeugung an, sie müssten ständig Entscheidungen ,raushauen“. Das Modell regt durch seine Differenzierung zu einer wichtigen Enttrübung an: Leitung ist wesentlich Steuerung von Prozessen. Ständige Entscheidungen top down von oben nach unten führen zu Unselbstständigkeit und Passivität „unten“. Regie führen und für Entscheidungen sorgen fördert Verantwortungsbewusstsein und Selbstständigkeit bei allen Systemmitgliedern. ${ }^{69}$ Frauen sind durch ihre geschlechtsspezifische Sozialisation besser darauf vorbereitet, soziale Organisationen zu entwickeln: „Frauen neigen stärker als Männer dazu, Konflikte so zu handhaben, daß gute Arbeitsbeziehungen bestehen bleiben (anstatt Streitigkeiten als eine Frage von Sieg oder Niederlage zu betrachten), und sie neigen eher dazu, Beziehungen als einen Wert an sich zu betrachten (anstatt nur als Mittel zum Zweck).“(Fullan 1999, 126 f)

\subsubsection{Der kritische Blick eines Wirtschaftswissenschaftlers}

F. Malik (2006) bezieht sich in seinem Management-Lehrbuch direkt auf die Lewinschen Führungsstile. Deren Bedeutung hält er für zweitrangig. Entscheidend für die Arbeitsqualität einer Organisation sind für ihn die Ergebnisse, die erreicht werden. „Natürlich gebe ich gerne zu, dass man autoritär das Falsche machen kann. Aber man kann eben auch kooperativ das Falsche tun. Autorität, aber richtig in den Resultaten, ist besser als kooperativ, aber falsch.“ (Malik 2006, $147 \mathrm{f}$ )

Wenn das die Alternative ist, stimme ich zu. Wenn damit der autoritäre, Angst produzierende Führungsstil einiger deutscher Großkonzerne gemeint ist, denke ich an den riesigen volkswirtschaftlichen Schaden, den z. B. die Autobranche bewirkt hat, der sich zu Milliarden summiert und einen enormen Ansehensverlust für den deutschen Wirtschaftsstandort verursacht hat. Es ist nicht egal, wie ein Leitungsverantwortlicher sich selbst versteht und was für ein Mensch er sein will. Will er herrschen, oder will er ernsthaft dienen? „Willst du den Charakter eines Menschen erkennen, so gib ihm Macht.“ (Abraham Lincoln zugeschrieben)

69 „Ein interaktiver, kooperativer Führungsstil soll sowohl delegieren und beteiligen als auch zu Entscheidungen führen.“ So die Bildungskommission NRW 1995, S.. 323, zustimmend bei Boettcher/Mosing (2006, 872 f) zitiert, die ergänzend erläutern: „Rollendiagnostisch sehr genau finden wir ... das Bild ,zu Entscheidungen führen“. Der Unterschied zu ,entscheiden“ markiert den springenden Punkt: Als Schulleiter/in bin ich der Garant, dass notwendige Entscheidungen von den für ein Problem Zuständigen getroffen werden, nur im Grenzfall treffe ich die Entscheidung allein...“ „Ich unterstütze die Beteiligungsmöglichkeiten der anderen und verweise sie auf ihre Einflussspielräume..." - Covey (1995, 124f) leitet eine Klausur in einem Tagungshotel; er ist beeindruckt von der Hilfsbereitschaft der Angestellten und spricht den Hotelmanager darauf an. Der erklärt das mit dem Leitbild, die speziell für dies Hotel entwickelt wurde, und zwar von allen. Jeder im Hotel war an der Aussage beteiligt. Coveys Fazit: „Ohne Beteiligung gibt es keine Bindung. Schreiben Sie's hin, kreuzen Sie's an, unterstreichen Sie's. Keine Beteiligung, keine Verbindlichkeit.“ 
Malik vermischt die Begriffe ,autoritär“ und „Autorität“; das Dimensionsmodell (Grafik 14) kennt er nicht. Grundsätzlich aber meint auch Malik: „Es gibt kooperative Führungskräfte, die auch hervorragende Resultate erzielen. Das ist großartig, und man kann jeder Organisation nur wünschen, möglichst viele solche Leute als Manager zu haben." (A. a. O., 146) Bei Schwierigkeiten solle man aber die psychologische Brille nicht zu früh aufsetzen. „Nach meiner Auffassung sind die allermeisten scheinbar psychologischen Schwierigkeiten darauf zurückzuführen, dass es an eben der handwerklichen Professionalität mangelt, dass die elementaren Aufgaben von Management gar nicht oder schlecht erfüllt werden. Da kann auch noch so viel und gute Psychologie nicht helfen."(A. a.O., 53)

Zuzugeben sei: „Psychologie ist für jedes Management wichtig. Schädlich hingegen ist das, was man die Psychologisierung von Management nennen kann. ... Die Führung von Menschen ist ... ein Teil von Management, aber es gehört viel mehr dazu, nämlich die Gestaltung, Entwicklung und Lenkung einer Institution in ihrer Gesamtheit. Man kann den Teilaspekt der Menschenführung gar nicht verstehen, wenn man ihn aus diesem Kontext herauslöst.“(A.a.O., 53) Dass Personalführung auf die Führung des Gesamtsystems zu beziehen ist, also auf die Primärziele eines Unternehmens, auch einer Schule, sollte m. E. nicht strittig sein.

Vielleicht bietet die Gartenteich-Metapher einen Ansatz zur friedlichen Einigung? Kultur ist wichtig, aber nicht alles. Struktur ist auch nicht alles; aber ohne Struktur ist alles nichts. Maliks Deutlichkeit und Entschiedenheit hinsichtlich der Ergebnisorientierung würde mancher Schule, aber auch unserem gesamten Bildungssystem gut tun. Denken Sie an die fünf Mythen, die J. Allmendinger zerpflückt hat und die unser Bildungssystem lähmen (s. o. 2.1).

Nach der ausführlichen Darstellung des Konsensverfahrens (s.o. 7.3) stutzt man erstmal, wenn Malik schreibt: „Ein weiterer Fehler oder Irrtum, der behandelt werden muss, ist die weitverbreitete Meinung, Konsens sei wesentlich für die Führung einer Organisation." Er differenziert sogleich: Wichtig ist Konsens am Schluss eines Entscheidungsprozesses. Denn dann werden Entscheidungen eher realisiert. Kritisch sieht er ein verbreitetes mentales Modell: „Auch die besten Manager sind ... nur Menschen, und viele von ihnen gehen einem Streit, einem Konflikt lieber aus dem Weg. Sie versuchen daher, viel zu schnell und zu früh Konsens herbeizuführen. ... Was wirklich wichtig ist, ist aber nicht Konsens, sondern Dissens. Wirklich tragfähiger Konsens entsteht nicht aus allgemeinem Harmoniestreben, sondern nur aus ausgetragenem Dissens.“(A.a. O., 209)

Diese Kritik an der Psychologisierung von Leitungshandeln geht an den konfliktpsychologischen Ansätzen bei Tuckman und Fourier vorbei (s.o. 5.2); auch das Konzept der gewaltfreien Kommunikation (6.6) steht nicht für oberflächliche Harmonisierung. Und Schritt III der sechs Schritte der Problemlösung nach Gordon sieht ebenfalls kritische Diskussion bei der Bewertung der Ideen aus dem Brainstorming vor (s. Download 3).

Wenn Harmoniebedürfnisse notwendige Klärungen verhindern, dann wäre Maliks Polemik die bessere Psychologie. Er pointiert: „Es gibt nur drei Methoden, Dissens auszutragen, und zwar - erstens offen, zweitens offen und drittens offen. Es gibt keine andere Möglichkeit, so schwierig und lästig dies gelegentlich auch sein kann.“(A.a.O., 209) 
Leuchtendes Vorbild ist für ihn Alfred Sloan, der Dissens zu einer systematischen Methode der Entscheidungsfindung bei General Motors gemacht hat, als GM noch erfolgreich war.

„Normalerweise ging es in den Sitzungen jener Entscheidungsgremien, in denen Sloan den Vorsitz hatte, ziemlich hitzig zu. In einer dieser Sitzungen konstatierte Sloan aber allgemeine Zustimmung zu einer wichtigen Entscheidung. Er vergewisserte sich nochmals, dass offenbar bezüglich dieser Frage alle einer Meinung waren. Die Antwort war allgemeines Kopfnicken. Daraufhin sagte Sloan sinngemäß: ,Wenn das so ist, dann schlage ich vor, dass wir die Sitzung hier unterbrechen - und uns Zeit nehmen, zu unterschiedlichen Meinungen zu gelangen ...! ““(A.a. O., 209f $)^{70}$

Wenn Argumente und nicht Statusunterschiede den Ausschlag für Entscheidungen geben, hat ein Team (einschließlich Leitung!) auch nach Gordon den notwendigen Reifegrad erreicht (Gordon 1989, 153; s. a. Newmark 2020, 104)

Maliks Lehrbuch bietet einen interessanten Überblick über wirksames Management, manchmal in der Polemik überzogen, dennoch im Sinne eines externen Blicks mindestens überprüfenswert. Die Leitung eines Unternehmens versteht er als eigenen Beruf, indem er auf die hohe Verantwortung z. B. von Chefärzten und Firmenchefs verweist. Die Leitung einer Schule hat er nicht im Blick. Käme er Sie in Ihrer Schule besuchen, wäre er mit Fragen nicht zimperlich. Ich schlüpfe jetzt in seine Rolle und stelle Ihnen zu jedem seiner Kapitel eine schulbezogene Frage. Wie würden Sie antworten?

\section{GRUNDSÄTZE: Woran orientieren Sie sich?}

1.1 Ergebnis: Was können Ihre Schulabgänger, wenn sie die Schule verlassen?

1.2 Beitrag: Welchen Sinn sehen Sie in der Zielsetzung Ihrer Schule? Welchen Sinn möchten Sie Ihren Schulabgängern nahe bringen?

1.3 Konzentration auf Prioritäten: Was sind die drei wichtigsten Faktoren, durch die Ihre Schule auf Schülerinnen, Lehrer und Eltern attraktiv wirkt?

1.4 Stärken nutzen: Wie finden Sie die Stärken Ihrer Kollegen heraus? Was können Einzelne besser als Sie selbst? Wie lassen Sie sie zum Zug kommen?

1.5 Vertrauen: Welche Erfahrungen ermutigen Sie, Vertrauen in Ihr Kollegium zu setzen?

1.6 Positiv denken: Nennen Sie Beispiele dafür, wie Sie Probleme als Lernchance nutzen konnten.

2. AUFGABEN: Was ist zu tun?

2.1 Für Ziele sorgen: Wie entwickeln Sie zusammen mit dem Kollegium eine gemeinsame Vision für Ihre Schule?

70 Die Gründer der Münchner Schachakademie empfehlen ganz analog als Strategie den „kreativen Kreislauf“, eine Verteilung der Rollen Träumer, Kritiker und Realist auf drei Personen, die ein Problem aus diesen unterschiedlichen Perspektiven diskutieren, nacheinander, bewusst kontrovers (Kindermann / v. Weizsäcker 2010, 107); das Verfahren ist für Teamarbeit geeignet; tatsächlich wurde es bei der Erfindung des amerikanischen Supermarkts im Gefolge der Weltwirtschaftskrise 1929 praktiziert.) 
2.2 Organisieren: Wie trägt Ihre Gremienstruktur zu kontinuierlicher Schulentwicklung und zu gutem Unterricht bei?

2.3 Entscheiden: Wie sorgen Sie für Entscheidungen, und wie sichern Sie Trägerschaft bei den Betroffenen?

2.4 Kontrollieren: Wie überprüfen Sie die Qualität des Unterrichts in Ihrer Schule? Wie nutzen Sie Kontrolle als Basis für Anerkennung?

2.5 Menschen entwickeln: Wie fördern Sie die persönliche und fachliche Entwicklung Ihres Kollegiums?

3. WERKZEUGE: Wie gehen Sie konkret vor?

3.1 Sitzungen: Wie sorgen Sie dafür, dass Sitzungen die Schulentwicklung effektiv voranbringen?

3.2 Protokoll: Wie sichern Sie verlässliche Dokumentation und die Umsetzung von Arbeitsergebnissen?

3.3 Einsatzsteuerung: Wie berücksichtigen Sie Fähigkeiten und Stärken bei der Vergabe von Funktionen und bei der Delegation von Aufgaben?

3.4 Persönliche Arbeitsmethodik: Welche Kompetenzen würden Sie in Ihrer Arbeit entlasten? Was tun Sie konkret, um kompetenter zu werden?

3.5 Budgetierung: Wie sorgen Sie für Klarheit hinsichtlich der finanziellen (und auch der rechtlichen und strukturellen) Rahmenbedingungen, die bei der Entwicklung Ihrer Schule zu berücksichtigen sind?

3.6 Leistungsbeurteilung: Woran können Ihre KollegInnen merken, welche Kompetenzen Sie an ihnen schätzen?

3.7 Entmüllung: Wie konsequent verabschieden Sie und Ihre KollegInnen sich von unnötigen oder unnötig gewordenen Arbeiten? Wie entlasten Sie die Tagesordnung der Sitzungen von unnötigem Ballast?

\subsubsection{Situative Führung}

Trotz Maliks Bedenken scheint mir für die unmittelbare Personalführung das Konzept situativer Führung von Blanchard et al. (2006) sinnvoll zu sein. Es unterscheidet unterschiedliche Reifegrade von Mitarbeiterinnen und leitet den situativen Führungsstil von Kompetenz und Motivation der einzelnen Personen ab. Grundsätzlich wird der Führungsstil nach den bekannten zwei Führungsdimensionen Aufgabenorientierung (dirigierend) und Mitarbeiterorientierung (sekundierend) differenziert. (Graphik 16; Steyrer 1996, 211).

Aufgabenorientierung besagt, dass ich den Nachgeordneten klar sage, was zu tun ist, wie es zu tun ist, wo es zu tun ist und wann es $\mathrm{zu}$ tun ist. (Damit wird Maliks Interesse am Organisationsbezug bei der Personalführung berücksichtigt.) Anschließend überwache ich gewissenhaft ihre Arbeit. Ich lenke also entschieden, ohne dabei etwa geringschätzig aufzutreten (s. o. 9.5.1).

Mitarbeiterorientierung besagt, dass ich ihnen zuhöre, sie in ihren Bemühungen unterstütze und ermutige und dann ihre Beteiligung an Problemlösungs- und Entscheidungsprozessen fördere. Durch Unterscheidung von hoher bzw. niedriger 


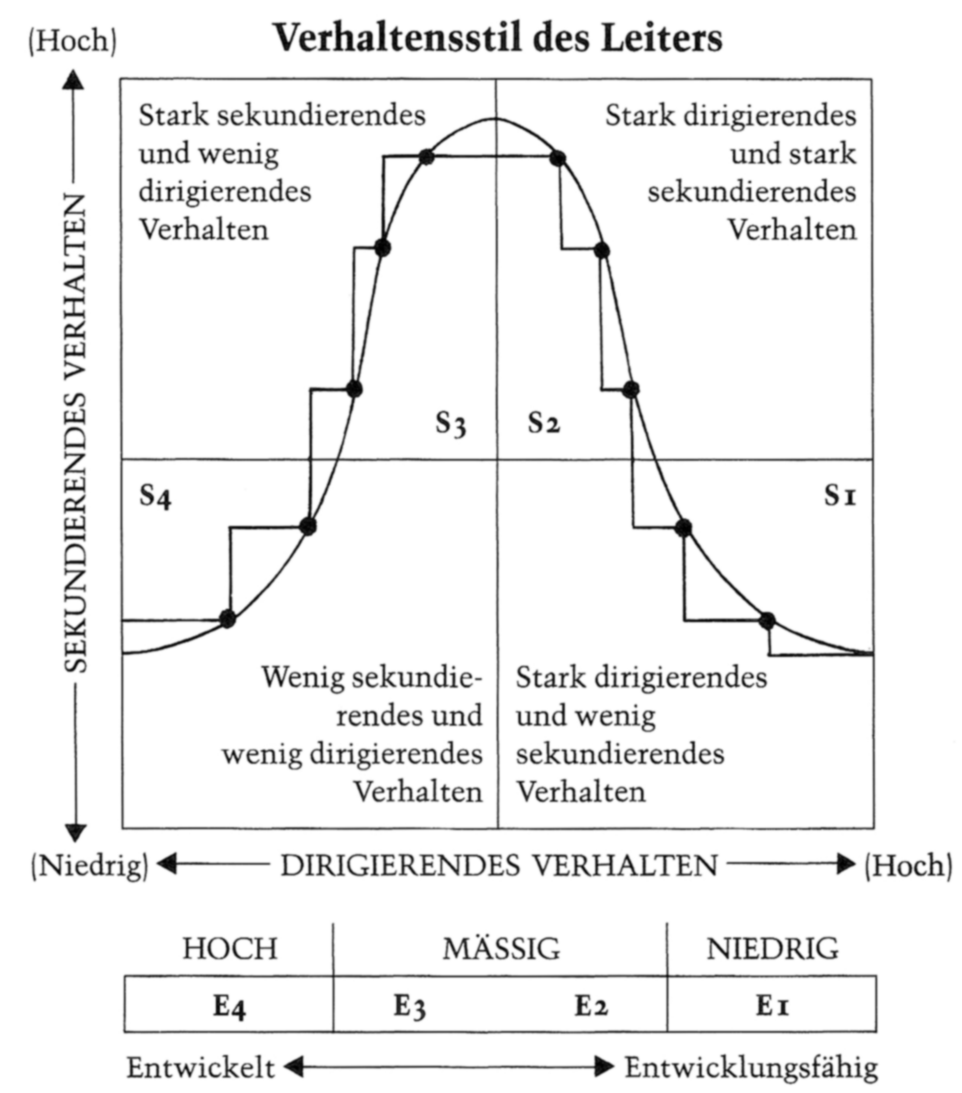

Grafik 16: Situative Führung nach Blanchard et al. 2006, 76

Ausprägung dieser Dimensionen ergeben sich vier Führungsstile. Die Entwicklungsstufe einer Mitarbeiterin wird nach Kompetenz und Motivation eingeschätzt (Grafik 17).

Die zentrale Idee dabei: Bei steigendem Entwicklungsstand ist die Aufgabenorientierung zu reduzieren und die Mitarbeiterorientierung auszubauen; auf der letzten Stufe kann beides zurückgenommen werden. Das Ziel der Führung liegt darin, einen kontinuierlichen Entwicklungsprozess einzuleiten, an dessen Ende Selbstständigkeit und Selbstmotivation des Mitarbeiters stehen. Aus den unterschiedlichen Entwicklungsstufen (E1-4) folgen entsprechende Interventionen:

E4: hohe Kompetenz, hohes Engagement: $\rightarrow$ delegieren

E3: hohe Kompetenz, schwankendes Engagement $\rightarrow$ sekundieren (unterstützen)

E2: einige Kompetenz, wenig Engagement $\rightarrow$ trainieren

E1: wenig Kompetenz, hohes Engagement $\rightarrow$ dirigieren

Vielleicht haben Sie in Ihrer Schule Quereinsteiger; die brauchen klare Anleitung für den Einstieg. Sie haben vermutlich auch ,alte Hasen“, die eigenständig, verantwortlich und motiviert arbeiten und Delegationsaufgaben übernehmen. Wenn jemand zwar kompetent ist, aber in Routine zu erstarren droht, die Freude an der 


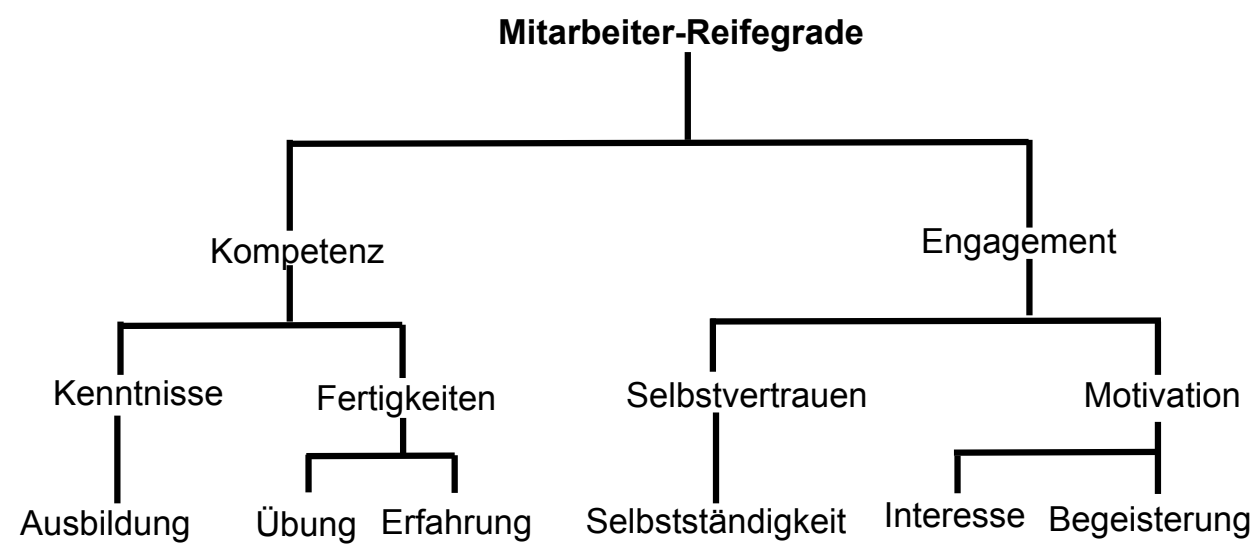

Grafik 17: Aufschlüsselung von Mitarbeiter-Reifegraden (nach Steyrer 1996, $208 \mathrm{ff}$.)

Arbeit verliert, erste Anzeichen für Burnout aufweist, dann ist Beratung, Coaching anzuraten (im Modell: sekundieren). Möglicherweise stoßen Sie auch auf Einsteigerkandidaten mit wenig Kompetenz und wenig Motivation; die sollten eine für sie passendere Arbeit suchen.

Der Überblick über die Zusammensetzung der Mitarbeiter-Reifegrade kann Ihnen helfen, in einem Einstellungsgespräch Kompetenz und Engagement der Person, die sich bewirbt, einzuschätzen. Sie können sich so auch auf das im Mitarbeitergespräch vorgesehene Feedback vorbereiten (s.u. 12.1).

Steyrer $(1996,211)$ lobt das Modell und warnt zugleich: „Positiv hervorzuheben ist der Aspekt der Mitarbeiterentwicklung hin zu Selbstführung und -kompetenz. Mit der Stilflexibilität bietet das Konzept aber auch die ideale Legitimationsbasis für jedes Führungsverhalten eines Vorgesetzten, denn dieses, so kann er rechtfertigend behaupten, habe eigentlich nichts mit seiner Person, sondern stets nur mit seinen Mitarbeitern zu tun.“

\subsection{Zwischenbilanz}

Die Kapitel 7-9 nahmen die Schule als Gesamtsystem in den Blick. Zwei schwierige Hürden sind da zu beachten. Das Modell „Partizipativ-kontinuierliche Schulentwicklung" steht für ein wichtiges kulturelles Element, für Prozess-Steuerung, für Beteiligung des gesamten Kollegiums an der Schulentwicklung. Spätestens, wenn diese Hürde genommen ist, meldet sich die Frage: Wie ist die Fortsetzung dieses Prozesses strukturell zu sichern? Das führt auf die zweite Hürde, auf das Thema Konferenzmanagement.

Wenn alle an diesem Prozess beteiligt sind, haben Sie die Arbeitsfähigkeit Ihres Leitungsteams mit Erfolg auf das Gesamtsystem ausgeweitet. Sie wissen, wie Sie strategische Themen ins System bringen können. Sie sind Ihrerseits strategisch vorgegangen, indem Sie den Themen des Kollegiums Priorität eingeräumt haben, dabei aber auf methodischer Bearbeitung bestanden haben.

Damit haben Sie ein wichtiges eigenes Thema bearbeitet, das in Ihrem eigenen Interesse liegen müsste. Denn wenn alle Beteiligten mit der Zeit methodisch geübt 
sind, komplexe Themen in Projektgruppen zu bearbeiten, dann können sie auch sperrige Themen, z. B. strategische Vorgaben ,,von oben“, methodisch bearbeiten, ${ }^{71}$ dann ist die Lernende Organisation auf dem Weg, dann ist es Ihre Aufgabe, die Arbeit der Projektgruppen im Blick zu haben, zu unterstützen und aus den Ergebnissen konkrete Entscheidungen zu formen.

Wenn ein Kollegium auf diese Weise methodisch versiert arbeiten kann, dann lassen sich alle möglichen Themen konstruktiv bearbeiten. Beispiele:

- Aufbau einer durchgängigen Feedback-Kultur

- Rhythmisierung des Unterrichts

- Verbesserung der Unterrichtsqualität (KUR, Unterrichtsbesuche)

- Lehr- und Lernvertrag mit Schülern einführen

- Aufwand für Unterrichtsvorbereitung reduzieren

- Korrekturaufwand reduzieren

- normative und ipsative Benotung ${ }^{72}$

- Mobbing-Prävention / Konflikt- und Streitkultur

- Einführung regelmäßiger kollegialer Beratung

- Lärmreduktion in der Schule

- Inklusion

- Digitalisierung (Corona!)

- Konstruktive Elternarbeit

- Vernetzung der Schule mit anderen Schulen und mit der Kommune

- Öffentlichkeitsarbeit

Die bisherige prozessorientierte Darstellung erlaubt jetzt einige Systematisierungen und begriffliche Klärungen. In der Literatur wird nicht immer klar zwischen verschiedenen Aspekten von Schulleitung unterschieden; die Begriffe Leitung, Führung, Leadership, Management, Steuerung werden von unterschiedlichen $\mathrm{Au}-$ toren unterschiedlich gewichtet. Rolff (2017, $11 \mathrm{ff})$ macht einen einleuchtenden

71 Ein Beispiel für ein eher sperriges Thema brachte eine Kursteilnehmerin mit: Ihr Trägergremium verlange „Knall auf Fall“ in drei Tagen von ihr ein Inklusionskonzept. Steuerung von Prozessen war gerade unser Thema; auch die sechs Schritte der Problemlösung waren vorgesehen. So wählten wir ihr Thema als Übungsmöglichkeit: Zwei Projektgruppen wurden gebildet. Zwei Sonderschul-Expertinnen, die glücklicherweise am Kurs teilnahmen, wurden auf die Gruppen verteilt, die sechs Schritte wurden bis zum Schritt III (Bewertung) bearbeitet; nach ca. zwei Stunden hatte unsere anfangs recht gestresste Teilnehmerin zwei Versionen, zwei Brainstormings mit konkreten Handlungsmöglichkeiten, aus denen sie die ihr geeignet erscheinenden Ideen herauspicken konnte. - Im Folgeseminar berichtete sie, dass das Ganze am Ende gar keine Eile hatte. Na gut, auch daraus lässt sich lernen. Sie war jetzt so vorbereitet, dass sie in Ruhe einen ähnlichen Prozess in ihrem Kollegium initiieren konnte.

72 Ein besonders heißes Thema: „Qualitätsorientiertes Feedback sollte förderorientiert sein. Es erfordert diagnostische Fähigkeiten der Lehrpersonen und ist mit Vorschlägen zur individuellen Förderung (Förderdiagnostik) verbunden.“ (Rolff 2017, 31) Riegel (2004,134 ff) verweist auf die empirisch nachgewiesene Schwankungsbreite bei Ziffernnoten. „Erfahrene Lehrer wissen, dass differenziertes Lob, durch das sich der Schüler in seinen Bemühungen verstanden fühlt und das ihm zugleich zeigt, wie er dies und jenes noch verbessern könnte, fast immer deutlich leistungssteigernder wirkt als eine schlechte Zensur.“ 
Vorschlag: „Leitung“ der Schule ist der Oberbegriff; der lässt sich differenzieren in Führung, Management und Steuerung. „Führung“ lässt sich als ziel- und ergebnisorientierte, aktivierende und wechselseitige soziale Beeinflussung zur Erfüllung gemeinsamer Aufgaben in und mit einer strukturierten Arbeitssituation verstehen. Die oben geschilderte Erarbeitung einer effektiven Konferenzstruktur ist dafür ein Beispiel (Kapitel 7 und 8).

Rolff unterscheidet weiterhin personal-interaktive direkte Führung und strukturelle indirekte Führung. Personal-interaktives Vorgehen wäre z. B. die Aufforderung an ein Kollegium, selbst eine Diagnose der Arbeitssituation vorzunehmen, und der Anspruch, das Kollegium entsprechend zu moderieren.

Strukturell-indirekte Führung sorgt für die Vorbereitung eines geeigneten Settings, die notwendige Zeitstruktur, die kommunikationsförderliche Raumgestaltung, die benötigten Materialien für Visualisierung und Dokumentation usw. Insgesamt sorgt sie für Rahmenbedingungen, die Arbeitsfähigkeit sichern; dazu gehören Organigramme, Geschäftsverteilungspläne, Zuständigkeitsregelungen, vor allem der Aufbau einer Binnengliederung der Schule in Klassenteams, Jahrgangsstufen, Fachkonferenzen usw. Diese Aspekte wurden im Zusammenhang mit Vertragsklärung (5.4) und mit dem Aufbau einer Infrastruktur (9.4) behandelt. Zur strukturellen Führung gehört auch die Aufteilung der Führung auf mehrere Personen (,verteilte Führung"); dazu vgl. Kap. 5 und 12.2.

Interaktive Führung richtet sich auf Personal; ,Management“ nimmt die Schule als Betrieb in den Blick (Ressourcenbeschaffung, Gebäudenutzung usw.). Steuerung ist als Begriff im Zusammenhang mit Schulentwicklung aufgetaucht; er bezieht sich auf die Gestaltungsautonomie der ,selbstständigen“ Schule und charakterisiert Führung als prozessorientierte Regiearbeit.

Bei aller begrifflichen Differenzierung bleibt die Erkenntnis, dass alles das die Aufgaben benennt, für deren Bearbeitung eine erweiterte Schulleitung zuständig ist.

\subsection{Vertiefung: Rückschläge überwinden}

Von der Übernahme Ihrer Leitungsrolle an bis hin zu einer arbeitsfähigen Konferenzstruktur für das Gesamtsystem Schule habe ich die einzelnen Schritte beschrieben, die zu diesem Ziel führen bzw. führen können. So ein Fahrplan ist eine Idealvorstellung. Im wirklichen Leben kommt immer was dazwischen. Der Schulleiter, der sein Kollegium mit einem Evaluationsprojekt schockierte, dachte nach seiner Abfuhr daran, sein Amt aufzugeben (s. o. 9.1). So manche Schulleiterin, mancher Schulleiter hat in Krisenzeiten schon geseufzt: Warum tu ich mir das überhaupt an? Die Schwierigkeit, Schulleiterstellen zu besetzen, unterstreicht das Problem. Das ist die eine Seite.

Die andere: Die Wahrnehmung von Führung, auch die beste, ist von Scheitern begleitet, immer wieder. Lincoln und Churchill hatten zahllose Rückschläge zu bestehen und waren zeitweise extrem unbeliebt. Gandhi scheiterte an seinem Traum, Moslems und Hindus in einer gemeinsamen Nation zu vereinen. Nelson Mandela verbrachte 27 Jahre im Gefängnis, angeklagt als Verräter und gewaltsamer Auf- 
rührer. Nur im Rückblick sehen solche Helden wie Helden aus. Nur im Rückblick erweisen Rückschläge sich als Stufen auf dem Weg zum Sieg. Unter günstigen Bedingungen ist es nicht schwer, erfolgreich zu sein. Menschliche Größe beweisen die, die Rückschläge verkraften, die nicht aufgeben, die von jedem Fehler lernen, die Fehler als Lernchancen begrüßen. Und jede Weigerung, sich geschlagen zu geben, macht sie stärker, weiser, entschlossener.

Mit Recht könnten Sie einwenden: Bin ich Lincoln? Churchill? Mandela? Nein, sind Sie nicht. Rabbi Sussja kannte den Einwand. Er sagte: In der kommenden Welt wird man mich nicht fragen: „, Warum bist du nicht Mose gewesen?“ Man wird mich fragen: „Warum bist du nicht Sussja gewesen?“

Sussjas Frage gilt natürlich schon in der Gegenwart. Mose zum Beispiel: Widerstrebend folgt er Gottes Anweisung, vom Pharao Freiheit für sein Volk zu fordern. Das erste Treffen: ein Desaster: Pharao verschärft die Ausbeutung. Nächster Versuch: der Zaubertrick mit dem Stab, der zur Schlange wird. Pech: Pharaos Magier können das auch. Dann die erste der zehn Plagen; nichts ändert sich. Die zweite, die dritte und so weiter. Als die Flucht endlich gelungen ist, findet man sich in der Wüste wieder. Die Befreiten murren, sehnen sich nach den Fleischtöpfen Ägyptens, nach der Bequemlichkeit, die die Sklaverei doch schließlich auch zu bieten hatte.

Rückschläge, Widerstände, Enttäuschungen schmerzen. Sie schmerzen auch Mose. Schluss a maiore ad minus, vom Größeren zum Kleineren: Wenn selbst ein Mose, ein Gandhi, wenn selbst die Größten davon nicht verschont werden - dann muss ich es nicht persönlich nehmen, wenn es mich auch trifft. Dann gehört das eben dazu. Dann ist das sogar nötig. Groß hat die Großen gemacht, dass sie weiter gingen. „Gerechte fallen siebenmal und stehen wieder auf. “(Sprüche 24,16)

Calvin Coolidge schrieb einem verzagten Freund: Talent, Genie, Bildung sind nicht entscheidend. Beharrlichkeit und Entschlossenheit sind allem überlegen. Also: nicht auf die Großen schielen. Nicht andere imitieren, sondern sich selbst in unterschiedlichen Rollen steuern und Rückschläge wie Sparringspartner behandeln, die das Wachstum fördern. „Dies über alles: sei dir selber treu. “ (Shakespeare, Hamlet 1. Aufzug, 3. Szene)

Rabbi Sacks, dem ich diese Vertiefung verdanke, fügt hinzu: „, God never loses faith in us, even if we sometimes lose faith in ourselves. " (Sacks 2015b, 70)

\section{Lesetipp}

Malik (2006): Führen - Leisten - Leben. Eine Führungslehre für Wirtschaftsmanager, die Leitung als eigenen Beruf auffasst, Ihnen einen fremden Blick auf die Schule als Organisation ermöglicht und zu interessanten Vergleichen zwischen Profit- und Non-Profit-Organisation anregt.

Hiebl und Seitz (2014): 2.4; 3.4 


\section{Kapitel 10: Schluss mit Warten auf Godot: alles bedacht?}

Mit Hilfe einiger Experten-Beiträge möchte ich überprüfen, wie weit es mir gelungen ist, eine Schule als Lernende Organisation zu verstehen, ohne dabei wesentliche Fragen und Einwände zu übersehen.

\subsection{Skeptische Analyse einer Erziehungswissenschaftlerin: Ilka Bormann (2001)}

Ich fasse Bormanns Analyse in Thesen zusammen und kommentiere sie in Klammern.

- Veränderungsprozesse könnten in Schulen durchaus stattfinden, wenn den einzelnen Schulen erweiterte Handlungsspielräume zugestanden werden, die schulischen Akteure sich in Überzeugungen und Zielen einig sind und hohe Bereitschaft und Kompetenz zeigen, innovative Prozesse in Gang zu setzen.

- Schulen sind aber (leider) „lose gekoppelte Systeme“, in denen die einzelnen Akteure weitgehend autonom voneinander und ohne verpflichtende organisationsbezogene Ziele effektiv agieren können.

(Lehrer sind Einzelkämpfer, die ohne organisationsbezogene Ziele effektiv arbeiten können. Wirklich effektiv? Steht so die Leiter an der richtigen Wand?)

- Weiter: Schulen sind hochgradig strukturarme Organisationen; elaborierte Kommunikations- oder Teamstrukturen oder kritische Auseinandersetzungen zwischen den Lehrkräften sind selten.

(Hinweise, wie dem beizukommen ist, geben die Kapitel 5 und 8 und 9.4. Dass das möglich ist, haben viele Schulen hinlänglich bewiesen; s. u. 13.3).

- Als lose gekoppelte Systeme sind Schulen lern- und innovationsunfreundlich.

Zwar werden inzwischen Schulprogramme mit pädagogischen Zielsetzungen häufiger erwartet. Aufgrund der pädagogischen Freiheit der Akteure ist das Kerngeschehen, der Unterricht, jedoch nur bedingt steuerbar und kontrollierbar. (Teamlernen, Schülerfeedback, kollegiale Unterrichtsreflexion (KUR) sind 2001 noch nicht im Blick; vgl. Kap. 5 und 6.7.)

- Lehrkräfte konzentrieren sich auf den Unterricht, nicht auf die Organisation als Ganzes. Konsequenz: Ein Lernen der Schule als Organisation ist weitestgehend ausgeblendet. (Top-down-Steuerung ist diesem mentalen Modell nicht gewachsen; systemtheoretische Überlegungen zur Steuerung von Prozessen sind umso wichtiger, s. o. 7.2.)

- Schulleitungen sind nur selten für die Ausübung ihres Amtes besonders geschult worden. (Das ist seit 2001 besser geworden. 120 Stunden Weiterbildung sind allerdings als Vorbereitung auf die Leitungsrolle kaum mehr als ein Anfang, wenn man Leitung - auch Schulleitung - mit Malik als eigenen Beruf versteht.) 
- Institutionalisierte Unterstützung fehlt. Auswege sieht Bormann im Konzept der Selbstorganisation, d.h. des partizipativen Managements.

(Also: Warten Sie nicht auf Godot! Entscheidend ist, ob eine Schule eine lernende Schule werden will. Schulleitungen haben für partizipatives Management eine Schlüsselfunktion.)

- Bormann fordert systematische interne oder externe Evaluation, partizipative Führung, permanente Qualitätsverbesserung und Rechenschaftspflicht der Schulen gegenüber ihrem Träger.

(WIE eine Leitung dieser Fülle an Anforderungen gerecht werden kann, bleibt offen - wie auch bei Kools and Stoll (2016) und bei Fullan (1999).)

- Skeptisches Fazit: Lehrerfort- und -weiterbildung könnte dazu verhelfen, individuelle und kollektive Lernprozesse in den Kollegien freizusetzen. Ob es aber neben der Ermöglichung von Lernen in der Organisation Schule dann auch zu einem Lernen der Organisation Schule selbst kommt, muss offen bleiben. (Bormanns Artikel lässt sich als Appell an die Erziehungswissenschaftler lesen. Die Lehrerausbildung muss radikal verändert werden. Das heißt: Die zuständigen akademischen Institutionen müssten sich erst einmal selbst in Richtung Lernende Universität entwickeln. ${ }^{73}$ Ruht alle Hoffnung auf der nachwachsenden Generation? Soll man warten, bis eine veränderte Lehreraus- und -fortbildung Wirkung zeigt?)

\subsection{Demotivierende Analyse eines Soziologen: Stefan Kühl (2007)}

- Ähnlich wie Bormann sieht Kühl die Spielräume der Schule stark begrenzt. Man hoffe, mit Personalentwicklung, mit Lehrerfortbildung die Schule verändern zu können. Programme, Technologien und Dienstwege würden als Hardware der Organisation gesehen, alles, was „den Menschen“ betrifft, falle (irrigerweise) unter die Software: Spielwiese für Psychologie und Pädagogik.

Als Organisationssoziologe dreht Kühl diese Einteilung auf überraschende Weise um: Für ihn sind die Strukturen der Organisation die Software. Wieso? Weil sie durch ,einfache Entscheidungen“ umzuprogrammieren sind. Die Personen dagegen sind die Hardware, ,weil sie sich diesen einfachen Programmierprozessen entziehen." (Kühl 2007, 7)

- Zwei Beispiele für diese Schwierigkeit mit der „Hardware“ Personal: „Der Schulleiter kommt hoch motiviert von einer Schulung zurück und will einiges anders machen. Dann stößt er aber auf Vorgesetzte, Kollegen und Lehrkräfte, die mit ihren alten Fremderwartungen an ihn herantreten, und innerhalb von wenigen Tagen ist der Effekt der Schulung verpufft.“(A.a.O., 7)

73 „Die Fähigkeit zur Selbstentwicklung wird häufig mit der Formel der Lernenden Schule ausgedrückt; von Lernenden Ministerien hört man übrigens so gut wie gar nichts. “ Dieser Hinweis von Rolff $(2019,47)$ könnte auch für Schulträger relevant sein. 
Begeistert versucht ein ,normaler Lehrer“ eine in der Fortbildung gelernte Methode im Unterricht; sehr schnell wird er durch die eigenen Schüler wieder im traditionellen Sinn eingenordet. Kühl zitiert Luhmann: „,Selbst wenn der einzelne bereit wäre, sich zu ändern, sieht er sich durch die sozialen Erwartungen festgelegt, mit denen er sich tagtäglich konfrontiert findet ..."

- Langjährig eingespielte Erwartungshaltungen kurzfristig ändern $\mathrm{zu}$ wollen, zeuge von unrealistischen Steuerungsfantasien. Darum seien die Personen die Hardware, die Strukturen die Software.

(Kühls Analyse benennt zutreffend die Hindernisse, ohne deren Überwindung Schule als Lernende Organisation keine Chance hat, ${ }^{74}$ gibt aber keine Hinweise auf sinnvolle Maßnahmen.)

Ich fasse zusammen, welche Chancen ich sehe:

(1) Seit Jahren wird inzwischen ,von oben“ die selbstständige Schule propagiert; schon lange sind Schulen in mancher Hinsicht freier, als sie wissen und realisieren. Beispiel: Rhythmisierung des Unterrichts, jahrgangsübergreifende Unterrichtsorganisation (JÜL), Projektunterricht usw. (Zum Spielraum konfessioneller „freier Schulen“ s. u. 13.2).

(2) Eingespielte Erwartungshaltungen des Kollegiums lassen sich nicht kurzfristig ändern, wenn die Leitung Ideen aus der Fortbildung umsetzen will, ja. Jedoch: Die Systemtheorie, an der Kühl sich orientiert, bewahrt ja gerade vor der naiven Vorstellung, dass Systeme sich direkt steuern lassen (s. o. 7.2). Arbeit am System heißt nicht, einsame Entscheidungen „mit einem Federstrich“ zu verhängen, sondern für Entscheidungen zu sorgen, also die notwendigen Beteiligungsprozesse zu organisieren. Was hindert die Experten für Lernprozesse, auf sich selbst anzuwenden, was sie den Kindern und Jugendlichen vermitteln? ${ }^{75}$

(3) Kühl gibt nur der Wissenserweiterung durch Fort- und Weiterbildung gewisse Chancen. Das im Konzept der Lernenden Organisation gemeinte Lernen ist aber viel umfassender. Für Teamlernen ist entscheidend, dass eine Gruppe gemeinsame Lernerfahrungen macht, die die Einzelnen für sich nicht machen könnten. Solche Erfahrungen vermittelt die Arbeit an komplexen strategischen

74 Noch fünf Jahre später (2012) stößt der Experte für Qualitätsmanagement Wolfgang Böttcher in dasselbe Horn: Schulen sind monoprofessionelle Einrichtungen. „Für die vielfältigen pädagogischen Aufgaben, die über das Fachliche hinausgehen, sind Lehrkräfte zuständig kaum Sozialpädagogen, kaum Moderatoren, kaum Psychologen, kaum Bildungsberater, kaum Pädagogen mit besonderem Wissen über die Förderung von Kindern mit Lernschwierigkeiten." (Zitiert von Rolff 2017, 5 f)

75 Im Rahmen einer Klausur traf ich mich mit einer Arbeitsgruppe zum Thema „Verbesserung unserer Kommunikationskultur" in einem Klassenraum, an dessen Wänden mir gleich die schön geschriebenen Grundsätze der themenzentrierten Interaktion auffielen; Beispiele: Sprich von dir, nicht per man oder wir! Nur einer redet zur Zeit! Seitengespräche gehören in die Gruppe! Wenn du etwas fragst, sag, was der Hintergrund deiner Frage ist! Verblüfft sagte ich der Gruppe: „Da hängt ja an der Wand, was Sie brauchen!“ Die amüsierte Reaktion: „Ja, aber das ist doch für die Kinder!“” 
Themen im Rahmen von Projektgruppen; Informationen, Ideen, Ressourcen werden gemeinsam gesammelt, erste Schritte gemeinsam entschieden. Wie das geht, wurde oben erläutert $(5.2 ; 7.3)$.

Wenn tief eingraviertes Konkurrenzdenken solche Kooperation erschwert, so wirken gute Erfahrungen mit Teamlernen als corrective emotional experience. Menschen sind von Geburt an auf Kooperation angelegt. In unserer Konkurrenzgesellschaft wird diese Anlage leicht verschüttet. Umso wichtiger, dass Schülerinnen und Schüler von Personen unterrichtet werden, die regelmäßig gute Erfahrungen mit beruflicher Kooperation machen (Bauer 2008). ${ }^{76}$

\subsection{Vertiefung: Von der Sklaverei in die Freiheit}

Das Buch Exodus, das 2. Buch Mose, berichtet von Auszug und Übergang: Aus einer Familien- und Vätergeschichte wird die Geschichte eines Volkes; das Volk Israel ist auf dem Weg aus der Sklaverei in Ägypten in die Freiheit, auf einer Reise, geprägt von Beschwerden und Klagen. Mose geht zu Pharao: Let my people go! Pharao verschärft die Bedrückung der Steineklopfer, bis er sie endlich ziehen lässt. Durstig in der Wüste treffen sie auf bitteres Wasser. Dann meldet sich der Hunger. Immer wieder sorgt Gott für Abhilfe: Quellwasser, Manna, Wachteln. Dann machen sie ein goldenes Kalb und beten es als Götzen an. Wenn all diese Wunder keine reife, erwachsene Reaktion bewirken - was hilft dann überhaupt?

Gott greift zu einem gruppendynamischen Prinzip. Er sagt zu Mose: Lass sie etwas zusammen bauen. Ein Tabernakel sollen sie herstellen, eine Art tragbares Heim für die göttliche Gegenwart. Eine echte Herausforderung. Das ganze letzte Drittel des Buches Exodus ergeht sich in detaillierten Beschreibungen mit genauesten Ausmaßen und Verzierungen dieses Projekts. Alle tragen etwas bei: Gold, Silber, Bronze, Felle, Teppiche, Zeit, Geschicklichkeit. Und siehe da: während der gesamten Bauzeit - keine Klagen!

J. Sacks folgert: Es kommt nicht so sehr darauf an, was Gott für uns tut; es geht um das, was wir für Gott tun. Solange jede Krise durch ein Wunder bewältigt wurde, blieben alle im Zustand der Abhängigkeit, der Reaktivität. Warten auf Godot. Erwachsen und verantwortlich wurden sie, als sie von passiven Empfängern göttlicher Segnungen zu aktiven Schöpfern wurden. Ihre Großzügigkeit und

76 Begriffe wie „Konkurrenz“ und „Überlebenskampf“ sind menschliche Konstruktionen, die aus dem Wirtschaftsleben kommen und von außen an die Biologie herangetragen wurden. Die Biologie kennt kein Erfolgsdenken, wie es die Wirtschaft beherrscht (Bauer 2008, 20 f). Fatalerweise wirken solche mentalen Modelle leicht im Sinne von sich selbst erfüllenden Prophezeiungen: „Eine tief verwurzelte Grundüberzeugung, dass Menschen von Natur aus zur Bosheit neigen, wird ... einen Lehrer nicht nur im Einzelfall auf eine bestimmte Weise auf ein Kind reagieren lassen, das zum Beispiel einen Fehler gemacht hat, sie wird vielmehr seinen gesamten Erziehungsstil prägen.“(A. a. O., 12) „Für den Menschen bedeutet dies: Kern aller Motivation ist es, zwischenmenschliche Anerkennung, Wertschätzung, Zuwendung oder Zuneigung zu finden und zu geben. Wir sind - aus neurobiologischer Sicht - auf soziale Resonanz und Kooperation angelegte Wesen.“(A.a.O., 36) 
Geschicklichkeit war gefragt, um Gott ein wenig von dem zurückzugeben, was er für sie getan hatte.

Wenn eine zentrale Macht alles für die Menschen tut, bleiben sie in einem Zustand gefesselter Entwicklung. Sie jammern, statt aktiv zu werden. Wenn Mose auf den Berg Sinai steigt und seine Führung fehlt, machen sie dummes Zeug, dann beten sie Stärke und Reichtum an; Symbol dafür: ein goldenes Kalb. (Vielleicht war ein Stier gemeint.) Die Lösung: die Leute zu Co-Architekten ihres Geschicks machen, sie etwas zusammen bauen lassen, sie zu einem Team bilden und sie erfahren lassen, dass sie nicht hilflos sind, sondern verantwortlich und fähig zu Zusammenarbeit (Sacks 2015b, 93ff).

\subsection{Trias der Schulentwicklung: Hans-Günter Rolff (2010 und 2019)}

Personal-, Organisations- und Unterrichtsentwicklung machen nach Rolff (2010, 34 und 2019,13) die Trias der Schulentwicklung aus. In den Mittelpunkt dieses Dreiecks setzt er als ultimativen Bezugspunkt aller Schulentwicklung die Lernfortschritte von SchülerInnen. Folgende Hintergrundfaktoren sind dabei zu berücksichtigen:

1. Schulentwicklung muss von der Einzelschule her gedacht und konzipiert werden. „Jede Schule ist ein Unikat; zentrale Lösungen bei Innovationen greifen nicht.“ $(2019,38)$ Seit Ende der neunziger Jahre propagiert die Schulpolitik die Entwicklung von Einzelschulen als selbstständige, eigenverantwortliche oder teilautonome Schulen.

2. Organisationsentwicklung bedeutet, die Schule von innen heraus weiterzuentwickeln, durch die Mitglieder selbst, die einen Lernprozess von Personen und Organisation initiieren. „Nur wer etwas selber macht, kann von einer Woge des Engagements getragen werden. Und nur kooperative Planung kann diejenigen einbeziehen, denen die Ausführung obliegt.“ (2010, $30 \mathrm{f})$

3. Orientierungspunkt ist die evolutionäre Systemtheorie: Gemeinsame Prozessplanung ist die Basis einer sich selbst entwickelnden Schule. Teamförmige Arbeitsgruppen sichern die Selbststeuerung (2010, 36). Holtappels stimmt dem zu: „Je stärker die in Schulen entwickelte Kapazität von Organisationslernen, desto höher ist die Arbeitszufriedenheit, desto besser ist das Arbeitsklima und desto besser sind auch die Unterrichtsqualität und das Schülerlernen ..." (2010, 104)

4. Der Leitung kommt dabei besondere Bedeutung zu. „Die oberste Führung muss Schulentwicklung genauso wollen wie die mittleren und unteren Führungskräfte und sie müssen dabei auf einer Linie liegen (,alignment")." Und Führung muss resolut sein, transparent und konsequent handeln und wissen, dass heute niemand mehr eine Schule allein leiten kann. (Rolff 2019, 38 f) ${ }^{77}$

77 Darum halte ich es - anders als Rolff $(2019,47)$ und andere - für konsequent, diese Schulentwicklungsaufgabe der erweiterten Schulleitung zuzuschreiben und sie nicht in eine 
5. Strategie, Struktur und Kultur sind die wesentlichen Bausteine dieses Vorgehens: Klärung und Vereinbarung mittelfristiger Ziele (Strategie), dauerhafte Basis für die Umsetzung, z. B. durch feste Teams, neue Organisationsformen der Infrastruktur der Schule u. a. (Struktur) und Normen, Werte und Interaktionsformen, die ,lebendiges Lernen“ (Cohn 2018) ermöglichen (Kultur). Die Ziele müssen allen bekannt sein und von allen getragen werden. „Am besten ist, sie werden von allen gemeinsam entwickelt." (Rolff 2019, 37)

6. An welchem Eckpunkt der Trias man den Prozess ansetzt, bleibt der Entscheidung der selbstständigen Schule überlassen. Jeder eingeschlagene Weg führt notwendig zu den beiden anderen. „Wer den Unterricht verändern will, muss mehr als den Unterricht verändern“", z. B. in Richtung Kooperation, Teamarbeit, überfachliches Lernen, erweiterte Unterrichtsformen usw. (2010, 34). Das nötigt zu organisatorischen Veränderungen, also zur Organisationsentwicklung. Den Königsweg sieht Rolff $(2019,42)$ in der Bildung ,„professioneller Lerngemeinschaften“, z. B. als Klassen- und Jahrgangsteams, Fachteams, Projektteams und Schulleitungsteams.

7. Wesentlicher Bezugspunkt sind immer die Lernfortschritte der SchülerInnen. „Lernen ist mehr als kognitives Lernen und auch mehr als fachliches Lernen.“ Auch soziales, emotionales, überfachliches, ästhetisches Lernen gehört dazu. Pestalozzis klassische Formel „Kopf, Herz und Hand“ drückt das komprimiert aus (Rolff 2010, 35).

Die skeptischen Urteile von Bormann und Kühl sind also nicht das letzte Wort. Rolffs Trias der Schulentwicklung ist kompatibel mit dem Leitkonzept der Lernenden Organisation: ,Schulentwicklung zielt darauf ab, Lernende Schulen ... zu schaffen, die sich selbst organisieren, reflektieren und steuern.“ $(2010,36)$ WIE das im Einzelnen geht, das ist auch seiner Darstellung nicht zu entnehmen. Konzepte dafür gibt es aber genug; deren Kenntnis und kompetente Anwendung gehört m. E. zur notwendigen Professionalität. Also: Warten Sie nicht auf Godot! Am ehesten gedeihen Schulen, deren Kollegien sich auf ihre eigenen Kräfte besinnen, die gemeinsam Verantwortung für ihre Schule übernehmen und auf das Lernen aller mit

Steuergruppe auszulagern. Gründe: Mitglieder einer erweiterten Schulleitung sind oft die „A-15er“, sehr gut bezahlte und langjährig erfahrene Kräfte, die die Schule kennen und sich in jeder Leitungssitzung mit der Schule als Gesamtsystem befassen. Wenn die die Schulleiterin bei der Prozesssteuerung unterstützen, halte ich das für entschieden wirksamer, als wenn das von Mitgliedern einer Steuergruppe erwartet wird, die sich eher selten trifft, weniger formale Autorität verkörpert und deren Mitglieder mit Recht fragen könnten, wieso das nicht zum Aufgabenspektrum der beförderten Kolleginnen und Kollegen gehört. Immer wieder haben wir gehört, dass diese Personengruppe kaum dazu zu bewegen ist, Schulentwicklung als wesentlichen Teil ihrer Aufgabe zu verstehen. Wenn die strategische Arbeit in eine Steuergruppe ausgelagert wird - bleibt dann für das Schulleitungsteam nur das operative Geschäft? Rolff $(2017,18)$ verstärkt meine Skepsis: „Steuergruppen gehören nicht zum Führungssystem und auch nicht zum Co-Management, weil sie ... aus Mitgliedern bestehen, die über keine institutionell angelegten Entscheidungsbefugnisse verfügen." Sehr sinnvoll wäre es m.E., wenn sie sich zu einem Pool von kompetenten Moderatorinnen und Moderatoren fortbilden. 
Kopf, Herz und Hand setzen. Die Schulleitung kann viel dazu beitragen. (Beispiele dafür: s. 8.1 und 13.3).

\section{Lesetipp}

Rolff (2017): Schulleitung - auf den Punkt gebracht. Maliks Hinweis, dass Leitung ein eigener Beruf ist, stimmt Rolff entschieden zu! $(2017,24)$

Hiebl und Seitz (2014): 2.4; 2.7.2; 3.1 



\section{Kapitel 11: Persönliche Meisterschaft: Stress erkennen und regulieren}

Schulentwicklung ist komplex und anspruchsvoll, geht nicht schnell, ist nie zu Ende und stellt darum insbesondere an Sie, die Leitung, erhebliche Anforderungen. Vermutlich sind Ihnen beim Lesen einige strategische Baustellen in Ihrer Schule aufgefallen. Wie können Sie die so anpacken, dass die Schule voran kommt und Sie selbst gesund und guten Mutes bleiben? Also eine doppelte Herausforderung: Wie können Sie auch sich selbst in Ihrer Arbeit so organisieren, dass die Arbeit Sie nicht auffrisst? Sie sind mit dieser Frage nicht allein. Eine Forsa-Umfrage unter 1014 Bundesbürgern zwischen 14 und 65 Jahren zu Druck und Stress in Arbeit und Freizeit fand düstere Fakten (Hassel 2009):

80 Prozent der Deutschen empfinden ihr Leben als stressig. Jeder Dritte klagt über Dauerdruck im Job und Haushalt, Schule und Studium. Mehr als die Hälfte der Deutschen fühlt sich erschöpft, teils ausgebrannt. Fehlende Anerkennung von Vorgesetzten tut ein Übriges. Einige Schlaglichter:

Stress verursacht immer häufiger Herz- und Kreislauferkrankungen, Rückenbeschwerden oder psychische Erkrankungen. Deutschlands Unternehmen kosten Stressfolgen inzwischen jedes Jahr etliche Milliarden Euro. Das Drama beginnt schon in der Schule. $30 \%$ der Schüler und Studenten klagen über häufigen oder ständigen Druck, meist durch Prüfungen und allgemeinen Leistungsdruck. Bei den Berufstätigen klagen $32 \%$ über häufigen oder ständigen Druck. Stressgrund Nummer eins sind für $42 \%$ der Befragten Probleme im Beruf, Schule oder Studium.

Typische Gründe: Termindruck am Arbeitsplatz (52\% der Befragten), Informationsüberflutung, ständige Erreichbarkeit via Handy oder Blackberry (33\%), ungenaue Anweisungen der Vorgesetzten, zu hohes Arbeitspensum, Lärmbelastung, Konflikte mit Kollegen oder Vorgesetzten.

Beim Kampf gegen den Stress indes lügen sich die Deutschen offenbar gern in die Tasche. Eines der effektivsten Mittel der Stressbewältigung findet vor allem rhetorisch hohe Zustimmung: Satte $72 \%$ der Bundesbürger geben an, Sport oder Bewegung sei ihr bestes Mittel gegen Stress. In Wirklichkeit treiben nur $22 \%$ der Deutschen ausreichend Sport, fand die Techniker Krankenkasse in einer anderen Studie heraus. Ausgleich wäre gut, eine gesunde Balance von Arbeitsbelastung und Erholung, von Investition in die Arbeit und in nötigem Ausmaß in die Arbeitskapazität.

\subsection{Balance von Arbeitsleistung und Arbeitskapazität}

Schon Aesop kannte das Problem; er illustriert es mit einer Fabel. Ein armer Bauer entdeckt eines Morgens im Nest seiner Lieblingsgans ein glänzendes goldenes Ei. Er lässt es schätzen: ein Ei aus reinem Gold. Am nächsten Morgen wieder ein goldenes Ei und so weiter. Er wird reich und reicher, zugleich auch gierig und ungeduldig. Er will nicht mehr jeden Tag auf das goldene Ei warten; er will die 
Eier alle auf einmal haben und schlachtet die Gans. Und stellt fest: Sie ist leer. Keine goldenen Eier - und keine Möglichkeit mehr, noch welche zu bekommen.

Die Fabel zielt auf eine häufige mentale Verirrung hin, auf die fixe Idee: Je mehr ich produziere, desto mehr schaffe ich, desto effektiver bin ich. Wahre Effektivität ist jedoch eine Funktion von zwei Dingen: dem, was produziert wird (den goldenen Eiern) und dem produzierenden Faktor, der Gans. Sie steht für die Produktionskapazität. „Wenn Ihr Lebensmuster nur auf goldene Eier ausgerichtet ist und die Gans vernachlässigt, wird es Ihnen bald an dem Faktor fehlen, der die goldenen Eier produziert. Wenn Sie sich andererseits nur um die Gans kümmern und die Eier ignorieren, werden Sie bald nichts mehr haben, um sich selbst oder die Gans zu ernähren.“ (Covey 1995, 54)

Aesops Fabel setzt auf Balance, auf die Ausgewogenheit von Produktion und Produktionskapazität. Dazu gehört die Pflege der Gans. Sie sind nicht nur der Bauer, Sie sind auch die Gans. Wenn Sie in Ihrer Arbeit so sehr aufgehen, dass sie sich selbst erschöpfen, dass Sie immer wieder über Ihre Grenzen gehen, sich fremd steuern lassen statt selbst zu steuern, dann leidet nicht nur Ihre Arbeitsleistung, sondern auch Ihre Arbeitskapazität.

Ihre Aufgabe ist dann: innehalten, sich besinnen, die Hamstertrommel mit Abstand anschauen: Selbstdiagnose betreiben. Dazu gibt es eine Reihe von nützlichen Brillen: Wie und wo meldet sich Stress? Welches Ausmaß ist in Ordnung, wo stecken Probleme? Falls Sie bei sich nicht fündig werden - umso besser! Fragen Sie aber sicherheitshalber auch Ihre Angehörigen nach deren Eindruck. Und wenn Sie selbst entspannt zur Arbeit gehen, kann das für Ihre Lehrkräfte ganz anders aussehen. Die folgenden Konzepte können Ihnen Augen und Ohren dafür schärfen.

\subsection{Eustress und Distress}

Nicht jeder Stress ist ungünstig. Die Beziehung zwischen Stresspegel und der eigenen Leistungsfähigkeit, also der „Produktionskapazität“, lässt sich als umgekehrt U-förmige Beziehung darstellen (Grafik 18). Ein hohes Ausmaß an Stress führt

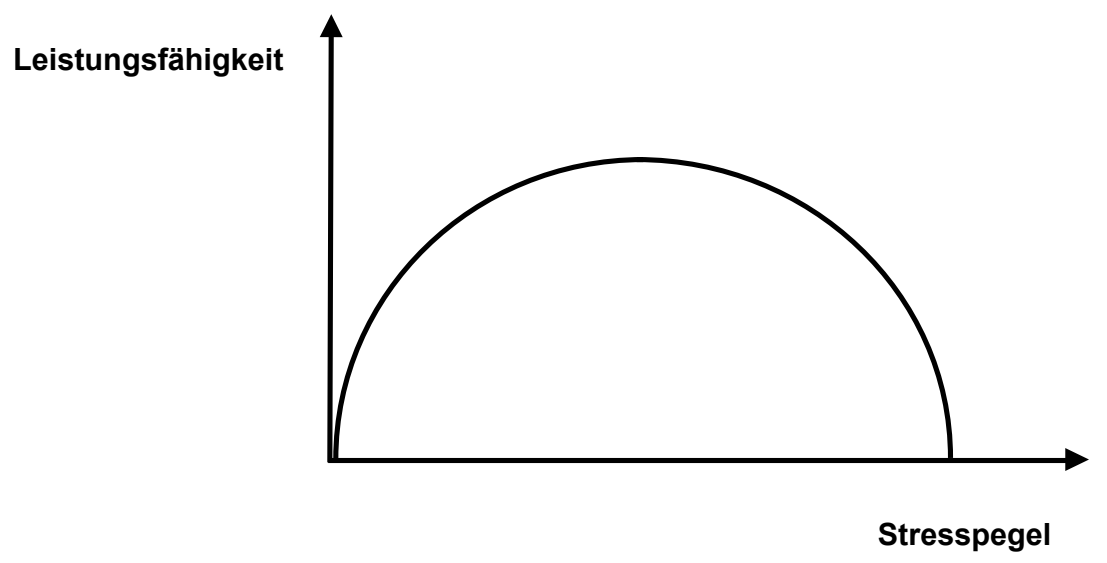

Grafik 18: Umgekehrt U-förmige Beziehung zwischen Leistungsfähigkeit und Stresspegel 
zu Minderleistung, Erschöpfung usw.; ein niedriges Ausmaß ist auch nicht die Lösung; das führt zu Langeweile, Unterforderung, Demotivation. Optimal ist ein mittleres Ausmaß; man spricht dann von anregendem Eustress im Unterschied zum problematischen Distress. Überlegen Sie also, wie Sie Ihren eigenen Stresspegel auf ein sinnvolles Maß regeln können.

\subsection{Energiequellen und Energieräuber}

Michael Stark (Stark/Sandmeyer 1999, 33 ff) vergleicht unseren Energiehaushalt mit einem Fass, gefüllt mit Energie, mit der wir wirtschaften können und müssen. Die Fassfüllung ist nicht immer gleich hoch, je nachdem, ob wir Energie hinzugewinnen oder verbrauchen. Stellen Sie sich vor, das Energiefass ist mit durchlässigen Wänden in vier Kammern geteilt: die erste Kammer steht für Ihre physische Existenz (Nahrung, Schlaf, Bewegung), die zweite für Partnerschaft und Familie, die dritte für Arbeit und Beruf, die vierte für Ihr persönliches Netzwerk von Freunden, Freizeitaktivitäten und sozialen Kontakten. In jedem Bereich schöpfen Sie Kraft; in jedem müssen Sie aber auch Kraft investieren. Halten sich Investition und Gratifikation die Waage, stimmt die Bilanz.

Unter höherem Stress beginnt der Energieraub, häufig in der Arbeitskammer. Der Energiespiegel dort sinkt, kann aber durch die Energie einer anderen Kammer ausgeglichen werden. Beide Kammern haben nun weniger Energie, sind aber noch ausreichend gut gefüllt. Läuft nun aber eine Kammer leer und gelingt es nicht, sich um die bisher funktionierenden Bereiche zu kümmern, dann wird es dramatisch. Der Energienachschub wird spärlicher, das Leben fühlt sich anstrengender an. Alles wird noch verschlimmert, wenn Risse und Löcher im Boden des Fasses, die vorher nur ganz klein waren, plötzlich größer werden. Ursachen dafür sind Verletzungen und Wunden, die ein Mensch im Laufe seines Lebens erlitten hat, die er gut kompensieren konnte, die jetzt aber unter Stress aktualisiert werden.

Wenn Energieräuber am Werke sind, dann kostet es zusätzliche Kraft, wieder aufzutanken, z. B. ins Kino oder Theater zu gehen oder früh aufzustehen und zu joggen, wenn das hilft, innerlich abzuschalten. Wichtig wäre es, Pausen zu machen, ausreichend zu schlafen, Entspannung zu üben usw. Das weiß im Grunde alle Welt. Der Energiegewinn wäre höher als die Investition und würde sich lohnen. Wenn erst einmal alle Reserven aufgebraucht sind, dann habe ich auch keine Kraft mehr für Veränderungen, die dringend notwendig sind, um einen gesunden Kurs einzuschlagen. Dann bin ich auf Hilfe von außen angewiesen.

Besser wäre es, sich rechtzeitig einige Fragen zu stellen: Wie verteilt sich meine Gesamtenergie? Das Maximum wäre $4 \times 100 \%$. Wo sind meine Energiefresser? Wo sind die Lecks ohne Zufuhr? Wobei könnte ich auftanken? Finde ich für jede Kammer eine hilfreiche Aktivität, die mir gut täte? Und wie oft pro Woche komme ich dazu? 


\subsection{Das Vulnerabilitäts-Stress-Modell}

Den Leckagen in Starks Modell vom Energiefass entspricht bei Luc Ciompi die unterschiedliche Verletzlichkeit, die Vulnerabilität. Wir kommen unterschiedlich robust auf die Welt und erleben unterschiedlich günstige Entwicklungsbedingungen. Das Zusammenspiel beider Faktoren macht unsere Empfänglichkeit für Stress aus (s. Grafik 19).

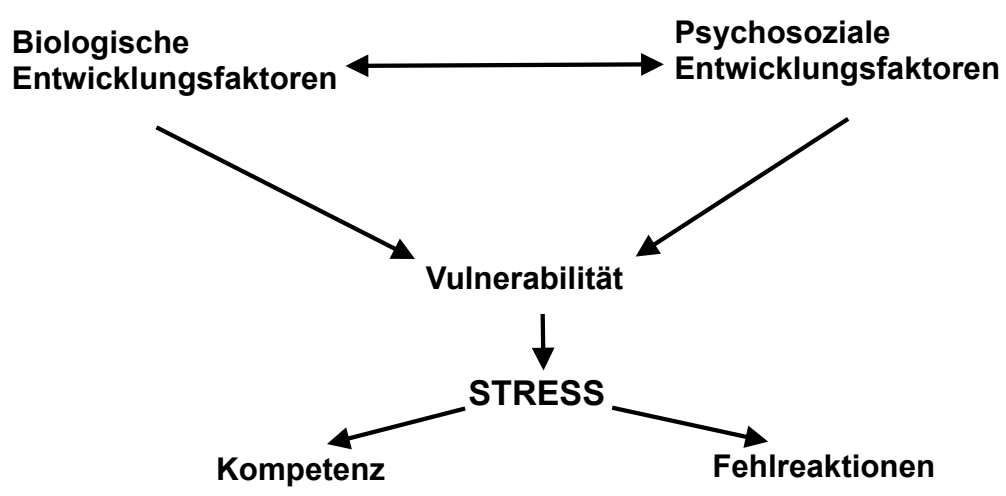

Grafik 19: Ciompis Vulnerabilitäts-Stress-Modell (vereinfachte Darstellung)

Was Frau Müller mit links nebenbei erledigt, ist für Herrn Meier schon eine Herausforderung. Bei Anforderungen gleich zurückzuschrecken, wäre eher eine Fehlreaktion; immer wieder souverän über die eigenen Grenzen zu gehen allerdings auch. Besser ist es, genau wahrzunehmen, wie ich mir selbst Stress mache. Dann habe ich die Chance, die Stresskompetenz zu lernen, die für mich passt.

\subsection{Wie wir körperlich auf Stress reagieren}

Das Flussdiagramm (Grafik 20) zeigt in vereinfachter Form die physiologischen Vorgänge, mit denen unser Körper auf Stress reagiert. Es zeigt auch, wie leicht es ist, die eigene Verletzlichkeit noch zusätzlich zu erhöhen. Wenn ich mit der nötigen Entspannungsphase zu lange warte, schalte ich mein Immunsystem aus und mache mich damit für allerlei Krankheiten empfänglich. Dass viele Menschen sich zu Beginn eines Urlaubs erstmal eine Infektion zuziehen, ist ein Indiz für problematischen Umgang mit Stress. Und wenn der Stress gar nicht aufhört, droht Burnout. Es kommt also darauf an, diese Eskalation zu unterbrechen.

\subsection{Wie mentale Modelle uns unter Stress steuern}

Ein einfacher Slogan geht in die richtige Richtung: Stress fängt im Kopf an! Oder in der Seele, der Psyche. Jedenfalls: im Inneren. Schon der weise Stoiker Epiktet wusste: „Die Dinge sind weder gut noch schlecht. Unser Denken macht sie so.“ 


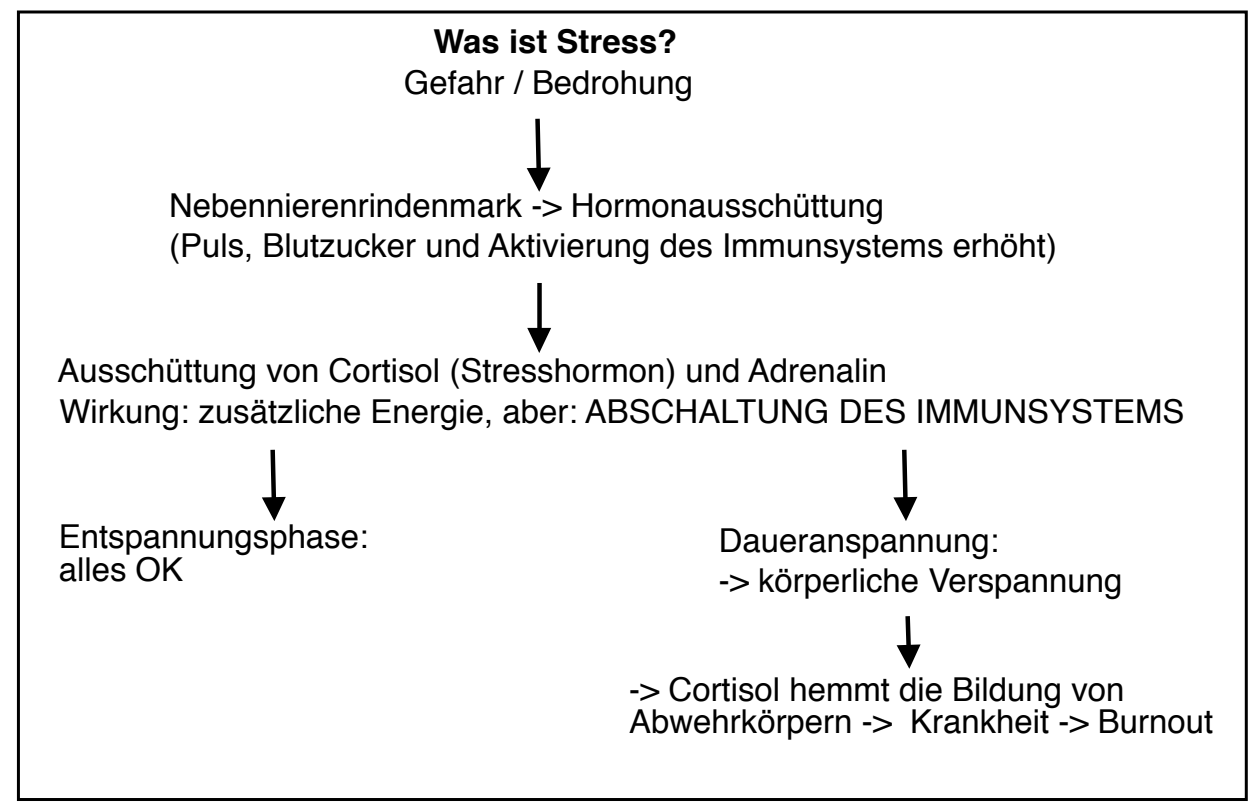

Grafik 20: Flussdiagramm zum physiologischen Verlauf von Stress (vereinfachte Darstellung)

Darum hat Eva Wengle $(1986,113 \mathrm{ff})$ in ihrem Stressmodell als stressfördernde Belastungen nicht einfach äußere Faktoren aufgeführt, sondern zusätzlich die stressende Bewertung dieser Faktoren. Und gleichrangig dazu die subjektive Bewertung der eigenen Bewältigungsfähigkeiten. Beide Aspekte summieren sich zum subjektiv empfundenen Stress, der sich in unterschiedlichen Stimmungen und Gefühlen zeigen kann (s. Grafik 21).

Bei diesen Stimmungen und Gefühlen hat die Analyse anzusetzen; Wengle nutzt dafür das ABCD-Modell der rational-emotiven Therapie von Albert Ellis. Die Diskussion ( $\mathrm{D}=$ Dispute) setzt an beim $\mathrm{C}$ (Consequence): Wie genau sieht das Stresserleben aus? Dann wird nach dem A gefragt, den auslösenden Reizen (Activating Stimulus): Was geht dem Stresserleben voraus? Wie kommt die Stressreaktion, die Konsequenz, dieses $\mathrm{C}$ zustande? Was ist in der Situation passiert, in der der Stress entstand? In der Regel lässt sich ein Auslöser, ein aktivierender Reiz, ein A, dingfest machen. Aber der entscheidende Punkt ist: So ein Auslöser hat keineswegs von sich aus die Macht, die Konsequenz, das C, zu bestimmen.

Entscheidend ist, mit welchem Bewertungs- oder Glaubenssystem, mit welchem mentalen Modell ich auf den Auslöser reagiere. Andernfalls wäre ich die Marionette von Außenreizen, die mein Denken, Fühlen und Verhalten völlig unter Kontrolle hätten. So einfach (und deprimierend) ist es nicht, wie folgendes Beispiel zeigt:

Angenommen, Sie sind unterwegs auf der Autobahn. Die Sonne scheint, das Radio spielt Ihren Lieblingssender, Sie haben Zeit und Muße. Wie fühlen Sie sich? Wahrscheinlich entspannt, fröhlich, heiter, ruhig. Nun überholen Sie gerade auf einer zweispurigen Strecke einen LKW; im Rückspiegel sehen Sie ein Fahrzeug mit hoher Geschwindigkeit auf Sie zukommen, das bis auf einen Meter an Ihre 


\section{Äußere und / oder innere Anforderung / Belastungen}

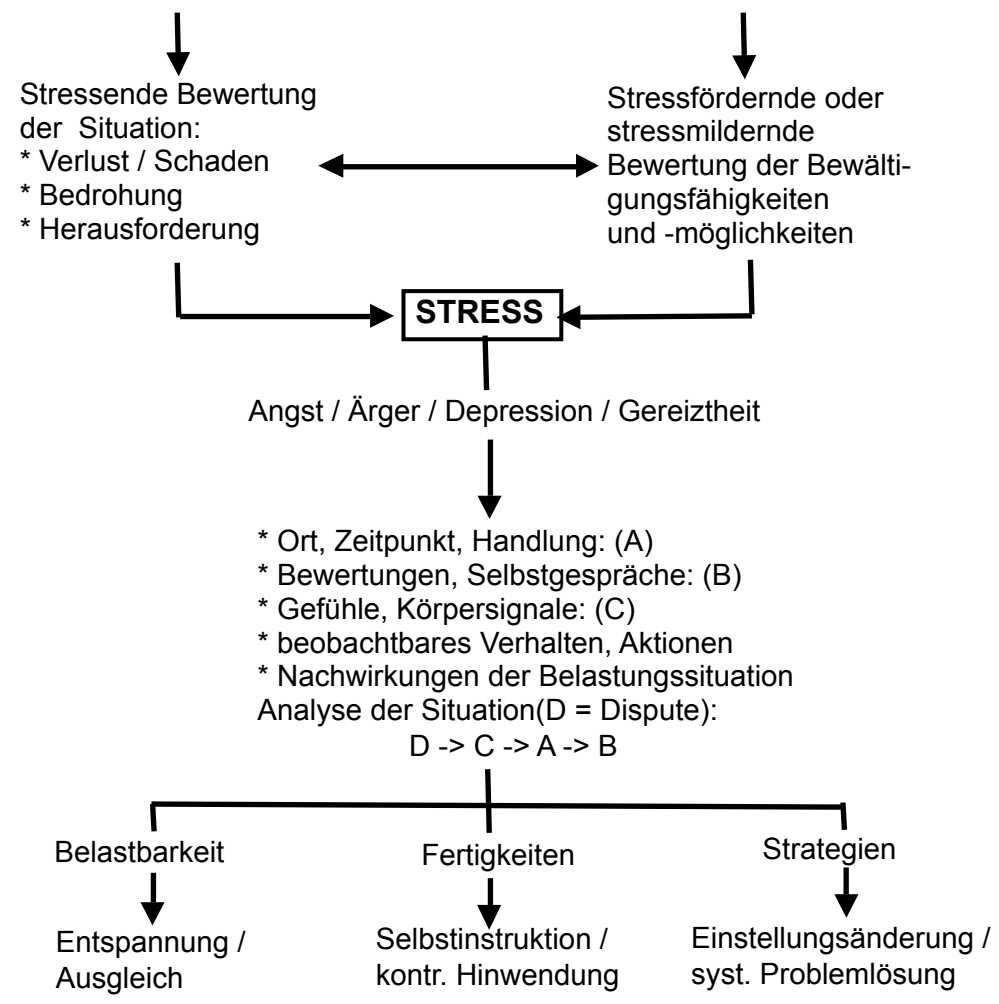

Grafik 21: Modell zu Entstehung, Analyse und Bewältigung von Stress

Stoßstange heranfährt. Drinnen sitzt ein Mann mit grimmiger Miene, der heftig die Lichthupe betätigt. Wie fühlen Sie sich? Sind Sie erschrocken und irritiert? Ängstigen Sie sich, sind Sie angespannt?

Plötzlich wird die Radiosendung mit einer Durchsage unterbrochen: „Achtung, Achtung, wir bitten um Ihre Unterstützung. Der Fahrer des PKW mit dem Kennzeichen ... (der hinter Ihnen) ist ein Kinderarzt und muss so schnell wie möglich in die nächste Klinik." Wie fühlen Sie sich jetzt? Wahrscheinlich ändert sich Ihre Gefühlslage in Richtung Mitgefühl und Sorge und vielleicht auch Erleichterung obwohl die äußere Situation unverändert ist. (Gens 2005)

Das Beispiel zeigt, wie sehr unsere Gefühle durch Gedanken und Informationen beeinflusst sind. Was wir fühlen, hängt entscheidend von unseren Deutungsmustern ab. Die meisten Menschen machen sich in so einer Situation negativ bewertende Gedanken wie: Spinner, Angeber, unsensibler Drängler, gefährlicher Idiot. Angenommen, Sie würden laut aussprechen, was Sie in der Situation beschäftigt, als Ich-Formulierung, als Selbstaussage, wie klänge das?

Und dann vergleichen Sie: Wie klänge das mit dem neuen Deutungsmuster „Kinderarzt im Notfalleinsatz“? Wenn Sie wissen (glauben, vermuten ...), dass da ein Mensch mit „edlen“ Absichten unterwegs ist, werden Sie eher Verständnis und Mitgefühl entwickeln, zum Beispiel so: „Ich bleibe ruhig und mache bei der nächsten Gelegenheit Platz für Eilige. Ich muss nicht mit Rasern konkurrieren. Wer 
weiß, was diesen Drängler so treibt?“ Und wie wirkt sich diese Selbstinstruktion auf Ihr Fahrverhalten aus? Auf Ihren Kreislauf, Ihren Puls, Ihre Magengegend?

Kurzum, das Gedankenexperiment mit dem Kinderarzt kann Ihnen ein Mantra liefern, das Sie in Zukunft in ähnlichen Situationen nutzen können. So eine Selbstinstruktion wäre eine Fertigkeit, die Sie immer wieder mobilisieren können. Etwa wenn ein aggressiv gestimmter Vater eines Schülers in Ihr Büro stürmt. Ein gutes Mantra kann Ihnen helfen, dann erstmal ruhig zuzuhören, nach dem ,,ToreroPrinzip“. Lassen Sie den Stier an sich vorbei, und studieren Sie ihn. Und achten Sie auf Ihren eigenen Ich-Zustand. Falls der Vater Sie in unbedingt negativer Weise abwertet, könnten Sie ihm mit einer deutlichen Ich-Botschaft Grenzen setzen. Und hinterher könnten Sie die Situation mit dem ABCD- Modell analysieren, im Sinne der kontrollierten Hinwendung. Das wäre dann Fortbildung durch Praxisreflexion, in der Arbeitszeit! Solche Situationen werden für Sie dann immer mehr zu einer sportlichen Herausforderung.

Wenn Sie merken, dass Sie in der letzten Zeit leicht mal gereizt oder übermäßig heftig reagieren, könnten Sie etwas für Ihren Allgemeinzustand tun. E. Wengle nennt sechs sinnvolle Bereiche: Ausgleichssport treiben, Entspannungsübungen genießen usw. (s. Grafik 21). Wenn Sie in diesem Sinn freundlicher mit sich umgehen, können Sie darauf achten, wie sich das insgesamt auf Ihre Einstellung zum Leben auswirkt. Und zur systematischen Problemlösung könnte es gehören, dass Sie die Belastungen pro Tag so planen, dass Ihnen Zeit für kurze Pausen, für Bewegung, für Besinnung bleibt.

Wenn Sie immer noch überzeugt sind, Sie bräuchten das alles nicht, können diese Verfahrensweisen Ihnen dennoch nützlich sein, wenn Ihnen jemand gegenüber sitzt, der oder die über beruflichen Stress klagt, z. B. im Rahmen eines Mitarbeitergesprächs. Dann können Sie die Rolle der aufmerksamen Zuhörerin (Dispute) übernehmen, das ABC-Modell im Hinterkopf aktivieren und die andere Person mit freundlichen MiniMax-Interventionen zum Denken bringen.

\subsection{Wie mentale Modelle Stress verursachen}

E. Wengles Konzept beantwortet die Frage, wie Stress entsteht und wie Sie stressenden Situationen begegnen können. Im Fokus steht die innere Bewertung der jeweiligen Auslöser, die von außen auf Sie zukommen. Zusätzlich legt das Modell nahe, präventiv die eigene Belastbarkeit zu trainieren, Fertigkeiten einzuüben, die Ihre Stress-Kompetenz betreffen, und langfristige Strategien zu planen, mit denen Sie Stress-Situationen von vornherein vermeiden können.

\subsubsection{Antreiber steuern unsere Prioritäten}

Wie kommt es aber, dass solche plausiblen Vorschläge ähnlich wie gute Neujahrsvorsätze immer wieder auf der Strecke bleiben? Die Antwort hat wieder mit verborgenen mentalen Modellen zu tun. Dafür ein Beispiel: Der Leiter einer sozialen Einrichtung klagt im Coaching über Zeitdruck. Ihn nerven die ständigen 
Telefonanrufe, die irrtümlich auf seinem Apparat landen und jedes Mal seine Arbeit unterbrechen. Seine bisherige Strategie: Er gibt den Anrufenden die korrekte Nummer und hofft (vergeblich) auf künftige Besserung. Beim nächsten Treffen berichtet er, er habe verstärkt auf die Fehlanrufe geachtet: ca. $80 \%$ der Anrufe seien gar nicht für ihn. Und eine Kollegin, die ihn drei Tage vertreten hatte, habe ihn gefragt, wie er diesen Wahnsinn auf Dauer aushalte.

Auch Schulleiterinnen und Schulleiter berichten von häufigen ungeplanten Arbeitsunterbrechungen. Dieselben Personen verlangen von sich, bei offener Tür zu arbeiten, um ständig erreichbar zu sein. Natürlich gäbe es praktische Lösungen: $80 \%$ jener Fehlanrufe ließen sich durch automatische Anrufumleitung und die Einrichtung einer neuen Nummer für erwünschte Anrufe beseitigen. Ein Türschild mit der Aufschrift „Bitte nicht stören“ und ein Anrufbeantworter könnten Schutz gegen spontane Unterbrechungen bieten. Wieso denken die Betroffenen nicht von sich aus an so naheliegende Lösungen?

Die Antwort: Weil mentale Modelle sie blockieren. Sinnvolle, praktische Lösungen greifen erst dann, wenn die betreffende Person innerlich für eine Änderung bereit ist. Bis dahin verhalten sich die Betroffenen so, als stünden sie unter dem geheimen Befehl: Sei gefällig! Mach's anderen recht! Und zwar immer! Und dieser „Antreiber“ ist ebenso streng wie unbewusst. Für den jeweils Betroffenen fühlen sich Reaktionen dieser Art als selbstverständlich richtig und angemessen an.

Mein nüchterner Hinweis, dass es dem Arbeitgeber schlicht zu teuer sein könnte, wenn ein Leiter seine Zeit als Telefonist verbringt, kam beim Betroffenen gut an; er musste ja nur die Adresse wechseln: Mach's dem Arbeitgeber recht! Die Orientierung am Bedürfnis eines anderen war ihm ja geläufig. Dass auch er selbst den Wunsch hatte, sinnvoller zu arbeiten, das wahrzunehmen, sich zu erlauben und in die Tat umzusetzen erforderte einen längeren Prozess des Dialogs und der Ermutigung.

Die Transaktionsanalyse unterscheidet fünf solche inneren Antreiber. Alle fünf basieren auf einer Grundeinstellung zum Leben und zu sich selbst, auf dem Glauben, dass ich mir und anderen meinen Wert, meine Lebensberechtigung immer wieder beweisen muss, indem ich mich besonders gefällig (1), stark (2), perfekt (3), anstrengungsbereit (4) und schnell (5) zeige (Stewart/Joines 1993, Kap. 10-16).

Der Antreiber „Sei anderen gefällig!“ folgt aus der Selbstabwertung „Ich bin nicht OK, nicht wertvoll, nicht wichtig“ und der Aufwertung der anderen: „,Du bist / Ihr seid OK“. Wertvoll sein kann ich nur, wenn ich etwas für die Wertvollen tue, also für die anderen.

„Sei stark!“ ' beschreibt die Einstellung zu mir selbst, die notwendig ist, um mein Ziel, es den anderen recht zu machen, so oft und so weitgehend wie nur möglich zu erreichen; dieser Antreiber spricht mich auf Durchhaltevermögen an, auf souveränes Auftreten um jeden Preis. Beispiel: Ein Top-Manager bemerkt beiläufig, in einer Kaffeepause: „Würde ich Supervision brauchen, käme ich mir vor wie ein Versager.“

Die Antreiber „,Beeil dich!“”, „Streng dich an!““ und „Sei perfekt!“ beziehen sich auf konkrete Aufgaben; sie fordern allesamt dazu auf, ein mögliches Scheitern zu verhindern; denn als Versager kann ich anderen nicht nützlich sein.

Wenn diese Antreiber die Oberhand gewinnen, können sie sich sehr destruktiv auswirken. Ein Leiter, der eine neue Stelle übernommen und dort großen Verände- 
rungsbedarf diagnostiziert hat, berichtet im Coaching, wie er den Kontakt zu seinem Arbeitsteam gefährdet:

„Ich glaube, ich krieg das immer besser hin, mir Zeit zu lassen, nur manchmal stoßen diese uralten Antreiber durch: Du schaffst nur was, wenn du immer fleißig bist; wer das nicht bringt, der hat's echt nicht drauf, auf den kannst du nicht zählen, der ist das Letzte - damit wurde ich ja auch konfrontiert, als ich klein und jung war. Das hat sehr viel Verärgerung und Angst bei mir ausgelöst und Wut, und wenn du das nicht perfekt alles hinkriegst, und zwar möglichst schnell, dann kriegst du keine Zuwendung mehr, dann bist du die letzte Sau, und ich hab manchmal den Eindruck, wenn die Pferde mit mir durchgehen, dann bin ich auch so hart und irgendwie unzugänglich, weil diese alten Emotionen wieder hochkommen. Und das ist dann immer so, dass ich denke: mein Gott-wenn dir das passiert, schaffst du's, wochenund monatelange mühselige Arbeit - plobb - kaputt zu machen. “

„Ich muss schnell und perfekt arbeiten“ - das sind die Antreiber, die der Leiter für sich identifiziert und mit denen er nicht nur seiner Umgebung Druck macht, sondern auch sich selbst schadet - bis hin zu ernsthafter gesundheitlicher Gefährdung. Beachtlicherweise versteht er den fatalen Wenn-Dann-Zusammenhang:

Nur wenn ich den Antreibern folge, werde ich anerkannt. Wenn ich immer alles perfekt hinkriege, dann bekomme ich Zuwendung, dann darfich dazu gehören, dann bin ich in dieser Welt willkommen. Dagegen: „Wer das nicht bringt, der hat's echt nicht drauf, auf den kannst du nicht zählen, der ist das Letzte. “

\subsubsection{Einschärfungen und Antreiber formen das Lebensdrehbuch}

Die Psychoanalyse nennt solche Wenn-Dann-Lebensmuster Wiederholungszwang. Eric Berne veranschaulicht den als Drehbuch, einem Filmskript ähnlich, nach dem unser Leben abläuft, ohne dass wir selbst dahinter kommen: das Ergebnis kindlicher Schlussfolgerungen aus den Erfahrungen mit Autoritätspersonen, mit der Realität und mit sich selbst; die kindlichen Schlussfolgerungen werden scheinbar oder tatsächlich durch Eltern oder andere Autoritätspersonen verstärkt; durch spätere Ereignisse werden sie zusätzlich „gerechtfertigt“, oft nur scheinbar, weil die Realität sich immer so interpretieren lässt, dass sie unsere Grundüberzeugungen bestätigt (vgl. 6.9.11; ausführliche Darstellung bei Stewart/Joines, 1993, Kapitel IV, S. $151 \mathrm{ff})$. 


\subsubsection{Antreiber kompensieren destruktive Einschärfungen}

Kinder bekommen Antreiber-Botschaften von Autoritätspersonen, Eltern, Großeltern, Lehrern usw., die wiederum aus deren Eltern-Ich-Zustand stammen und verbal mitgeteilt werden (s. Grafik 22, Pfeile 1 und 4). Verhängnisvoll wirken die, wenn sie Einschärfungen kompensieren müssen, die den Lebensmut bedrohen.

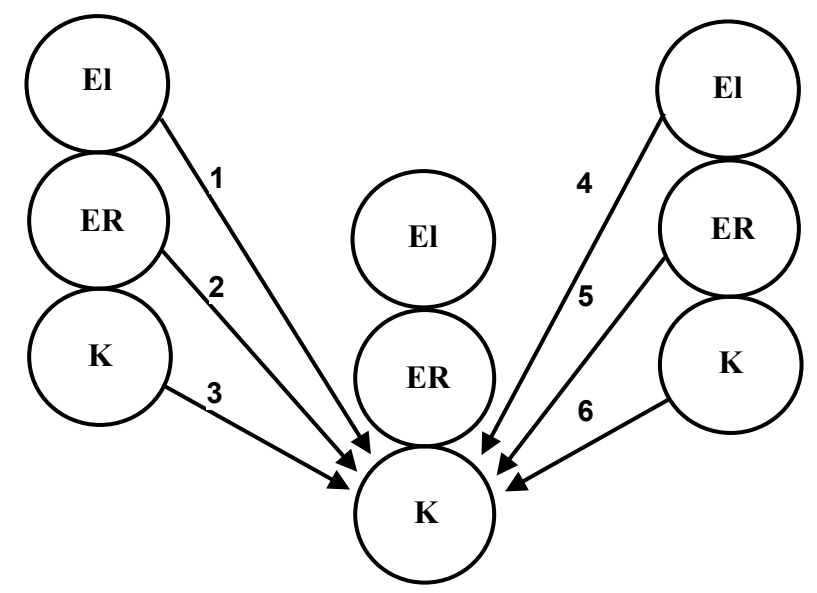

Grafik 22: Skriptmatrix

Zwölf solcher typischen Einschärfungen hat man zusammengestellt: Sei nicht! Sei nicht du selbst! Sei kein Kind! Werde nicht erwachsen! Schaff's nicht! Lass das / tu nichts! Sei nicht wichtig! Sei nicht zugehörig! Sei nicht nahe! Sei nicht gesund (normal)! Denk nicht! Fühle nicht!

Als Kinder sind wir solchen verbalen und nicht-verbalen Botschaften in der Regel wehrlos ausgesetzt. Manche schlucken wir wörtlich, manche verstehen wir ganz verquer. Solche aus dem Kindheits-Ich-Zustand der Autoritätspersonen stammenden Bann-Botschaften werden in der Regel in der frühen Kindheit mitgeteilt, oft nonverbal, in spezifischer Auswahl und nicht unbedingt in dieser Formulierung (Grafik 22, Pfeile 3 und 6).

Wenn die Kinder heranwachsen und verbal erreichbar sind, mildern die Autoritäten die Absolutheit der Einschärfungen, indem sie sie mit Antreibern verkoppeln. Das klingt dann so: Sei immer ein nettes braves Mädchen - dann bist du uns willkommen. Streng dich immer an, dann gewinnst du unsere Achtung. Sei immer perfekt - dann darfst du erfolgreich sein. Sei immer ein starker Junge, lass dir keine Schwäche anmerken - dann darfst du dazu gehören, wirst du anerkannt. Die Forderungen werden als Glaubenssätze verinnerlicht: „Ich darf nicht leben, es sei denn, dass ich dem Antreiber XY folge.“ „Ich darf nicht dazu gehören, es sei denn, dass ich..." usw. Je mehr ich mich bemühe, diesen Antreibern gehorsam zu sein, desto mehr verstricke ich mich in den Versuch, mir meine Lebensberechtigung, meine Anerkennung, mein Bejaht- und Geliebtsein selbst zu verschaffen (vgl. 6.7.1; 11.7.8). Die destruktiven Einschärfungen werden in Schach gehalten, indem ich mich von scheinbar einleuchtenden Antreibern scheuchen lasse.

Jeder Ich-Zustand lässt sich konstruktiv oder destruktiv mit Energie besetzen. Aus dem Eltern-Ich-Zustand kommen zum Glück auch Botschaften, die fürsorgli- 
che Zuwendung und orientierenden Schutz vermitteln. Im Kind-Ich-Zustand zeigen Erwachsene je nach Situation auch Spontaneität, Zivilcourage und die Fähigkeit, sich in eine Gruppe einzufügen (s. o. 6.9.3). Und aus dem Erwachsenen-Ich-Zustand hören Kinder schon früh und mit der Zeit zunehmend programmatische Botschaften, die lebenspraktische Kompetenzen vermitteln: Wie man im Straßenverkehr zurecht kommt, wie man die Zähne putzt, Kleider und Schuhe anzieht, mit Geld umgeht usw. (Grafik 22, Pfeile 2 und 5).

\subsubsection{Antreiber entwickeln Fähigkeiten}

Alle Antreiber fördern Fähigkeiten, solange sie nicht zwanghaft gelebt, nicht für die Erlaubnis zum Leben missbraucht werden. So fördert der Antreiber „Mach’s immer recht!“ in Zeiten von Eustress die Tugend der Empathie; folge ich ihm jedoch zwanghaft, lande ich in der Selbstaufgabe. Dann bin ich unfähig, überhaupt eigene Wünsche zu spüren, geschweige denn ihnen zu folgen. Ein sinnvolles Entwicklungsziel wäre es dann, Selbstbewusstsein zu entwickeln und eine Balance zwischen Empathie und Selbstbewusstsein herzustellen.

Aristoteles ergänzt in seiner Tugendlehre einzelne Tugenden jeweils um eine zugleich positive und kontrastierende Schwestertugend. Ideal ist die Balance der beiden, die jeweils bei Übertreibung ihre Schattenseiten haben: Empathie wird dann zur Selbstaufgabe, Selbstbewusstsein zu Egoismus. So lassen sich Entwicklungsziele in Wertequadraten darstellen (Schulz von Thun 1989, 38 ff; s. Grafik 23). Wer sich an Selbstaufgabe gewöhnt hat, kann durch Entwicklung von Selbstbewusstsein lebendiger werden (Pfeil von links unten nach rechts oben). Wer sich durch Egoismus isoliert hat, könnte Empathie lernen und seine Einsamkeit überwinden (Pfeil von rechts unten nach links oben).
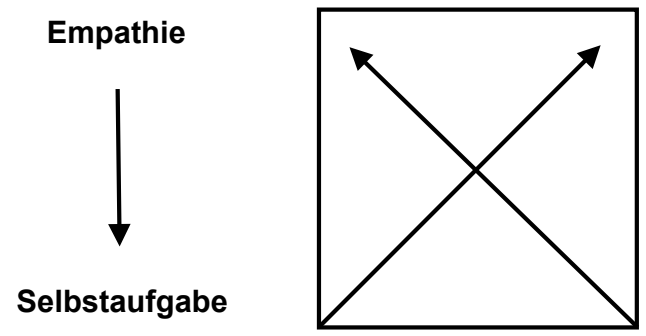

\section{Selbstbewusstsein}

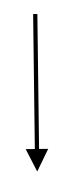

Egoismus

Grafik 23: Beispiel für ein Wertequadrat

\subsubsection{Antreiber springen an bei Distress}

Starker Stress wirkt bedrohlich; er gefährdet unsere psychische Stabilität, er trifft uns in unserem grundlegenden Lebensgefühl, im Bereich der Einschärfungen, Bann-Botschaften, Flüche, stellt bisher Erreichtes in Frage, nagt an unserem Selbstwertgefühl. 
Antreiber wirken also vor allem in Stress-Situationen; wenn Stress zur Regel wird, können sie sich verselbstständigen, sie können Stress-Situationen von sich aus erzeugen und sich schlimmstenfalls bis zum Burnout austoben. Sie werden dann als unumstößlich aufgefasst, ohne situativen Bezug übertrieben und befolgt, als ob eine Katastrophe hereinbrechen würde, wenn man sich nicht nach ihnen richtet. Die Katastrophe wäre, dass die „unter“ den Antreibern liegenden Einschärfungen die Oberhand gewönnen, uns den Boden unter den Füßen wegzögen. Damit das nicht passiert, aktivieren wir die Antreiber, um die lebensfeindlichen Einschärfungen „unter dem Deckel“ zu halten. Wir folgen dann wieder ihren Befehlen, obwohl sie für Erwachsene nicht mehr passen. Und ihre nützlichen Wirkungen verflüchtigen sich.

In ihrer Absolutheit sind die Antreiber nie erfüllbar; sie verursachen letztlich Enttäuschungen und Niedergeschlagenheit, Erschöpfung oder Wut. Um diese Gefühle zu vermeiden, versucht man, dem Antreiber noch besser gerecht zu werden ein Teufelskreis.

\subsubsection{Antreiber verhindern Autonomie}

Ein englischer Polizist beobachtet einen vierjährigen Jungen, der immer wieder um den Häuserblock herumläuft. Als er ihn das zehnte Mal an derselben Stelle vorbeikommen sieht, fragt er ihn, was er da treibe. Der Junge antwortet: „Ich habe mich entschlossen, von zu Hause wegzulaufen, aber mein Vater hat mir verboten, über die Straße zu gehen. “ (Negt 2002, 147)

Negts Kommentar dazu: „Der innere Zwang, etwas zu tun, dessen Ziele und Motive vom einzelnen gar nicht mehr wahrgenommen werden, befestigt sich bereits in früher Kindheit.“ „Selbst unter der Voraussetzung, daß äußere Bewegungsfreiheit vorhanden sein sollte, ist es keineswegs schon selbstverständlich, daß sie von der inneren Motivationskraft her auch benutzt werden kann." Gefangene Vögel singen von Freiheit, freie Vögel fliegen (2002, 146f).

Die Begegnung mit den eigenen Antreibern zeigt, wie wenig selbstverständlich es ist, sich als autonom, innerlich frei zu erfahren und zu verhalten. „Niemand ist mehr Sklave als der sich (für) frei hält, ohne es zu sein." (Goethe) Nach Berne, dem Begründer der Transaktionsanalyse, ist autonom, „wer die durch die Eltern vermittelten Werte nicht unbesehen übernimmt, wer sich von seinem Skript befreit hat, wer als ,Erwachsenenperson " ungetrübt urteilt, entscheidet und handelt und demnach frei über seine Ich-Zustände verfügen kann sowie keine symbiotische Haltung ... einnimmt.“ (Schlegel 1993, 22) Die Schwierigkeit dabei: Antreiber haben immer auch einen emotionalen Hintergrund: die Bindung an die Eltern oder wichtige Bezugspersonen, denen man Loyalität zu schulden meint, ohne sie gründlich zu prüfen. 


\subsubsection{Antreiber werden entschärft durch Erlaubnisse}

Die Befreiung aus dem Antreiberzwang muss da ansetzen, wo auch der Stress ansetzt: an den Einschärfungen. Entscheidend sind ermutigende Botschaften: „Wir freuen uns, dass du da bist.“ „Du schaffst das.“ „Du gehörst dazu.“ Wir erleben ja auch solche Gegenbotschaften, machen auch gute Erfahrungen mit Eltern und anderen Autoritätspersonen, die für einen förderlichen Ausgleich sorgen. Je früher die vermittelt werden, desto besser für die psychische Entwicklung. Da es selten jemanden geben wird, der oder die ganz ohne einschränkende Antreibererfahrungen durchs Leben kommt, sind immer wieder auch spätere korrigierende Erfahrungen notwendig.

Was ich brauche, wenn ich unter Antreiberdruck geraten bin, ist die glaubhafte, erfahrbare Erlaubnis, auch meine eigenen Bedürfnisse wahrnehmen und leben zu dürfen, um Hilfe zu bitten, zu improvisieren, mir Zeit zu lassen und Schritt für Schritt vorzugehen. Dabei kann ich die unter den Antreibern erworbenen Kompetenzen als wichtige Fähigkeiten für bestimmte Aufgaben einsetzen.

Die Transaktionsanalyse kennt ein wirksames Ritual für die Entschärfung von Antreibern, die Erlaubnistransaktion. Dies Ritual vermittelt die Gegenbotschaft zu dem Antreiber, der mir das Leben vergiftet, z. B.: Ich darf meine Wünsche wichtig nehmen. Statt: Sei immer gefällig! Ich kann aus Fehlern lernen. Statt: Sei immer perfekt! Zuvor wird herausgearbeitet: Was hättest du damals gebraucht? Welche verbale oder auch nonverbale Botschaft hätte dir Boden unter den Füßen vermittelt? Und dies Wort wird dann der Klientin oder dem Klienten zugesprochen, wie ein Mantra. Und so kann dies Mantra den Klienten im Alltag begleiten. (Schlegel, 1993, $72 \mathrm{ff})$

So ein Zuspruch besagt: Ich muss mich nicht verschämt verstecken. Ich kann für andere wichtig sein. Ich bin willkommen auf der Welt. Ich verstehe das als Einladung zur Selbstverwirklichung im Unterschied etwa zu Vater- oder Mutterverwirklichung. Der Theologe Eberhard Jüngel warnt in diesem Zusammenhang vor rücksichtsloser Selbstverwirklichung (Jüngel 1998, 45 f). ${ }^{78}$ Rücksichtslosigkeit wäre allerdings kein Zeichen wirklicher innerer Freiheit. Als Lebensziel würde kein guter Therapeut das unterstützen - nachzulesen z. B. bei Yalom $(2008)^{79}$.

78 Jüngel wendet sich gegen die verbreitete Auffassung, der Mensch könne den Wert seines Selbst aus eigenem Vermögen herstellen; tut er das „rücksichtslos“, wäre er rücksichtslos auch gegen sich selbst. Vgl. Anm. 79.

79 ,Solange man die Verantwortung ganz und gar auf andere schiebt, die einen unfair behandeln - ein rüpelhafter Ehemann, ein fordernder und nicht fördernder Chef, schlechte Gene, unwiderstehliche Zwänge -, wird die eigene Situation in der Sackgasse verharren. Sie selbst und nur Sie allein sind für die entscheidenden Aspekte Ihrer ganz persönlichen Lebenssituation verantwortlich, und nur Sie selbst haben die Macht, sie zu verändern." (Yalom 2008, $101 \mathrm{f}$; s. a. 41 und 142) 


\subsubsection{Vertiefung: Autonomie oder Freiheit eines Christenmenschen ${ }^{80}$}

1520 geschrieben, wurde Luthers Schrift „Von der Freiheit eines Christenmenschen" bald zum Bestseller; er traf damit einen bis heute entscheidenden Nerv. Wer diese Schrift versteht, der versteht die ganze Summe eines christlichen Lebens, behauptet Luther. Kern der Schrift ist die berühmte Doppelthese: „Ein Christenmensch ist ein freier Herr aller Dinge und niemandem untertan. Ein Christenmensch ist ein dienstbarer Knecht aller Dinge und jedermann untertan. "Recht verstanden sei das kein Widerspruch!

Wer möchte nicht frei sein? Sind wir frei? Wie frei bin ich wirklich? Was macht mir Angst? Was schüchtert mich ein? Was ist mir peinlich? Wie drücke ich mich nieder? Wie schade ich mir selbst? Die Fragen zielen ins Innere jedes Menschen, das er nach außen selten zeigt. „Immer nur lächeln und immer vergnügt, immer zufrieden, wie's immer sich fügt, Lächeln trotz. Weh und tausend Schmerzen, doch niemals zeigen sein wahres Gesicht.... Und wenn uns Chinesen das Herz auch bricht, wen geht das was an, wir zeigen es nicht." (Text: Ottilie Léon) So geht es zu im Land des Lächelns, in der Operette von Franz Lehar, nicht nur bei den Chinesen. Wer sich jemals geschämt hat und sich äußerlich zusammenreißt, der kann das nachfühlen, wie anstrengend das ist: äußerlich Haltung zu bewahren und innerlich tief verletzt zu sein.

Nur wer so zwischen innen und außen unterscheidet, meint Luther, kann verstehen, was christliche Freiheit ist und beruft sich auf Paulus: mehrfach beinahe $z u$ Tode gesteinigt, inhaftiert, geprügelt und doch guten Mutes: „Wenn auch unser äußerer Mensch zerstört wird, so wird doch unser innerer Mensch erneuert von Tag zu Tag. “ (2. Korinther 4,16) Das heißt, ich bin nicht die Marionette meiner jeweiligen äußeren Umstände.

Dazu als Beispiel eine Schlüsselszene, in der mir Luthers Verständnis der christlichen Freiheit aufging. Ein mir befreundeter Theologieprofessor hatte zu seinem 65. Geburtstag eingeladen. Im Laufe des Festes sprachen mehrere Redner darüber, was sie dem Jubilar verdanken. Ein Freund, auch ein Theologieprofessor, fiel mit seinem Beitrag aus der Reihe: „Ich teile“, sagte er, „mit unserem Geburtstagskind das Schicksal, dass ich nicht singen kann. Das hat mich immer sehr bedrückt, besonders in Gottesdiensten und bei Andachten. Mein Sternzeichen ist der Fisch, insofern lag es nahe, mein Handicap mit Hilfe der typischen Maulbewegungen der Fische zu vertuschen, also zwar nicht zu singen, aber doch so zu tun, als ob ich mitsänge. Ich fühlte mich allerdings nicht gut dabei. “

Kommentar dazu: Nicht singen können - das ist ein Charakteristikum des äußeren Menschen. Der Freund hält das für einen Makel, den er vertuschen möchte; er fürchtet vermutlich, sich zu blamieren, wenn andere das merken. Das ist eine Reaktion des inneren Menschen. Vielleicht hat er als Junge erlebt, dass er damit bloßgestellt wurde, z. B. beim Vorsingen in der Schule. Ein Musiklehrer z. B. lässt ihn vorsingen und sagt abfällig: „Ab in die Brummerabteilung, hoffnungsloser

80 Diese Vertiefung entspricht weitgehend dem ersten Teil meines Vortrags vor katholischen Ordensdirektoren (Christiansen 2017). 
Fall! “ Und die Mitschüler lachen. Das kann wie ein Fluch wirken. ${ }^{81}$ Falls der Junge davon zu Hause erzählt, wird er womöglich nochmals ausgelacht, vom Vater, von der Mutter oder von einem älteren Geschwisterkind.

So eine Beschämung kann sich tief in die Seele graben. So kommt der Glaubenssatz zustande: Mit mir stimmt was nicht. Wer nicht singen kann, ist behindert, ist kein vollwertiger Mensch, muss sich schämen. Ein Satz, mit dem er sich niederdrückt, der ihn anhält, sich zu verstecken, sich vor Blamage zu schützen. Und später: Es wäre peinlich, als Theologe nicht singen zu können. Ein Satz also auch, mit dem er einen Teil seines Lebensdrehbuchs schreibt, so dass er immer wieder dieselbe niederdrückende Erfahrung machen wird. Ein Satz des inneren Menschen, ein Satz der Unfreiheit. Die Notlösung des kleinen Pfiffikus: Fischmaulbewegungen. Und indem er so tut, als ob er singen könne, folgt sein äußerer Mensch der unfreien Direktive seines inneren Menschen.

Weiter: „Einmal geschah es, im Laufe eines mehrtägigen Seminars, bei einer Morgenandacht, da saß ich neben unserem Jubilar. Der kann auch nicht singen. Und der sang nicht nur nicht, der tat auch nicht so, als ob er sänge. Er merkte meine Schauspielerei und sagte halblaut zu mir: ,Du musst nicht singen. Und du musst auch nicht so tun, als ob du sängest!' Das war für mich der entscheidende Satz. Die Erlaubnis! Ich brauchte nicht mehr zu schauspielern. Und von da an das war eine ganz neue Erfahrung für mich - von da an konnte ich mich sogar an dem freuen, was andere können und ich nicht: am Gesang der anderen. “

Kommentar dazu: Der Theologe fürchtet die Blamage, fühlt sich unter Druck und schützt sich, indem er schauspielert, immer wieder. Jetzt aber hört er in dieser Schauspielerei ein befreiendes Wort, ein Wort von außen, das er sich selbst so wenig sagen kann, wie er sich durch Kitzeln selbst zum Lachen bringen könnte. Ein befreiendes Wort; genau so versteht Luther das Evangelium: als befreiendes Wort. Dies Wort holt ihn aus sich heraus, so dass er sein altes Schauspieler-Ich verlassen kann; es löst ihn heraus aus seiner krampfhaften Verkrümmung in sich selbst und bringt ihn dann zu sich selbst zurück, aber nicht in die alten Verhältnisse, sondern zu einem neuen Menschen, der so frei ist, sich am Gesang der anderen zu freuen und der sogar so frei ist, auf seine ihn beschämende Vergangenheit witzig und öffentlich zurückzublicken. Er verlässt sich in doppeltem Sinn: Er geht weg von seinem alten Menschen und verlässt sich auf das befreiende Wort, traut diesem Wort, schenkt ihm Glauben und kann so zu sich zurückkehren als zu einem neuen Menschen. „Er kommt von außen zu sich.“ (Jüngel 1978, 54ff.76)

So hat Eberhard Jüngel den Kern der Freiheitsschrift zusammengefasst. Das Evangelium ereignet sich als ein Wort, das den Menschen aus sich heraus holt, so dass er sein altes Ich verlassen kann, raus aus der Verkrümmung in sich selbst, um ihn dann freundlich zu sich selbst zurück zu bringen, jetzt aber zu einem neuen Menschen, der so frei ist, sich nicht mehr grundlegend um sich, um seinen Wert,

81 Seit ich dieses Beispiel in unseren Kursen erläutere, hat sich jedes Mal mindestens eine Person gefunden, die solche beschämende Erfahrung im Musikunterricht gemacht hat. Eine Stimmtherapeutin hat mir versichert, solche Erfahrungen seien ziemlich verbreitet und keineswegs eine Bagatelle. 
um sein Ansehen, ja: um seine Existenzberechtigung sorgen zu müssen. Auf solche Erfahrungen redet das Evangelium mich an.

Herbert Marcuse und Max Scheler kritisieren Luther: Dann ist Freiheit nur eine Sache der Innerlichkeit, die äußere Freiheit dagegen mehr oder weniger belanglos? Luther ein frommer Fürstenknecht? (Vgl. Jüngel 1978, 59ff). Das sagen auch smarte Schüler, die im Geschichtsunterricht aufgepasst haben. Sie verweisen auf den Bauernkrieg, 1525. Wo war da Luther mit seiner Freiheit? Den Schülern wäre zu sagen: Luther hatte viel Sympathie für die Forderungen der Bauern. Aber er war strikt gegen die politische Instrumentalisierung des Evangeliums. Die Verwicklung von Religion und Politik in den heutigen kriegerischen Auseinandersetzungen könnte uns entsprechend nachdenklich machen.

Entscheidend ist für Luther: Nicht nur die Freiheit hat ihren Ort im inneren Menschen, sondern auch die Unfreiheit. (Jüngel 1978, 72f u. 76) Das ist der zentrale Punkt. Der innere Mensch, die Seele ist der anthropologische Ort, an dem sich sowohl Freiheit als auch Knechtschaft des Menschen entscheiden. Seine Frömmigkeit und Freiheit wie auch seine Bosheit und sein Gefängnis sind nicht leiblich noch äußerlich. Gesundheit, Krankheit, Hunger, Durst, Gefängnis oder Freizügigkeit - von all diesen äußerlichen Dingen „,reicht keins bis an die Seele, sie zu befreien oder zu fangen, fromm (d.h. Gott recht) oder böse zu machen. " (Luther [1520] 1982, Absatz 3)

Auch Reisefreiheit, Konsumfreiheit, Wahlfreiheit - so schön sie oft sind: Sie schaffen mir Bewegungsfreiheit, Freiheit für meinen äußeren Menschen; meinen inneren Menschen aber nehme ich dabei immer mit. Mein innerer Mensch: Das bin ich mit all meiner Vergangenheit, also auch mit allen jemals erfahrenen Einschärfungen und Antreibern, die mich innerlich besetzen und mich äußerlich in meinem Verhalten steuern.

Wirkliche Freiheit ist Freiheit von der eigenen Gefangenschaft und fängt darum in der Seele, im Innersten an. Was reicht denn bis in die Seele, sie zu verändern? In die Tiefe der Seele reicht nach Luther nur das Wort, eine bestimmte Qualität des Wortes. Wie es der Seele ergeht, das hängt davon ab, an welches Wort sie sich klammert. „Wie das Wort ist, so wird auch die Seele durch es, gleichwie das Eisen glutrot wird wie das Feuer durch die Vereinigung mit dem Feuer. " (A. a. O., Abs. 10) Die Seele, das Innere des Menschen, ist der Ort der Entscheidung über Freiheit und Unfreiheit des Menschen, sie lebt davon, dass sie auf das Wort hört, auf das zur Freiheit rufende Wort: nicht auf ein Wort, das der Mensch sich selber sagt, sondern auf ein fremdes, von außen auf ihn zukommendes Wort. So wie das Wort für den schauspielernden Theologen: „Du musst nicht singen. Und du musst auch nicht so tun, als ob du sängest! “ Das war die Erlaubnis, die Einladung in die Freiheit. Strukturell eine frappierende Ähnlichkeit mit der Erlaubnistransaktion bei Eric Berne! (Vgl. 11.7.7 und 6.7.1) 


\subsubsection{Antreiber können Sie selbst diagnostizieren}

Sie können sich Ihre bevorzugten Antreiber mit Hilfe des Antreibertests von Kälin und Müri bewusst machen. Gehen Sie ins Internet und geben Sie ein: https://www.transaktionsanalyse-online.de/wp-content/uploads/2017/09/Die-in neren-Antreiber.pdf

Sinnvoll ist die Auseinandersetzung mit folgenden Fragen:

- Wie weit ist der Antreiber heute noch sinnvoll?

- Wie weit verzerrt er meine Wahrnehmung der gegenwärtigen Situation?

- Was würde geschehen, wenn ich den Antreiber in sämtlichen Situationen ernst nähme? Und was, wenn ich ihn über Bord würfe?

- Welche Vor- und Nachteile bringt die rigorose Befolgung des Antreibers in der gegenwärtigen Situation?

- Welche Vor- und Nachteile bringt eine situationsbedingte Einhaltung des Antreibers, und wie müssten die Bedingungen aussehen?

Wenn Sie auf diese Weise Ihre Selbstwahrnehmung schärfen, können Sie mit der Zeit Stress frühzeitig erkennen, steuern und von vornherein durch geeignete Strategien vermeiden. Sie schärfen damit zugleich Ihren Blick für bestimmte Verhaltensweisen bei Ihren Kolleginnen und Kollegen, die auf Antreibermuster schließen lassen. Tabelle 7 bietet einen Überblick und einige Beispiele.

Tabelle 7: Übersicht über Antreibersymptome und Erlaubnisse

\begin{tabular}{|l|l|l|l|}
\hline Symptome & Antreiber & Erlaubnis & Maßnahmen \\
\hline $\begin{array}{l}\text { Ständige Erreichbar- } \\
\text { keit, Unterbrechungen, } \\
\text { unangemeldete } \\
\text { Besucher }\end{array}$ & $\begin{array}{l}\text { Ich muss es anderen } \\
\text { immer recht machen. }\end{array}$ & $\begin{array}{l}\text { Ich darf eigene } \\
\text { Wünsche haben und } \\
\text { mich abgrenzen. }\end{array}$ & $\begin{array}{l}\text { Nein sagen; } \\
\text { Anrufbeantworter } \\
\text { nutzen; Sprechzeiten } \\
\text { angeben. }\end{array}$ \\
\hline $\begin{array}{l}\text { Ich gehe über meine } \\
\text { Belastungsgrenze, bin } \\
\text { verspannt und müde. }\end{array}$ & $\begin{array}{l}\text { Ich muss mich immer } \\
\text { anstrengen. }\end{array}$ & $\begin{array}{l}\text { Ich darf Pausen } \\
\text { machen und mich } \\
\text { erholen. }\end{array}$ & $\begin{array}{l}\text { Pausen, Entspannung, } \\
\text { Bewegung; Feierabend } \\
\text { ohne Arbeit }\end{array}$ \\
\hline $\begin{array}{l}\text { Ich halte eine Fassade } \\
\text { aufrecht: „Da muss ich } \\
\text { jetzt durch!“ }\end{array}$ & $\begin{array}{l}\text { Ich muss immer stark } \\
\text { sein. }\end{array}$ & $\begin{array}{l}\text { Ich darf wichtig } \\
\text { nehmen, wie mir } \\
\text { zumute ist. }\end{array}$ & $\begin{array}{l}\text { Mich mitteilen, um } \\
\text { Hilfe bitten, Ärger, } \\
\text { Enttäuschung u.a. } \\
\text { äußern. }\end{array}$ \\
\hline $\begin{array}{l}\text { Ich halte mich an } \\
\text { Details fest. }\end{array}$ & $\begin{array}{l}\text { Ich muss immer } \\
\text { perfekt sein. }\end{array}$ & $\begin{array}{l}\text { Ich darf aus Fehlern } \\
\text { lernen. }\end{array}$ & $\begin{array}{l}\text { Ich konzentriere mich } \\
\text { auf das Wesentliche. }\end{array}$ \\
\hline $\begin{array}{l}\text { Ich erledige alles } \\
\text { sofort, auch zwischen } \\
\text { Tür und Angel. }\end{array}$ & $\begin{array}{l}\text { Ich muss mich immer } \\
\text { beeilen. }\end{array}$ & $\begin{array}{l}\text { Ich darf mich an } \\
\text { meinem Rhythmus } \\
\text { orientieren. }\end{array}$ & $\begin{array}{l}\text { Ich lasse mir Zeit. } \\
\text { Langsamer ist oft } \\
\text { schneller. }\end{array}$ \\
\hline
\end{tabular}

Nicht zuletzt können Sie bei auffälligem Verhalten von Kindern und Jugendlichen überlegen, welche Muster da im Hintergrund eine Rolle spielen könnten. Beispiele: Einer Tochter, die sich um gute Schulnoten müht, schärft die Mutter ein: „Wir sind Arbeiter. Bild dir nicht ein, du seist was Besseres!“

Ein Sohn, der sein Examen immer wieder aufschiebt, hat vom Vater gehört: „Ich bin ein Versager, und du wirst es auch nicht schaffen!“

Wenn Sie solche inneren Botschaften bei einer Schülerin oder einem Schüler vermuten - welche Botschaften könnten Sie dagegen aufbieten? 
Schließlich können Sie - mit etwas innerem Abstand - beobachten, welche Antreibermuster möglicherweise das gesamte Schulklima beeinflussen oder sogar prägen. Wie wird im täglichen Miteinander autonomes Verhalten gefördert? Woran ist zu merken, dass die Freiheit eines Christenmenschen nicht nur zitiert, sondern auch erfahren werden kann?

\subsection{Stress und Überlastungsreaktion (Burnout) im Schulalltag}

Sie haben das Thema Stress aus verschiedenen Perspektiven angesehen: das Energie-Modell von M. Stark, das Kompetenz-Modell von E. Wengle mit der Bewertung sowohl der Stressreize als auch der eigenen Bewältigungsfähigkeit. Diese inneren Aspekte wurden durch das Skript- und Antreiberkonzept der Transaktionsanalyse vertieft. Viele Anregungen für Sie, über sich selbst, über Ihren Eustress und Distress, nachzudenken und Ihre mentalen Modelle zu überprüfen - ein wichtiges Thema im Sinne persönlicher Meisterschaft, Ihrer Fähigkeit, mit Ihrem eigenen Stress zurecht zu kommen.

Im Schulalltag werden Sie in Ihren täglichen Kontakten, in Einzelgesprächen und auch in der Arbeit mit Ihrer Leitungsgruppe immer wieder auf Stress-Signale stoßen. Wenn Distress sich in Ihre Gremienarbeit einschleicht, leidet die Stimmung. So berührt das Thema auch die Dimension des Teamlernens. Arbeitstreffen werden dann als lästige Pflicht erlebt, nicht als anregende Gelegenheit, sich gegenseitig zu beraten, voneinander zu lernen, kreative Strategien zu ersinnen.

Je mehr das der Fall ist, desto wahrscheinlicher werden Sie sich fragen, was die Stressanzeichen im Kollegium mit der Struktur Ihrer Schule zu tun haben; auch Systemdenken ist also angebracht. Um bei dieser Gelegenheit alle fünf Dimensionen zu würdigen: Eine attraktive Vision für alle könnte es sein, dass man morgens erwartungsvoll die Schule aufsucht und sich am Nachmittag angeregt und nachdenklich nach Hause begibt.

Bleiben wir beim Schulalltag: Wie können Sie Stress in Ihrer persönlichen Umgebung erkennen? Es gibt Lehrerinnen und Lehrer, denen ihr Beruf Freude macht, auch nach vielen Jahren noch, die ihren Eustress als sportliche Herausforderung nehmen. Und es gibt die, die über Überlastung klagen. Hingeworfene Bemerkungen, ,,alles wird zu viel“, gereizte Reaktionen, Zeitdruck, Krankmeldungen werden Sie, die Leitung veranlassen, hinzuhören und hinzusehen. Wie wirkt sich das aufs Gesamtklima aus? Wer steckt wen an? Wie sind die Reaktionen, wenn jemand länger ,ausfällt“? Die stabilen Lehrkräfte müssen zusätzliche Vertretungsstunden übernehmen, die Stundenplaner kommen unter Druck, die Kontinuität des Unterrichts leidet; folglich liegt es im Interesse aller Beteiligten, es möglichst nicht so weit kommen zu lassen, sondern das Thema präventiv zu bearbeiten. 


\subsubsection{Die Diagnose steuert die Behandlung}

Statistiker der Krankenkassen analysieren die Stressbelastung in der deutschen Arbeitswelt (einschließlich der Schulen); die Zahlen liegen durchweg deutlich über $50 \%$. Überdurchschnittlich hoher Dauerstress kann zur Krankschreibung führen. Schnell ist dann von Burnout die Rede. ${ }^{82}$ Schaarschmidt und Kieschke (2007) berichten dramatische Befunde: die an mehr als 10.000 Personen durchgeführte Potsdamer Lehrerstudie ergab vier Belastungstypen unter den Lehrkräften: ${ }^{83}$

- Muster G (Gesundheit): $17 \%$

- Muster S (Schonung): $23 \%$

- Risikomuster A (Selbstüberforderung): 30

- Risikomuster B (Resignation): $30 \%$

Demnach wären $60 \%$ aller Lehrkräfte burnoutgefährdet oder schon im Burnout. Scheuch et al. (2015) relativieren diese Zahlen; sie weisen kritisch darauf hin, dass es bis heute keine einheitliche Definition des Burnout-Syndroms gibt. Die Messinstrumente unterscheiden sich stark und erfüllen nicht die klassischen TestGütekriterien.

Kundige wenden ein, Burnout gebe es gar nicht und sprechen stattdessen von Überlastung und depressiver Störung. ${ }^{84}$ Im aktuellen ICD-Schlüssel, den die Ärzteschaft für die Diagnostik gebraucht und mit dem sie die Finanzierung ärztlicher Behandlung begründen muss, kommt Burnout tatsächlich nicht vor; hartes Faktum! So kommt es - über den ICD-Schlüssel - immer wieder zu langen Aufenthalten in Rehabilitationseinrichtungen; wenn eine ,ausgebrannte Lehrkraft“ von dort zurückkommt, hat sich allzu häufig weder für sie persönlich noch hinsichtlich ihrer Arbeitsverhältnisse Wesentliches geändert. Schnell stellen sich dann die Überlastungssymptome wieder ein.

Kraemer (2010, $96 \mathrm{ff})$ polemisiert heftig gegen diese Steuerung. Angesagt sei nicht Warten auf Gesundheit in langen Reha-Zeiten, sondern ambulantes Coaching zur Umstellung von Arbeits- und Lebensgewohnheiten. Auftanken gehe nicht durch

82 In den neunziger Jahren wurde jedes Jahr noch über die Hälfte der Lehrkräfte wegen Dienstunfähigkeit pensioniert. 2012 war das nur noch bei 15 Prozent der Pensionierungen der Grund. Die Erklärung für den Rückgang scheint zu sein, dass es Versorgungsabschläge bei vorzeitiger Pensionierung gibt. Seit diese Regel gilt, sinkt die Zahl kontinuierlich. (o. V. 2014)

83 Als belastend nennen die Lehrkräfte das Verhalten schwieriger Schüler, große Klassen und hohe Stundenzahlen. Selbst die Lehrkräfte mit dem günstigsten Beanspruchungsmuster G teilen diese Sicht.

84 „Ausgebranntsein (burn-out): Ein moderner, umgangssprachlicher Begriff für ein Syndrom körperlicher, emotionaler oder auf die Einstellung bezogener Erschöpfung, das durch verminderte Arbeitskraft, Müdigkeit, Schlaflosigkeit, Depression, vermehrte Anfälligkeit für körperliche Erkrankungen und - zur zeitweiligen Erleichterung - Neigung zu Alkohol oder zu anderen psychotropen Substanzen gekennzeichnet ist.“ (Dilling 2009, 26) Das Syndrom sei als Belastungsreaktion gegenüber zu hohen Leistungs- oder emotionalen Anforderungen zu verstehen, die sich aus übermäßigem beruflichem Engagement herleitet; meistens handele es sich um depressive Störungen. 
Nichtstun; das mache eher immer schlapper. Die Lösung liege im Wechsel von Anspannung und Entspannung.

Fellner (2011) bestätigt die Notwendigkeit, die Symptombilder genau zu unterscheiden: Antriebsstörung, Grübeln und die Unfähigkeit, irgendeine Freude zu empfinden, das sind die typischen Symptome, für die kein klarer Anlass zu finden ist. Diese Personen brauchen eine andere Behandlung als Personen, die depressive Störungen im Zusammenhang mit einer Überlastungsreaktion entwickeln.

Die Behandlung der Überlastungsreaktion (früher: „Burnout“) muss sowohl die innere Dynamik als auch die Situation am Arbeitsplatz in den Blick nehmen so auch Schulze und Sejkora $(2015,39)$. Eine begrenzte zeitliche Arbeitsbefreiung sei angezeigt, um somatische Beeinträchtigungen aufzufangen (s.o. 11.5). Für die Zeit danach gehe es um eine detaillierte Auseinandersetzung mit Stressfaktoren am Arbeitsplatz, um alternative Strategien für das Arbeitsumfeld, um Entspannungsverfahren und Stressbewältigungstechniken.

Welche Möglichkeiten haben Sie als Leitung, um betroffenen Lehrkräften eine nahe liegende Fehlsteuerung zu ersparen? Wichtig ist es in jedem Fall, Augen und Ohren für erste Anzeichen von Überlastungsreaktionen offen zu halten: Sawu bona! Dazu folgen jetzt einige zusätzliche Hinweise. Danach geht es um die Frage, wie Sie im Einzelfall intervenieren können.

\subsubsection{Indikatoren für Überlastungsreaktionen (Burnout)}

So wie nicht alles Mobbing ist, was Mobbing genannt wird, so ist auch nicht alles krankhafte Überlastung, was im Alltag schnell mit „Burnout“ bezeichnet wird. Ähnlich wie bei Mobbing ist zwischen einzelnen Symptomen und einem ausgeprägten Krankheitssyndrom zu unterscheiden, was allerdings nicht dazu führen sollte, Einzelsymptome zu bagatellisieren. Übereinstimmung besteht darin, dass eine Kombination der folgenden Kriterien typischerweise zur Überlastungssymptomatik führt: geringe Distanzierungsfähigkeit von der Arbeitssituation, starke Resignationstendenz bei Misserfolgen und geringe Fähigkeit zum Einholen sozialer Unterstützung.

Durchgängig wird - in der Burnout-Begrifflichkeit - eine prozesshafte Entwicklung beschrieben, die in einem massiven Krankheitszustand ihren Tiefpunkt erreicht. Einige Fachleute kommen mit drei Phasen aus (Kraemer 2010) ${ }^{85}$, andere unterscheiden sieben (Schröder 2008, 21 ff) bzw. sogar zwölf Stadien (Fellner 2011). Einen Kompromiss bringt P. Schulte (Schulte 2018, 15 ff):

\section{Enthusiasmus:}

Nur wer einmal für etwas gebrannt hat, kann auch ausbrennen. Symptome: Selbstüberschätzung, zu hohe Identifikation mit der Arbeit; Vernachlässigung von regelmäßigen Pausen.

85 Die drei Phasen Überlastung, Alarmierung und Knockout bei Kraemer entsprechen bei Schulte den Phasen 3-5. 


\section{Stagnation:}

Mentales Modell: Je mehr ich mich anstrenge, um so erfolgreicher bin ich. Dies Bild kommt ins Wanken. Mehr und mehr Energie muss eingesetzt werden, um die Ziele zu erreichen. Folge: Ängste, Spannungen, Reizbarkeit, Erschöpfung.

\section{Frustration:}

Selbst höchster Energieaufwand ist vergebens. Folge: Frustrationsgefühl. Reaktionen: krankhaftes Konsumverhalten: Essen, Trinken, Alkohol, Drogen. Körperliche Symptome stellen sich ein.

\section{Apathie:}

Innere Kündigung; eventuell Boykott. Vermeidung von Veränderung; Probleme werden ignoriert. Das berufliche und private Sozialleben ist ernsthaft in Gefahr. Wer keine Hilfe findet, landet in Phase 5.

\section{Burnout-Syndrom:}

Schwere Lebenskrise; professionelle Hilfe ist nötig. Gefühle von Sinnlosigkeit, Versagen, Misstrauen. Starke negative Gefühle gegen sich selbst und andere.

Schulze und Sejkora $(2015,50)$ zeigen an einem konkreten Beispiel, wie die innere Dynamik einer Überlastungsreaktion mit transaktionsanalytischen Konzepten zu erfassen ist. In Frage kommen dafür u.a. das Zuwendungs-Muster (s. o. 6.7.1), Skript-Einschärfungen, Antreiber-System und die Skript-Matrix (s.o. 11.7), Konzepte also, die Sie bereits kennengelernt haben; Beispiele:

Positive Zuwendung wird nur als bedingte wahrgenommen; daran, an freundlichem Feedback also, besteht hoher Bedarf. Negative Zuwendung wird nur als unbedingte wahrgenommen, als Ablehnung und Vernichtung der Person.

Die Skript-Einschärfung ist typischerweise „Sei nicht!“, der damit verbundene Glaubenssatz „Ich bin nicht willkommen.“ Kompensiert wird diese Einschärfung durch drei, nicht nur einen, Antreiber, nämlich:

- Sei perfekt! („Ich mache meine Arbeit zu $150 \%$ !“)

- Streng dich an! (Zur durchschnittlichen Wochenarbeitszeit: „60, 70 Stunden, das ist halt notwendig.")

- Mach es allen recht! (,Mehr Sorgen macht mir die Einschätzung des Chefs.“)

So hofft der Betroffene, Daseinsberechtigung für sich zu erlangen. ${ }^{86}$ Zusätzlich zu diesen Indikatoren lässt sich mit Hilfe der Abwertungstabelle ermitteln, in welchem Ausmaß jemand Stress-Symptome wahrnehmen, als bedeutsam zulassen und

86 Kraemer (2010, $161 \mathrm{f})$ schreibt als ehemals von Burnout Betroffener; früh eingeschult hatte er Mühe, den Anforderungen gerecht zu werden. In seiner Familie galt er als Schulversager und erinnert sich aus dieser Zeit an elterliche Einschärfungen: „Das schaffst du sowieso nicht ...“, „Aus dir wird sowieso nichts ...“. Mit der Parole „Euch zeig ich’s!“ wollte er das kompensieren. Diesem Antreiber folgte er so bedingungslos, dass der berufliche Erfolg irgendwann im Burnout endete und eine grundlegende Neuorientierung nötig machte. Die 
als veränderbar ansehen kann (s. o. 6.9.11.3). Je weniger jemand diese Realitäten ausblendet, desto eher ist ein Coaching-Ansatz geeignet, einen Weg aus der Überlastungsreaktion heraus zu finden.

Je hartnäckiger dagegen Ausgangsreize, deren Bedeutung und Verhaltensalternativen ausgeblendet werden, Realität also verleugnet wird, desto eher ist eine längere Psychotherapie angezeigt. Eine für Verleugnung typische Äußerung: „Mit dem ständigen Kopfschmerz und der Müdigkeit muss ich einfach leben, die merke ich schon gar nicht mehr." (Schulze \& Sejkora 2015, 48; ausführlich Sejkora und Schulze 2016, $206 \mathrm{ff}$ )

Die Kenntnis dieser Konzepte kann z.B. im Rahmen kollegialer Beratung in Gruppen die Wahrnehmung für solche Prozesse schärfen und so präventive Wirkung haben. Coaching bzw. Therapie aber sind außerhalb der Schule in Anspruch zu nehmen.

\subsubsection{Systemische Präventionsmöglichkeiten}

Umgang mit Stress und Überlastung ist ein allgemein gesellschaftliches Thema. Scheuch et al. kommen zu dem Fazit: Die widersprüchlichen Befunde reichen nicht aus, Burnout als typische „Lehrerkrankheit“ zu bezeichnen. Dennoch komme dem Burnout-Syndrom, insbesondere der Erschöpfungskomponente, eine zentrale Bedeutung unter den Gesundheitseinschränkungen bei Lehrkräften zu.

Auch wenn manche Experten den Schwerpunkt der Problematik weniger in den arbeitsorganisatorischen als vielmehr in den intrapersönlichen und zwischenmenschlichen Bedingungen sehen (Schröder 2008, 13), hilft der Zugang über das System, das Thema zu enttabuisieren und die einzelnen Betroffenen zu entlasten. Der intrapersönliche Antreiber „Sei immer stark!“ trägt dazu bei, das Thema überhaupt zu vermeiden.

Je besser ein Schulkollegium mit Stress und Überlastungsgefahr zurecht kommt, desto günstiger für die Arbeitszufriedenheit, für die Qualität der Arbeit, für die Verlässlichkeit des Unterrichts. Wie können Sie dies Thema ins System bringen? Systemorientierte Prävention können Sie betreiben, indem Sie eine Selbstdiagnose Ihres Kollegiums zum Thema Stress anregen. Ich sehe mehrere Möglichkeiten:

- Wenn in Ihren Gesamtkonferenzen in Projektgruppen gearbeitet wird, wäre das Thema „Stressreduktion und Gesundheitsförderung in unserer Schule“ für eine der Arbeitsgruppen geeignet. Die Teilnehmerinnen könnten die Fragestellung in Richtung ihrer Interessen präzisieren und mit den ,sechs Schritten der Problemlösung" bearbeiten (s. o. Kapitel 7 und 8).

- In diesem Zusammenhang könnte diese Gruppe das Angebot der Potsdamer Lehrerstudie nutzen. Schaarschmidt und Kieschke (2007) fanden hohe Zahlen zur Burnout-Gefährdung von Lehrkräften. Die Autoren bieten ein Online-Verfah-

paulinische Rechtfertigungslehre (zusammen mit dem eformatorischen Freiheitsverständnis) bildet dazu einen deutlichen Kontrast (vgl. die Vertiefung 11.7.8); sie berührt sich dabei m.E. mit dem Konzept der Skriptfreiheit. 
ren an, mit dem die Stress verursachenden Faktoren eines ganzen Schulsystems identifiziert werden können. ${ }^{87}$ Die auf diese Weise gefundenen Baustellen lassen sich dann methodisch bearbeiten.

- Gute Anregungen bietet auch das Wiener Resilienz-Modell ${ }^{88}$, das im Rahmen des Betrieblichen Gesundheitsmanagements entwickelt wurde und mehrere der bisher aufgeführten Konzepte benutzt. Wenn Sie eine gesundheitsbewusste Haltung auch im Kollegium fördern, beugen Sie Tendenzen zu Fluktuation, Absentismus und höherem Krankenstand wirksam vor (Rolff 2017, 40).

Beide Vorgehensweisen wären zugleich ein geeigneter Einstieg ins ,,Systemdenken“, in die „fünfte Dimension“ einer Lernenden Organisation.

- Mehrere Experten empfehlen Gruppensupervision und kollegiale Beratung als optimales Mittel gegen die Burnout-Gefahr ${ }^{89}$. Zur kollegialen Beratung haben Sie mehrere Varianten bereits kennengelernt (s. o. 5.3). Das wäre ein Ansatz über das Teamlernen.

Die Resonanz auf kollegiale Beratung in unseren Kursen verblüfft uns immer wieder: Ja, wer einen Fall einbringt, erlebt den Gruppenprozess als angenehme und hilfreiche Zuwendung; ja, die Gruppe empfindet die Zusammenarbeit und die Konzentration auf eine konkrete Situation als lehrreich und teamfördernd. Ja, es wäre durchaus wünschenswert, diese Art der Beratung strukturell in den Schulalltag einzubauen. Und dann: Aber dafür fehlt die Zeit! Klingt nach Absurdistan - oder? Diese Reaktionen unterstreichen die Bedeutung einer sinnvollen Konferenzstruktur; Möglichkeiten dazu wurden in Kapitel 8 diskutiert.

\subsection{4 Überlastete MitarbeiterInnen führen}

Prävention ist gegenüber der notfallartigen Schadensbearbeitung in jeder Hinsicht günstiger: Zeitaufwand und Kosten sind erheblich geringer, von den persönlichen Schädigungen ganz zu schweigen. Es kommt also darauf an, auf frühe Warnzeichen zu achten - bei sich selbst und bei anderen - und nicht zu warten, bis es zu einem Totalausfall kommt. Die Phasen-Charakteristika und das Antreiberverhalten sind deutliche Warnzeichen.

Petra Bernatzeder $(2018$, 39) bietet einen hilfreichen Fragenkatalog an, der im Sinne von Burnout-Prävention auch für Schulen geeignet ist, solange die letzte Stufe des Burnout-Verlaufs noch nicht erreicht ist (s. o. 11.8, P. Schulte zu Stufe 5):

- Woran könnten Sie sehen, dass jemand burnoutgefährdet ist? Sie nehmen z. B. wahr, dass eine Lehrerin seit Wochen reizbar, müde, unwirsch wirkt. Sie möchten, dass sie weiß: Sie wird wahrgenommen. Sie laden sie zu einem Gespräch ein,

$87 \mathrm{Zu}$ finden unter: https://www.vbe.de/service/potsdamer-lehrerstudie

88 www.impulspro-wien.at, www.lebensberater.at; Rolff (2017, $40 \mathrm{ff})$ empfiehlt ebenfalls, Gesundheitsförderung als Teil der Schulentwicklung zu betreiben und verweist auf positive Forschungsergebnisse zur Arbeit mit dem Salutogenese-Konzept von Antonovsky.

89 Schaarschmidt/Kieschke 2007; Bauer 2007, 207 ff und Bauer o. J.a 
etwa so: „Ich finde es wichtig, einmal in Ruhe über ein paar Dinge zu sprechen, die unsere Arbeit betreffen.“

- Zu Beginn des Gesprächs schildern Sie Ihre Wahrnehmung, als Ich-Botschaft, z. B.: „Frau X., ich mache mir Sorgen. Seit drei Wochen erscheinen Sie mir übermüdet und in Teambesprechungen wirken Sie häufig abwesend." (Ich-Botschaft: s. o. 6.4.1)

- Bieten Sie Unterstützung an: „Mir ist Ihr Wohlbefinden wichtig. Wie kann ich Sie unterstützen?“ „Sind organisatorische Bedingungen zu ändern?“"Wichtig: Hören Sie aktiv zu, und bringen Sie sie mit konstruktiven W-Fragen zum Denken.

- Sollte die Lehrerin beim ersten Gespräch blockieren: Nehmen Sie die Blockade hin, beenden Sie das Gespräch freundlich. Ändert sich nach 2-3 Wochen nichts: Führen Sie ein erneutes Gespräch und fragen Sie nach Lösungsideen. Achten Sie auf die Umsetzung, und führen Sie ein weiteres Gespräch, falls die Symptome anhalten.

- Ein Tipp der Autorin zum Schluss: Vermeiden Sie unbedingt die Frage „Warum ist es so?" Betroffene wissen oft selbst nicht, was los ist. Sie stehen stark unter Druck. Die Frage nach Gründen für ihr verändertes Verhalten verstärkt den Druck und führt zu nichts.

Zur Vorbereitung auf ein solches Gespräch haben Sejkora und Schulze (2016, $228 \mathrm{ff}$ ) eine detaillierte Checkliste erstellt, die Ihnen hilft, Warnzeichen zu sammeln und konkret und verhaltensbezogen zu formulieren.

Sie können im Rahmen solcher Gespräche einen wichtigen Hinweis geben. Wenn eine Lehrkraft deutliche Überlastungssymptome bemerkt, sollte sie nicht ,automatisch“ den Hausarzt aufsuchen, sondern sich zunächst mit ihrer Krankenkasse in Verbindung setzen. Es gibt seit einiger Zeit ein standardisiertes Verfahren, das den Weg zu einer spezifischen Behandlung bei Überlastungssymptomen bahnt und eine unspezifische Krankschreibung vermeidet.

Der erste Schritt also: Anruf bei der Krankenkasse; dort nach Kontakten zu niedergelassenen Psychotherapeutinnen oder einer psychotherapeutischen Ambulanz fragen, wo kurzfristig eine psychotherapeutische Sprechstunde zu erreichen ist. Dann die genannte Person anrufen und einen Termin für eine Sprechstunde vereinbaren. In dem Gespräch ist dann das weitere Vorgehen zu besprechen.

Zur Vorbereitung sind wichtige Informationen unter dieser Adresse zu finden: ${ }^{90}$ https://www.therapie.de/psyche/info/fragen/wichtigste-fragen/psychothe rapie-kostenerstattung/

Diese Information ist natürlich auch für eine mögliche Projektgruppe zum Thema wichtig. Sie sollte auch in einer allgemeinen Information (Aushang, Intranet o. ä.) zu finden sein.

90 Auch unter dieser Adresse stoßen Sie auf die problematische Burnout-Terminologie; sie ist nun mal eingebürgert. Entscheidend ist, dass Sie auf dem angegebenen Weg die für Sie passende Behandlung samt Finanzierungsmöglichkeit finden. 


\subsection{Konkrete Maßnahmen für den Umgang mit Stress und Antreibern}

Stress erkennen und regulieren: Der Weg ging von innen nach außen, von inneren Fesseln zu äußeren Symptomen, von innerer Erlaubnis und Autonomie zu äußerem Handwerk. Persönliche Meisterschaft schließt ein, dem Stress auf die Schliche zu kommen: Was steckt dahinter, wie tragen Sie selbst zu Ihrem Stress bei, und wie kommen Sie dem bei? Selbstreflexion kommt vor Selbstmanagement.

In manchen Bereichen wissen Sie längst, was helfen würde. Denken Sie an das Energiefass und an Ihre Möglichkeiten, es immer wieder aufzufüllen (11.3). Wie kommt es, dass wir das Selbstverständliche oft nicht tun? Die Antwort darauf liegt in mir selbst, in meinen Denk-, Gefühls- und Verhaltensmustern, die - biographisch geprägt - mit der Schwerkraft einer Apollo-11-Rakete vergleichbar sind (s. o. 7.5).

Was ist Ihnen wirklich wichtig? Wie bleiben Sie gesund und konzentrationsfähig? Wie können Sie Ihre Arbeitsfreude erhalten oder steigern? Was könnten Sie verändern, um Ihrem Leben, Ihrer Leitungsarbeit einen wichtigen Impuls zu geben? Wenn Ihnen das klar ist, dann können Sie sich aus dem Arsenal bewährter Instrumente des Selbst- und Zeitmanagements passende Anregungen holen. Ohne Anspruch auf Vollständigkeit sortiere ich die üblichen Instrumente zum Selbst- und Zeitmanagement $^{91}$ in vier Kategorien: priorisieren - delegieren - organisieren rekreieren.

\subsubsection{Priorisieren}

Prioritäten können Sie nur setzen, wenn Ihnen Ihre Ziele klar sind. Und Ziele können Sie sinnvoll nur verfolgen, wenn Sie sich als proaktiv, als selbstwirksam verstehen können. Das ist für Covey der Weg von innen nach außen, der ,private Sieg“ über die Schwerkraft der Gewohnheiten. ${ }^{92}$ Ist das Ziel geklärt, können Sie sich immer wieder fragen: Steht die Leiter an der richtigen Wand? (Vgl. 11.11)

\subsubsection{Proaktiv sein}

Jonathan Sacks erinnert sich an ein Schlüsselerlebnis während seines Studiums. Mit großer Mühe und wider Erwarten war es ihm gelungen, einen Gesprächstermin bei dem berühmten Rabbi Schneersohn in Brooklyn/New York zu bekommen, für ein paar Minuten nur. Im Lauf des Gesprächs fragte der ihn zu seiner Überraschung, was er persönlich zum jüdischen Gemeindeleben an der Harvard-Universität beitrage.

Sacks antwortete: „In the situation in which I find myself. . “ " und wurde gleich unterbrochen: ,,You do not find yourself in a situation; you put yourself in one.“ „Du

91 Quellen u. a.: Seiwert 1995; Deister 2005 (speziell für Schulleitungen!)

92 Erst dann folgt der ,öffentliche Sieg“ im Kontakt mit der Außenwelt: Weg 4: Gewinn-Gewinn-Denken (s. o. 6.3); Weg 5: mitfühlende Kommunikation (s.o. Kap. 4); Weg 6: Synergie erzeugen (s. o. Kap. 5). 
findest dich nicht in einer Situation, du begibst dich in sie. Und wenn du dich in eine Situation begeben kannst, kannst du dich auch in eine andere begeben." Diese kurze Konfrontation trug entscheidend dazu bei, dass aus dem Studenten Sacks kein Jurist und kein Betriebswirt wurde, sondern ein Rabbi, dann ein Lehrer von Rabbis und schließlich der renommierte Leitende Rabbi der jüdischen Gemeinden im britischen Commonwealth (Sacks 2015b, XXVI). Sein Idol hatte einen wesentlichen Punkt getroffen: unsere Neigung, uns selbst als Opfer der Umstände zu sehen.

Covey (1995) sieht in der Überwindung dieser Opferrolle den ersten seiner „Sieben Wege zur Effektivität“, auf dem alle weiteren gründen. Nur wer sich als proaktiv verstehen kann, als selbstwirksam, als jemand, der Einfluss hat auf sich selbst und - wenn auch in Grenzen - auf seine Umgebung, nur so jemand kann sich Ziele setzen. Und nur, wer sich Ziele setzt, kann unterscheiden, welche Aktivitäten diesen Zielen dienen und welche nicht. Nur so jemand kann also bewusst Prioritäten wählen. Sich nicht als reaktiv, sondern als proaktiv verstehen, sich Ziele vornehmen und Prioritäten setzen - das sind die ersten drei Wege zur Effektivität. „Wer kein Ziel hat, für den ist jeder Schuss ein Treffer!“ Das wäre totale Beliebigkeit, die Bereitschaft, sich von Anfragen, Wünschen, Zielen anderer steuern zu lassen. Wer aber weiß, was er wirklich will, der kann sich so organisieren, dass er seinen Zielen näher kommt, auch wenn ihm Störungen dazwischen kommen.

\subsubsection{Nein sagen, Grenzen setzen}

Sehr häufig klagen Leitungskräfte, sie würden ständig in ihrer Arbeit unterbrochen; wichtige Arbeiten könnten sie erst am Ende des Tages erledigen, wenn alle „Störenfriede" zu Hause sind. So ging es auch dem Leiter, der im Coaching über die ständigen Telefonanrufe klagte, die irrtümlich auf seinem Apparat landeten und immer wieder seine Arbeit unterbrachen (s. o. 11.7.1). Er erlebte sich als Opfer widriger Umstände und ist damit kein Einzelfall.

Über 700 Arbeitsstunden hat ein Team per Stoppuhr die Arbeitsabläufe von hochrangigen Mitarbeitern einer Firma erfasst. Ergebnis: Elf Minuten lang kann sich der durchschnittliche Büroarbeiter mit einem Thema beschäftigen, bevor er unterbrochen wird. Bis so jemand wieder die Konzentration vor der Unterbrechung erreicht hat, vergehen rund acht Minuten. Bleiben noch drei Minuten effektive Arbeitszeit bis zur nächsten Unterbrechung. Und das Spiel beginnt von vorn: einen Schritt vor, vier Schritte zurück, jeweils mit hoher Geschwindigkeit, unter vollem Einsatz. So wirkt der bekannte Sägeblatt-Effekt (s. Grafik 24).

Ungeplante Unterbrechungen machen bis zu $28 \%$ der Bürozeit aus. Addiert man die dadurch verursachten Leistungsverluste auf, kommt man auf 588 Milliarden Dollar Leistungsverlust, den die amerikanische Volkswirtschaft jedes Jahr auf diese Weise verbucht. Bei der untersuchten Organisation handelte es sich nicht um einen Kindergarten oder Chaotenhaufen, sondern um eine durchorganisierte kalifornische Hi-Tech-Firma, bei der es unter Hochdruck jederzeit um sehr viel Geld ging (von Rutenberg 2006).

Wissenschaftler am Londoner King's College wollten herausfinden, wie leistungsfähig die Empfänger hereinströmender E-Mails sind. Zum Vergleich verabreichten sie einer Kontrollgruppe Marihuana und stellten beiden Gruppen dieselben 
mittelschweren Aufgaben. Die Kiffer schnitten besser ab, wenn auch dramatisch schlechter als Nüchterne ohne E-Mails.

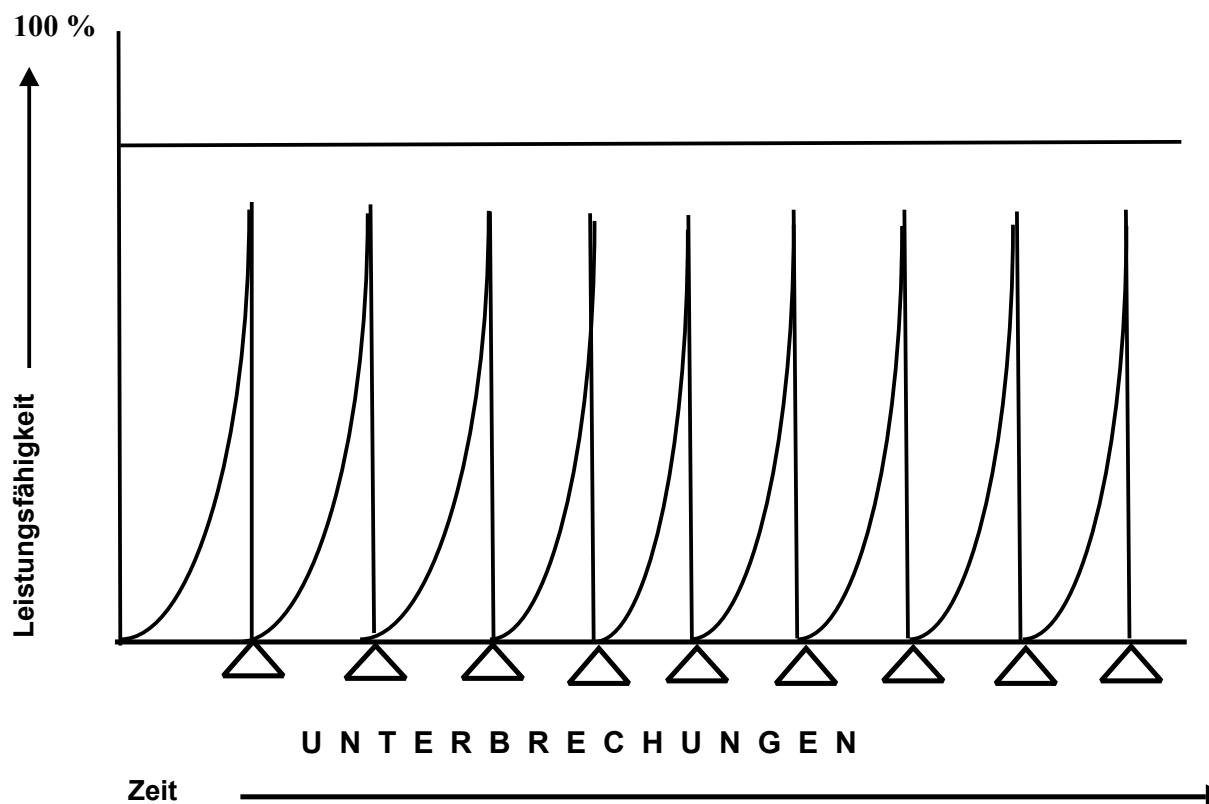

Grafik 24: Sägeblatt-Effekt bei ungeplanten Arbeitsunterbrechungen

In einer früheren Untersuchung gab ein Manager zu Protokoll: „Ich bin abhängig von Unterbrechungen. Wenn ich nicht unterbrochen werde, weiß ich nicht, was ich als Nächstes machen soll." Ein anderer beschrieb seine absolute Unfähigkeit, eine E-Mail oder einen Anruf nicht sofort entgegenzunehmen: „Es ist wie mit Schokolade oder Kartoffelchips. Ich weiß, ich sollte meine Hand nicht nach ihnen ausstrecken, aber mir fehlt die Willenskraft." (von Rutenberg 2006) So zeigt sich Suchtverhalten. Diese Art von Sucht ist inzwischen Grundlage für das Geschäftsmodell, das in vielen digitalen Geräten steckt. ${ }^{93}$

Der Leiter, den die ständigen Anrufe stören, wäre also (im Sinne des ersten Weges) zu fragen: Wie tragen Sie dazu bei, dass Sie dauernd gestört werden? Kein Arzt könnte in seiner Praxis so arbeiten. Als Patient wäre man befremdet, wenn sich während einer Konsultation oder gar einer Untersuchung immer wieder andere Patienten in den Untersuchungsraum drängten. Konkrete Maßnahmen gegen Unter-

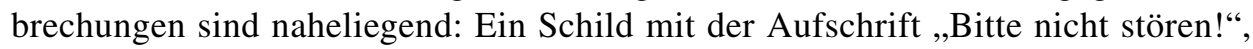
ein Anrufbeantworter, der zur selbst gewählten Zeit abgehört werden kann, die Bekanntgabe von Sprechzeiten - alles im Sinne des gesunden Menschenverstands. Aber: Wären die Kollegen nicht frustriert, wenn sie nur gerade mal schnell eine

93 Alle Akteure, die Werbeflächen bieten, müssen immer aggressiver unsere Aufmerksamkeit einfordern - schreibt die IT-Expertin Sarah Spiekermann (2019, 103). „Damit Geld verdient wird, muss glaubhaft argumentiert werden, dass wir Nutzer die Werbung tatsächlich gesehen haben. ... Es ist diese Marktdynamik, die Serviceanbieter dazu verleitet, unsere Geräte mit einem Eigenleben auszustatten, das uns abhängig macht.“ 
Kleinigkeit klären möchten? So wirkt der Antreiber „Ich muss es immer allen recht machen“. Und im Hintergrund rumort eine alte Einschärfung: Nur so wirst du akzeptiert, gemocht, nur so gehörst du dazu.

Der Preis für solchen Antreiber-Gehorsam kann sehr hoch sein. Sie zahlen mit der Qualität Ihrer Arbeit, wenn Sie nicht dazu kommen, die Leiter an die richtige Wand zu stellen (s.o. 5.2: B-Themen in der Eisenhower-Box). Und der Manager mit der Schokolade und den Chips steht für die Anfälligkeit, Kontakt zu brauchen, dazu gehören zu wollen. Alles das läuft darauf hinaus, dass er sich, seine Ziele, seine Prioritäten weniger wichtig nimmt als mehr oder weniger zufällige Kontakte, die mit den Unterbrechungen verbunden sind.

Was wäre ein konkreter Schutz gegen unnötige Unterbrechungen? Die naheliegenden Ideen sind offenbar nicht wirksam. Wirksam können sie erst werden, wenn ihnen eine innere Erlaubnis voraus geht, die Erlaubnis: Ich darf es auch mir selbst recht machen. Nicht unbedingt immer, aber doch immer wieder. Eine Erlaubnis, die selbst einem Papst einmal so ans Herz gelegt wurde:

„Wie lange noch schenkst Du allen andern Deine Aufmerksamkeit, nur nicht Dir selbst? Du fühlst Dich Weisen und Narren verpflichtet und verkennst einzig Dir selbst gegenüber Deine Verpflichtung? Narr und Weiser, Knecht und Freier, Reicher und Armer, Mann und Frau, Greis und junger Mann, Kleriker und Laie, Gerechter und Gottloser - alle schöpfen aus Deinem Herzen wie aus einem öffentlichen Brunnen, und Du selbst stehst durstig abseits? ... Und bist Du nicht jedem fremd, wenn Du Dir selbst fremd bist? Ja, wer mit sich selbst schlecht umgeht, wem kann der gut sein? Denk also daran: Gönne Dich Dir selbst. Ich sage nicht: Tu das immer; ich sage nicht: Tu das oft; aber ich sage: Tu es immer wieder einmal. Sei wie für alle anderen auch für Dich selbst da, oder jedenfalls sei es nach allen anderen."

Das schrieb Bernhard von Clairveaux $(2007,30)$ Mitte des 12. Jahrhunderts an Papst Eugen III.

M. Rosenberg gesteht, dass er gelegentlich bei seinen Konfliktberatungen so unter Druck geraten ist, dass er sich eine Auszeit gönnte, um wieder zu sich selbst zu finden. Seine Empfehlung: Gib dir in solchen Situationen selbst Empathie, mach dir klar, was dich gerade blockiert, lass dir Zeit, übernimm dich nicht. Also auch hier: Gönne dich dir selbst! Der Antreiber „Sei immer stark!“ produziert Fassadengehabe. ${ }^{94}$ Eine Fassade aufrecht zu erhalten ist anstrengend. Stattdessen: Nimm andere wichtig, und nimm auch dich selbst wichtig.

\subsubsection{Vertiefung: Auch Jesus sagt mal Nein.}

Jesus ist erschöpft, er braucht Abstand, eine Auszeit, er zieht sich zurück. Er ist an seine Grenze gestoßen. Und er geht an die Grenze von Galiläa, ganz in den Norden. Er sucht Ruhe in einem Haus, vermutlich bei Freunden, und will sich nicht ansprechen lassen. Markus schreibt: Er wollte nicht, dass es jemand erführe

94 Der Echtheit und Aufrichtigkeit von Lehrpersonen im Unterschied zu Fassadenhaftigkeit widmen Tausch und Tausch (1998, 214 ff) ein ganzes Kapitel mit eindrucksvollen Beispielen in beiden Richtungen. 
(7,24ff). Aber das klappt nicht. Das Haus stand offenbar unter scharfer nachbarschaftlicher Beobachtung. Es sprach sich herum bis zu einer Frau, die einen großen Kummer hatte. Ihr Töchterlein hatte einen unreinen Geist. Was das für ein Geist war, erfahren wir nicht. Wir bekommen aber indirekt einen Hinweis.

Also, die Frau kam, warf sich Jesus zu Füßen und bat ihn, den Dämon aus ihrer Tochter auszutreiben. Für sie war klar: Die Tochter ist das Problem.

Für Jesus sah das anders aus. Er wollte Ruhe, und da kommt diese Frau herein, sozusagen ohne anzuklopfen, und nimmt ihn sofort in Anspruch. Matthäus (15,22) ergänzt noch: Sie schrie laut: Erbarme dich meiner, Herr, du Sohn Davids. Er wollte Ruhe, und sie schreit laut. Er zieht sich in ein Haus zurück, und sie marschiert hinein. Er braucht Zeit für sich; sie braucht ihn für ihren großen Wunsch. Verständlich ist das schon, aber doch sehr unvermittelt. Sehr fordernd. Sehr wenig situationsbezogen. Sehr drängend, sehr antreibend. Kurz: Sie geht über seine Grenze, seine seelische Grenze.

Bei den Transaktionsanalytikern habe ich gelernt: Achte auf die erste Transaktion in einer Begegnung, z. B. bei einem Elterngespräch: Was sagt, was tut, was kommuniziert die Mutter, der Vater, der gerade den Raum betritt? Die Art, wie jemand auf dich zugeht, ist mit hoher Wahrscheinlichkeit typisch dafür, wie der oder die auch sonst Kontakt aufnimmt, fordernd, unterwürfig, respektvoll, abwartend, drängend. Das geht nach der sogenannten Fraktaltheorie, die besagt: Wenn du auf einen kleinen Teil eines Musters triffst, sagt dir das wahrscheinlich etwas über das ganze Muster. Wie beim Brokkoli: Wenn man da einen kleinen Teil abbricht, sieht der kleine Teil immer noch aus wie ein Brokkoli.

Also: Die Frau bricht ins Haus ein. Was tut Jesus? Er setzt ihr eine Grenze, eine deutliche, eine beinahe beleidigende Grenze. „Lass zuerst die Kinder satt werden; denn es ist nicht recht, den Kindern das Brot zu nehmen und es den Hunden hinzuwerfen. " Eine heftige Grenze. Die Freunde drum herum haben vermutlich den Atem angehalten. Hochspannung. Wie wird sie reagieren?

„Gewiss, Herr. “ Sie stimmt ihm zu. Sie akzeptiert die Grenze. Es ist nicht selbstverständlich, dass sie als Heidin dazugehört. Aber vielleicht doch so, wie die Hunde die Krümel bekommen. „Gewiss, Herr; auch die Hunde zehren ja nur von den Brosamen der Kinder. “

Und Jesus sagt: „Um dieses Wortes willen geh hin; der Dämon ist aus deiner Tochter ausgefahren. " Um dieses Wortes willen - weil sie so geschickt auf seine Bildsprache eingegangen ist? Oder weil sie mit ihrer Antwort die Grenze respektiert, die Jesus ihr setzt? Weil sie sich in dieser kurzen Begegnung verändert hat? Das würde dann auch die Tochter spüren. Töchter können sehr widerspenstig reagieren, wenn die Mutter über ihre Grenzen geht, wenn die Mutter sich in der Seele der Tochter besser auszukennen meint als diese selbst. Wenn die Mutter in der Begegnung mit Jesus gelernt hat, seelische Grenzen zu respektieren-dann hat auch der Dämon zu Hause keine Chance mehr, sich auszutoben. (Diese Auslegung verdanke ich Kurt Lückel (1997, 40ff.).) 


\subsubsection{Fünf-Minuten-Coaching}

Nein sagen steht als Maßnahme in der Übersicht der Tabelle 7 (s. o. 11.7) an erster Stelle. Es geht darum, sich zurückzunehmen, nicht auf jede Aufgabe anzuspringen, sondern die Eigenständigkeit der Kolleginnen und Kollegen zu aktivieren. Es gibt eine kreative Möglichkeit, die schroffe Zurückweisung vermeidet und für alle Beteiligten einen sinnvollen Lernprozess anbietet: das „Fünf-Minuten-Coaching“ (Meier/Szabó 2007). Dafür ein Beispiel:

Der Inhaber eines Produktionsbetriebs betritt am Morgen das Verwaltungsgebäude. Am Empfang wird er bereits vom Produktionsleiter erwartet, der ihm aufgeregt erzählt, dass es in der Nachtschicht einen gravierenden technischen Störfall gegeben hat. Alle Maschinen mussten gestoppt werden. „Ich bin so froh, dass Sie jetzt da sind, denn wir haben noch nicht alle Probleme beheben können!“

Der Inhaber hört sorgfältig zu und stellt dann folgende Coaching-Frage: „Nehmen wir an, ich wäre heute aus irgendeinem Grund hier nicht erschienen, wie würden Sie die Sache jetzt anpacken?" Dem Produktionsleiter wird beim Beantworten der Coaching-Frage klar, was er bereits alles zur Lösung weiss, und er beginnt sogleich, die nächsten Schritte in Form von eigenen Aktivitäten zu planen. Der Firmeninhaber gewinnt im gleichen Zug Zeit für andere Aufgaben - eine klassische Gewinn-Gewinn-Situation.

Ein solches „Fünf-Minuten-Coaching“ hat zwei sehr wertvolle Auswirkungen auf den Produktionsleiter: Sein Bewusstsein für die Lösungsfindung wird erhöht. Seine Eigenverantwortlichkeit wird gesteigert. Und er muss sich nicht ,abgewimmelt" fühlen. Dies Kurz-Coaching ist natürlich nur dann angebracht, wenn der Firmeninhaber dem Produktionsleiter die Gestaltung der notwendigen Maßnahmen vertrauensvoll überlassen kann und bereit ist, seine eigenen Vorstellungen von der „richtigen“ Vorgehensweise loszulassen. Es ist als Werkzeug gedacht, um Mitarbeitende in der Erreichung ihrer eigenen Ziele, die im Rahmen der generellen Unternehmensziele stehen sollen, zu unterstützen, ebenso in der Planung und Umsetzung ihres Wegs zum Ziel, und ihr Lernen im Alltag zu fördern.

Meine Frau hat als Leiterin einer psychiatrischen Rehabilitationsklinik gelegentlich dies Verfahren benutzt - mit Erfolg. Das ging so weit, dass sie bei manchen Mitarbeitern im Wiederholungsfall fragte: „Was glauben Sie, werde ich Sie jetzt gleich fragen?" Der Mitarbeiter musste lachen, dachte nach und war zufrieden. Eine wichtige Erkenntnis für meine Frau war, dass die Ermutigung, seine Lösungsidee eigenständig weiter zu verfolgen, den Mitarbeiter verblüffte. Die Kenntnis wichtiger Rahmenbedingungen erwies sich in dem Zusammenhang allerdings als verbesserungswürdig.

\subsubsection{Eisenhower-Box}

Die Eisenhower-Box (s.o. 5.2.2.1) hilft Ihnen, Krisen, Routine und strategische Themen zu unterscheiden und den Papierkorb für Themen zu nutzen, die weder wichtig noch dringlich sind. Sie können so Ihre persönliche Arbeitszeit auswerten; wie verteilt sie sich prozentual auf die vier Quadranten? Für welche Routinetätigkeiten (C-Themen) sind Sie überqualifiziert und nicht wirklich zuständig? Wie oft kommen Sie zu Ihren wichtigen, aber nicht dringlichen strategischen Themen? 
Sie können die Themen gewichten, die für die nächste Sitzung Ihres Leitungsgremiums angemeldet sind. Nehmen Sie die Kriterien für die Aufnahme in die Tagesordnung ernst, damit die Leiter an der richtigen Wand steht (5.2.2.1). Wenn Sie Ihre Vorentscheidung zur Diskussion stellen, fördern Sie den Sinn Ihrer Teammitglieder für das unterschiedliche Gewicht der Themen.

\subsubsection{Pareto-Prinzip}

Der italienische Ökonom Vilfredo Pareto fand im 19. Jahrhundert durch statistische Untersuchungen heraus, dass $20 \%$ der Bevölkerung $80 \%$ des Volksvermögens besaBen. Es zeigte sich, dass diese Relation auf viele Lebensbereiche übertragen werden kann (Deister 2005, 39 f): 20\% der Zeitungstexte enthalten $80 \%$ der wichtigen Nachrichten; $20 \%$ der Lehrkräfte einer Schule sorgen für $80 \%$ der Beschwerden. Deister folgert, dass wir mit $20 \%$ unserer strategisch richtig eingesetzten Zeit und Energie $80 \%$ unseres Arbeitsergebnisses erbringen könnten. Das heißt, „dass ich mit einem verhältnismäßig geringen Aufwand an Zeit das Gros meiner Ergebnisse erreichen könnte, wenn ich mich auf wenige wichtige Aktivitäten konzentriere, statt mich um viele relativ nebensächliche Probleme und Aufgaben zu kümmern." Listen Sie die Tätigkeiten eines Tages auf, vom Aufstehen bis zum Schlafengehen und stellen Sie fest, welche Ihrer Aktivitäten in direktem Zusammenhang mit Ihren Zielen und Schlüsselverantwortlichkeiten stehen. Ein häufiger Trugschluss suggeriert, dass zwischen Arbeitsaufwand und den Ergebnissen ein proportionales Verhältnis besteht.

\subsubsection{Delegieren}

Wenn Sie nicht gerade eine Zwergschule leiten, haben Sie Erfahrung mit Delegation. Über die Verteilung der Unterrichtsverpflichtungen hinaus sind wichtige Funktionen delegiert. Normalerweise gibt es in größeren Schulen eine Person, die den jährlichen Stundenplan erarbeitet. Eine andere Person bearbeitet die Krankmeldungen und regelt die Vertretungen. Last, but not least haben Sie ein Sekretariat mit kompetenter Besetzung. In großen Schulzentren gibt es eine Expertin für Finanzen und Verwaltung. Müssten Sie alle diese Funktionen selbst übernehmen, würden Sie im operativen Geschäft versinken und kämen nicht zu Ihren eigentlichen Leitungsaufgaben.

Als Leitung sind Sie verantwortlich für die Arbeit am System. Diese Aufgabe verantwortlich wahrzunehmen, dürfte Ihr Hauptinteresse sein. Damit ist Ihnen permanent die Frage gestellt: Bringt mich das, was ich gerade tue, meinen Zielen näher? Muss ich das tun? Entspricht das meinen strategischen Prioritäten? Fördert das meine Arbeit am System? Wenn nicht - können Sie loslassen? Kennen Sie die Macherinnen in Ihrem System, und sind Sie willens, die auch machen zu lassen? ${ }^{95}$

Sind Sie bereit, nicht nur Aufgaben, sondern auch Kompetenzen und Verantwortung zu übertragen und Informationen zur Verfügung zu stellen? Und stellen

95 Vgl. die archetypischen Rollen im Team (s.o. 5.2.2.1 zu Fourier) und die Antreiber „Sei immer stark!“ und ,Streng dich immer an!“” 
Sie sich darauf ein, Zeit in den Delegationsprozess zu investieren? Überprüfen Sie immer wieder im Kontakt mit den Personen, an die Sie delegieren, ob und wie die vereinbarten Ziele erreicht werden können? Ein guter Stundenplan und eine verlässliche Vertretungsplanung sichern die Abläufe im System Schule; indem Sie in diese Delegationsprozesse investieren, arbeiten Sie am System. Motto: Wer führt, delegiert.

Für Verwaltung und Sekretariat existieren in der Regel klare Aufgabenbeschreibungen. Die Frage, wie Sie sinnvoll delegieren können, stellt sich vor allem im Blick auf Lehrkräfte, denen Sie über den Unterricht hinaus Aufgaben übertragen möchten. Die Aufgabe sollte wichtig sein, eine Chance für die weitere professionelle Entwicklung bieten. Sie sollte von einer Person übernommen werden, die Lernbereitschaft gezeigt hat, die sich in begrenzte zusätzliche Verantwortung einarbeiten und sich in einem neuen Rollensegment erproben möchte.

Ist so jemand gefunden, wäre auszuhandeln: Welche Entlastung ist mit der zusätzlichen Aufgabe zu verbinden, z. B. in Form von Abminderungsstunden? Welche bisherigen Aufgaben könnten abgegeben, neu organisiert oder neu verteilt werden? Wie wird der laufende Delegationsprozess zwischen den Beteiligten abgestimmt? Es geht nicht darum, ungeliebte Chefaufgaben ,,abzuwimmeln“; es geht bei sinnvoller Delegation um strategische Themen, um die Sicherung der notwendigen Abläufe und zugleich um Personalentwicklung.

Covey $(1995,155)$ schlägt vor: Erstellen Sie eine Liste der Aufgaben, die Sie persönlich delegieren möchten, und der Leute, an die Sie delegieren oder die Sie so trainieren könnten, dass sie für diese Aufgaben verantwortlich sein könnten. Wie könnte Ihre Sekretärin Sie entlasten; was müsste sie lernen, worin müsste sie gefördert werden, um verantwortlichere Aufgaben übernehmen zu können? Widerstehen Sie der Versuchung, Hausmeistertätigkeiten zu übernehmen.

Überlegen Sie, was Sie im Bereich Ihrer privaten Haushaltsführung delegieren, was da noch ergänzt werden könnte und wie Sie diesen Ansatz auf Aktivitäten in der Schule übertragen könnten. Sie brauchen im Rahmen der partizipativ-kontinuierlichen Schulentwicklung unbedingt Lehrkräfte, die eine Projektgruppe moderieren wollen und können (s.o. 7.4). An erster Stelle kommen dafür die Mitglieder der erweiterten Schulleitung in Frage, deren Aufgabe es ist, den Kontakt des Leitungsgremiums zur nächsten Ebene sicher zu stellen (s. o. 9.4).

Erfahrungsgemäß werden Sie auf deutliche Reserve stoßen, wenn Sie Wünsche in dieser Richtung äußern. Das kann mit perfektionistischen Vorstellungen zu tun haben, mit der Scheu, als ein Gegenüber der Kolleginnen und Kollegen aufzutreten, mit einem klaren Amt und Auftrag; es kann auch schlicht an mangelnder Moderationserfahrung liegen, obwohl jede Unterrichtsstunde Moderation erfordert. Jedenfalls wäre das m.E. kein Anlass zu Resignation, sondern zu einer weiteren strategischen Aktion: Moderationsfortbildung planen und durchführen - wie z. B. in Neuruppin geschehen (s. o. 8.1).

Wenn Ihnen diese Art von Delegation immer mehr gelingt, vervielfachen Sie Ihre eigene Wirksamkeit, fördern Sie die Arbeitsfähigkeit Ihrer Schule, so dass sie in der Lage ist, wichtige strategische Themen methodisch im Sinne kontinuierlicher Schulentwicklung zu bearbeiten. Wie weit sind Sie damit gekommen, die Mitglieder der erweiterten Schulleitung an der Leitungsverantwortung zu beteiligen? Wie 
gut gelingt es denen, Fachkonferenzen, Projektgruppen zu moderieren (s.o. 8.1; 9.4)?

\subsubsection{Organisieren}

Die Sozialpsychologin Wendy Wood hat sich ihr Forscherleben lang mit der Macht der Gewohnheit beschäftigt und einen Bestseller dazu veröffentlicht. ${ }^{96}$ Ihre Hauptbotschaft: Willenskraft reicht nicht aus, um das Verhalten zu ändern. Stattdessen: Entwickeln Sie eine neue Gewohnheit! „Organisieren Sie Ihre Umgebung so, dass das schlechte Verhalten umständlich wird und das gewünschte Verhalten einfacher. Zum Beispiel: Bringen Sie das Smartphone gar nicht erst mit an den Essenstisch. Schalten Sie es stumm, deaktivieren Sie die Push-Nachrichten, kaufen Sie sich eine Uhr. Gehen Sie in die Mittagspause und lassen Sie Ihr Handy im Büro. Wiederholen Sie dieses Verhalten mehrere Wochen lang und Sie werden eine neue Gewohnheit formen, die Ihr Familienleben nachhaltig verändern wird.“

Sie hat Recht, schon Aristoteles wusste das: „Wir sind das, was wir wiederholt tun, Vorzüglichkeit ist daher keine Handlung, sondern eine Gewohnheit." (Zitiert von Covey 1995, 45) Klingt einfach. Hätte ich Ihnen den langen Weg über Skript, Antreiber und Einschärfungen also ersparen können? Covey erläutert Aristoteles mit einer Lebensregel: „Säe einen Gedanken und ernte eine Tat; säe eine Tat und ernte eine Gewohnheit; säe eine Gewohnheit und ernte einen Charakter; säe einen Charakter und ernte ein Schicksal.“ Am Anfang steht Reflexion. Dann folgt die Umsetzung der Erkenntnisse. Wählen Sie aus, was Sie z.Zt. weiter bringt. Beispiele:

Geben Sie Zeitfressern keine Chance. Stoppen Sie unangemeldete Besuche. Ein Leiter half sich mit einer Karte auf seinem Schreibtisch; deutlich sichtbare Aufschrift: „Wenn Sie nichts zu tun haben, tun Sie es bitte nicht hier!“ Schließen Sie die Tür, wenn Sie Ruhe und Konzentration brauchen. Aktivieren Sie Ihren Anrufbeantworter. Richten Sie Sprechzeiten ein (11.7.1 und 11.11). Planen Sie schriftlich: Schreiben Sie abends auf, was Sie am nächsten Tag erledigen wollen; das entlastet Ihr Gedächtnis und fördert ungestörten Nachtschlaf. Schreiben Sie auf, welche Ziele Sie in der kommenden Woche bearbeiten wollen. Das zwingt Sie zu gedanklicher Klarheit, verhindert, dass Sie Wichtiges vergessen, erinnert sie an Ihre Prioritäten, ermöglicht Erfolgskontrolle und hilft Ihnen, den Zeitbedarf besser einzuschätzen (Einzelheiten und weitere Anregungen bei Deister 2005, $31 \mathrm{ff}$ ).

Viele Möglichkeiten. Häufig ist die erste Reaktion: Geht das nicht auch „so“? Ohne so viel Disziplin? Ist die Macht der Gewohnheit wirklich so mächtig, wie

96 Titel: Good Habits, Bad Habits. Interview dazu mit der Autorin in der Süddeutschen Zeitung vom 7.1.2020, S. 8: „Die Vorstellung, die wir von Selbstkontrolle haben, gilt in der Forschung mittlerweile als überholt. Die meisten glauben, erfolgreiche Unternehmer, Sportler oder Schriftsteller wären überdurchschnittlich selbstkontrolliert. Dabei nutzen Menschen, die bei Selbstkontroll-Tests gut abschneiden, in der Regel gar keine Selbstkontrolle im Sinne von Selbstdisziplin. Sie sind lediglich gut darin, gewünschte Handlungen in Gewohnheiten zu verwandeln." 
Wendy Wilson behauptet? Und meine Willenskraft so schwach? Der US-Präsident Calvin Coolidge (1923-1929) setzte für die Übung des Neuen allein auf Beharrlichkeit und Entschlossenheit (vgl. 9.7; Deister 2005, 80).

Wie entschlossen sind Sie, eine neue sinnvolle Gewohnheit zu etablieren, auf einer Skala von 0 bis 10? Für welchen Skalenpunkt haben Sie sich entschieden? Überlegen Sie: Welche ermutigenden Aspekte haben Sie bewogen, diesen Skalenpunkt zu wählen? (Pause zum Nachdenken) Und welchen Schritt müssten Sie oder könnten Sie tun, um einen (nur einen!) Skalenpunkt weiter in Richtung $10 \mathrm{zu}$ kommen? Wann werden Sie damit beginnen? Und wie wollen Sie sich gegen die Macht der Schwerkraft behaupten?

\subsubsection{Rekreieren}

„Zur Rekreation des Gemüts“ - so überschrieb J.S. Bach einige seiner Werke, zur Ermunterung des Gemüts; die Auffrischung von Geist und Körper macht bei Covey (1995) den siebten Weg aus, die Erneuerung. Er unterscheidet dafür vier Dimensionen: physisch - mental - sozial-emotional - spirituell.

\subsubsection{Physische Erneuerung}

Physische Auffrischung war schon beim Energiefass Thema (11.3), zuletzt bei Wendy Wilsons Tipp, wie Sie nützliche Gewohnheiten entwickeln können. Besondere Beachtung verdient Ihre persönliche Bio-Kurve, die Ihre individuelle Leistungsbereitschaft darstellt. Bei den meisten Leuten liegt der Höhepunkt etwa bei 10 Uhr vormittags; das Nachmittagstief ("Suppenkoma“) reicht etwa von 14 bis $16 \mathrm{Uhr}$; darauf folgt für einige Stunden ein flacher Anstieg (Deister 2005, 78 ff). Wenn Sie sich Ihre persönliche Kurve bewusst gemacht haben, können Sie anspruchsvolle Tätigkeiten gezielt in Ihre Hochenergiephase legen und Einfacheres in die energieärmere Zeit steuern, z. B. den Anrufbeantworter abhören und Anrufe beantworten. Beratungsgespräche zu zweit oder in kleinen Gruppen wirken anregend wie eine gute Tasse Kaffee.

Wenn das „Suppenkoma“ zuschlägt, ist eine Pause sehr empfehlenswert, zehn Minuten etwa, nicht länger (!), z. B. in einem Bürosessel mit verstellbarer Lehne, in den Sie kurz versinken können, mit geschlossenen Augen, vielleicht mit einem Mantra im Sinn, das Ihnen hilft, innerlich abzuschalten. Auch ein paar Sätze aus dem autogenen Training kommen dafür in Frage. Den Vorbehalt dagegen kennen Sie ja, den Antreiber: Sei immer stark! Keine Schwäche zeigen, durchhalten! Dass das die Qualität der Arbeit nicht fördert, wird ignoriert. Es gibt erfolgreiche Firmen, die Ihren Betriebsangehörigen eine Pause nicht nur ermöglichen, sondern sogar nahelegen; die werden ihre Gründe dafür haben. ${ }^{97}$

97 Leistungsforscher preisen mittlerweile die kurze Mittagsruhe. Das Nickerchen heißt heutzutage „Powernap“ - und verspricht eine erstaunliche Leistungssteigerung für müde Arbeitnehmer. „Studien haben zeigen können, dass ein Nickerchen die Leistungsfähigkeit um bis zu 35 Prozent steigern kann“, sagt der renommierte Schlafexperte Jürgen Zulley, Professor 


\subsubsection{Mentale Erneuerung}

Für mentale Erneuerung sorgt eine regelmäßige „stille Stunde“. „Stille Stunde“ bedeutet: mindestens eine Stunde pro Woche für strategische Arbeit, fest notiert in Ihrem Kalender. Vielleicht erschrecken Sie über Coveys Rat: „Ich empfehle, mit einem Buch pro Monat zu beginnen, dann eines alle vierzehn Tage und schließlich eins pro Woche. ,Wer nicht liest, ist nicht besser dran als der, der nicht lesen kann. ““ (Covey 1995, 260)

Erfreulicherweise gibt es lehrreiche Bücher, die unterhaltsam geschrieben sind, ohne banal zu sein. ${ }^{98}$ Es gibt preislich günstige Taschenformate zu den hier behandelten Themen, ${ }^{99}$ es gibt eine Serie speziell für Schulen (,Auf den Punkt gebracht“), ${ }^{100}$ knappste Zusammenfassungen, die kompetenten Überblick vermitteln; vgl. Lesetipp zu Kapitel 7.

Zeitmanager empfehlen, diesen Termin mit sich selbst wie einen Außentermin in den Kalender einzutragen, bei dem Sie gar nicht im Schulgebäude wären. So wie ein Arzt seine Arbeit steuert: Störungsschild, Anrufbeantworter, Sprechzeiten, stille Stunde, Prioritäten klären - das sind die gängigen Empfehlungen der Organisationsexperten. Was spricht dagegen? Bleibt da ein Rest an Unbehagen? Wenn ich auf diese Weise immer deutlicher Nein sage - fühlen die Kollegen sich dann im Stich gelassen? Oder eher: Brauche ich selber diese Art von Kontakt? Sie wären damit nicht allein. Die Grundfrage dabei: Lass ich mich steuern, oder steuere ich mich selbst? Welche Ziele sind mir wichtig? Wie kann ich mich so organisieren, dass ich meinen Zielen entsprechende Prioritäten setze? So wie Schulentwicklung ein langfristiger Prozess ist, so ist auch die eigene Entwicklung nicht auf Knopfdruck zu haben.

Wie können Sie Professionswissen in Ihr System bringen? Sie könnten die Mitglieder Ihres Leitungsteams fragen, welches der in diesem Buch behandelten Themen einzelne besonders interessiert - Konfliktmanagement, Mobbing, GFK, kollegiale Beratung, Basiskompetenz Gesprächsführung, Zeitmanagement o. ä. An brauchbaren Konzepten, mit denen sich die fünf Dimensionen einer Lernenden Organisation konkretisieren lassen, herrscht kein Mangel. Sie könnten einzelne bitten, sich ein Thema besonders vorzunehmen und um Vorschläge bitten, wie dies Thema dem Gesamtkollegium nahe gebracht werden kann. Sie könnten pro Dimension je eine Projektgruppe bilden, die im Laufe der Zeit als Expertenquelle angesprochen werden kann. Das alles wären wünschenswerte Merkmale für eine Lernende Organisation.

für Biologische Psychologie an der Universität Regensburg (http://www.uni-regensburg. de/). In einer großen Studie wurden die Gesundheitsdaten von knapp 23.700 Teilnehmern ausgewertet. Ergebnis: Durch regelmäßige Nickerchen kann das Risiko für Herzerkrankungen um 37 Prozent gesenkt werden. Die mutmaßlichen weiteren Wirkungen reichen von Stressabbau über eine Verbesserung der Stimmung bis hin zu einer Reduktion des DiabetesRisikos (Langemak 2013; ebenso Deister 2008, 74).

98 Beispiele: Gordon 1989; Fisher u.a. 1995; Covey 1995; Prior 2002 und 2009; Riegel 2004; Rosenberg 2004; 2013 a, 2013b, 2013c; Malik 2006.

99 Schröder 2008; Herzlieb 2008; Klein/Frank 2008; Schröder/Blank 2008; Deister 2005.

100 Rolff 2017 und 2020. 


\subsubsection{Sozial-emotionale Erneuerung}

Sozial-emotionale Aktivitäten, z.B. Freundestreffen, kulturelle Veranstaltungen, Sport- und Hobbygruppen, gemeinsames Musizieren helfen Ihnen, abzuschalten, Kraft zu schöpfen, Themen aus anderen Lebensbereichen zu diskutieren. Wenn das auf Dauer zu kurz kommt, nehmen Sie es als Warnzeichen.

Organisation und Rekreation hängen eng zusammen. Wie eng, das zeigt die folgende Kurzberatung. In einem Fortbildungskurs werde ich (Kursleiter, KL) von einem Teilnehmer (TN) gefragt:

TN: Welche Techniken kennen Sie denn, die mir helfen könnten, meine Terminverabredungen einzuhalten?

KL: Als erstes fällt mir ein Kalender ein.

TN: Ja, den hab' ich auch. Aber der nützt mir nichts

KL: Schreiben Sie denn Ihre Verabredungen da rein?

TN: Ja, schon.

KL: Und gucken Sie dann auch jeden Morgen hinein?

TN: Nein!

KL: Ach - dann müssen Sie das ja alles im Kopf haben. Das ist ja wirklich schwierig.

TN: Ja, das ist manchmal sehr peinlich, wenn sich offizielle Besucher angemeldet haben und ich die dann ganz entgeistert anstarre, wenn die vor der Tür stehen.

KL: Ja, das kann ich gut verstehen. Das muss peinlich sein. Welche Idee haben Sie denn, wie das besser werden könnte?

TN: Vielleicht müsste ich meinen Kalender sichtbar auf den Schreibtisch packen, damit er mir immer gleich auffällt, wenn ich morgens komme.

KL: Aha, das wäre eine Möglichkeit. Und wie müssten Sie da konkret vorgehen?

TN: Tja, das Problem ist: mein Schreibtisch ist so voll, da fällt der Kalender gar nicht auf.

KL: Der käme Ihnen gar nicht richtig in den Blick. Wie könnten Sie das hinkriegen, dass der Kalender Ihnen auffällt?

TN: Ja, vielleicht müsste ich mir ein Podest bauen, auf das ich den Kalender dann lege.

KL: Ein Podest - dann wäre der Kalender deutlich herausgehoben. Wie würde sich das auf Ihre Aufmerksamkeit für Termine auswirken?

TN: Da bin mir eben nicht so sicher.

KL: Hat das denn überhaupt schon mal geklappt?

TN: Ja, manchmal schon.

KL: Und was meinen Sie, woran es dann gelegen hat?

TN: (denkt nach) Ich glaube, es klappt dann am besten, wenn ich gut von zu Hause wegkomme, ohne Stress und Ärger.

KL: Dann wäre das ja ein wichtiger Punkt. Wie können Sie es in Zukunft hinkriegen, morgens ohne Stress und Ärger aus dem Haus zu kommen?

TN: Ja, das wäre gut. ...

Kalenderkauf, Schreibtisch-Organisation - die üblichen Tipps greifen hier nicht, jedenfalls nicht gleich. Stress und Ärger zwischen dem Aufstehen mit Wecken und Versorgung der Kinder bis zum Verlassen der Wohnung sind eher das entscheidende 
Thema. ${ }^{101}$ „Positiv beginnen“ gehört zum Repertoire der Zeitmanager. Was hilft Ihnen morgens, mit Ruhe in den Tag zu kommen?

\subsubsection{Spirituelle Erneuerung}

Die spirituelle Dimension spricht die Frage nach meiner Identität an: Was für ein Mensch möchte ich sein? Was ist mir wirklich wichtig? Covey schlägt dafür eine sehr ernsthafte Meditation vor: Wählen Sie sich vier Personen, eine aus Ihrer Familie, eine aus Ihrem Arbeitsbereich, eine aus dem Freundeskreis und eine aus einer Freizeitgruppe. Nehmen sie sich eine halbe Stunde Zeit und schreiben Sie in Kurzform eine ungeschönte, ehrliche kleine Rede, die diese Personen z. B. bei Ihrem nächsten runden Geburtstag als Würdigung Ihrer Person halten könnten. Wie würden Sie sich diese Reden wünschen? Wie möchten Sie wahrgenommen werden? Der Sinn der Übung: Welche Wirkung hätten diese vier Würdigungen auf Ihre jetzige Art zu leben und zu arbeiten? ${ }^{102}$

R. Tausch hat die 10. Auflage der Erziehungspsychologie um ein Kapitel über förderlichen Umgang mit Stress-Belastungen ergänzt. Anlass war seine Beobachtung, dass viele jüngere Lehrkräfte zwar einen partnerschaftlichen, zugewandten Unterrichtsstil bevorzugten, aber an stressenden Umständen, störendem Verhalten von Schülerinnen und Schülern scheiterten und so zu einem autoritären Stil Zuflucht nehmen. Sein sehr persönlich gehaltener Überblick ist lesenswert. Im Blick auf sich selbst schreibt er: „In einer schwierigen Situation frage ich mich häufig: wie wichtig werde ich es ansehen, wenn ich bei meinem Sterben darauf zurückblicke?" (1998, 411) Er schließt das Buch mit einer Aufzählung eigener Möglichkeiten, u. a.: Gelungenes würdigen, Belastendes aufschreiben, externalisieren und nennt zuletzt: „Das Gute sehen - Empfindung von Dankbarkeit““.

\subsubsection{Vertiefung: Pferd oder Maultier?}

Ein Pferd läuft, wenn sein Reiter darauf besteht, so lange weiter, bis es zusammenbricht. Wenn es nicht ausgespannt wird, läuft es weiter, bis es nicht mehr kann, vielleicht um in den Sielen zu sterben. Ein Maultier dagegen legt sich, wenn es einen bestimmten Erschöpfungsgrad erreicht hat, einfach nieder und lässt sich weder durch gutes Zureden noch durch die Schläge seines Antreibers dazu bewegen, weiter zu gehen.

$101 \mathrm{Als}$ unsere Kinder klein waren, fanden wir es günstig, morgens vor ihnen einsatzbereit zu sein. - W. Deister landete morgens für längere Zeit immer wieder in einem unvermeidbaren Stau. Seine Lösung: , „.. seitdem ich jeden Morgen eine Lieblingsmusik mitnehme, sie bewusst höre und den Stau als Chance dafür wahrnehme, ist meine morgendliche Fröhlichkeit wieder hergestellt.“ $(2005,58)$

102 Covey (1995, 87 ff), schlägt für diese Übung die Vorstellung vor, diese Reden würden bei Ihrer Beerdigung in drei Jahren gesprochen. Ich habe die Übung vor Jahren gemacht und den Termin längst überschritten. Wenn Sie lieber den runden Geburtstag nehmen, achten Sie auf die Neigung zu Schönfärberei. - Anregende Varianten zur Reflexion von Lebenszielen und zur konsequenten Umsetzung von Prioritäten bei Deister (2005, 19 ff und 31 ff). 
Wir Menschen bilden uns manchmal ein, wir könnten uns über unsere natürlichen Instinkte, die Grenzen unserer menschlichen Natur, hinwegsetzen. Unser rastlos schaffender Geist ist ein unbarmherziger Herr, der unsere natürlichen Grenzen nicht kennt und uns allzu leicht zu Tode hetzt. Der Schöpfer selbst hat die natürlichen Instinkte in uns hineingelegt, gleichsam rote Ampeln. Wer sie nicht beachtet, verachtet den Schöpfer. (Steffen 1968, 44)

Im ersten Buch der Bibel wird der Mensch erst am 6. Tag geschaffen (1. Mose 1,26-2,2). Das heißt, der erste volle Tag, den der Mensch erlebte, war ein Ruhetag! Ich lese die Bibel nicht als astrophysikalisches Protokoll, sondern als eine Bibliothek von Büchern und Schriften, gesammelt über mehr als 1.000 Jahre und voller bedenkenswerter Hinweise, wie wir Menschen uns, das Leben, die Welt verstehen können. Wenn Adam, der „Erdling “, der Mensch schlechthin, den ersten Tag seines Lebens als Ruhetag erfährt, dann haben die alten Erzähler uns alle gedacht als Wesen, die aus der Ruhe kommen, um dann erst tätig zu werden, alle Morgen neu.

\section{Lesetipp}

Deister (2005): Der 48-Stunden-Tag. Hier finden Sie viele nützliche Ergänzungen zu der überblicksartigen Darstellung in diesem Buch.

Sejkora und Schulze (2016, 206-234): Die Kunst der starken Führung (s. o. Lesetipp zu Kapitel 5). Die Autoren thematisieren im Rahmen typischer Führungsherausforderungen ausführlich auch das Thema Burnout; sie listen Frühwarnsignale auf und geben weitere hilfreiche Hinweise für eigene Anfälligkeit und für das Ansprechen betroffener Personen.

Hiebl und Seitz (2014): 6.1.1 bis 6.1.4; 6.2 


\section{Kapitel 12: Individuelle Förderung von Lehrkräften oder Teamstärkung?}

Das Mitarbeitergespräch gilt als wichtiges Instrument für personale Führung. Neuerdings gibt es Zweifel an seiner Bedeutung: Teamstärkung sei wichtiger. Aber der Reihe nach.

\subsection{Das Mitarbeitergespräch (Personalentwicklungsgespräch, Jahresgespräch)}

Einmal jährlich soll die Schulleiterin bzw. der Schulleiter mit jeder Lehrkraft ein Gespräch führen, in dem beide sich über Ziele für das nächste Jahr verständigen, persönliche Entwicklungsperspektiven der Lehrkraft miteinander klären und sich reziprokes Feedback zur Mitarbeit bzw. zum Leitungsverhalten geben. Für das Gespräch ist wie bei jedem anderen Beratungsgespräch eine störungsfreie Zeit und ein ruhiger Raum vorzusehen. Für die Vorbereitung gibt es unterschiedlich umfangreiche Materialien, ebenso für die Dokumentation der Ergebnisse und Verabredungen.

\subsubsection{Schwierigkeiten und Chancen des Modells}

Die Einführung dieses Instruments war oder ist immer noch mit einiger Angst und Reserve auf Seiten der Lehrkräfte, auch auf Seiten der Leitungen verbunden, insbesondere im Blick auf das Thema Feedback. Befürchtet wird Beurteilung, einseitige Kritik, Minderung von Beförderungschancen, ungünstiger Vergleich mit Kolleginnen usw. Dass eine Schulleiterin einen professionellen Anspruch darauf hat, mit Hilfe solcher Gespräche ein komplexeres Bild von der Schule zu bekommen, ist auf beiden Seiten kaum im Blick (Boettcher/Mosing 2006, 965).

Umso skrupulöser werden formale Aspekte beachtet, sorgfältige Vorbereitung und textlich präzise abgestimmte Dokumentation. Nicht selten führt das dazu, dass auch im eigentlichen Gespräch die in den Vorbereitungsmaterialien vorgeschlagenen Fragen zu den drei Hauptthemen katalogmäßig abgearbeitet werden. Für einen ,Durchgang“ mit Vor- und Nachbereitung wird pro Person ein Zeitaufwand von zwei bis drei Stunden und manchmal noch mehr angegeben. Kurz, das umfangreiche Vorbereitungsmaterial, in manchen Fällen auch die Kontrolle über die Zahl der abgeleisteten Gespräche, die Unsicherheit über die Folgen führen bei der Einführung dieses Instruments dazu, dass der eigentlich gewünschte persönliche Austausch über Arbeitsfragen zu einer Zwangsveranstaltung wird oder zu werden droht. ${ }^{103}$

103 Beispiel: Die „Verordnung über die Durchführung von Mitarbeitendenjahresgesprächen in der Föderation Evangelischer Kirchen in Mitteldeutschland“ (2005) klärt auf sechs Seiten 
Um diesen Effekt zu vermeiden und um den Sinn dieses Führungsinstruments zu sichern, scheinen mir einige Klärungen nötig zu sein, die zur wechselseitigen Entspannung und zur Qualität des Gesprächs beitragen.

Das Mitarbeitergespräch ist ein Gespräch. Das heißt, was in einem sonstigen Gespräch, in dem es etwas zu klären gilt, hilfreich und förderlich ist, ist auch hier hilfreich und förderlich (s.o. Kapitel 4 und 6.7). Als regelmäßiges Gespräch zwischen Schulleiterin und jeder einzelnen Lehrkraft verdeutlicht es die Beteiligung aller an der Verantwortung für die Arbeit in ihrer Schule. Das heißt, dass die Beteiligten ein klares, professionelles Rollenverhalten zeigen, nicht aus einer OpferRetter- oder Opfer-Verfolger-Konstellation heraus interagieren, insofern dem SachOhr Priorität vor dem Beziehungs-Ohr einräumen und auf der Beziehungsebene ihren Erwachsenen-Ich-Zustand aktivieren (Boettcher/Mosing 2006, bes. 975 ff). ${ }^{104}$

Ein sinnvolles Klärungsgespräch ist ein lebendiger Prozess, im Bild: eine Reise mit übersichtlichen Strecken, überraschenden Einblicken, plötzlichen Hindernissen, unvorhergesehenen Aufenthalten usw. Das alles gehört dazu und erfordert Übersicht, Steuerungskompetenz, Geduld, Aufmerksamkeit und Interesse für sich selbst und für die Gesprächspartnerin. Ein starres Raster würde den lebendigen Prozess verhindern.

Ein Gespräch, das diesen anspruchsvollen Kriterien genügt, wird ganz von selbst kaum länger als eine Stunde dauern können. Die Beratungsübungen in unseren Kursen erfordern erhebliche Konzentration auf beiden Seiten. Dabei ist u. a. zu berücksichtigen, dass auch Pausen zum Nachdenken dazu gehören; schon 15 Sekunden lösen bei dem, der das Gespräch führt, Nervosität aus. Also: Lieber Klasse statt Masse, lieber Qualität statt Quantität, lieber knapp und konzentriert als ausufernd und ergebnislos.

Entscheidendes Ziel des Gesprächs ist die Verständigung über die Qualität der Arbeit. Mitarbeitergespräche hängen nicht in der Luft, finden nicht isoliert statt, sondern in einem Kontext, im Kontext von Aufgaben, Kompetenzen, Verantwortung und Teamarbeit; dieser Kontext sollte als Schulkonzept bzw. Schulprogramm beschrieben sein. (Falls nichts dergleichen existiert, stellt sich ernsthaft die Frage nach den Prioritäten.) Damit hat das Mitarbeitergespräch zwei wesentliche Bezugspunkte:

Es bezieht sich auf das vorhandene Schulkonzept bzw. Schulprogramm. Bezugsbasis sind Vereinbarungen, rechtliche Vorgaben, vor allem das Schulprogramm, also Ziele und Konzeption der jeweils spezifischen Schule (Boettcher/Mo-

in zehn Paragraphen den kirchenrechtlichen Rahmen und verweist darin zur Vorbereitung und Durchführung des Gesprächs auf die 34 Seiten umfassende Handreichung. Boettcher/ Mosing (2006, 985 ff) kommen mit sieben Seiten aus.

104 Boettcher/Mosing bieten eine umfangreiche und detaillierte Darstellung von Konflikt-, Beratungs- und Mitarbeitergesprächen; sie beziehen sich durchgängig auf transaktionsanalytische Konzepte (vor allem auf das Drama-Dreieck und die Ich-Zustände) und schärfen mit heilsamer Strenge die Verantwortung für Leitende ein, auch in schwierigen Situationen heimliche Verträge zu konfrontieren und sich nicht aus der professionellen Leitungsrolle bringen zu lassen; wie das geht, demonstrieren sie an transskribierten Beispielen aus dem Schulbereich: zur Vertiefung eine sehr empfehlenswerte Lektüre. 
sing 2006, 964). Wie sieht die Lehrkraft ihren Beitrag in diesem Zusammenhang? Da geht es um Zielklärung und Ergebnisüberprüfung. Die Ziele sollten sich am aktuellen Entwicklungsbedarf der jeweiligen Schule und der betroffenen Lehrkraft orientieren.

Es bezieht sich weiterhin auf die individuelle Entwicklung der Lehrkraft: Welche Förderung braucht sie? Welche ist sinnvoll im Blick auf die Bedarfslage des Systems? Welche Fähigkeiten und Begabungen könnte sie stärker einbringen?

Die Orientierung an Zielen ist die Richtschnur für die Gestaltung des Gesprächsprozesses, nicht etwa ein Gesprächsformular! Wenn ein Formular benutzt wird, sollte es dem Prozess dienen, ihn aber nicht steuern. Das Formular hat dienende Funktion z. B. dadurch, dass kein wichtiges Thema vergessen wird und dass konkrete Vereinbarungen kurz festgehalten werden, so dass Verbindlichkeit gesichert wird. Blickkontakt gilt der Gesprächspartnerin, nicht dem Formular.

Qualität statt Quantität - das heißt auch, dass nicht jedes der drei Hauptthemen in jedem Gespräch ausführlich behandelt werden muss. Zu Beginn des Gesprächs kann man sich über aktuelle Schwerpunkte verständigen (vgl. A - Z - A im Beratungskonzept von B. Lohmann, s. o. 5.3, Variante 3).

In einer Zeit allgegenwärtiger Klagen über Zeitknappheit erweist es sich als enorm entlastend, am Ende des Gesprächs gemeinsam die getroffenen Vereinbarungen in wenigen Sätzen zusammenzufassen und aufzuschreiben, handschriftlich und lesbar. Es geht um konkrete Vereinbarungen, nicht um Verlaufsprotokolle oder gar Psychogramme! Der Zeitaufwand für Vorbereitung, Durchführung und Dokumentation darf nicht so groß werden, dass die Durchführung illusorisch wird. Wenn Sie die konkreten Verabredungen in ein Formular eintragen, können Sie sich die kopieren und das Original der Lehrkraft geben. Eigene Notizen zum Gespräch helfen Ihnen, den Gesprächsprozess fortzusetzen (so auch Boettcher/Mosing 2006, 966).

Indem Sie dies Vorgehen vorab dem gesamten Kollegium erläutern, machen Sie zugleich Ihr eigenes Führungsverständnis transparent. Alles in allem: Nicht der Buchstabe, nicht das Formular, sondern der Geist ist entscheidend: „Der Buchstabe tötet, der Geist aber macht lebendig!“ (Paulus, 2. Korinther 3,6)

Wenn Sie Ihr Kollegium in diesem Sinn informieren, können Sie hoffentlich einige Vorbehalte abbauen. Tabelle 8 bietet Ihnen einen Überblick über die unterschiedlichen Charakteristika der drei Elemente des Mitarbeitergesprächs und verdeutlicht zugleich den gravierenden Unterschied zum Konfliktgespräch. Wenn Sie einen Konflikt mit einer Person registrieren, die demnächst für ein Mitarbeitergespräch vorgesehen ist, dann hat die Klärung des Konflikts Vorrang. Es geht dann z.B. um die Sicherung von Regularien und Verfahren. Das Mitarbeitergespräch sollte davon unbelastet sein (so auch Boettcher/Mosing 2006, 985). Falls eine Lehrkraft von sich aus einen Konflikt im Mitarbeitergespräch vorbringt, sollten Sie den Konflikt zuerst klären und das Mitarbeitergespräch verschieben. 
Tabelle 8: Synopse zur Unterscheidung des Mitarbeitergesprächs vom Konfliktgespräch

\begin{tabular}{|c|c|c|c|c|}
\hline Synopse & Konfliktgespräch & $\begin{array}{l}\text { Zielvereinba- } \\
\text { rungsgespräch }\end{array}$ & Fördergespräch & $\begin{array}{l}\text { Feedback- } \\
\text { gespräch }\end{array}$ \\
\hline Anlass & $\begin{array}{l}\text { Lehrkraft } \\
\text { (LK) verletzt } \\
\text { vertragliche } \\
\text { Vereinbarungen. }\end{array}$ & $\begin{array}{l}\text { Auswertung von } \\
\text { Vereinbarungen; } \\
\text { Verabredung neuer } \\
\text { Ziele }\end{array}$ & $\begin{array}{l}\text { Planung der } \\
\text { beruflichen } \\
\text { Entwicklung } \\
\text { der LK }\end{array}$ & $\begin{array}{l}\text { Personalentwick- } \\
\text { lungsgespräch }\end{array}$ \\
\hline $\begin{array}{l}\text { Vertrags- } \\
\text { aspekte }\end{array}$ & $\begin{array}{l}\text { Behebung von Ver- } \\
\text { tragsverletzungen }\end{array}$ & $\begin{array}{l}\text { Arbeitsvertrag } \\
\text { als Basis für } \\
\text { detaillierte } \\
\text { Vereinbarungen }\end{array}$ & $\begin{array}{l}\text { Detaillierte } \\
\text { Vereinbarungen } \\
\text { im Rahmen des } \\
\text { Arbeitsvertrages }\end{array}$ & $\begin{array}{l}\text { Arbeitsbe- } \\
\text { dingungen; } \\
\text { Zusammenarbeit }\end{array}$ \\
\hline Ziel & $\begin{array}{l}\text { Sicherung der } \\
\text { Verfahren und } \\
\text { Regularien }\end{array}$ & $\begin{array}{l}\text { Sicherung von } \\
\text { Kooperation und } \\
\text { Konzept }\end{array}$ & $\begin{array}{l}\text { Förderung des } \\
\text { Potentials der } \\
\text { Lehrkraft }\end{array}$ & $\begin{array}{l}\text { Arbeitszufrieden- } \\
\text { heit }\end{array}$ \\
\hline $\begin{array}{l}\text { Interessen- } \\
\text { lage }\end{array}$ & $\begin{array}{l}\text { Institutionsinter- } \\
\text { essen stehen im } \\
\text { Vordergrund. }\end{array}$ & $\begin{array}{l}\text { Interessen der } \\
\text { Organisation und } \\
\text { der Lehrkraft } \\
\text { balancieren }\end{array}$ & $\begin{array}{l}\text { Die beruflichen } \\
\text { Interessen der } \\
\text { LK stehen im } \\
\text { Vordergrund. }\end{array}$ & $\begin{array}{l}\text { LK übernimmt } \\
\text { Verantwortung } \\
\text { für Entwicklung; } \\
\text { beide lernen. }\end{array}$ \\
\hline $\begin{array}{l}\text { Rolle der } \\
\text { Leitung }\end{array}$ & $\begin{array}{l}\text { Hüterin der } \\
\text { Regularien und } \\
\text { Verfahren }\end{array}$ & $\begin{array}{l}\text { Prozess-Steuerer, } \\
\text { soziale Architektin }\end{array}$ & Beraterin, coach & $\begin{array}{l}\text { Leitung gibt und } \\
\text { nimmt Feedback. }\end{array}$ \\
\hline Zeitbezug & $\begin{array}{l}\text { Schnell intervenie- } \\
\text { ren }\end{array}$ & $\begin{array}{l}\text { Mindestens } 1 \mathrm{x} \\
\text { jährlich; außerdem } \\
\text { kurze Abstim- } \\
\text { mungsgespräche }\end{array}$ & $\begin{array}{l}\text { Mindestens } 1 \mathrm{x} \\
\text { jährlich; außerdem } \\
\text { kurze Abstim- } \\
\text { mungsgespräche }\end{array}$ & $\begin{array}{l}\text { Regelmäßig, } \\
\text { im Rahmen des } \\
\text { Personalentwick- } \\
\text { lungsgesprächs }\end{array}$ \\
\hline $\begin{array}{l}\text { Interven- } \\
\text { tionen }\end{array}$ & $\begin{array}{l}\text { Einstieg mit } \\
\text { Ich-Botschaft; } \\
\text { dann aktiv } \\
\text { zuhören; } \\
\text { Denkanstöße } \\
\text { (W-Fragen) }\end{array}$ & $\begin{array}{l}\text { Aktiv zuhören; } \\
\text { Ich-Botschaften; } \\
\text { Denkanstöße } \\
\text { (konstruktive } \\
\text { W-Fragen) }\end{array}$ & $\begin{array}{l}\text { Aktiv zuhören; } \\
\text { Denkanstöße } \\
\text { (konstruktive } \\
\text { W-Fragen) }\end{array}$ & $\begin{array}{l}\text { Aktiv zuhören, } \\
\text { nachfragen, nicht } \\
\text { verteidigen, } \\
\text { Vorschläge } \\
\text { anregen }\end{array}$ \\
\hline
\end{tabular}

\subsubsection{Grenzen des Modells}

Das Mitarbeitergespräch gilt als Hauptinstrument für personale Führung. In der Praxis stehen dem erhebliche Hürden entgegen. Schon aus zeitlichen Gründen kann die Schulleiterin bzw. der Schulleiter bereits bei einer mittelgroßen Schule nicht mehr jeden einzelnen Lehrer persönlich führen, meinen übereinstimmend H.-G. Rolff $(2017,16)$ und Boettcher/Mosing (2006, 970 ff). Das Konzept stammt aus der Wirtschaft, in der Leitungsspannen von 1:40 oder gar 1:90 undenkbar sind. Weil sich das jedem Schulleiter sehr schnell erschließt, erfahren wir regelmäßig in unseren Kursen, dass das Mitarbeitergespräch entweder gar nicht oder ,nach Bedarf“, also nur mit einigen Personen oder nur alle zwei Jahre stattfindet. Das heißt, dass dies Instrument angesichts der realen Verhältnisse keine entscheidende Bedeutung für strategische Schulentwicklung haben kann.

Hinzu kommt der Zweifel, ob es selbst bei einer Leitungsspanne von 1:10 oder 1:15 von seiner Anlage her überhaupt für strategische Schulentwicklung geeignet wäre. Armin Trost (2015) nennt mehrere beachtliche Gründe für diesen Zweifel: 
Personalleiter in Wirtschaftsbetrieben kritisieren die Führungskräfte: Die sollten besser in der Lage sein, Ziele zu vereinbaren, Feedback zu geben, konsequent mit leistungsschwachen Mitarbeitern umzugehen und Talente klarer zu erkennen. Motto: A fool with a tool is still a fool. Das heißt, den Führungskräften (wohlgemerkt: in der Wirtschaft) fehlt die Qualifikation, dies Instrument überhaupt kompetent einzusetzen. Vorauszusetzen wäre grundsätzliche Kommunikationskompetenz.

Einmal pro Jahr reden Führungskraft und Mitarbeiter über die Leistung des Mitarbeiters in der Vergangenheit, über Erwartungen für die Zukunft, über Lernbedarfe, Entwicklungsmaßnahmen und langfristige Perspektiven. Verbindlichkeit wird hergestellt durch Dokumentation und oft auch zentrale Verwaltung. Es geht also um die individuelle Arbeitsleistung einer einzelnen Person, ohne dass die vorgesetzte Instanz in professioneller Gesprächsführung versiert ist.

Aber, meint Trost, die Schwierigkeiten liegen vermutlich im Instrument selbst: „Tatsächlich handelt es sich beim jährlichen Mitarbeitergespräch nicht um ein Gespräch“, sondern um ein Managementsystem, bei dem auch ein Gespräch vorgesehen ist. Denn das Ergebnis der ganzen Prozedur sind Urteile und Entscheidungen über den Mitarbeiter, sein Vorankommen oder gar seinen Verbleib im Unternehmen. Man versucht, die Besten zu belohnen, die Schwachen zu behandeln, Talente zu identifizieren, interne Eignung festzustellen, Perspektiven zu bieten, Personal zu entwickeln, durch Feedback zu lernen, das Unternehmen zu steuern, durch Ziele zu motivieren und Mitarbeiter zu halten. Das alles ist durchweg gut gemeint. Die Frage ist aber, ob dies Instrument mit den strukturellen und kulturellen Rahmenbedingungen eines Unternehmens kompatibel ist.

Wirklich funktionieren kann das Instrument nur im Kontext einer streng hierarchischen Arbeitswelt. Dafür wurde es entworfen. Da definiert man langfristige strategische Ziele oder einen ultimativen Unternehmenszweck, um den herum das komplette System aufgebaut wird: hierarchische arbeitsteilige Strukturen, Verantwortlichkeiten, Entscheidungs- und Weisungsbefugnisse. Es dominiert die Maschinenmetapher: Das Unternehmen wird als komplexes Uhrwerk verstanden. Führung bedeutet da: Klare Anweisungen und Anreize geben, motivieren, kontrollieren, koordinieren, Feedback geben, beurteilen, entwickeln. Oben wird gedacht, unten wird gefolgt. Das Mitarbeitergespräch ist der Transmissionsriemen zwischen den Hierarchiestufen. Übergeordnete Ziele werden schrittweise von oben nach unten herunter gebrochen. Aufgaben werden als arbeitsteilig und voneinander unabhängig betrachtet. Im Fokus steht immer das Individuum, nicht etwa das Team oder die Abteilung. ${ }^{105}$

105 Der Geschäftsführer einer Firma klagte Covey (1995, 186f) sein Leid: Seine Leute kooperierten einfach nicht. Es stellte sich heraus, dass der Chef einmal pro Woche seine Mitarbeiter in seinem Büro versammelte, über Kooperation sprach und dann einen Vorhang zur Seite zog. Auf einem Schaubild waren Rennpferde zu sehen, die startbereit an der Ausgangslinie standen. Jedes Pferd trug ein Foto von einem der versammelten Manager. Die Rennstrecke mündete in einem idyllischen Bermuda-Poster. Der Chef beendete seinen Kooperationsappell mit der Frage: „Wer von Ihnen wird die Reise nach Bermuda gewinnen?“ Covey dazu: „Er wollte Kooperation. Er wollte, daß seine Leute zusammenarbeiten und ihre 
Das jährliche Mitarbeitergespräch in traditioneller Form ist hierarchisch konzipiert. Die Personalabteilung fordert die Beteiligten zu einem angeblich vertrauensvollen Gespräch auf. Aber: Es ist Pflicht. Die Ergebnisse werden zentral dokumentiert. Der Nutzen ist unklar: Geht es um Feedback oder um Beurteilung? Was passiert mit den Ergebnissen? Was sind die Folgen für Gehalt und Karriere?

Das Instrument passt immer schlechter in den heutigen Kontext: Komplexität, Wandel, Dynamik, Unsicherheit. Unternehmen müssen veränderungsfähig und innovativ sein. Agilität ist gefordert: agile Führung und agile Organisation. Für die Mitarbeiter bedeutet das: hohe Eigenverantwortung und Selbststeuerung innerhalb heterogen besetzter vernetzter Teams bei höchstmöglicher Kundennähe. Die Teams sind in erster Linie ihren internen und externen Kunden verpflichtet nicht ihren direkten Führungskräften. Gute Führungskräfte coachen und befähigen ihre Mitarbeiter. Über allem steht laterale Kooperation und Kommunikation, abteilungsübergreifende Zusammenarbeit. Die Metapher dafür: Die Organisation wird als Netzwerk eigenständiger, eng miteinander verbundener Einheiten verstanden. In der agilen Organisation ist die Führungskraft Coach, und ein Coach urteilt niemals. Im hierarchischen Modell wird aus Feedback ein Urteil, und die Führungskraft wird zum Richter.

In der agilen Organisation stehen heterogen besetzte Teams im Mittelpunkt. Es geht um Teamziele, Teamentwicklung und Teamleistung. Unternehmen, die sich teamorientiert geben, aber individuelle Mitarbeitergespräche führen, widersprechen sich. Denn da werden individuelle Ziele vereinbart; Leistung wird individuell thematisiert. In agilen Organisationen sehen sich Teams ihren Kunden gegenüber verpflichtet. Eigenverantwortlichkeit bedeutet für die Mitarbeitenden, dass sie für die Vereinbarung von Zielen mit ihren Kunden selbst verantwortlich sind, dass sie selbst entscheiden, wann sie mit wem worüber sprechen sollten. Kunden geben Feedback. In der Hierarchie dagegen geht es dem Mitarbeiter darum, dass der Chef zufrieden ist.

Summe: In seiner traditionellen Form hat das Mitarbeitergespräch in agilen Organisationen keine Zukunft. Angesagt sind Gruppenfeedback-Runden, Customer Roundtables, Workshops für Gruppenentwicklung oder Peer Reviews.

\subsubsection{Realistische Zeitstruktur}

Die von Trost vertretene fundamentale Kritik lässt sich unter zwei Bedingungen entschärfen: Ihre Leitungsspanne ist erträglich, und Sie praktizieren das Instrument im Sinne der oben genannten Leitlinien, vermeiden also die von Trost mit Recht kritisierte Vorgehensweise. Dann bleibt immer noch die Frage, wie sich das individuelle Mitarbeitergespräch mit der von Trost bevorzugten Teamförderung verträgt.

Zur Zeitstruktur und den mit ihr verbundenen kulturellen Folgen haben Boettcher/Mosing (2006, 970 ff) mehrere Möglichkeiten durchdacht:

Ideen austauschen. ... Aber er ließ seine Leute zugleich in einer Art Wettbewerb antreten. Der Erfolg des einen Managers bedeutete Versagen für die anderen.“ 
- Maximale Lösung: Die Schulleiterin spricht mit allen Lehrkräften, muss dafür andere Aufgaben streichen oder delegieren, setzt sich damit unter den Druck, das jährlich durchzuhalten, ohne sich zeitlich zu überfordern und damit ein ungünstiges Modell zu bieten. Maximale Leitungsspanne: $<1: 30$.

- Reduzierung der Häufigkeit der Gespräche, z.B. auf einen Zweijahres-Turnus. Fraglich ist, ob dann noch eine Linie in diese Gespräche kommt und ob sie so wirklich zur Schulentwicklung beitragen.

- Reduktion der Gesprächsdauer von 90 auf 60 Minuten - vielleicht auf Kosten der Themenbreite, der Gründlichkeit und der wünschenswerten Ruhe. Die Konzentrationsfähigkeit der Beteiligten scheinen die Autoren recht optimistisch einzuschätzen.

- Die Schulleiterin spricht nur mit den Funktionsträgern ihrer Schule, also mit Multiplikatoren, steht aber zur Verfügung, wenn einzelne Lehrkräfte selbsttätig ein Gespräch wünschen.

- Entgegengesetzte Variante: Die Schulleiterin spricht nur mit den Nicht-Funktionsträgern, da sie mit den Funktionsträgern ohnehin in häufigem Kontakt ist. Bei großer Leitungsspanne wäre das kein zeitlicher Gewinn, und die Arbeitsbeziehung zu den Funktionsträgern verdient besondere Pflege.

- Die Schulleiterin spricht nur mit neu eingestellten Lehrkräften. Nachteil: Allmählich entstünde so eine Zwei-Klassen-Gesellschaft im Kollegium.

- Die Schulleiterin spricht nur mit den ihr wenig vertrauten und/oder problematischen Lehrkräften. In der Wahrnehmung des Kollegiums würden die Gespräche zu heimlichen Kritikgesprächen umdefiniert.

\subsection{Verteilte Führung: Kombination von individueller Förderung und Teamstärkung}

Wie wird Ihre Schule eine Lernende Organisation? Das ist die Leitfrage. Klar dürfte sein, dass Schulentwicklung die Verantwortung aller Systemmitglieder sein muss. Daraus folgt, dass große Systeme eine Infrastruktur brauchen, die die aktive Mitarbeit aller an der Schulentwicklung ermöglicht. Das geht leichter, wenn große Kollegien sich an einem fest eingeplanten Konferenznachmittag regelmäßig treffen, um in unterschiedlichen wechselnden Teams methodisch an Entwicklungsprojekten, an strategischen Themen, an kollegialer Beratung zu arbeiten.

Damit das gelingt, brauchen Sie Lehrkräfte, die für die Moderation solcher Gruppen fortgebildet sind. Vornehmlich kommen dafür die Funktionsträger, insbesondere die Mitglieder der erweiterten Schulleitung, in Frage. Das läuft auf den vierten der oben genannten Strukturvorschläge hinaus: Sie führen nur mit den abteilungsleitenden Funktionsstellen-Inhabern die Gespräche, letztere dann mit den schwerpunktmäßig in ihren Abteilungen arbeitenden Lehrkräften. Dafür spricht die überschaubare Anzahl von Personen auf beiden Ebenen sowie Ihr Interesse, mit den Funktionsträgern in gutem kooperativem Kontakt zu sein. ${ }^{106}$

106 So argumentiert auch Rolff $(2017,16)$ : „Bei verteilter Führung führt die Schulleiterin bzw. der Schulleiter die innerschulischen Führungskräfte und diese wiederum führen die 
Also, im Sinne von Fourier: Macher fördern und sie machen lassen (s.o. 5.2.2.1). „Lehrkräfte, deren Hauptarbeitsplatz oder gar ausschließlicher Arbeitsplatz der Unterricht ist, sind ... fachlich, pädagogisch und beziehungsmäßig mindestens ebenso gut bei den entsprechenden Abteilungsleitenden aufgehoben.“ (Boettcher/Mosing 2006, 972) Koppelt man das Mitarbeitergespräch mit einem vorherigen Unterrichtsbesuch, ist die Schulleiterin erst recht zeitlich überfordert. Dagegen wäre ein Feedback durch Funktionsträger sehr nützlich (s. o. 6.7.4: KUR).

Die Mitarbeitergespräche geben Ihnen die Chance, die Frage nach der Moderationskompetenz der Funktionsträger in der Zielvereinbarung anzusprechen und entsprechende Förderung anzubieten. ${ }^{107}$ Als Basiscurriculum für den Erwerb von Moderationskompetenz scheinen mir einige Teile der bisherigen Darstellung durchaus geeignet (Kapitel 4 und 5 sowie 6.1-6.8). Gelegenheit zum Üben gibt es im Schulalltag genug.

Ein Gesichtspunkt, der offenbar wenig beachtet wird: Wenn es Ihnen zusammen mit Ihrer erweiterten Schulleitung gelingt, projektbezogene Arbeitsfähigkeit in Ihrem Gesamtkollegium zu etablieren, dann haben Sie als Schulleitung auch durch Besuche bei den einzelnen Projektgruppen und bei der Präsentation von Projektergebnissen in der Gesamtlehrerkonferenz Gelegenheit, Fähigkeiten und Kreativität bei einzelnen Lehrkräften zu entdecken, die ohne diese Arbeitsstruktur gar nicht zum Zuge kämen.

\subsection{Gefühle in der Kommunikation}

Wenn ein Mitarbeitergespräch seinen Zweck erfüllen soll, ist es von Konflikten frei zu halten. Gewünscht ist eine zugewandte, einigermaßen entspannte Atmosphäre, in der in Ruhe nachgedacht werden kann. Da sollten Angst, Ärger, Enttäuschung nicht dazwischen funken.

Konflikte sind in der Regel emotional anstrengend. Stören Gefühle die Kommunikation? Verhindern sie Verständigung? Sind sie nicht eher das Salz in der Suppe? Zeichen für Lebendigkeit? Ist Kommunikation ohne Gefühle überhaupt möglich? Wäre das wünschenswert?

Darf eine Schulleiterin überhaupt Gefühle äußern? Wäre das ein Zeichen von Schwäche? Verliert sie dann an Autorität? Kann sie dann noch allparteilich moderieren oder gar Konflikte regeln? Sind Gefühle Privatsache?

einzelnen Lehrpersonen. Die Schulleiterin bzw. der Schulleiter kann bereits bei einer mittelgroßen Schule nicht mehr jeden einzelnen Lehrer persönlich führen. Schon aus zeitlichen Gründen kann er nicht mit jedem einzeln jährliche Mitarbeitergespräche realisieren und Zielvereinbarungen schließen. Er kann sich auch nicht immer selbst um die Problemfälle unter den Lehrkräften kümmern, die in Schulen nicht selten tabuisiert werden, aber dennoch vorkommen und allen bekannt sind.“

107 Boettcher/Mosing (2006, 969) zitieren zustimmend die Sicht der Bildungskommission Nordrhein-Westfalen (1995) zum Sinn dieser Gespräche: „Mit interessierten und geeigneten Lehrerinnen und Lehrern soll eine auf die Übernahme von Leitungsfunktionen zielende Planung des beruflichen Werdegangs erfolgen." 
Sind die Männer matt gesetzt, wenn eine Frau sich auf ihr Gefühl beruft? Ende der Diskussion? Kann man gegen Gefühle argumentieren? Loriot hat gezeigt, wohin das führt. Ein älteres Paar am Frühstückstisch:

Er klagt, das Frühstücksei sei zu hart. Sie kontert, sie habe es wie immer gekocht. Viereinhalb Minuten. „Eine Hausfrau hat das im Gefühl ...

Er: Im Gefühl? Was hast du im Gefühl?

Sie: Ich habe es im Gefühl, wann das Ei weich ist ...

Er: Aber es ist hart ... vielleicht stimmt da mit deinem Gefühl was nicht ...

Sie: Mit meinem Gefühl stimmt was nicht? Ich stehe den ganzen Tag in der Küche, mache die Wäsche, bring deine Sachen in Ordnung, mache die Wohnung gemütlich, ärgere mich mit den Kindern rum und du sagst, mit meinem Gefühl stimmt was nicht?“

Sie fühlt sich gekränkt. Der Sketch endet mit Verachtung bei ihr, mit Mordgedanken bei ihm. Eine Fundgrube für unsere Themen: Vier Seiten einer Nachricht, Geben und Nehmen von Feedback, Ich-Zustände. Welche Hilfen stecken in den Konzepten?

\subsubsection{Rückblick und Überblick}

Im Kurs wurden alle Konzepte gesammelt, die sich auf Gefühle beziehen. Grafik 25 gibt das Flipchart-,,Tafelbild“ wieder, eine ungeordnete Sammlung, zugleich ein guter Anlass, die Erinnerung aufzufrischen.

Den Anfang machen die Ich-Zustände und das Drama-Dreieck der Transaktionsanalyse. Jeder Ich-Zustand ist ein integriertes System von Denken, Fühlen und Verhalten, auch der Erwachsenen-Ich-Zustand (6.9.1). Die Auseinandersetzung mit der Realität im Hier und Jetzt schließt emotionale Beteiligung ein. Die ,erwachsene“ Beachtung von Emotionen ist wesentlicher Teil der Realitätswahrnehmung. Die erwachsenen Möglichkeiten, Emotionen zu erleben und zu äußern, unterscheiden sich deutlich von den Spielarten, die im Kind-Ich-Zustand bzw. Eltern-Ich-Zustand gängig sind.

Das Drama-Dreieck beschreibt das problematische Zusammenspiel von Verfolger-, Retter- und Opfer-Rolle, die Ausblendung wichtiger Realitätsaspekte (s. o. 6.9.3). In allen drei Rollen wird die Fähigkeit des Opfers, selbst zu einer Problemlösung beizutragen, abgewertet. Ärger, Wut, Mitleid, Selbstmitleid und Ohnmacht bilden eine brisante Mischung, ohne dass die Beteiligten diese Emotionen so äußern, dass erwachsene Lösungen möglich würden.

Konflikte mobilisieren Gefühle, je heftiger, desto wichtiger ist besonnenes Verhalten und Übersicht: Sie spüren Ärger, Frust, Empörung? Dann liegt es auch bei Ihnen, aktiv zu werden, den Konflikt anzusprechen (Typ I, s. o. 6.4.1). Wenn Sie selbst angegriffen werden, sagt Ihr Gefühl Ihnen, welches Grundbedürfnis gefährdet ist; unter Stress auf den Konfliktpartner nicht defensiv zu reagieren, sondern aktiv zuzuhören, erfordert einige Nervenstärke (Typ II, s. o. 6.4). Wenn Sie einen Konflikt schlichten müssen, müssen Sie Allparteilichkeit gegenüber den Streitenden einnehmen, ohne die Verantwortung für die Schule aus dem Blick zu 


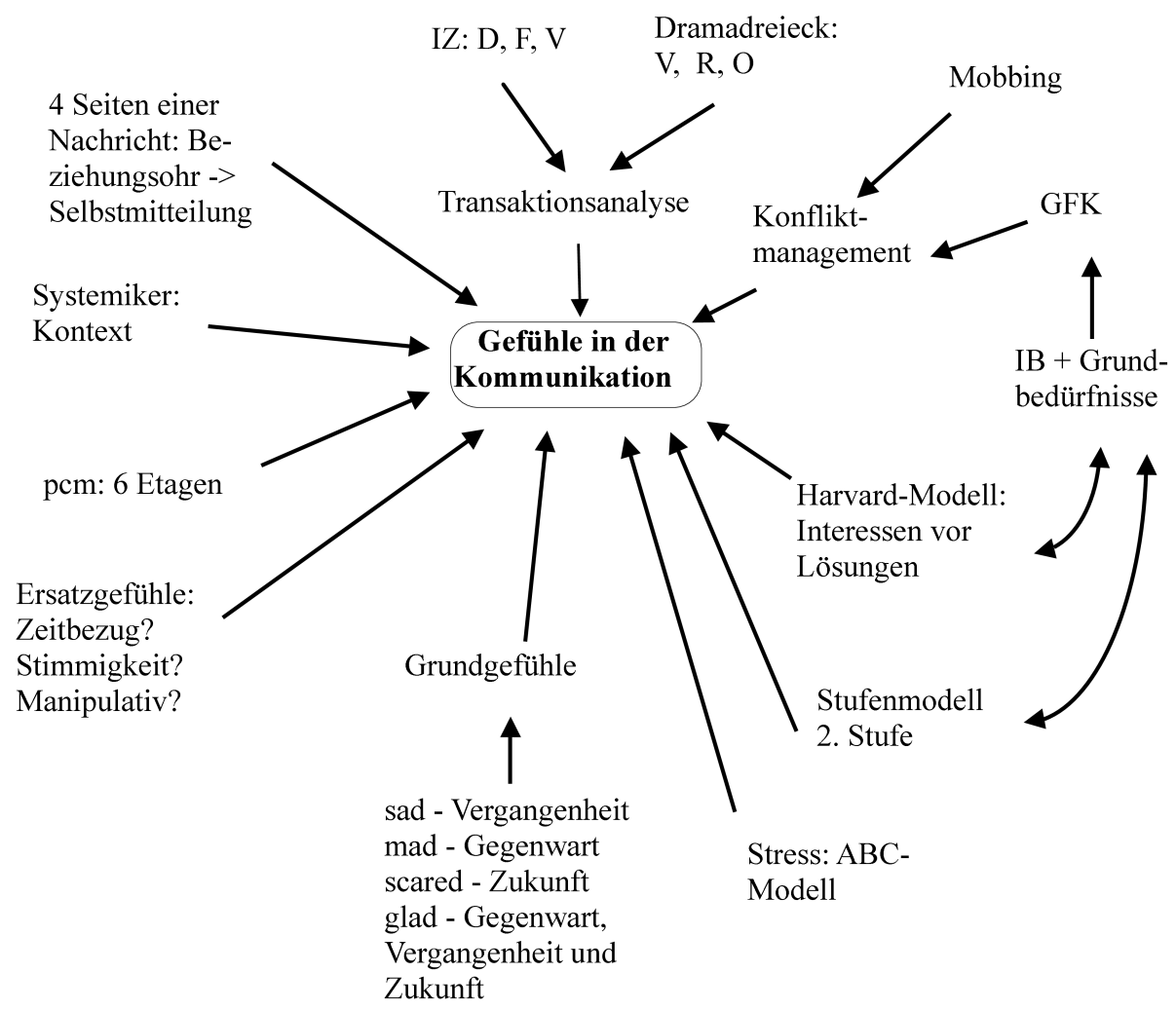

Grafik 25: Gefühlsaspekte in Kommunikationskonzepten

verlieren. Da kann Ihr Gefühl Ihnen signalisieren, wann Ihre Grenze erreicht ist. Mitarbeitergespräche sind von Konflikten frei zu halten; sie bieten Ihnen Gelegenheit, anerkennende Rückmeldungen zu geben und zu bekommen; emotionaler Rückenwind gehört dazu.

Mobbing geschieht, weil die Leitung es zulässt - diese provokante These soll Leitungen ermutigen, klar und deutlich Abwertungs- und Ausgrenzungsprozesse zu stoppen, Angreifer zu konfrontieren und auf ihre eigene emotionale Beteiligung hin anzusprechen (s.o. 6.5). Angriffe sind kein Zeichen von Offenheit; sie verbergen, worum es geht. Das zu lernen ist den Angreifern zuzumuten.

Die Gewaltfreie Kommunikation versteht die in Konflikten auftretenden Gefühle von Ärger, Wut, Enttäuschung, Misstrauen usw. als Hinweise auf zugrunde liegende Grundbedürfnisse (s.o. 6.6); wenn die wahrgenommen und beachtet werden, wird klar, worum es im Konflikt eigentlich geht.

Das Harvard-Konzept (s. o. 6.3) empfiehlt dringend: Löse dich von vorschnellen Lösungen! Interessiere dich für die Interessen! Auch hier sind also die Grundbedürfnisse, die eigenen und die der anderen Seite, zu berücksichtigen. Die herauszufinden ist wesentlicher Teil der Arbeit am Konflikt. Wie bei Eisbergen ist in Konflikten oft nur ein Siebtel zu sehen; sechs Siebtel liegen unter der Oberfläche. Werden die ignoriert, wird die Einigung auf eine Lösung kaum Bestand haben. Vorsicht also vor dem Beeil-dich-Antreiber; langsamer ist schneller. 
Das Stufenmodell der Supervision übt auf der 1. Stufe aktives Zuhören ein und spricht dann die emotionale Resonanz zum vorgestellten Fall an (s.o. 5.3, Variante 4). In der Durchführung zeigt sich, wie schwer dieser Schritt manchmal fällt. „Ich habe das Gefühl, dass da jeder gegen jeden...“ - das klingt wie eine Gefühlsäußerung, ist aber eine Diagnose, die die Moderatorin freundlich, aber bestimmt für Stufe $4 \mathrm{zu}$ reservieren hat. Gelegentlich äußert jemand (eher ein Mann) als Gefühl: „,ganz normal“ oder ,,irgendwie schlecht“. Dann hilft eine hartnäckige, mehrfach wiederholte Frage der Moderatorin weiter: Und wie fühlt sich das für Sie an? ${ }^{108}$ Wichtig ist die Erfahrung für die Fallgeberin: Meine Gefühle sind einfühlbar; andere kennen das auch. Und interessant ist für sie: Auch ganz andere emotionale Reaktionen als meine sind möglich. Die Beachtung der Gefühle vertieft die Erfahrung, wirklich verstanden zu werden (s.o. 4.4) und erweitert den emotionalen Horizont.

Die Stressanalyse mit Hilfe des ABC-Modells von Albert Ellis (s.o. 11.6) führt auf die wenig gewohnte Einsicht, dass das von mir empfundene Symptom (das C) sich nicht einem Automatismus verdankt, ausgelöst durch einen Außenreiz, sondern dem mentalen Prozess zwischen Reiz und Reaktion. Wir sind keine Marionetten - wie erfreulich. Unsere mentalen Modelle tragen erheblich zu unserer psychischen Belastung bei - schon weniger erfreulich, aber entscheidend wichtig. Wenn ich diesen Zusammenhang durchschaue, wenn ich meine innere Bewertung also erkenne, kann ich meine alten Glaubenssätze in Frage stellen und durch produktivere ersetzen. Ärger, Wut oder Enttäuschung und Verletzung stellen sich oft als C, als Konsequenz, ein.

Starke Gefühle wirken dann wie neue Ausgangsreize, die zu eskalierenden Handlungen führen. Das ABC liefe dann so weiter: A1-B1-C1-B2-C2. Typische Sequenz bei Gewalttätern: Wenn meine Frau an mir herumnörgelt, macht mich das so wütend (C1) - dann muss ich ihr eine reinhauen (B2). Die schwierige Aufgabe: diesen „Muss“-Glaubenssatz entdecken, entschärfen und durch eine günstigere Selbstinstruktion ersetzen. Die erste Aufgabe also: Wenn mich das so wütend macht - wie sähe eine emotionale Alternative aus? Die zweite Aufgabe: Wenn ich so wütend bin - wie könnte ich dies Gefühl neu bewerten und dann anders handeln? Beide Male läuft die Veränderung über das Zwischenglied, über die nicht bewussten Glaubenssätze, also die mentalen Modelle, die im Konzept der Lernenden Organisation entscheidendes Gewicht haben.

Grundgefühle und Ersatzgefühle gehören ins Gesamtbild, werden aber ausführlich im folgenden Abschnitt dargestellt.

Zum Prozesskommunikationsmodell: Wenn es in einer Beziehung regelmäßig „knirscht“, z. B. zwischen zwei Lehrkräften oder zwischen einem Lehrer und einem Schüler, dann befinden die beiden sich möglicherweise auf ganz unterschiedlichen

108 Stewart $(1993,121)$ zeigt das Vorgehen an einem Beispiel. „Berater: Gehen Sie für einen Augenblick davon aus, daß Sie, als Sie sich gereizt fühlten, ein anderes Gefühl überdeckten. Wenn es ein anderes Gefühl gab, welches würden Sie vermuten? Klient: Ich glaube, ich fühlte mich machtlos. Berater: Und was fühlen Sie, wenn Sie sich machtlos fühlen? Klient: Ich bin zornig. Berater: Auf wen? Klient: Auf mich selbst. Berater: Und was fühlen Sie, wenn Sie auf sich selbst zornig sind? Klient: (Pause) Angst.“ 
inneren „Etagen“. Dann kann es helfen, eine oder zwei Treppen zu ersteigen, um miteinander in Kontakt zu kommen. Das Prozesskommunikationsmodell (pcm, s. o. 6.10) nennt die unterschiedlichen emotionalen Bedürfnisse, die mit jedem der sechs Grundtypen verbunden sind und die zu berücksichtigen sind, wenn der Kontakt gelingen soll. Das entspricht den Grundbedürfnissen in der Gewaltfreien Kommunikation und den Interessen im Harvard-Konzept.

Systemiker interessieren sich für die Funktion von Gefühlen im jeweiligen Kontext: Was ging dem Gefühl voraus? Das entspricht dem auslösenden Reiz im ABC-Modell. Und was folgt auf die Äußerung eines Gefühls? Wie wird es verstärkt, belohnt, ignoriert, missbilligt? Systemiker fragen nicht „,vertikal“ zurück nach der biographischen Herkunft eines Gefühls, sondern danach, wie das Gefühl horizontal in den Interaktionsverlauf eingebettet ist. Sie unterstellen nicht, dass da jemand ein problematisches Gefühl ,hat“, sondern fragen danach, wie zwei oder mehrere Personen in einer speziellen Situation eine emotionale Verwirrung oder Blockade oder Spannung zustande bringen. Weiterhin interessiert sie, wann das mal schlimmer und vor allem, wann das mal besser war oder überhaupt nicht vorkam. Damit vermeiden sie naheliegende Schuldzuweisungen und verstehen die thematisierte Schwierigkeit als ein gemeinsam produziertes Problem und eine gemeinsam zu bewältigende Aufgabe. 109

Das Konzept der vier Seiten einer Nachricht ist ein einfaches Reflexionsinstrument für den täglichen Gebrauch (s. o. 6.2). Eine scheinbar sachliche Äußerung (,Das Ei ist hart!“) entpuppt sich als versteckter Appell, der auf der Beziehungsebene gehört und aus dem kritischen Eltern-Ich-Zustand zurückgewiesen wird. Das Modell ist leicht zu verstehen, erfordert in der Praxis aber einige Geistesgegenwart.

\subsubsection{Grundgefühle und Ersatzgefühle}

Der Überblick legt verschiedene Schlussfolgerungen nahe. Zum einen: Konflikte sind brisant und gefährlich, weil sie Emotionen auslösen und von Emotionen genährt werden. Warum sonst werden so differenzierte Konfliktmodelle entworfen? Also: Vorsicht! Emotionen in Schach halten! Dazu raten nicht nur Top-Manager, sondern schon die alten Griechen, respektable Philosophen. ${ }^{110}$

Zum anderen: Gefühle sind Wegweiser, die tragfähige Lösungen von Konflikten ermöglichen. Wenn wir sie aufmerksam wahrnehmen, werden uns unsere

109 Diese Sichtweise können Sie einüben, wenn Sie Transkripte systemischer Beratung lesen, z.B. bei de Shazer (1998, 85 ff).

110 Die antike Tragödie z.B. inszeniert die verheerendsten Ausbrüche des Zorns, um zum maßvollen Umgang mit dem Affekt anzuleiten und aus dem Zorn ein Werk zu machen, ihn in weniger ruinöse Formen einzubinden. In der Philosophie der Lebenskunst war die Frage des Verhaltens im Moment des Zorns ein immer neues Thema. Schmid (2000, $87 \mathrm{ff})$ verweist auf Aristoteles: Wer zum Zorn fähig sei, verdiene grundsätzlich Respekt, da der Eifer seiner Seele ihn zu großen Anstrengungen antreibe; unverzichtbar sei gleichwohl das kluge Kalkül, „wie, wem, worüber und wie lange man zürnen soll.“ Es geht um das rechte Maß, das nicht normativ feststeht, sondern vom Urteil des Individuums und der Besonderheit der Situation abhängig ist. (W. Schmid 2000, 87 ff) 
Grundbedürfnisse klar, die auf Erfüllung aus sind. Wenn wir diese Grundanliegen würdigen, die eigenen und die der anderen Seite, können wir zielgerichtet Lösungen konstruieren, die auf diesen Grundanliegen aufbauen.

Weitere Möglichkeit: Gefühle sind nicht richtig oder falsch, sondern um ihrer selbst willen zu würdigen, Ausdruck dafür, lebendig zu sein. Sie sind dazu da, gelebt, nicht bewertet zu werden. In diesem Sinn galt es in den 70er Jahren des letzten Jahrhunderts als emanzipiert, Gefühle als nicht hinterfragbare, natürliche Lebensäußerungen aufzufassen. Die darunter liegenden Bedürfnisse wurden jedoch kaum thematisiert. Stattdessen folgten aus den Gefühlen scheinbar schlüssige Verhaltenserwartungen. Dann stand Gefühl gegen Gefühl, Verhaltenserwartung gegen Verhaltenserwartung; das konnte in Frust, Kränkungen, Verletzungen enden.

Die Transaktionsanalyse hat einige Unterscheidungen eingeführt, mit deren Hilfe sich Verwicklungen entwirren lassen; ich gebe eine Kurzfassung der Darstellung bei Stewart (1993, $118 \mathrm{ff})$.

Vor der Sprachentwicklung äußern kleine Kinder einige wenige elementare Grundgefühle: Freude, Angst, Wut und Trauer - adjektivisch durch den Gleichklang leicht zu merken: glad - scared - mad - sad. (Inzwischen fügen mehrere Autoren Schmerz als weiteres Grundgefühl hinzu.) Doch merken Kinder bald, dass diese Gefühle nicht immer willkommen sind. Statt des wirklichen Gefühls wird dann ein Gefühl gezeigt, das von der Umgebung eher toleriert wird.

So lernt ein kleines Mädchen von wichtigen Bezugspersonen z. B., dass Zorn sich nicht gehört. Stattdessen wird es belohnt, wenn es übersprühend strahlend und fröhlich ist. Auch als erwachsene Frau bekommt sie immer wieder Anerkennung dafür, dass sie ein wahrer Sonnenschein ist. So kommt es, dass sie das verbotene Gefühl, ihren Zorn, überdeckt; auch als Erwachsene verbietet sie sich dies Gefühl und zeigt stattdessen Fröhlichkeit und Erregtheit. Das überdeckende Gefühl (Fröhlichkeit) ersetzt das ursprüngliche, echte, authentische Gefühl des Zorns; es heißt darum „Ersatzgefühl“. Weitere Beispiele:

Ein Junge, der in einer neuen Situation, etwa bei einem Schulwechsel, nicht (authentisch) mit Unsicherheit und Angst reagieren darf, wird sich womöglich besonders aggressiv verhalten. Er zeigt dann Wut als Ersatzgefühl. Oder ein Mädchen, das nicht in gesunder Aggression auf etwas Neues zugehen kann, wird sich besonders furchtsam verhalten. Wieder einem anderen Jungen wird vermittelt, er müsse seine Wutausbrüche unterlassen - mit der Folge, dass er sich noch als Erwachsener eher (traurig) in sich zurückzieht, wenn seine Wünsche übergangen werden.

Auf diese Weise entwickeln sich Ersatzgefühle. Jedes Gefühl kann zu einem Ersatzgefühl werden. Auf einem Schulausflug wird ein Schüler vermisst. Das primäre Gefühl des Lehrers ist Angst. Als das Kind endlich gefunden wird, tobt der Lehrer und schreit: „Du darfst dich niemals von der Gruppe entfernen! Warum kannst du nicht lernen, dich nach den Vorschriften zu richten?“ (Gordon 1981, 121) ${ }^{111}$ Er überdeckt seine Angst mit Wut.

111 Gordon bringt weitere lehrreiche Beispiele für Lehrer-Schüler-Interaktionen. Problematisch scheint mir seine These: „Wut ist ein sekundäres Gefühl, dem immer ein primäres Gefühl vorausgeht." (A.a. O., 122) 
Ein Lehrer verhält sich unkooperativ; der betroffene Kollege erzählt davon zu Hause und bemerkt, das mache ihn traurig. Wut hat er sich schon als Kind verbieten lassen.

Die Transaktionsanalyse unterscheidet also elementare, ,,authentische“ Grundgefühle von solchen überdeckenden Gefühlen, die die Grundgefühle ersetzen. Beide Gefühlsweisen, auch die „Ersatzgefühle“, werden als echt erlebt, bis ins Erwachsenenalter hinein. Man kennt es gar nicht anders. Aber anderen fällt in bestimmten Situationen auf, dass das vom Erwachsenen geäußerte Gefühl nicht zur Situation passt. Typischerweise geschieht das unter Stress.

Im Laufe der Sprachentwicklung verbinden sich Gefühle mit Denkprozessen, zu den Grundgefühlen gesellen sich komplexe Gefühle: Neid, Eifersucht, Scham, Stolz, Schuldgefühl, Gekränktheit, Minderwertigkeitsgefühl, Verlegenheit, Verwirrtheit. Komplexe Gefühle sind eine Verbindung von Überlegungen und Grundgefühlen; spürt man das zugehörige Grundgefühl auf, wird auch die nötige Energie für eine Lösung zugänglich. Stewarts hartnäckige Frage ,Und wie fühlt sich das an?" hilft dem Gegenüber, sich auf das zugehörige Grundgefühl und die damit verbundenen Energie zu besinnen (s. Anm. 108).

Die Skriptanalyse hatte gezeigt, dass Kinder in der präverbalen Phase häufig Einschärfungen von Bezugspersonen ausgesetzt sind, die sie als Glaubenssätze verarbeiten: Ich darf nicht wichtig sein, ich darf kein Kind sein, nicht nahe sein, nicht denken, nichts tun ... usw. (s.o. 11.7.2). Die Einschärfung „Ich darf nicht fühlen“ wird durch Reaktionen der Bezugspersonen in Richtung bestimmter verbotener, unerwünschter Gefühle präzisiert: Ich darf nicht wütend sein, nicht traurig sein usw.; so kommt es zu Ersatzgefühlen, die darum auch als Skriptgefühle bezeichnet werden. Diese Skriptgefühle wirken auf das Denken und Verhalten, das seinerseits durch bestätigende Erfahrungen, Resonanz von den Bezugspersonen usw. scheinbar gerechtfertigt wird, so dass diese gesamte Abfolge laufend verstärkt wird (Grafik 26); diesen fatalen Kreislauf hat man als „Maschensystem“ konzipiert (Grafik 26).

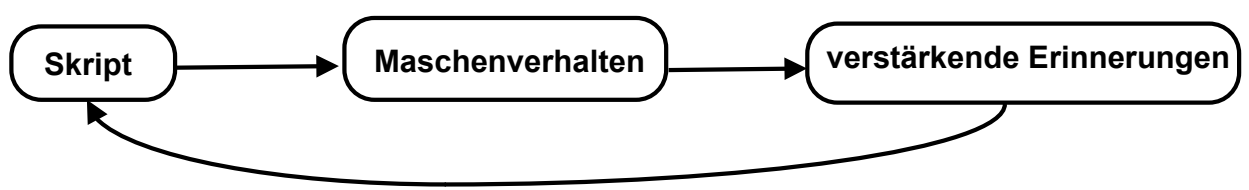

Grafik 26: Das sich selbst verstärkende Maschensystem

Das zusammen mit dem Ersatzgefühl gezeigte Verhalten wirkt auf Außenstehende wie eine Masche, wie ein erpresserisches Verhalten, das auf Reaktionen aus ist, die das Problemverhalten verstärken statt es zu problematisieren. ${ }^{112}$ Der manipulative Charakter solcher Ersatzgefühle wird deutlich, wenn man eine Reihe von Ersatzgefühlen Revue passieren lässt: beleidigt sein, missgünstig, schmollend oder rachsüchtig sein, ironisch, gehässig oder selbstgerecht sein. Der Ausdruck solcher Ersatzgefühle wirkt nicht konfliktlösend! (Risto 2003, 118) Wenn z. B. ein Leh-

112 Der amerikanische Ausdruck für „Masche“ ist racket: Schutzgelderpressung. 
rer den Chemieraum im Chaos hinterlässt, würde der nachfolgende Kollege das Problem eher lösen, wenn er seinen Ärger kundtut statt verdruckst zu schweigen, traurig zu reagieren und sich von seiner Frau zu Hause bedauern zu lassen.

$\mathrm{Ob}$ ein Gefühl zur Situation passt, wird an seinem Zeitbezug deutlich (s. Tabelle 9). Die Grundgefühle richten sich spezifisch entweder auf die Gegenwart oder auf die Vergangenheit oder auf die Zukunft. Authentischer Zorn liefert die nötige Energie, um Probleme in der Gegenwart zu lösen. Authentische Trauer hilft, Probleme der Vergangenheit zu verarbeiten. Wenn ich einen schweren Verlust erlitten habe, werde ich durch den Prozess des Trauerns geheilt.

Tabelle 9: Lösungspotential und Zeitbezug der Grundgefühle

\begin{tabular}{|l|l|l|l|}
\hline & Auslöser & Handlungsimpuls & Zeitbezug \\
\hline Ärger & Frustration & Etwas verändern & Gegenwart \\
\hline Trauer & Verlust & Loslassen & Vergangenheit \\
\hline Angst & Bedrohung & sich schützen & Zukunft \\
\hline Schmerz & Verletzung & heil werden & Gegenwart \\
\hline Freude & $\begin{array}{l}\text { Stimmigkeit: einig } \\
\text { mit sich selbst, mit } \\
\text { anderen, mit der } \\
\text { Situation }\end{array}$ & $\begin{array}{l}\text { Gemeinschaft } \\
\text { stiften }\end{array}$ & $\begin{array}{l}\text { Vergangenheit, } \\
\text { Gegenwart und } \\
\text { Zukunft }\end{array}$ \\
\hline
\end{tabular}

Authentische Angst hilft, Schwierigkeiten zu bewältigen, die in der Zukunft entstehen können. Nachts allein in einer Stadt könnte ich versucht sein, eine dunkle Gasse als Abkürzung zu nehmen. Spüre ich aber meine Angst, wähle ich die gut beleuchtete Straße und vermeide eine mögliche Gefahr. Schließlich: authentische Freude ist ganz in der Gegenwart, kann sich aber auch als Vorfreude auf künftige Ereignisse beziehen oder von vergangenen Erlebnissen zehren. Wenn ein Gefühl sich auf die zugehörige Zeit richtet, leistet es einen wichtigen Beitrag zur Problemlösung.

Wie können Sie Ersatzgefühle erkennen? Einige Fragen helfen weiter:

- Erkennen Sie im Hier und Jetzt einen passenden Anlass für das geäußerte Gefühl?

- Sehen Sie im gezeigten Gefühl bzw. Verhalten die Voraussetzungen für eine konstruktive Lösung des Problems?

- Merken Sie oder andere Beteiligte ein ungutes Gefühl, z.B. aufkommenden Ärger, oder den Eindruck, manipuliert oder erpresst zu werden?

- Erinnert Sie die Gefühlsäußerung an eine Position im Dramadreieck (Opfer, Retter, Verfolger)? Fühlen Sie sich in eine der Positionen eingeladen?

Ersatzgefühle werden so früh gelernt, dass sie sich als ebenso echt anfühlen wie ein authentisches Grundgefühl. Wird ein Ersatzgefühl von anderen Personen z. B. im Rahmen von Feedback in Frage gestellt, wird das vom Betreffenden leicht als Missachtung, als Mangel an Empathie oder gar Parteinahme für die Gegenseite empfunden. Konfrontation kann fatal wirken: „,... vielleicht stimmt da mit deinem Gefühl was nicht..." Berta reagiert nicht amüsiert. Nichtbeachtung hilft auch nicht; Menschen wollen emotional ernst genommen werden. 
Wie könnten Sie wirksam reagieren, wenn Ihnen eine Gefühlsreaktion „schräg“ vorkommt? Einige Möglichkeiten:

- Sie könnten von sich sprechen, z. B.: „Wenn ich mich in Ihre Situation versetze, merke ich, dass ich stocksauer wäre und das Verhalten von NN nicht einfach hinnehmen würde."

- Grundsätzlich empfiehlt es sich, Ersatzgefühle möglichst wenig zu beachten, stattdessen positiv auf das Zeigen ursprünglicher Gefühle und auf klares und konstruktives Verhalten zu reagieren (Risto 2003, 119).

- Wenn Sie registrieren, dass ein Lehrer sich nicht an Regularien hält - welches Gefühl empfinden Sie dabei? Wie äußern Sie es? Mit welchem Gefühl überdecken Sie möglicherweise das zeitlich angemessene Grundgefühl? Wie trägt das von Ihnen empfundene Gefühl zur Lösung bei? Sie wissen ja: Falls Sie Ihren Ärger überdecken, drohen heimliche Verträge. Was aber, wenn Sie gar keinen Ärger empfinden? Wenn Sie sich Ärger nie erlauben durften?

- Angenommen, Sie wären Mitglied in einer kollegialen Intervisionsgruppe, die nach dem Stufenmodell von Heigl-Evers arbeitet - dann würden Sie bei der Stufe 2 unterschiedliche emotionale Reaktionen auf Ihren Bericht hören. Wenn Sie berichten, dass Ihr Konfliktpartner auf Regularien pfeift, könnte ein Gruppenmitglied eine Stinkwut empfinden und das auch sagen; vielleicht geht das sogar mehreren so. Das könnte Sie zum Nachdenken bringen. Auf Stufe 4 (Diagnose) würde dann deutlich, dass Sie das Problem nicht lösen, indem Sie Ärger vermeiden. Und auf Stufe 5 würden Sie Vorschläge hören, wie Sie - wenn vielleicht auch nicht gleich ärgerlich - mindestens sehr bestimmt auf Regularien bestehen könnten. Das heißt, durch Vergleich mit den Reaktionen anderer, durch Überprüfung des Zeit- und Lösungsbezugs Ihrer gewohnten Reaktionsweise könnten Sie lernen, Ihren Gefühls- und Verhaltensspielraum zu erweitern.

\subsubsection{Auflösung von Blockierungen}

Berücksichtige ich den Zeitbezug der Grundgefühle, dann drängt sich mir auch auf, was in einer Situation jeweils dran ist und welches Lösungspotential in jedem Grundgefühl steckt. In diesem Zusammenhang steckt ein wichtiger Hinweis für alle, die Konflikten lieber aus dem Weg gehen, auch wenn sie „eigentlich“ dran wären. Sejkora und Schulze (2016, 182 f. 193 f. 282 f. 312) sprechen mehrfach die Schwierigkeit an, sich im Rahmen der Leitungsverantwortung in konfliktgeladenen Situationen zu einer klaren Stellungnahme durchzuringen. Erlebt wird das als eine innere Blockierung, in der man nicht weiter weiß.

Mehrfach haben Sie gelesen, dass Sie als Leiterin Hüterin und Wächterin von Regularien und Verfahren sind, dass Ihre Rolle Sie also nötigt, die Einhaltung von Rahmenbedingungen, Verträgen und Konzepten zu sichern. Andernfalls würden Sie heimliche Verträge hinnehmen und ein problematisches Leitungsvakuum in Kauf nehmen. Wenn Sie das nicht wollen, kommen Sie nicht drum herum, die Person anzusprechen, bei der Sie eine Vertragsverletzung wahrnehmen. Wie Sie dabei pragmatisch vorgehen können, wurde im Zusammenhang mit Konfliktmanagement 
erläutert (s. o. 6.4.1Typ I: Ich habe einen Konflikt mit Dir: Wie steuere ich mich?) Vorausgesetzt war dabei, dass Sie aufgrund Ihrer Rolle bereit sind, so einen Konflikt anzusprechen. Genau das kann aber gerade das Problem sein.

Dafür ein Beispiel: Angenommen, Sie bekommen mehrfach mit, dass eine Lehrerin notorisch zu spät zu ihrem Unterricht kommt. Sie schätzen sie als sensibel und kompetent; des Öfteren haben Sie sie als kreativ und innovativ erlebt. So jemand brauchen Sie, um die Entwicklung Ihrer Schule weiter voran zu bringen. Aber sie ist eben oft unpünktlich. So beschäftigen Sie vermutlich einige Fragen, z. B.:

Wie würde diese Lehrerin reagieren, wenn Sie dies Fehlverhalten ansprechen? Würde sie sich zurückziehen, ihre bisherige konstruktive Mitarbeit einstellen? Würde die bisher gute Beziehung zwischen Ihnen beiden einen Riss bekommen? Solche Fragen sind aus transaktionsanalytischer Sicht typisch für den Kind-IchZustand.

Wenn Sie also lieber ein Auge zudrücken, welche Folgen hätte das? Wer würde das kritisch registrieren? Wie stünde es um Ihre Autorität im Schulsystem? So melden sich elterliche Stimmen. Beide Vorgehensweisen haben ihre Tücken. Kein Wunder, wenn Sie erstmal nicht weiter wissen. Sie sind blockiert, aus zwei unterschiedlichen Richtungen in die Enge getrieben. Sie stecken in einem Engpass; so bezeichnet die Transaktionsanalyse eine Situation, ,in der sich Kind-Ich und Eltern-Ich mit ihren unterschiedlichen Ansprüchen gegenseitig blockieren und so das Erwachsenen-Ich daran hindern, seine lösungsorientierte Funktion umfassend wahrzunehmen." (Sejkora und Schulze 2016, 305; weitere Beispiele: $182 \mathrm{f} .193 \mathrm{f}$. 282 f. 312) Eltern-Ich-Zustand und Kind-Ich-Zustand halten sich gegenseitig in Schach.

Sejkora und Schulze (2016, $26 \mathrm{ff})$ beschreiben, wie sie in einer CoachingSituation so eine Blockierung bearbeiten. Sie stellen drei leere Stühle auf, einen für den Eltern-Ich-Zustand, einen für den Kind-Ich-Zustand und einen für den Erwachsenen-Ich-Zustand. Dann wird die blockierte Person gebeten, diese Stühle nacheinander zu besetzen. In unserem hypothetischen Fall würde ein Coach dann etwa sagen: „Denken Sie an die unpünktliche Lehrerin, und sprechen Sie laut aus, ohne innere Zensur, was Ihnen angesichts des unerwünschten Verhaltens durch Kopf und Herz geht.“ Aus dem kEl könnten Sie sagen: „Wie kann die sich das rausnehmen!? Hetzt mir unzufriedene Eltern auf den Hals. Hält sich wohl für was Besseres."

Im unschlüssigen, ängstlichen Kind-Ich-Zustand klänge es vielleicht so: „Ich will mir's ja nicht mit der verderben. Ich brauche ihre Unterstützung. Und ihre Sympathie möchte ich auch nicht verlieren.“

Sie können mehrfach den Stuhl wechseln. Dann nehmen Sie die Position des Erwachsenen-Ichs ein. Als Erwachsene sprechen Sie die beiden anderen Positionen direkt an. Die Antreiber-Stimme können Sie fragen: Worum geht es dir? Welche Gefühle stecken hinter deinem Drängen? Es geht also darum, dem Eltern-Ich aktiv zuzuhören und Verständnis zu zeigen. Dann wechseln Sie den Stuhl und reagieren darauf aus dem Eltern-Ich. Mit dem hilflos unschlüssigen Kind gehen Sie ebenso vor: Wovor fürchtest du dich? Welche Einschärfung nagt an deinem Selbstgefühl? Dieser Trialog kann mehrfach hin und her gehen. 
Schließlich fragen Sie aus dem Erwachsenen-Ich heraus das Eltern-Ich: Wie kannst Du Deine berechtigte Kritik so äußern, dass du das problematische Verhalten klar benennst, eine Abwertung der Person dabei aber vermeidest? Und das KindIch sprechen Sie ähnlich an: Wie kannst du als jetzt erwachsene Person deine Angst vor Sympathieverlust überwinden? Wie realistisch ist deine Vorstellung, unter allen Umständen mit allen immer harmonisch auskommen zu wollen? Wenn du spürst, dass die Leitungsposition dich auf schmerzliche Weise einsam macht, wie wird es dir gehen, wenn du deinen kindlichen Wunsch loslässt, wenn du dich auf die Trauer darüber einlässt? Wie kannst du persönliche Beziehungen außerhalb des beruflichen Bereichs intensivieren?

Zur inneren Blockade kommt es also durch die scheinbare Unvereinbarkeit unterschiedlicher Gefühle, die darum zu beachten und $\mathrm{zu}$ würdigen sind, wenn eine Auflösung gelingen soll. Gefühle wirken als Problemanzeiger, aber auch als Wegweiser für mögliche Lösungen. Ärger kann die Energie liefern, einen Konflikt anzugehen; Trauer kann sich als Aufgabe einstellen, wenn es darum geht, ein gewohntes Muster loszulassen. Als Leitung sind Sie Gegenüber, nicht Kollegin. Das schließt in der Regel ein, dass Sie sich von gewohnten Beziehungsmustern verabschieden müssen, wenn Sie bei Vertragsverletzungen die Primärinteressen der Schule zu vertreten haben. Je transparenter und souveräner Sie das hinkriegen, desto eher können Sie auch in der professionellen Arbeit einen wertschätzenden und verlässlichen Beziehungsstil leben und fördern.

Wie man Blockierungen auflösen kann - mit dieser schönen Perspektive beende ich die Rückgriffe auf den Fundus der Transaktionsanalyse (TA), mit denen ich (zusammen mit anderen Instrumenten) die fünf Dimensionen einer Lernenden Organisation zu konkretisieren vorschlage. Die TA ist das gemeinsame Dach für die genannten und für noch weitere nicht genannte Modelle, die alle einen gemeinsamen Ausgangspunkt haben: den Bezug auf die Ich-Zustände. Sie ist eine umfassende sozialpsychologische Theorie und Methode; drei Konzepte tragen das Dach: Persönlichkeit, Kommunikation und Beratung/Therapie:

- Das Persönlichkeitskonzept erklärt, warum Menschen sich so verhalten, denken und fühlen, wie sie es tun; Modelle dafür: Ich-Zustände, Trübungen, Bezugsrahmen, Skript, Antreiber, Einschärfungen, Maschensystem, Ersatzgefühle, Engpass.

- Das Kommunikationskonzept erklärt, wie Menschen miteinander kommunizieren und interagieren und wo und wie dabei Probleme entstehen können; Modelle dafür: Transaktionen, Zuwendungsvarianten, Dramadreieck, Prozesskommunikationsmodell (pcm), Drei-Welten-Modell, Organisationsmodell.

- Das Beratungskonzept zeigt, wie Menschen, Gruppen und Systeme diese Probleme konstruktiv lösen und sich gesund weiterentwickeln können: Vertragsarbeit, Abwertungstabelle, Enttrübung, Konfrontation, Erlaubnis, Zeitbezug und Lösungspotential der Grundgefühle. Mit A. Wyler-Krisch (2001) sehe ich die Modelle als Landkarten, als Orientierung für personenzentrierte systemische Interventionen (s. o. Anm. 43).

- Diese Konzepte tragen das gemeinsame Dach, das Menschenbild, das die Personen als Wert an sich, als „okay“ ansieht und problematische und destruktive Ver- 
haltensverwicklungen in Richtung bezogener Autonomie aufzulösen versucht; Modell dafür: die Grundpositionen (Näheres dazu s. u. 14.5).

Die aufgezählten Modelle finden Sie mit Hilfe des Index schnell im Text wieder; die Definition der TA übernehme ich von Sejkora und Schulze (2016, 443). Wenn Sie die TA näher kennenlernen möchten, empfehle ich Ihnen aus den Literaturangaben Brown/Woollams/Huige (1995), Risto (2003), Sejkora/Schulze (2016), Stewart/ Joines (1993) und Schlegel (1995).

\subsubsection{Gefühl und Urteilskraft}

Gefühle in der Kommunikation - das Thema ist zu komplex für ein paar Buchseiten. Es durchzieht die gesamte Philosophiegeschichte; W. Schmid (2000, $87 \mathrm{ff})$ gibt seinem Überblick den Titel „Die Kunst des Zorns“ und verweist auf große Denker: Aristoteles, Seneca, Plutarch, Montaigne und Kant. Im Wesentlichen sind die sich einig: Lass dich nicht von Gefühlen steuern, sondern entscheide bewusst, wie sehr du ein Gefühl zulassen willst.

Kant zählt zu den Affekten neben Freude, Traurigkeit, Hoffnung, Scham usw. auch den Zorn. Man handele im Zorn nicht so, wie man es sich überlegt hat; Zorn sei darum der wandelnde Widerspruch zur Klugheit. Der Zorn aber, der andauert, werde zur Leidenschaft, schließlich zum Hass. Daher rät Kant zu pragmatischer, kluger „Regierung des Gemüts“, nicht etwa, um die Affekte auf stoische Weise auszuschalten, ihnen jedoch auch nicht freien Lauf zu lassen; vielmehr rät er, den reflektierten Umgang mit ihnen zum Prinzip pragmatischer Lebensführung zu machen (W. Schmid 2000, 90).

W. Schmid schließt sich Kant an; es komme darauf an, sich nicht beliebig zum Zorn verleiten zu lassen, sondern selbst darüber zu befinden, ob ihm nachzugeben sei oder nicht, wenn ja, wann, wie lange, in welchem Maße usw., um in der Woge der Wut einen Augenblick der Reflexion zu bewahren und sich aus der Situation retten zu können, wenn es geboten erscheint. Dem Zorn eignet die Macht, Menschen und ihre Beziehungen zu zerfetzen, nur um hinterher zu sagen: „Es tut mir leid.“

Auch der Philosoph Peter Bieri sieht die Affekte als Bedrohung innerer Selbstständigkeit: „Wir können uns fragen, ob unsere Affekte der Situation angemessen sind: ob sie zu der Situation und ihrer Geschichte passen. Denn wir möchten nicht von Affekten bestimmt und getrieben werden, die jeder Grundlage entbehren: Das ließe die Affekte wie ein Gefängnis erscheinen." (Bieri 2013, 73)

Es kommt also auf das an, was zwischen Gefühl und Handlung stattfindet. Was kann der Zorn dafür, wenn die zornige Person unbedacht handelt? Zwischen Gefühl und Handlung sind mehrere Entscheidungen möglich; fünf Stufen lassen sich unterscheiden (Risto 2003,114):

Stufe 1: Das Gewahrwerden eines Gefühls

Stufe 2: Das Benennen des Gefühls mit einfachen Worten

Stufe 3: Das Zulassen des Gefühls bei sich selber

Stufe 4: Der Entschluss, ob man es zeigen will oder äußert oder ob man es verbirgt Stufe 5: Der Entschluss, wie man aufgrund des Gefühls handelt 
Auch heftige Gefühle müssen nicht gefährlich sein, solange sie nicht automatisch zu Gewalt gegen andere oder gegen mich selbst führen (s.o. 12.3.1). ${ }^{113}$ Handelt es sich aber um ein Ersatzgefühl, so wäre ich dadurch an frühere Erfahrungen gebunden, also innerlich unfrei.

Bieri beschreibt unsere innere Unfreiheit ähnlich wie Transaktionsanalyti$\operatorname{ker}^{114}$ und fährt dann fort:

„Doch wir können selbständig werden und selbstbestimmt. Das heißt zunächst: die zensierten Wünsche und Affekte bewußtmachen. Bemerken lernen, daß sie da sind, und die Routine erkennen, mit der wir sie der Zensur unterwerfen: Begierden und Sehnsüchte, Angst, Neid und Eifersucht, auch verbotene Wut, etwa auf den Lebenspartner, die eigenen Kinder oder auf religiöse Autoritäten. In einem zweiten Schritt dann bedeutet Selbständigkeit: sie neu bewerten im Lichte des eigenen Urteils, das wir inzwischen über diese Dinge haben.“(A.a.O., 76)

Wir können selbstständig werden, meint Bieri, meint auch Kant, meint auch W. Schmid. Die Frage ist, wie wir das erreichen. Gleicht das dem Appell, uns selbst am Schopf aus dem Sumpf zu ziehen? Einen bemerkenswerten interdisziplinären Konsens sehe ich darin, dass Philosophen, Psychologen und Theologen innere und äußere Freiheit unterscheiden, dass sie die Unfreiheit, den Mangel an Autonomie im Inneren des Menschen verankert sehen und dass darum auch die Befreiung im Inneren des Menschen anzusetzen hat. So dass zu folgern ist, dass die Qualität der gewonnenen äußeren Freiheit derjenigen der (eigenständig erworbenen oder der geschenkten) inneren Freiheit entsprechen sollte; andernfalls wäre das nach außen gezeigte Verhalten ein Indiz für nach wie vor bestehende innere Unfreiheit. ${ }^{115}$

113 Zur Erinnerung: Ärger, Wut oder Enttäuschung und Verletzung stellen sich oft als C, als Konsequenz, ein. Sie verwandeln sich dann leicht in neue Ausgangsreize, die zu eskalierenden Handlungen führen. Das ABC liefe dann so weiter: A1-B1-C1-B2-C2. Die Wut (C1) muss nicht zu Gewalt (C2) führen.

114 „Was wir an Selbstbildern und Zensur mit uns herumtragen, haben wir ursprünglich durch Nachahmung und Anerziehen erworben. Andere haben es uns vorgesagt und vorgelebt, und wir haben es in uns nachgebildet. Es ist ein Prozeß, in dem das Diktat äußerer Autoritäten verinnerlicht wird: das Diktat von Eltern, Lehrern, religiösen Führern, Institutionen mit Gruppenidealen. Innere Autorität beginnt als verinnerlichte äußere Autorität. In diesem Sinne beginnen wir alle mit Unselbständigkeit: Die verinnerlichte Autorität ist übermächtig und unverfügbar. Sie ist es auch deshalb, weil sie nicht bewußt ist und nicht als Autorität erkannt wird. Sie operiert hinter unserem Rücken.“(Bieri 2003, 76)

115 Luther (1520) hat behauptet, ohne die Unterscheidung von innerem und äußerem Menschen lasse sich gar nicht verständlich machen, was es mit dem Christentum auf sich hat (vgl. 11.7.8). Freiheit gehört ins Zentrum eines theologisch reflektierten Bildungsverständnisses: „Es geht um Freiheit und um Subjektwerdung. Sowohl schöpfungs- als auch rechtfertigungstheologisch gilt, dass die von Gott zugesprochene Würde und Achtung der Person keine Instanz in Frage zu stellen vermag. Die Würde der Person, die mit der Gottebenbildlichkeit dem Menschen unverlierbar geschenkt wird, begründet die Freiheit zu einer Subjektwerdung, die auch Möglichkeiten von Widerspruch und Distanzierung von gesellschaftlichen Rollen einschließt." (Schreiner 2015, 14) 
Die Transaktionsanalyse handelt das Thema menschlicher Freiheit und Unfreiheit im Zusammenhang mit dem Skript- bzw. Maschensystem ab. Kinder zeigen schon sehr früh, vor dem Spracherwerb, Grundgefühle: glad, sad, mad, scared; pain (Schmerz) ist zu ergänzen. Aus den Reaktionen ihrer Pflegepersonen schließen sie, welche Gefühle verstärkt und welche eher missbilligt werden. Missbilligte Gefühle werden überdeckt, manchmal so stark, dass sie gar nicht mehr empfunden werden; Ersatzgefühle sind in der Lage, Grundgefühle zu verdecken.

Eine wesentliche Hilfe bietet das Konzept der Ersatzgefühle für die Frage, wie wir uns der skriptbedingten mentalen Einschränkungen bewusst werden können. Es geht dann nicht nur darum, Gefühle in Schach zu halten, als ob sie bedrohlich wären, sondern sie auf ihre Stimmigkeit und Angemessenheit abzuklopfen, ihren Zeitbezug zu prüfen und so Zugang zur eigenen Lösungsenergie zu gewinnen. Ersatzgefühle passen nicht zum Zeitbezug: Trauer statt Zorn, Zorn statt Angst, Angst statt Wut usw. - solche Verschiebungen sind skriptgebunden, Signale für innere Unfreiheit; sie lähmen die mit den Grundgefühlen verbundene Energie, versperren den Zugang zu den Grundbedürfnissen, tragen nicht zum kompetenten Umgang mit den Schwierigkeiten des Lebens bei und stehen so möglicher Erweiterung von Autonomie im Weg.

Zurück zu den Fragen am Anfang dieses Abschnitts. Sie lassen sich jetzt begründet beantworten. Ich gehe sie einzeln durch:

Frage: Stören Gefühle die Kommunikation?

Antwort: Emotionale Äußerungen können die Kommunikation z. B. in einer Konferenz irritieren, aber auch voranbringen. Wenn Konfliktlösungen üblicherweise nach ausschließlich rationalen Gesichtspunkten entworfen werden, wertfrei, ohne Ideologie, wie dann gern betont wird, dann werden Grundbedürfnisse möglicherweise ignoriert. Dann wäre eine gekreuzte Transaktion eine Chance, diese Fixierung bewusst zu machen und den Horizont zu erweitern. Je nach Gruppenklima kann das einigen Mut erfordern.

Frage: Verhindern Gefühle Verständigung?

Antwort: Gemeinsam geteilte Empfindungen und Gefühle können als erfreuliche Harmonie erlebt werden. Wenn unterschiedliche Gefühle geäußert werden, kann die Frage nach den Grundbedürfnissen weiter führen. Wenn sogenannte Sachzwänge gegen Grundbedürfnisse ausgespielt werden, dann werden solche Spannungen ausgeblendet oder gar nicht wahrgenommen.

Carola Meier-Seethaler, Philosophin und Psychologin, diskutiert Sachzwänge in globalem Maßstab und sieht in authentischen Gefühlen eher die Rettung: „Die Energie für zukunftsgerichtetes Handeln ist nur aus der emotionalen Identifikation mit unserer Erde, mit der Vielfalt ihrer Lebewesen und den kommenden Generationen der Menschheit zu schöpfen. “ (Meier-Seethaler 1998, 367) Die Unterdrückung der Emotionen in Erkenntnistheorie und Wertphilosophie kritisiert sie scharf: „Es ist die stereotype Berufung auf Sachzwänge, womit man alle Reformvorschläge von vornherein ablehnt, ohne daß diese Zwänge selbst auf ihre Stichhaltigkeit geprüft würden. In Wahrheit gibt es aber als einzige Sachzwänge die ökologischen Gesetze der Natur, an die auch menschliches Handeln gebunden 
ist."116 Die Autorin plädiert also für die Berücksichtigung der Gefühle und der mit ihnen verbundenen Grundbedürfnisse, aber auch dafür, die damit verbundenen Konflikte mit emotionaler Vernunft auszutragen.

Sind diese Fragen zu weit hergeholt? Gegenfrage: Welche Sachzwänge bremsen gute Ideen bei Ihrer Schulentwicklung? Wie kommen Sie mit dem Gefühl von Ohnmacht und Ratlosigkeit zurecht? Und mit Wut? Meier-Seethaler analysiert die Spannung zwischen Gefühl und Vernunft in planetarer Perspektive. Wenn das sinnvoll ist - ist es dann nicht eine wesentliche Bildungsaufgabe, diese Spannung auch in einer Lernenden Organisation fortlaufend zu reflektieren? So dass vermeintliche Sachzwänge auch in der praktischen Schulentwicklung auf den Prüfstand kommen? Einiges dazu wurde bereits besprochen, unter der Überschrift ,,realitätsferne mentale Modelle“ (6.9.8-6.9.11). Kapitel 13 wird die Freiheit der freien Schulen thematisieren und dabei vermeintliche Sachzwänge diskutieren.

Frage: Sind Gefühle nicht eher das Salz in der Suppe? Zeichen für Lebendigkeit?

Antwort: Ja, wenn sie authentisch, nicht manipulativ gelebt und geäußert werden. Ein gefühlloses Leben wäre auch ein empathieloses Leben. Ernst Tugendhat (1994, 22) sieht in den Gefühlen eine konsensfähige Quelle ethischer Orientierung. ${ }^{117}$ (Näheres dazu s.u. 13.4.4)

Frage: Ist Kommunikation ohne Gefühle überhaupt möglich?

Antwort: K.R. Popper würde sich das wünschen, allerdings nur für das Wissenschaftsgeschäft. Für ihn sind Wertvorstellungen wichtige, aber persönliche Entscheidungen; im rein sachlich-wissenschaftlichen Diskurs hätten die aber nichts zu suchen (Meier-Seethaler 1998, 124). Innerhalb dieses Diskurses aber ist der objektive und wertfreie Wissenschaftler nicht der ideale Wissenschaftler: „Ohne Leidenschaft geht es nicht, und schon gar nicht in der Wissenschaft.“ (A.a.O., 132) Im „Positivismusstreit“ spielte diese Frage eine zentrale Rolle (Meier-Seethaler, a.a.O., Kap. 11, 120 ff). Habermas hielt Popper vor, dass die

116 Fortsetzung: „Alle anderen Sachzwänge beruhen auf willkürlichen menschlichen Setzungen: Nur wir selbst haben uns zum Ziel gesetzt, technische Neuerungen immer weiter voranzutreiben und immer größere Mengen von Waren herzustellen, ohne nach ihrem Sinn und ihren Auswirkungen auf die Umwelt zu fragen.“ „Nur die Gesellschaft bzw. ihre mächtigen Exponenten definieren, was Produktivität beinhaltet und an welche Maßstäbe sie zu binden sei. ... Wenn dann diese selbstgesetzten Zwänge zu ökologischen und sozialen Katastrophen führen und wir gleichzeitig behaupten, es gäbe für dieses System keine Alternative, so bedeutet dies offensichtlich eine Bankrotterklärung für die menschliche Vernunft." (A.a.O., 367)

117 Ohne die Fähigkeit zur Empörung würden wir unsere Mitmenschen nur noch als eine Art wilder (manchmal auch sanfter) Tiere ansehen. Sie wären keine Subjekte mehr, mit denen wir uns moralisch streiten könnten, sondern Objekte, vor denen wir uns gegebenenfalls zu hüten hätten. Wir könnten uns zueinander nur noch instrumentell verhalten. (Tugendhat 1994, 22) In zwei eindrucksvollen biblischen Erzählungen sorgt Empörung für unmittelbare Plausibilität: Das Nathan-Gleichnis konfrontiert König David mit dem Mord an Uria (2. Samuel 12). Einem Fürsten wird eine astronomisch hohe Schuldsumme erlassen. Als er selbst um Zahlungsaufschub für ,peanuts“ angefleht wird, reagiert er mit äußerster Härte (Matthäus 18, 23 ff). 
Beschränkung auf ein technisches Erkenntnisinteresse eben dies Interesse undiskutiert zur Herrschaft bringt, statt den Forschungsprozess normativ an Motive der Lebenspraxis zu binden (A.a. O., 126f). ${ }^{118}$

In vielen Organisationen scheint es noch immer das Ideal zu sein, Probleme rein sachlich, ganz unemotional anzugehen. Der damit verbundene Kraftaufwand wird leicht unterschätzt. Die dafür nötige Willenskraft ist eine begrenzte Ressource, die sich mit der Zeit verbraucht. Je länger man gegen seine Gefühle arbeiten muss, desto höher ist die Gefahr, dass sie mit einem durchgehen, ähnlich wie bei einer Bremse, die zu fest betätigt wird: Das Rad blockiert, das Fahrzeug schleudert unkontrolliert. Um es in der Spur zu halten, muss man von der Bremse gehen.

Gleiches gilt für die Gefühle: Wenn man sie unterdrückt, werden sie nicht schwächer, sondern stärker. Für Neuro-Experten ist die Konsequenz daraus klar: „Um Gefühle zu zähmen, müssen wir ihnen Raum geben.“ Die planmäßige Unterdrückung von Gefühlen macht es Führungskräften unmöglich, gleichzeitig offen für die emotionalen Bedürfnisse ihrer Mitarbeiter zu bleiben und sensibel auf sie zu reagieren. Außerdem kostet die Unterdrückung mentale Ressourcen: Eine willentliche Kontrolle der Gefühle blockiert die Denkfähigkeit; das legen psychologische Experimente nahe. Fazit: „Emotionsarbeit geht zulasten anderer Hirnprozesse.“ Wer seine Gefühle unterdrückt, denkt schlechter. ${ }^{119}$ (Reimann 2014, 40)

Alle diese Hinweise setzen voraus, dass wir auch unter Stress in der Lage sind, unseren präfrontalen Kortex zu aktivieren. Die Neurowissenschaftler Franz Hütter warnt jedoch: Die emotionale Erstreaktion auf einen Reiz findet in den evolutionär ältesten Regionen des Gehirns statt, im „Reptiliengehirn“! Erst in zweiter Instanz wird der Affekt dem Bewusstsein zugänglich, im präfrontalen Kortex. Zwischen beiden Hirnregionen gibt es direkte Verbindungen, über die eine Regulation stattfindet. Am ursprünglichen Affekt ändert das erst einmal nichts, wohl aber daran, ob und wie ein Affekt zum Ausdruck kommt.

Das Verhältnis der beiden Reaktionsinstanzen kann man sich vorstellen wie das von Dirigent und Orchestergraben. Bei Stress oder anderen emotionalen Ausnahmezuständen wird dieser Dirigent regelrecht ausgeschaltet. Auch Schlafmangel und Alkohol schwächen ihn. Je nach emotionalem Zustand reagieren wir dann wütend, genervt oder panisch - und wenig diplomatisch. Die Fähigkeit zum bewussten

118 Die Wissenschaften ,antworten auf keine einzige der wesentlichen Fragen, die wir uns stellen, nicht einmal auf die, die sie uns stellen. Auf die Frage ,Soll man Mathematik betreiben?" kann es keine mathematische Antwort geben. Auf die Frage „Sind die Wissenschaften wahr?" kann es keine wissenschaftliche Antwort geben. Genauso wenig wie auf die Fragen über den Sinn des Lebens, die Existenz Gottes oder den Wert unserer Werte. Und doch können wir auf diese Fragen nicht verzichten." (Comte-Sponville 1996, 187)

119 „Aus der Perspektive der emotionalen Vernunft besteht Sachlichkeit nicht in einer kühlen, von den eigenen und den Gefühlen anderer abgespaltenen Denkart, sondern läßt sich eher mit dem Begriff der Besonnenheit umschreiben. Besonnenheit nimmt zwar Abstand zur eigenen Betroffenheit in der Reflexion, aber im Spiegel ihres Bewußtseins erscheinen Ich und Mitwelt als lebendige Wirklichkeiten, denen wir nur gerecht werden, wenn die Erkenntniskräfte des Denkens und Fühlens zusammenwirken. " So fasst Meier-Seethaler (1998, 395) ihr gelehrtes Plädoyer für die emotionale Vernunft am Ende zusammen. 
Denken oder zum Perspektivwechsel ist in dieser Situation stark eingeschränkt, weswegen Konflikte im Affekt leicht eskalieren. Der ordnende Einfluss der höheren Instanz geht verloren, der „Graben“ übernimmt (Reimann, a.a. O.); die oben genannten fünf Stufen der Bewusstwerdung fallen dann aus. Wenn der Stresspegel solche Höhen erreicht, ist Stressmanagement angesagt (s. o. Kapitel 11).

Frage: Darf eine Schulleiterin überhaupt Gefühle äußern? Wäre das ein Zeichen von Schwäche? Verliert sie dann an Autorität?

Antwort: Gefühle sind wichtige Signale, die im Erwachsenen-Ich-Zustand berücksichtigt werden können und sollten. Wie wir über eine gewisse kognitive Intelligenz verfügen, so können wir auch emotionale Intelligenz entwickeln und nutzen. Hier sind einige Vorschläge (Ernst 2005, 27):

- „Identifizieren Sie Ihre Gefühle, statt Menschen oder Situationen zu etikettieren: ,Ich bin ungeduldig' statt ,Das ist doch lächerlich!‘ oder ,So eine Schlafmütze!‘

- Unterscheiden Sie zwischen Gedanken und Gefühlen: ,Das verwirrt mich ziemlich, was du da sagst!' (Gedanke) und ,Ich bin ziemlich down!' (Gefühl)

- Vergewissern Sie sich immer wieder einmal, ob Sie die Gefühle anderer richtig erkennen (,lesen').

- Nutzen Sie Ihre Gefühle bei Entscheidungen, indem Sie sich fragen: ,Wie werde ich mich fühlen, wenn ich das mache? Und wie, wenn ich es nicht mache?‘

- Fragen Sie auch andere Menschen: ,Wie wirst du dich fühlen, wenn du dieses oder jenes tust (sein lässt)?

- Stehen Sie für Ihre Gefühle ein: ,Ich bin eifersüchtig!‘ statt ,Du machst mich eifersüchtig!‘

- Üben Sie sich in der Kunst, Gefühle ins Positive zu wenden: ,Wie fühle ich mich jetzt - und was könnte ich tun (oder unterlassen), damit ich mich besser fühle?'

- Meiden Sie Menschen, die Ihnen Ihre Gefühle absprechen oder sie ,ummünzen“ wollen: ,Du bist jetzt bloß neidisch!‘ (wenn Sie in Wirklichkeit traurig sind)."

Frage: Kann eine Schulleiterin allparteilich moderieren oder gar Konflikte regeln, wenn sie eigene Gefühle zulässt?

Antwort: Gerade dann kann sie es; Empathie für beide Seiten ist wichtig.

Frage: Sind Gefühle Privatsache?

Antwort: Soweit sie sich auf private Aspekte beziehen, ja. Pädagogische Arbeit ist Beziehungsarbeit. Da ist emotionale Beteiligung nicht nur erlaubt, sondern erwünscht.

Frage: Sind die Männer matt gesetzt, wenn eine Frau sich auf ihr Gefühl beruft? Ende der Diskussion?

Antwort: Bertas Mann hat den Konflikt eskaliert: „Vielleicht stimmt da mit deinem Gefühl was nicht ..." Berta antwortet mit einer Aufzählung ihrer Haushaltsbelastungen. Sie wirkt gereizt. Offensichtlich fehlt ihr Anerkennung. Das Grundgefühl geht dann wohl in Richtung Wut. Dass eine Hausfrau die Kochzeit „,im Gefühl“ hat, ist m. E. eher eine Fehlbenennung, die sie wohl besser für sich behielte. 


\subsubsection{Vertiefung: Alle Gäste sagen ab ...}

Weghören vom Beziehungsohr, unterscheiden zwischen Interesse und Lösungsplan, sich lösen von der Lösungsidee, aus einer Kränkung keine Affekthandlung werden lassen, das Gefühl vielmehr wahrnehmen als Hinweis auf ein wichtiges Grundbedürfnis - das alles ist anspruchsvoll. In der Analyse sieht das kompliziert aus, im Leben geht das zusammen. Gute Geschichten zeigen uns das; sie produzieren innere Bilder, die sich gut merken lassen. Und man kann sie so erzählen, dass auch Kinder sie verstehen. Ein Beispiel:

Ein Mann plant ein Fest, lädt seine vielen Freunde ein, persönlich, durch Boten. Am Tag des Festes schickt er den Boten nochmals los; so war es in besseren Kreisen in seiner Kultur üblich. Jetzt hört der Bote nur Absagen: dringende Geschäfte haben Vorrang, Vergrößerung des Landbesitzes, Erweiterung des Viehbestands - Qualitätssicherung ist dran. Haben die Verwalter das vernünftig erledigt? Der Dritte fürchtet Ehestress: Bin gerade verheiratet, kann sie jetzt nicht allein lassen. (Frauen durften nicht mitfeiern - Patriarchat!)

Der Bote erstattet Bericht. Wie reagiert sein Chef? Was fühlt er? Wie würden Sie reagieren?

„Schwer ward dieser Mann gekränkt. / Wenn er das nicht gleich verdrängt:

Wird das beugen seinen Rücken / und ihn seelisch niederdrücken?

Reagiert er depressiv, landet er im Dauertief? ...

Mancher würde toben, platzen, / und es würde ihn nicht kratzen, daß er die Verkehrten trifft; / raus muss eben all das Gift.

Der hier tobt die Wut nicht aus, / läßt die Sau nicht einfach raus.

Ist sein Zorn auch ungeheuer, / er beherrscht sich, hält das Steuer.

Schön man hier erkennen kann: / Freiheit fängt tief innen an. ...

Selbst wenn alle ihn versetzen, / kann ihn das nicht so verletzen, daß er alles platzen läßt; / so sehr liegt ihm an dem Fest.

Gäste lassen sich auch finden / bei den Lahmen und den Blinden, die sich gern am Festmahl laben, / weil sie sonst ja gar nichts haben, keine Pflichten, keine Bürde, / nichts was sie dran hindern würde, zu dem Festmahl gleich zu eilen / und dort fröhlich zu verweilen."

(Christiansen 1997, 56ff zu Lukas 14, 16-24)

Das Gedicht zeigt hier einen Entwicklungsprozess: Gekränktheit, Depression wären verständlich, lösen aber das Problem nicht. Es geht dem Mann um das Fest, das soll stattfinden. Sein Zorn schadet seiner Kreativität nicht; er liefert ihm die nötige Energie. Von der ursprünglichen Lösungsidee löst er sich. Am Ende lässt er noch die Leute von den Landstrassen und Zäunen holen. Eine Inklusionsgeschichte. Manche Schulen besinnen sich auf Inklusion, wenn die Schülerzahlen absacken. Auch das ist depressiven Reaktionen vorzuziehen.

Lukas erzählt die Geschichte als Antwort auf die Bemerkung eines Tischgenossen, wie schön es einmal sein wird, im Reich Gottes am Tisch zu sitzen. Jesus liegt eher an der Gegenwart: Das Fest findet jetzt statt. „Reich Gottes“, basileia, kann man auch mit Herrschaft übersetzen. So geht es zu, wenn Gott zur Herrschaft kommt - und nicht destruktiv wirkende Affekte. 
Mit dürftiger Resonanz hatte Jesus Erfahrung. Vielleicht hat er sich selbst mit dieser Geschichte Mut gemacht? Oder wollte er seine kleine Gruppe stärken?

Wie geht es Ihnen, wenn Sie auf Beteiligung hoffen, auf gemeinsames Lernen und Arbeiten und die erhoffte Resonanz ausbleibt?

\section{Lesetipp}

Boettcher/Mosing (2006): Leitungskommunikation. Dieser Artikel in Buchens Sammelband zeigt, wie Sie in Konflikt-, Schlichtungs- und Jahresgesprächen mit Hilfe transaktionsanalytischer Konzepte vorgehen können, mit realistischer Einschätzung von Delegationsnotwendigkeiten (Leitungsspanne!) und einer spürbaren professionellen Strenge, die die Verantwortung der Leitungsrolle anregend unterstreicht.

Hiebl und Seitz (2014): Kapitel 4 


\section{Kapitel 13: Die Freiheit „freier" Schulen}

Schulen sind mehr oder weniger frei. Je nach gesetzlichen Vorgaben kann ihr Spielraum enger oder weiter sein. Über die Vorgaben hinaus gibt es Regularien und Verfahren in den einzelnen Schulen. Und die in den Schulen Handelnden machen unterschiedlichen Gebrauch von ihrer Freiheit.

Der Philosoph Peter Bieri unterstreicht den Sinn von Vorgaben für die Freiheit: Frei sein heißt, innerhalb des vorgegebenen Rahmens eigenwillig zu sein, zwischen einem Willen unterscheiden zu können, der einem von anderen aufgezwungen wird, und einem, in dem die eigene Individualität zum Ausdruck kommt. „Freiheit des Willens bedeutet also nicht seine vollständige Ungebundenheit, im Gegenteil: Es macht die Freiheit eines Willens aus, dass er auf bestimmte Weise gebunden ist. Die Welt mit ihren Angeboten setzt fest, was ich zu einem gegebenen Zeitpunkt wollen kann. Der Rest liegt bei mir.“ (Homann 2002) ${ }^{120}$

O-Ton Bieri $(2005,125)$ :

„Es könnte einer erschrecken, weil er gedacht hatte, die Freiheit des Willens müsse darin bestehen, dass der Wille durch nichts bedingt sei. Dass er unter exakt denselben inneren und äußeren Bedingungen ganz unterschiedliche Wege nehmen könnte. ... Doch einen in diesem Sinne freien Willen kann sich niemand wünschen, denn er wäre ein Wille, der niemandem gehörte: verknüpft weder mit dem Körper noch dem Charakter, noch dem Erleben, noch der Lebensgeschichte einer bestimmten Person. Er wäre vollkommen zufällig, unbegründet, unbelehrbar und unkontrollierbar. Einen solch launischen Willen zu haben wäre nicht die Erfahrung der Freiheit, sondern ein Alptraum.“

\subsection{Vorgaben der Freiheit: Allgemeine rechtliche Rahmenbedingungen}

Als Schulleiterin sind Sie vor allem gefordert, am System zu arbeiten. Dazu gehört die Wächterschaft über Regularien und Verfahren. Sie können sich diese Aufgabe erleichtern, indem Sie Ihr Kollegium über die wichtigsten Rahmenbedingungen auf dem Laufenden halten, über relevante gesetzliche Bestimmungen und Trägergrundsätze, über Ihr Leitbild, Ihr Schulprogramm, über vorliegende Dienstvereinbarungen und konzeptionelle Verabredungen. Sorgen Sie dafür, dass allen Schulmitgliedern klar sein kann, wo diese Rahmenbedingungen dokumentiert und nachzulesen sind. Dafür ist elektronische Kommunikation nützlich; Konferenzen sind dafür zu schade. So definieren Sie gleichzeitig den Spielraum, in dem Ihre Schule sich bewegen kann (s. Grafik 27). Auch das ist Arbeit am System.

Bei aller Bemühung um Klarheit und Transparenz kommt es auch in Schulen immer wieder zu Konflikten: Regularien werden unterschiedlich verstanden; oder sie werden nicht so wichtig genommen, werden schlicht vergessen. Dasselbe gilt

120 Rezension zu Peter Bieri: Das Handwerk der Freiheit. 


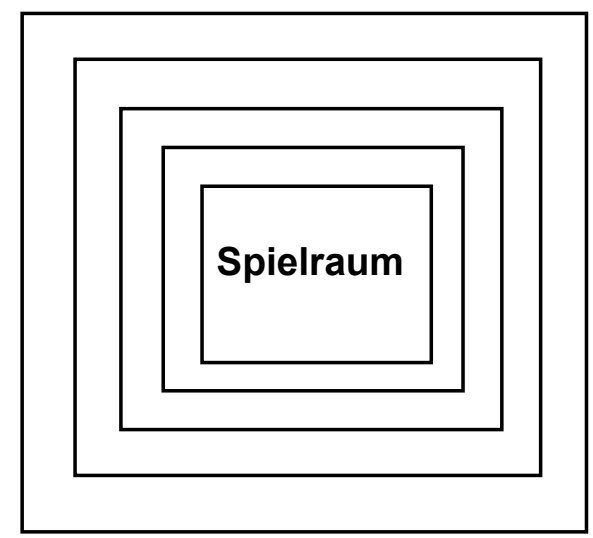

Grafik 27: Schulischer Spielraum innerhalb gegebener und verabredeter Grenzen

für Schulverträge, für das Schulkonzept usw. Je nachdem müssen Sie gegenüber Lehrkräften, gegenüber Schülerinnen und Schülern oder gegenüber deren Eltern vertragliche Vereinbarungen vertreten.

Eltern beklagen sich über schulische Entscheidungen: Ihr Kind werde gemobbt, ungerecht beurteilt usw.; Schüler ignorieren die Hausordnung; eine Lehrkraft kommt regelmäßig zu spät zum Unterricht. Je nach Eskalationsstufe so eines Konflikts (s. o. 6.4.1) lässt sich das gütlich regeln, wenn nötig mit externer Hilfe. Wenn Verständigung nicht möglich scheint, wenn externe Beratung nicht greift, wenn juristische Schritte drohen, dann ist Rechtskunde gefragt, jedoch nicht etwa voreiliges Handeln, das sich in Form überraschender juristischer Folgen rächen würde.

Überfordern Sie sich nicht, wenn die Sprache der Auseinandersetzung zunehmend juristische Färbung annimmt. Lassen Sie sich von einem doppelten Experten warnen: Günther Hoegg, selbst Lehrer und Jurist, hat die aus seiner Sicht ,50 wichtigsten Schulrechtsurteile" auf vergnügliche und gut verständliche Weise so zusammengestellt und erläutert, dass die Lektüre Sie für juristische Fallstricke sensibilisiert. Suchen Sie im Ernstfall aber lieber fachjuristischen Rat, statt selbst mit Paragraphen zu wedeln.

Hoegg konzentriert sich auf fünf Gebiete; ich nenne Ihnen als Appetitanregung jeweils einen interessanten Fall pro Gebiet:

- Grundrecht: Sportbefreiung aus religiösen Gründen.

- Beamtenrecht: Nichtbefolgen einer Weisung.

- Schulrecht: Verletzung durch Mitschüler in der Pause.

- Leistungsbewertung: Notenbildung für das gesamte Schuljahr.

- Ordnungsmaßnahmen: Cybermobbing gegen Lehrer.

Hoegg bringt typische Beispiele, die Ihnen ein orientierendes Grundverständnis ermöglichen. Er will aber keine Amateur-Juristin aus Ihnen machen.

Wir haben in unseren Kursen in 19 Jahren mit ca. 300 Teilnehmerinnen und Teilnehmern nur zwei Fälle miterlebt, in denen es zu arbeitsgerichtlichen Entschei- 
dungen kam. Beide bezogen sich nicht auf Eltern von Schülerinnen oder Schülern, auch nicht auf deren Kinder, auch nicht auf Lehrkräfte, sondern auf Konflikte mit dem jeweiligen Schulträger. In beiden Fällen hat der Schulträger Kündigungen ausgesprochen, die weder juristisch haltbar waren noch einem halbwegs kompetenten Konfliktmanagement entsprachen. Der jeweilige Arbeitsrichter hat hohe Abfindungen auferlegt, die dem Träger dann in seinem Schulsystem fehlten.

Zwei weitere Fälle betrafen Fehlverhalten von Lehrkräften, die auf juristischem Weg gelöst wurden und von denen wir nur am Rande hörten.

In einem fünften Fall drohte einem Leiter die Kündigung; der vom Kollegium „Angeklagte“ bestand jedoch erfolgreich auf einer Klärungsklausur mit dem gesamten Kollegium einschließlich des Trägervertreters, die auf seinen beharrlich vertretenen Wunsch hin von uns moderiert wurde. Dabei ist es gelungen, zu einer einvernehmlichen Lösung zu kommen, die die Stellung des Leiters konsolidierte und Perspektiven für die künftige Zusammenarbeit von Leiter und Kollegium eröffnete.

\subsection{Was nicht verboten ist, ist erlaubt: Das Grundrecht der Privatschulen}

So winzig Ihr Spielraum in der Grafik 27 wirken mag, so erstaunlich groß ist die Freiheit der „freien“ Schulen. Ich fasse knapp zusammen, was die Juristin und katholische Ordensschwester Hanna Sattler (2013) den Schulleitungen in einem munteren Vortrag ans Herz gelegt hat, unter dem schönen Titel: „Privatschulen im Rechtskorsett? Mehr Mut zur Freiheit!“

- Die Kulturhoheit liegt bei den 16 Bundesländern. Das heißt, es gibt 16 verschiedene Schulgesetze, teilweise auch eigene Privatschulgesetze. Diese länderspezifischen Gesetze für Privatschulen sollten Sie genau studieren. Die Institutsgarantie besagt: Der Staat muss das private Schulwesen stützen und fördern. Das schließt die Pflicht zur finanziellen Förderung ein. Das WIE der Förderung allerdings differiert von Bundesland zu Bundesland.

- Die Privatschulfreiheit ist nach Art. 7, Abs. 4 GG ein Grundrecht. Die Grundrechte sind Freiheitsrechte. „Das bedeutet: Freiheit ist der Grundsatz, Beschränkung die Ausnahme. Nicht die Freiheitsausübung bedarf der Rechtfertigung, sondern die Einschränkung. Einfacher gesagt: es ist alles erlaubt, was nicht ausdrücklich verboten ist. Oder kurz gefasst: in dubio pro libertate!“(A. a. O. 33)

- Die Errichtungsgarantie ist in Art. 7, Abs. 4, Satz 1 GG geregelt: freie Entscheidung über Lehrziele, Lehrstoff, Lehrmethode, Lehrerwahl und Schülerwahl.

- Die Institutsgarantie besagt, dass der Staat das private Schulwesen schützen und fördern muss, auch finanziell. WIE die Förderung aussieht, ist allerdings Sache des Landesgesetzgebers, so dass es sehr unterschiedliche und teilweise recht sparsame Modelle der Schulfinanzierung gibt.

Einschränkungen:

- Private Schulen bedürfen der Genehmigung des Staates, sie unterstehen den Landesgesetzen. 
- Privatschulen müssen gleichwertig sein, aber nicht gleichartig. Sie dienen der Aufgabe, das öffentliche Schulwesen zu vervollständigen und zu bereichern (so z. B. BayEUGArt. 90, Satz 1). „Um diese Aufgabe zu erfüllen, müssen private Schulen anders sein als öffentliche. Eine bloße Kopie reicht nicht.“(A.a. O. 36)

- Die Verwaltungspraxis und teilweise auch die Landesgesetzgebung hält sich allerdings nicht durchweg an die vom Grundgesetz gewährleistete Freiheit. Darum ist die Kenntnis der landesgesetzlichen Regelungen wichtig. Solange sie nicht als verfassungswidrig erwiesen werden, müssen die einzelnen Schulen sich daran halten.

- Die leistungsbezogenen Aufnahmekriterien der staatlichen Schulgesetze sind anzuwenden.

- Bei den freien Schulen ist ein defizitäres Freiheitsbewusstsein zu konstatieren: Viele Privatschulen trauen sich nicht, zu dürfen. Es gibt Einengungen durch Aufsichtsbehörden (Kultusministerien, Regierungen, Bezirksregierungen usw.) und durch vorauseilenden Gehorsam von kirchlichen Schulträgern und Schulleitungen (alle Sperrungen von HC).

- Eine Privatschule ist ein „Ersatz“ für öffentliche Schulen. Wichtig ist staatliche Anerkennung: die Schule wird ja hoheitlich tätig durch Zeugnisse und Prüfungen. (Ist eine Privatschule nur eine genehmigte Schule, müssen die Schüler sich als Externe prüfen lassen.)

- Die für öffentliche Schulen geltenden Regelungen sind im Rahmen der Privatschulfreiheit anzuwenden. Vorschriften der Schulgesetze gelten, soweit es um die Erfüllung oder Einhaltung von Genehmigungs- und Anerkennungsvoraussetzungen geht. Die Vorschriften, z. B. zum Lehrplan oder zur Schulorganisation, gelten ,nur soweit, nur in dem Maße, in dem es erforderlich ist, um die geforderte Gleichwertigkeit zu erreichen. Sie gelten nicht 1 : 1.“(A.a.O. 42)

Die den freien Schulen geltenden Rechte bieten erstaunliche Möglichkeiten:

- Der Unterricht ist hinsichtlich des pädagogischen Konzepts frei.

- Klassengliederung und Rhythmisierung können frei gestaltet werden; 45 Minuten sind nicht zwingend. Kleinere Klassen sind zulässig, aber finanziell problematisch.

- Lage und Dauer der Ferien sind nicht verbindlich vorgegeben. Schulfreie Tage sind zulässig: Besinnungstage, Orientierungs- und Umwelttage sowie Praktika sind möglich, solange der Pflichtstoff nicht leidet.

- Die Lehrerwahl ist frei, muss aber genehmigt werden. Bedingung ist eine wissenschaftliche Ausbildung der Lehrkräfte; z. T. wird eine bestimmte Quote gefordert.

- Die Landesgesetze fordern, dass die Gehälter der Lehrkräfte an privaten Schulen nicht wesentlich hinter denen der Lehrkräfte an vergleichbaren öffentlichen Schulen zurückbleiben, d.h. nicht mehr als um 10-20\%.

- Lehrer- und Klassenkonferenzen sind nur zwingend, wo staatliche Vorschriften eingehalten werden müssen: bei Versetzung und Zeugnissen. Sonst besteht große Freiheit hinsichtlich Konferenzen.

- Die Schülerwahl ist frei; eine Sonderung nach Besitzverhältnissen der Eltern 
darf nicht gefördert werden. Schulgeld in Höhe von 60-120€ monatlich gilt als angemessen.

- Ordnungsmaßnahmen: Rechtliche Grundlage für Maßnahmen ist der Schulvertrag, nicht das jeweilige Schulgesetz oder die Schulordnung!

- „In Bayern gelten die Vorschriften über Elternmitwirkung und Schülermitverantwortung an privaten Schulen nicht; andere Länder fordern gleichwertige Formen der Mitwirkung oder Formen der Mitwirkung in angemessener Weise. Es ist ratsam, eine eigene Schulmitwirkungsordnung zu erlassen." (S. 50) ${ }^{121}$

Art. 7, Abs. 1 GG sagt: Das gesamte Schulwesen steht unter der Aufsicht des Staates. Bei Privatschulen gibt es Einschränkungen: Die Schulaufsichtsbehörde darf nur handeln, soweit es um die Einhaltung von Genehmigungs- und Anerkennungsvoraussetzungen oder um das Berechtigungswesen geht. Adressat ist dann der Schulträger!

Schlusswort der Autorin:

„Gestalten Sie das Schulleben und das Miteinander so, dass erfahrbar wird: Wir sind eine Schule aus christlichem Geist. Wir sind eine kirchliche Schule. Gestalten Sie Ihre Schule so, dass sie ein Lebensraum wird, in dem der Geist der Freiheit und der Liebe des Evangeliums lebendig ist. ... Dazu brauchen Sie vor allem eine entsprechende Grundhaltung und ein daraus erwachsendes Engagement, dazu brauchen sie überzeugende Lehrerpersönlichkeiten; ein entsprechendes Bildungs- und Erziehungskonzept kann hilfreich sein. ... Der Ihnen verfassungsrechtlich und einfachgesetzlich zustehende Gestaltungsspielraum ist weit. Sie dürfen - trauen Sie sich! Nur wenn Sie selbst Freiheit wagen, können Sie zur Freiheit erziehen und ermutigen.“ (A. a. O. 52) Schöner hätte ich’s nicht sagen können.

\subsection{Beispiele: Wie Schulen ihren Spielraum erweitern}

Schulentwicklung muss von der Einzelschule her gedacht und konzipiert werden. „Denn jede Schule ist ein Unikat, weshalb zentrale Lösungen bei Innovationen nicht greifen." (Rolff 2019, 38; s. o. 10.4)

„Erneuern können sich Schulen nur selbst. Aber sie können das nicht allein. ... Sie brauchen Ideen und Unterstützung, sie brauchen Aufmerksamkeit und Freundlichkeit. Vor allem aber brauchen sie den Austausch untereinander. ... Sollen Schulen gelingen, dürfen sie keine geklonten Exemplare eines ,richtigen “ Modells sein. ... Werden sie institutionelle Individuen, gelingt ihnen etwas, das nur Individuen können: sie lernen. Das stärkste Gegengift zu Freudlosigkeit und Lernschwäche vieler Schulen sind Geschichten vom Gelingen.“ (Kahl 2007, S. 3)

121 „Wenn kirchliche Schule Erziehungsgemeinschaft ist, dann bedingt dies Elternmitwirkung und Schülervertretung.“ (A.a.O. 50) Zur konkreten Gestaltung der Mitwirkung vgl. aber Anm. 49. Für NRW gilt: „Ersatzschulen müssen gleichwertige Formen der Mitwirkung von Schülerinnen, Schülern und Eltern im Sinne des Siebten Teils dieses Gesetzes gewährleisten." (Schulgesetz NRW §100, Abs. 5) 
Reinhard Kahl hat solche Geschichten erzählt, mit filmischen Mitteln hat er Schulen gezeigt, die ihren Freiraum auf ihre eigene Weise nutzen, in Deutschland und im Ausland. Seine Filme zeigen erstaunliche Möglichkeiten, die mich (Abitur 1960) manchmal neidisch reagieren lassen. Sie zeigen, wie groß die Freiheit unserer Schulen ist, nicht nur der konfessionellen. Wir haben Ausschnitte davon in unserem Kurs gezeigt. Die Resonanz? Eher verhalten, sehr zu unserem Erstaunen. Vielleicht, weil der Kontrast zur Wirklichkeit der eigenen Schule Veränderungen utopisch erscheinen lässt?

In einen Kurs haben wir Enja Riegel, die Leiterin der Wiesbadener HeleneLange-Schule, als Gastdozentin eingeladen; sie erzählte von heftigen Auseinandersetzungen und geglückten Neuerungen in ihren 20 Jahren dort. Begeisterter Beifall? Eher nicht. Höfliche Fragen, auch Fragen nach dem Wie und nach den Wirkungen, mehr aber nicht. Vielleicht wirkte da auf der persönlichen Ebene ein innerlich empfundene Kontrast zum selbstgewissen Auftreten unseres Gastes.

In einem späteren Kurs berichtete Margret Rasfeld von ihrem EduActionAnsatz in der Evangelischen Schule Berlin-Mitte (esbz). Ihr Konzept für solche Begegnungen: Sie bringt einen Schüler oder eine Schülerin mit. So auch bei uns. Der Schülerin war anzumerken, wie gern sie diese Schule besuchte. In der 11. Klasse hat sie die obligatorische Zeit im Ausland absolviert, in China, und nach dem Abitur ein Studium aufgenommen.

Anke Bachmann hat das Neuruppiner Konferenzsystem in einem Follow-upKurs dargestellt. In einem Folgekurs hat ihre Stellvertreterin, Bettina Labahn, auf detaillierte Fragen geantwortet (s.o. 8.1). Im Laufe der Zeit haben wir gehört, dass einige Lehrerinnen und Lehrer Besuche gemacht haben, in der von M. Rasfeld geleiteten Evangelischen Schule Berlin Zentrum (esbz) und im von A. Bachmann geleiteten Gymnasium in Neuruppin, in den Schulen also, deren Leitungen sie bei uns kennengelernt hatten.

Der unmittelbare Kontakt scheint stärker zu wirken als die Filme. Und wenn einzelne innovative Elemente mit der eigenen Schule kompatibel erscheinen, werden die eher übernommen. Bei einem Besuch in Neuruppin erzählen Jugendliche davon, wie sie zu Beginn eines Schuljahres eine Woche lang in kleinen Gruppen in Deutschland unterwegs waren, um eine selbst gewählte Herausforderung zu bestehen, mit sehr begrenzten finanziellen Mitteln, begleitet von Studentinnen der Pädagogik, so wie M. Rasfeld das initiiert hat, nach Abstimmung mit den Eltern (Rasfeld 2012, 61 ff). Das klingt zunächst exotisch, hat aber in Bochum zu kreativer Nachahmung geführt.

Veränderungen gelingen nur, ,wenn sie von den Schulen selbst gewollt und auf ihre jeweils eigene Art gestaltet werden. Damit verhält es sich so wie mit dem Lernen.“ (Kahl 2011, 109) Es geht Lehrerinnen und Lehrern also nicht anders als Kindern und Jugendlichen.

„Wie kann ein Modell für alle sinnvoll sein und trotzdem jede Schule in ihrer Besonderheit und Einzigartigkeit fördern?" Diese in Kapitel 2 gestellte Frage (s.o. 2.3) lässt sich jetzt beantworten: Es bleibt wichtig, mit Hilfe der fünf Dimensionen immer wieder auf die Realität zu schauen. Leitfrage dabei: Haben wir uns so organisiert, dass wir lernfähig sind? Die konkreten Realisierungen sollten ganz individuell sein, abgestimmt auf die Kompetenzen und Begabungen der 
Lehrkräfte, die materiellen Ressourcen, die Unterstützungsbereitschaft des Umfelds.

Schulen könnten von anderen Schulen auch lernen, wie man sich organisieren kann, so dass auch exotisch wirkende Möglichkeiten Realität werden. So wird eine Schule ein lernendes Unternehmen.

25 Schulen hat R. Kahl in seinem Begleitbuch zur DVD kurz dargestellt. Im Internet sind die Schulen zu finden, die in den letzten Jahren den Deutschen Schulpreis gewonnen haben - Beispiele dafür, wie sich schulischer Spielraum nutzen lässt, Beispiele dafür, dass kommunale und „freie“ Schulen voneinander lernen können. Kommunale Schulen sind nicht von vornherein unfrei und sogenannte freie Schulen nicht von vornherein leuchtende Beispiele für Freiheit. Auf einige Beispiele möchte ich hinweisen, auf Beispiele für genutzte Freiheit.

- Enja Riegel hat die Zahl der Fachstunden reduziert, um Zeit für Theaterprojekte zu gewinnen. Sie hat die Schülerschaft dafür gewonnen, den Putzdienst selbst zu übernehmen, so dass mit dem eingesparten Geld (27.000 Euro!) externe Fachleute für Schauspiel und Regie engagiert werden konnten. ${ }^{122}$ Theaterspielen verlangt ein Maß an Beteiligung, das in dieser Intensität und Vielseitigkeit in der Schule selten oder nie gefordert wird. Das verträgt sich nicht mit dem 45-Minuten-Rhythmus von Schulstunden. An der Helene-Lange-Schule gibt es darum „Theater-Intensivphasen“: Vier Wochen lang für alle Beteiligten kein Fachunterricht, keine Klassenarbeiten, keine Hausaufgaben; die üblichen Regeln einer Schule werden außer Kraft gesetzt (Riegel 2004, $100 \mathrm{f}$ ). Das bedeutet weniger Mathematikstunden, weniger Englischunterricht, weniger Naturwissenschaften als in den Rahmenrichtlinien vorgesehen. Bei Vergleichsuntersuchungen (TIMSS und PISA) gab es dennoch überdurchschnittlich gute Ergebnisse. Enja Riegel ist sich sicher: „Wer viel Theater spielt, wird auch besser in Mathematik.“ (Zitiert von Kahl 2011, 73)

- Vor 20 Jahren waren 45-Minuten-Unterrichtsstunden noch weitgehend Standard. Die Umstellung auf 60 oder 80 oder 90 Minuten wurde vor allem von den Sprachlehrern vehement abgelehnt. Inzwischen gibt es Beispiele, dass nicht nur Theater, sondern auch Sprachunterricht in Epochen betrieben werden kann. Eine Bremer Schule veranstaltet in den Ferien ein Sommercamp mit täglich zwei Stunden Sprachunterricht und zwei Stunden Theater. Die Auswertung durch das Max-Planck-Institut für Bildungsforschung verblüffte die Untersucher: „Die Sprachkompetenz der Kinder war in den drei Wochen Sommercamp stärker gewachsen als üblicherweise im Verlauf eines ganzen Schuljahres." (Kahl 2011, 82) Eine Brennpunktschule in Dortmund-Nord setzt ebenfalls auf Kultur und erntet bei den Leistungen beste Ergebnisse. Ihr Motto: „Ganz viel Kultur, Kunst und Musik." (Kahl 2011, 65)

- Die Umstellung auf längere Unterrichtsstunden erlaubt stärkere Beteiligung der Schülerinnen und Schüler, z. B. in Form von Gruppenarbeit. Aber Vorsicht:

122 Der Leiter des Ordnungsamtes besuchte die Schule, lernte das Gesamtkonzept kennen und überzeugte dann zwei weitere Instanzen, die die Putzidee dreimal abgelehnt hatten (Riegel 2004, 194). 
Lernwirksame Formen von Gruppenarbeit eröffnen keineswegs Zeiträume, in denen Lehrer in Ruhe Hefte korrigieren oder gar ihre privaten Mails checken könnten. Es handelt sich vielmehr um komplex strukturierte, anspruchsvolle Arbeitsformen, an die man Schüler schrittweise heranführen muss, und die enge Begleitung und intensive Materialvorbereitung (Tests und Musterlösungen) auf Seiten der Pädagogen erfordern - meint der Gymnasiallehrer Michael Felten. ${ }^{123}$ Es ist wie beim Mobile: Wenn Sie ein Element in Bewegung bringen, löst das Bewegung im ganzen System aus. Wenn die neue Struktur erst einmal Zeit für Gruppenunterricht erlaubt, wächst auch die Erwartung, dass die Unterrichtenden lernen, wie Gruppenarbeit sinnvoll einzusetzen ist.

- In der Evangelischen Schule Berlin Zentrum (esbz) spielt das Lernbüro eine zentrale Rolle, in der Max-Brauer-Schule in Hamburg ebenfalls: „Jeden Tag stehen zunächst zwei Stunden Arbeit im Lernbüro auf dem Plan. In Englisch, Deutsch und Mathe arbeitet jeder an etwas anderem, besser gesagt, jeder arbeitet an sich. Statt Noten gibt es Kompetenzraster." (Rasfeld 2012, 93 ff; Kahl 2011, 66) Positive Ansteckung funktioniert.

- Die Alemannenschule in Wutöschingen (Deutscher Schulpreis 2019), eine Gemeinschaftsschule mit gymnasialer Oberstufe, setzt sich zum Ziel, jedem Lernpartner einen individuellen Lernweg zu ermöglichen. ${ }^{124}$ Voraussetzung dafür ist eine neue Einteilung von Lernzeit, Arbeitszeit, Lernräumen und Lerngruppen. Der Rektor der Schule, Stefan Ruppaner (2020), schreibt: „Es gibt keine Klassen, Klassenräume, Unterrichtsstunden, Tafeln, Bücher, Hefte, Strafarbeiten, Hausaufgaben, Schulklingel, Deputate in Stunden, Vertretungspläne und Klassenbücher.“ Klingt unglaublich, ist schwer zu beschreiben. Ruppaner lädt ein: „Komm einfach mal vorbei und schau dir alles an.“

- Einer ähnlich anspruchsvollen Herausforderung stellt sich das Evangelische Schulzentrum Hilden. Nach anstrengenden Auseinandersetzungen mit der Bezirksregierung ist es gelungen, zwei internationale Klassen für junge Flüchtlinge und Migranten einzurichten und Lehrerstellen dafür zu bekommen. In so einer Klasse werden ca. 25 Schülerinnen und Schüler (bürokratisch als „Nullsprachler" klassifiziert) im Alter von 9 bis 18 Jahren aus 12 Nationen unterrichtet. Es gibt für den Unterricht erfreulicherweise keinerlei Vorgaben aus dem Schulministerium. ${ }^{125}$

- Die Leitung der Matthias-Claudius-Gesamtschule in Bochum hat sich von der esbz anstecken lassen. Seit dem Schuljahr 2017/18 ermöglicht die Schule es allen Schülerinnen und Schülern der 8. Klassen, eine selbstgewählte Herausforderung zu bestehen. Nach intensiver Vorbereitungszeit haben sie im Anschluss an die

123 http://www.zeit.de/gesellschaft/schule/2013-10/schule-frage-gruppenarbeit/komplettansicht 124 Die leitende Vision: Das „7-G-Modell“ (Alle gleichaltrigen Kinder sollen beim gleichen Lehrer mit dem gleichen Lehrmittel im gleichen Tempo das gleiche Ziel zur gleichen Zeit gleich gut erreichen) wird durch eine „V-8-Begleitung“ ersetzt (Auf vielfältigen Wegen mit vielfältigen Menschen an vielfältigen Orten zu vielfältigsten Zeiten mit vielfältigen Materialen in vielfältigen Schritten mit vielfältigen Ideen in vielfältigen Rhythmen zu gemeinsamen Zielen).

125 Einzelheiten: https://dbg.esz-web.de/index.php/schule2/internationale-klassen 
Sommerferien drei Wochen Zeit, um ihr Abenteuer zu bestehen. Pro Person gibt es ein Budget von 150,00 € für Reisekosten und Verpflegung. In Gruppen begeben sie sich auf Wander- und Radtouren, nehmen sich ökologische, diakonische oder soziale Projekte vor, arbeiten auf dem Bauernhof oder schreiben ganze Romane. Sie lernen, sich selbst Ziele zu stecken, mutig zu sein, Risiken einzugehen, zu scheitern und wieder aufzustehen. ${ }^{126}$

- Das Kollegium der eszb nutzt diese Zeit, um die neu aufgenommenen Schüler und Schülerinnen der 7. Klasse mit der Schule vertraut zu machen. Sie lernen, wie es in dieser Schule zugeht, wie das Lernen organisiert ist, welche Personen sie ansprechen können, wenn sie mit den Aufgaben nicht zurechtkommen oder andere Schwierigkeiten haben. Ein entsprechendes Verfahren wünschte ich allen Schülerinnen und Schülern, die einen Wechsel zu bewältigen haben, von der Kita in die Grundschule und von der Grundschule in eine weiterführende Schule.

- Im Evangelischen Gymnasium Neuruppin übernehmen an einem Tag im Jahr die Elftklässler den kompletten Betrieb der Schule. Lehrer, Schulleitung, Sekretärinnen, Hausmeister - alle Erwachsenen verlassen das Gelände, und die Schüler schlüpfen in deren Rollen. Lange im Voraus wird der Tag geplant. Die Elftklässler wählen in den Monaten davor eigenständig eine Schulleitung, schreiben Raum- und Stundenpläne, entwickeln Unterrichtskonzepte für mehr als 1.000 Schülerinnen und Schüler an drei Standorten. Die Idee zu dem Experiment fand die Schulleiterin A. Bachmann in einem Fachjournal. Als sie ihren Schülern im Leistungskurs Mathematik davon erzählte, waren die gleich Feuer und Flamme. (Klovert 2019). Beide Seiten profitieren. Die Schülerinnen und Schüler erfahren sich selbst mit ihren Kompetenzen und Schwächen; die Lehrkräfte nutzen den Tag für die eigene Fortbildung.

- Letztes Beispiel: Das Gymnasium Alsdorf hat eine Form von Gleitzeit eingeführt. Die Oberstufenschüler erarbeiten sich in zehn Stunden einen Teil des Stoffs in zeitlich variablen Projektphasen nach dem Dalton-Plan. Fünf von diesen Stunden wurden auf die Zeit zwischen acht und neun Uhr gelegt, so dass die Schüler wählen konnten, ob sie in dieser Stunde in der Schule lernen oder später kommen wollen, um den Stoff in Freistunden oder nach Schulschluss nachzuholen. Ergebnis: Es wirkt sich positiv auf Schlaf und Leistungsfähigkeit aus, wenn Schüler selbst entscheiden, ob sie um acht oder um neun Uhr zum Unterricht erscheinen. Fast alle Schüler profitieren vom flexiblen Schulbeginn. Sie fühlten sich ausgeruhter und konnten sich tagsüber besser konzentrieren. ${ }^{127}$

126 Und das Ganze inklusiv. Begleitet werden die Schülergruppen - ob mit oder ohne Handicap - während der Planung und der Durchführung von einer erwachsenen Person, die diesen Prozess pädagogisch unterstützt und nur in grenzwertigen Situationen kompetent einschreitet. http://herausspaziert.mcs-bochum.de/

127 Anders als erwartet, nutzten die Schüler ihre neue Freiheit nur in Maßen; sie ließen die erste Stunde im Mittel nur zweimal pro Woche ausfallen. Ihre durchschnittliche Schlafdauer verlängerte sich somit nur geringfügig. Trotzdem waren sie begeistert von der Wahlfreiheit. Schon die Möglichkeit, frei entscheiden zu können, macht offenbar einen Unterschied. Chronischer Schlafmangel unter Jugendlichen ist weltweit ein Problem. Folgen: Konzentrationsmangel, Halbschlaf in den ersten Unterrichtsstunden, auch erhöhte Unfallrisiken. 
Die Beispiele ließen sich leicht vermehren. Es geht nicht darum, einzelne Ideen nachzuahmen, obwohl das natürlich auch möglich ist. Schön wär's, wenn sich viele Schulen von der Freiheit anstecken lassen, die sich an den ungewöhnlichen, überraschenden, anziehenden Beispielen zeigt. Der Spielraum ist größer als gemeinhin gedacht. Kreativität ist möglich und von vielen gewünscht. Vor einzelnen Veränderungen könnte der erste Befreiungsschritt darin bestehen, eine Arbeits- und Kommunikationstruktur aufzubauen, die Bewegung ermöglicht.

\subsection{Die Schlüsselfunktion mentaler Modelle}

Rahmenbedingungen, Regularien, Gesetze sind wichtig für die Orientierung, und sie sind lästig, sie engen ein, oft mehr als nötig. „Aber Gesetze kann man auslegen - sehr restriktiv oder sehr extensiv. Wichtig ist hier vor allem, vernünftige und nachvollziehbare Begründungen liefern zu können, warum man etwas tut.“ (Rasfeld 2012, 200) Damit bezieht M. Rasfeld sich auf bremsende Behörden und Aufsichtsgremien; auch E. Riegel kennt sich damit aus (vgl. Anm. 122).

Angenommen, der rechtliche Spielraum sei für Ihre Schule geklärt, neue Möglichkeiten hätten sich aufgetan, dann versteht es sich dennoch nicht von selbst, dass Ihre Kollegiumsmitglieder sich anschicken, sie zu nutzen. Da lauern noch einige mentale Modelle, die das Abheben von der Gewohnheitsgravitation erschweren, nicht irgendwo draußen in Vorschriften und Paragraphen, sondern in den Herzen und Köpfen der Hauptakteure, der Lehrkräfte.

„Wir sind zwar gut darin trainiert, unsere Strategien zu ändern, aber nicht unsere dahinter stehenden ,mentalen Modelle', die das beeinflussen, was wir überhaupt wahrnehmen, das, was wir als wichtig, als Realität, interpretieren. Sie beeinflussen auch das, was wir als Wahlmöglichkeiten erkennen. Insofern steuern sie unser Handeln und damit die Ergebnisse. Unsere erlernten Strategien zu ändern fällt uns leichter, als die Basis in Frage zu stellen, auf denen sie entstanden sind und die im Konzept der Lernenden Organisation als ,mentales Modell“ bezeichnet wird.“ (Hartkemeyer 2001)

Es geht also nicht in erster Linie darum, ein bestimmtes Thema $\mathrm{zu}$ bearbeiten, sondern darum, ,,sich darüber klar zu werden, wie das eigene Denken unbewusst die Kommunikation und Interaktion bestimmt." Das erinnert an die Schwierigkeit, sich der eigenen blinden Flecken bewusst zu werden. Das geht nur mit Hilfe anderer. Wenn ich mit mir selbst weiter kommen möchte, bin ich auf andere Menschen angewiesen, auf ihre Sicht, auf ihr Feedback. So kommt Dialog zustande, ohne Rechthaberei, ohne Bewertungsautomatismen. Wenn es gelingt, solche Kommunikationsprozesse anzuregen, kann sich mehr Freiheit ausbreiten (Hartkemeyer, a.a.O.).

Wieso sind mentale Modelle so mächtig? Ein ehrenwerter Grund: Die Probleme von heute sind die Lösungen der Probleme von gestern. Das war doch mal

Außerdem fördert zu wenig Schlaf Übergewicht, Diabetes und Gedächtnisschwäche. „Dem Schulerfolg schadet der spätere Unterrichtsbeginn jedenfalls nicht, im Gegenteil. Das Gymnasium Alsdorf erhielt für sein Gleitzeitmodell den deutschen Schulpreis.“ (Bartens 2020) 
sinnvoll! War denn alles schlecht, womit wir uns hier seit Jahren und Jahrzehnten abrackern? Es kann den Bremserinnen und Zögerern also um Loyalität gehen, um Selbstachtung, um Treue zur bisherigen Lebensleistung. Wie können Sie als Leitung die achten und trotzdem über gewohnte Grenzen hinauskommen?

2010 präsentierte die Schulaufsichtsbehörde dem Kollegium der ReinholdBurger-Schule in Berlin einen neuen Schulleiter: Guido Landreh. Altersdurchschnitt des Kollegiums: etwas unter fünfzig; die meisten Lehrkräfte waren schon seit 10, 15 Jahren da. Die Schule befand sich in der Krise. Landreh stellte sein Konzept vor, und die Kollegen sagten: „Nein danke.“ In den ersten Monaten war keinerlei inhaltliche Diskussion mit dem Kollegium möglich. Landreh blickt im Interview zurück: „Obwohl ich selbst lange an einer Art Leuchtturmschule gearbeitet habe, ging es mir im Regelschulbetrieb plötzlich so, dass ich manchmal selbst nicht mehr geglaubt habe, dass bestimmte Dinge gehen. Die Strukturen sind hier derart eng, dass Menschen, die seit Jahrzehnten darin arbeiten müssen, sich nicht vorstellen können, dass es anders, geschweige denn vielleicht sogar viel besser geht. Hier einen Neuanfang zu wagen, dazu bedarf es aus Sicht der Lehrer einer hohen Risikobereitschaft und auch Experimentierfreude. Als Schulleiter trägt man die Verantwortung - und läuft Gefahr, eine Bauchlandung zu machen." (Rasfeld 2012, $191 \mathrm{ff}$ )

Sechs Kolleginnen fanden sich schließlich als Innovationsteam und begannen mit Lernbüros in Mathe, Deutsch und Englisch; so gelang der entscheidende Schritt im Paradigmenwechsel vom Lehrer zum Lernbegleiter. Landrehs Fazit: Wenn die historisch gewachsene autoritäre Struktur partizipativ und demokratisch werden soll, geht es an die Glaubenssätze, und die sind erfahrungsgemäß ganz schwer zu verändern. Es geht nur durch Erfahrung, Reflexion und Reden. „Ich glaube, Kommunikation ist die wichtigste Aufgabe eines Schulleiters." 128

„Es liegt in der Natur der Sache, dass Reformprozesse von Minderheiten begonnen werden. Fangen Sie mit den reformwilligen Kollegen an zu arbeiten, auch wenn es nur wenige sind. Haben Sie eine klare Vision und kommunizieren Sie diese. Seien Sie bei alldem authentisch, empathisch und zuversichtlich." So macht M. Rasfeld Ihnen Mut $(2012,200)$ Wenn J. Hartkemeyer, E. Riegel, M. Rasfeld, G. Landreh mit ihren Hinweisen auf die Wirkung mentaler Scheuklappen Recht haben, und dafür spricht viel, dann könnte es sehr sinnvoll sein, sich über produktive mentale Modelle zu verständigen, über Glaubenssätze, die den Bremseffekt der hinderlichen mentalen Modelle lockern.

Zur Erinnerung: Kabat-Zinn erzählt in seinem Meditationsbuch von den Affen, die gefangen werden, weil sie die Banane nicht loslassen wollen. Wenn ich innerlich besetzt bin, unfähig, mich auf die Individualität, die Eigenart, das Anderssein meines Gesprächspartners zu konzentrieren, dann gelingt kein Kontakt (s. o. Kap. 4). Es kommt darauf an, loszulassen. Nicht einfach. Erst recht nicht, wenn das einem ganzen Kollegium gelingen soll.

128 Wenn Sie mit ähnlichen Erfahrungen konfrontiert sind, lesen Sie das ganze Interview, bevor Sie aufgeben und resignieren. Sie sind nicht allein. Nutzen Sie alle möglichen Hilfsangebote. 


\section{Lesetipp}

Sattler (2013): Privatschulen im Rechtskorsett? Mehr Mut zur Freiheit! Eine erfrischende juristische Stimme, die Sie anregen kann, enge Spielräume kritisch auf ihre Berechtigung hin zu überprüfen, um so neue Gestaltungsmöglichkeiten zu gewinnen. Im Zweifelsfall empfiehlt es sich, juristische Expertise in Anspruch zu nehmen.

Vertiefung: Hoegg (2012): Schulrecht - ein Beispiel Ihrer Wahl pro Kapitel wird Sie auf den Geschmack bringen. 


\section{Kapitel 14: Religiös frei, säkular frei - worin unterscheiden wir uns?}

M. Rasfeld zeigt Flagge; als Vision der Schule formuliert sie: „Das Schulethos der esbz: protestantisch - mutig - weltoffen. ... Wir wollen ein ,Haus des Lernens“ sein, in dem alle willkommen sind. Kinder mit Begabungen aller Art, auch Kinder mit Handicap sowie Kinder aus vielen Kulturen sollen sich in unserer Schule angenommen fühlen.“ (Rasfeld 2012, 30.160)

Rituale verankern solche Grundsätze im Schulalltag. „Ihr seid das Salz der Erde“ - dieser Zuspruch aus der Bergpredigt (Matthäus 5, 13) wird sinnenfällig, wenn die älteren Mitschülerinnen den Neuankömmlingen am ersten Tag ein Tütchen Salz mit dieser Aufschrift überreichen (Rasfeld 2012, 177). Ein Indikativ, Wirklichkeitsform, kein Appell, kein ethischer Anspruch, kein erhobener Zeigefinger, sondern offene Arme. Das kleine Tütchen Salz spricht den Neuankömmlingen Bedeutung zu: Ihr seid wichtig. Mit euch kommt neue Würze in unsere Schule. Ohne euch könnte es fad werden.

Darin steckt eine starke Gegenbotschaft gegen alle Einflüsterungen von Einschärfungen und Antreibern, mit denen Kinder in die Schule kommen. Der inneren Propaganda der Unfreiheit wird so öffentlich widersprochen - gegen die inneren Stimmen, die so oft die Lebensfreude, auch die Freude am Lernen verhageln.

\subsection{Innere Freiheit, protestantisch verstanden}

Freiheit fängt innen an, weil auch die Unfreiheit von innen kommt. Das ist protestantisch: „Ein Christenmensch ist ein freier Herr über alle Dinge und niemandem untertan. " Erster Satz in Luthers Doppelthese von 1520 (oben in Vertiefung 11.7.8 zitiert und interpretiert). Nichts ist so mächtig, das Innere, die „Seele“ des Menschen aus der Selbstverkrampfung zu befreien, wie das Wort, das qualifizierte Wort, der ernsthaft freundliche Widerspruch gegen die Bannbotschaften, die wir mit uns herumtragen. ${ }^{129}$

Bin ich aus der Verkrampfung in mich selbst heraus, ${ }^{130}$ muss ich mich nicht mehr grundlegend um mich, um meinen Wert, um mein Ansehen, um meine Existenzberechtigung sorgen. So wie wir täglich Brot und Nahrung brauchen, so lebt der Christ, so lebt grundsätzlich jeder Mensch von dem Wort, das ihn aus seiner inneren Unfreiheit herauslockt. Unser Leben lässt sich verstehen als ein Prozess von Lauschen und Hören, von Hunger nach guten Worten und dem Leben von guten

129 In der Vertiefung 11.7.8 hoffe ich gezeigt zu haben, dass diese sprachliche Struktur der Struktur des Evangeliums entspricht und dass das so verstandene Evangelium die Tendenz hat, den Kirchenraum zu verlassen, im Alltag der Welt wirksam zu sein und dabei keine religiöse Sondersprache benötigt.

130 Luther nennt das die incurvatio in se ipsum, Verkrümmung in sich selbst; biblisches Beispiel: Die Heilung der verkrümmten Frau, Lukas 13, 10-17. 
nährenden Worten. Der Mensch: ein Hör-Wesen. ${ }^{131}$ Das schließt ein, dass er auch weghören kann. Er hört dann auf andere Stimmen. „Gebet nun acht, wie ihr hört!“ (Lukas 8,18)

Meine Identität hängt an dem Wort, auf das ich mich verlasse. Ich täusche mich, wenn ich glaube, mich selbst entkrümmen zu können. Ich müsste dazu ja in der Lage sein, mich selbst als verkrümmt nicht nur wahrzunehmen, sondern auch anzunehmen. ${ }^{132}$

Innere Freiheit wird immer wieder bedroht, wir lassen uns in unfreie Zwänge verführen, in narzisstischen Größenwahn, in Verzweiflung und bleiben darum lebenslang auf die Zusage unbedingter Bejahung, auf den Ruf zur Freiheit angewiesen. Freiheit ist keine abgespeicherte Qualität in mir, kein persönlicher Besitz; vielmehr ist sie das Beziehungsgeschehen von Wort und Glaube, auf das wir lebenslänglich angewiesen bleiben und durch das unser Leben auf Gott bezogen ist und bleibt - so die evangelische Sicht. ${ }^{133}$

Eine wichtige Konsequenz: Ich bin nicht die Summe meiner Taten, auch nicht die Summe meiner Untaten. Das mich befreiende Wort unterscheidet mich von meinen Taten, sowohl den guten wie den schlimmen (s. o. Text zu Grafik 5, Stichwort: Daseinsberechtigung).

\section{2 Äußere Freiheit, protestantisch verstanden}

Herbert Marcuse, Max Scheler und andere kritisieren Luther: Diese Freiheit sei ja nur eine Sache der Innerlichkeit, die äußere Freiheit dagegen mehr oder weniger belanglos. Im Bauernkrieg habe Luther sich als frommer Fürstenknecht entpuppt (Jüngel 1978, 59 ff). ${ }^{134}$

131 „Der Mensch lebt nicht vom Brot allein, sondern von einem jeglichen Wort, das aus dem Munde Gottes kommt.“ (5. Mose 8,3 und Matthäus 4,4, von Luther in Abs. 5 zitiert.) „Christianus non fit operando, sed audiendo.“ Christ wird man nicht durch Tun, sondern durch Hören (Luther, 1531, zit. bei Ebeling 1985, 62). Es geht keineswegs darum, die Werke nicht zu tun, vielmehr darum, sich nichts auf sie einzubilden und nicht auf sie zu vertrauen. Luther 1517 gegen Aristoteles: „Nicht ,dadurch werden wir gerecht, daß wir das Rechte tun“, sondern als Gerechtfertigte (als gerecht gemachte Menschen) tun wir das Rechte." (Jüngel 1990, 204)

132 „Wer mit Hilfe der modernen Psychologie nicht nur hinter die Kulissen seiner Patienten, sondern vor allem hinter seine eigenen geblickt hat ..., der muß gestehen, daß es das Allerschwierigste, ja das Unmögliche ist, sich selber in seinem erbärmlichen So-sein anzunehmen. Schon der bloße Gedanke daran kann einen in Angstschweiß versetzen, deshalb zieht man mit Vergnügen und ohne Zögern das Komplizierte vor, nämlich das Nichtwissen um sich selbst und die geschäftige Bekümmerung um andere und anderer Schwierigkeiten und Sünden. Dort winken sichtbare Tugenden, die die andern und einen selbst wohltätig täuschen. Man ist - Gott sei Dank - sich selbst entlaufen.“(C. G. Jung, 1971, 143 f)

133 Vgl. Ebeling 1961, $219 \mathrm{ff}$.

134 Sie zielen auf Luthers Haltung im Bauernkrieg 1525. Wo war er da mit seiner Freiheit? In Kürze: Luther hatte viel Sympathie für die Forderungen der Bauern, solange sie nicht gewalttätig wurden. Aber er war strikt gegen die politische Instrumentalisierung des Evangeliums. 
Der Einwand geht an Luther vorbei; entscheidend ist für ihn: Nicht nur die Freiheit, auch die Unfreiheit hat ihren Ort im Inneren des Menschen (Jüngel 1978, 72 f.76). Das ist der zentrale Punkt. Der innere Mensch, die Seele ist der anthropologische Ort, an dem sich sowohl Freiheit als auch Knechtschaft des Menschen entscheiden. ${ }^{135}$

Die humanistische Psychologie sieht wie Luther den Ort der Freiheit und der Unfreiheit im Inneren des Menschen. Ihre Konzepte schärfen den Blick und das Ohr für die vielen Anzeichen von innerer Unfreiheit, wie sie sich tagtäglich in oft ganz unauffälligen Begegnungen zeigen. Antreiber sind oft Signale dafür. An ihnen zeigt sich, dass die Selbstverkrümmung des Menschen tiefer sitzt als auf der Verhaltensebene; mit moralischen Appellen ist ihr darum nicht beizukommen, mit verharmlosender Bagatellisierung auch nicht.

Es geht bei der christlichen Freiheit primär nicht um liberale Lebensweise und Toleranz, auch nicht um Religionsfreiheit, die - im Westen - kaum strittig ist. ${ }^{136}$ Freiheit und Unfreiheit sitzen nach Luthers Verständnis tiefer. Die von mir angeführten psychologischen Konzepte gehen m. E. in dieselbe Richtung.

Das radikale protestantische Freiheitsverständnis heißt aber keinesfalls, dass ein so befreiter Mensch es sich dort, in seinem Inneren, gut gehen lassen könnte, ohne sich dem rauen Wind der Welt auszusetzen. Versuchte er das, wäre er bereits wieder gefangen. O-Ton Luther: „Ein Christenmensch ist ein dienstbarer Knecht aller Dinge und jedermann untertan." So der zweite Teil seiner Doppelthese. Wir

Die Verwicklung von Religion und Politik in den heutigen kriegerischen Auseinandersetzungen (Irak, Syrien, Iran) könnte uns entsprechend nachdenklich machen.

135 Seine Frömmigkeit und Freiheit wie auch seine Bosheit und sein Gefängnis sind nicht leiblich noch äußerlich. Gesundheit, Krankheit, Hunger, Durst, Gefängnis oder Freizügigkeit von all diesen äußerlichen Dingen ,reicht keins bis an die Seele, sie zu befreien oder zu fangen, fromm (d.h. Gott recht) oder böse zu machen.“ (Luther 1520, Neudruck 1982, Absatz 3)

136 Das Verständnis des Glaubens als Befreiung aus innerer Verkrümmung hat sich in der Folgezeit verschoben: Anstatt Freiheit aus Glauben (an den Zuspruch des Evangeliums) zu empfangen, wird nun Freiheit für den Glauben und für dessen Ausübung gefordert. Diese Freiheit für den Glauben wird nicht von Christus (nicht vom Evangelium), sondern vom Staat erwartet und gegebenenfalls gewährt. Unter dem Gesichtspunkt einer allgemeinen religiösen Toleranz verhält sich die dafür maßgebende Freiheit völlig indifferent zum Glauben. Es ist gleichgültig, um welchen Glauben es sich handelt, ihm wird jedenfalls grundsätzlich Freiheit in Aussicht gestellt, auch einem sogenannten Glauben, der völlig unfrei macht. „Deshalb ist das Prinzip der Glaubensfreiheit im neuzeitlichen Sinne, nämlich die Gleichgültigkeit in bezug auf die Art des Glaubens, zugleich bedrohlich für die Glaubensfreiheit. Denn um der Freiheit willen kann es offenbar nicht gleichgültig sein, was man vom Glauben hält und durch welchen Glauben man gehalten ist.“ Wohlgemerkt: „Glaubenszwang ist ein Widerspruch in sich und als solcher Zerstörung des Glaubens.“ (Ebeling 1979, 85 f; ebenso 1964, 244) „Ich kan nit weytter kommen dann zu den orn, ins hertz kan ich nit kommen: dieweyl ich dann den glauben jns hertz nit giessen kann, so kann noch sol ich niemants darzu zwingen noch dringen, wenn got thut das alleyne und macht, das er vor jm hertzen lebt." (Luther 1522, zit. bei Ebeling 1985, 61) Diese Unterscheidungen verständlich zu machen halte ich für eine zentrale Aufgabe christlicher Bildung. 
müssen jeder seinen eigenen Leib regieren, den äußeren Menschen, und wir müssen mit Leuten umgehen. Von Selbstverkrümmung befreit geht der Christ mit Freude und Liebe an das Werk freiester Knechtschaft, in der er dem anderen gern und aus freien Stücken dient. Die Sorge um sich selbst ist er ja los. Also hat er Zeit. (Jüngel $1978,100 \mathrm{ff})^{137}$

Da ist nun der Leib, der äußere Mensch, zu einer Tätigkeit anzuhalten, die der Befreiung des inneren Menschen entspricht. Auch Reisefreiheit, Konsumfreiheit, Wahlfreiheit - so schön sie oft sind: Sie schaffen mir Bewegungsfreiheit, Freiheit für meinen äußeren Menschen; meinen inneren Menschen aber nehme ich dabei immer mit. Mein innerer Mensch - das bin ich mit all meiner Vergangenheit, also auch mit allen jemals erfahrenen Einschärfungen und Antreibern, die mich innerlich besetzen und mich äußerlich in meinem Verhalten steuern. Wirkliche Freiheit ist Freiheit von dieser Gefangenschaft.

Luther bezieht sich auf Paulus: „Ich bin frei in allen Dingen und habe mich eines jedermanns Knecht gemacht.“(1. Korinther 9,19) Die Liebe ist dienstbar und untertan dem, was sie lieb hat; sie folgt aus der Freiheit; fehlt sie, so fehlt auch die Freiheit! „Die Freiheit, die der Christ durch den Glauben hat, ist gerade Freiheit zur Dienstbarkeit der Liebe. Und nur dann ist es Dienstbarkeit der Liebe, wenn es aus Freiheit geschieht.“ (Ebeling 1964, 242)

Umgekehrt folgt daraus eine sehr ernüchternde Erkenntnis: „Liebe ohne Glauben wird zur eigensüchtigen Liebe, die den andern, statt ihm zu helfen, geradezu blutsaugerisch ausnützt. ,Es ist", sagt Luther drastisch, , eine Liebe von der Art, wie eine Laus einen Bettler liebt. ““ (Ebeling 1985, 149) Denn: Die Liebe des Menschen entsteht an ihrem Gegenstand; Gottes Liebe schafft ihn sich (Luther 1951,137; Heidelberger Disputation, 1518, These 28). Menschen urteilen nach Sympathie; Gott genügt es, dass ich ein Mensch bin. ${ }^{138}$

Aus der Doppelthese folgt, dass die Qualität des Dienstes der Qualität der Freiheit entspricht. Nicht etwa so, dass Christen brav dem Antreiber „Sei immer gefällig!“ folgen sollten. Sondern konkret und handfest geht es für Christen darum, im rauen Wind der Welt diese innere Freiheit zu verbreiten, mit Worten und Taten. Den Freiheitsspielraum einer Schule in diesem Sinn auszuweiten ist harte Knochenarbeit, von der die genannten Autorinnen und Autoren und viele andere erzählen können und in ihren Büchern berichtet haben (Riegel 2004, Rasfeld 2012; s. o. 13.4).

137 Schöne Geschichte dazu: Markus 5, 1-20: Der von seinen Zwängen befreite Gerasener will bei Jesus bleiben, aber der schickt ihn los, in seine Welt, um für die Freiheit zu sprechen. Die Aussendungsrede Matthäus 10 geht in dieselbe Richtung: Ausbreitung von Freiheit ist angesagt. „Wahre Freiheit befindet sich immer auf Entdeckungsreise. Und das muss die Welt merken, verehrte Christenmenschen! Die christliche Freiheit muss kenntlich werden in unserer Welt. Und das wird sie nicht durch Anpassung, nicht durch Gleichschaltung. Die Gesellschaft, in der wir leben, ist diffus genug. Ihr kann gar nichts besseres widerfahren, als auf eine kenntliche Christenheit, auf eine kenntliche Kirche zu stoßen. Die Christenmenschen müssen endlich wieder den Mut haben, Flagge zu zeigen: die Flagge der christlichen Freiheit!“ (Jüngel, 2003)

138 Ausführliche Darstellung in meinem ODIV-Vortrag 2017. 
Ob die äußerlich realisierte Freiheit in der inneren gründet, ist ihr von außen nicht anzusehen. Was dem einen als gnädiger Mantel christlicher Nächstenliebe angebracht zu sein scheint, kann jemand anderem wie ängstliche Konfliktvermeidung vorkommen. Was als unermüdlicher Einsatz für „die gute Sache“ imponiert, kann sich auch einem unbarmherzigen Antreiber verdanken, einem Skript, das Dominanz und Herrschaft über andere fordert. Wirkliche Freiheit ist Freiheit von solcher Gefangenschaft.

Die reformatorisch verstandene Freiheit verdankt sich dem Hören auf Gottes Wort, auf das Freiheit zusprechende Wort, ist kein substanzhafter Besitz, bleibt vielmehr auf diese Beziehung angewiesen. Sie gründet auf Zuspruch und bleibt gebunden an diesen Zuspruch. Andernfalls würde Gott nach der einmal geschenkten Freiheit überflüssig, die Gabe würde wichtiger als der Geber. Der Zuspruch ist da zu hören, wo immer das Evangelium sich ereignet, ist nicht beschränkt auf Kirchenmauern und sonntägliche Gottesdienste. Möglicherweise ereignet er sich, wenn ein Kind am ersten Tag in der neuen Schule ein Tütchen Salz mit dem Wort aus der Bergpredigt geschenkt bekommt.

\subsection{Säkulare und konfessionelle Schulen - Verschiedenheit und Konsens}

Dass eine Schule sich als evangelische Schule organisiert, schließt nicht ein, dass alle ihre Akteure eine klare Vorstellung von evangelischer Identität haben, auch nicht, dass sie sich persönlich zu dieser Identität bekennen. Umso wichtiger scheint es mir, Zeit für solche Klärungen vorzusehen, nicht um zu indoktrinieren, wohl aber um Sprachfähigkeit zu fördern, aller Zeitknappheit zum Trotz. Einige Anlässe für meine Einschätzung:

Nach der Wende 1989 haben kirchliche und diakonische Träger kommunale Schulen und Sozialeinrichtungen übernommen und deren Überleben ermöglicht. Von heute auf morgen fanden sich religiös kaum oder gar nicht geprägte Lehrkräfte in einem evangelischen Unternehmen mit evangelischer Leitung wieder, konfrontiert mit der Erwartung, die evangelische Prägung zu akzeptieren, lieber noch: sie aktiv zu vertreten. Das führte zu vielen Konflikten, die längst nicht ausgeräumt sind. Ein Beispiel: Eine evangelische Schulleiterin wird Leiterin eines renommierten Gymnasiums, das sich bisher in staatlicher Trägerschaft befand. Sie war es gewohnt, eine Konferenz der Lehrkräfte mit einer kurzen Besinnung zu eröffnen, in der sie auch auf biblische Hintergründe Bezug nahm. Massiver Protest schlug ihr entgegen. Man habe sich nicht jahrzehntelang das Kreuz ideologisch durch den Staat verbiegen lassen, um nun ein weiteres Mal ideologisch indoktriniert zu werden. Frage: Wie kann man an einer evangelischen Schule ohne Glaubenszwang in ein sinnvolles Gespräch z. B. über christliche und säkulare Freiheit kommen?

In Ratzeburg prangt an der Lauenburgischen Gelehrtenschule in großen Lettern über dem Eingang das Motto DOCTRINAE - SAPIENTIAE - PIETATI. Schon 1160 als Domschule gegründet, ist sie inzwischen längst ein kommunales Gymnasium in städtischer Trägerschaft, hat aber das alte Motto beibehalten. Im Schulprogramm 
wird erklärt: „In diesem Sinne haben die alten Leitbegriffe doctrinae, sapientiae, pietati, die auch wieder am Eingang unseres neuen Schulgebäudes zu finden sind, für uns immer noch eine Bedeutung, wobei wir aus heutiger Sicht doctrina als ,umfassendes Wissen“, sapientia als „Klugheit“, auch im Sinne von „Lebensklugheit“, und pietas als allgemein moralisches Verantwortungsbewusstsein verstehen." Frage: Ist das Christentum noch Christentum, wenn es auf Moral reduziert wird?

Im „Lutherjahr“ 2017 war die katholische Ordensdirektorenvereinigung so frei, mich als Referenten in ihre Jahrestagung einzuladen, zum Thema „Was können freie Schulen von Luthers Freiheitsverständnis lernen?" Etwa 100 katholische Schulleitungen und Ordensleute hörten meiner Darstellung aufmerksam zu. Inhaltlich entsprach sie obiger Interpretation der Doppelthese, die Sie jetzt ja kennen. Am Ende bat ich um Resonanz und hatte längeres Schweigen auszuhalten. Dann sagt die Oberin, sie sei noch ganz sprachlos. Ich frage nach - inwiefern denn? Ihre Antwort: Die Unterscheidung von innerer und äußerer Freiheit, die habe sie besonders beeindruckt. Nach einigen weiteren Beiträgen stellt jemand eine mich verblüffende Frage: „Worin unterscheiden wir uns denn?“ Offenbar wirkte das von mir Vorgetragene plausibel. Niemand rügte den Frager. Frage: Wie gut kennen wir unsere eigene religiöse Identität?

Was würde Rabbi Sacks zum protestantischen Freiheitsverständnis sagen? „Action“ gegen Passivität - im letzten Drittel des Buches Exodus mutet Mose seinen Flüchtlingen eine große Baumaßnahme zu, in Gottes Namen, als therapeutische Intervention; indem sie aktiv werden, überwinden sie Resignation und Depression (s. o. 10.3). Luther schätzte die hebräische Bibel hoch. Trotzdem schreibt er: Christ wird man nicht durch Tun, sondern durch Hören. Wie verträgt sich das? Rabbi Sacks könnte erwidern: Das wissen wir doch längst: „Der Mensch lebt nicht vom Brot allein, sondern von einem jeglichen Wort, das aus dem Munde Gottes kommt.“ (Vgl. Anm. 131). Er könnte auf das zentrale Credo der hebräischen Bibel verweisen: „Höre, Israel: der Herr, unser Gott, ist ein Herr. Und du sollst den Herrn, deinen Gott, lieben von ganzem Herzen, von ganzer Seele und mit aller deiner Kraft.“ (5. Mose $6,4 \mathrm{f})$ Was wiederum nach Matthäus (22,37 f) und Markus (12,29f) von Jesus zitiert wird, ergänzt um das Gebot der Nächstenliebe, das ebenfalls in der Tora zu finden ist (3. Mose 19,18). Viel Konsens also. Worin unterscheiden wir uns denn nun?

\subsection{Logische Ebenen als Klärungshilfe}

Ebenso wichtig scheint mir die Frage: Worin sind wir uns denn einig? Und weiter: Was können wir voneinander lernen? Wie werden wir gesprächsfähig? Rabbi Sacks hat vorgemacht, wie das geht, in einem öffentlichen Dialog mit dem dezidierten Atheisten Richard Dawkins, auf Youtube nachzuerleben. Seine Eröffnung (sinngemäß): Dear Richard, lass mich von vornherein eins klar stellen: Alles, was die moderne Wissenschaft herausgefunden hat über Weltentstehung, Evolution usw., das unterschreibe ich, darüber müssen wir uns nicht streiten. ${ }^{139}$

139 In meinem Freundes- und Bekanntenkreis ,gestehen“ mir immer häufiger langjährige Kirchgängerinnen, sie könnten das Glaubensbekenntnis im Gottesdienst nicht mehr mitsprechen. 
Ein Fortschritt wäre es schon, wenn wir in diesen Fragen wenigstens nicht aneinander vorbei redeten. Ich nehme dafür das Konzept der logischen Ebenen zu Hilfe. Auch evangelische Schulen kennen die Frage: Wie unterscheiden wir uns denn, nämlich von den kommunalen Schulen? Sind die kommunalen nicht oft viel freier, experimentierfreudiger, engagierter, schülerzentrierter? Lässt sich das mit Ritualen, Gottesdiensten, Festgestaltungen kompensieren?

Pauschale Antworten führen nicht weiter. Mit den logischen Ebenen lässt sich die Frage differenzieren. In Tabelle 10 skizziere ich exemplarisch Qualitätsmerkmale von drei Schultypen. Zwei haben sich partizipativ-kontinuierliche Schulentwicklung auf die Fahne geschrieben. Beide grenzen sich von einem passiv-resignativen Extremtyp ab. Die charakteristischen Merkmale sind sechs unterschiedlichen logischen Ebenen zugeordnet.

Tabelle 10: Qualitätsmerkmale von Schulen auf unterschiedlichen logischen Ebenen

\begin{tabular}{|l|l|l|l|}
\hline & Christliche Identität & Humanistische Identität & $\begin{array}{l}\text { Opfertyp (Reaktive } \\
\text { Identität) }\end{array}$ \\
\hline Spiritualität & $\begin{array}{l}\text { Hören, danken, klagen, } \\
\text { feiern }\end{array}$ & Werde, der du bist! & Suche nach Sicherheit. \\
\hline Identität & $\begin{array}{l}\text { Ich bin bejaht, zur Freiheit } \\
\text { berufen. Ich darf Mensch } \\
\text { sein, muss nicht Gott sein. }\end{array}$ & $\begin{array}{l}\text { Ich habe ein Recht, auf der } \\
\text { Welt zu sein. Würde hat } \\
\text { keinen Preis (Kant). }\end{array}$ & $\begin{array}{l}\text { Ich bin nicht wichtig. Ich } \\
\text { bin ein Verlierer. }\end{array}$ \\
\hline $\begin{array}{l}\text { Glaubens- } \\
\text { sätze/ } \\
\text { Werte }\end{array}$ & $\begin{array}{l}\text { „Ich glaube, dass ich mein } \\
\text { Leben nicht von mir selbst } \\
\text { habe. Ich glaube, dass ich } \\
\text { mein Leben nicht für mich } \\
\text { selbst habe.“(Manfred } \\
\text { Mezger) }\end{array}$ & $\begin{array}{l}\text { Einsatz für Menschen- } \\
\text { rechte; Ehrfurcht vor } \\
\text { dem Leben (Albert } \\
\text { Schweitzer); Biophilie, } \\
\text { Liebe zum Leben (Erich } \\
\text { Fromm) }\end{array}$ & $\begin{array}{l}\text { Sachzwänge sind stärker } \\
\text { als noch so schöne Ideale. }\end{array}$ \\
\hline Fähigkeiten & $\begin{array}{l}\text { Gewinn-Gewinn-Haltung } \\
\text { auch unter Stress. }\end{array}$ & $\begin{array}{l}\text { Gewinn-Gewinn-Haltung } \\
\text { auch unter Stress. }\end{array}$ & $\begin{array}{l}\text { Ich habe ein gutes Gespür } \\
\text { für die Erwartungen von } \\
\text { Leuten, die mächtiger sind } \\
\text { als ich. }\end{array}$ \\
\hline Verhalten & $\begin{array}{l}\text { Gewinn-Gewinn-Haltung, } \\
\text { innerer Seitenwechsel } \\
\text { (Goldene Regel). }\end{array}$ & $\begin{array}{l}\text { Gewinn-Gewinn-Haltung, } \\
\text { innerer Seitenwechsel } \\
\text { (Goldene Regel). }\end{array}$ & $\begin{array}{l}\text { Ich tue, was mir gesagt } \\
\text { wird. Lieber tue ich gar } \\
\text { nichts, als dass ich einen } \\
\text { Fehler riskiere. }\end{array}$ \\
\hline Umgebung & $\begin{array}{l}\text { Spielraum nutzen für die } \\
\text { Gestaltung der Schule als } \\
\text { Lebensraum. }\end{array}$ & $\begin{array}{l}\text { Spielraum nutzen für die } \\
\text { Gestaltung der Schule als } \\
\text { Lebensraum. }\end{array}$ & $\begin{array}{l}\text { Wenn du nicht wärst ..., } \\
\text { wenn XY nicht wäre ..., } \\
\text { wenn ich keinen Stress } \\
\text { hätte ... wenn ich eine } \\
\text { bessere Kindheit gehabt } \\
\text { hätte ..., }\end{array}$ \\
\hline
\end{tabular}

Schöpfungsglaube und Naturwissenschaft halten sie für unvereinbar - wie R. Dawkins; ein Opfer des Verstandes komme nicht in Frage. Kritische Theologie ist in vielen Gemeinden nicht angekommen; s. o. 1.2 und 7.1 (Sacks zu Verantwortung) sowie im Vorwort Lapide zur Bibel: „Man kann sie wörtlich nehmen, oder man nimmt sie ernst." Wörtlichkeit endet in Absurditäten. Zur Kritik an Dawkins’ soziobiologischen Thesen s. Meier-Seethaler (1998, $140 \mathrm{ff})$. 
Sie sehen exemplarische Merkmale einer sich evangelisch verstehenden Schulleitung im Unterschied zu einer nicht-religiösen kommunalen, daneben zur Verdeutlichung ein Extrembeispiel reaktiven Vorgehens. Jede einzelne logische Ebene nimmt eine spezielle Sichtweise auf das Gesamtsystem ein.

Robert Dilts (1993, 16f) erläutert diese unterschiedlichen Sichtweisen an einem Schulbeispiel: Eine Schülerin hat in einem Mathe-Test ganz und gar versagt. Mit welchen Sichtweisen, mit welchen logischen Ebenen lässt sich dies Versagen diagnostizieren? Je nach gewählter Ebene würde der Lehrer unterschiedlich intervenieren.

Nehmen wir an, er beginnt mit dem Kontext des Problems, mit dem Einfluss der Umwelt. Dann könnte er sagen: Es lag nicht an dir; es war zu viel Lärm im Raum oder vor dem Fenster.

Auf der nächsten Ebene spricht er das Verhalten der Schülerin an: Du hast einfach zu wenig geübt.

Oder er sieht auf ihre Fähigkeiten, ihre Begabung: Mathe ist ein Fach, das dir nun mal nicht liegt.

Auf der vierten Stufe arbeitet er mit Glaubenssätzen und Werten. Er könnte sie trösten: Spaß am Lernen ist wichtiger als Zensuren. Damit geht er über das Fach Mathematik hinaus, ins Grundsätzliche.

Auf der fünften Stufe, der Ebene der Identität könnte er sagen: Du bist ein Mensch mit Lernschwierigkeiten. Oder, noch schlimmer: Du bist nun mal eine schlechte Schülerin. Damit bezöge er sich auf das Sein des Kindes. Sein und Verhalten ist nicht dasselbe. Es ist ein entscheidender Unterschied, ob jemand sagt: Ich beherrsche mein Trinkverhalten nicht, oder: Ich bin Alkoholiker. Das zweite, die Seinsaussage, ist eine sehr wirksame Selbstfestlegung.

Auch die Schülerin könnte sagen: Ich bin eben unbegabt. Ich bin nun mal so - das heißt: Nichts zu machen! Wenn Sie bei Schülerinnen und Schülern auf solche „Ichbin-Aussagen“ stoßen, dann hilft es nicht, sie zum Üben zu motivieren. Es ist dann durchaus etwas zu machen, aber zunächst auf der angesprochenen logischen Ebene. Das Thema ist nicht Üben, sondern Identität; Üben wäre nach der Klärung dran.

Und schließlich die Ebene der Spiritualität, die Frage: Was ist mein Platz in der Welt, im Leben? Früher bekamen Mädchen oft zu hören: Du heiratest doch mal; Familie und Kinder sind wichtig; da brauchst du Mathe nicht.

Wenn Sie mit der „Brille“ der logischen Ebenen auf Ihre Schule blicken, werden Ihnen Merkmale einfallen, die insgesamt die wünschenswerte Identität Ihrer Schule ausmachen. Ich ergänze die Tabelle pro Ebene um ein weiteres Beispiel:

Umwelt: Einführung stressmindernder Arbeitsbedingungen (Baumaßnahmen, Rhythmisierung).

Verhalten: Strukturierung von Konferenzen so, dass alle aktiv beteiligt sind und von den Ergebnissen profitieren können.

Fähigkeiten: Schrittweiser Aufbau einer Feedbackkultur.

Glaubenssätze/Werte: Bekräftigung förderlicher mentaler Modelle.

Identität: Konzept- und Schulentwicklung zur Frage: Was für eine Schule wollen wir sein?

Spiritualität: Förderung der Ressourcen im Kollegium, Beispiel: Religionslehrerinnen lernen die Arbeit mit dem Bibliolog, einem Auslegungsverfahren, bei dem 
Schülerinnen und Schüler ihre persönliche auch emotionale Resonanz auf einer biblische Geschichte mitzuteilen lernen. ${ }^{140}$

Wenn Sie die genannten Merkmale einer evangelischen Schule mit denen der humanistisch geprägten Schule vergleichen, wird Ihnen auffallen, dass sie sich auf den unteren drei Ebenen völlig gleichen. Diese Ebenen stehen für die erkennbare Qualität einer Schule. Die oben angeführten Beispiele, wie Schulen ihren Spielraum erweitern, zeigen, dass es da kein Monopol gibt, dass jeder Schultyp besondere Qualitäten entwickeln kann und dass es nahe liegt, voneinander zu lernen (s. o. 13.3).

\section{Einige Folgerungen:}

- Die drei unteren Ebenen sind keine Spezialität einer christlichen Schule. Sie lassen sich dem zweiten Teil von Luthers Doppelthese zuordnen, dem Dienst an anderen. Gute humanistische Schulen bemühen sich nicht weniger um eine Schule, die den Jugendlichen hilft, sich im Leben zurechtzufinden und in den Herausforderungen unserer Zeit zu bestehen.

- Ethische Orientierung und ethische Praxis ist kein christliches Privileg. Nicht jede Lehrkraft in evangelischen Schulen wird sich mit Luthers Doppelthese identifizieren; das heißt aber nicht, dass ethische Orientierung damit hinfällig wäre. (Näheres dazu s.u. 13.4.4)

- Auch die Ebene der Glaubenssätze und Werte ist kein Monopol konfessioneller Schulen. Das Konzept der Lernenden Organisation fordert, hinderliche Glaubenssätze zu identifizieren und förderliche Glaubenssätze ans Licht zu bringen, ganz gleich, ob sie religiöser Natur sind oder nicht.

- Werden die unteren drei Ebenen vernachlässigt, wird die spirituelle Identität, werden die Glaubenssätze sehr schnell unglaubwürdig, die christlichen und auch die humanistischen. Die Lösung liegt dann nicht etwa in der absurden Hoffnung, dass die Spiritualität eben das Besondere ausmache und unvermeidliche Mängel kompensiere. Sie liegt in konsequenter Arbeit an der Qualität der Schule: Auswertung $\rightarrow$ Diagnose $\rightarrow$ Ist-Soll-Vergleich $\rightarrow$ Baustellen usw. (s.o. Kapitel 7-9).

- Andererseits wird ernst gemeinte Spiritualität auf jede Ebene ausstrahlen. Wenn z. B. im katholischen St. Benno-Gymnasium für einen Raum der Stille gesorgt ist, der den Schülerinnen und Schülern und auch den Lehrkräften jederzeit offen steht, dann verweist dies Angebot auf eine bewusste spirituelle Einstellung.

Auch zum Konfliktmanagement gehört über das Handwerkliche hinaus eine spirituelle Seite, die Fähigkeit zum inneren Seitenwechsel. Dazu ein Lutherzitat: „So lerne nun ein jeglicher Mensch, daß er nicht sich selbst ansehe, sondern merke, wie sein Nächster beschaffen sei und sich in ihm spiegle. So muß er gewiß sagen: ,Ei, da hat mir Gott einen Spiegel vor meine Augen gehangen, und ein Buch, daraus ich mich selbst soll erkennen lernen. Ach Gott, ich sehe nun wohl, was mein Bruder auswendig ist, bin ich innen." (Marquardt 1990, 211)

140 Im Kurs stieß das Verfahren auf reges Interesse. Eine gute Einführung bietet U. PohlPatalong (2009). Ähnlich wie beim Stufenmodell und Brainstorming gilt auch hier: Keine Kritik! Wer den Bibliolog anleitet, sollte aktives Zuhören verinnerlicht haben. 
Psychologen formulieren das spröder: ,You don't like in others, what you don't like in yourself." Wir projizieren unsere Schattenseiten in andere, die uns fremd sind. Stattdessen ginge es darum, in Konflikten auch unter Stress aktiv zuzuhören und die Interessen der anderen Seite zu beachten - ein hoher Anspruch.

Also rücksichtsvoll zu den Menschen, mit Harvard, Probleme aber benennen: Auch in evangelischen Schulen kommt Mobbing vor, auf allen hierarchischen Ebenen. In festgefahrenen Konflikten erweisen sich Problemanzeigen an leitende Instanzen oft als kontraproduktiv; da wird lange weggeschaut, dann schnell Partei ergriffen, ein Sündenbock gesucht und im schlimmsten Fall eine Menge Geld für Abfindungen gezahlt, das besser und in erheblich geringerem Umfang in einen Beratungsprozess investiert wäre. Die von Luther so schön beschriebene christliche Freiheit ist ein zartes Pflänzchen, kein Besitz, immer wieder gefährdet und bedroht. Umso wichtiger, sich immer wieder auf sie zu besinnen.

Auch im Zusammenhang mit Feedback sehe ich diesen spirituellen Aspekt, z.B. bei Paulus, der von seiner Gemeinde in Korinth heftig kritisiert wurde: große Versprechungen per Brief aus der Ferne, aber rhetorisch schwach, wenn er denn mal da ist; kein Vergleich mit den gnostischen Power-Predigern (s.o. 6.8). Wie reagiert Paulus? „Es ist mir etwas ganz Geringes, von euch beurteilt zu werden.“ (1. Korinther 4,3; vgl. Anm. 13) Ein starker Satz!

\subsection{Ethik ohne religiöse Begründung}

Moralisches Verantwortungsbewusstsein, ethische Werte sind zu unterscheiden von individueller Identität und Spiritualität. ${ }^{141}$ Im Vergleich der zwei Schultypen mit Hilfe der logischen Ebenen sind Werte und entsprechende Glaubenssätze natürlich auch für ein humanistisches Selbstverständnis benannt. Zwar meinte Dostojewski noch: „Wenn es Gott nicht gibt, ist alles erlaubt.“ Zwar pries Peter Sloterdijk 2004 im Philosophischen Quartett die Religion als unerschöpfliche Quelle für „Misanthropiedämpfung“ - für die Dämpfung von Menschenhass. Und Bazon Brock, Professor für Ästhetik, bedauerte in der gleichen Sendung, dass Gott keinen Platz in der EU-Verfassung bekommen habe; wie könne man nun dem Staat noch Grenzen setzen?! Ein Literat protestierte zwar gegen diese Instrumentalisierung der Religion, fand jedoch kein Gehör. Gott als Garant des Überichs - diese offensichtliche menschliche Projektion dominierte das Gespräch.

Von theologischer Seite hätte der Kritiker Unterstützung bekommen. Ein französischer Dominikaner z.B. meint: „Der Glaube an Gott ist nicht nötig, um eine Moral zu begründen. ... Behaupten, wie es Dostojewski tat, daß, wenn es Gott nicht gibt, alles erlaubt ist', bedeutet, daß man sich eine klägliche Idee macht vom Menschen, von Gott und von der Moral. “ ${ }^{142}$ Der evangelische Theologe Eberhard

141 Zum Sprachgebrauch: Man unterscheidet zwischen faktisch vorhandener Moral einerseits und reflektierter, begründeter Moral andererseits; die Reflexion und Begründung von Moral nennt man Ethik.

142 Grosser 1993, 283. 
Jüngel spitzt das zu: „Gott ist um seiner selbst willen interessant.“ (1986, 196; 1998, 45 u. 226) In ökumenischer Eintracht verwahren sich die Theologen gegen die Instrumentalisierung Gottes für moralische Zwecke. Und das ist gut so. ${ }^{143}$

Religion als alle verbindende Basis ist ohnehin nicht vorauszusetzen, auch nicht in konfessionellen Schulen; gebraucht wird Allgemeinverständlichkeit. ${ }^{144}$ Völliger Verzicht auf Ethik wäre erst recht nicht konsensfähig. ${ }^{145}$ Wie lässt sich dann heutzutage ethische Plausibilität aufweisen? Diese Frage stellte der Mailänder Kardinal Martini dem Schriftsteller Umberto Eco in einem Briefwechsel mit dem Titel „Woran glaubt, wer nicht glaubt?“ Wie kann die absolute Unverfügbarkeit, Würde und Unverletzlichkeit des Menschen einleuchtend begründet werden - in einer Zeit religiöser Schwindsucht? Ecos Antwort, knapp zusammengefasst:

Wir sind Tiere, die aufrecht gehen; es strengt uns an, längere Zeit mit dem Kopf nach unten zu verharren; wir wissen, was oben und was unten ist, und ziehen das erste dem zweiten vor. Desgleichen haben wir eine gemeinsame Vorstellung vom Stehen und vom Liegen, vom Wachsein und Schlafen, vom Sehen, Hören, Essen und Trinken. Und jeder weiß, was wahrnehmen, erinnern, wünschen, Angst haben, Vergnügen oder Schmerz empfinden heißt; und was es heißt, diese Gefühle auszudrücken. Kurz, wir haben universale Begriffsvorstellungen über den Zwang: Wir wünschen nicht, dass jemand uns hindert $\mathrm{zu}$ reden, $\mathrm{zu}$ sehen, $\mathrm{zu}$ hören, $\mathrm{zu}$ schlafen, uns frei zu bewegen usw. Wir leiden, wenn jemand uns fesselt, schlägt, verwundet, foltert, tötet.

Wie aber lernt der einsame Adam, dass er anderen nicht antun darf, was er sich selbst nicht angetan haben möchte? Dadurch, dass sich der Garten Eden zum Glück rasch bevölkert. Die ethische Dimension beginnt, wenn der andere ins Spiel kommt. Wir müssen in erster Linie die Rechte der Körperlichkeit anderer respektieren, zu denen auch das Recht zu reden und zu denken gehört. Hätten unsere Artgenossen diese „Rechte des Körpers“ respektiert, hätte es keinen Kindermord zu Bethlehem,

143 Auch ein Mensch ist um seiner selbst willen interessant. Wenn das schon für Menschen gilt - wie viel mehr dann von Gott? „Was man Menschen zugesteht, sollte man Gott auch nicht einmal in der Theorie vorenthalten.“ (Jüngel 1986, 196)

144 Nach der durch die Reformation ausgelösten konfessionellen Spaltung hatte der christliche Glaube faktisch die Geltung als allgemein verpflichtende Wahrheit eingebüßt. „Die zuvor als selbstverständlich empfundene Identität von Christsein und Menschsein war in Frage gestellt, seitdem das Christsein selbst strittig geworden war. Das Sittliche aber mußte als das schlechterdings für jeden Verbindliche, als Gewährleistung des Zusammenlebens und als Basis gemeinsamer Kultur notwendig allgemeiner Art sein. Seine Geltung durfte nicht beschränkt sein auf die Zugehörigkeit zu einer bestimmten Glaubensgemeinschaft.“ (Ebeling 1969, 4) Am Beispiel des barmherzigen Samariters (s. o. 3.4) weist Ebeling die „Evidenz des Ethischen“ auf, was nicht ausschließt, „,aß der Mensch selbst für das Nächstliegende und Evidente blind sein kann.“ (A.a.O. 10)

145 Tugendhat $(1994,11)$ stellt zumindest die Frage: Warum soll man sich überhaupt mit Ethik beschäftigen? Skeptiker befürchten, „daß hier ohnehin nichts Verbindliches auszumachen sei, es sei denn, man greife auf christliche oder andere religiöse Traditionen zurück. Ist es denn das Ethische oder sind es nicht vielmehr die Machtverhältnisse, die im gesellschaftlichen Leben ausschlaggebend sind? Und bestimmen diese nicht ihrerseits die ethischen Vorstellungen einer Zeit?““ 
keine im Zirkus den Löwen vorgeworfenen Christen, keine Bartholomäusnacht, keine Ketzerverbrennungen, keine Vernichtungslager gegeben.

Wieso gibt oder gab es dann aber Kulturen, die das Massaker, den Kannibalismus, die Erniedrigung des Körpers anderer billigten? Einfach weil diese Kulturen die Anerkennung auf die Angehörigen des eigenen Stammes oder Volkes reduzieren und alle anderen als Barbaren, als nichtmenschliche Wesen betrachten. Die Notwendigkeit, die Anerkennung des anderen zu universalisieren, ist das Ergebnis eines jahrtausendelangen Lernprozesses - meint Eco (1998, 82 ff).

Hat dieser Lernprozess wirklich stattgefunden? Eco argumentiert mit unserer Körperlichkeit, mit unserem Abscheu gegen Zwang und mit der Universalität dieses Abscheus, mit der Anerkennung der anderen als Menschen - das alles, ohne sich auf Gott zu berufen. Die Volksweisheit weiß das längst: „Was du nicht willst, das man dir tu, das füg auch keinem andern zu!" So die Goldene Regel. Sie begegnet in allen Religionen, auch in der antiken Philosophie. Sie spricht die Fähigkeit zum inneren Seitenwechsel an (vgl. 6.11): Wie sieht die Welt nicht nur in meinen Augen, sondern in den Augen der anderen Person oder Gruppe aus?

In der jüdischen Tradition wird erzählt: Einmal kam ein Heide zu Schammai (um 30 v. Ch.); er sprach zu ihm: Nimm mich als Schüler auf, unter der Bedingung, dass du mich die ganze Tora lehrst, während ich auf einem Bein stehe. Er stieß ihn (empört) mit einem Baumaß, das er in seiner Hand hatte, fort. Er ging zu Hillel (um 20 v. Ch.); dieser nahm ihn als Schüler auf. Er sprach zu ihm: Was dir unlieb ist, tue keinem anderen; das ist die ganze Tora und das andre (übrige) ist Erklärung; geh und lerne!

Lernen wir also! Z.B. von George Bernard Shaw, dem Spötter, der warnt: „Tu einem andern nicht an, wovon Du wünscht, dass man's Dir antäte, denn er könnte einen anderen Geschmack haben als Du!“ (Erikson 1971, 193) Vorsicht also mit Überfürsorge nach dem Motto: „Kind, zieh dir was an! Mir ist kalt!“ Die Bergpredigt dagegen schreibt der Goldenen Regel höchste Bedeutung zu: „Alles, von dem ihr wollt, dass es die Leute euch tun, das tut ihr genau so auch ihnen: Das ist es, was das Gesetz und die Propheten sagen." (Matthäus 7,12)

Wenn ich in der U-Bahn sehe, wie ein Rowdy eine Frau belästigt, dann könnte ich aus dem Fenster gucken und mir sagen: „Was du nicht willst, das man dir tu usw." Ich will nicht, dass mir so etwas geschähe, also werde ich mich an dieser Belästigung nicht beteiligen. Damit ist der Frau nicht geholfen. Die Positivversion in der Bergpredigt dagegen würde mir sagen: Wenn ich belästigt, bedroht, gezwungen werde, dann möchte ich, dass mir jemand beisteht, - also bin ich jetzt gefordert, dieser Frau beizustehen. Das heißt, die positive Fassung der Goldenen Regel impliziert die Subregel, dass ich mich in die Lage des anderen einzufühlen habe und dann entsprechend aktiv werde. G. Enderle (1987) hat vier Subregeln aufgestellt, die den Gebrauch der Regel situationsbezogen präzisieren: Einfühlungsregel, Autonomieregel, Gegenseitigkeitsregel und Klugheitsregel. ${ }^{146}$ Werden die beachtet, könnte Shaw zufrieden sein. Vielleicht auch Kant?

146 (1) Einfühlungsregel: Durch Einfühlung in die Rolle des Betroffenen nehme ich die Wertbasis des anderen ernst. (2) Autonomieregel: Indem ich mein Handeln von der sittlichen Forderung leiten lasse, an die der Betroffene sich hält, achte ich die Autonomie des anderen. 
Dem war der Klugheitsaspekt ein Greuel. Nur taktische Berechnung sah er in der Goldenen Regel und hat sie darum scharf abgelehnt. Eine qualifizierte ethische Orientierung müsse unbedingt gelten, unabhängig von den egoistischen Interessen der Person, die sie praktiziert: „Handle nur nach derjenigen Maxime, durch die du zugleich wollen kannst, dass sie ein allgemeines Gesetz werde.“ Das ist der berühmte kategorische, d.h. unbedingt gültige Imperativ. ${ }^{147}$ Darin steckt - wie in der Goldenen Regel - die Wechselseitigkeit, durch die die Würde und Unverletzlichkeit der Person gesichert werden soll. Tugendhat bringt diesen Imperativ auf zwei Wörter: „Instrumentalisiere niemanden!“‘ $(1994,80)^{148}$

Günther Anders fragt kritisch: ,Wie fänden Sie eine Mutter, die nicht aus Neigung, also aus Liebe (ein Wort, das Kant vermeidet wie die Katze den heißen Brei) gut zu ihren Kindern wäre, nein: das noch nicht einmal dürfte? Sondern allein, weil , die Maxime ihres Handelns als Prinzip einer allgemeinen Gesetzgebung gelten könnte“?“ „Ist das human?“ „Da lobe ich mir jede Bruthenne, die ihr Junges unter ihre Fittiche nimmt.“ (Anders 1995,112f)

Der kategorische Imperativ ist abstrakt, unpersönlich, kalt. Also wurde er repersonalisiert, fatalerweise, von einem Obernazi: „Handle so, daß, wenn der Führer von deinem Handeln Kenntnis hätte, er dieses Handeln billigen würde." So Hans Frank, in der Hitlerzeit Präsident der nationalsozialistischen Akademie für deutsches Recht (Anders 1995,110). Damit, meint Anders, hat er Millionen Deutschen aus der Seele gesprochen. Einem abstrakten Prinzip zu gehorchen, sei nun einmal nur einer winzigen Minderheit von Mitmenschen möglich; die große Mehrheit lasse sich von der selbstverständlichen Gehorsamserwartung faszinieren.

Kant könnte sagen: Da sieht man ja, was dabei rauskommt: selbst verschuldete Unmündigkeit! Autonomie ist anstrengend. Und Günther Anders hätte er entgegnet: Die Liebe einer Mutter ist durchaus legal, keineswegs verboten; sie ist

(3) Gegenseitigkeitsregel: Was ich von einem anderen erwarte, lasse ich auch für mich selbst gelten. (4) Klugheitsregel: Ich hoffe, dass der andere mir so entgegen kommt wie ich ihm: das muss nicht unmoralisch sein. Und die Goldene Regel geht auf dreifache Weise (s. o.) über eine bloße Klugheitsregel hinaus. Ich lasse für mich gelten, was ich von dir fordere.

147 So von Tugendhat $(1994,136)$ zitiert. Tugendhat erläutert: „Z.B. wollen wir nicht - auf Grund unseres Eigeninteresses -, daß uns andere ein Leid zufügen, und daraus folgt, daß wir nicht ,wollen können', daß die (z.B. von mir gerade befolgte oder erwogene) Maxime, einem anderen Leid zuzufügen, wann immer es mir paßt, ,ein allgemeines Gesetz‘ werde, denn das hieße ja, daß mir dauernd alle, wann immer es ihnen paßte, Leid zufügen würden.“ (Tugendhat 1994, 138)

148 „Die Forderung, Personen jederzeit zugleich als Zweck und niemals bloß als Mittel zu gebrauchen, schließt nicht aus, daß Personen auch als Mittel gebraucht werden können, wohl aber, daß sie bloß als Mittel gebraucht werden. In jeder (z.B. ökonomischen) Kooperation werden Personen (z.B. ihre Arbeitskraft) als Mittel verwendet, um gewisse Kooperationsziele zu erreichen. Die Selbstzweckformel verbietet lediglich, daß Personen in dieser Mittelbewandtnis aufgehen. So vielfältig Menschen einander als Mittel dienen können, sie müssen ,jederzeit zugleich “ auch als Selbstzweck anerkannt sein.“ (Anzenbacher 1992, 60) Aber auch Kants Formel ist nicht über jede Kritik erhaben. Schiller macht sich über seinen unbedingten Pflichtbegriff lustig: „Gerne dient' ich den Freunden; / doch tu ich es leider aus Neigung. / Und so wurmt es mich oft, / dass ich nicht tugendhaft bin.“ 
aber nicht im strengen Sinn moralisch qualifiziert. Auch Aristoteles, der antike Altmeister der Ethik, hätte Bedenken angemeldet: Im Dienste des Bösen oder der Ungerechtigkeit wären Klugheit, Mäßigung oder Mut keine Tugenden mehr, sondern nur noch Talente. Aus Liebe ungerecht sein, ist ungerecht - und die Liebe dann nur noch Begünstigung oder Parteilichkeit (Comte-Sponville 1995, 79). Jede Tugend, auch die Liebe, muss sich an der Kardinaltugend messen lassen, an der Gerechtigkeit. Kann Liebe zu einem Verbrecher tugendhaft sein? Ist er denn mehr, anderes als die Summe seiner Taten? Säe einen Gedanken, ernte eine Tat; säe eine Tat, ernte eine Gewohnheit; säe eine Gewohnheit und ernte einen Charakter (Covey 1995, 45) - das ist Aristoteles. Und das ist modern. Ist der Mensch etwa mehr als die Summe seiner Taten?

Das Christentum hat diese Frage allerdings bejaht, sofern es nicht unter seinem eigenen Niveau geblieben ist. Ja, der Mensch ist mehr als die Summe seiner Taten (Jüngel 1998, 219 ff). Unsere Lebensbasis ist uns geschenkt; das ist unsere Würde. Das schließt durchaus ein, dass jeder sich für seine Taten verantworten muss. Aber die Person bleibt frei in dem Sinn, dass ihre Würde unbedingt geachtet wird. Die Würde der Person ist - nun wieder mit Kant - das, was keinen Preis hat, was nicht gekauft oder erarbeitet werden kann. Hinter diese ursprünglich christliche Auffassung vom Menschen kann nun auch die Welt nicht mehr zurück, vielmehr: sie konnte und sie kann es durchaus, aber nur um den Preis der Barbarei.

Kant will eine Orientierung bieten, die sich weder kulturell noch zeitlich noch örtlich relativieren lässt; der kategorische Imperativ soll universal gelten. Die Fachphilosophen haben allerdings herausgefunden: So unbedingt, wie er klingt, ist er nicht (Tugendhat 1994, 138). Michael Walzer vergleicht universale Regelwerke dieser Art mit der Ausstattung von Hilton-Hotel-Zimmern, die zwar überall auf der Welt den gleichen Minimalkomfort bieten, in denen man sich aber nie zu Hause fühle (Breuer 1996, 204). Martha Nussbaum (1999, 227-263) hat sich darum auf Aristoteles und seine Tugendethik zurückbesonnen; darin sieht sie den Vorteil, Gefühle und Bedürfnisse der Menschen in der ethischen Orientierung berücksichtigen zu können.

Mit Aristoteles geht sie aus von elementaren kulturübergreifenden Grunderfahrungen: Jeder hat eine Einstellung und ein bestimmtes Verhalten gegenüber dem eigenen Tod, den eigenen körperlichen Begierden, der persönlichen Lebenseinstellung usw. Man kann sich diesen Fragen nicht entziehen, solange man ein lebendiges menschliches Wesen ist. So korrespondiert der Grunderfahrung der Todesfurcht die Tugend der Tapferkeit, der Erfahrung der körperlichen Begierden die Tugend der Mäßigung, der Erfahrung der Begrenztheit von Ressourcen die Gerechtigkeit, der Erfahrung von Freud und Leid anderer Menschen das Verständnis usw.

Die Tugenden sind die Antwort auf solche Grunderfahrungen: Sie sind lebensweltlich konkret, zeit- und situationsbezogen und darum immer wieder auf ihre Angemessenheit hin zu überprüfen. Die Tugendethik arbeitet also deduktiv und induktiv zugleich; sie geht (induktiv) aus von dem, was in einer bestimmten Situation gilt; Begierden, Empfindungen, Gefühle werden berücksichtigt, so wie Friedrich Schiller (s. Anm. 148) und Günter Anders das wünschen. Und sie überprüft ihre Ergebnisse (deduktiv) an den universalen Grunderfahrungen des Menschseins.

In diesem Sinn verweist Meier-Seethaler (1998, $157 \mathrm{ff})$ auf die neuere amerikanische Emotionsforschung, die den Gefühlen wesentliche Bedeutung für die 
Beurteilung konkreter Situationen zuschreibt; es gebe kein Erkennen ohne Gefühl, keine Handlung ohne Gefühl, keine Wahrnehmung ohne Gefühl, keine Erinnerung ohne Gefühl. Dieser Ansatz wird inzwischen auch in Deutschland aufgenommen. Nicht das cartesianische „Ich denke“ gilt mehr als Basis menschlicher Identifikationsfindung; vielmehr werden die Emotionen als das eigentliche Charakteristikum der Persönlichkeit, der Identität gesehen. Im kritischen Rückblick auf die traditionelle Philosophie könne man den Eindruck gewinnen, Gefühle seien etwas, was man besser gar nicht hätte (a. a. O., 173; s. o. 12.3.3).

Verzichte man auf religiöse und metaphysische Begründung von Ethik, sei der Personwert des Menschen nur als ein Faktum gelebter Mitmenschlichkeit und als Folge von Sozialisation zu erklären: Indem das Kind Liebe und Wertschätzung durch seine nächsten Bezugspersonen erfährt und durch Billigung und Tadel seiner Handlungen auch den Wert anderer als Personen respektieren lernt, ${ }^{149}$ bildet sich seine moralische Identität und seine Gemeinschaftsfähigkeit heraus; so gibt MeierSeethaler die Position E. Tugendhats wieder; sie folgert, dass sich keine strikte Grenze zwischen Philosophie und Psychologie ziehen lässt (a. a. O., 176-178), und endet bei der (klein geschriebenen) goldenen Regel, dass ich die Wünsche anderer im gleichen Maße zu berücksichtigen habe, wie ich das für meine Wünsche erwarte (a. a.O., 179).

Zurück zur Ausgangsfrage: Wie ist eine ethische Orientierung zu finden, die keine religiöse Voraussetzung erfordert und doch nicht beliebig ist? Vorausgesetzt war dabei, dass eine ethische Orientierung für menschliches Zusammenleben unabdingbar ist. Wie können Sie sich in einem Leitungsgremium, in einem Schulkollegium auf eine praktikable Alltagsethik verständigen, die von der religiösen Identität einer evangelischen Schule unabhängig ist, ihr aber auch nicht widerspricht?

Ein erster Ansatz wäre die Goldene Regel, die zusammen mit vier Subregeln plausibel wirkt. Dieser Ansatz vereint vier Aspekte: Einfühlung, Autonomie, Gegenseitigkeit und Klugheit.

Für Eric Berne, den Begründer der Transaktionsanalyse, macht Autonomie den grundlegenden Wert aus, der sein Menschenbild prägt. Menschen sind grundsätzlich so, wie sie sind und in ihrem Menschsein in Ordnung, was nicht bedeutet, dass auch jedes Verhalten in Ordnung wäre. Auf den grundlegenden Unterschied zwischen Person und Verhalten habe ich mehrfach aufmerksam gemacht (6.7.1; 11.7.3). Berne legte Wert auf einprägsame Alltagssprache. Tabelle 11 zeigt vier zwischenmenschliche Positionen als grundlegende Einstellungen und Haltungen mit den entsprechenden Kurzformeln.

„Echte Wertschätzung, konstruktive Beziehung und damit starke Führung sind nur von der Haltung ,Ich bin OK - du bist OK “ aus möglich.“ (Sejkora und Schulze 2016, 185) Mit diesem mentalen Modell ist gemeint, dass Mensch zu sein ein grundsätzlicher Wert ist, der Respekt verdient. Menschen haben grundsätzlich die Möglichkeit, dieses OK-Sein für sich selbst und für andere zu bejahen oder zu verneinen, so dass sich für menschliche Beziehungen nur eine konstruktive und drei destruktive bzw. dysfunktionale Haltungen ergeben. Die konstruktive Version $(++)$

149 Ebenso J. Bauer, vgl. Anm. 76. 
ist das leitende mentale Modell für die konstruktive Bearbeitung von Konflikten; dem entspricht die Gewinn-Gewinn-Haltung im Harvard-Konzepts und die Berücksichtigung der Grundbedürfnisse bei der gewaltfreien Kommunikation (s. o. 6.3 und 6.6).

Tabelle 11: Grundpositionen der Transaktionsanalyse

\begin{tabular}{|l|l|l|}
\hline & Du bist OK, so wie du bist. & $\begin{array}{l}\text { Du bist nicht OK, so wie du } \\
\text { bist. }\end{array}$ \\
\hline Ich bin OK, so wie ich bin. & kooperative Position $(++)$ & arrogante Position $(+-)$ \\
\hline Ich bin nicht OK, so wie ich bin. & demütige Position $(-+)$ & aussichtslose Position $(--)$ \\
\hline
\end{tabular}

Die Grundpositionen sind als Seins-Aussagen formuliert und können so verstanden werden, dass menschliche Autonomie eine dem Menschen innewohnende Qualität darstellt. Demgegenüber hält reformatorische Theologie daran fest, dass der zur Freiheit gerufene und befreite Mensch lebenslang auf diese Zusage unbedingter Bejahung, auf den Ruf zur Freiheit angewiesen bleibt. „Was hast du aber, das du nicht empfangen hast?" Diese radikale Frage (1. Korintherbrief 4,7) schützt davor, die geschenkte Freiheit selbstgefällig als eigene Leistung, als verdienten Erfolg auszugeben (vgl. Jüngel Anm. 13, 78 u. 129). Diese bleibende Angewiesenheit betont auch der Philosoph Ernst Tugendhat (s. Anm. 152); für den Ruf in die Autonomie und für deren Zusage sieht er uns Menschen verantwortlich.

Die konstruktive OK-Position fordert den inneren Seitenwechsel der Goldenen Regel. Mit der von Enderle ergänzten Einfühlungsregel wird der Bereich der Emotionen angesprochen. Damit hat die Goldene Regel gegenüber Kants kategorischem Imperativ den Vorzug, sich auf sehr unterschiedliche Situationen differenziert zu beziehen. Authentisch empfundene und kommunizierte Emotionen verweisen auf unterschiedliche Grundbedürfnisse, denen plausible ethische Grundsätze korrespondieren.

Der von Kant formulierte kategorische Imperativ beansprucht universale Geltung, ist aber so abstrakt formuliert, dass er in der Alltagspraxis vor allem als Gegenseitigkeitsregel auftaucht. Seine Kurzformel „Instrumentalisiere niemanden!“ impliziert die Unterscheidung von Person und Verhalten und wahrt zumindest als Postulat die unverlierbare Würde jedes Menschen.

Ernst Tugendhat $(1994,22)$ nimmt die Impulse aus der amerikanischen Emotionsforschung auf und sieht in unserer Fähigkeit, uns zu empören, einen plausiblen Zugang zu ethischen Grundsätzen. Ein gefühlloses Leben wäre auch ein empathieloses und beziehungsunfähiges Leben (s.o. Anm. 117). Ich habe ihn beim Wort genommen und seine Behauptung getestet, mehrfach, in verschiedenen Gruppen, indem ich einen einfachen Fragebogen im DIN-A4-Format zusammengestellt und ausgeteilt habe, einen Empörungsfragebogen, dessen einzelne Items sich je nach Gruppe leicht variieren lassen.

Es empört mich, wenn ... 1. mein Vorgesetzter / meine Vorgesetzte ... 2. ein Kollege / eine Kollegin ... 3. eine Schülerin in meinem Unterricht... 4. ein Familienangehöriger ... 5. ein Nachbar / eine Nachbarin ... 6. jemand in einer wichtigen Diskussion ... 7. ein Politiker / eine Politikerin ... 8. jemand auf der Straße / beim Fahren auf der Autobahn ... 9. jemand im Kino, im Konzert, im Theater (usw.) ... 
Alle Gruppenmitglieder bekommen die angefangenen Sätze als Liste ausgedruckt und füllen sie individuell aus; dann setzt man sich zu zweit zusammen und erzählt sich von seinen Empörungssituationen, ca. 10 Minuten. Wenn die Gruppe größer ist, kann man das zwanzig Minuten lang zu viert fortsetzen. Aufgabe ist es jetzt, von den konkreten Empörungssituationen zu abstrahieren: Was wird in den beschriebenen Situationen verletzt? Worum geht es da? Häufige Nennungen: wertschätzender Umgang, offene Kritik, gerechte Arbeitsverhältnisse usw. Die Ergebnisse werden im Plenum visualisiert und nochmals diskutiert - und auf diese Weise ergibt sich erstaunlich schnell eine gemeinsame Verständigung, eine Art Alltagsethik, für diese Gruppe. Einige Beispiele (in drei Kategorien sortiert):

Im Interaktionsbereich wird gefordert, die andere Person, ihre Ehre und Würde unbedingt zu achten, ihre physische und psychische Unverletzlichkeit zu respektieren, die Privatsphäre zu schützen, offen, direkt zu kommunizieren, andere Sichtweisen zuzulassen, Verantwortung zu übernehmen, Vereinbarungen einzuhalten.

Im Organisationsbereich gehört es sich, Betroffene an Entscheidungen zu beteiligen, für gerechte Arbeitsbedingungen zu sorgen, Strukturen und Abläufe transparent zu machen.

Und individuell sollte man nicht Wasser predigen und Wein saufen, sondern Forderungen an andere auch für sich selbst gelten lassen. ${ }^{150}$

Im Grunde also Selbstverständlichkeiten; es ist trotzdem sinnvoll, diese Selbstverständlichkeiten ins Bewusstsein zu rufen. Zum einen, weil es auch in konfessionellen Einrichtungen Intrigen gibt, Mobbing, Sündenbocksuche, Machtmissbrauch und Schlendrian. Zum anderen, weil es zur Leitungsrolle gehört, eine gedeihliche Arbeitskultur zu fördern. Und da ist es günstig, wenn man sich bei Störungen der Kultur auf gemeinsam getroffene Vereinbarungen berufen kann. Wenn ich mich in Konflikten auf Vereinbarungen beziehen kann, bin ich als Person entlastet; ich muss dann nicht gleich mit meinen persönlichen Empfindungen argumentieren. Und ganz grundsätzlich: Pädagogische Arbeit ist Beziehungsarbeit.

Sie können sich als Leitungsverantwortliche die Zusammenarbeit erheblich erleichtern, wenn Sie sich auf diese Weise im Rahmen Ihrer Vertragsarbeit (s. o. 5.4.4) mit ihrem Leitungsteam verständigen. Allein dieser Prozess würde schon etwas von dem schaffen, worum es in der Ethik geht. Und die Hürde, Irritationen oder Ärger anzusprechen, wäre niedriger.

\subsection{Fazit}

Ausgangsfrage war: Wie frei sind „freie“ Schulen, und wie unterscheiden sie sich von kommunalen Schulen? Ich gebe einige Hinweise in Thesenform:

150 Oft werden nur Stichworte genannt; die lassen sich zu Sätzen ergänzen. Vor tüfteligen Begriffsdefinitionen ist allerdings auch hier zu warnen; vgl. Anm. 54. Mit diesem Verfahren können Sie auch in Grundschulen die Mädchen und Jungen zum Nachdenken bringen: Wie wollen wir in dieser Klasse lernen und leben? Wöchentliche Auswertung ist sehr zu empfehlen. 
- Nach Luthers Doppelthese ist befreiender Zuspruch die Quelle der christlichen Ethik. ${ }^{151}$ Wer Befreiung erfährt, kann und wird Befreiung weiter geben, verbreiten - spontan, ohne Zwang. Diese Freiheit ist kein Besitz; sie bleibt auf den Zuspruch des Evangeliums (und damit auf die Beziehung zu Gott) angewiesen, sie ist und bleibt Geschenk.

- Auch für ein humanistisches Selbstverständnis ist die spirituelle Ebene die Quelle der Ethik. Für Kant ist es das Bewusstsein der Würde und der Pflicht, in der er jeden Menschen sieht. Erich Fromm nennt Biophilie (Liebe zum Leben) als Orientierung. Auch diese unantastbare Würde des Menschen ist kein Besitz; auch sie wird zugesprochen, von uns Menschen verliehen, indem wir einander als absolut wertvoll achten. ${ }^{152}$ Und der Staat verpflichtet sich, sie zu schützen (GG Artikel 1). Die spirituelle Ebene wird hier also durch menschliche Aktivität hergestellt.

- Dieser Unterschied zwischen christlichem und humanistischem Selbstverständnis ist auszuhalten. Ein gemeinsames Thema könnte die Frage sein, ob und wie sich das in ethischer Praxis auswirkt. Tugendhat dazu: Ich mache immer wieder die Erfahrung, dass von vielen bedauert wird, dass die Moral die Stütze verliert, die sie zu haben schien, solange man der Auffassung war, dass sie von Gott, der Natur oder der Vernunft gestiftet ist. „Aber eine solche Stütze ist natürlich fiktiv. Selbst wenn es sie gäbe, hätte sie ja nur den Sinn: wenn ich mich der Natur oder der Vernunft verpflichtet fühle, muß ich moralisch sein, aber inwiefern sollen wir eher ein Motiv haben, uns zur Natur oder zur Vernunft oder zu sonst etwas zu bekennen als zur Moral selbst?“ (1994, 346)

- Was für ein Mensch will ich sein? Woran liegt mir im Leben, und was hängt für mich davon ab, ob ich mich als zugehörig zur moralischen Gemeinschaft verstehe? Auf die Beantwortung dieser Fragen läuft nach Tugendhat die Begründung ethischer Überzeugungen hinaus. So schwach sei nun einmal die Basis der Ethik, und kein Versuch, sie künstlich stärker erscheinen zu lassen als sie ist, habe die Menschen eher dazu bewegt, moralisch zu sein. So sieht auch H. Arendt (2019, 46) das entscheidende Motiv der Widerständler in der Nazi-Diktatur in der Frage, ,inwiefern sie mit sich selbst zusammenleben könnten“, wenn sie sich konformistisch verhielten.

151 Kurzformel Luthers: „Also bleibt der Glaube der Täter und die Liebe bleibt die Tat.“ (Zit. bei Ebeling 1964, 178) Ebeling interpretiert: „Darum also ist die Unterscheidung von Glaube und Liebe erforderlich, weil der Mensch in grundverschiedener Hinsicht angegangen, gefordert und in Frage gestellt ist: als er selbst, der er nicht in seiner eigenen Macht steht, und in Hinsicht auf das, worüber er Macht hat und was darum Gegenstand seines Tuns ist."(A.a. O., 192) Der Aktivität geht also Passivität voraus.

152 „Es ist nicht sinnvoll zu sagen: den Menschen kommt an und für sich zu, Zweck an sich zu sein oder einen absoluten Wert und das heißt Würde zu haben. Das bleiben leere Worte, deren Sinn nicht ausweisbar ist. Hingegen kann man sagen: indem wir einen Menschen als ein Rechtssubjekt achten und d.h. als ein Wesen, demgegenüber wir absolute Pflichten haben, verleihen wir ihm Würde und einen absoluten Wert. Dann sind absoluter Wert und Würde auf diese Weise definiert und nicht als etwas Vorhandenes vorausgesetzt." (Tugendhat 1994, 145) 
Gott, Natur, Vernunft - „Hitler, Stalin und Pinochet und ihre Henkersknechte haben sich von solchen Berufungsinstanzen genausowenig beeindrucken lassen wie von der Moral selbst, und das einzige, wodurch sich vermeiden läßt, daß sich die Verbrechen immer wieder ereignen, ist, daß möglichst viele Menschen an die Menschenrechte glauben bzw. sich moralisch verstehen." Das sollte zwischen Christen und Humanisten nicht strittig sein.

- Georges Enderle interpretiert die Goldene Regel u.a. mit der Einfühlungsregel; damit ist eine Brücke von der Universalethik zur Tugendethik gebaut. Einfühlung ist Arbeit. Geh hin und lerne! Die so differenzierte Goldene Regel bietet keine „pfannenfertigen“ Konzepte, wohl aber sinnvolle Denkrichtungen. Dies Verständnis der Goldenen Regel verträgt sich m. E. gut sowohl mit christlichem wie mit humanistischem Selbstverständnis.

- Mit dem „Empörungsfragebogen“ können Sie mit Ihrer Leitungsgruppe und auch mit Ihrem Kollegium eine Alltagsethik entwerfen, die Sie in Konflikten als Orientierung heranziehen können, zusammen mit weiteren Aspekten, die im Harvard-Konzept als Lösungskriterien (4. Prinzip) genannt werden.

Indem Sie mit Ihrem Kollegium an einem ethischen Grundkonsens arbeiten, zeigen Sie, dass es in einer freien Schule nicht um religiöse Indoktrinierung geht. So eine grundsätzliche Orientierung wird Ihnen die Arbeit an Konflikten nicht ersparen; die Chance, solche Konflikte gewaltfrei zu lösen, dürfte so aber höher sein. ${ }^{153}$

- Christliche Spiritualität drängt zur Aktivität. Aus christlicher Sicht geht es dabei um die Verbreitung von innerer Freiheit. Da liegt es nahe, dass dies Verständnis von Freiheit alle Aktivitäten auf allen logischen Ebenen färbt und prägt. Als ein Beispiel habe ich die Einrichtung eines Meditationsraums in einer freien Schule genannt.

Ein Kollegium könnte so immer aufmerksamer dafür werden, wo innere Unfreiheit in Konferenzen, im Unterricht, in den Pausen erkennbar wird. In einem Konflikt unter Stress interessiert zuhören - nicht einfach! Wenn eine Schülerin oder ein Schüler kaum erreichbar scheint - dann an die unterschiedlichen inneren Etagen denken, die den Kontakt erschweren können - das ist anspruchsvoll, eine tägliche Herausforderung, aber auch eine Chance für Freiheitsgewinn im Alltag.

- Freiheit verbreiten - das schließt ein, sich immer wieder auf die Quelle der Freiheit zu beziehen, auf Befreiungserfahrungen zu achten. Die haben ErlaubnisStruktur: Du musst nicht singen und auch nicht so tun, als ob ... Du musst nicht immer stark sein. Du musst nicht immer alles recht machen.

153 Enja Riegel traf in ihrem Kollegium auf völlige Ablehnung (s.o. Anm. 50). Vermutlich waren die Lehrkräfte empört. Welche Grundbedürfnisse des Kollegiums waren verletzt? Wurde es gehört? Wie sahen die Befürchtungen aus? Wurden die ausgesprochen? Welche Notwendigkeiten und welche Grundbedürfnisse vertrat der Träger? Wie hat er seine Kandidatin inthronisiert? Und falls es um inhaltliche Differenzen ging, um konkrete pädagogische Maßnahmen: Was geschieht, wenn eine Leitung sich freier verhält als das Kollegium? Dann gehört zur Freiheit, die aus Freiheit entwickelten Ideen vernünftig zu begründen. Wie das geht, kann man von Enja Riegel und anderen lernen. 
Die biblischen Wundergeschichten erzählen von solchen Gangwechseln, die der Rabbi aus Nazareth anstößt, indem er dem einen die Augen auftut, dem anderen die Ohren öffnet, den dritten aus seiner Lähmung in Bewegung bringt und einen vierten sogar aus seinem vorzeitigen Grab herausholt. Das muss ich nicht als biologisches Mirakel verstehen. Ein arabisches Sprichwort hilft mir auf die Sprünge: „Die Menschen schlafen, solange sie leben; erst in ihrer Todesstunde erwachen sie." Dem korrespondiert ein biblischer Weckruf: „Wache auf, der du schläfst, und steh auf von den Toten, so wird Christus dir als Licht aufgehen." (Epheser 5,14)

- Auch humanistische Spiritualität bleibt nicht selbstzufrieden bei sich; auch sie drängt nach außen. Typische Stichworte sind Menschenwürde, Mündigkeit, Autonomie ${ }^{154}$, aufrechter Gang. Auch bei unterschiedlichem spirituellem Hintergrund ist auf der logischen Ebene der Ethik eine beträchtliche Schnittmenge zu finden; Kooperation bei der Verbreitung äußerer Freiheit ist also ganz selbstverständlich. Gute Ideen, innovative Praxisbeispiele können anregend auf die eigene Arbeit wirken (s. o. 13.3).

- Die jeweilige spirituelle Ausrichtung einer Schule färbt den Alltag; sie wirkt in, mit und unter den normalen Tätigkeiten, nicht aufdringlich, trotzdem spürbar. Diese These habe ich bewusst im Indikativ formuliert. So ist es faktisch, weil auch spirituelle Dürftigkeit im Alltag spürbar ist.

Ist es nötig, diese Ausrichtung gesondert zu reflektieren, zu bestimmten Zeiten zum Thema zu machen? Die Frage erinnert mich an den Mann, der Obst wollte, statt sich konkret für Äpfel, Pflaumen, Trauben o. ä. zu entscheiden. Für Odo Marquard steht so jemand für den Versuch, den Sinn des Lebens durch direkten Zugriff zu erreichen, statt darauf zu setzen, dass er sich hier und da und immer wieder einmal einstellen wird, wenn ich mich auf die mich unmittelbar umgebende Alltagswelt einlasse (Marquard 2001, $43 \mathrm{f}$ ). ${ }^{155}$

Dennoch hat es guten Sinn, Rituale, Feste, Gottesdienste, Meditationen, Konzerte, Theater zu veranstalten, in denen der spirituelle Hintergrund sich auf bunte Weise ausdrückt. Wenn das alles fehlt, dann würde das den Alltag verändern. Ich bin oft gefragt worden, was denn das Christliche in einer Organisation ist, in der Diakonie, in einer Gemeinde, in einer evangelischen Schule. Allmählich bin ich zu einer ersten Antwort gekommen: Das Christliche ist die Zeit, die wir uns dafür nehmen. Wir. Nicht nur individuell, nicht einsam. Dazu gehört, dass wir uns spirituelle Erfahrungen erzählen, Geschichten von Freiheitsgewinn, von persönlichem Gangwechsel, von empfangenen wichtigen Impulsen. Und dass wir der Freiheit eine Chance geben, möglichst oft.

154 Wichtige Klarstellung: „Nie wird in der Transaktionsanalyse der Begriff Autonomie als selbstherrlich verstanden; es handelt sich immer um mitmenschlich bezogene Autonomie ..." (Schlegel 1993, 22)

155 So jemand ,wählt den einzigen mit Sicherheit erfolgreichen Weg, gerade das nicht zu erreichen, was er doch will: nämlich Sinn; denn Sinn ist - jedenfalls für uns Menschen - stets nur auf dem Weg über Beruf, Familie, Einsamkeit, Staat, Kunst, Wirtschaft, Wissenschaft, Pflichten, Neigungen, Mitleid und so weiter zu erreichen, und ihn anders erreichen zu wollen ist Unsinn." (Marquard a.a. O.) 


\subsection{Vertiefung: Auch Jesus hat dazugelernt}

Die Frau aus Syrophönizien, die sich so resolut für ihre kranke Tochter einsetzte, lernte in der Begegnung mit Jesus, dessen Grenzsetzung zu respektieren (s.o. 11.9.1.3). Und im gleichen Moment macht Jesus überraschenderweise einen Schritt über die von ihm gesetzte Grenze hinaus. Erst weist er sie ab:

„Es ist nicht recht, den Kindern das Brot zu nehmen und es den Hunden hinzuwerfen." Die Kinder gehören dazu. Die Hunde stehen für Ausländer, für Heiden. Die Frau von jenseits der Grenze akzeptiert die Grenze und bittet nur um eine kleine Inkonsequenz, so wie die Hunde von den Brotkrümeln der Kinder profitieren. Davon lässt Jesus sich rühren. Er lässt sich über die Grenze ziehen: „Um dieses Wortes willen geh hin; der Dämon ist aus deiner Tochter ausgefahren. “ Die Frau macht eine wichtige Lernerfahrung; Jesus ebenso - historisch gesehen eine Erfahrung von größter Bedeutung. Er erweitert sein mentales Modell. Genau das geschieht, wenn Lernen geschieht.

Die hebräische Schrift macht das anschaulich. Wie bei uns lernen Kinder das Alphabet mit Merkwörtern, A wie Affe, B wie Bär usw., in Israel mit einer Besonderheit. Die hebräische Schrift besteht ursprünglich nur aus Mitlauten, Konsonanten. Schwer zu lesen. Die Konsonanten bilden eine Quadratschrift; jeder Konsonant könnte in ein quadratisches Kästchen eingezeichnet werden und würde dann entweder ein ganzes, ein halbes oder auch ein viertel Quadrat füllen. Das

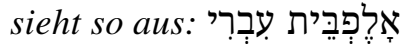

Zu lesen ist da, von rechts nach links: Alephbeth iwri, Alphabet hebräisch. (Die Punkte und Striche unter den Buchstaben stehen für die Vokale.) Jeder Buchstabe lässt sich in ein Quadrat einfügen, mit einer Ausnahme: der zweite Buchstabe von rechts, das Lamed (unser L); das ragt ein wenig über das gedachte Quadrat, das Kästchen hinaus. Und das Merkwort dafür heißt: Lamad, und Lamad heißt: Lernen. (Ebach 2011, 22) Damit ist symbolisch ausgedrückt: Lernen geschieht, wenn ich eine gewohnte Grenze überschreite, wenn Denk-, Fühl-und Handlungsgewohnheiten erschüttert werden, wenn Scheuklappen überflüssig werden.

Sie kennen die Denkaufgabe mit den neun Punkten, angeordnet zum Quadrat, die mit vier geraden Linien verbunden werden sollen, ohne dass man den Stift absetzen darf (s.o. Grafik 4). Die Lösung: aus dem als selbstverständlich angenommenen Quadrat ausbrechen. Watzlawick nennt das einen Gangwechsel. Ein Gangwechsel ist angesagt, wenn mehr vom selben, wenn das Beharren auf alten Wegen, auf eingefahrenen Lösungen nicht weiter führt, wenn ein neuer Ansatz dran wäre. Beispiele:

Wenn Sie nachts nicht schlafen können, trotz To-do-Liste, klarer Prioritäten und guter Vorbereitung auf den Morgen, wenn Sie sich dann immer mehr anstrengen, jetzt endlich einzuschlafen, damit Sie am Morgen wach in den Tag kommen, dann tun Sie „mehr desselben“. Angesagt wäre stattdessen ein Gangwechsel: Aufstehen, irgendwelche Haushaltspflichten erledigen, ein Buch lesen, Wäsche bügeln usw. - bis Sie merken, dass Sie müde werden. Schlaf ist ein Spontanphänomen, stellt sich von selbst ein; antreiben hilft nicht.

Zweites Beispiel: Eine „Alkoholiker-Ehe“. Dauernde Appelle halten das Problem aufrecht: A nörgelt an B herum; $B$ trinkt, weil A nörgelt. So ein Interpunk- 
tionsproblem bleibt in der Lösung erster Ordnung stecken. Gangwechsel, Lösung zweiter Ordnung, hieße: Klare Konfrontation, z. B. so: Entscheide dich: Ich oder die Flasche.

Lösungen erster Ordnung, mehr desselben, sind sinnvoll, wenn es darum geht, etwas einzü̈ben: Tennisaufschlag verbessern, Ski fahren, ein Instrument spielen, eine Sprache lernen usw. Wenn aber Ihre Lebens- und Weltsicht, Ihr Bezugsrahmen, Ihr mentales Modell Sie unbeweglich macht, dann könnte ein Gangwechsel dran sein.

So einen Gangwechsel, so eine Lernerfahrung schreibt Markus in dieser Geschichte Jesus zu. Markus schreibt etwa um 70 nach Christus, 15-20 Jahre nach Paulus. Er zeigt mit dieser Geschichte, dass Jesus den weltgeschichtlichen Grenzüberschritt des Paulus vorbereitet hat, den Schritt von Kleinasien über den Bosporus nach Europa. Mindestens legt er nahe, dass er in der Logik der Verkündigung Jesu lag. Schließlich hatte Gott ja schon dem Abraham versprochen: In dir sollen gesegnet werden alle Geschlechter auf Erden! Dieser Segen war Jesus natürlich vertraut. Also: Gangwechsel: Die Nichtjuden, die Heiden gehören dazu.

Solange das Anfangschristentum als eine jüdische Spielart auftrat, war das eine höchst umstrittene Entscheidung. Das herrschende mentale Modell ging so: Erst müssen die Heiden zu Juden werden; dann erst sind sie fähig, die Botschaft von der befreienden Gnade zu verstehen. Konkret: Erst Beschneidung, dann Aufnahme in die christliche Gemeinde. Das war die Denkgewohnheit. Wie schafft Markus es, diese Denkgewohnheit zu erschüttern? Indem er erzählt, dass Jesus, sogar Jesus, dazu gelernt hat. Das sollte den Gemeinden, für die er schreibt, doch Eindruck machen.

Bei Lukas steht die Geschichte nicht, obwohl Lukas doch das Markusevangelium kannte. Aber bei Lukas, und nur bei Lukas, lesen wir vom 12-jährigen Jesus im Tempel. Da erstaunten alle, die ihn hörten, über seine Einsicht und seine Antworten. Vielleicht meinte Lukas, er habe damals schon ausgelernt. Und Lukas schreibt ca. 20 Jahre später als Markus. Er schreibt für Heidenchristen. Da brauchte er diese Geschichte nicht. Die hatten andere mentale Scheuklappen im Kopf. Lernen sollten die auch, aber eben nicht dasselbe. So wie wir.

Viele biblische Geschichten zielen darauf ab, den Bezugsrahmen der Zuhörenden und damit den Spielraum des Lebens zu erweitern. Jesus greift in die Konflikte seiner Zeit ein, indem er raffinierte Geschichten erzählt, ungewöhnliche Vorgänge, die den Angesprochenen spontan ein Urteil nahe legen, meist so spontan, dass sie erst hinterher merken, dass sie gerade sich selbst widersprochen haben. Das ist persönliche Meisterschaft.

Teamlernen finde ich auch bei Jesus. Er schickt seine Anhänger los, in die Welt, dahin, wo es an Freiheit mangelt, nachdem er ihnen vermittelt hat, wie sie selbst frei werden können. Treibt Dämonen aus! (Matthäus 10, 7-8) Auch der von seiner Besessenheit befreite Gerasener darf nicht bleiben. Freiheit verrottet, wenn sie nicht verbreitet wird.

Damit sind wir bei Jesu Vision. Freiheit ist Gegenbegriff zu Herrschaft. Freiheit hieße: Keine Herrschaft von Menschen über Menschen: „Ihr wisst, dass die Fürsten der Völker sie knechten und die Großen über sie Gewalt üben. Unter euch soll es nicht so sein ... “ (Matthäus 20, 25f) 
Schließlich Systemdenken: Er unterscheidet weltliche Herrschaft mit Geboten und Zwang von Gottes Herrschaft als Befreiung von inneren Zwängen. Man stellt ihm eine Fangfrage: Soll man dem Kaiser Steuern zahlen? Im Klartext: Bist du für Kollaboration mit dem Besatzerregime? Er lässt sich eine Münze zeigen und stellt - geistesgegenwärtig - die Gegenfrage: Welches Bild seht ihr auf der Münze? Antwort: „Das des Kaisers. “ Also: „Gebt dem Kaiser, was des Kaisers ist, und Gott, was Gottes ist." Er verkündete das „Reich Gottes“, die basileia. Ein Reich stellen wir uns räumlich vor. Basileia kann aber mit gleichem Recht als „Herrschaft“ ïbersetzt werden, mit einem interaktionellen Begriff. Also: kein theokratisches Gesellschaftssystem!

\section{Lesetipp}

Ebeling (1964): Luther. 1964 als Vorlesung für Hörer aller (!) Fakultäten geschrieben, 2017 in 6. Auflage, setzt das Buch keine Fachkenntnisse voraus, wohl aber die Bereitschaft zum Mitdenken.

Sacks (2015b): Lessons in Leadership. Sacks liest die biblischen Mose-Geschichten als Anregung, die eigene Leitungspraxis zu überdenken, und zeigt, wie grundlegende Führungsfragen schon in alten Zeiten tief reflektiert wurden. Bieri (2013): Eine Art zu leben. Über die Vielfalt menschlicher Würde. - „Unser Leben als denkende, erlebende und handelnde Wesen ist zerbrechlich und stets gefährdet - von außen wie von innen. Die Lebensform der Würde ist der Versuch, diese Gefährdung in Schach zu halten. Es gilt, unser stets gefährdetes Leben selbstbewußt zu bestehen. Es kommt darauf an, sich von erlittenen Dingen nicht nur fortreißen zu lassen, sondern ihnen mit einer bestimmten Haltung zu begegnen, die lautet: Ich nehme die Herausforderung an." (A. a. O. $14 \mathrm{f}$ )

Hiebl und Seitz (2014): Kapitel 1.

\subsection{Wie können Sie jetzt weiter machen?}

Angenommen, Sie teilen meinen Traum, dass Schulleitungen und Geleitete die Entwicklung ihrer Schule als gemeinsame Aufgabe ansehen und anpacken wollen, dann können Sie das Open-Access-Angebot des Waxmann Verlags nutzen, indem Sie die elektronische Fassung dieses Buches Ihrem Kollegium zur Verfügung stellen. Je nach Erfordernis können Sie strategische Klausuren mit Hilfe einzelner Abschnitte oder Kapitel vorbereiten. Passend zum jeweiligen Thema können sich alle vorbereiten, z.B. auf effektive Moderation, und die Erfahrung machen, dass Zusammenarbeit mehr bringt als Einzelkämpfertum.

Diesen Schritt sollten Sie gut vorbereiten. Ihr Leitungsteam sollte Sie dabei unterstützen. Also verbreiten Sie die elektronische Fassung besser zunächst in Ihrer Leitungsgruppe, um die wichtigsten Konzepte gemeinsam einzuüben.

Bevor Sie diesen Schritt gehen, überlegen Sie, wie aufnahmebereit und innovationsfreudig Ihr Team ist. Wie Sie in kleinen Schritten über persönliches Feedback vorgehen können, habe ich beschrieben. 
Möglicherweise ist keiner der genannten Schritte ein Selbstgänger. Sie könnten stecken bleiben. Leitungsarbeit ist komplex und anspruchsvoll. Eine Schule zu leiten halten manche Experten sogar für unmöglich (s.o. Anm. 74). Vermutlich kannten die all die nützlichen Konzepte, Brillen, Landkarten, mentalen Modelle nicht, auf die Sie jetzt zugreifen können.

Ich halte Konzepte für wichtig; sie garantieren aber nicht, dass alles so schön klappt, wie es sich schriftlich darstellen lässt. Falls Sie also im Prozess der Schulentwicklung fest stecken und nicht recht weiter wissen, bedenken Sie: Das ist normal.

Dann hilft Beratung. Sie können sehr schnell jemanden finden, der oder die unseren Kurs absolviert und sich als Online-Coach zur Verfügung gestellt hat. Die Kontaktdaten finden Sie auf der Internet-Schulbundseite (s.o. Anm. 3) unter der Überschrift Online-Coaching.

Falls Sie grundsätzliche Fragen zum Verständnis meines Textes haben, schreiben Sie mir per E-Mail; vermerken Sie im Betreff: Torero. Auch kritische Hinweise, am liebsten verbunden mit Verbesserungsvorschlägen, sind mir willkommen.

E-Mail: HaukeChristiansen@gmx.de 


\section{Literatur}

Adler, Alfred: Quelle im Internet: http://www.zitatekiste.com/zitate/show/bevor-ein-kindschwierigkeiten-macht-hat-es-welche; Ablesedatum: 11.07.2020

Allmendinger, Jutta: Bildung für alle; Süddeutsche Zeitung Nr. 177, 2. 8. 2019, 16

Anders, Günther: Lager Mauthausen, in: Ulrich Wickert: Das Buch der Tugenden, Hamburg 1995, 105-116

Anzenbacher, Arno: Einführung in die Ethik, Düsseldorf 1992

Arendt, Hannah: Was heißt persönliche Verantwortung in einer Diktatur? 3. Aufl. München 2019

Axline, Virginia: Dibs 1965; Neuauflage München 2004

Bartens, Werner: Ausgeruht zur zweiten Stunde, Süddeutsche Zeitung, 2. 1. 2020, S. 1

Barth, Karl: Kirchliche Dogmatik, Zürich 1970, Band III/4, $781 \mathrm{f}$

Basu, Andreas/Faust, Liane: Gewaltfreie Kommunikation, 2. Aufl. Freiburg 2013

Bauer, Joachim: Stress und Burnout. Seelische Gesundheit im Beruf. Download, o. J. a. Fundort: http://www.psychotherapie-prof-bauer.de/burnout2.html

Bauer, Joachim: Gesundheitsprophylaxe für Lehrkräfte - Manual für Lehrer-Coachinggruppen nach dem Freiburger Modell; Download, o. J. b. Fundort: http://www.psychotherapieprof-bauer.de/coachinggrlehrerfreiburgermodellbaua07.pdf

Bauer, Joachim: Das Gedächtnis des Körpers. Wie Beziehungen und Lebensstile unsere Gene steuern, 10. Aufl. Frankfurt/M. 2007

Bauer, Joachim: Prinzip Menschlichkeit. Warum wir von Natur aus kooperieren, München, Zürich 2008

Bernatzeder, Petra: Care for Health in: Special Gesundheit, Beilage zu managerSeminare Heft 248, November 2018, 34-41

Berne, Eric: Struktur und Dynamik in Organisationen und Gruppen, München 1979

Bieri, Peter: Unser Wille ist frei, in: DER SPIEGEL 2/2005, 124-125

Bieri, Peter: Eine Art zu leben. Über die Vielfalt menschlicher Würde, München 2013

Blanchard, Kenneth/Zigarmi, Patricia/Zigarmi, Drea: Führungsstile, 4. Aufl. Reinbek 2006

Böhmer, Otto A.: Sternstunden der Philosophie Bd. 1, 4. Aufl. 1996

Böttcher, Vanessa/Spethmann, Eckhard: KUR, Pädagogik Heft 1, 2010, 24-27

Boettcher, Wolfgang/Mosing, Georgia: Leitungskommunikation, in: Buchen, Herbert/ Rolff, Hans-Günter (Hrsg.): Professionswissen Schulleitung, Weinheim und Basel 2006, 870-991

Bohl, Thomas/Helsper, Werner/Holtappels, Heinz Günter/Schelle, Carla: Handbuch Schulentwicklung, Bad Heilbrunn 2010

Brakelmann, Günter: Abschied vom Unverbindlichen, Gütersloh 1976

Breuer, Ingeborg/Leusch, Peter/Mersch, Dieter: Welten im Kopf, Bd. 3, England/USA, Hamburg 1996

Brown, Michael/Woollams, Stan/Huige, Kristyn: Abriss der Transaktionsanalyse, 4. Aufl. Frankfurt/M. 1995,

Buber, Martin: Die Erzählungen der Chassidim, Zürich 1949

Buchen, Herbert/Rolff, Hans-Günter (Hrsg.): Professionswissen Schulleitung, Weinheim und Basel 2006

Canerik, Cansu: Traut euch was, Süddeutsche Zeitung Nr. 9, 13.1.2020, 12 
Christiansen, Hauke: Von Versagern und Talenten in entscheidenden Momenten, Göttingen 1997

Christiansen, Hauke: Was können freie Schulen von Luthers Freiheitsverständnis lernen? in: Referate und Berichte zur 62. Jahrestagung der ODIV, Dresden 2017, 25-48. Als Download erhältlich über www.odiv.de/Jahrestagungen/2017

Christiansen, Johanna: Systemische Supervision von Gruppentherapien, in: Ich-du-wir und wer sonst noch dazugehört. Systemisches Arbeiten mit und in Gruppen, Dortmund 2002, S. $155-172$

Cohn, Ruth C.: Große Gruppen - kleine Gruppen - kleine Schritte - große Schritte, in: Themenzentrierte Interaktion, 22. Jg, Heft 2, 2008, 65-79

Cohn, Ruth C.: Von der Psychoanalyse zur themenzentrierten Interaktion. Von der Behandlung einzelner zu einer Pädagogik für alle; Neuauflage Stuttgart 2018

Comte-Sponville, André: „Ermutigung zum unzeitgemäßen Leben“ - Ein kleines Brevier der Tugenden und Werte, Hamburg 1996

Covey, Stephen: Die sieben Wege zur Effektivität, Frankfurt/M., 1995 u.ö.

de Shazer, Steve: „...W Worte waren ursprünglich Zauber“. Lösungsorientierte Therapie in Theorie und Praxis, 2. Aufl. Dortmund 1998

Deister, Winfried: Der 48-Stunden-Tag. Zeitmanagement für Schulleitungen, München 2005

Die Ecke/Natürlicher Kreislauf, FR vom 11.10.2000; Quelle: AP; Ablesedatum: 11.07. 2020

Dilling, Horst (Hg.): Lexikon zur ICD-10-Klassifikation psychischer Störungen, 2. Aufl. Bern 2009

Dilts, Robert B.: Die Veränderung von Glaubenssystemen, Paderborn 1993

Dorsemagen, Cosima; Krause, Andreas; Lacroix, Patrick: Arbeitsplatz Schule: Die Arbeitszeiten der Lehrerinnen und Lehrer, in: Bohl, Thomas/Helsper, Werner/Holtappels, Heinz Günther/Schelle, Carla: Handbuch Schulentwicklung, Bad Heilbrunn 2010, 244-250

Ebach, Jürgen: Ein Gott der Rache? Bibelarbeit, Deutscher Katholikentag 2008, unveröffentlicht

Ebach, Jürgen: SchriftStücke. Biblische Miniaturen, Gütersloh 2011

Ebeling, Gerhard: Das Wesen des christlichen Glaubens, Tübingen 1961

Ebeling, Gerhard: Luther: Einführung in sein Denken, 1964; 6. Aufl. Tübingen 2017

Ebeling, Gerhard: Die Evidenz des Ethischen und die Theologie, in: Wort und Glaube II, Tübingen 1969, 1-41

Ebeling, Gerhard: Dogmatik des christlichen Glaubens, Band I, Tübingen 1979

Ebeling, Gerhard: Luthers Kampf gegen die Moralisierung des Christlichen, in: Lutherstudien III, Tübingen 1985, 44-73

Ebeling, Gerhard: Einfalt des Glaubens und Vielfalt der Liebe. Das Herz von Luthers Theologie, in: Lutherstudien III, Tübingen 1985, 126-153

Eco, Umberto: Wenn der andere ins Spiel kommt, beginnt die Ethik; aus: Carolo Maria Martini, Umberto Eco: Woran glaubt, wer nicht glaubt? Wien 1998, 82-93

Ellis, Albert: Die rational-emotive Therapie. Das innere Selbstgespräch bei seelischen Problemen und seine Veränderung, München 1975 u.ö.

Enderle, Georges: Die Goldene Regel für Manager?, in: Ch. Lattmann (Hg.), Management Forum: Ethik und Unternehmensführung, Berlin und Heidelberg 1987, 130-148

Erikson, Erik H.: Die Goldene Regel im Licht neuer Einsicht; in: Einsicht und Verantwortung, Hamburg 1971

Ernst, Heiko: Wie man emotionale Intelligenz entwickelt, in: PSYCHOLOGIE HEUTE, Februar 2005, 27 
Fehlau, Eberhard G.: Konflikte im Beruf. TASCHENGUIDE, Augsburg 2000

Feldhoff, Tobias: Selbstständigkeit als Kapazität organisationalen Lernens und Qualität des Unterrichts, in: Holtappels, Heinz Günter/Klemm, Klaus/Rolff, Hans-Günter (Hg.): Schulentwicklung durch Gestaltungsautonomie. Ergebnisse der Begleitforschung zum Modellvorhaben Selbstständige Schule in Nordrhein-Westfalen. Münster 2008, 62-76.

Fellner, Richard L., Burnout oder Depression, in: Psychotherapiepraxis.at 2011; https:// www.psychotherapiepraxis.at/artikel/depression/burnout-symptome.phtml

Feuersenger, Elisabeth: Prozesskommunikation. Der Schlüssel für konstruktive Kommunikation, Weilheim, 4. Aufl. 2011

Fischer-Epe, Maren: Coaching: Miteinander Ziele erreichen, 3. Aufl. Reinbek 2003

Fisher, Roger/Ury, William/Patton, Bruce: Das Harvard-Konzept. Sachgerecht verhandeln erfolgreich verhandeln, 14. Aufl. Frankfurt/M. 1995 u.ö.

Fourier, Stefan: Teams formen, in: humanagement o.J.; https://www.humanagement.de/ news-wissen/humanagement-blog/10-teams-formen

Frech, Monika: Arbeit in und mit Gruppen, in: Kasper, Helmut/Mayrhofer, Wolfgang (Hg.): Personalmanagement Führung Organisation, 2. Aufl. Wien 1996, 293-336

Frech, Monika/Schmidt, Angelika: Theoretische und praktische Perspektiven der Kommunikation, in: Kasper, Helmut/Mayrhofer, Wolfgang (Hg.): Personalmanagement Führung Organisation, 2. Aufl. Wien 1996, 257-292

Fullan, Michael: Die Schule als Lernendes Unternehmen. Konzepte für eine neue Kultur in der Pädagogik, Stuttgart 1999

Gens, Klaus-Dieter: Nie mehr ärgern? Ärger aus der Sicht der Gewaltfreien Kommunikation, 2005; www.gewaltfreiforum.de 5/2005MultiMind 17

Goethe, Johann Wolfgang von; Quelle: https://www.aphorismen.de/zitat/171) Ablesedatum: 11.07. 2020

Gordon, Thomas: Lehrer-Schüler-Konferenz. Wie man Konflikte in der Schule löst, Reinbek 1981

Gordon, Thomas: Managerkonferenz. Effektives Führungstraining, München 1989 u.ö.

Grosser, Alfred: Mein Deutschland, 3. Aufl. Hamburg 1993

Haberleitner, Elisabeth/Deistler, Elisabeth/Ungvari, Robert: Führen, Fördern, Coachen. So entwickeln Sie die Potenziale Ihrer Mitarbeiter, 4. Aufl. 2012

Haeske, Udo: Team- und Konfliktmanagement. Teams erfolgreich leiten. Konflikte konstruktiv lösen, 3. Aufl. Berlin 2008 (POCKET BUSINESS)

Hartkemeyer, Johannes F.: Wir können doch nicht alles wissen - Die Mythen der Bildung und die Chancen der Volkshochschulen, Frankfurter Rundschau 2001

Hassel, Florian (Mai 2009) Jeder dritte Deutsche fühlt sich im Dauerstress; Fundort: URL: http://www.welt.de/wirtschaft/article3738169/Jeder-dritte-Deutsche-fuehlt-sichim-Dauerstress.html

Hattie, John: Developing Potentials for Learning: Evidence, assessment, and progress, University of Auckland, New Zealand, EARLI 2007

Heigl-Evers, Annelise: Die Stufentechnik der Supervision - eine Methode zum Erlernen der psychoanalytischen Beobachtung- und Schlußbildungsmethode im Rahmen der angewandten Psychoanalyse, in: Gruppenpsychotherapie und Gruppendynamik (1975), 9, 4354

Herrmann, Sebastian: Starrköpfe überzeugen, Reinbek 2013

Herrmann, Sebastian: Niemand wird aus Fehlern klug. Süddeutsche Zeitung Nr. 275, 28. 11.2019, 14

Herzlieb, Hans-Jürgen: Konflikte lösen, 3. Aufl. Berlin 2008 
Hiebl, Petra/Seitz, Stefan (Hg.): Wegweiser Schulleitung, Berlin 2014

Hoegg, Günther: Schulrecht: kurz und bündig. Die 50 wichtigsten Urteile, 4. Aufl. 2012

Holtappels, Heinz Günter: Schule als Lernende Organisation, in: Bohl, Thomas/Helsper, Werner/Holtappels, Heinz Günter/Schnelle, Carla (Hg.), Handbuch der Schulentwicklung, Bad Heilbrunn 2010, 99-105

Homann, Ursula: Buchbesprechung zu Peter Bieri: Das Handwerk der Freiheit, in: Annotationen Heft 2/2002

Horster, Leonhard/Rolff, Hans-Günter: Reflektorische Unterrichtsentwicklung, in: Buchen, Herbert/Rolff, Hans Günter (Hg.) Professionswissen Schulleitung, Weinheim und Basel 2006, 789-809

Jüngel, Eberhard: Zur Freiheit eines Christenmenschen. Eine Erinnerung an Luthers Schrift, München 1978

Jüngel, Eberhard: Gott - um seiner selbst willen interessant. Theologische Erörterungen II, 2. Aufl. München 1986

Jüngel, Eberhard: Der menschliche Mensch, in: Wertlose Wahrheit, Theologische Erörterungen III, München 1990

Jüngel, Eberhard: Das Evangelium von der Rechtfertigung des Gottlosen als Zentrum des christlichen Glaubens, Tübingen 1998

Jüngel, Eberhard: Befreiende Freiheit - als Merkmal christlicher Existenz, Kirchentag Berlin 2003

Jung, Carl Gustav: Über die Beziehung der Psychotherapie zur Seelsorge, in: Psychologie und Religion, 5. Aufl. Olten 1971, 131-152

Kabat-Zinn, Jon: Gesund durch Meditation. Das große Buch der Selbstheilung, 5. Aufl. Bern u. a. 1998

Kahl, Reinhard: Programmheft zum Kongress „Treibhäuser \& Co“, Hamburg 2007

Kahl, Reinhard: Individualisierung - das Geheimnis guter Schulen. 25 Filmclips und zwei Essays, Archiv der Zukunft, Hamburg 2011

Kasper, Helmut: Vom Management der Organisationskulturen zur Handhabung lebender sozialer Systeme; in: ders.: Post-graduate Managementwissen, Wien 1995, $189 \mathrm{ff}$

Kasper, Helmut/Mayrhofer, Wolfgang (Hg.): Personalmanagement Führung Organisation, 2. Aufl. Wien 1996

Keller, Tonio: „Extra berechnet“, Lübecker Nachrichten 22.5.2008

Kindermann, Stefan/von Weizsäcker, Robert K.: Der Königsplan. Strategien für Ihren Erfolg, Hamburg 2010

Klein, Hans-Michael/Frank, Jasmin: Raus aus der Mobbing-Falle!, Berlin 2008

Klovert, Heike: Wenn Elftklässler den Unterricht übernehmen, https://www.spiegel.de/ lebenundlernen/schule/schule-in-neuruppin-wo-elftklaesslerden-unterricht - ueberneh men, 1.7.2019

Kluge, Jürgen: Schul-Aufgaben, aus: Schluss mit der Bildungsmisere. Ein Sanierungskonzept, Frankfurt/Main 2003, $149 \mathrm{ff}$

Kools, M./Stoll, L.: „What Makes a School a Learning Organisation?“, OECD Education Working Papers, No. 137, Paris 2016

Kopp, Sheldon B.: Triffst du Buddha unterwegs ... Psychotherapie und Selbsterfahrung, Düsseldorf/Köln 1978

Kraemer, Horst: Soforthilfe bei Stress und Burn-out, München 2010

Krieghofer, Gerald: „Lernen ist wie Rudern gegen den Strom. Hört man damit auf, treibt man zurück.“ Laotse (angeblich). Zitatforschung. 08.01.2019. Quelle: https://falschzitate. blogspot.com/2019/01/lernen-ist-wie-rudern-gegen-den-strom.html; Ablesedatum: 11.07.2020 
Kühl, Stefan: Die Grenzen der Personalentwicklung in Schulen, in: Buchen, Herbert/ Horster, Leonhard/Rolff, Hans-Günther (Hrsg.), Schulleitung und Schulentwicklung. Erfahrungen. Konzepte. Strategien, Berlin 2007, 1-11

Langemak, Shari: Was Sie beim Powernap beachten müssen, welt.de 15.9.2013 Quelle: https://www.welt.de/gesundheit/article120004211/Was-Sie-beim-Powernap-beachtenmuessen.html; Ablesedatum: 11.07.2020

Lapide, Pinchas: Glauben, wissen oder zweifeln? Siebenstern 1420, Gütersloh 1988

Léon, Ottilie: Immer nur lächeln ..., Liedtext zur Operette „Das Land des Lächelns“ von Franz Lehar, Quelle: http://mosapedia.de/wiki/index.php/Immer_nur_lächeln_und_im mer_vergnügt; Ablesedatum: 11.07.2020

Lewin, Kurt; Quelle: https://de.wikipedia.org/wiki/Aktionsforschung; Ablesedatum: 11.07. 2020

Leymann, Heinz: Mobbing, Reinbek 1993

Lincoln, Abraham; Quelle: http://zitate.net/zitat?id=1640; Ablesedatum: 11.07.2020

Lohmann, Bettina: Effiziente Supervision, 5. Aufl., Vorwort, Baltmannsweiler 2000

Lückel, Kurt: Geschichten erzählen vom Leben, 3. Aufl. Göttingen 1997

Luft, Joseph: Einführung in die Gruppendynamik, Stuttgart 1971

Luther, Martin: Heidelberger Disputation 1518, in: Ausgewählte Werke, hg. von H.H. Borcherdt und Georg Merz, 3. Aufl. 1. Band, München 1951, 125-138

Luther, Martin: Von der Freiheit eines Christenmenschen (1520) in: Martin Luther, Ausgewählte Schriften, hg. von K. Bornkamm und G. Ebeling, Frankfurt/Main 1982, Erster Band, 238-263

Malik, Fredmund: Führen - Leisten - Leben. Wirksames Management für eine neue Zeit. Frankfurt/Main 2006

Marquard, Odo: Apologie des Zufälligen, Stuttgart 2001

Marquardt, Friedrich-Wilhelm: Gott oder Mammon, in Marquardt u. a.: Einwürfe 1, München 1990, 176-216

Meier, Daniel/Szabó, Peter: Wirksam: Fünf-Minuten-Coaching; Fundort: www.organisator. ch Nr. 4/2007

Meier-Seethaler, Carola: Gefühl und Urteilskraft. Ein Plädoyer für die emotionale Vernunft, 2. Aufl. München 1998

Mentzel, Wolfgang: Mitarbeitergespräche, Augsburg 2001

Mosing, Georgia: Kollegiale Fallberatung, in: Buchen, Herbert/Rolff, Hans-Günter (Hrsg.): Professionswissen Schulleitung, Weinheim und Basel 2006, 992-1029

Negt, Oskar: Arbeit und menschliche Würde, 2. Aufl. Göttingen 2002

Newmark, Catherine: Warum auf Autoritäten hören? Berlin 2020

Nietzsche, Friedrich: Götzendämmerung, in: Werke in drei Bänden, Bd. 2, hg. v. Walther Linden/Wolfgang Deninger, 2. Aufl. Zürich 1974

Nussbaum, Martha C.: Gerechtigkeit oder Das gute Leben, Frankfurt am Main 1999

Omer, Haim/von Schlippe, Arist: Stärke statt Macht. Neue Autorität in Familie, Schule und Gemeinde, 2. Aufl. Göttingen 2015

o. V.: Lehrer gehen in Scharen in den Ruhestand. Spiegel Online. 24.01.2014. Quelle: https://www . spiegel.de/lebenundlernen/schule/lehrer-gehen-in-scharen-in-den-ruhestand-a-945368.html; Ablesedatum: 11.07.2020

o. V.: Französischer Spitzenkoch will seine drei Sterne zurückgeben. Focus online. 20.09.2017. https://www.focus.de/panorama/welt/michelin-sternevergabe-franzoesischer-starkoch-willseine-drei-sterne-zurueckgeben_id_7618155.html; Ablesedatum: 11.07.2020

Oz, Amos: Wie man Fanatiker kuriert, Frankfurt/M. 2004 
Pásztor, Susann: „Eine Sprache des Lebens“ - Ein Interview mit Marshall B. Rosenberg, in: Heft 2/2004 der Zeitschrift MultiMind

Pauley, Judith A./Bradley, Dianne E./Pauley, Joseph F.: So kannst Du mich erreichen. Prozesskommunikation in Schule und Erziehung, 2. Aufl., Weilheim 2012

Pohl-Patalong, Uta: Bibliolog. Impulse für Gottesdienst, Gemeinde und Schulen, Bd. 1: Grundformen, Stuttgart 2009

Prior, Manfred: MiniMax-Interventionen, 2. Aufl. u.ö. Heidelberg 2002

Prior, Manfred: MiniMax für Lehrer, Weinheim und Basel, 2009

Rasfeld, Margret/Spiegel, Peter: EduAction. Wir machen Schule. Hamburg 2012

Reimann, Sascha: Gefahrenzone Gefühle: Emotionen in Unternehmen, in: managerSeminare Heft 200, 38-44, November 2014

Reisner, Andreas: Die Rollenvielfalt des Managers, in: Organisationsberatung - Supervision - Clinical Management, Heft 3/1995, 213-219

Riegel, Enja: Schule kann gelingen! Bundeszentrale für politische Bildung, Band 446, Bonn 2004

Risto, Karl-Heinz: Konflikte lösen mit System. Mediation mit Methoden der Transaktionsanalyse, Paderborn 2003

Rolff, Hans-Günter: Schulentwicklung als Trias von Organisations-, Unterrichts- und Personalentwicklung, in: Bohl, Thomas/Helsper, Werner/Holtappels, Heinz Günter/Schelle, Carla (Hg.), Handbuch der Schulentwicklung, Bad Heilbrunn 2010, 29-36

Rolff, Hans-Günter: Qualität mit System - Praxisanleitung zum Unterrichtsbezogenen Qualitätsmanagement (UQM), Online-Ausgabe 2011

Rolff, Hans-Günter: Schulleitung auf den Punkt gebracht, Frankfurt/Main 2017

Rolff, Hans-Günter: Schulentwicklung auf den Punkt gebracht, Frankfurt/Main 2019

Rosenberg, Marshall B.: Gewaltfreie Kommunikation. Aufrichtig und einfühlsam miteinander sprechen. Neue Wege in der Mediation und im Umgang mit Konflikten, 3. Aufl. 2002

Rosenberg, Marshall B.: Konflikte lösen durch Gewaltfreie Kommunikation. Ein Gespräch mit Gabriele Seils, Freiburg 7. Aufl. 2004

Rosenberg, Marshall B.: Erziehung, die das Leben bereichert. Gewaltfreie Kommunikation im Schulalltag, Paderborn 2013 a

Rosenberg, Marshall B.: Das können wir klären! Wie man Konflikte friedlich und wirksam lösen kann, Paderborn 2013 b

Rosenberg, Marshall B.: Was deine Wut dir sagen will, Paderborn 2013 c

Ruppaner, Stefan: Aus alt mach neu, in: +3 Magazin Nr. 62 der Süddeutschen Zeitung, März 2020; außerdem: Web-Seite der Alemannenschule.

Sacks, Jonathan: Not in God's Name, London 2015a

Sacks, Jonathan: Lessons in Leadership, Jerusalem 2015b

Sander, Oliver: Ein Schulleiter ist mehr ein Vorstandsvorsitzender. Kreiszeitung Wochenblatt. Quelle: https://www.kreiszeitung-wochenblatt.de/buchholz/c-panorama/ ein-schulleiter-ist-mehr-ein-vorstandsvorsitzender_a144242, 25.6.2019; Ablesedatum: 11.07.2020

Sattler, Hanna: Privatschulen im Rechtskorsett? Mehr Mut zur Freiheit! in: Referate und Berichte zur 58. Jahrestagung der ODIV, Würzburg 2013, 32-53; als Download zugänglich: www.odiv.de/Jahrestagungen 2013

Sauer, Martin: Einige Erkenntnisse der „Neueren Systemtheorie“, unveröffentlichtes Arbeitsblatt o. J.

Scala, Klaus: Supervision in der Schule, in: Klaus Scala/Ralph Grossmann: Supervision in Organisationen, 2. Aufl., 1. Aufl. 1997, Weinheim u. München 2002, 119-157 
Schaarschmidt, Uwe/Kieschke, Ulf: Gerüstet für den Schulalltag. Psychologische Unterstützungsangebote für Lehrerinnen und Lehrer, Weinheim 2007

Scheuch, Klaus/Haufe, Eva/Seibt, Reingard: Lehrergesundheit, www.aerzteblatt.de 2015; 112: 347-56

Schiefenhövel, Wulf: Kulturkampf mal anders. Quelle: Frankfurter Rundschau 10.5.2007. (S. war z.Zt. des Interviews Ethnologe, ao Prof. für Medizinische Psychologie und Ethnomedizin an der Ludwigs-Maximilians-Universität München)

Schlegel, Leonhard: Handwörterbuch der Transaktionsanalyse. Sämtliche Begriffe der TA praxisnah erklärt, Freiburg i. Br. u. a. 1993

Schlegel, Leonhard: Die Transaktionale Analyse, 4. Aufl. Tübingen, Basel 1995

Schmid, Bernd: Wo ist der Wind, wenn er nicht weht? Professionalität \& Transaktionsanalyse aus systemischer Sicht, Paderborn 1994

Schmid, Bernd: Fragen an Dr. Bernd Schmid. Coaching-Pionier Dr. Bernd Schmid beantwortet Fragen aus der Praxis. Coaching-Magazin 4/2016. Quelle: https://www.coachingmagazin.de/beruf-coach/fragen-bernd-schmid; Ablesedatum: 11.07.2020.

Schmid, Wilhelm: Schönes Leben? Einführung in die Lebenskunst. st 3664, Frankfurt/Main 2000

Schmidt, Hans-Joachim: Die nächste Sitzung kommt bestimmt. Konferenzen vorbereiten, durchführen, auswerten, SCHULMANAGEMENT KONKRET, BAND 3, München 2004

Schreiner, Peter: Religionsunterricht zwischen Pluralisierung und Konfessionalität - Zugänge, Stolpersteine, Perspektiven. Referat Lehrerinnen- und Lehrertag in Tecklenburg, 18. November 2015; https://www.comenius.de/Comenius-Institut/mitarbeiter/schreiner. php

Schröder, Jörg-Peter/Blank, Reiner: Stressmanagement, 3. Aufl. Berlin 2008

Schröder, Hans-Peter: Wege aus dem Burnout, Berlin 2. Aufl. 2008

Schulte, Peter: Burnout-Phasenmodell, 2018, dargestellt in: https://www.wegezurenergie. at/wp-content/uploads/2018/10/Wiener-Resilienz-Modell-2018.pdf,14f

Schulz von Thun, Friedemann: Miteinander reden 1. Störungen und Klärungen; Reinbek 1981

Schulz von Thun, Friedemann: Miteinander reden 2. Stile, Werte und Persönlichkeitsentwicklung, Reinbek 1989

Schulze, Henning/Sejkora, Klaus: Burnout: Psychodynamik und Behandlungsansätze, Zeitschrift für Transaktionsanalyse (ZTA) 1/2015, 38-59

Seiwert, Lothar: Das $1 \times 1$ des Zeit-Management, 13. Aufl. München 1995.

Sejkora, Klaus/Schulze, Henning: Die Kunst der starken Führung. Persönliche Potenziale kraftvoll nutzen. Ressourcen der Mitarbeiter stärken, Munderfing 2016

Senge, Peter M.: Das Fieldbook zur Fünften Disziplin, 2. Aufl. Stuttgart 1997

Senge, Peter M.: Die fünfte Disziplin. Kunst und Praxis der lernenden Organisation, 6. Aufl. Stuttgart 1998

Shakespeare, William: Shakespeares Dramatische Werke, übs. von Aug. Wilh. von Schlegel und Ludw. Tieck, 2. Aufl., 4. Band, o. J.

Specht, Catarina/Penland, Paige R.: Wer etwas zu sagen hat, muss zuhören können. ZEIT Online, 17. Februar 2016; https://www.zeit.de/karriere/2016-02/aktives-zuhoeren-kom munikation-verbesserung

Spiekermann, Sarah: Digitale Ethik. Ein Wertesystem für das 21. Jahrhundert, München 2019

Stark, Michael/Sandmeyer, Peter: Wenn die Seele S. O. S. funkt, Hamburg 1999

Steffen, Uwe: Alltagsgeschichten, Heide 1968 
Steffens, Ulrich/Höfer, Dieter: Was ist das Wichtigste beim Lernen? Folgerungen aus der Hattie-Studie, Teil 1: Die Lehrperson im Zentrum der Betrachtungen; Institut für Qualitätsentwicklung Wiesbaden, August 2012

Stein, Holger: Erfolgreich durchsetzen. Standpunkte überzeugend vertreten, Berlin 2008

Stevenson, Robert Louis: Erzählungen, München 1974

Stewart, Ian: Transaktionsanalyse in der Beratung. Grundlagen und Praxis transaktionsanalytischer Beratungsarbeit, 2. Aufl. Paderborn 1993

Stewart, Ian/Joines, Vann: Die Transaktionsanalyse, 3. Auflage, Freiburg u. a. 1993 u.ö.

Steyrer, Johannes: Theorien der Führung, in: Kasper, Helmut/Mayrhofer, Wolfgang (Hg.): Personalmanagement Führung Organisation, 2. Aufl. Wien 1996, 153-223

Tausch, Reinhard/Tausch, Anne-Marie: Erziehungspsychologie, Göttingen 6. Aufl. 1971; 11. Aufl. 1998

Trost, Armin: Das jährliche Mitarbeitergespräch (MAG), managerSeminare Heft 211, Okt. 2015, 28-34

Tugendhat, Ernst: Vorlesungen über Ethik, Frankfurt/Main, 2. Aufl. 1994

Verordnung über die Durchführung von Mitarbeitendenjahresgesprächen in der Föderation Evangelischer Kirchen in Mitteldeutschland vom 12. März 2005 (PDF); https://www. kirchenrecht-ekm.de/pdf/9745

von Clairveaux, Bernhard: De consideratione: Über die Besinnung, geschrieben Mitte des 12. Jahrhunderts, Mahn- und Warnwort gegenüber Papst Eugen III. Quelle: Psychologie Heute, Januar 2007

von Rutenberg, Jürgen: Der Fluch der Unterbrechung; DIE ZEIT, 09. 11. 2006 Nr. 46

Walter, Hans-Jürgen: Warum Mitarbeitergespräche scheitern; Umfrage bei 43 Trainern und Personalentwicklern, in: managerSeminare Jan/Febr. 2000

Watson, David/Tharp, Roland: Einübung in Selbstkontrolle. Grundlagen und Methoden der Verhaltensänderung, München 1975

Watzlawick, Paul/Weakland, John H./Fisch, Richard: Lösungen. Zur Theorie und Praxis menschlichen Wandels, Bern 1974

Weil, Thomas: Stufen der Eskalation. Wächterschaft über Strukturen und Prozesse, unveröffentlichtes Arbeitspapier, 2004

Wengle, Eva: Der erfolgreiche Umgang mit täglichen Belastungen. Programm zur Stressbewältigung, in: Pullig, Karl-Klaus/Schäkel, Uwe/Scholz, Jürgen (Hg.): Stress im Unternehmen, Hamburg 1986

Wiener Resilienzmodell; Fundort: https://www.wko.at/site/ImpulsPro/WRM-Heft-2018-a. pdf

Wimmer, Rudolf: Die Steuerung komplexer Organisationen. Ein Reformulierungsversuch der Führungsproblematik aus systemischer Sicht; in: Sandner, Karl (Hg.): Politische Prozesse in Unternehmen. Berlin, Heidelberg 1992, 131-156

Wright, Lawrence: Dreizehn Tage im September. Das diplomatische Meisterstück von Camp David, Darmstadt 2016

Wyler-Krisch, Annette: Die Transaktionsanalyse und der lösungsorientierte, kurzzeittherapeutische Ansatz. Wie lassen sich beide Konzepte sinnvoll verbinden? Paderborn 2001

Yalom, Irvin D.: Die Liebe und ihr Henker, München 2001; USA: 1989

Yalom, Irvin D.: In die Sonne schauen, München 2008

Zimbardo, Philip G.: Psychologie, 4. Aufl. Berlin u. a. 1983 


\section{Widmung}

Den Teilnehmerinnen und Teilnehmern, die seit 2001 einen der 19 Weiterbildungskurse für die Leitung in einer Evangelischen Schule besucht haben, widme ich dieses Buch

- als Erinnerung an gemeinsame intensive Lernerfahrungen,

- als Ermunterung zu immer weiterem Lernen

- und als Dank für das uns gezeigte Vertrauen, das uns sehr persönliche Einblicke in die anspruchsvolle und wichtige Aufgabe, eine Schule zu leiten, ermöglichte.

\section{Dank}

Vor gut einem Jahr wurde ich gefragt, wie es denn mit den Kursen für die Schulleitungen weitergehen solle - ,angesichts meiner Endlichkeit“. So kam ich auf die Idee, unsere Lernerfahrungen aus 19 Jahreskursen, aus vielen Kollegiumsklausuren, Teamberatungen und Einzelcoachings zusammenzufassen. Wenn damit einigermaßen erfasst ist, was Leitungen in Schulen brauchen, lässt sich vielleicht eher planen, was an Fortsetzung sinnvoll ist.

Ich danke vor allem meinem Auftraggeber, dem Vorstand des Evangelischen Schulbunds Nord e. V., für die Bereitschaft, die Kosten für die Veröffentlichung zu übernehmen.

Für praktische Unterstützung danke ich Timm Boeken für einen Schnellkurs zur Optimierung von Grafiken, den Freunden Hermann Jaeger ( $\dagger$ ) und Hermann Meyer für scharfsichtiges Korrekturlesen samt inhaltlicher Anregungen, Henning Christiansen für das Umschlagbild sowie allen im Waxmann Verlag Beteiligten, insbesondere meiner Lektorin Laura Peters, für freundliche Begleitung bei allerlei technischen Herausforderungen.

Ein umfassender Dank gilt meiner Frau Veronika Christiansen für die überwiegend harmonische und immer anregende und verlässliche Zusammenarbeit in den Kursen, in Schulklausuren, in Team- und Einzelberatungen. Ohne sie wäre das alles höchstens die Hälfte wert gewesen.

Ratzeburg, August 2020

\section{Der Autor}

Hauke Christiansen, Jg. 1941, Pastor i.R., Dipl.-Psych., Transaktionsanalytiker (CTA-O, DGTA, EATA). Fortbildungsdozent, Projektmanager und Geschäftsführer in den v. Bodelschwinghschen Stiftungen Bethel (1975-1999). Einzel- und Organisationsberatung in Diakonie, Schulen und Betrieben. Seit 2001 jährlich Weiterbildungskurse für Schulleitungen im Auftrag des Ev. Schulbundes Nord e. V. 


\section{Index}

Abwertungstabelle 113. 193. 228

Affen 35. 72.247

Aktives Zuhören 37. 52f. 55. 221. 257

Antisemitismus 111

Antreiber 85. 102. 179-190. 193-200. 203.

205f. 209. 220. 227f. 249. $251 \mathrm{ff}$

Arbeitsfähigkeit $41 \mathrm{ff} .57 \mathrm{ff}$. 64. 67. 72. 74. 77. 113. 123. 126. 132. 140. 145. 161. 163. 204. 218

Augenarzt 34f

Autonomie 21. 82. 100ff. 104. 108. 112. 163. 184. 186. 197. 229f. 231. 260ff. 268. 297

Beratung 30.33.36ff. 46. 52-57. 61. 76. 80. 84. 89. 103f. 110. 112 ff. 118. 141. 144. 146ff. 152. 161f. 194f. 200. 206f. 208. 211. 212f. 217. 222. 228. 238. 258. 272

Bezugsrahmen 106ff. 110ff. 124. 228. 270

Blinder Fleck 86

Blockierung 226ff

Burnout 29. 57. 152. 161. 176f. 184. 190-196. 210

Cappuccino $33 \mathrm{f}$.

Delegation 159f. $203 \mathrm{ff} .236$

Dramadreieck 92 ff. 220. 225. 228. 294

Drei-Welten-Modell 27f. 228

Effektivität 23.32. 42. 46. 51.57f. 65. 87. 109. 128. 139ff. 148f. 159. 163. 165. $173 \mathrm{f}$. 198. 271.290

Einschärfungen 181-186. 193. 205. 224. 228. 249. 252

Empörung 219. 232. 264f. 267

Engpass 101.227f

Enttrübung $108 \mathrm{ff} .111 \mathrm{ff} .115 .154 .156 .228$

Erlaubnis 183. 185. 187 ff. 197. 200. 228. 267

Ersatzgefühle 220-226. 228. 230f.

Ethik 258ff. 262f. 265-268

Evangelium 78. 187f. 241. 249f. 251. 253. 266. 270

Feedback 12. 18f. 21. 43. 51f. 59ff. 62. 69. 76. 80. 84-90. 103. 115f. 123. 137. 146-154. 161f. 165. 193. 211.214ff. $218 \mathrm{f}$. 225. 246. 256. 258. 271. 285. 295. 299

Freiheit 15.23.35. 43. 64. 70. 86. 102. 104. 125. 136. 164f. 168. 184-188. 190. 194. 230ff. 235. 237-246. 248. 249-255. 258. 264. $266 \mathrm{ff} .270$
Führung, situative 159-161; allgemein: 14. 39. 41. 58. 64f. 74. 80. 88. 91. 104. 111. 125. 128. 152f. 154. 157. 162f. 164. 166. 169. 170. 210 ff. 213 f. 215 ff. 233. 263. 271

Führungsstil 80.112. 147. 153f. 155f. 159f. 295. 299

Führungstypen 152-156

Gangwechsel 71.268ff

Gans, goldene $173 \mathrm{f}$

Gartenteich 13f. 17.42.44.60.127. 152. 157

Gefühl 36f. 54f. 68. 74f. 77. 80ff. 86. 101. 117. 120f. 177f. 183f. 193. 197. 218-235. 259. $262 \mathrm{ff}$

Gewaltfreie Kommunikation 61.74. 80-83. 106. 112. 121. 157. 220. 222. 264. 267

Glaubenssätze 19. 109. 182.221. 224. 247. 255 ff. 258

Godot, warten auf 11.24. 143. 165f. 168. 170

Grundgefühle 220-226. 228. 231. 294

Grundpositionen 229. 264

Harvard-Konzept 70ff. 76. 84. 121. 147. 220. 222. 258. 264. 267

Ich-Botschaft 50. 65. 68. 73 ff. 77. 81. 86. 179. 196. 214. 286. 297

Ich-Zustand 93-107. 112f. 116. 147. 154. 179. 182 ff. 212. 219. 222. 227 f. 234. 294

Johari-Fenster 86f. 115

Konferenzen 21. 29. 41f. 46. 52. 65. 83f. 100. 102f. 128. 132. 135f. 139-151. 161. 163. 194f. 205. 217f. 231. 237. 240. 242. 253. 256. 267

Konfliktmanagement 50f. 61f. 67-79. 131. 207. 220. 226. 239. 257. 298

Konflikteskalationsstufen 74. 77. 80. 238

Konfliktvermeidung 30. 148. 253

Konfrontation 30.73f.97.112f. 117. 181. 198. 212. 220. 225. 228. 232. 247. 253. 270

Konsensverfahren 127. 129ff. 132. 136. 139. 143. 148.157

Kreativität 18. 35f. 44. 50. 70 ff. 77. 82. 87. 93. 103. 116. 119. 142f. 158. 190. 202. 218. 227. 235. 242. 246. 286. 288. 297

Kultur 13f. 17. 21.28.42.44.52.63.80.83. 96. 107. 110. 112. 115. 124f. 127. 129. 131. 135. 137. 140f. 152. 154. 157. 161f. 167. 
170. 208. 215 f. 235. 239. 243. 249. 256.

259f. 262. 265. 295. 299

Laus 252

Leitungsteam 42.52.58ff. 67. 113. 116. 137. 140. 161. 170. 207. 265

Lebensberechtigung 85.180. 182

Lehrerarbeitszeit 142

Leitung als eigener Beruf 28. 148. 171

Leitungsrolle 4.15.21.27f. 30. 41.67.72f. 76f. 123. 154. 163. 165. 212. 236. 265. 295

Lernende Organisation 11. 17-24. 29. 38. 51. 57. 104. 109. 126. 152. 162. 165. 167. 207. 217

Liebe 96. 120. 241. 252 ff. 255. $261 \mathrm{ff} .266$

Logische Ebenen 254-258

Macher 43. 48f. 80. 88. 116f. 203. 218. 285. 295

Maschensystem 224. 228. 231

Mentale Modelle 19ff. 24. 86. 89. 105. 108f. 111. 115. 176ff. 179 ff. 232. 246f. 299

Mitarbeitergespräch 36.43.52.161. 179. 211-218. 220

Mobbing 46. 62f. 77. $79 \mathrm{ff}$

Nickerchen $206 \mathrm{f}$

Organisationsmodell (Berne) 127. 129. 132. 147. 228

Partizipation 42. 62f. 67. 125. 129 ff. 132. 135 ff. 138. 141. 143. 145 ff. 152 ff. 161. 166. 204. 247. 255. 299

Persönliche Meisterschaft 18. 24. 33-39. 42. 51f. 57. 72. 87f. 173-210. 270

Proaktivität, proaktiv 11.32. 58. 112. 123. 134. 148. $197 \mathrm{f}$

Problemlösung (6 Schritte) 43. 49. 52. 87. 134. 141. 157. 159. 162. 178f. 194. 219. 225. 285f. 288

Prozesskommunikationsmodell $(\mathrm{pcm})$ 116-118. 221 f. 228

Rahmenbedingungen 44. 47f. 50.63.71.87f. 110. 125. 131. 155. 159. 163. 202. 215. 226. 237. 246

Rennpferde 215

Rollenmodell 27.101.104f

Sawu bona 31.34. 36. 68. 74. 84. 192

Scheiterstrategie $67 \mathrm{ff} .72$ f. $75.145 \mathrm{ff} .148$. 291

Schulentwicklung 12f. 23f. 27-31. 46. 49. 52. 62. 67 ff. 125f. 129. 132. 135-138. 143. 150. 159. 161. 163. 169ff. 173. 195. 204. 207. 214. 217. 232. 241. 255f. 272
Schulrecht 140.238. 248. 291

Seitenwechsel, innerer 14. 120. 255. 257. 260. 264

Selbstorganisation 24.125.131. 166

Singen 184. 186 ff. 267

Skript 181f. 184. 190. 193f. 205. 224. 228. 231. 253

Spiritualität $255 \mathrm{ff} .258 .267 \mathrm{f}$

Stress 18. 49. 57f. 67. 70.75f. 82. 85. 94. 110. 116. 126. 143. 162. 173-210. 219f. 221. 224. 233f. 235. 255f. 258.267

Struktur 13f. 17f. 21 f. 24. 28f. 36. 41 f. 44. 52. 54f. 56. 58. 60. 64f. 73. 78. 80. 89f. 92. 110. 112. 123f. 127f. 129. 132. 139-148. 151f. 155. 157. 159. 161. 163. 165 ff. 170. 188. 190. 195. 215-218. 244. 246f. 249. 256. 265.267

Systemdenken 20ff. 27. 30. 57. 89. 127. 129. 139 ff. 190. 195. 271

Teamarbeit 45-57. 137. 144. 158. 170. 212. 299

Teamlernen 18. 24. 41f. 48. 52. 57.67. 74. 87 ff. 101. 118. 125. 165. 167f. 190. 195. 270

Top down Führung 41.58f. 67f. 110. 124. 137. $142.145 \mathrm{ff} .156 .165$

Torero 70. 76. 123. 179. 272

Transaktionen 97-103.201.228. 231

Transaktionsanalyse $84.93 \mathrm{ff} .100 \mathrm{ff} .113 \mathrm{f}$. 180. 184f. 189f. 219f. 223f. 227f. 231. 263f. 268

Trübung 105-108. 113. 115. 147. 228

Unfreiheit 187f. 230f. 249. 251. 267

Unterricht 21.29f. 41. 44. 49. 52. 57. 72. 84. 87. 89f. 98. 101. 105f. 110. 113f. 118. 131. 137. 140. 142. 144f. 149. 159. 162. 165. 167 ff. 187f. 190. 194. 203f. 209. 218. 227. 238. 240. 243-246. 264. 267

Vertrag, Vertragsarbeit 50f. 57-63.67.71-75. 80. 86. 88. 101. 104. 112. 128f. 147. 154. 162f. 212. 214. 226. 228. 238. 241. 265. 289. 291. 299

Vier Seiten einer Nachricht 69. 219. 222

Vision 17. $21 \mathrm{ff} .24 .32 .88 .123 \mathrm{ff} .127 \mathrm{ff}$. 132ff. 137. 141. 143. 158. 190. 244. 247. 249. 270

Zeitmanagement 29.197. 207

Zuwendung, Zuwendungsmuster 84ff. 129. 168. 181. 183. 193. 195. 228 



\section{Downloads}

\section{(DOWNLOAD 1) Leviten lesen}

Der Hintergrund zu folgendem Text:

Laura Schlessinger ist eine US-Radio-Moderatorin, die Leuten, die in ihrer Show anrufen, Ratschläge erteilt. Kürzlich sagte sie, als achtsame Christin, dass Homosexualität unter keinen Umständen befürwortet werden kann, da diese nach Leviticus 18:22 ein Greuel wäre. Der folgende Text ist ein offener Brief eines US-Bürgers an Dr. Laura, der im Internet am 4. 7. 2013 verbreitet wurde.

\section{Liebe Dr. Laura}

Vielen Dank, dass Sie sich so aufopfernd bemühen, den Menschen die Gesetze Gottes näher zu bringen. Ich habe einiges durch Ihre Sendung gelernt und versuche das Wissen mit so vielen anderen wie nur möglich zu teilen. Wenn etwa jemand versucht seinen homosexuellen Lebenswandel zu verteidigen, erinnere ich ihn einfach an das Buch Mose 3, Leviticus 18:22, wo klargestellt wird, dass es sich dabei um ein Greuel handelt. Ende der Debatte!!!

Ich benötige allerdings ein paar Ratschläge von Ihnen im Hinblick auf einige der speziellen Gesetze, und wie sie zu befolgen sind,

a) Wenn ich am Altar einen Stier als Brandopfer darbiete, weiß ich, dass dies für den Herrn einen lieblichen Geruch erzeugt (Lev. 1:9). Das Problem sind meine Nachbarn. Sie behaupten, der Geruch sei nicht lieblich für sie. Soll ich sie niederstrecken?

b) Ich würde gerne meine Tochter in die Sklaverei verkaufen, wie es in Exodus 21:7 erlaubt wird. Was wäre Ihrer Meinung nach heutzutage ein angemessener Preis für sie?

c) Ich weiß, dass ich mit keiner Frau in Kontakt treten darf, wenn sie sich im Zustand ihrer menstrualen Unreinheit befindet (Lev. 15:19-24). Das Problem ist, wie kann ich das wissen? Ich hab“ versucht zu fragen, aber die meisten Frauen reagieren darauf pikiert.

d) Lev. 25:44 stellt fest, dass ich Sklaven besitzen darf, sowohl männliche als auch weibliche, wenn ich sie von benachbarten Nationen erwerbe. Einer meiner Freunde meint, das würde auf Mexikaner zutreffen, aber nicht auf Kanadier. Können Sie das klären? Warum darf ich keine Kanadier besitzen?

e) Ich habe einen Nachbarn, der stets am Samstag arbeitet. Exodus 35:2 stellt deutlich fest, dass er getötet werden muss. Allerdings: Bin ich moralisch verpflichtet ihn eigenhändig zu töten?

f) Ein Freund von mir meint, obwohl das Essen von Schalentieren, wie Muscheln oder Hummer, ein Greuel darstellt (Lev. 11:10), sei es ein geringeres Greuel als Homosexualität. Ich stimme dem nicht zu. Könnten Sie das klarstellen?

g) In Lev. 21:20 wird dargelegt, dass ich mich dem Altar Gottes nicht nähern darf, wenn meine Augen von einer Krankheit befallen sind. Ich muss zugeben, dass 
ich Lesebrillen trage. Muss meine Sehkraft perfekt sein oder gibt's hier ein wenig Spielraum?

h) Die meisten meiner männlichen Freunde lassen sich ihre Haupt- und Barthaare schneiden, inklusive der Haare ihrer Schläfen, obwohl das eindeutig durch Lev. 19:27 verboten wird. Wie sollen sie sterben?

i) Ich weiß aus Lev. 11:16-8, dass das Berühren der Haut eines toten Schweines mich unrein macht. Darf ich aber dennoch Fußball spielen, wenn ich dabei Handschuhe anziehe?

j) Mein Onkel hat einen Bauernhof. Er verstößt gegen Lev. 19:19 weil er zwei verschiedene Saaten auf ein und demselben Feld anpflanzt. Darüber hinaus trägt seine Frau Kleider, die aus zwei verschiedenen Stoffen gemacht sind (Baumwolle/Polyester). Er flucht und lästert außerdem recht oft. Ist es wirklich notwendig, dass wir den ganzen Aufwand betreiben, das komplette Dorf zusammenzuholen, um sie zu steinigen (Lev. 24:10-16)? Genügt es nicht, wenn wir sie in einer kleinen, familiären Zeremonie verbrennen, wie man es ja auch mit Leuten macht, die mit ihren Schwiegermüttern schlafen? (Lev. 20:14)

Ich weiß, dass Sie sich mit diesen Dingen ausführlich beschäftigt haben, daher bin ich auch zuversichtlich, dass Sie uns behilflich sein können. Und vielen Dank nochmals dafür, dass Sie uns daran erinnern, dass Gottes Wort ewig und unabänderlich ist.

Ihr ergebener Jünger und bewundernder Fan Jak 


\section{(Download 2) Moderation Managementteam}

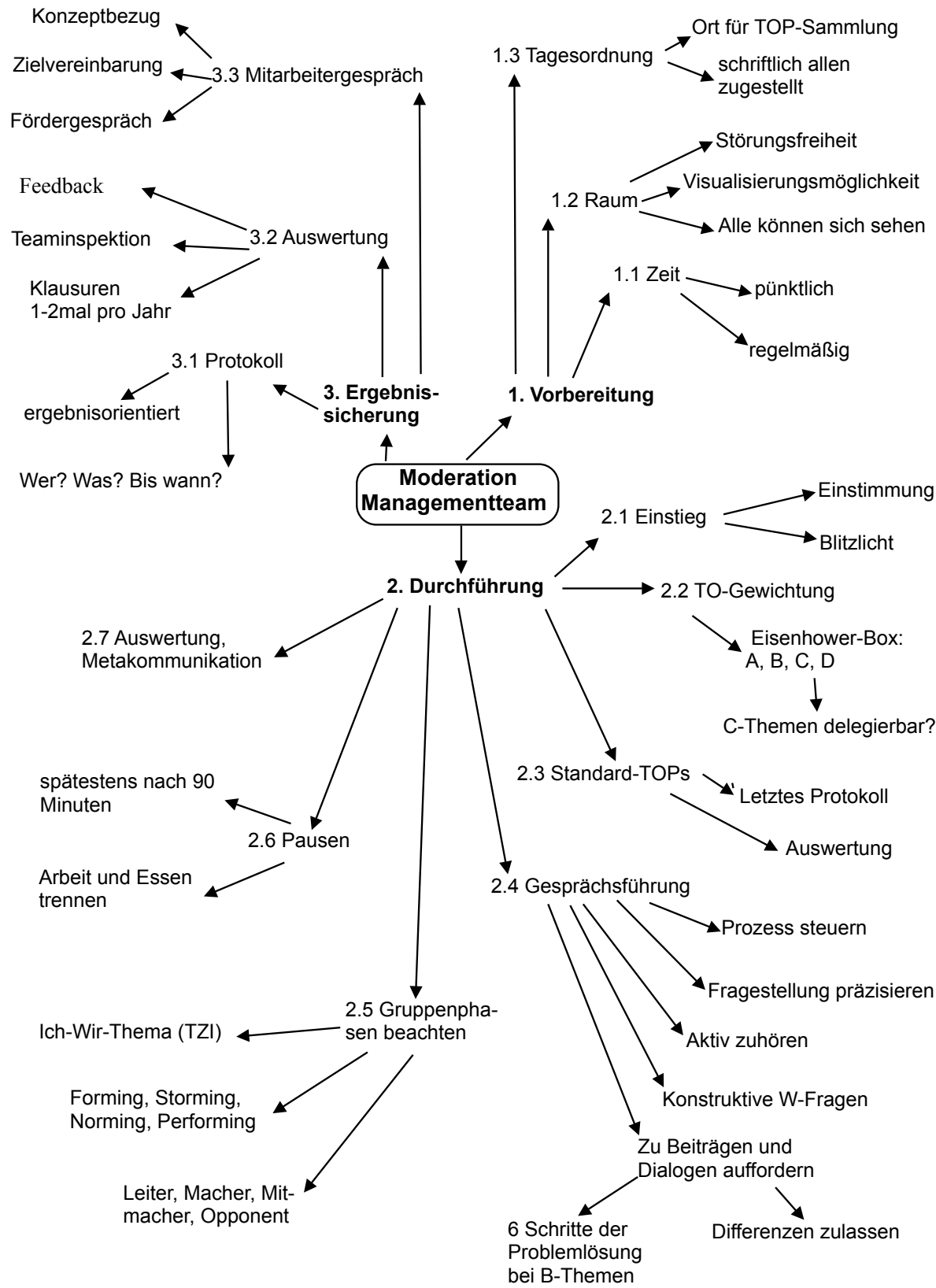




\section{(DOWNLOAD 3) Die sechs Schritte der Problemlösung nach Th. Gordon}

\section{Start:}

Formulierung der Fragestellung: positiv, verständlich, konkret, erreichbar, verhaltens- und handlungsbezogen

\section{Schritt I: Das Problem wird erkannt und definiert:}

a. Zahlen, Daten, Fakten (ZDF)

b Hintergründe, weiche Daten.

c. Wünsche, Interessen (Wünsche und Interessen sind Kriterien für spätere Lösungen!)

Schritt I kann eine ganze Sitzung lang dauern. Die Teamsitzung ist dann ein Treffen zur Problemfindung. Probleme sind Trüffel! Leitungspersonen sollen die Trüffel suchen. Sie sind Modell dafür, dass man sich für Schwierigkeiten interessieren soll (Qualitätssicherung!), und auch dafür, dass man Schwierigkeiten konstruktiv angehen kann.

\section{Schritt II: Alternative Lösungen werden entwickelt:}

- kreative Phase.

- Technik: Brainstorming

- Wichtig: keine Wertungen! Die Moderationsperson muss Wertungen sofort unterbinden. Falls ein Team darin noch nicht geübt ist, empfehlen sich MetaplanKärtchen zur Ideensammlung; dann aber: ganze Sätze schreiben!

\section{Schritt III: Die alternativen Lösungen werden bewertet:}

- Hat eine der Lösungen einen Haken?

- Welche Lösungsvorschläge leisten einen Beitrag zur Wunscherfüllung?

- Welche Lösungsvorschläge berücksichtigen hinreichend die geltenden Rahmenbedingungen (vgl. Schritt I a)?

\section{Schritt IV: Die Entscheidung wird getroffen:}

- Erst jetzt!

- Oft empfiehlt sich eine Lösung ganz von selbst, sobald erst einmal alle Fakten und Interessen ausgebreitet sind.

- Nicht überreden!

\section{Schritt V: Die Entscheidung wird ausgeführt:}

- Wer tut was wann?

- Falls jemand sich nicht an Abmachungen hält: mit Ich-Botschaften intervenieren.

\section{Schritt VI: Auswertung:}

- Auswertung der Lösung für einen späteren Zeitpunkt vereinbaren. 
- Andernfalls besteht die Gefahr, dass gute Ansätze versickern und dass sich die Norm ausbreitet: Was wir miteinander erarbeiten und beschließen, nehmen wir anschließend selbst nicht ernst.

Quelle: Thomas Gordon: Managerkonferenz. Effektives Führungstraining. München 2005. 


\section{(DOWNLOAD 4) Zur Moderation der sechs Schritte der Problemlösung nach Th. Gordon}

(Kursivtext: Anregungen für die Moderation)

\section{Start}

Formulierung der Fragestellung; Struktur: Wie können wir das Problem XY so lösen, dass wir $1 . \ldots, 2 . . ., 3 . . .$. erreichen?

\section{Schritt I: Das Problem wird erkannt und definiert:}

a. Zahlen, Daten, Fakten (ZDF); Welche wichtigen ZDF sind bei unserem Thema zu berücksichtigen? Diskutieren Sie zu zweit darüber (5 Min.). - Dann: Welche ZDF finden Sie wichtig? Was genau ist Ihr Punkt? Wie lässt er sich knapp zusammenfassen? Wenn alle zu Wort gekommen sind, können Sie als Moderatorin bei jedem Schritt noch ergänzen, was aus Ihrer Sicht wichtig ist.

b. Hintergründe: Welche Denkgewohnheiten erschweren kreative Lösungsmöglichkeiten? Welche Ressourcen und Potentiale bleiben bisher ungenutzt?

c. Wünsche, Interessen: An welche Interessenvertreter ist zu denken? Worum geht es denen?

\section{Schritt II: Alternative Lösungen werden entwickelt:}

Kreative Phase; Technik: Brainstorming; Formulieren Sie konkrete Maßnahmen: Wer sollte was tun? “ Wichtig: keine Wertungen durch andere Teilnehmer zulassen! Falls sie doch vorkommen, intervenieren: „Bitte nicht kritisieren! Sagen Sie stattdessen Ihren Vorschlag. Was genau würden Sie vorschlagen?

Falls Schritt II in einer späteren Sitzung bearbeitet wird: „Welche Ideen sind Ihnen inzwischen noch zusätzlich gekommen?"

Wichtig: Nicht nur Stichworte, sondern ganze Sätze aufflip notieren.

\section{Schritt III: Die alternativen Lösungen werden bewertet:}

Aus Zeitgründen empfiehlt es sich, einen thematischen Schwerpunkt auszuwählen; fragen Sie die Gruppe:

„Welcher Themenschwerpunkt würde uns deutlich voranbringen, wenn wir zu guten Lösungen finden? Welche Punkte gehören zusammen?

Falls es unterschiedliche Meinungen gibt: Lassen Sie die diskutieren. Welche Argumente sind zu beachten? Statt „geht ja doch nicht!“: Welche Bedingungen müssten erfüllt sein, damit eine Lösung möglich wird? Neue Gesichtspunkte ans Ende der alternativen Lösungen schreiben.

Anregungen für die Diskussion: Hat unsere Lösungsidee einen Haken?

Inwiefern leistet unsere Lösungsidee einen Beitrag zur Wunscherfüllung?

Wie werden die geltenden Rahmenbedingungen (vgl. Schritt I a) durch unsere Lösungsidee berücksichtigt?

\section{Schritt IV: Die Entscheidung wird getroffen:}

Oft empfiehlt sich eine Lösung fast von selbst, sobald erst einmal alle Fakten und Interessen ausgebreitet sind. 
Bei parallel arbeitenden Gruppen: Klären Sie, wer Ihren Entscheidungsvorschlag im Plenum präsentiert.

\section{Schritt V: Die Entscheidung wird ausgeführt:}

Im Plenum ist zu klären, wie mit den Entscheidungsvorschlägen verfahren wird und wer was wann zu tun hat, falls der Vorschlag offiziell beschlossen wird.

\section{Schritt VI: Auswertung:}

Empfehlung an das Entscheidungsgremium: Zur Sicherung der Verbindlichkeit empfiehlt sich sehr, eine Auswertung der Lösung an einem verabredeten Zeitpunkt zu vereinbaren.

Andernfalls besteht die Gefahr, dass gute Ansätze versickern und dass sich die Norm ausbreitet: Was wir miteinander erarbeiten und beschließen, nehmen wir anschließend selbst nicht ernst. Das wäre ein destruktiver heimlicher Vertrag. 


\section{(DOWNLOAD 5) Teaminspektion}

1. Was läuft gut, was läuft nicht so gut in der Gruppe?

2. Wie ist die Aktivität (Redezeit) zwischen allen Beteiligten verteilt?

3. Wie ist die Stimmung in der Gruppe: angeregt, gelangweilt, schlaff, lahm, energiegeladen, munter, missmutig, gespannt, heiter ...? Womit hängt die Stimmung zusammen? Wie erklären Sie sich das?

4. Wie findet die Gruppe heraus, was wirklich wichtig ist? Wie konsequent setzt sie Prioritäten?

5. Welche wichtigen Themen werden vermieden? Welche Hinweise auf vermiedene Themen gibt es in den Pausen, in Andeutungen zwischendurch, in nonverbalen Mitteilungen?

6. Wie verständigen die Gruppenmitglieder sich? Wie hören sie einander zu? Wie beziehen sie sich auf die Beiträge anderer?

7. Welche Konflikte sind in der Gruppe spürbar? Wie werden sie geregelt?

8. Wie verfährt die Gruppe mit heiklen Themen? Wie schafft sie es, solche Themen offen anzusprechen?

9. Wie verbindlich werden die gemeinsam vereinbarten Spielregeln eingehalten?

10. Wie effektiv arbeitet die Gruppe an ihren Zielen?

11. Wann wird in den Sitzungen gelacht, wann geht es ernst zu, wann hektisch?

12. Wie funktionieren Meinungsbildung und Entscheidungsfindung in der Gruppe?

13. Wenn man die Ergebnisse insgesamt betrachtet: Ist die gemeinsam verbrachte Zeit gut genutzt?

14. Welches Potential in der Gruppe könnte zu einer Verbesserung beitragen?

15. Wie ernst nehmen die Gruppenmitglieder in der Regel ihre Beschlüsse?

16. Wie konsequent wertet die Gruppe die Moderation ihrer Sitzung aus? 


\section{(DOWNLOAD 6) Strukturierung von Beratungsprozessen}

\section{Orientierungsphase $(A-Z-A)$}

\subsection{A: Benennung des Anliegens:}

Grundsätzlich: von Anfang an den anderen zum Denken bringen, darum: ganz kurz, z. B.: Worum geht es Ihnen? Was wäre ein treffendes Stichwort oder ein Roman- oder Filmtitel?

1.2 Z: Beratungsziel: Verständigung über das Ziel der Beratung: ,Was möchten Sie für sich selbst erreicht haben, wenn unser Gespräch zu Ende ist?" Das Beratungsziel bezieht sich also auf den anwesenden Gesprächspartner, nicht auf Dritte (also nicht auf schwierige Schüler, störende Kollegen, unzufriedene Eltern usw.).

1.3 A: Auftrag an den Berater bzw. die Beraterin:

Was soll ich zur Erreichung des Beratungsziels beitragen?

Mögliche Schwierigkeiten dabei: Der Auftrag ist zu unpräzise, zu komplex oder unerfüllbar, passt mit dem Ziel nicht zusammen oder überschreitet Kompetenz oder Befugnisse der Lehrperson.

\section{Problemanalyse}

(IST-Analyse; Problemsprache):

Klärung problemrelevanter Aspekte auf drei Ebenen; Empfehlung: Klärungsprozess von außen nach innen steuern; Vorsicht mit persönlichen Aspekten.

2.1 Organisation/System:

Vertragslage (Schulrechtliche Bestimmungen, Dienstvertrag, Schulvertrag, Leitbild, Konzept, Verabredungen in einer Klasse usw.)

2.2 Interaktion:

Scheiterstrategien, z. B. Lösungen statt Interessensklärung, Hören auf dem Beziehungsohr, Du-Botschaften, Vorwürfe statt Wunschäußerung, Ausblendung/Abwertung von Realitätsaspekten, Problemen oder Verhaltensalternativen, Rechthaberei statt Bemühung um einvernehmliche Lösungen, Beleidigungen, Drohungen.

2.3 Person:

Bedeutung/Wichtigkeit des Problems; Gefühlslage; Fähigkeit, Denken, Fühlen und Verhalten zu steuern und aufeinander abzustimmen; ungünstige Beziehungsgewohnheiten.

\section{Zielanalyse}

(Veränderungsziel)

3.1 Welche Ziele strebt die Gesprächspartnerin an?

3.2 Kriterien für Ziele (SMARTI: spezifisch, messbar, aktivierend u. attraktiv, realistisch, terminiert $=$ zeitbezogen, interaktionell)

\section{Interventionen}

(Mittel zur Zielerreichung, Lösungssprache) 
4.1 Klärung von Informationsaspekten

4.2 Nachdenken fördern mit Mini-Max-Interventionen, z. B. VW-Regel, Frage nach positiven Ausnahmen, nach Verhalten statt nach Eigenschaften, nach konkreten (,smarten“) Zielen anstelle von frei schwebenden Vergleichen.

\section{Abschluss}

Zielüberprüfung, z. B. mit Hilfe einer Skalierung von 0 bis 10

(Struktur: Bettina Lohmann: Effiziente Supervision, 5. Aufl. Baltmannsweiler 2010; Schulbezug und Details: Hauke Christiansen) 


\section{(DOWNLOAD 7) Das Göttinger Stufenmodell der Supervision}

\section{Einstieg: Bericht}

Eine Teilnehmerin berichtet über ein Vorkommnis aus dem Kern ihrer Arbeit: Eine Irritation (erfreulich oder unerfreulich), ein Unbehagen, eine körperliche Reaktion o. ä., kein langer Bericht, 3 bis 5 Minuten.

\section{Schritt I: Wahrnehmung}

Was habe ich gehört? (Sammlung der Passagen, die die Einzelnen besonders beeindruckt haben.)

\section{Schritt II: Emotionale Resonanz}

Die Gruppenmitglieder konzentrieren sich auf den Bericht und teilen ihre persönliche Resonanz mit, keine Kritik (!!), sondern Stimmungen und Gefühle.

Die Moderatorin fragt die Fallgeberin, was davon sie besonders angesprochen hat.

\section{Schritt III: Assoziationen, Einfälle, Fantasien}

Die Gruppenmitglieder nennen Einfälle, Phantasien, innere Bilder (Ich-Sätze!), Geschichten, Märchen, Filmszenen, die ihnen im Zusammenhang des Berichts eingefallen sind bzw. die ihnen einfallen, wenn sie jetzt danach suchen. Die Moderatorin fragt die Fallgeberin, was davon sie besonders angesprochen hat.

\section{Schritt IV: Diagnose der Situation}

Die Gruppenmitglieder äußern Hypothesen zur Diagnose der Situation: Was ist da los zwischen den beiden oder zwischen den Beteiligten? Welche Dynamik spielt sich da ab? Teufelskreise? Sackgassen? Psychologische „Spiele“? Die Moderatorin fragt die Fallgeberin, was davon sie besonders angesprochen hat.

\section{Schritt V: Interventionen}

Die Gruppenmitglieder sagen, was sie selbst in so einer Situation täten bzw. was sie der Fallgeberin vorschlagen möchten: neue Sichtweisen, erste Schritte, konkrete Verhaltensweisen. Die Moderatorin fragt die Fallgeberin, was davon sie besonders angesprochen hat, an welcher Stelle sie möglicherweise Ideen zu ihrem weiteren Vorgehen bekommen hat, und zum Abschluss, wie es der Fallgeberin jetzt geht. 


\section{(DOWNLOAD 8) Zur Moderation des Stufenmodells}

Grundregel wie beim Brainstorming: Keine Kritik untereinander zulassen; stattdessen: Was ist Deine Idee dazu?

Auf jeder Stufe darauf bestehen, dass alle Teilnehmenden sich äußern. Sinn der Übung ist facettenreiche Resonanz.

\section{Falldarstellung}

Sie sollte nicht zu lang und nicht zu kurz sein, also ca. 3-5 Minuten. Am Schluss der Falldarstellung nachfragen, welche Frage die Fallgeberin beschäftigt.

Nach der Falldarstellung kann die Fallgeberin sich zurücklehnen; sie sollte auch im Laufe des Prozesses nicht direkt angesprochen werden; nur nach jeder Stufe wird sie gefragt: Was davon hat dich angesprochen?

\section{Stufe I}

Nicht diagnostizieren; wörtlich, kurz wiederholen, was besonders hängen geblieben ist. Die Stufen einhalten: Diagnose und Interventionen kommen zum Schluss.

Wer moderiert, kann sich auch inhaltlich beteiligen; empfehlenswert: sich erst vergewissern, ob sich alle geäußert haben; dann die eigene Idee beisteuern.

Schlussfrage an die Fallgeberin: Was haben wir möglicherweise überhört?

\section{Stufe II}

Gefühle präzisieren: „Ich habe das Gefühl, dass ...“ ist keine Gefühlsäußerung, sondern eine Vermutung. Oft lohnt sich die Nachfrage zu einer ersten Äußerung: ...und wie fühlt sich das an? Grundgefühle sind Ärger, Freude, Angst, Wut.

Schlussfrage an die Fallgeberin: Was davon hat dich besonders angesprochen?

\section{Stufe III}

Assoziationen lassen sich einüben, z. B. mit der Frage: Wenn du malen könntest wie würdest du das malen, welche Stimmung, welche Farben?

Schlussfrage an die Fallgeberin: Was davon hat dich besonders angesprochen?

\section{Stufe IV}

Die Diagnose der Beziehung ist entscheidend; es geht nicht um Individualdiagnosen, sondern um Beziehungsmuster: Was passiert immer wieder zwischen den Beteiligten? Welche Ich-Zustände sind erkennbar, welche Transaktionsmuster, welche psychologischen „Spiele“ (z. B. Dramadreieck), welche Machtspiele?

Schlussfrage an die Fallgeberin: Was davon hat dich besonders angesprochen?

\section{Stufe V}

Auch bei den Interventionen geht es nicht um Rechthaberei, sondern um die Frage, was für die Fallgeberin passend ist, womit sie im Moment etwas anfangen kann.

Schlussfrage an die Fallgeberin: Was davon hat dich besonders angesprochen?

\section{Schluss}

Kurze Auswertung: Die Fallgeberin fragen, wie's ihr geht und gegangen ist. Und die Gruppe fragen, wie sie das Verfahren erlebt hat. 


\section{(DOWNLOAD 9) Raus aus der Mobbing-Falle!}

\section{Aller Anfang tut weh!}

$95 \%$ derjenigen, die sich ,gemobbt“ fühlen, werden gar nicht gemobbt! Sind Sie wirklich sicher, dass Sie gemobbt werden, oder begegnet Ihnen ,nur“ der alltägliche Wahnsinn am Arbeitsplatz mit all seinen Intrigen, Ungerechtigkeiten und fiesen Tricks? Übliche Reibereien, die als unsensibel, unhöflich, ungerecht empfunden werden, ein nicht erwiderter Gruß, eine unsachliche Kritik - das alles ist nicht schon Mobbing.

\section{Was ist Mobbing - und was ist es nicht?}

Mobbing ist ein aus den Fugen geratener Konflikt; Mobbing dauert an. Ziel ist es, eine Person auszuschließen, loszuwerden. Die Person fühlt sich diskriminiert, zu Unrecht angegriffen, abgewertet. Die Angriffe richten sich auf

- die Möglichkeit, sich mitzuteilen,

- die sozialen Beziehungen,

- das soziale Ansehen,

- die Qualität der Berufs- und Lebenssituation,

- die Gesundheit.

\section{Wie entsteht Mobbing?}

Grundsätzlich (so Heinz Leymann): Mobbing entsteht, weil die Leitung es zulässt! Das heißt, zur Leitungsrolle gehört es wesentlich, so zu leiten, dass solche Prozesse gar nicht erst entstehen können. Mobbing, dem nicht entgegengetreten wird, breitet sich aus, qualitativ und quantitativ.

Die Auslöser sind zahlreich und liegen im Bereich der Unternehmensstruktur (Arbeitsdruck, Personalabbau usw.), der Arbeitsmoral (Klima, Feedbackkultur usw.), des Führungsstils (Umgang mit Konflikten, Laissez-faire-Stil) und der gesellschaftlichen Situation (Arbeitslosigkeit, Zukunftsängste).

Wer mobbt? Grundsätzlich kann jeder und jede zum Mobber, zur Mobberin werden, z. B. wer Kritik sehr persönlich nimmt, gern stichelt, auf Höflichkeit pfeift, Angst vor Abstieg hat, auf „Opfer-Typen“ herabsieht usw.

\section{Wer ist betroffen?}

Es kann jeden treffen, einige mit größerer Wahrscheinlichkeit. Klein und Frank nennen die Betriebsnudel, den Moralapostel, den Karrieristen, den Macher und den Softi.

\section{Welche Folgen hat Mobbing?}

Unternehmen: Die Arbeitsleistung sinkt, die Gemobbten fallen durch Krankheit aus, die Fehlerquote steigt. Etwa 1,6 Mio. Menschen leiden unter Mobbing am Arbeitsplatz; nach einer Angabe von Stegmann (2000) liegen in der Bundesrepublik die Kosten, die durch Mobbing entstehen bei 15-50 Mrd. Euro jährlich (pro Fall 15.000 bis 50.000 Euro)

Betroffene: Psychische Störungen (Gereiztheit, zerstörtes Selbstwertgefühl, Nervenzusammenbruch, psychosomatische Beschwerden, soziale Isolation)

Täter: Personalrechtliche Folgen; Kündigung 


\section{Gegenmaßnahmen}

Konfliktkompetenz im Unternehmen stärken, Mobbing ächten, konstruktive Kritik fördern, notfalls Berater engagieren.

Für die Betroffenen: Der pauschalen persönlichen Abwertung auf keinen Fall Glauben schenken (Ergänzung von HC); Unterstützung suchen; von Leitung und Betriebsrat Schutz fordern. Beratung, Supervision, Coaching nutzen, notfalls einen Anwalt engagieren. Mobbing-Literatur (Internet!) studieren!

\section{Rechtliches}

Klein und Frank $(2008,122)$ verweisen auf den Schutz der Menschenwürde durch das Grundgesetz und auf die Definition von Mobbing im Sozialgesetzbuch (SGB) als „,berufsbedingte gesundheitliche Gefährdung“. „Die Krankenkassen werden dort aufgefordert, Fälle von Mobbing an die zuständigen Stellen für Arbeitsschutz und die Unfallversicherungsträger zu melden.“

Das Strafgesetzbuch erfasst als Mobbing-Handlungen „Beleidigungen, Verleumdung, üble Nachrede, Körperverletzung, Nötigung und Bedrohung“ (a.a.O. 122).

Quelle: Hans-Michael Klein/Jasmin Frank, Raus aus der Mobbing-Falle, Ber$\operatorname{lin} 2008$ 


\section{(DOWNLOAD 10) Die vier Komponenten der Gewaltfreien Kommunikation (GFK)}

\section{Beobachtungen:}

Was passiert in einer Situation? Beschreiben, nicht bewerten!

\section{Gefühle:}

Was lösen die Beobachtungen in mir aus? Bin ich verletzt, erschrocken, froh, amüsiert, irritiert o. ä.?

\section{Bedürfnisse:}

Welche Bedürfnisse stecken hinter meinen Gefühlen? Worum geht es mir dabei? Was ist mir wichtig? Was brauche ich? (Dies ist die wichtige Ergänzung zu den bekannten Ich-Botschaften.)

\section{Bitten:}

Ich teile mit, was ich von einer anderen Person will. Was kann die Person tun, um meine (und auch ihre) Lebenssituation zu verbessern?

\section{Beispiel:}

Eine Mutter zu ihrem Sohn: „Felix, ich ärgere mich, wenn ich zwei zusammengerollte schmutzige Socken unter dem Kaffeetisch sehe und noch drei neben dem Fernseher, weil ich in den Räumen, die wir gemeinsam benutzen, mehr Ordnung brauche. Würdest du bitte deine Socken in dein Zimmer oder in die Waschmaschine tun?"

Diese vier Komponenten bieten eine wichtige Orientierung, wenn ich etwas „auf dem Herzen“ habe, wenn also die Veränderungsenergie bei mir liegt.

Ebenso wichtig sind sie, wenn jemand mir gegenüber Irritation, Ärger, Kritik usw. äußert. Dann hilft es, diese Äußerung auf konkrete Situationen zu beziehen (Wann genau hast du mich so erlebt?), das damit verbundene Gefühl der anderen Person wichtig zu nehmen (,Ich merke, dass dich das ziemlich aufbringt.“), das mit dem Gefühl verbundene Grundbedürfnis zu beachten (,DDu wünscht dir Respekt für deine Entscheidung.“) und schließlich zu fragen, was ich konkret tun kann, um die Situation zu bereinigen.

\section{Beispiele für existentielle Grundbedürfnisse:}

Autonomie: die eigenen Träume, Ziele, Werte bestimmen

Integrität: Authentizität, Kreativität, Sinnhaftigkeit, Selbstwert

Interdependenz/Kontakt mit anderen: Wertschätzung, Nähe, Rücksichtnahme, emotionale Sicherheit, Respekt, Verständnis

Nahrung für den Körper: Luft, Essen, Bewegung, Schutz vor gefährlichen Lebewesen, Ruhe

Spielen

Spirituelle Verbundenheit: Schönheit, Harmonie, Inspiration, Ordnung, Friede 


\section{Verbindung zum Konfliktmanagement:}

I: Ich habe einen Konflikt mit dir: Vorgehen wie oben geschildert

II: Du hast einen Konflikt mit mir -> Ich höre aktiv zu (auch unter Stress!)

1. Welches Verhalten, welche Situation genau meinst du?

2. Wie geht es dir dabei? Wie fühlst du dich?

3. Welches Grundbedürfnis empfindest du als verletzt?

4. Was wünscht du dir von mir?

III: Ihr habt einen Konflikt miteinander und kommt damit zu mir: Ich bin ,allparteilich" und lasse

1. beide Seiten ohne Wertung die kritischen Situationen beschreiben,

2. beide Seiten deutlich machen, wie sie sich dabei fühlen,

3. beide Seiten herausfinden, welche Grundbedürfnisse ihnen wichtig sind,

4. beide Seiten ihre Wünsche formulieren und Gewinn-Gewinn-Lösungen erfinden.

Zusammenfassung: Hauke Christiansen; Quelle: Rosenberg, Marshall B.: Erziehung, die das Leben bereichert. Gewaltfreie Kommunikation im Schulalltag, Paderborn 2013 a 


\section{(Download 11) Vier Qualitätskriterien}

Anregungen zur Auswertung der Schulqualität, spaltenweise als Aufzählung zu lesen und eventuell zu ergänzen; nutzbar zur Selbstdiagnose eines Kollegiums; Zusammenstellung: H. Christiansen, angelehnt an www.schule-management.de

\begin{tabular}{|c|c|c|c|}
\hline $\begin{array}{l}\text { Strukturqualität } \\
\text { Wie sind die Rahmen- } \\
\text { bedingungen? }\end{array}$ & $\begin{array}{l}\text { Orientierungsqualität } \\
\text { Gibt es ausreichend } \\
\text { Absprachen/Regeln? }\end{array}$ & $\begin{array}{l}\text { Prozessqualität } \\
\text { Wie gut sind Ihre } \\
\text { Kernleistungen? }\end{array}$ & \begin{tabular}{|l} 
Ergebnisqualität \\
Was kommt heraus?
\end{tabular} \\
\hline $\begin{array}{l}\text { Aussagekräftiges } \\
\text { Organigramm }\end{array}$ & $\begin{array}{l}\text { Werte, Normen, } \\
\text { Verträge, Konzepte, } \\
\text { Leitbild, Vision }\end{array}$ & $\begin{array}{l}\text { Erziehung innerhalb } \\
\text { und außerhalb der } \\
\text { Schulstunden }\end{array}$ & $\begin{array}{l}\text { Hohe Lernmotivation } \\
\text { der Schülerinnen und } \\
\text { Schüler }\end{array}$ \\
\hline $\begin{array}{l}\text { Transparente Gremien- } \\
\text { und Kommunikations- } \\
\text { struktur }\end{array}$ & $\begin{array}{l}\text { Verständnis der } \\
\text { Schule als Lernende } \\
\text { Organisation }\end{array}$ & Unterrichtsqualität & $\begin{array}{l}\text { Erwerb sinnvollen } \\
\text { Fachwissens }\end{array}$ \\
\hline $\begin{array}{l}\text { Wo werden Entschei- } \\
\text { dungen getroffen? }\end{array}$ & $\begin{array}{l}\text { Grundkonsens über } \\
\text { Zielvorstellungen; } \\
\text { Identifikation mit der } \\
\text { Schule }\end{array}$ & $\begin{array}{l}\text { Geklärter partizipativer } \\
\text { Führungsstil, Koopera- } \\
\text { tion im Leitungsteam }\end{array}$ & $\begin{array}{l}\text { Stärkung der } \\
\text { Persönlichkeit durch } \\
\text { Lebensbezug des } \\
\text { Unterrichts }\end{array}$ \\
\hline $\begin{array}{l}\text { Erwartungen des } \\
\text { Umfelds an die Schule }\end{array}$ & $\begin{array}{l}\text { Identifikation } \\
\text { mit der Schule; } \\
\text { Verantwortung aller } \\
\text { für das Gesamtsystem }\end{array}$ & $\begin{array}{l}\text { Zusammenarbeit mit } \\
\text { Elternvertretungen, } \\
\text { Gemeinden, Firmen }\end{array}$ & $\begin{array}{l}\text { Lehrkräfte erlernen } \\
\text { Moderations- und Team } \\
\text { kompetenz }\end{array}$ \\
\hline $\begin{array}{l}\text { Zusammensetzung der } \\
\text { Schülerschaft }\end{array}$ & Umgang mit Vielfalt & $\begin{array}{l}\text { Feedbackkultur: Re- } \\
\text { gelmäßige Auswertung } \\
\text { von Unterricht und } \\
\text { Teamarbeit }\end{array}$ & $\begin{array}{l}\text { Durchgängig gewalt- } \\
\text { freie Kommunikation } \\
\text { im Gesamtsystem }\end{array}$ \\
\hline $\begin{array}{l}\text { Finanzielle und } \\
\text { personelle Ressourcen }\end{array}$ & $\begin{array}{l}\text { Rollenklarheit der } \\
\text { Lehrkräfte }\end{array}$ & $\begin{array}{l}\text { Möglichkeit kollegialer } \\
\text { Beratung }\end{array}$ & $\begin{array}{l}\text { Vernetzung mit } \\
\text { anderen Schulen und } \\
\text { Einrichtungen }\end{array}$ \\
\hline $\begin{array}{l}\text { Gebäude- und } \\
\text { Raumsituation }\end{array}$ & $\begin{array}{l}\text { Produktive mentale } \\
\text { Modelle }\end{array}$ & Schulklima & $\begin{array}{l}\text { Angebot lebensnaher } \\
\text { Praktika }\end{array}$ \\
\hline $\begin{array}{l}\text { Ziel: } \\
\text { Dokumentieren Sie IST } \\
\text { und SOLL. }\end{array}$ & $\begin{array}{l}\text { Ziel: } \\
\text { Klären Sie, ob } \\
\text { genügend Orientierung } \\
\text { vorhanden und } \\
\text { zugänglich ist. }\end{array}$ & $\begin{array}{l}\text { Ziel: } \\
\text { Legen Sie den } \\
\text { Schwerpunkt der } \\
\text { Evaluation auf die } \\
\text { Kernprozesse. }\end{array}$ & $\begin{array}{l}\text { Ziel: } \\
\text { Überprüfen Sie den } \\
\text { Erfolg quantitativ und } \\
\text { qualitativ. }\end{array}$ \\
\hline
\end{tabular}


(Download 12) Qualitätsmerkmale (Steuerrad)

\section{Qualitätsmerkmale}

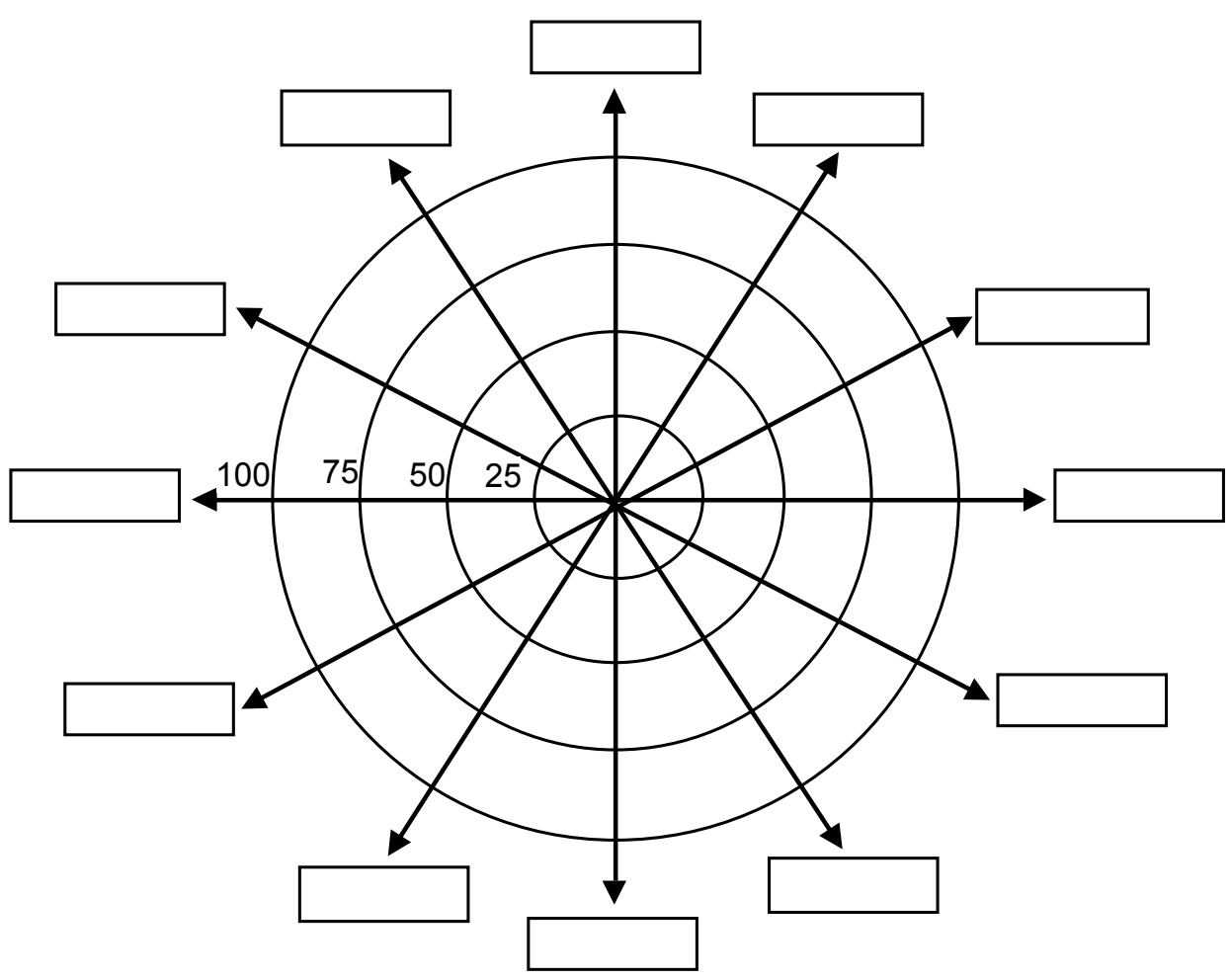

